\title{
Role of RAS signaling in Hedgehog-associated embryonal rhabdomyosarcoma
}

\author{
Dissertation \\ for the award of the degree \\ "Doctor rerum naturalium" (Dr.rer.nat.) \\ of the Georg-August-Universität Göttingen
}

within the doctoral program Molecular Medicine

of the Georg-August University School of Science (GAUSS)

submitted by
Julia Bauer

born in Göttingen

Göttingen 2018 


\section{Members of the Thesis Committee:}

Supervisor

Prof. Dr. Heidi Hahn

Institute of Human Genetics, University Medical Center Göttingen

Second member of the thesis committee

Prof. Dr. Matthias Dobbelstein

Institute of Molecular Oncology, University Medical Center Göttingen

Third member of the thesis committee

Prof. Dr. Dieter Kube

Department of Haematology and Oncology, University Medical Center Göttingen

\section{Members of the Examination Board:}

Reviewer

Prof. Dr. Heidi Hahn

Institute of Human Genetics, University Medical Center Göttingen

Second reviewer

Prof. Dr. Matthias Dobbelstein

Institute of Molecular Oncology, University Medical Center Göttingen

Further members of the Examination Board:

Prof. Dr. Dieter Kube

Department of Haematology and Oncology, University Medical Center Göttingen

Prof. Dr. Peter Burfeind

Institute of Human Genetics, University Medical Center Göttingen

\section{Prof. Dr. Frauke Alves}

Department of Haematology and Oncology, University Medical Center Göttingen

Prof. Dr. Hubertus Jarry

Institute of Clinical and Experimental Endocrinology, University Medical Center Göttingen

Date of Disputation: $18^{\text {th }}$ December 2018 


\section{Affidavit}

Here I declare that my doctoral thesis entitled "Role of RAS signaling in Hedgehogassociated embryonal rhabdomyosarcoma" has been written independently with no other sources and aids than quoted.

Julia Bauer

Göttingen, October 2018 


\section{Contents}

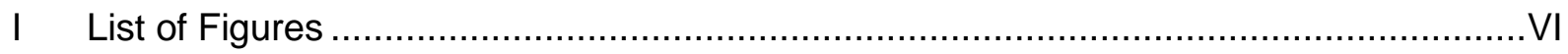

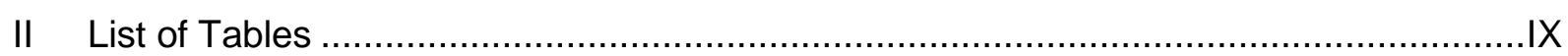

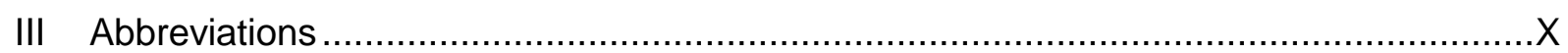

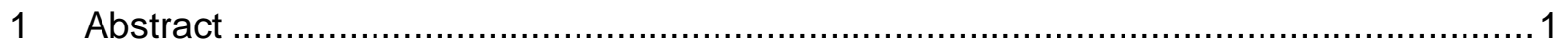

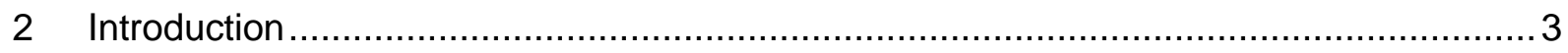

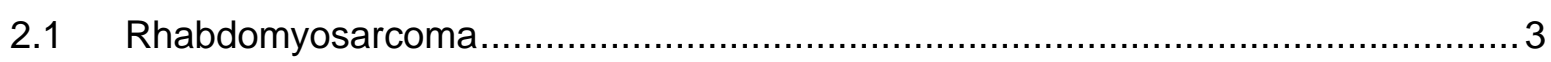

2.1.1 Current prognostics and therapy strategies.......................................... 4

2.2 The Hedgehog signaling pathway .............................................................. 4

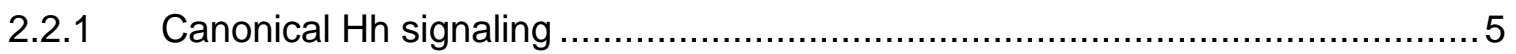

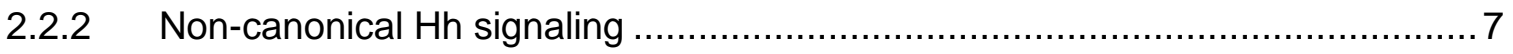

2.2.3 Canonical HH signaling in human cancer....................................................... 9

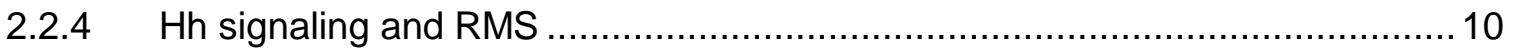

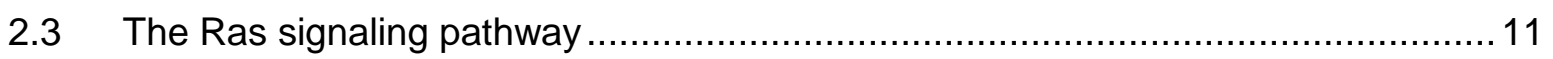

2.3.1 Specific features of different Ras isoforms ............................................... 14

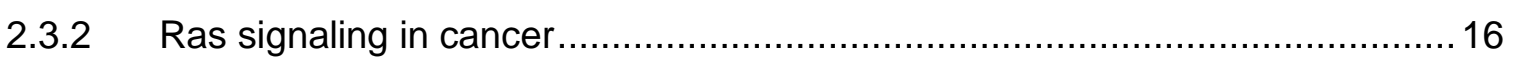

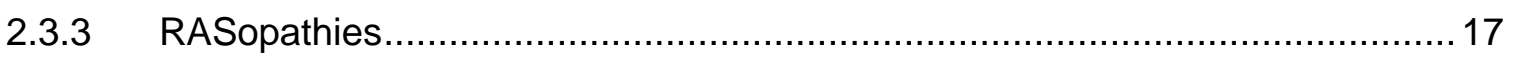

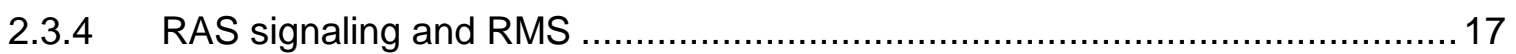

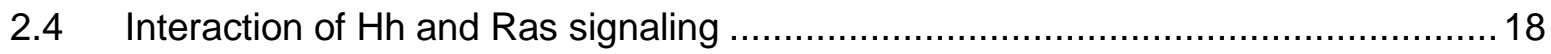

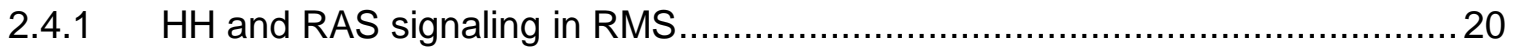

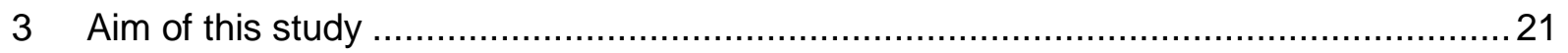

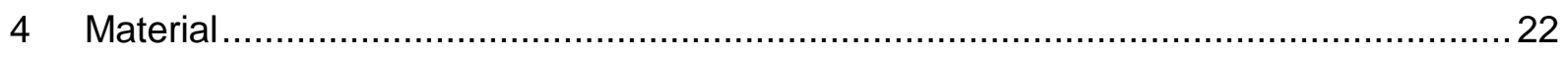

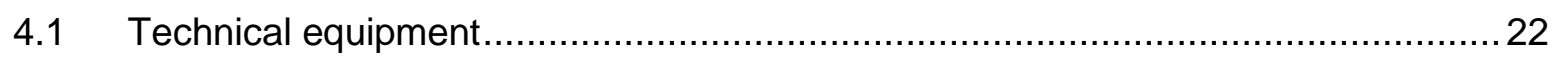

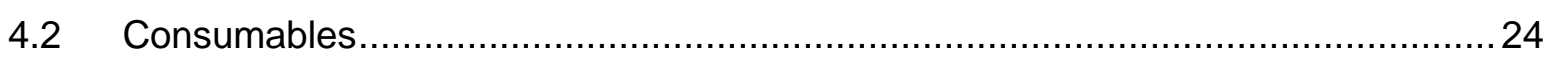

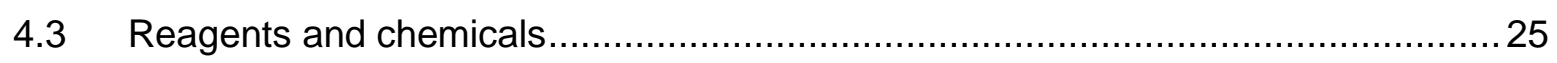

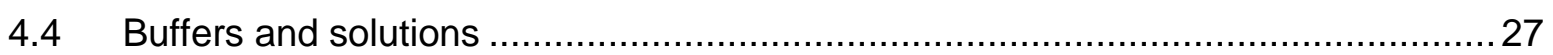

4.5 Kits and ready-to-use reaction systems ...................................................... 30

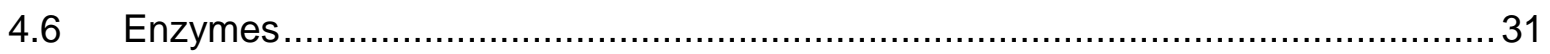

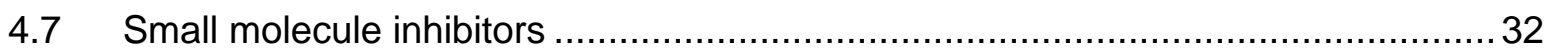

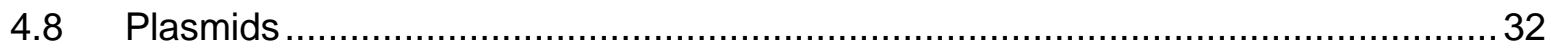

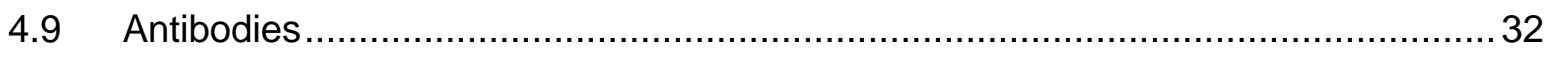

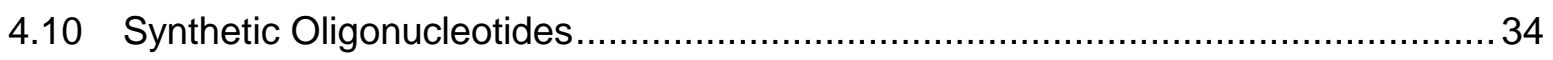

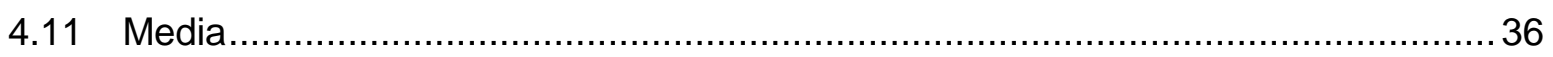

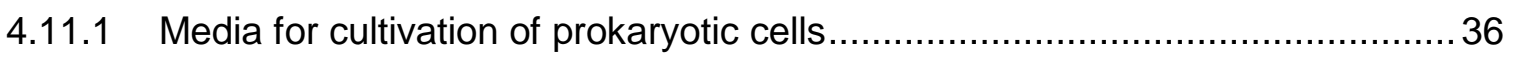

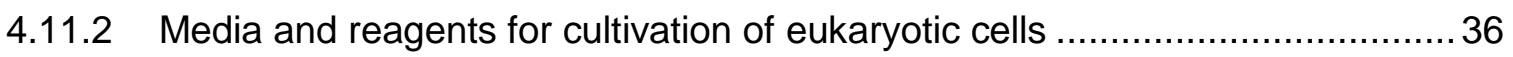




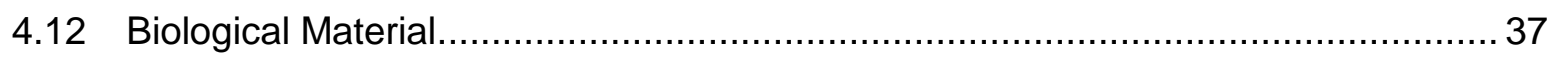

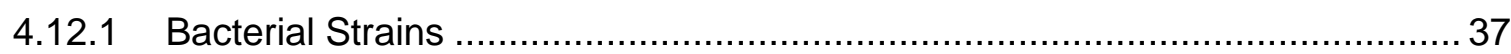

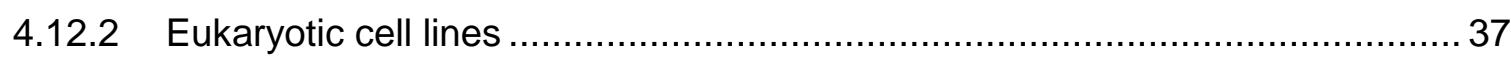

4.12.3 Genetically modified mouse lines....................................................... 39

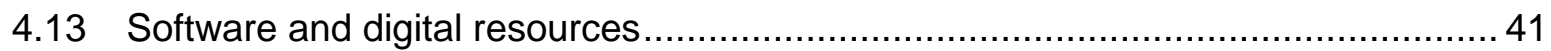

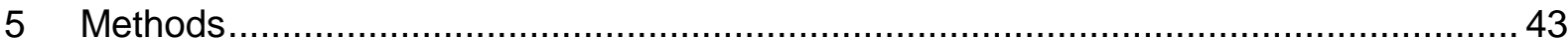

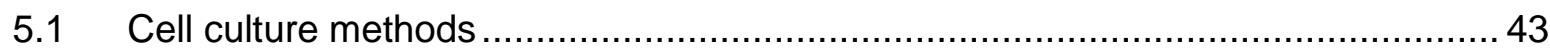

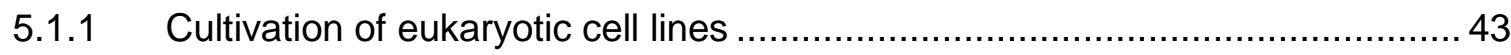

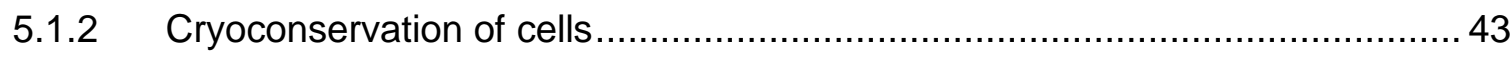

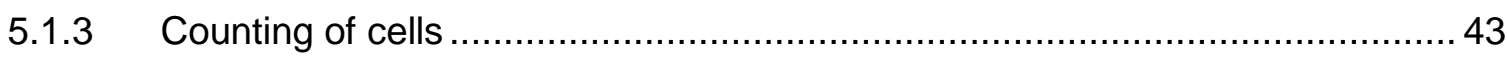

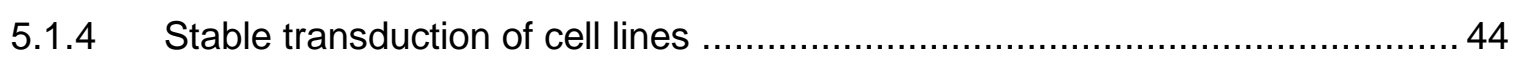

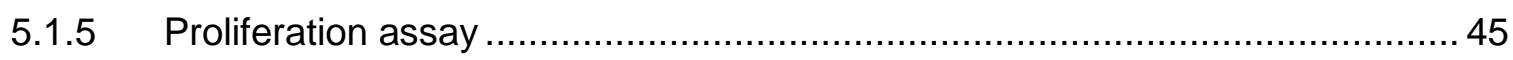

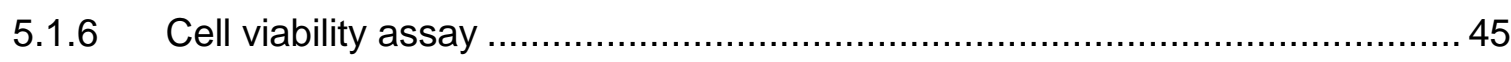

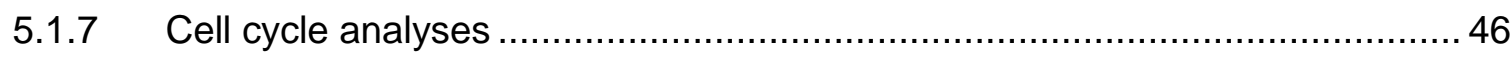

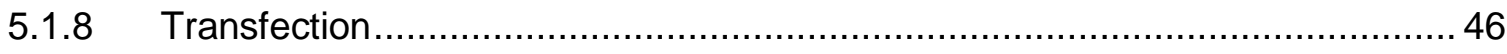

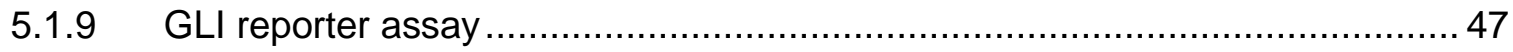

5.1 .10 Dual luciferase reporter assay ......................................................... 47

5.1.11 Generation of conditioned medium (CM) .............................................. 48

5.1.12 Analyses of $\mathrm{HH}$ ligand secretion and responsiveness ................................ 48

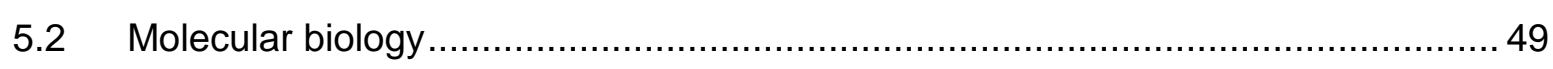

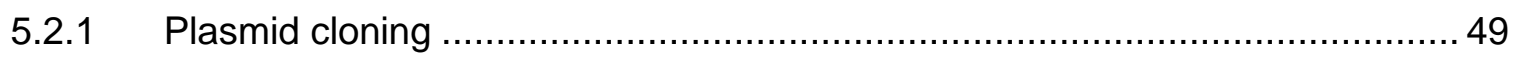

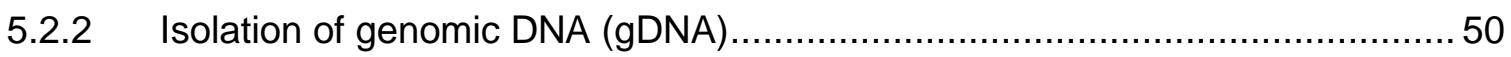

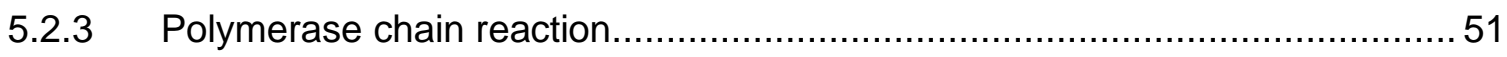

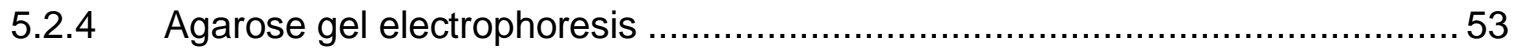

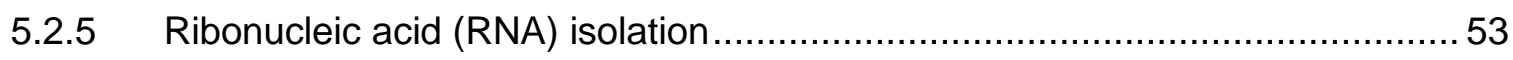

5.2.6 Photometric quantification of nucleic acids ........................................... 54

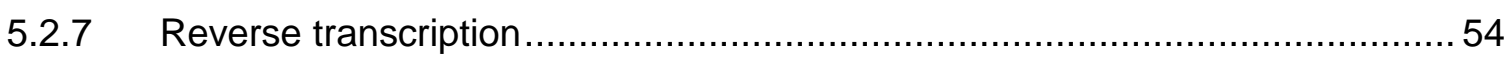

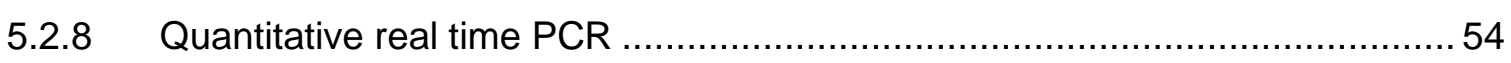

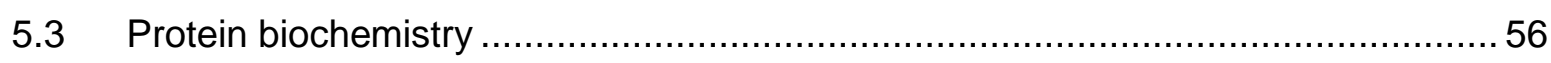

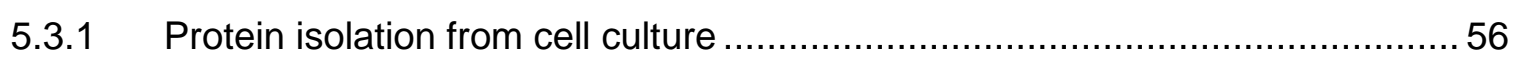

5.3.2 Subcellular fractionation of cellular lysates ................................................. 56

5.3.3 Protein isolation from murine tissue samples ........................................... 57

5.3.4 Quantification of isolated protein samples............................................. 57

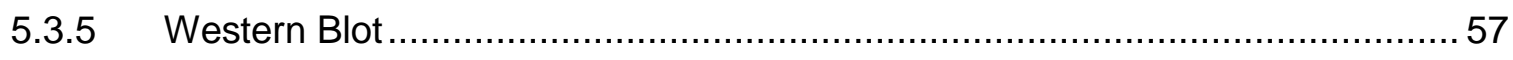

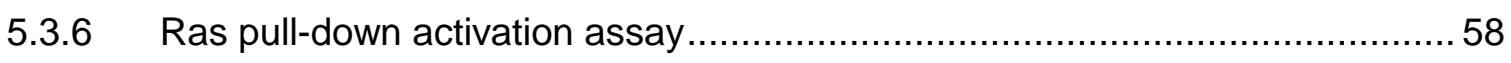

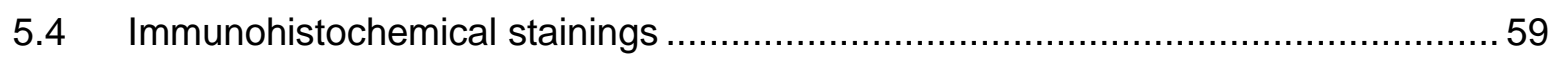

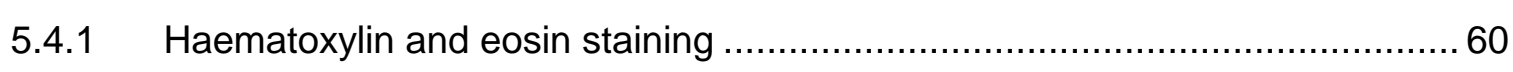

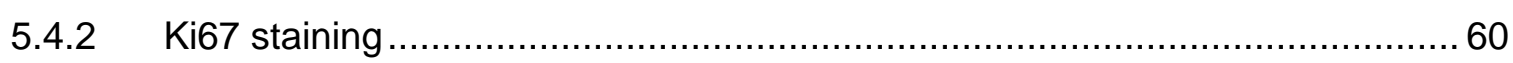




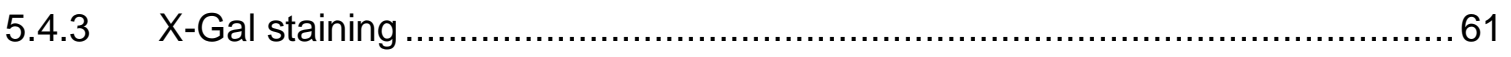

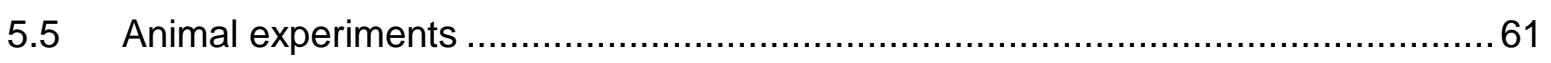

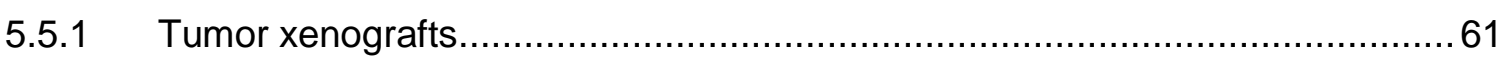

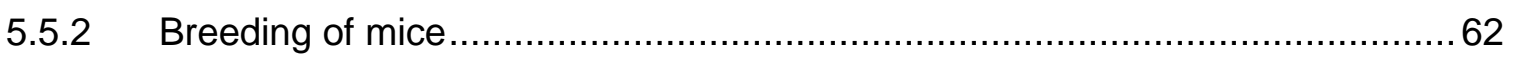

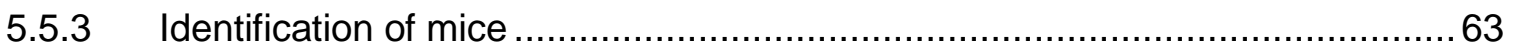

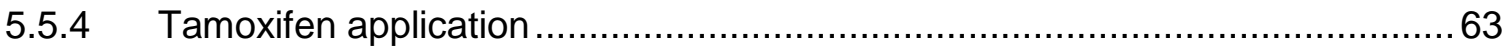

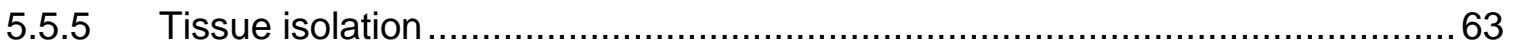

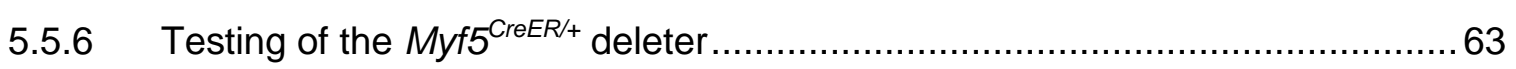

5.5.7 Tumor monitoring: induction of oncRas in ERMS precursor lesions ................63

5.5.8 Tumor monitoring: induction of oncRas in already established ERMS ............64

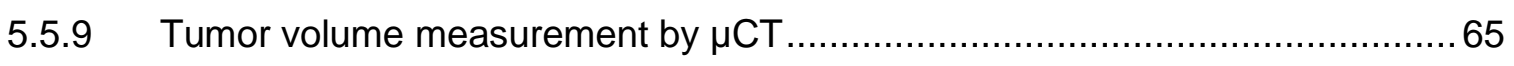

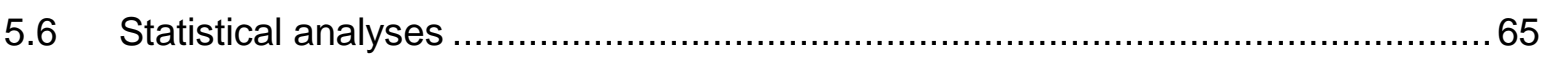

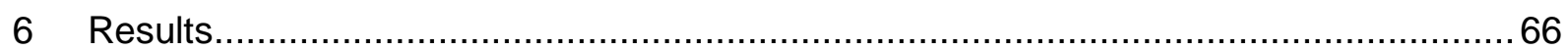

6.1 Effects of oncogenic RAS mutations on human ERMS cell lines ..........................66

6.1.1 Characterization of stably transduced RMS cell lines with oncRAS isoforms .. 66

6.1.2 OncRAS isoforms modulate mRNA expression of $\mathrm{HH}$ signaling pathway

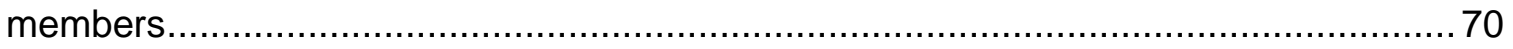

6.1.3 Canonical HH signaling plays a subordinate role in ERMS cell lines ...............73

6.1.4 OncRAS isoforms regulate GLI1 expression in ERMS cells via the MEK/ERK

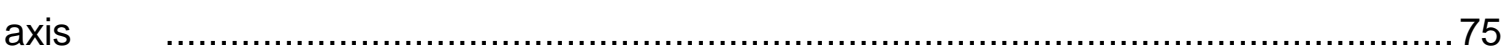

6.1.5 OncRAS isoforms induce proliferation of TE617.T and RUCH-2 cells ............91

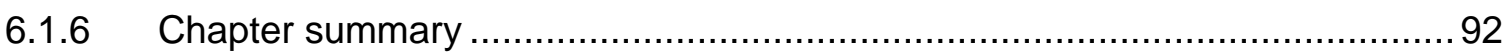

6.2 Effects of oncRAS isoforms on xenografts derived from ERMS cell lines ..............93

6.2.1 OncRAS increase tumorigenicity of TE617.T cells .......................................93

6.2.2 OncKRAS and oncNRAS increase tumorigenicity of $\mathrm{RUCH}-2$ cells................ 95

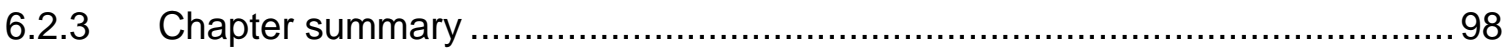

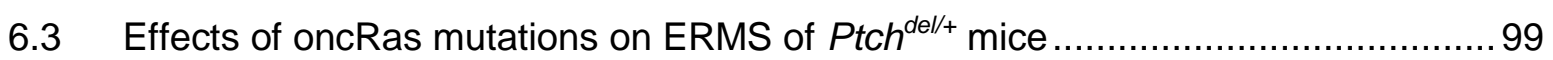

6.3.1 Pilot testing and validation of the utilized mouse models...............................99

6.3.2 Activation of oncRas in ERMS precursor lesions ....................................... 104

6.3.3 Activation of oncRas in established ERMS …........................................... 117

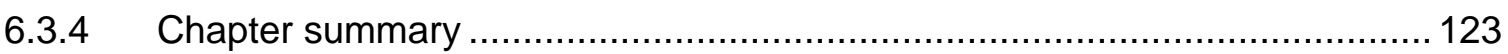

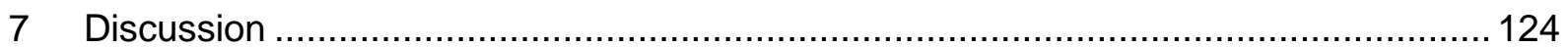

7.1 OncRAS mutations stimulate growth of cell lines derived from sporadic ERMS

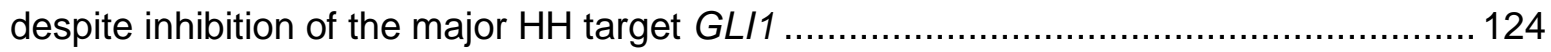

7.1.1 Differences and limitations of the utilized RMS cell lines ............................. 124

7.1.2 Influence of oncRAS mutations on expression of GL/1 and the related mechanisms. 
7.1.3 Influence of oncRAS mutations on expression of further genes implicated in the $\mathrm{HH}$ signaling cascade 130

7.1.4 Influence of oncRAS mutations on proliferation .......................................... 133

7.2 Specific oncRas mutations can increase Hh/Ptch-driven ERMS incidence and growth when expressed at an early tumor stage 135

7.2.1 Influence of oncRas mutations on Hh/Ptch-associated ERMS precursor lesions 136

7.2.2 Influence of oncRas mutations on $\mathrm{Hh} / \mathrm{Ptch}$-associated full-blown ERMS 139

7.3 Potential roles of active Ras or Hh signaling in ERMS initiation and progression. 140

8 Summary and Conclusion.... 145

9 Bibliography. 147

Acknowledgements. 


\section{List of Figures}

Figure 1: The Hh signaling pathway ..................................................................... 7

Figure 2: Canonical HH signaling in human cancer ...................................................... 10

Figure 3: Activation of RAS and its downstream effector pathways .................................. 12

Figure 4: Interactions of $\mathrm{HH}$ and RAS signaling in cancer .............................................. 19

Figure 5: Potential readouts from HRas recombination assays .........................................53

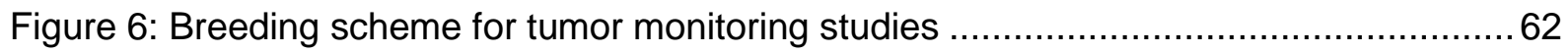

Figure 7: Study design focusing on induction of Ras mutations in ERMS precursor lesions . 64

Figure 8: Study design focusing on induction of Ras mutations in established ERMS ..........64

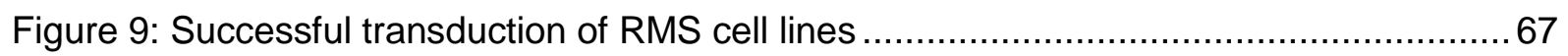

Figure 10: Characterization of protein expression of transduced RMS cell lines ...................68

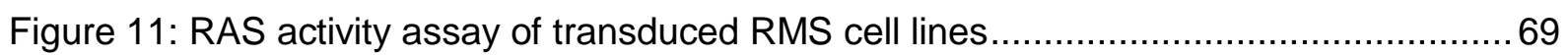

Figure 12: OncRAS isoforms do not influence cell cycle distribution of TE617.T and RMS-13

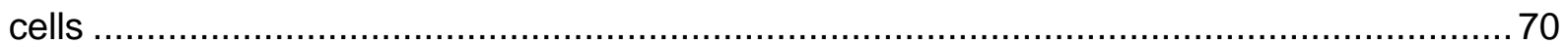

Figure 13: OncRAS isoforms downregulate relative GLI1 expression in RMS cell lines .......71 Figure 14: OncKRAS decreases $S H H$, whereas oncH-/NRAS decrease GLI3 in TE617.T

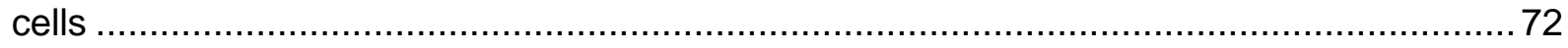

Figure 15: OncRAS isoforms modify GLI2 and SHH expression in RUCH-2 cells ...............73

Figure 16: OncRAS-transduced TE617.T cells are not able to secrete $\mathrm{HH}$ ligands ..............74

Figure 17: OncRAS-transduced RUCH-2 cells and RD cells do not stimulate Gli reporter activity in co-cultured $\mathrm{SHH}$ light II cells.

Figure 18: SHH moderately induces GLI1 transcription in oncRAS-expressing RUCH-2 cells 75

Figure 19: $\mathrm{SCH} 772984$ inhibits phosphorylation of ERK in different concentrations 76 Figure 20: $\mathrm{PI}-103, \mathrm{UO} 126$ and $\mathrm{SCH} 772984$ inhibit phosphorylation of their downstream

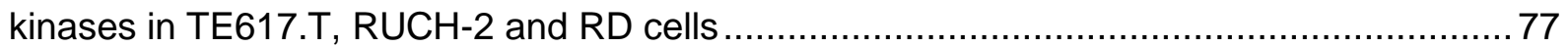

Figure 21: MEK and ERK suppress GL11 in TE617.T irrespective of oncRAS mutations......78 Figure 22: ERK mediates oncRAS-induced downregulation of GLI1 in RUCH-2 cells ..........79 Figure 23: ERK inhibition increases GLI1 expression in RD cells .................................. 80

Figure 24: ERK inhibits PTCH and SHH expression in TE617.T pMSCV cells 81 Figure 25: ERK activates GLI2 and inhibits PTCH expression in TE617.T KRAS cells and restores oncKRAS-dependent decrease of $S H H$ back to basal level 82

Figure 26: ERK inhibits PTCH and SHH expression in TE617.T H-/NRAS cells.

Figure 27: ERK inhibition does not influence expression of $\mathrm{HH}$ signaling genes in $\mathrm{RUCH}-2$

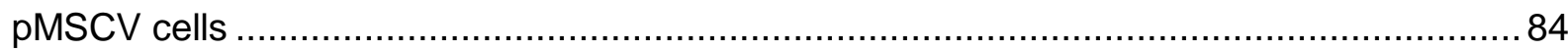

Figure 28: ERK mediates oncHRAS-dependent increase of $S H H$ in RUCH-2 cells .............. 84

Figure 29: ERK mediates oncKRAS-dependent increase of $\mathrm{SHH}$ in RUCH-2 cells ..............85 
Figure 30: ERK mediates oncNRAS-dependent decrease in GLI2 and increase in SHH in $\mathrm{RUCH}-2$ cells 86

Figure 31: ERK inhibits GL/3 expression in RD cells 87

Figure 32: ERK suppresses GLI activity in RD cells but not in stably transduced RUCH-2 cell lines.....

Figure 33: OncRAS isoforms modulate GLI protein expression in different cellular compartments in $\mathrm{RUCH}-2$ cells

Figure 34: ERK inhibition reverses oncRAS-dependent decrease of GLI1 protein in RUCH-2 cells .

Figure 35: Impact of oncRAS on proliferation and metabolic activity of ERMS cell lines ......92

Figure 36: OncRAS isoforms increase tumor growth and weight of TE617.T xenografts...... 94 Figure 37: OncRAS do not significantly change the expression of $h$ GLI1/mGli1, hGLI2/mGli2 in TE617.T xenografts.

Figure 38: OncKRAS and oncNRAS increase tumor growth and weight of $\mathrm{RUCH}-2$ xenografts

Figure 39: OncKRAS significantly induces mGli2 expression in the stroma of RUCH-2 xenografts

Figure 40: OncNRAS significantly decreases $h G L / 1$ expression in tumor cells of RUCH-2 xenografts. 98

Figure 41: X-Gal staining of skeletal muscle and ERMS isolated from solvent- or tamoxifentreated Ptch ${ }^{\text {del/+}}$ Myf5 ${ }^{\mathrm{CreER/+}} R 26 R^{+/-}$mice. 100

Figure 42: Ras isoforms are expressed in SM and ERMS tissue samples of Ptch $^{\text {del/t }}$ mice 101

Figure 43: Recombination assays for the floxed HRas loci 102

Figure 44: Recombination assays for the floxed KRas loci. 103

Figure 45: Recombination assays for the floxed NRas loci 103

Figure 46: Ras is active in ERMS tissue samples of tamoxifen-treated Ptch $^{\text {del/+ }}$ oncRas ${ }^{f /+}$ Myf5 $5^{\text {CreER/+ }}$ mice. 104

Figure 47: Tamoxifen treatment does not influence ERMS development in Ptch $^{\text {del/+ }}$ mice .. 106 Figure 48: OncHRas increases tumor incidence and slightly reduces ERMS-free survival in Ptch $^{\text {del/t}}$ mice 107

Figure 49: OncKRas increases tumor incidence and decreases ERMS-free survival in Ptch $^{\text {del/t+ }}$ mice 108

Figure 50: OncNRas does not influence ERMS-free survival, tumor incidence or multiplicity in Ptch $^{\text {del/t+ }}$ mice 109

Figure 51: OncHRas and oncKRas increase the percentage of $\mathrm{Ki}^{+} 7^{+}$nuclei in ERMS from Ptch $^{\text {del/t }}$ mice 110

Figure 52: OncRas does not influence the expression of Hh signaling genes in ERMS 112 
Figure 53: OncNRas induces expression of myogenic differentiation markers in ERMS, whereas oncHRas and oncKRas do not 115

Figure 54: Impact of oncHRas and oncKRas on phosphorylation of Erk, Akt and S6 and caspase cleavage in ERMS of $P t c h^{d e l /+}$ mice 116

Figure 55: Tamoxifen treatment and oncRAS mutations do not influence growth of established ERMS of $\mathrm{Ptch}^{\mathrm{del/+}}$ mice 118

Figure 56: Percentage of $\mathrm{Ki}^{+} 7^{+}$nuclei in established ERMS from $\mathrm{Ptch}^{\text {del/+ }}$ mice with and without oncRas 119

Figure 57: Tamoxifen treatment and oncRas mutations do not influence expression of Gli1 and Gli2 in established ERMS in Ptch ${ }^{\text {del/t }}$ mice..... 120

Figure 58: Tamoxifen treatment and oncRas mutations do not influence myogenic differentiation in established ERMS in $\mathrm{Ptch}^{\text {del/+ }}$ mice................................................ 122

Figure 59: Model system for HH/RAS interactions in ERMS with oncRAS mutations 133 


\section{List of Tables}

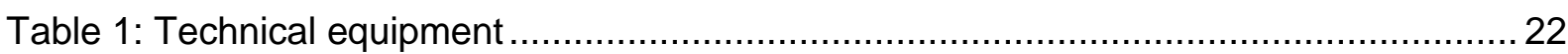

Table 2: Consumable materials ........................................................................ 24

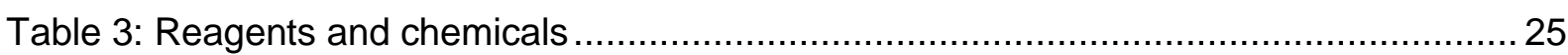

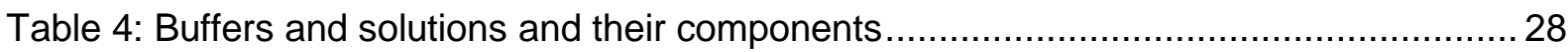

Table 5: Commercially available kits and ready-to-use reaction systems ........................... 30

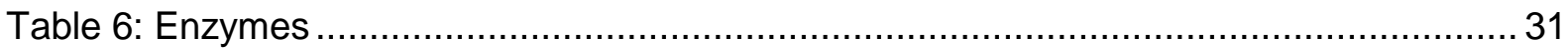

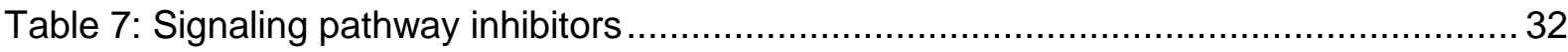

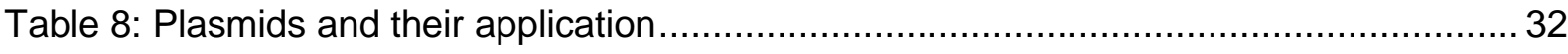

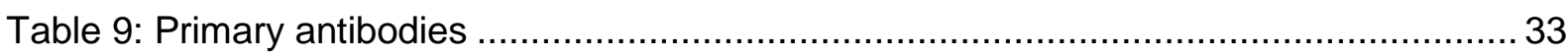

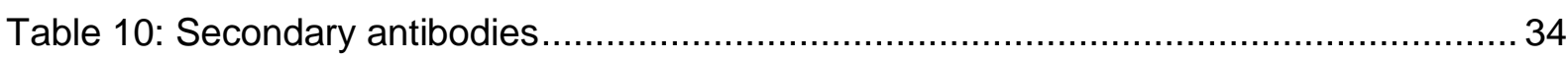

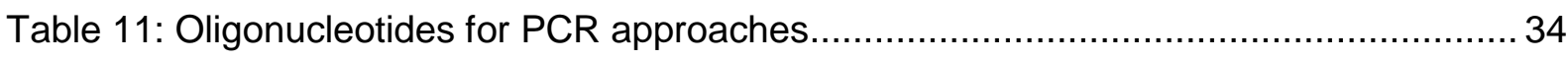

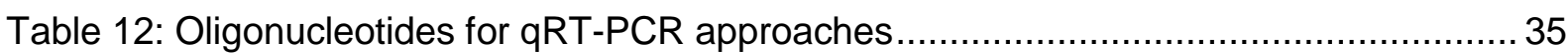

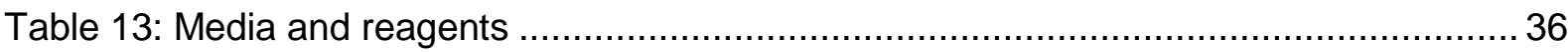

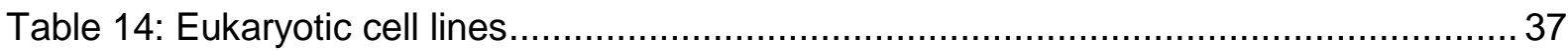

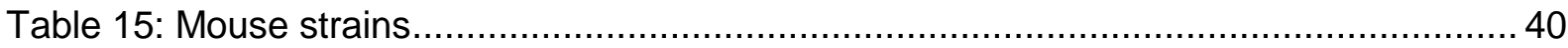

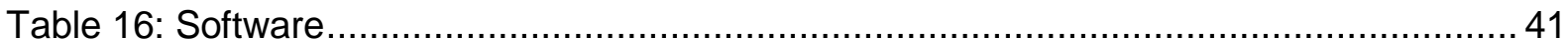

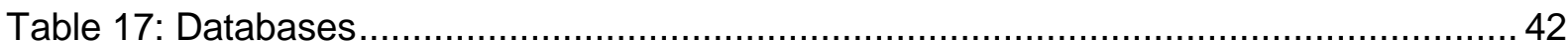

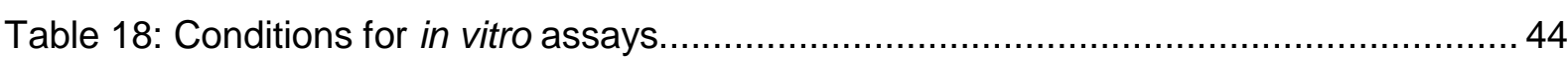

Table 19: Electroporation conditions for ERMS cell lines .............................................. 46

Table 20: Plasmid composition for GLI reporter assay in ERMS cell lines.......................... 47

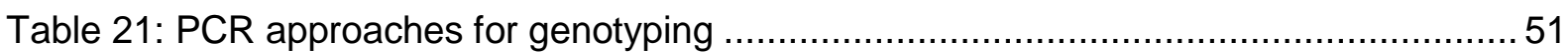

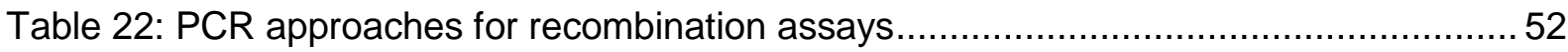

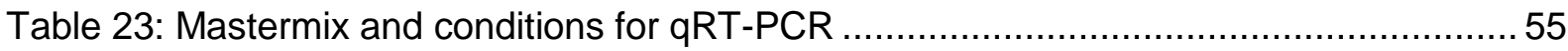

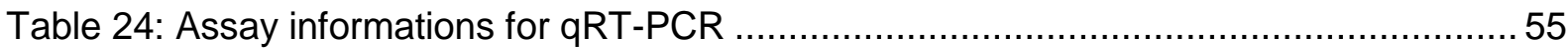

Table 25: Influence of tamoxifen treatment on ERMS development of 4 week old Ptch ${ }^{\text {del/+ }}$

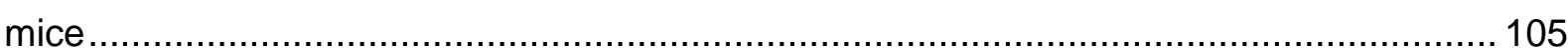

Table 26: Influence of oncHRas on ERMS development of 4 week old

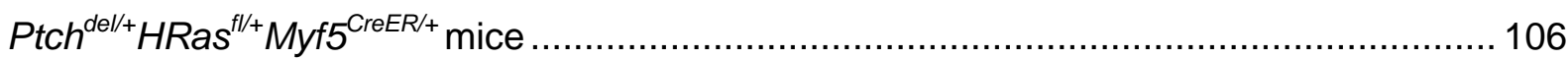

Table 27: Influence of oncKRas on ERMS development of 4 week old

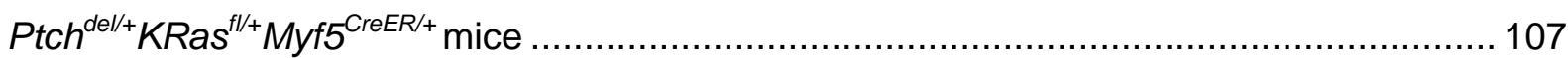

Table 28: Influence of oncNRas on ERMS development of 4 week old

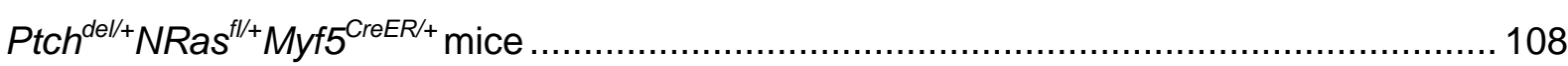

Table 29: Overview of oncRas-dependent effects in cell lines derived from sporadic ERMS, $\mathrm{Hh} / \mathrm{Ptch}$-driven ERMS precursor lesions and full-blown ERMS 


\section{Abbreviations}

$\mu \mathrm{CT}$

$\mathrm{Ab}$

AEC

AKT

ALDH

ANG

ANOVA

ARF

ARMS

ATCC

B6

Balb

BCA

BCC

$\mathrm{BCL}$

BD

BLAST

BOC

BrdU

BSA

bp

CAMP

Casp 3

CDK

CDKN

CDNA

CDO

ChIP

CM

CMV

COSMIC

Cre

CSC

CT

CTNNB

CXCR

DAB

DAPI

$\mathrm{ddH}_{2} \mathrm{O}$

Del

$\mathrm{DHH}$

DISP

DMBA
Micro computed tomography

Antibody

3-Amino-9-ethylcarbazole

Protein kinase B

Aldehyde dehydrogenase

Angiopoietin

Analysis of variance

ADP ribosylation factor

Alveolar RMS

American type culture collection

C57BL/6N

$\mathrm{BALB} / \mathrm{C}$

Bicinchoninic acid

Basal cell carcinoma

B-cell lymphoma

Binding domain

Basic Local Alignment Search Tool

Brother of CDO

5-bromo-2'-deoxyuridine

Bovine Serum Albumin Fraction V

Base pairs

Cyclic adenosine monophosphate

Caspase 3

Cyclin-dependent kinase

Cyclin-dependent kinase Inhibitor

Complementary DNA

Cell adhesion molecule-related/downregulated by oncogenes

Chromatin immunoprecipitation

Conditioned medium

Cytomegalovirus

Catalogue Of Somatic Mutations In Cancer

Cyclization recombination

Cancer stem cell

Cycle threshold

Catenin beta-1 ( $\beta$-catenin)

$\mathrm{C}-\mathrm{X}-\mathrm{C}$ motif chemokine receptor

3,3'-Diaminobenzidine

4',6-diamidino-2-phenylindole

Double-distilled water

Deleted

Desert Hedgehog

Dispatched

1,3-Dimethylbutylamine 


\begin{tabular}{|c|c|}
\hline DMEM & Dulbecco's Modified Eagle Medium \\
\hline DMF & Dimethylformamide \\
\hline DMSO & Dimethylsulfoxide \\
\hline DNA & Deoxyribonucleic acid \\
\hline DNMT & DNA methyltransferase \\
\hline dNTP & Deoxyribonucleotide triphosphate \\
\hline DTT & Dithiothreitol \\
\hline DYRK & Dual-specificity tyrosine-(Y)-phosphorylation-regulated kinases \\
\hline ECL & Enhanced chemiluminescence \\
\hline EDTA & Ethylenediamine tetraacetic acid \\
\hline e.g. & exempli gratia (lat. for example) \\
\hline EGF & Epidermal growth factor \\
\hline EGFP & Enhanced green fluorescent protein \\
\hline EGFR & EGF receptor \\
\hline EGTA & Ethyleneglycol tetraacetic acid \\
\hline ELISA & Enzyme-linked immunosorbent assay \\
\hline ELK & ETS-like gene 1, tyrosine kinase \\
\hline ERBB & Erb-B2 Receptor Tyrosine Kinase \\
\hline ERK & Extracellular-signal regulated kinase \\
\hline ERMS & Embryonal RMS \\
\hline $\mathrm{EtBr}$ & Ethidium bromide \\
\hline $\mathrm{EtOH}$ & Ethanol \\
\hline FACS & Fluorescence-activated cell scanning \\
\hline FCS & Fetal calf serum \\
\hline FGF & Fibroblast growth factor \\
\hline FGFR & FGF receptor \\
\hline Fig. & Figure \\
\hline $\mathrm{fl}$ & Floxed \\
\hline FOXO1 & Forkhead box protein $\mathrm{O} 1$ \\
\hline FU & Fused \\
\hline GAP & GTPase activating protein \\
\hline GAS1 & Growth arrest specific 1 \\
\hline gDNA & Genomic DNA \\
\hline GDP & Guanosine diphosphate \\
\hline GLI & Glioma-associated oncogene \\
\hline $\mathrm{GLI}^{\mathrm{A}}$ & GLI activator form \\
\hline Gli BS & Gli binding site \\
\hline $\mathrm{GLI}^{\mathrm{R}}$ & GLI repressor form \\
\hline GOI & Gene of interest \\
\hline GPCR & G-protein-coupled receptor \\
\hline GTP & Guanosine triphosphate \\
\hline GEF & Guanine nucleotide exchange factors \\
\hline h & Hour \\
\hline$h$ & Human \\
\hline $\mathrm{HA}$ & Hemagglutinin \\
\hline $\mathrm{HE}$ & Haematoxylin and eosin \\
\hline
\end{tabular}




\begin{tabular}{|c|c|}
\hline HEPES & 4-(2-hydroxyethyl)-1-piperazineethanesulfonic acid \\
\hline $\mathrm{HH}$ & Hedgehog \\
\hline $\mathrm{HhA}$ & HhAntag \\
\hline HHIP & $\mathrm{HH}$ interacting protein \\
\hline HIS & Histidin \\
\hline HRAS & Harvey rat sarcoma \\
\hline HPRT & Hypoxanthine phosphoribosyltransferase \\
\hline HRP & Horseradish peroxidase \\
\hline HSC70 & Heat shock cognate $71 \mathrm{kDa}$ protein \\
\hline HSV-TK & Herpes simplex virus thymidine kinase \\
\hline i.e. & id est (lat. that is) \\
\hline $\lg G$ & Immunoglobulin G \\
\hline IGF & Insulin-like growth factor \\
\hline $\mathrm{IHC}$ & Immunohistochemistry \\
\hline $\mathrm{IHH}$ & Indian Hedgehog \\
\hline IKK & Inhibitor of $\mathrm{kB}$ kinase \\
\hline IL & Interleukin \\
\hline i.p. & Intraperitoneally \\
\hline ISH & In situ hybridization \\
\hline i.v. & Intravenously \\
\hline JNK & C-Jun N-terminal kinase \\
\hline $\mathrm{kb}$ & Kilobase \\
\hline KRAS & Kirsten rat sarcoma \\
\hline $\mathrm{kDa}$ & Kilo Dalton \\
\hline LB & Lysogeny broth \\
\hline $\log$ & Logarithm to base 10 \\
\hline $\mathrm{LOH}$ & Loss of heterozygosity \\
\hline LoxP & Locus of crossing-over of bacteriophage $\mathrm{P} 1$ \\
\hline$m$ & Murine \\
\hline $\mathrm{mAb}$ & Monoclonal antibody \\
\hline MAPK & Mitogen-activated protein kinase \\
\hline MB & Medulloblastoma \\
\hline MDM2 & Mouse double minute 2 homolog \\
\hline MEK & Mitogen-activated kinase \\
\hline $\mathrm{MeOH}$ & Methanol \\
\hline MEKK1 & Mitogen-activated protein kinase kinase kinase 1 \\
\hline $\min$ & Minute \\
\hline MMP & Matrix metalloproteinase \\
\hline MolTaq & Taq-Polymerase (named after Thermus aquatius) \\
\hline MRF & Myogenic regulatory factor \\
\hline mRNA & Messenger RNA \\
\hline mTOR & Mammalian target of rapamycin \\
\hline MYC & Avian myelocytomatosis virus oncogene cellular homolog \\
\hline Myf & Myogenic factor \\
\hline MyHC & Myosin heavy chain \\
\hline
\end{tabular}




\begin{tabular}{|c|c|}
\hline MyoD & Myogenic differentiation antigen \\
\hline $\mathrm{N}$ & Sample size \\
\hline NC & Nitrocellulose \\
\hline $\mathrm{NCBI}$ & National Center for Biotechnology Information \\
\hline NF1 & Neurofibromin 1 \\
\hline NFKB & Nuclear factor 'kappa-light-chain-enhancer' of activated B-cells \\
\hline NLB & Nuclear lysis buffer \\
\hline NIK & NFKB inducing kinase \\
\hline NRAS & Neuroblastoma RAS viral oncogene homolog \\
\hline n.s. & Not significant \\
\hline OD & Optical density \\
\hline OMIM & Online Mendelian Inheritance in Man \\
\hline oncRAS & Oncogenic RAS \\
\hline $\mathrm{pAb}$ & Polyclonal antibody \\
\hline pAKT & Phosphorylated AKT \\
\hline PAX & Paired box gene \\
\hline PBS & Phosphate buffered saline \\
\hline PBST & PBS-Tween 20 \\
\hline PCR & Polymerase chain reaction \\
\hline PDGFR & Platelet-derived growth factor receptor \\
\hline pDNA & Plasmid DNA \\
\hline pERK & Phosphorylated ERK \\
\hline PFA & Paraformaldehyde \\
\hline $\mathrm{pH}$ & lat. potentia hydrogenii \\
\hline $\mathrm{PI}$ & Propidium iodide \\
\hline PI3K & Phosphatidylinositol-4,5-bisphosphate 3-kinase \\
\hline PIK3CA & Phosphoinositide-3-kinase, catalytic, alpha polypeptide \\
\hline PKC & Protein kinase $\mathrm{C}$ \\
\hline PL & Phospholipase \\
\hline pMSCV & Plasmid derived from Murine Stem Cell Virus \\
\hline PRMS & Pleomorphic RMS \\
\hline $\mathrm{P} / \mathrm{S}$ & Penicillin/Streptomycin \\
\hline pS6 & Phosphorylated S6 \\
\hline PTCH & Patched \\
\hline$p$-value & Probability value \\
\hline qRT-PCR & Quantitative real-time PCR \\
\hline RAF & Rat fibrosarcoma \\
\hline RAG & Recombination activating gene \\
\hline RAS & Rat sarcoma \\
\hline $\mathrm{Rb}$ & Retinoblastoma \\
\hline RBD & Ras-binding domain \\
\hline RIPA & Radioimmunoprecipitation assay buffer \\
\hline RLU & Relative light unit \\
\hline RMS & Rhabdomyosarcoma \\
\hline rpm & Rounds per minute \\
\hline
\end{tabular}




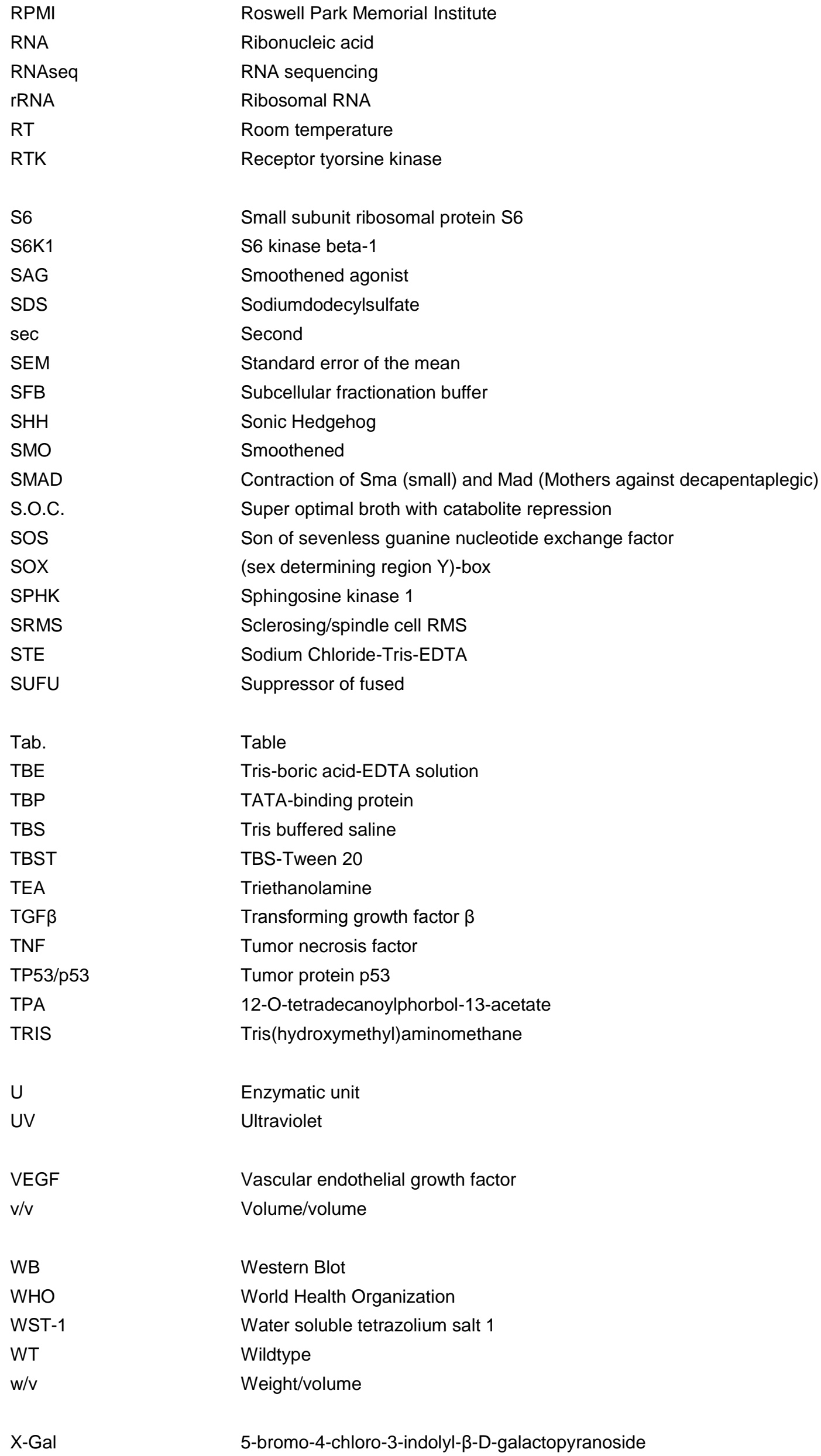

Western Blot

World Health Organization

Water soluble tetrazolium salt 1

Wildtype

Weight/volume 


\section{Abstract}

Rhabdomyosarcoma (RMS) are the most common pediatric soft tissue sarcomas. RMS of the embryonal subtype (ERMS) are characterized by high expression of markers of an activated Hedgehog $(\mathrm{HH})$ signaling cascade, i.e. they overexpress GLI1, GLI2 and PTCH. However, they very infrequently show pathway-activating mutations e.g. in PTCH, although inherited PTCH/Ptch mutations act as ERMS-drivers both in humans and mice. This is different for oncogenic mutations in the 3 RAS genes ( $\mathrm{H}$-, K-and NRAS; oncRAS), which are a very common in ERMS. Since the literature provides evidence for crosstalks between $\mathrm{HH}$ and RAS signaling in other tumor entities, this thesis aimed at a better understanding of a potential interaction of $\mathrm{HH}$ and RAS signaling in ERMS and of their roles in ERMS pathogenesis, growth and aggressiveness. This is particulary important for improvement of treatment strategies, which currently show only moderate efficiencies and sometimes cause severe side effects.

First, the role of oncRAS isoforms in regulation of $\mathrm{HH}$ targets and associated cellular responses were studied in human cell lines derived from sporadic (full-blown) ERMS. The in vitro data from TE617.T, RUCH-2 and RD highlight that oncRAS isoforms decrease the expression of the major HH-target GLI1 in dependency of ERK. GLI1 downregulation was also seen on protein level in both the nucleus and cytoplasm. This indicates that oncRAS/ERK probably act on GLI1 transcription. In addition, oncRAS/ERK also regulate the expression of other $\mathrm{HH}$ pathway members e.g. of $\mathrm{SHH}, \mathrm{PTCH}$ and $\mathrm{GL} / 2$, which however depends on the oncRAS isoform and the individual cell line. Although oncRAS mutations can modify the expression of $S H H$, the cell lines are in all likeliness not able to secrete $\mathrm{HH}$ ligands and are not $\mathrm{HH}$-responsive. Together, this supports an oncRAS-mediated noncanonical suppression of $\mathrm{HH}$ signaling, or at least of GL/1/GLI1 expression, in sporadic ERMS.

Interestingly, oncRAS isoforms increase proliferation and tumorigenicity of ERMS cell lines despite downregulation of GL/1/GLI1. This indicates that proliferation of the cells is independent of $\mathrm{HH}$ signaling or at least of GL/1/GLI1. Since oncRAS-mediated GL/1downregulation is only moderate in xenografts, it is likely that the tumor microenvironment also influences $\mathrm{HH}$ signaling.

OncKRas and oncHRas also aggravate formation of $\mathrm{Hh} /$ Ptch-driven ERMS from heterozygous Ptch ${ }^{\text {del/t }}$ mice. This is in contrast to oncNRas, which induces expression of myogenic markers without otherwise affecting the tumor. This suggests that the 3 oncRas isoforms have divergent functions in ERMS, at least in Hh/Ptch-driven tumors. Interestingly, these oncRas-mediated changes are only seen when the oncRas genes are expressed at a 
very early ERMS stage, i.e. in ERMS precursor lesions. However, they do not occur when the mutations are induced at the full-blown tumor stage. Since, according to the literature, oncRas mutations themselves do not drive ERMS formation and since none of the oncRas genes significantly influence $\mathrm{Hh}$ signaling activity in $\mathrm{Hh} / \mathrm{Ptch}$-driven ERMS, these findings open the possibility that the mutational status of PTCH/Ptch may influence the importance of oncRAS mutations in ERMS. On the other hand it is possible that oncRAS mutations are rather passenger mutations, which only affect already initiated ERMS precursor cells and/or cancer stem cells (CSCs), but not the ERMS bulk populations. Indeed, a preliminary analysis shows that cell lines from sporadic (full-blown) ERMS have a subpopulation, which is positive for the CSC marker CD133. Of whether full-blown ERMS of heterozygous Ptch ${ }^{\text {del/t }}$ mice lack this population is not clear at the moment and further experiments need to be done to shed light on these hypothesis. Together, these interesting results help to better understand the pathology of ERMS and hopefully will also be valuable to improve current therapies for this childhood sarcoma. 


\section{Introduction}

\subsection{Rhabdomyosarcoma}

Soft tissue sarcomas are a very heterogeneous group of over 50 rare tumor entities that occur throughout the lifespan ${ }^{1}$. They account for about $2 \%$ of malignant tumors in adults and $7 \%$ of pediatric malignancies ${ }^{2,3}$. In children, rhabdomyosarcoma (RMS) account for approximately $50 \%$ of all soft tissue tumors and thereby are the third most common extracranial solid tumor ${ }^{3,4}$. RMS have an incidence of 4.5 cases per million children per year and most frequently occur in children younger than 10 years of age ${ }^{5}$.

Originally RMS were thought to develop from cells committed to the skeletal muscle lineage, because they frequently show aberrant muscle differentiation and develop in the skeletal muscle. However, since these tumors can also arise from other anatomic sites, such as the genitourinary region, it is thought that they rather are of mesenchymal origin ${ }^{1,6-8}$.

RMS represent a heterogeneous group of soft tissue sarcomas. They can be divided into several histopathological subtypes, which differ in their clinical and morphological phenotype and molecular features. The current classification from the World Health Organization (WHO) divides RMS into alveolar RMS (ARMS), which are characterized by tumor cells separated by thin fibrovascular septa and embryonal RMS (ERMS) with small round blue cells and partial rhabdomyoblastic differention. ERMS can also show botryoid and pleomorphic growth patterns. Other RMS variants are pleomorphic RMS (PRMS), and sclerosing/spindle cell RMS (SRMS) ${ }^{5,9-11}$. The two major RMS subtypes in children are ARMS and ERMS and they differ in their prevalence, clinical features and outcome ${ }^{6}$.

ARMS account for approximately one-third of all RMS and frequently occur in adolescents. They are found most commonly in the deep tissue of the extremities and show an alveolar pattern in histology ${ }^{5}$. On molecular level they can be divided into fusion-positive and fusionnegative tumors. Fusion-positive ARMS (75\%) show chromosomal translocations $[\mathrm{t}(2 ; 13)(\mathrm{q} 35, \mathrm{q} 14)$ or $\mathrm{t}(1 ; 13)(\mathrm{p} 36 ; \mathrm{q} 14)]$ leading to Forkhead box protein $\mathrm{O}$ (FOXO)1-Paired box gene (PAX)3/PAX7 fusion proteins, which contribute to pathogenesis ${ }^{12}$. Fusion-negative ARMS, lacking PAX-FOXO1 fusion proteins, are clinically and biologically similar to ERMS ${ }^{13}$. ERMS account for approximately two-thirds of all RMS and occur mainly in young children. Histologically, they resemble undifferentiated embryonic mesenchyme with isolated immature myoblastic cells. They are often found in the head and neck region and in the genitourinary tract ${ }^{5}$. Whole-genome sequence projects reveal that ERMS in general possess a higher background mutation rate than ARMS ${ }^{14,15}$. On molecular level, ERMS frequently show loss of heterozygosity ( $\mathrm{LOH}$ ) at chromosome $11 \mathrm{p} 15$, which is the locus of Insulin-like growth factor 2 (IGF2) ${ }^{4}$. In addition, mutations in the rat sarcoma (Ras) signaling pathway (NRAS, 
KRAS, HRAS and Neurofibromin 1(NF1)) are frequently described for ERMS ${ }^{5,6,15}$ (compare section 2.3.4). Moreover, they can carry mutations in Myogenic differentiation antigen (MYOD), Fibroblast growth factor receptor (FGFR)4, catalytic Phosphoinositide-3-kinase alpha polypeptide (PIK3CA), Catenin beta 1 (CTNNB1) genes and in the tumour suppressor genes tumor protein 53 (TP53) and Retinoblastoma (RB)1. However and in contrast to ARMS, they are always fusion-negative ${ }^{6,8,16}$.

RMS have been associated with several hereditary diseases. These include hereditary retinoblastoma, neurofibromatosis type 1, Li-Fraumeni syndrome, Rubinstein-Taybi syndrome, Beckwith-Wiedemann syndrome, Costello syndrome, Noonan syndrome and Gorlin (basal cell carcinoma nevus) syndrome ${ }^{8,17-22}$. However, most cases of RMS are considered sporadic in their origin ${ }^{8,20}$.

\subsubsection{Current prognostics and therapy strategies}

The tumor size, age at diagnosis, histological type, tumor stage and already conducted therapies are significantly associated with the overall survival of RMS. In general, patients with RMS show a 10-year overall survival rate of $62 \%$. More precisely, the rates range between $75 \%$ for fusion-negative ARMS, $65 \%$ for ERMS and $20 \%$ for fusion-positive ARMS ${ }^{13,23}$. This highlights that fusion-positive ARMS are associated with a poorer prognosis than ERMS and fusion-negative ARMS.

RMS are considered a systemic disease with the possibility of micro- and macrometastasis, which are found in $46 \%$ of fusion-positive RMS and $17 \%$ of fusion-negative RMS 1,13,24. Thus an effective treatment should not only target the primary tumor but also distant tumor seeds. The currently available multimodal therapy, which encompasses surgery, radiation and chemotherapeutic drugs, leads to the recovery of $60 \%$ of all RMS patients. However, less than $30 \%$ of high-risk patients (metastatic or fusion-positive tumors, adults) are cured ${ }^{13,25}$. In addition, many patients suffer from adverse side effects and treatment-related late effects ${ }^{8}$. Thus, more effective and less harmful therapy options are needed, which requires a better understanding of biology and molecular mechanisms of RMS pathogenesis.

\subsection{The Hedgehog signaling pathway}

The Hedgehog $(H h)$ ligand and its receptor Patched (Ptch) were first discovered in a mutational screen in larvae of Drosophila melanogaster. The mutations in the respective genes lead to segmentation defects, which in case of $H$ h results in a surface reminding of hedgehog spines ${ }^{26}$. A few years later, Hh was shown to influence pattern formation in surrounding cells in a paracrine manner ${ }^{27-29}$.

Today it is known, that the Hh signaling pathway is one of the most important signal transduction pathways during embryonic development. In general, $\mathrm{Hh}$ signaling is quiescent in the adult organism but it is implicated in cell differentiation, stem cell maintenance, 
metabolic homeostasis, tissue homeostasis and repair ${ }^{30,31}$. As a consequence, pathological activation of the pathway plays a crucial role in initiation and formation of various cancers ${ }^{32}$.

\subsubsection{Canonical Hh signaling}

In mammals $3 \mathrm{Hh}$ homologs, namely Indian Hedgehog (Ihh), Desert Hedgehog (Dhh) and Sonic Hedgehog (Shh), with distinct expression patterns were discovered ${ }^{33}$. Shh, the best studied Hh ligand, has a high functional similarity to Hh of Drosophila. It affects cells of the developing embryo, especially during formation of the ventral neural tube, the anteriorposterior limb axis and the ventral somites. Furthermore and as already said, it controls tissue homeostasis, stem cell maintenance and differentiation processes of mesenchymal cells in adults ${ }^{33,34}$. Ihh is involved in chondrogenesis, whereas Dhh regulates germ-cell proliferation and development of peripheral nerves. Dhh is also expressed in adult nerves ${ }^{33,35-37}$. Hh proteins are synthesized as precursors and are matured by autocatalytic cleavage and posttranslational modifications. Thus, a cholesterol moiety is attached to the Nterminal product and thereby restricts the ligand to the cell surface. If required for signaling, the processed $\mathrm{Hh}$ ligands are secreted with the help of the transmembrane protein Dispatched (DISP) ${ }^{32,38-40}$.

Two Ptch homologs Patched1 (Ptch) and Patched 2 (Ptch2) are present in mammals. Ptch is a 12-pass transmembrane protein and the major Hh receptor. It has 2 extracellular loops, which are required for $\mathrm{Hh}$ binding, a cytoplasmic C-terminus that is involved in signal transduction and a sterol-sensing domain that mediates the intracellular trafficking of Ptch. It constitutively represses $\mathrm{Hh}$ signaling and thereby acts as a tumor suppressor ${ }^{41-43}$. The binding of $\mathrm{Hh}$ ligands to Ptch is supported by its co-receptors Cell adhesion moleculerelated/downregulated by oncogenes (Cdo), Brother of Cdo (Boc) and Growth arrest specific 1 (Gas 1$)^{44}$. In its unbound state, Ptch is localized in the primary cilium und suppresses the activity of its interaction partner Smoothened (Smo) via a poorly understood mechanism ${ }^{45}$. Smo is a seven transmembrane receptor of the G-protein-coupled receptor (GPCR) superfamily ${ }^{46,47}$. Its activation triggers processing and modifications of glioma-associated oncogene (Gli) proteins (Cubitus interruptus in Drosophila melanogaster) and thereby the activity of the $\mathrm{Hh}$ signaling cascade ${ }^{42}$.

The Gli proteins act as activator or repressor of transcription, which is reliant on the availability of $\mathrm{Hh}$ ligands ${ }^{48,49}$. Gli1 is a transcriptional target of $\mathrm{Hh}$ signaling and provides a positive feedback loop in the pathways activity, whereas Gli2 and Gli3 are the main mediators of $\mathrm{Hh}$ signaling ${ }^{50}$. Gli2 and $\mathrm{Gli} 3$ are bifunctional transcription factors, which can act as full length activator forms $\left(G \mid i^{A}\right)$ or truncated repressor forms $\left(G i^{R}\right)$. The activator forms are stabilized in the presence of $\mathrm{Hh}$ ligands. Gli proteins are processed into their truncated repressor forms when $\mathrm{Hh}$ ligands are absent. The balance between activator and repressor forms is very important for the regulation of $\mathrm{Hh}$ signaling activity ${ }^{51-53}$. The 
processing into truncated Gli proteins is triggered by phosphorylation of amino acids that are located N-terminally or C-terminally of the DNA binding domain. Strong phosphorylation of both regions promotes the processing into truncated $\mathrm{Gli}^{\mathrm{R}}$ forms or triggers degradation. Partially phosphorylated Gli proteins are processed and act as weak Gli ${ }^{\mathrm{A}}$ (phosphorylation Cterminally of the DNA binding domain) or weak Gli ${ }^{\mathrm{R}}$ (phosphorylation N-terminally of the DNA binding domain). Dephosphorylated Gli proteins are not processed and act as strong $\mathrm{Gli}^{\mathrm{A}}{ }^{54,55}$. Since Gli1 misses the N-terminal region after the zinc-finger DNA binding domain, it is supposed to act only as a Gli ${ }^{A}$ form. Gli1 and Gli2 have strong activator functions when present as the full length $\mathrm{Gli}^{\mathrm{A}}$ form. Gli2 can be processed into a $\mathrm{Gli}^{\mathrm{R}}$ form with low efficiency in mouse embryos and it is therefore considered to have a weak repressor activity ${ }^{56}$. In contrast, full-length Gli3 protein, which acts as a weak Gli $^{\mathrm{A}}$ form especially in early developmental processes like spinal cord patterning and sclerotome development ${ }^{56-58}$, is efficiently processed into its truncated $\mathrm{Gli}^{\mathrm{R}}$ form that acts as a strong transcriptional repressor.

A simplified scheme of the Hh pathway is shown in Figure 1 (Fig. 1). Fig. $1 \mathrm{~A}$ shows the pathway in its inactive state, whereas Fig. 1B shows the active pathway upon binding of the Hh ligand.

In the absence of $\mathrm{Hh}$ ligands, Ptch is located in the primary cilium of the cell where it represses the activity of its interaction partner Smo ${ }^{45}$. The Gli proteins are prevented from entering the nucleus through interactions with the serine/threonine kinase fused $(\mathrm{Fu})$ and suppressor of fused (Sufu) ${ }^{59}$. The Gli proteins are phosphorylated, which results in their proteolytic cleavage to truncated $\mathrm{Gli}^{\mathrm{R}}$ proteins. $\mathrm{Gli}^{\mathrm{R}}$ proteins, mainly $\mathrm{Gli}{ }^{\mathrm{R}}$, translocate into the nucleus and repress target gene transcription. In addition, surplus Gli proteins are ubiquitinated and subsequently proteasomally degraded ${ }^{60,61}$.

Upon binding of $\mathrm{Hh}$ ligands, Ptch is inactivated and its inhibitory effect on Smo is abrogated. This results in enrichment of Smo in the primary cilium. As a consequence Sufu is degraded and releases Gli proteins ${ }^{62,63}$. The Gli proteins are dephosphorylated and stabilized in their full length $\mathrm{Gli}^{\mathrm{A}}$ form. Thereupon, $\mathrm{Gli}^{\mathrm{A}}$ proteins, mainly $\mathrm{Gli}^{\mathrm{A}}$, translocate into the nucleus and activate the transcription of $\mathrm{Hh}$ target genes ${ }^{42,49,64}$. Among others, the mammalian $\mathrm{Hh}$ target genes include Gli1, Ptch and Hh interacting protein (Hhip). Additionally, Gli proteins can regulate genes implicated in proliferation (Igf2, Platelet-derived growth factor receptor (Pdgfr), myelocytomatosis virus oncogene cellular homolog $(M y c)$ ), cell cycle progress and apoptosis (Cyclin D1, Cyclin D2, N-Myc, B-cell lymphoma (Bcl) 2), angiogenesis (Vascular endothelial growth factor (Vegf), Angiopoietin (Ang)1/2), epithelial-mesenchymal transition (Matrix metalloproteinase (Mmp)9, Snail) or in regulation of stem cells (Nanog, (sex determining region Y)-box 2 (Sox2)) ${ }^{31,32,42,60,65-67}$. However, the most reliable and robust readout of an active $\mathrm{Hh}$ signaling pathway is considered to be Gli1 expression ${ }^{46,68,69}$. The activity of the Hh signaling pathway is not only regulated by its ligands, but partly also 
through its targets genes. Whereas expression of Gli1 amplifies the Hh signal, expression of Ptch and Hhip decreases the signal in a negative feed-back loop.
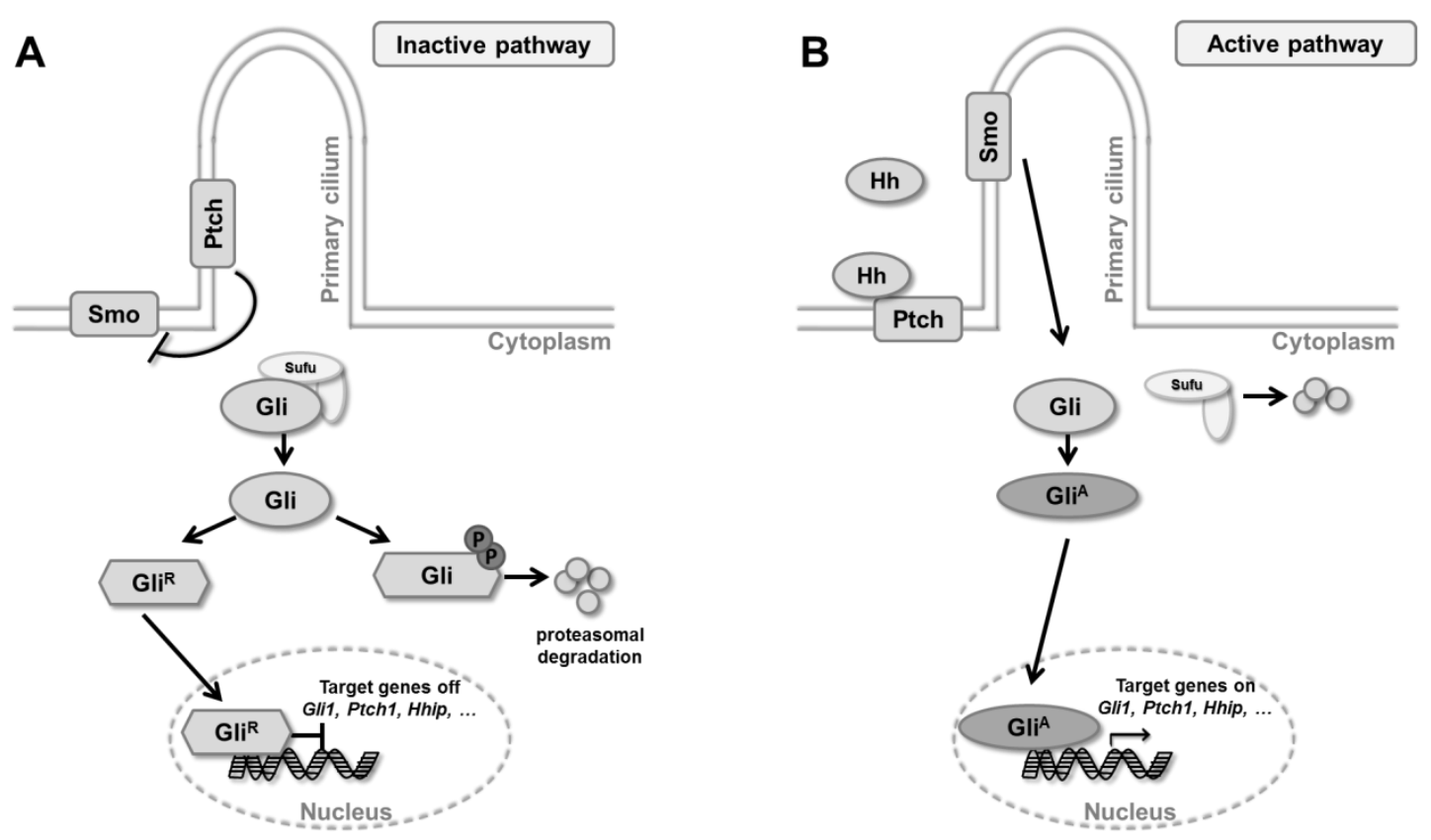

Figure 1: The Hh signaling pathway

(A) In the absence of its ligands the Hh signaling pathway is inactive. The transmembrane protein receptor Patched (Ptch) inhibits the activity of its interaction partner Smoothened (Smo). As a consequence, the gliomaassociated oncogene (Gli) transcription factors, which are downstream targets of Smo, are kept in the cytoplasm by interaction with suppressor of fused (Sufu). Gli proteins are processed and act in their truncated repressor forms $\left(\mathrm{Gli}{ }^{\mathrm{R}}\right)$, which block target gene expression. Additionally, Gli proteins are proteasomally degraded. Consequently, transcription of $\mathrm{Hh}$ target genes is repressed. (B) Hh ligands bind to their receptor Ptch. This inactivates Ptch, which results in activation of Smo and the stabilization of Gli activator forms $\left(\mathrm{Gli}^{\mathrm{A}}\right)$. Gli ${ }^{\mathrm{A}}$ translocates into the nucleus and activates the transcription of Hh target genes. One of these targets is Glit, which can amplify the Hh signal and provides a reliable marker of the pathway's activity. Additionally, Hh siganling promotes proteasomal degradation of Gli inhibitor Sufu. For more details see text. Modified according to ${ }^{32}$.

\subsubsection{Non-canonical Hh signaling}

Besides canonical regulation (see section 2.2.1), Hh signaling can be regulated in a noncanonical manner. Non-canonical Hh signaling is divided into signaling processes, which do not require Smo (see section 2.2.2.1) and those which do not require Gli transcription factors (see section 2.2.2.2) ${ }^{70}$.

\subsubsection{Smo-independent Hh signaling}

Smo-independent $\mathrm{Hh}$ signaling summarizes the regulation of expression, stability and transcriptional activity of Gli transcription factors by interaction with other signaling pathways or regulatory proteins. Smo-independent regulation of Gli proteins by other oncogenes and tumor suppressors is particularly involved in cancers ${ }^{51,52,69,71}$.

The tumor suppressor p53 can inhibit Gli transcriptional activity because it can hamper the nuclear localisation of Gli1. This has been shown in melanoma ${ }^{72}$. Vice versa, Gli1 can also repress the activity of p53 in mouse embryonic fibroblasts by upregulation of the p53 inhibitor Mouse double minute 2 homolog (Mdm2). This results in degradation of p53 ${ }^{73}$.

The transforming growth factor $\beta(\operatorname{Tgf} \beta)$ can indirectly induce Gli1 and Gli2 expression in 
different cell lines without involving the Ptch/Smo axis. Thus, activation of Tgf $\beta$ can cooperate with Smad3 or $\beta$-catenin, which in turn bind to the Gli2 promotor and thereby regulate the activation of Gli2 and Gli1 ${ }^{74}$.

The phosphatidylinositol-4,5-bisphosphate 3-kinase (PI3K)/ protein kinase B (Akt)/ mammalian target of rapamycin (mTOR) signaling cascade can enhance nuclear localization and transcriptional activity of Gli1 and Gli2 in different human an murine model systems ${ }^{75-78}$. Thus, activated mTOR/Small subunit ribosomal protein S6 kinase beta (S6K1) signaling downstream of PI3K/Akt can modify phosphorylation and enhance activity of Gli1 ${ }^{79}$. Additionaly, AKT1 itself is a transcriptonal target of the $\mathrm{HH}$ signaling cascade in B-cell lymphoma. This connection is a hint for a regulatory feed-back mechanism between Akt and Hh signaling ${ }^{80}$.

Furthermore, the dual-specificity tyrosine-(Y)-phosphorylation-regulated kinases (Dyrk) $1 \mathrm{~A}$ and $1 \mathrm{~B}$ and also Dyrk2 can regulate Gli1 and Gli2 activity by phosphorylation ${ }^{81-83}$. As already mentioned above, phosphorylation of Gli proteins leads to processing into the respective $\mathrm{Gli}^{\mathrm{A}}$ or $\mathrm{Gli}^{\mathrm{R}}$ forms ${ }^{54}$. Dyrk1A can phosphorylate GLI1, which promotes its nuclear localization ${ }^{81,82}$. Dyrk1B was reported to either inhibit or stimulate Hh signaling, dependent on the Dyrk1B expression level and the used model systems ${ }^{84-87}$. It was suggested that Dyrk1B activates mTOR/Akt, which promotes Gli1 stabilization ${ }^{87}$. Finally, Dyrk2 can phosphorylate Gli2, thereby inducing its degradation in mouse embryonic fibroblasts and COS1 cells ${ }^{83}$.

Finally, oncogenic Ras (oncRas) isoforms can directly influence Gli transcription factors with diverse outcomes in different tumor entities. This is reviewed in detail in section 2.4.

\subsubsection{Gli-independent Hh signaling}

The Hh receptor Ptch can regulate cell survival through apoptosis induction. This does not involve $\mathrm{Hh}$ ligands, Smo or Gli, but the formation of a caspase-activating complex ${ }^{88,89}$. Furthermore, Ptch can regulate cell cycle progression through interaction with Cyclin B1 without the involvement of the Smo/Gli axis ${ }^{90,91}$.

In addition, Hh ligands can alter cell morphology and migratory capacity without Gli transcription activity in murine and human cells. However, this requires Smo activity, which in turn can activate PI3K or small guanosine triphosphate (GTP)ases like RhoA resulting in cytoskeletal changes ${ }^{89,92}$. The Smo-mediated cytoskeletal rearrangements and migration requires the metabolism of arachidonic acid through the 5-lipoxygenase pathway ${ }^{92,93}$. Moreover, Shh can stimulate Src kinases to control guidance of murine commissural axons. This also requires Smo, but not Gli proteins ${ }^{94}$. Additionally, Shh stimulates intracellular $\mathrm{Ca}^{2+}$ spike activity in neurodevelopment ${ }^{95}$. Vice versa, intracellular $\mathrm{Ca}^{2+}$ release and Protein kinase c (Pkc) activation can stimulate Shh gene expression ${ }^{96}$ and these activities do not require Gli proteins. Finally, Smo can trigger intracellular signaling via second messengers like $\mathrm{Ca}^{2+}$ and cyclic adenosine monophosphate (cAMP) ${ }^{97}$. Indeed, Smo is supposed to 
influence physiological $\mathrm{Ca}^{2+}$ fluctuation and $\mathrm{Ca}^{2+}$-dependent signaling pathways in a Gliindependent manner ${ }^{96}$. Moreover, Smo, $\mathrm{Ca}^{2+}$ and CAMP are involved in Warburg-like metabolic reprogramming in muscles and brown fat ${ }^{98}$.

\subsubsection{Canonical HH signaling in human cancer}

Several cancers are caused by pathological activation of the Hh signaling pathway. Indeed, the first link between a predisposition to tumors and mutations within the $\mathrm{HH}$ signaling pathway was the discovery of $\mathrm{PTCH}$ mutations in patients with Gorlin syndrome ${ }^{99-102}$. Besides developmental defects, patients with Gorlin syndrome develop basal cell carcinoma (BCC) and have an increased risk of developing other cancers such as medulloblastomas (MB), RMS, fibromas, glioma and meningioma $21,66,102-107$.

Subsequently, aberrant activation of the $\mathrm{HH}$ signaling cascade due to inactivating mutations in $P T C H$ or SUFU, activating mutations in SMO or mutations of other $\mathrm{HH}$ pathway molecules have been shown in the majority of both familial and sporadic forms of BCC and a subset of MB ${ }^{108-117}$. In the latter cancer entity a signature of the $\mathrm{HH}$ pathway activation status (GLI1, SPHK1, SHROOM2, PDLIM3, OTX2) has been established and serves as a diagnostic tool in the treatment of these tumors with $\mathrm{HH}$ inhibitors ${ }^{118}$. In addition, mutations in members of the $\mathrm{HH}$ signaling pathway have also been reported in other cancers associated with Gorlin syndrome, including RMS (see section 2.2.4) and meningiomas ${ }^{119,120 .}$

Thereupon, pathological activation of $\mathrm{HH}$ signaling was detected in a huge variety of other cancer types. As in $B C C$ and $M B$, the dysregulation of the signaling pathway can be mutation-driven (Fig. 2A). However, it also can be ligand-driven (Fig. 2B) or can be dysregulated due to amplification of GLI (Fig. 2C). This dysregulation can occur tumorintrinsically or in the surrounding stromal tissue, or in both.

Examples for mutation-driven $\mathrm{HH}$-associated tumors are $\mathrm{BCC}$ and $\mathrm{MB}$, as already said. In contrast, lymphomas are ligand-driven tumors and show constitutive activation of the $\mathrm{HH}$ pathway due to overexpression of $\mathrm{SHH}{ }^{121}$. Similarly, the expression of $S H H$ and $G L / 1$ is increased in a subset of small lung cell carcinoma ${ }^{122}$. An amplification of GLI transcription factors has been described in glioblastoma, BCC and bladder cancer ${ }^{123-125}$.

However, in the majority of tumor entities showing $\mathrm{HH}$ signaling activity, both mutations and overexpression of the ligands can be responsible for pathological activation of the pathway. For example tumors of the foregut, oesophagus, stomach and biliary tract can either show an increased level of $\mathrm{SHH}$ or $\mathrm{IHH}$ or genetic alterations in PTCH, SMO or SUFU ${ }^{126,127}$. In a subgroup of pancreatic adenocarcinoma and its precursor lesions, $\mathrm{HH}$ ligands are abnormally expressed or the $\mathrm{HH}$ signaling cascade is deregulated due to overexpression of $P T C H^{128}$. Overexpression of $\mathrm{HH}$ ligands is also frequently observed in bladder cancer, which also can show amplification of GL/1 or overexpression of GLI2 ${ }^{129,130}$. A subset of melanoma has mutations in PTCH, SMO, SUFU, GLI1 or GLI2. In addition, the vascularization of these 
tumors is regulated by $\mathrm{SHH}{ }^{75,131-133}$. In a subset of advanced human prostate cancers, activation of the $\mathrm{HH}$ pathway occurs due to $\mathrm{HH}$ ligands that act in an autocrine or paracrine manner. In another subset this is due to mutations in $P T C H$ and HHIP ${ }^{125,134}$. Similarly, the $\mathrm{HH}$ signaling pathway is activated due to mutations in $P T C H$ or SUFU in a subset of breast cancer patients ${ }^{135}$ and overexpression of $S H H, G L / 1$ or $P T C H{ }^{136}$ is associated with poor prognosis $^{136}$.
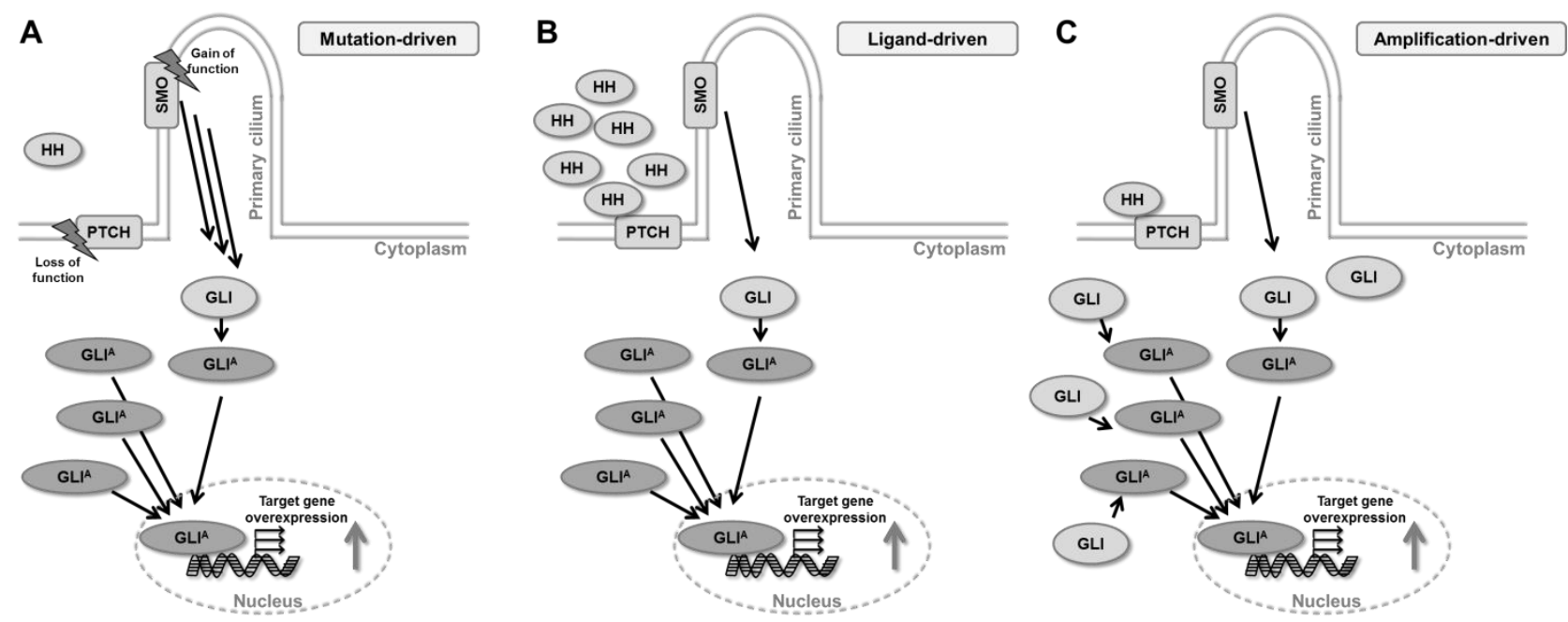

Figure 2: Canonical HH signaling in human cancer

Pathological activation of the $\mathrm{HH}$ signaling pathway plays a role in initiation, formation and progression of tumors (for details, see text). (A) Mutation-driven activation of the $\mathrm{HH}$ signaling pathway can be due to loss of function mutation in PTCH or gain of function mutations in SMO, which results in a permanent activation of the pathway. (B) Ligand-dependent dysregulation of the $\mathrm{HH}$ signaling pathway occurs due to overexpression of $\mathrm{HH}$ ligands. (C) Amplification-driven activation of the $\mathrm{HH}$ signaling pathway occurs due to amplification of GLI, which results in higher level of the respective proteins.

Taken together, a pathological activation of the canonical Hh signaling pathway can be caused by several mechanisms. These include mutations in members of the Hh signaling pathway (Fig. 2A), overexpression of Hh ligands (Fig. 2B) or amplification of Glis (Fig. 2C). Besides these modifications, Gli activity and thus $\mathrm{Hh}$ signaling can also be regulated in a non-canonical manner (see section 2.2.2).

\subsubsection{Hh signaling and RMS}

The spectrum of tumors found in Gorlin patients includes RMS, showing that germline mutations in PTCH enhance the susceptibility to this tumor entity (see section 2.2.3). This is similar in Ptch-heterozygous mice that develop RMS-like tumors ${ }^{21}$. These murine tumors resemble the embryonal RMS subtype in humans and as human ERMS, they show a strong expression of the $\mathrm{Hh}$ targets Gli1 and Igf2. In addition, they express terminal myogenic differentiation markers, like Desmin and $M y o D^{66,137,138}$. Moreover, a heterozygous deletion of Sufu in combination with loss of p53 or a constitutive activation of Smo leads to ERMS formation in mice ${ }^{139,140}$.

Besides GLI1, the average expression level of GLI2, GLI3 and PTCH are consistently elevated in human ERMS compared to normal skeletal muscle ${ }^{141,142}$. In addition, the level of 
these genes is higher in ERMS and fusion-negative ARMS compared to fusion-positive ARMS. It also seems to correlate with a worse outcome and survival rate ${ }^{143}$. However, mutations in the coding regions of the $\mathrm{HH}$ pathway genes that can activate $\mathrm{HH}$ signaling, are very rare in $\mathrm{RMS}{ }^{15,144,145}$.

Nevertheless, genomic loss of the PTCH locus on $9 q 22$ has been identified in $30 \%(4 / 12)$ of ERMS cases ${ }^{146,147}$. In other studies, LOH of the PTCH or SUFU loci has also been detected in ERMS (3/8 tumors showed LOH of the PTCH and 2/4 tumors of the SUFU locus; in a different RMS subset 1/14 tumors showed LOH of the PTCH locus) ${ }^{142,148 .}$

On the other hand, genomic gain of $12 q 13.3$ and $2 q 14.2$, which contain the GL/1 and GLI2 loci, respectively, have been reported in up to $54 \%$ (GLI1) and $92 \%$ (GLI2) of ERMS ${ }^{141,149}$. Consequently, multiple copies of GLI1 or GLI2 have been detected in the tumor samples ${ }^{141}$. Additionally, increased protein level of GLI1 were observed ${ }^{149}$. However, there are also studies, which describe no mutations in RMS ${ }^{15,144}$.

In addition, $\mathrm{HH}$ ligands were investigated in human RMS. Interestingly, SHH levels are not increased in ERMS ${ }^{141}$. However, $\mathrm{DHH}$ and $\mathrm{IHH}$ are expressed, which implicates a role of these ligands in this tumor entity ${ }^{150-152}$.

Taken together, these data show that the Hh pathway plays an important role in RMS. However, its activation in RMS on molecular level is not fully understood. Nevertheless, inhibitors of the $\mathrm{HH}$ signaling pathway are under investigation for targeted therapy of RMS. The Gli1/2 inhibitor GANT61 shows promising results in cultured RMS cells 153-155. Unfortunately, this inhibitor is unstable under acetic conditions and thus cannot be used in the clinics ${ }^{156}$. In addition, small molecule inhibitors for Smo are under investigation for RMS treatment. Cyclopamine, the first discovered natural Smo inhibitor, effectively reduces growth of different RMS cell lines ${ }^{157}$. However, in full-blown murine ERMS, application of cyclopamine does not inhibit tumor growth despite effectively inhibiting $\mathrm{Hh}$ signaling. In fact, cyclopamine rather induces tumor growth ${ }^{158}$. Recent analyses by our group with the Smo inhibitors cyclopamine, vismodegib, sonidegib and HhAntag (HhA) revealed that Smo inhibitors induce strong antitumoral effects in murine ERMS with a Ptch mutation, whereas cell lines derived from ERMS without Ptch mutation responded heterogeneously to Smo inhibition ${ }^{159,160}$. Therefore, Smo inhibitors are considered a good treatment option for ERMS that are caused by mutations upstream of Smo ${ }^{159,160}$.

\subsection{The Ras signaling pathway}

The Ras genes were originally discovered in the genome of Harvey and Kirsten rat sarcoma viruses in the 1960/70s. In 1982, different research groups described mutated RAS alleles in human tumors, which resulted in an enormous interest in these genes ${ }^{161}$. Today, 3 Ras isoforms have been identified in mammals, which are H-ras-I (HRas), K-ras-2 (KRas) with 
2 splice variants (K-ras-4a and the predominant splice variant K-ras-4b) and N-ras (NRas). Additionally, 2 pseudogenes, H-ras-2 and K-ras-I, have been characterized. All Ras genes are highly conserved during evolution ${ }^{162}$. The Ras proteins are low-molecular-weight GTPbinding proteins $(21 \mathrm{kDa})$, which are activated in response to different extracellular stimuli through their receptors. To deploy their biological activity the Ras proteins need to be localized at the inner plasma membrane. In addition, they need to be posttranscriptionally modified by farnesyltransferases. Then they interact with lipid groups, which stabilizes their position at the plasma membrane ${ }^{163-166}$.

Ras proteins control diverse cellular signaling pathways, which are involved in transcriptional regulation, translation, posttranslational modification and cellular processes, like growth, differentiation, survival, cell cycle progression, cytoskeletal remodeling, endocytosis and calcium signaling ${ }^{167}$. A simplified overview of Ras signaling and its different downstream axes is depicted in Fig. 3.

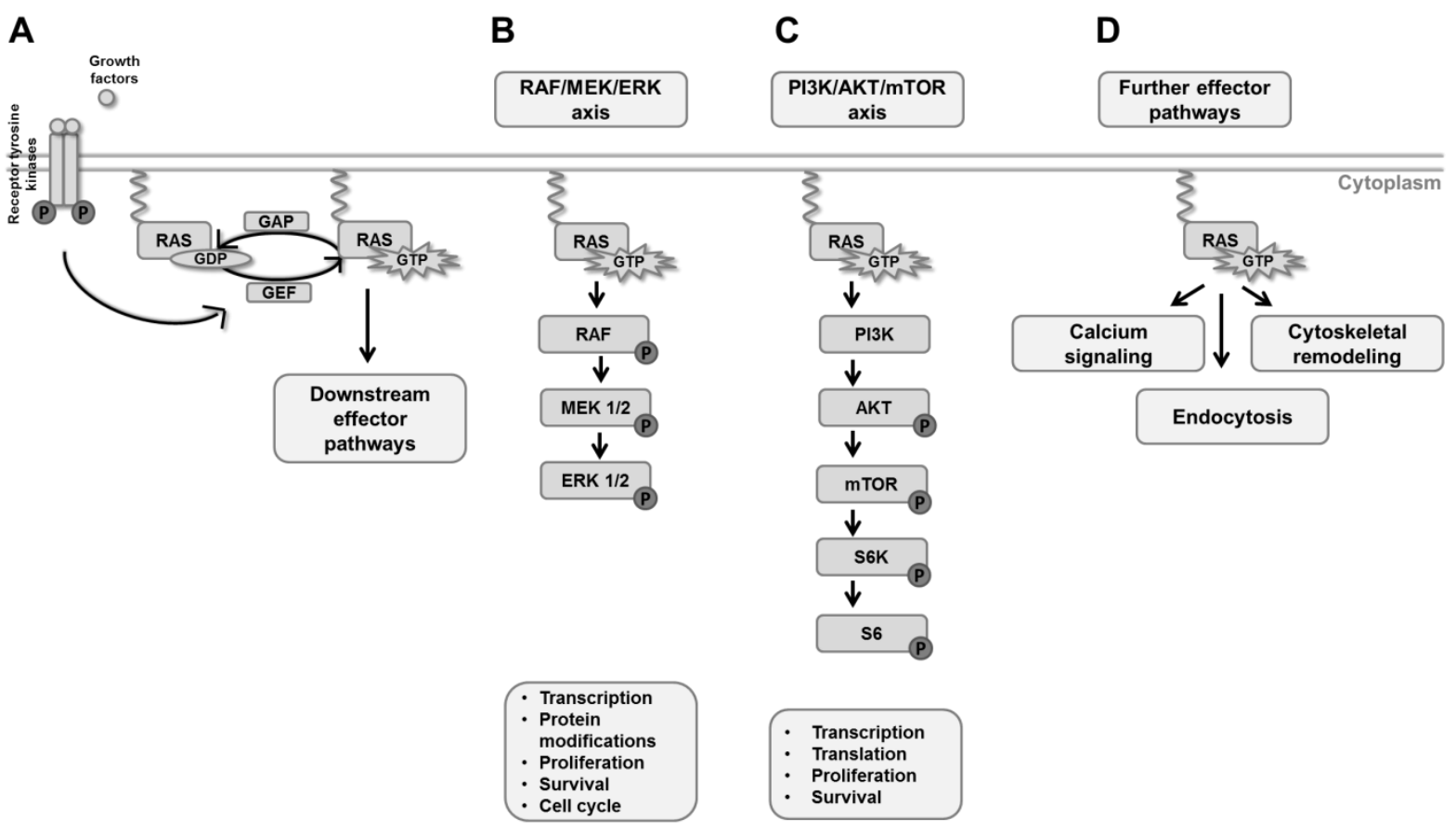

Figure 3: Activation of RAS and its downstream effector pathways

(A) RAS proteins are activated by various extracellular stimuli, which are mediated by receptor tyrosine kinases, G-Proteins or others. Consequently, guanine nucleotide exchange factors (GEF) promote the formation of active, GTP bound RAS. The return to the inactive state is controlled by GTPase activating proteins (GAP), which promote the hydrolysis of RAS-bound GTP. Active RAS controls the activity of several downstream signaling pathways. (B) The major effector pathway of active RAS is the RAF/MEK/ERK pathway. It predominantly controls transcription, posttranslational modifications, cellular proliferation and growth, as well as cell survival, differentiation and cell cycle progression. The signal is transmitted by sequential phosphorylation of the RAF, MEK and ERK kinases. (C) Another prominent effector pathway, which interacts with RAS, is the $\mathrm{PISK} / \mathrm{AKT} / \mathrm{mTOR}$ signaling pathway. This effector pathway controls transcription, translation, proliferation and survival. The signal is transmitted by sequential phosphorylation of the kinases AKT, mTOR, S6K and of S6. (D) Other downstream effector pathways of the RAS signaling cascade control calcium signaling, cytoskeletal remodeling and endocytosis. For more details, see text. Modified according to ${ }^{167}$.

As shown in Fig. 3A, the activity of Ras proteins is regulated by guanosine di- or triphosphate (GDP/GTP) binding, whereby GDP-bound Ras is inactive and GTP-bound Ras is active. The hydrolysis of GTP into GDP is catalyzed by GTPase activating proteins (GAPs) and the 
exchange of GDP by GTP is catalyzed by guanine nucleotide exchange factors (GEFs) ${ }^{168-}$ 171. Ras is activated through GEFs in response to activation of different receptor tyorsine kinases (RTK) or GCPRs ${ }^{172}$. Under physiological conditions, Ras activation is transient and strictly regulated. However, mutations in codon 12, 13, or 61 convert the Ras genes into active oncogenes. This is due to the fact that mutations at these conserved sites prevent the hydrolysis of GTP to GDP and are thereby promote constitutive activation of Ras ${ }^{173}$. Besides activating mutations errors in GDP/GTP regulation, loss of GAPs or persistent RTK activation of GEFs are additional mechanisms of Ras activation in cancer ${ }^{174}$. Activated Ras binds preferentially to its downstream Ras-binding-domain (RBD)- or Ras-association-domaincontaining targets and triggers the activity of other downstream effectors ${ }^{175}$.

The major target of Ras is rat fibrosarcoma (Raf), which in turn triggers the phosphorylation and activation of the downstream mitogen-activated protein kinase (Mapk) signaling pathway (Fig. 3B). In mammalian cells, 4 major Mapk kinases have been characterized, which are extracellular-signal regulated kinase (Erk) 1/2, c-Jun N-terminal kinase (Jnk), p38 and Erk5 ${ }^{176}$. Ras activates Raf by recruiting it to the plasma membrane. Three Raf isoforms exist, which are called Raf-1, A-Raf and B-Raf. B-Raf has a higher intrinsic kinase activity than Raf-1 and A-Raf. Nevertheless, all Rafs are activated by multiple dephosphorylation and phosphorylation processes by Ras when recruited to the membrane ${ }^{177,178}$. Activated Raf in turn triggers serine phosphorylation of several proteins ${ }^{179,180}$. Main targets of Raf are the mitogen-activated kinases (Mek)1 and Mek2. Activated Mek in turn phosphorylates and activates the Erk, which itself has several substrates ${ }^{180,181}$. This signaling cascade controls cellular growth, differentiation, proliferation and migration of cells. Moreover, it regulates cell cycle progression and cellular differentiation processes ${ }^{167,176,182-184}$. Additionally, this cascade can have tumor suppressor properties by promoting selective protein stabilization or degradation and cellular senescence ${ }^{185-188}$.

Ras signaling can also activate the PI3K/Akt/mTOR pathway ${ }^{189}$ (Fig. 3C). PI3K converts phosphatidylinositol (4,5)-bisphosphate into phosphatidylinositol(3,4,5)-trisphosphate and thereby stimulates the activity of Akt by phosphorylation at Thr308. For full activation Akt must also be phosphorylated at Ser473 in its C-terminal region. Akt can trigger various cellular responses and is embedded in a complex network of activators, inhibitors and second messengers ${ }^{190}$. For example, Akt can phosphorylate different kinases such as mTOR that in turn activates S6 kinase. This affects cell proliferation and survial, as well as transcriptional and translational events ${ }^{167,191-193}$. Ras can interact with PI3K in a direct manner through its RBD without involving any other proteins. Depending on the cellular context, activation of the PI3K signaling pathway can lead to an activation or inhibition in Raf/Mek/Erk signaling at the level of Raf. Vice versa, Raf can activate or inhibit the $\mathrm{PI3K} / \mathrm{Akt} / \mathrm{mTOR}$ at the level of Akt (not visualized in Fig. 3) ${ }^{189,194 .}$ 
In addition to these two main effector pathways, Ras also regulates a large amount of other pathways (Fig. 3D). For example, Ras phosphorylates and thus activates phospholipases (PL), i.e. PLCE. Activation of PLs influences the generation of bioactive lipid mediators and leads to the mobilization of calcium, generation of diacylglycerol and activation of PKC ${ }^{195-197}$. Additionally, RAS can stimulate endocytosis and hence influence cellular trafficking of specific molecules ${ }^{198,199}$. Moreover, Ras signaling can regulate actin cytoskeleton dynamics in cells. This remodeling process is required for cellular growth ${ }^{200,201}$.

\subsubsection{Specific features of different Ras isoforms}

The Ras genes show high homology and are co-expressed in most of mammalian tissues. However, whereas HRas level are high in brain, muscle and skin and low in liver of mice, KRas transcripts are most abundant in gut, lung and thymus and low in skin and skeletal muscle. NRas transcripts are elevated in testis and thymus. Additionally, the highest NRas level is observed at day 10 of gestation in mice, whereas KRas expression is highest at the beginning of gestation ${ }^{202,203}$. In general, the translation and protein expression of KRas messenger RNA (mRNA) is reduced relative to that of other Ras isoforms due to a high frequency of rare codons in KRas. These rare codons apparently enhance oncRas-driven tumorigenesis, because their conversion into common codons results in fewer tumors after carcinogen exposure in mice. ${ }^{204,205}$.

The 3 Ras proteins share $85 \%$ of their amino acid sequence, are activated through the same receptors and can exhibit functional redundancy. Nevertheless, activation of the Ras isoform can also have non-redundant functions ${ }^{206-208}$.

The 3 Ras proteins differ in their N-terminal amino acids, which contain membrane binding and trafficking informations ${ }^{209}$. They are differently lipidated and show a different intracellular distribution ${ }^{174,208}$. For example, at an inactive state, HRas and NRas are localized at the plasma membrane and Golgi membranes, whereas KRas is preferentially present at the plasma membrane ${ }^{210}$. Within the plasma membrane, Ras isoforms are located in different microdomains. KRas is located within non-lipid-raft plasma membrane, irrespective of its activation state. In contrast, HRas is distributed equally between the raft and non-raft regions, but GTP-loading increases its localization within the non-lipid-raft plasma membrane ${ }^{165,210}$. Besides this differential compartmentalization, ubiquitination can influence the ability of Ras proteins to activate their downstream effectors ${ }^{206}$.

In vitro experiments indicate that oncHRas might be a better activator of PI3K, whereas oncKRas and oncNRas activate predominantly Raf and Rac. This could result in different biological responses ${ }^{211-215}$. Additionally, the expression of oncHRas, but not oncKRas, can induce senescence ${ }^{174}$. On the other hand, oncNRas exerts anti-apoptotic effects, which are suppressed by oncKRas ${ }^{216,217}$. 
Furthermore, the biological outcome of a Ras mutation is strongly dependent upon the cellular context. For example, NRAS mutations are common in leukemia. Indeed, hematopoetic cells are easier transformed by oncNRas than by oncKRas or oncHRas. However, fibroblasts are more efficiently transformed by oncHRas than by oncKRas or oncNRas ${ }^{218}$. In addition, oncNRAS, but not oncKRAS, is able to transform melanocytes ${ }^{219}$. On the other hand, oncKRAS transforms colonic epithelial cell lines, whereas oncNRAS does not ${ }^{216}$. Similarly, oncKRas suppresses differentiation and promotes proliferation of murine colonic tumors. However, oncNRas does not promote proliferation, but rather suppresses apoptosis in this model (the effect of oncHRas was not investigated) ${ }^{220}$. Moreover, oncKRas promotes proliferation and maintains stem cell characteristics of endodermal progenitors. In contrast, oncHRas promotes differentiation and growth arrest of these cells, whereas oncNRas has no impact on none of these parameters ${ }^{221}$.

Finally, besides overlapping and redundant functions, isoform-specific differences of the Ras genes are also obvious during developmental processes in mice. Thus, a KRas knockout in the germline is embryonic lethal at day 12 to 14 of gestation ${ }^{222,223}$. In contrast, mice with a HRas or an NRas knockout in the germline are viable ${ }^{222,224}$. This could be due to the fact that KRas is essential for normal fetal liver erythropoiesis ${ }^{225}$. However, HRas can replace the function of KRas when it is expressed from the KRas locus. The resulting mice are viable despite a dilated cardiomyopathy associated with arterial hypertension ${ }^{226,227}$. This suggests that HRas can functionally substitute for KRas during development. However, a homozygous deletion of NRas is lethal in developing $\mathrm{KRas}^{+/}$mice, because of severe anemia and growth delays of the embryos ${ }^{222}$. This suggest, that NRas and KRas have partly overlapping functions in fetal liver erythropoiesis and other developmental processes.

As already mentioned, HRas knockout mice grow normally and are fertile. Most interestingly, they show a decreased tumor load after carcinogenic (1,3-Dimethylbutylamine (DMBA)/12-Otetradecanoylphorbol-13-acetate (TPA)) treatment. Thus, HRas knockout mice develop approximately six times less papillomas compared with wildtype (wt) mice after 20 weeks of treatment. In addition, $40 \%$ of the tumors of HRas-deficient mice show oncKRas mutations, which are not common in papilloma. This indicates that oncKRas can replace HRas in the initiation of papilloma ${ }^{224,228}$.

NRas knockout mice are viable, fertile and show no gross morphological or histological abnormalities. Nevertheless, these mice have an impaired immune response as measured by decreased thymocyte proliferation and lower numbers of $\mathrm{CD}^{+}$thymocytes upon an infection with influenza virus ${ }^{229,230}$. However, this immune defect was not seen in another model, in which NRas was knocked-out together with HRas ${ }^{224}$. Thus it remains open whether NRas is involved in a normal immune response. 


\subsubsection{Ras signaling in cancer}

Approximately $25 \%$ of all human tumors harbor oncogenic RAS mutations (HRAS: $2 \%$, KRAS: $18 \%$, NRAS: $5 \%$; according to COSMIC v86). These mutations create active Ras proteins and result in abberant proliferation or survival of tumor cells ${ }^{231,232}$. In the majority of cases (98\%), oncRas mutations are single base missense mutations at the residues $\mathrm{G} 12$, G13 or Q61. Interestingly, the predominant mutated Ras isoform and the respective mutated residue are specific for individual cancer types. However, in general G12 mutations occur more often in KRAS and HRAS, whereas Q61 mutations are predominant in NRAS ${ }^{233}$.

In pancreatic ductal adenocarcinoma (90\% of all pancreatic cancers) and lung adenocarcinoma (35\% of all lung adenocarcinoma) KRAS is the predominantly mutated RAS isoform whereas mutations in HRAS or NRAS are very rare. This is similar in colorectal cancers, in which KRAS is also the primarily mutated isoform (45\% of all colorectal cancers) and in which HRAS and NRAS mutations are infrequent. In melanomas (15\% of all melanomas), liver cancer (30\% of all liver cancers) and acute myelogenous leukaemias (30\% of all acute myelogenous leukaemias), NRAS is the predominant oncRAS isoform and mutations within HRAS or KRAS are rarely observed. HRAS mutations are more common than NRAS or KRAS mutations in bladder cancer (10\% of all bladder cancers show HRAS mutations) and in head and neck squamous cell carcinomas (4\% of these cancers have HRAS mutations) $167,233,234$. Conversely, oncogenic KRAS and NRAS are observed at equivalent frequencies in multiple myeloma and seminoma, whereas mutations in HRAS are barely observed. In thyroid carcinomas, all 3 RAS isoforms are mutated at a similar frequency ${ }^{167}$. The impact of oncRAS mutations in RMS is described in detail in sections 2.3.4 and 2.4.1.

This highlights that most cancer types show mutations in a specific Ras isoform. As described above, differen Ras isoforms can regulate distinct signaling pathways ${ }^{212-214}$. In addition, a completive function of different Ras isoforms due to none-overlapping functions are described. For example, both wtKRas and wtNRas are required for transformation of mouse fibroblast. Whereas wtNRas regulates adhesion, wtKRas coordinates the motility of the cells ${ }^{235}$. However, recent studies also suggest collaborative effects between oncRas and different wtRas proteins, which supposedly is specific for individual cancer phenotypes. For example, in colorectal cancer cell lines an oncogenic KRas allele results in elevated levels of GTP-bound wtNRas ${ }^{216}$. In pancreatic cancer cell lines or colon cancer cells oncKRas activates wtHRas via the GEF Son of sevenless (Sos) and thereby stimulates cancer cell growth and tumor growth in xenografts ${ }^{236}$. Downregulation of wtHRas or wtNRas in pancreatic cancer cell lines or colon cancer cells expressing oncKRas leads to overactivation of the Erk and PI3K/Akt pathways ${ }^{237}$. In cancer cell lines (oncHRAS: T24 bladder cancer cell line, oncKRAS: MIA PaCa-2 pancreatic cancer cell line, oncNRAS: RD RMS cell line) expressing oncRas, oncRas activates basal Mapk signaling despite negatively regulating 
RTK signaling on receptor level, whereas wtRas activates RTK signaling and acts as a driver of cell survival and proliferation ${ }^{238}$. In murine papilloma development, wtKRas acts cooperatively with oncHRas to promote papilloma development. Additionally, loss of wtNRas decreases the number of oncHRas-dependent papilloma ${ }^{239}$.

Beside this tumorpromoting role of wtRas in oncRas-expressing cancers, other studies suggest that wtRas can act as a tumor suppressor. For example, tumorigenesis in the mouse skin is associated with an elevated copy number of oncHRas and/or a loss of wtHRas, indicating a tumor suppressive function of wtHRas ${ }^{240}$. Similar, loss of wtHRas increases the tumor load and reduces survival in murine pancreatic adenocarcinoma expressing oncKRas $^{241}$. In addition, wtHRas inhibits oncKRas-dependent progression of murine lung cancers. Finally, loss of wtNRas increases the number of oncKRas-induced lung tumors ${ }^{239}$.

\subsubsection{RASopathies}

Oncogenic mutations in RAS (or in other regulators of RAS signaling) are not only found in sporadic cancers. As germline mutations, they also can cause autosomal dominant genetic syndromes. These diseases are called RASopathies and are frequently associated with $\mathrm{RMS}^{242,243}$. Examples are Neurofibromatosis type 1, which is caused by germline mutations in NF1, which is a GAP that regulates GDP/GTP exchange of RAS ${ }^{242,244,245}$. Other examples are the capillary malformation-arteriovenous malformation syndrome, which is caused by haploinsufficiency of the RAS signaling regulator gene $R A S A 1^{246}$, the cardio-facio-cutaneous syndrome, which is caused by germline mutations in BRAF, MAP2K1, MAP2K2 ${ }^{247,248}$ and the Legius syndrome, which is caused by inactivating mutations in SPRED1 that regulates the activation of the MAPK cascade ${ }^{249}$. Interestingly, 2 of the RASopathies, namely Noonan and Costello syndrome, can be caused by mutations in RAS and are associated with an increased susceptibility to RMS. Thus, patients with Costello syndrome have a dominant HRAS germline mutation ${ }^{17,250}$, whereas Noonan syndrome can be caused by germline mutations in KRAS or NRAS. The latter disease also can show germline mutations in PTPN11, SOS1, RAF1, SHOC2 and CBL, that, with the exception of CBL (E3 ubiquitin ligase), are all implicated in RAS signaling ${ }^{251-258}$.

\subsubsection{RAS signaling and RMS}

As already mentioned, patients with Costello syndrome or Noonan syndrome are predisposed to the development of RMS, which are predominantly of the embryonal subtype ${ }^{19,242,259-262}$. Additionally, a few cases of RMS have also been described in patients suffering from Neurofibromatosis type 1 or from cardio-facio-cutaneous syndrome ${ }^{263-265}$.

Interestingly, oncRAS mutations are also frequently found in sporadic RMS and are detected predominantly in the ERMS subtype ${ }^{14,15}$. Dependent on the analyzed tumor subset, $12 \%{ }^{16}$, $22 \%{ }^{266}, 35 \%{ }^{267}$ or even $46 \%{ }^{141}$ of RMS show oncRAS mutations. Although these mutations can occur in all 3 RAS genes, NRAS mutations are the most common 
ones ${ }^{14,15,141,266,267}$. With regard to the analyzed tumor subset, oncRAS mutations can positivity or negatively influence the outcome for patients with ERMS. On the one hand, activating mutations in HRAS, KRAS, NRAS or NF-1 genes were described in $75 \%$ of highrisk ERMS tumors ${ }^{5,6,15}$. On the other hand, gain-of-function mutations within the RAS genes were described to occur more frequently in ERMS patients with a better outcome ${ }^{267}$. Nevertheless mutations within the RAS genes at positions $\mathrm{G} 12$ and $\mathrm{Q} 61$ are more frequent than G13 mutations 15,141,231,232,267 (and according to COSMIC v86). Furthermore, wholeexome/-transcriptome sequencing, copy number and DNA methylome analyses of 60 RMS revealed activation of the FGFR4/RAS/AKT axis in up to $40 \%$ of the tumors (24/60 tumors, with 10/60 tumors showing mutations in HRAS, KRAS or NRAS), which was predominantly detected in ERMS. However, mutations affecting PI3K directly are very rare ${ }^{14,268}$. Together, these results led to the conclusion that the RAS signaling pathway could be a druggable target in RMS. Indeed, inhibition of MEK or combined inhibiton of MEK and PI3K/mTOR block proliferation and trigger apoptosis of RMS cells ${ }^{269-272}$.

Finally, it was proposed that oncRas mutations can either act as RMS-driver or as RMSmodifiers. However, this point is still a matter of debate ${ }^{273-277}$. Precisely, oncRas mutations were proposed to be necessary to convert normal primary human skeletal muscle myoblasts into tumorigenic cells mimicking ERMS ${ }^{278}$. This was shown by activation of oncKRas under the control of the recombination activating gene 2 (rag2) promotor, which is active in myoblasts in zebrafish ${ }^{274}$. On the other hand, microarray-based data of RMS samples suggest, that a RAS signature occurs only in combination with signatures of other activated pathways ${ }^{275}$. In support of an RMS-modifier is also the observation that oncKRas in combination with heterozygous p53 mutations induces pleomorphic RMS, whereas p53 mutations alone induce an other RMS subtype. RMS in oncKRas mice have not been described so far ${ }^{279-283}$. Similarly, xenografts from murine satellite cells with oncKRas result in a pleomorphic RMS phenotype, but only in combination with a Cyclin-dependent kinase inhibitior (Cdkn) 2a knockout ${ }^{273}$.

To sum up, these results show that active Ras signaling plays an extraordinarily important role in RMS pathogenesis. However, the precise role of oncRas mutations in ERMS pathogenesis is not well understood.

\subsection{Interaction of Hh and Ras signaling}

A non-canonical interaction between the $\mathrm{Hh}$ and Ras signaling pathways has been described frequently ${ }^{284}$. For example, the Shh/Ptch axis can stimulate activation of Erk in human mammary epithelial cells and in Shh Light II fibroblasts, which however does not require Smo ${ }^{285}$. Vice versa, Mek influences the transcriptional activity of Gli1 in murine fibroblasts. In this setting, the N-terminal domain of Gli1 is phosphorylated in a Mek-dependent manner, which however does not involve Erk2 ${ }^{286}$. Additionally, Gli1 and Gli3 have been identified as 
potential substrates of the Mapks Jnk and Erk in computational prediction and peptide binding arrays ${ }^{287}$. Indeed, Mapks can phosphorylate Gli1, Gli2 and Gli3 on residues located near the binding site for Sufu ${ }^{288}$. Furthermore, Gli proteins are stabilized by Epidermal growth factor receptor (EGFR)-mediated inhibition of proteasomal degradation in keratinocytes ${ }^{289}$. Therefore, it is speculated that Mapks can activate Gli transcription factors in a $\mathrm{Hh} / \mathrm{Ptch} / \mathrm{Smo}$-independent manner.

Activated $\mathrm{Hh}$ signaling and simultaneous oncRas mutations are found in several tumor entities ${ }^{284}$. This suggests a cooperation of both signaling pathways in tumor development, maintenance or progression. An overview of known interactions between $\mathrm{Hh}$ and Ras signaling in different tumor entities is depicted in Fig. 4.

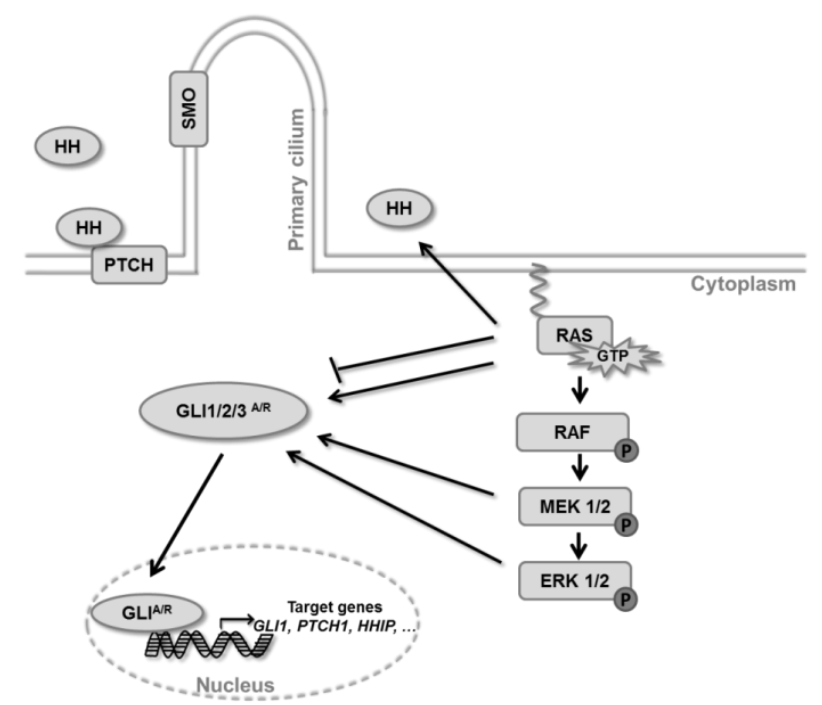

Figure 4: Interactions of HH and RAS signaling in cancer

$\mathrm{HH}$ signaling activity can be modified by RAS signaling in a non-canonical manner. In this setting, oncgenic actiovation of members of the RAS pathway induce or inhibit GLI transcription factors. In addition, oncRAS can induce secretion of $\mathrm{HH}$ ligands. The MEK/ERK casacde was shown to regulate GLI transcription factors. For more details, see text.

$\mathrm{Hh} /$ Ras interaction occurs for example in BCC, in which Hh and Egfr signaling synergistically contribute to oncogenic transformation via the Raf/Mek/Erk axis ${ }^{290,291}$ and synergistically regulate the expression of genes necessary for tumor growth (Sox2, Sox9, Jun, C-X-C motif chemokine receptor (Cxcr) 4 and Fgf19) ${ }^{292}$. Additionally, Egfr/ADP ribosylation factor (Arf)6 signaling triggers Hh signaling and tumor growth in a Drosophila oncRas-driven tumor model. Tumor growth in this model depends on oncRas and oncRas in turn induces the expression of Egfr ligands ${ }^{293}$.

In addition, oncRas-mediated modulation of Gli transcription factor can have oppositional outcomes in different tumor entities. Examples for activation of $\mathrm{Hh}$ signaling by oncRas are e.g. melanoma. In this tumor entity oncNRAS or oncHRAS can stimulate nuclear localization and transcriptional activity of $G L / 1^{75}$. In gastric cancer cells an active MEK/ERK cascade has a positive regulatory role in GLI1 transcriptional activity ${ }^{294}$. Another example is pancreatic cancer, in which GLI1 is required for oncKRAS-induced tumorgenesis ${ }^{295,296}$. Moreover, 
oncKRAS blocks proteasome-mediated GLI1 degradation and thereby activates the $\mathrm{HH}$ signaling cascade in pancreatic cancer cells ${ }^{297}$. OncRAS also triggers ligand-independent $\mathrm{HH}$ signaling activation in thyroid cancer cells via the MEK/ERK axis ${ }^{298}$. However, in contrast, Lauth and colleagues observed that oncKRAS can also abrogate $\mathrm{HH}$ signaling activity in pancreatic cancer cells by inhibition of GLI2 function and promotion of the formation of the GLI3 repressor form. Thus, oncRAS tumor-intrinsically blocks HH signaling. However, since oncKRAS tumorintrinsically also induces $\mathrm{SHH}$ expression and secretion, $\mathrm{HH}$ signaling activity is induced in neighboring stromal cells ${ }^{84}$.

In addition to the Ras/Mek/Erk axis, the PI3K/Akt/mTOR axis (which can also be regulated by Ras) can regulate Gli proteins and thus Hh signaling activity. For example, AKT enhances nuclear localization and activity of GLI1 in melanoma model systems ${ }^{75}$. In murine fibroblasts, $\mathrm{PI} 3 \mathrm{~K} / \mathrm{Akt} /$ signaling is required for Shh signal transduction and subsequent Gli activation ${ }^{76}$.

In summary, the literature provides evidence for both, positive and negative crosstalks between $\mathrm{Hh}$ and Ras signaling in that oncRas either positively or negatively influences transcriptional activity of Gli transcription factors. The outcome of regulation depends on the experimental setting and on the tumor entity. Vice versa, Shh can regulate Erk activity in non-cancerous epithelial cells.

\subsubsection{HH and RAS signaling in RMS}

As described in sections 2.2.4 and 2.3.4, Hh and Ras signaling play crucial roles in RMS. Although interactions of these pathways have been described for several tumor entities, almost nothing is known about an interaction in RMS. Preliminary work from our group indicates that there is indeed a crosstalk between both pathways in RMS. Thus, the expression of any oncRAS isoform decreases GLI1 expression in the ERMS cell line RUCH2 and in the ARMS cell line RMS-13. However, the mechanism behind this downregulation is different. Whereas the oncRAS-dependent decrease in GLI1 expression is mediated by MEK in RUCH-2 cells, MEK is not involved in GL/1-suppression in RMS-13 cells. Moreover, preliminary xenotransplantation studies and a genetic approach in the mouse indicate that oncRas isoforms change the growth behavior of Hh-associated RMS precursor lesions ${ }^{299}$. 


\section{Aim of this study}

RMS is the most common malignant soft tissue sarcoma in children. The efficiency of currently available multimodal therapies is limited and many patients suffer from severe adverse side effects and fatal long-term consequences. This indicates that it is of uttermost importance to better understand the tumor's pathology and to establish new therapeutic approaches.

The Hh signaling cascade and the Ras signaling pathway are frequently activated in RMS. This is in the first instance obvious in human ERMS that strongly express $\mathrm{HH}$ target genes and concurrently can show oncogenic $H-, K-$ or NRAS (collectively named oncRAS) mutations. Surprisingly, and as already mentioned, preliminary work from our group indicates that all oncRAS isoforms decrease the expression of the major HH-target GL/1 in an ERMS and also in an ARMS cell line. In ERMS the decrease apparently is mediated via MEK.

The main focus of this thesis was to investigate the role of oncRAS isoforms in regulation of $\mathrm{HH}$ targets and associated cellular responses of ERMS in more depth and thereby to validate the already gained results. Additionally, the consequences of a crosstalk between RAS and $\mathrm{HH}$ signaling for ERMS pathogenesis, growth and aggressiveness were analyzed.

For this purpose, the proliferation status and the activity of RAS and $\mathrm{HH}$ signaling were investigated in 3 different ERMS cell lines expressing oncRAS isoforms. In addition, it was examined whether the oncRAS-mediated decrease in GLI1 was caused downstream of MEK at the level of ERK. Moreover, the subcellular localization and the protein level of all $3 \mathrm{GLI}$ transcription factors were investigated. Finally, the cell lines were transplanted into immunosuppressed mice and the impact of oncRAS and the concomitant downregulation of GLI1 on tumor growth and $\mathrm{HH}$ signaling activity was analyzed.

In a second approach, the impact of oncRas signaling on growth, differentiation status and on Hh signaling genes was analyzed in genetically engineered $\mathrm{Hh} / \mathrm{Ptch}$-driven ERMS mouse models. For this purpose, Ptch ${ }^{d e l /+}{ }_{0} R_{R a s}^{f l /+} M_{y f 5}{ }^{C r e E R /+}$ mice were generated. In these mice, the expression of either oncHRas, oncKRas or oncNRas can be induced at different stages of tumor development. Using this model, the impact of the respective oncRas mutation on tumor incidence, tumor latency time or multiplicity and on proliferation, Hh signaling activity and myyogenic differentiation was investigated. The experiments were perfomed in mice, in which the mutation was induced either in tumor precursor lesions or in full-blown ERMS. The aim of this study was to analyze the impact of oncRas mutations on different developmental stages of ERMS. 


\section{Material}

\subsection{Technical equipment}

Table 1: Technical equipment

\begin{tabular}{|c|c|}
\hline Technical equipment & Supplier \\
\hline 7900HT Fast Real-Time PCR System & Applied Biosystems, Waltham, MA, USA \\
\hline Agarose gel electrophoresis chamber & $\begin{array}{l}\text { Peqlab Biotechnology GmbH, Erlangen, } \\
\text { Germany }\end{array}$ \\
\hline Autoclave (9216E) & Fedegari Autoclavi SpA, Albuzzano, Italy \\
\hline Autoclave (Systec DX-150) & Systec GmbH \& Co. KG, Linden, Germany \\
\hline $\begin{array}{l}\text { Centrifuges } \\
\text { (Biofuge pico, fresco, primo, Multifuge 3LR) }\end{array}$ & Heraeus Holding GmbH, Hanau, Germany \\
\hline Centrifuge (5427 R) & Eppendorf AG, Hamburg, Germany \\
\hline $\mathrm{CO}_{2}$-Incubator (CB220-230V-G) & Binder GmbH, Tuttlingen, Germany \\
\hline $\mathrm{CO}_{2}$-Incubator (6000, BBD, 6220) & $\begin{array}{l}\text { Thermo Fisher Scientific Inc., Waltham, MA, } \\
\text { USA }\end{array}$ \\
\hline Cooling plate (EG1150 C) & $\begin{array}{l}\text { Leica Microsystems GmbH, Wetzlar, } \\
\text { Germany }\end{array}$ \\
\hline $\begin{array}{l}\text { Digital monochrome thermal video printer } \\
\text { (P91D) }\end{array}$ & Mitsubishi Electric Co., Tokyo, Japan \\
\hline Digital photocamera (PowerShot G2) & $\begin{array}{l}\text { Canon Deutschland GmbH, Krefeld, } \\
\text { Germany }\end{array}$ \\
\hline Dispersing tool for homogenizer (DS-8/P) & Miccra GmBH, Heitersheim, Germany \\
\hline Dissection tools & $\begin{array}{l}\text { Karl Hammacher GmbH, Solingen, } \\
\text { Germany }\end{array}$ \\
\hline Flow cytometer (BD LSR II) & BD Biosciences, San Jose, CA, USA \\
\hline Flow cytometer (FACS Calibur) & BD Biosciences, San Jose, CA, USA \\
\hline Freezer $\left(-20^{\circ} \mathrm{C}\right)$ & Liebherr GmbH, Bulle, Switzerland \\
\hline Freezer $\left(-80^{\circ} \mathrm{C}\right)$ & Sanyo Electric Co., Ltd., Osaka, Japan \\
\hline Freezing container (Mr. Frosty ${ }^{\mathrm{TM}}$ ) & $\begin{array}{l}\text { Thermo Fisher Scientific Inc., Waltham, MA, } \\
\text { USA }\end{array}$ \\
\hline Fridge $\left(4^{\circ} \mathrm{C}\right)$ & Robert Bosch GmbH, Stuttgart, Germany \\
\hline Heating block shaker (ThermoMixer@) & Eppendorf AG, Hamburg, Germany \\
\hline $\begin{array}{l}\text { High-precision scales (Sartorius Basic plus } \\
2100 \text { ) }\end{array}$ & Sartorius AG, Göttingen, Germany \\
\hline Homogenizer (Miccra D-1) & Miccra GmBH, Heitersheim, Germany \\
\hline Hybridization oven (HB-1000 Hybridizer) & Analytik Jena US, Upland, CA, USA \\
\hline Gas burner & Campingaz, Hattersheim, Germany \\
\hline $\begin{array}{l}\text { Inverted fluorescence microscope } \\
\text { (Axiovert 25) }\end{array}$ & Carl Zeiss GmbH, Jena, Germany \\
\hline Inverted research microscope (IX71) & Olympus Optical Co., Ltd., Tokyo, Japan \\
\hline Cryostat (CM 1900-1-1) & $\begin{array}{l}\text { Leica Microsystems GmbH, Wetzlar, } \\
\text { Germany }\end{array}$ \\
\hline
\end{tabular}




\begin{tabular}{|c|c|}
\hline Liquid nitrogen tank & L'air liquid S.A., Paris, France \\
\hline Magnetic stirrer (MR3000/3001) & $\begin{array}{l}\text { Heidolph Instruments GmbH \& Co. KG, } \\
\text { Schwabach, Germany }\end{array}$ \\
\hline $\begin{array}{l}\text { Micro computed tomography ( } \mu \mathrm{CT} \text { ) system } \\
\text { (QuantumFX) }\end{array}$ & $\begin{array}{l}\text { PerkinElmer Health Sciences, Hopkinton, } \\
\text { MA, USA }\end{array}$ \\
\hline Microplate reader (SynergyMx) & $\begin{array}{l}\text { BioTek Instruments GmbH, Bad } \\
\text { Friedrichshall, Germany }\end{array}$ \\
\hline Microscope (Olympus BX 60) & Olympus Optical Co., Ltd., Tokyo, Japan \\
\hline Microtome (HN 40) & $\begin{array}{l}\text { Leica Microsystems GmbH, Wetzlar, } \\
\text { Germany }\end{array}$ \\
\hline Microwave oven (Dimension 4) & Panasonic Corp., Kadoma, Japan \\
\hline Neubauer counting chamber & $\begin{array}{l}\text { Brand GmbH \& Co KG, Wertheim, } \\
\text { Germany }\end{array}$ \\
\hline Neon ${ }^{\mathrm{TM}}$ Transfection system & $\begin{array}{l}\text { Thermo Fisher Scientific Inc., Waltham, MA, } \\
\text { USA }\end{array}$ \\
\hline Paraffin dispenser (PAG12) & $\begin{array}{l}\text { Medite Medizintechnik GmbH, Burgdorf, } \\
\text { Germany }\end{array}$ \\
\hline Paraffin tissue floating bath & $\begin{array}{l}\text { Medax GmbH \& Co. KG, Rendburg, } \\
\text { Germany }\end{array}$ \\
\hline PCR Thermocycler (Mastercycler®) & Eppendorf AG, Hamburg, Germany \\
\hline $\begin{array}{l}\text { PCR Thermocycler (Labcycler Basic, } \\
\text { Labcycler Gradient) }\end{array}$ & SensoQuest GmbH, Göttingen, Germany \\
\hline $\begin{array}{l}\text { pH-meter (inoLab, pH Level 1) and } \\
\text { electrode (SenTix 91) }\end{array}$ & WTW, Weilheim, Germany \\
\hline Pipette controller (accu-jet@ pro) & $\begin{array}{l}\text { Brand GmbH \& Co. KG, Wertheim, } \\
\text { Germany }\end{array}$ \\
\hline Pipettes (Multi- and single-channel pipettes) & Eppendorf AG, Hamburg, Germany \\
\hline Platform shaker (Unimax1010) & $\begin{array}{l}\text { Heidolph Instruments GmbH \& Co. KG, } \\
\text { Schwabach, Germany }\end{array}$ \\
\hline Precision weighing balance (ALC-210.4) & Sartorius AG, Göttingen, Germany \\
\hline $\begin{array}{l}\text { Power supply for agarose gel } \\
\text { electrophoresis }\end{array}$ & $\begin{array}{l}\text { Peqlab Biotechnology } \mathrm{GmbH} \text {, Erlangen, } \\
\text { Germany }\end{array}$ \\
\hline Power supply for Western Blot transfer & $\begin{array}{l}\text { Cleaver Scientific Itd., Rugby, United } \\
\text { Kingdom }\end{array}$ \\
\hline Spectrophotometer (NanoDrop 8000) & $\begin{array}{l}\text { Thermo Fisher Scientific Inc., Waltham, MA, } \\
\text { USA }\end{array}$ \\
\hline Stereo microscope (Stemi 2000) & Carl Zeiss GmbH, Jena, Germany \\
\hline Sterile workbench (Euroflow EF/A 5) & Clean Air Techniek, Woerden, Netherlands \\
\hline Tab. centrifuge (Micro Centrifuge SD) & $\begin{array}{l}\text { Carl Roth GmbH \& Co. KG, Karlsruhe, } \\
\text { Germany }\end{array}$ \\
\hline Tissue processor (TP1020) & $\begin{array}{l}\text { Leica Microsystems GmbH, Wetzlar, } \\
\text { Germany }\end{array}$ \\
\hline Ultraviolet (UV) light -Transilluminator & $\begin{array}{l}\text { INTAS Science Imaging Instruments } \\
\text { GmbH, Göttingen, Germany }\end{array}$ \\
\hline Vacuum pump (EcoVac) & Schuett-biotec GmbH, Göttingen, Germany \\
\hline Vortex mixer (Vortex-Genie2®) & Scientific Industries Inc, Bohemia, NY, USA \\
\hline Water bath (1083) & GFL mbH, Burgwedel, Germany \\
\hline
\end{tabular}




\begin{tabular}{|l|l|}
\hline Water purification system (Arium® 611 VF) & Sartorius AG, Göttingen, Germany \\
\hline $\begin{array}{l}\text { Western Blot imaging system } \\
\left.\text { (FluorChem }{ }^{\mathrm{TM}} \mathrm{Q}\right)\end{array}$ & Bio-Techne Corp., Minneapolis, MN, USA \\
\hline $\begin{array}{l}\text { Western Blot transfer system (Trans-Blot }{ }^{\circledR} \\
\text { SD semi-dry electroblotting system) }\end{array}$ & $\begin{array}{l}\text { Bio-Rad Laboratories GmbH, Munich, } \\
\text { Germany }\end{array}$ \\
\hline $\begin{array}{l}\text { Western Blot transfer system (Tank } \\
\text { electroblotting system OwITM VEP-2 Mini) }\end{array}$ & $\begin{array}{l}\text { Thermo Fisher Scientific Inc., Waltham, MA, } \\
\text { USA }\end{array}$ \\
\hline
\end{tabular}

\subsection{Consumables}

Table 2: Consumable materials

\begin{tabular}{|c|c|}
\hline Consumable & Supplier \\
\hline 6 well cell culture plate & Sarstedt AG \& Co., Nürnberg , Germany \\
\hline 24 well cell culture plate & $\begin{array}{l}\text { Corning Incorporated, New York City, NY, } \\
\text { USA }\end{array}$ \\
\hline $\begin{array}{l}96 \text { well assay plate (black plate, clear } \\
\text { bottom) }\end{array}$ & $\begin{array}{l}\text { Corning Incorporated, New York City, NY, } \\
\text { USA }\end{array}$ \\
\hline 384 well plate black \& adhesive seal sheet & 4titude® Ltd., Surrey, UK \\
\hline Cell scraper & Sarstedt AG \& Co., Nürnberg , Germany \\
\hline Centrifuge tubes (15 ml, 50 ml) & $\begin{array}{l}\text { Greiner Bio-One International GmbH, } \\
\text { Kremsmünster, Austria }\end{array}$ \\
\hline Coverslips & $\begin{array}{l}\text { Thermo Fisher Scientific Inc., Waltham, MA, } \\
\text { USA }\end{array}$ \\
\hline $\begin{array}{l}\text { Disposable needles (Sterican } \varnothing 0.45 \times \\
12 \mathrm{~mm} \text { or } \varnothing 0.30 \times 12 \mathrm{~mm} \text { ) }\end{array}$ & B.Braun AG, Melsungen, Germany \\
\hline $\begin{array}{l}\text { Disposable syringes (BD DiscarditTM II 2, } \\
10,20,50 \mathrm{ml} \text { ) }\end{array}$ & BD Biosciences, San Jose, CA, USA \\
\hline $\begin{array}{l}\text { Combitips advanced® }(0.2 \mathrm{ml}, 0.5 \mathrm{ml}, \\
2.5 \mathrm{ml}, 5 \mathrm{ml}, 10 \mathrm{ml})\end{array}$ & Eppendorf AG, Hamburg, Germany \\
\hline CryoPure tubes & Sarstedt AG \& Co., Nürnberg, Germany \\
\hline Delicate task wipes & Kimberly-Clark Europe Ltd., Surrey, UK \\
\hline Disposable cups (100 ml) & Sarstedt AG \& Co., Nürnberg, Germany \\
\hline $\begin{array}{l}\text { Filter tips (Biosphere } \AA^{2} 2 \mu \mathrm{l}, 100 \mu \mathrm{l}, 200 \mu \mathrm{l} \text {, } \\
1000 \mu \mathrm{l})\end{array}$ & Sarstedt AG \& Co., Nürnberg , Germany \\
\hline Flow cytometry tube & Sarstedt AG \& Co., Nürnberg , Germany \\
\hline Fluted filters & Sartorius AG, Göttingen , Germany \\
\hline Glassware & Schott AG, Mainz, Germany \\
\hline Insulin syringe (BD Microfine + Demi) & BD Biosciences, San Jose, CA, USA \\
\hline $\begin{array}{l}\text { Microscope slides \& Superfrost } \circledast \text { plus } \\
\text { microscope slides }\end{array}$ & $\begin{array}{l}\text { Thermo Fisher Scientific Inc., Waltham, MA, } \\
\text { USA }\end{array}$ \\
\hline $\begin{array}{l}\text { Nitrocellulose membrane (Hybond } \mathrm{ECL} \text { ), } \\
0.2 \mu \mathrm{M} \text { and } 0.45 \mu \mathrm{M} \text { pore size }\end{array}$ & $\begin{array}{l}\text { GE Healthcare Europe GmbH, Freiburg, } \\
\text { Germany }\end{array}$ \\
\hline $\begin{array}{l}\text { Nunclon }{ }^{\mathrm{TM}} \text { disposables for cell culture } \\
(10 \mathrm{~cm} \text { cell culture dish, } 96 \text {-well plate })\end{array}$ & $\begin{array}{l}\text { Thermo Fisher Scientific Inc., Waltham, MA, } \\
\text { USA }\end{array}$ \\
\hline NuPAGE Novex 3-8 \% Tris-Acetate Gel & Invitrogen, Carlsbad, CA, USA \\
\hline NuPAGE Novex 4-12 \% Bis-Tris Gel & Invitrogen, Carlsbad, CA, USA \\
\hline
\end{tabular}




\begin{tabular}{|l|l|}
\hline Parafilm® laboratory film & Bemis Company, Inc., Neenah, WI, USA \\
\hline Pasteur pipettes & $\begin{array}{l}\text { TH. Geyer GmbH \& Co. KG, Renningen, } \\
\text { Germany }\end{array}$ \\
\hline PCR tear-a-way plates \& cap strips & 4titude® Ltd., Surrey, UK \\
\hline Petri dishes & Ochs GmbH, Bovenden/Lenglern, Germany \\
\hline Pipette tips $(20 \mu \mathrm{l}, 200 \mu \mathrm{l}, 1000 \mu \mathrm{l})$ & Sarstedt AG \& Co., Nürnberg, Germany \\
\hline Reaction tubes $(1.5 \mathrm{ml}, 2 \mathrm{ml}, 5 \mathrm{ml})$ & Sarstedt AG \& Co., Nürnberg, Germany \\
\hline Safeseal microtubes $(1.5 \mathrm{ml}, 2 \mathrm{ml})$ & Sarstedt AG \& Co., Nürnberg, Germany \\
\hline $\begin{array}{l}\text { Serological pipettes }(2 \mathrm{ml}, 5 \mathrm{ml}, 10 \mathrm{ml}, \\
25 \text { ml) }\end{array}$ & Sarstedt AG \& Co., Nürnberg, Germany \\
\hline Softa-Man® hand disinfectant & B.Braun AG, Melsungen, Germany \\
\hline Sterile filters $(0.2 \mu \mathrm{m}, 0.45 \mu \mathrm{m})$ & Sartorius AG, Göttingen, Germany \\
\hline Surgical blades & Aesculap AG, Tuttlingen, Germany \\
\hline Whatman® Blotting paper $(\mathrm{GB} 33$ B003) & $\begin{array}{l}\text { Heinemann Labortechnik GmbH, } \\
\text { Duderstadt, Germany }\end{array}$ \\
\hline Weighing paper & $\begin{array}{l}\text { Macherey-Nagel GmbH \& Co. KG, Düren, } \\
\text { Germany }\end{array}$ \\
\hline
\end{tabular}

\subsection{Reagents and chemicals}

All chemicals, which are not listed in Table 3 (Tab. 3) were purchased from Merck KGaA, Darmstadt, Germany or Carl Roth GmbH \& Co. KG, Karlsruhe, Germany.

Table 3: Reagents and chemicals

\begin{tabular}{|l|l|}
\hline Reagent or chemical & Supplier \\
\hline 3-Amino-9-ethylcarbazole (AEC) & Sigma-Aldrich Co., St. Louis, MO, USA \\
\hline Acetic acid & $\begin{array}{l}\text { Carl Roth GmbH \& Co. KG, Karlsruhe, } \\
\text { Germany }\end{array}$ \\
\hline Agarose & $\begin{array}{l}\text { VWR International GmbH, Erlangen, } \\
\text { Germany }\end{array}$ \\
\hline $\begin{array}{l}\text { Aluminium potassium sulfate } \\
\text { dodecanhydrate }\end{array}$ & Merck KGaA, Darmstadt, Germany \\
\hline Ampicillin sodium salt & $\begin{array}{l}\text { Carl Roth GmbH \& Co. KG, Karlsruhe, } \\
\text { Germany }\end{array}$ \\
\hline Boric acid & $\begin{array}{l}\text { Carl Roth GmbH \& Co. KG, Karlsruhe, } \\
\text { Germany }\end{array}$ \\
\hline $\begin{array}{l}\text { Bovine serum albumin fraction V (BSA), } \\
\text { protease free }\end{array}$ & $\begin{array}{l}\text { Carl Roth GmbH \& Co. KG, Karlsruhe, } \\
\text { Germany }\end{array}$ \\
\hline Chloroform & $\begin{array}{l}\text { Carl Roth GmbH \& Co. KG, Karlsruhe, } \\
\text { Germany }\end{array}$ \\
\hline Citric acid monohydrate & $\begin{array}{l}\text { Carl Roth GmbH \& Co. KG, Karlsruhe, } \\
\text { Germany }\end{array}$ \\
\hline Contrast reagent Imeron 300 & Bracco Imaging GmbH, Konstanz, Germany \\
\hline Cresol red, sodium salt & $\begin{array}{l}\text { Aldrich Chemical Company Inc., Milwaukee, } \\
\text { WI, USA }\end{array}$ \\
\hline Cryoblock embedding medium & $\begin{array}{l}\text { Medite Medizintechnik GmbH, Burgdorf, } \\
\text { Germany }\end{array}$ \\
\hline
\end{tabular}




\begin{tabular}{|c|c|}
\hline Dimethylformamide (DMF) & Sigma-Aldrich Co., St. Louis, MO, USA \\
\hline Dimethylsulfoxide (DMSO) & $\begin{array}{l}\text { Thermo Fisher Scientific Inc., Waltham, MA, } \\
\text { USA }\end{array}$ \\
\hline Dithiothreitol (DTT) & $\begin{array}{l}\text { Thermo Fisher Scientific Inc., Waltham, MA, } \\
\text { USA }\end{array}$ \\
\hline Deoxyribonucleotide triphosphates (dNTPs) & $\begin{array}{l}\text { Roche Diagnostics } \mathrm{GmbH} \text {, Mannheim, } \\
\text { Germany }\end{array}$ \\
\hline Loading dye solution for DNA (6x) & $\begin{array}{l}\text { Thermo Fisher Scientific Inc., Waltham, MA, } \\
\text { USA }\end{array}$ \\
\hline $\begin{array}{l}\text { DNase/RNase-free distilled } \mathrm{H}_{2} \mathrm{O} \\
\text { (ultrapure } \mathrm{H}_{2} \mathrm{O} \text { ) }\end{array}$ & Invitrogen, Carlsbad, CA, USA \\
\hline Eosin $Y$ & Merck KGaA, Darmstadt, Germany \\
\hline Ethanol (EtOH) $99 \%$ & J.T. Baker B.V., Deventer, Netherlands \\
\hline Ethanol $99 \%$, denatured & $\begin{array}{l}\text { TH. Geyer GmbH \& Co. KG, Renningen, } \\
\text { Germany }\end{array}$ \\
\hline Ethidium bromide (EtBr) 0.07\% & $\begin{array}{l}\text { Inno-Train Diagnostik GmbH, Kronberg im } \\
\text { Taunus, Germany }\end{array}$ \\
\hline $\begin{array}{l}\text { Ethylenediamine tetraacetic acid (EDTA) } \\
\text { disodium salt dihydrate }\end{array}$ & $\begin{array}{l}\text { Carl Roth GmbH \& Co. KG, Karlsruhe, } \\
\text { Germany }\end{array}$ \\
\hline $\begin{array}{l}\text { GeneRuler DNA ladder ( } 50 \text { base pairs (bp), } \\
100 \text { bp plus, } 1 \text { kilobase (kb)) }\end{array}$ & $\begin{array}{l}\text { Thermo Fisher Scientific Inc., Waltham, MA, } \\
\text { USA }\end{array}$ \\
\hline Glutaraldehyde & Sigma-Aldrich Co., St. Louis, MO, USA \\
\hline Glycergel mounting medium & $\begin{array}{l}\text { Dako North America Inc., Carpinteria, CA, } \\
\text { USA }\end{array}$ \\
\hline Haematoxylin crystalline, Mayer's & Merck KGaA, Darmstadt, Germany \\
\hline Hydrochloric acid (37\%) & $\begin{array}{l}\text { Carl Roth GmbH \& Co. KG, Karlsruhe, } \\
\text { Germany }\end{array}$ \\
\hline Hydrogen peroxide (35 \%) & $\begin{array}{l}\text { Carl Roth GmbH \& Co. KG, Karlsruhe, } \\
\text { Germany }\end{array}$ \\
\hline $\begin{array}{l}\text { Immersion oil for microscopy (Immersion }{ }^{\mathrm{TM}} \\
518 \mathrm{~N})\end{array}$ & Carl Zeiss GmbH, Jena, Germany \\
\hline Isoflurane (FORENE) & $\begin{array}{l}\text { Abbott Laboratories Inc, Santa Clara, CA, } \\
\text { USA }\end{array}$ \\
\hline Isopropanol & $\begin{array}{l}\text { Carl Roth GmbH \& Co. KG, Karlsruhe, } \\
\text { Germany }\end{array}$ \\
\hline Kanamycin A & Sigma-Aldrich Co., St. Louis, MO, USA \\
\hline Liquid barrier marker & $\begin{array}{l}\text { Carl Roth GmbH \& Co. KG, Karlsruhe, } \\
\text { Germany }\end{array}$ \\
\hline $\begin{array}{l}\text { Matrigel basement membrane matrix } \\
\text { phenol red free }\end{array}$ & $\begin{array}{l}\text { Corning Incorporated, New York City, NY, } \\
\text { USA }\end{array}$ \\
\hline Methanol (MeOH) & $\begin{array}{l}\text { Carl Roth GmbH \& Co. KG, Karlsruhe, } \\
\text { Germany }\end{array}$ \\
\hline NuPAGE MES SDS running buffer, $20 \mathrm{x}$ & Invitrogen, Carlsbad, CA, USA \\
\hline $\begin{array}{l}\text { NuPAGE Tris acetate SDS running buffer, } \\
20 x\end{array}$ & Invitrogen, Carlsbad, CA, USA \\
\hline Paraformaldehyde (PFA) & $\begin{array}{l}\text { Carl Roth GmbH \& Co. KG, Karlsruhe, } \\
\text { Germany }\end{array}$ \\
\hline
\end{tabular}




\begin{tabular}{|c|c|}
\hline Pertex mounting medium & $\begin{array}{l}\text { Medite Medizintechnik GmbH, Burgdorf, } \\
\text { Germany }\end{array}$ \\
\hline $\begin{array}{l}\text { Phosphatase inhibitor cocktail Tab.ts } \\
\text { (PhosSTOP) }\end{array}$ & $\begin{array}{l}\text { Roche Diagnostics GmbH, Mannheim, } \\
\text { Germany }\end{array}$ \\
\hline Phosphate buffered saline (PBS) Tab.ts & Invitrogen, Carlsbad, CA, USA \\
\hline Powdered milk & $\begin{array}{l}\text { Carl Roth GmbH \& Co. KG, Karlsruhe, } \\
\text { Germany }\end{array}$ \\
\hline Protease inhibitor cocktail (cOmplete Mini) & $\begin{array}{l}\text { Roche Diagnostics GmbH, Mannheim, } \\
\text { Germany }\end{array}$ \\
\hline $\begin{array}{l}\text { Primer "random" p(dN)6 Hexamer- } \\
\text { oligonucleotides }\end{array}$ & $\begin{array}{l}\text { Roche Diagnostics } \mathrm{GmbH} \text {, Mannheim, } \\
\text { Germany }\end{array}$ \\
\hline $\begin{array}{l}\text { ProLong Gold antifade mountant with 4',6- } \\
\text { diamidino-2-phenylindole (DAPI) }\end{array}$ & $\begin{array}{l}\text { Thermo Fisher Scientific Inc., Waltham, MA, } \\
\text { USA }\end{array}$ \\
\hline RNaseZAP & Sigma-Aldrich Co., St. Louis, MO, USA \\
\hline $\begin{array}{l}\text { SeeBlue Plus2 Pre-Stained Protein } \\
\text { Standard }\end{array}$ & Invitrogen, Carlsbad, CA, USA \\
\hline $\begin{array}{l}\text { S.O.C. (Super optimal broth with catabolite } \\
\text { repression) medium }\end{array}$ & Invitrogen, Carlsbad, CA, USA \\
\hline Sodium chloride & AppliChem GmbH, Darmstadt, Germany \\
\hline Sodiumdodecylsulfate (SDS) & AppliChem GmbH, Darmstadt, Germany \\
\hline Sodium hydroxide & $\begin{array}{l}\text { Carl Roth GmbH \& Co. KG, Karlsruhe, } \\
\text { Germany }\end{array}$ \\
\hline Spectra multicolor high range protein ladder & $\begin{array}{l}\text { Thermo Fisher Scientific Inc., Waltham, MA, } \\
\text { USA }\end{array}$ \\
\hline Sucrose & Sigma-Aldrich Co., St. Louis, MO, USA \\
\hline Tamoxifen & Sigma-Aldrich Co., St. Louis, MO, USA \\
\hline Triethanolamine (TEA) hydrochloride & Sigma-Aldrich Co., St. Louis, MO, USA \\
\hline $\begin{array}{l}\text { Tris(hydroxymethyl)aminomethane (TRIS) } \\
\text { base }\end{array}$ & AppliChem GmbH, Darmstadt, Germany \\
\hline Triton $^{\mathrm{TM}} \mathrm{X}-100$ & Sigma-Aldrich Co., St. Louis, MO, USA \\
\hline Tropix® I-BLOCK ${ }^{\mathrm{TM}}$ & Applied Biosystems, Waltham, MA, USA \\
\hline Tryptone (peptone ex casein) & $\begin{array}{l}\text { Carl Roth GmbH \& Co. KG, Karlsruhe, } \\
\text { Germany }\end{array}$ \\
\hline TWEEN® 20 & Sigma-Aldrich Co., St. Louis, MO, USA \\
\hline $\begin{array}{l}\text { X-Gal (5-bromo-4-chloro-3-indolyl- } \beta \text {-D- } \\
\text { galactopyranoside) }\end{array}$ & $\begin{array}{l}\text { Carl Roth GmbH \& Co. KG, Karlsruhe, } \\
\text { Germany }\end{array}$ \\
\hline Xylene & J.T. Baker B.V., Deventer, Netherlands \\
\hline Yeast extract & $\begin{array}{l}\text { Carl Roth GmbH \& Co. KG, Karlsruhe, } \\
\text { Germany }\end{array}$ \\
\hline
\end{tabular}

\subsection{Buffers and solutions}

If not indicated otherwise all buffers and solutions were prepared using double-distilled $\mathrm{H}_{2} \mathrm{O}$ $\left(\mathrm{ddH} \mathrm{H}_{2} \mathrm{O}\right)$. 
Table 4: Buffers and solutions and their components

\begin{tabular}{|c|c|}
\hline Buffer & Composition \\
\hline $2 \times$ Laemmli buffer & $\begin{array}{l}65 \text { mM Tris-HCl, pH } 6.8 \\
25 \%(w / v) \text { Glycerol } \\
2 \%(w / v) \text { SDS } \\
0.01 \%(w / v) \text { Bromophenol blue }\end{array}$ \\
\hline $6 \times$ SDS loading buffer & $\begin{array}{l}375 \mathrm{mM} \text { Tris, } \mathrm{pH} 6.8 \\
12 \%(\mathrm{w} / \mathrm{v}) \text { SDS } \\
60 \%(\mathrm{v} / \mathrm{v}) \text { Glycerol } \\
0.6 \mathrm{M} \mathrm{DTT} \\
0.01 \%(\mathrm{w} / \mathrm{v}) \text { Bromophenol blue }\end{array}$ \\
\hline $\begin{array}{l}10 \times \text { PBS } \\
\mathrm{pH} 7.4\end{array}$ & $\begin{array}{l}1.4 \mathrm{M} \mathrm{NaCl} \\
65 \mathrm{mM} \mathrm{Na}_{2} \mathrm{HPO}_{4} \\
27 \mathrm{mM} \mathrm{KCl} \\
15 \mathrm{mM} \mathrm{KH}_{2} \mathrm{PO}_{4}\end{array}$ \\
\hline $\begin{array}{l}10 \times \text { Tris-boric acid-EDTA solution (TBE) } \\
\mathrm{pH} 8.0\end{array}$ & $\begin{array}{l}890 \mathrm{mM} \text { Tris/ } \mathrm{HCl}, \mathrm{pH} 8.0 \\
730 \mathrm{mM} \text { boric acid } \\
12.5 \mathrm{mM} \text { EDTA }\end{array}$ \\
\hline $\begin{array}{l}10 \times \text { Tris-buffered saline (TBS) } \\
\mathrm{pH} 7.4\end{array}$ & $\begin{array}{l}150 \mathrm{mM} \mathrm{NaCl} \\
10 \mathrm{mM} \text { Tris/HCl, } \mathrm{pH} 8.0\end{array}$ \\
\hline $\begin{array}{l}\text { AEC chromogen } \\
\mathrm{pH} 5.2\end{array}$ & $\begin{array}{l}70 \mathrm{mM} \text { Sodium acetate trihydrate } \\
30 \mathrm{mM} \text { Acetic acid } \\
16 \mathrm{mM} \text { 3-Amino-9 Ethylcarbazole } \\
\text { Dissolved in DMF }\end{array}$ \\
\hline Blotting buffer for semi-dry blotting & $\begin{array}{l}50 \mathrm{mM} \text { Tris } \\
40 \mathrm{mM} \text { Glycine } \\
20 \%(\mathrm{v} / \mathrm{v}) \text { Methanol } \\
0.0325 \%(\mathrm{w} / \mathrm{v}) \text { SDS }\end{array}$ \\
\hline $\begin{array}{l}\text { Blotting buffer for tank blotting } \\
\mathrm{pH} 8.3\end{array}$ & $\begin{array}{l}200 \mathrm{mM} \text { Glycin } \\
25 \mathrm{mM} \text { Tris } \\
20 \%(\mathrm{v} / \mathrm{v}) \text { Methanol } \\
0.1 \%(\mathrm{w} / \mathrm{v}) \text { SDS } \\
\end{array}$ \\
\hline BSA-azide & $\begin{array}{l}3 \mathrm{mM} \text { Sodium azide } \\
2 \%(\mathrm{w} / \mathrm{v}) \mathrm{BSA} \\
\text { Dissolved in PBST }\end{array}$ \\
\hline Casein & $\begin{array}{l}0.2 \%(\mathrm{w} / \mathrm{v}) \mathrm{l}-\mathrm{Block} \\
\text { Dissolved in TBS }\end{array}$ \\
\hline $\begin{array}{l}\text { Citric acid buffer } \\
\mathrm{pH} 3.0 \text { or } \mathrm{pH} 6.0\end{array}$ & 10 mM Sodium Citrate \\
\hline Cresol & $\begin{array}{l}0.1 \%(\mathrm{w} / \mathrm{v}) \text { Cresol red } \\
\text { Dissolved in saturated sucrose-solution }\end{array}$ \\
\hline dNTP-Mix & $\begin{array}{l}10 \mathrm{mM} \text { dATP } \\
10 \mathrm{mM} \text { dCTP } \\
10 \mathrm{mM} \text { dGTP } \\
10 \mathrm{mM} \text { dTTP }\end{array}$ \\
\hline Eosin solution & $\begin{array}{l}80 \%(v / v) \text { EtOH } \\
1 \%(w / v) \text { Eosin y (water soluble) }\end{array}$ \\
\hline
\end{tabular}




\begin{tabular}{|c|c|}
\hline Haematoxylin solution, Mayer's & $\begin{array}{l}300 \mathrm{mM} \text { Trichloro acetaldehyde hydrate } \\
100 \mathrm{mM} \text { Potassium aluminum sulfate } \\
50 \mathrm{mM} \text { Citric acid } \\
35 \mathrm{mM} \text { Haematoxylin } \\
75 \mathrm{nM} \text { Sodium iodate }\end{array}$ \\
\hline $\begin{array}{l}\text { Lysis buffer } \\
\mathrm{pH} 8.8\end{array}$ & $\begin{array}{l}150 \mathrm{mM} \mathrm{NaCl} \\
30 \mathrm{mM} \text { Tris/HCl, pH } 7.5 \\
10 \%(\mathrm{v} / \mathrm{v}) \text { Glycerol } \\
1 \%(\mathrm{v} / \mathrm{v}) \text { Triton X-100 } \\
1 \text { Tab.t/ } 10 \mathrm{ml} \text { phosphatase inhibitor and } \\
\text { protease inhibitor } \\
\text { added before use: } 2 \text { mM DTT, } \\
500 \mu \mathrm{M} \text { Phenylmethanesulfonylfluoride }\end{array}$ \\
\hline LacZ buffer & $\begin{array}{l}2 \mathrm{mM} \mathrm{MgCl} \\
0,02 \%(\mathrm{v} / \mathrm{v}) \mathrm{NP}-40 \\
0,01 \%(\mathrm{w} / \mathrm{v}) \text { Natrium Deoxycholat } \\
\text { Dissolved in PBS }\end{array}$ \\
\hline LacZ-staining buffer & $\begin{array}{l}5 \mathrm{mM} \mathrm{K}_{3} \mathrm{Fe}(\mathrm{CN})_{6} \\
5 \mathrm{mM} \mathrm{K}_{4} \mathrm{Fe}(\mathrm{CN})_{6} \\
2 \mathrm{mM} \mathrm{MgCl} \\
0.02 \%(\mathrm{v} / \mathrm{v}) \mathrm{NP}-40 \\
0.01 \%(\mathrm{w} / \mathrm{v}) \text { Natrium Deoxycholat } \\
500 \mu \mathrm{g} / \mathrm{ml} \mathrm{X-Gal} \\
\text { Dissolved in PBS }\end{array}$ \\
\hline Lysogeny broth medium (LB medium) & $\begin{array}{l}1 \%(\mathrm{w} / \mathrm{v}) \text { Bacto-tryptone } \\
1 \%(\mathrm{w} / \mathrm{v}) \mathrm{NaCl}(\mathrm{pH} 7.0) \\
0.5 \%(\mathrm{w} / \mathrm{v}) \text { Yeast extract }\end{array}$ \\
\hline Lysogeny broth agar (LB agar) & $\begin{array}{l}1.5 \%(w / v) \text { Agar } \\
\text { Dissolved in LB medium }\end{array}$ \\
\hline $\begin{array}{l}\text { Modified radioimmunoprecipitation assay } \\
\text { buffer (RIPA) }\end{array}$ & $\begin{array}{l}50 \mathrm{nM} \text { Tris/HCl, } \mathrm{pH} 7.4 \\
1 \%(\mathrm{v} / \mathrm{v}) \mathrm{NP}-40 \\
0.25 \%(\mathrm{v} / \mathrm{v}) \mathrm{Na}-\text { Deoxycholat } \\
150 \mathrm{mM} \mathrm{NaCl} \\
1 \mathrm{mM} \text { EDTA } \\
1 \mathrm{Tab} . \mathrm{t} / 10 \mathrm{ml} \text { phosphatase inhibitor and } \\
\text { protease inhibitor }\end{array}$ \\
\hline Nuclear lysis buffer (NL buffer) & $\begin{array}{l}50 \mathrm{mM} \text { Tris- } \mathrm{HCl}, \mathrm{pH} 8 \\
150 \mathrm{mM} \mathrm{NaCl} \\
1 \%(\mathrm{v} / \mathrm{v}) \mathrm{NP}-40 \\
0.5 \mathrm{M} \text { sodium deoxycholate } \\
0.1 \%(\mathrm{w} / \mathrm{v}) \mathrm{SDS} \\
1 \mathrm{Tab} / \mathrm{t} 10 \mathrm{ml} \text { phosphatase inhibitor and } \\
\text { protease inhibitor } \\
\text { added before use: } 10 \%(\mathrm{v} / \mathrm{v}) \text { Glycerol }\end{array}$ \\
\hline Paraformaldehyde & $\begin{array}{l}\text { 4\% (w/v) Paraformaldehyde } \\
\text { Dissolved in PBS }\end{array}$ \\
\hline PBS-Tween 20 (PBST) & $\begin{array}{l}0.1 \%(v / v) \text { Tween-20 } \\
\text { Dissolved in PBS }\end{array}$ \\
\hline
\end{tabular}




\begin{tabular}{|c|c|}
\hline Propidium iodide $(\mathrm{PI})$ staining solution & $\begin{array}{l}10 \mu \mathrm{g} / \mathrm{ml} \mathrm{PI} \\
100 \mu \mathrm{g} / \mathrm{ml} \text { RNase A } \\
\text { Dissolved in PBS }\end{array}$ \\
\hline $\begin{array}{l}\text { Proteinase K } \\
\text { pH } 8.0\end{array}$ & $\begin{array}{l}50 \mathrm{mM} \text { Tris/HCl } \\
5 \mathrm{mM} \text { EDTA } \\
10 \mathrm{mg} / \mathrm{ml} \text { Proteinase } \mathrm{K}\end{array}$ \\
\hline Subcellular fractionation buffer (SF buffer) & $\begin{array}{l}250 \mathrm{mM} \text { Sucrose } \\
20 \mathrm{mM} \mathrm{HEPES}, \mathrm{pH} 7.4 \\
10 \mathrm{mM} \mathrm{KCl} \\
1.5 \mathrm{mM} \mathrm{MgCl}{ }_{2} \\
1 \mathrm{mM} \text { EDTA } \\
1 \mathrm{mM} \text { Ethyleneglycol etraaceticacid (EGTA) } \\
1 \mathrm{Tab} . \mathrm{t} / 10 \mathrm{ml} \text { phosphatase inhibitor and } \\
\text { protease inhibitor } \\
\text { added before use: } 2 \text { mM DTT }\end{array}$ \\
\hline Sodium Chloride-Tris-EDTA (STE) buffer & $\begin{array}{l}100 \mathrm{mM} \mathrm{NaCl} \\
50 \mathrm{mM} \mathrm{Tris} / \mathrm{HCl} \\
1 \mathrm{mM} \text { EDTA } \\
1 \%(\mathrm{w} / \mathrm{v}) \mathrm{SDS}\end{array}$ \\
\hline Stripping buffer & $\begin{array}{l}62.5 \mathrm{mM} \text { Tris, } \mathrm{pH} 6.7 \\
2 \%(\mathrm{w} / \mathrm{v}) \text { SDS } \\
100 \mathrm{mM} \text { B-Mercaptoethanol }\end{array}$ \\
\hline TBS-Triton X-100 & $\begin{array}{l}0.1 \% \text { Triton X-100 } \\
\text { Dissolved in TBS }\end{array}$ \\
\hline TBS-Tween 20 (TBST) & $\begin{array}{l}0.5 \%(v / v) \text { Tween-20 } \\
\text { Dissolved in TBS }\end{array}$ \\
\hline $\begin{array}{l}\text { Tris-EDTA (TE) buffer } \\
\mathrm{pH} 8.0\end{array}$ & $\begin{array}{l}10 \mathrm{mM} \text { Tris } \\
1 \mathrm{mM} \text { EDTA } \\
\end{array}$ \\
\hline Trypan blue staining solution & $\begin{array}{l}0.4 \%(w / v) \text { Trypan blue } \\
\text { Dissolved in PBS }\end{array}$ \\
\hline X-Gal stock solution & $\begin{array}{l}4 \%(w / v) X-G a l \\
\text { Dissolved in DMSO }\end{array}$ \\
\hline
\end{tabular}

\subsection{Kits and ready-to-use reaction systems}

Unless indicated otherwise, all commercially available kits and ready-to-use reaction systems listed in Tab. 5 were used according to the manufacturer's instructions.

Table 5: Commercially available kits and ready-to-use reaction systems

\begin{tabular}{|c|c|}
\hline Reaction system & Supplier \\
\hline $\begin{array}{l}\text { Amersham enhanced chemiluminescence } \\
\text { (ECL) Western Blotting detection reagents }\end{array}$ & $\begin{array}{l}\text { GE Healthcare Europe GmbH, Freiburg, } \\
\text { Germany }\end{array}$ \\
\hline $\begin{array}{l}\text { Cell proliferation Enzyme-linked } \\
\text { immunosorbent assay (ELISA), BrdU } \\
\text { chemiluminescent }\end{array}$ & $\begin{array}{l}\text { Roche Diagnostics } \mathrm{GmbH} \text {, Mannheim, } \\
\text { Germany }\end{array}$ \\
\hline $\begin{array}{l}\text { Dako REAL }{ }^{\mathrm{TM}} \text { EnVision }^{\mathrm{TM}} \text { detection system, } \\
\text { Peroxidase/3,3'-Diaminobenzidine (DAB) +, } \\
\text { Rabbit/Mouse }\end{array}$ & $\begin{array}{l}\text { Dako North America Inc., Carpinteria, CA, } \\
\text { USA }\end{array}$ \\
\hline
\end{tabular}




\begin{tabular}{|c|c|}
\hline Dual-Luciferase® Reporter assay system & Promega GmbH, Mannheim, Germany \\
\hline NEON Transfection kit & $\begin{array}{l}\text { Thermo Fisher Scientific Inc., Waltham, MA, } \\
\text { USA }\end{array}$ \\
\hline Pierce BCA Protein assay kit & $\begin{array}{l}\text { Thermo Fisher Scientific Inc., Waltham, MA, } \\
\text { USA }\end{array}$ \\
\hline $\begin{array}{l}\text { Platinum }^{\text {TM }} \text { SYBR }{ }^{\mathrm{TM}} \text { Green } \mathrm{qPCR} \\
\text { SuperMix-UDG w/ROX }\end{array}$ & Invitrogen, Carlsbad, CA, USA \\
\hline PureLink®HiPure Plasmid Midiprep Kit & Invitrogen, Carlsbad, CA, USA \\
\hline QIAamp DNA FFPE Tissue Kit & Qiagen GmbH, Hilden, Germany \\
\hline QuantiTect SYBR® Green RT-PCR Kit & Qiagen GmbH, Hilden, Germany \\
\hline $\begin{array}{l}\text { Ras Pull-down activation assay biochem kit } \\
\text { (bead pull-down format) }\end{array}$ & Cytoskeleton Inc, Denver, CO, USA \\
\hline $\begin{array}{l}\text { RevertAid }{ }^{\mathrm{TM}} \mathrm{H} \text { Minus First Strand cDNA } \\
\text { Synthesis Kit }\end{array}$ & $\begin{array}{l}\text { Thermo Fisher Scientific Inc., Waltham, MA, } \\
\text { USA }\end{array}$ \\
\hline TRIzo|® Reagent & Life Technologies Co., Camarillo, CA, USA \\
\hline $\begin{array}{l}\text { Water soluble tetrazolium salt (WST-1) } \\
\text { reagent }\end{array}$ & $\begin{array}{l}\text { Roche Diagnostics GmbH, Mannheim, } \\
\text { Germany }\end{array}$ \\
\hline
\end{tabular}

\subsection{Enzymes}

All enzymes were stored at $-20^{\circ} \mathrm{C}$. Enzymatic reactions were performed according to the manufacturer's recommendations.

Table 6: Enzymes

\begin{tabular}{|l|l|}
\hline Enzyme & Supplier \\
\hline BamH1 & New England Biolabs, Ipswich, MA, USA \\
\hline Bpml & New England Biolabs, Ipswich, MA, USA \\
\hline EcoRI & New England Biolabs, Ipswich, MA, USA \\
\hline Hind III & New England Biolabs, Ipswich, MA, USA \\
\hline Kpnl & New England Biolabs, Ipswich, MA, USA \\
\hline Nhel & New England Biolabs, Ipswich, MA, USA \\
\hline Not1 & New England Biolabs, Ipswich, MA, USA \\
\hline Proteinase K & $\begin{array}{l}\text { Carl Roth GmbH \& Co. KG, Karlsruhe, Ger- } \\
\text { many }\end{array}$ \\
\hline RNase A & $\begin{array}{l}\text { Carl Roth GmbH \& Co. KG, Karlsruhe, } \\
\text { Germany }\end{array}$ \\
\hline SuperScript ${ }^{\text {TM }}$ II Reverse Transcriptase & $\begin{array}{l}\text { Thermo Fisher Scientific Inc., Waltham, MA, } \\
\text { USA }\end{array}$ \\
\hline Taq-Polymerase (MolTaq) & $\begin{array}{l}\text { Molzym GmbH \& Co. KG, Bremen, } \\
\text { Germany }\end{array}$ \\
\hline
\end{tabular}




\subsection{Small molecule inhibitors}

Table 7: Signaling pathway inhibitors

\begin{tabular}{|l|l|l|l|}
\hline Inhibitor & Solvent & $\begin{array}{l}\text { Applied } \\
\text { concentration }\end{array}$ & Supplier \\
\hline HhAntag (HhA) & DMSO & $30 \mu \mathrm{M}$ & $\begin{array}{l}\text { Genentech, San } \\
\text { Francisco, CA, USA }\end{array}$ \\
\hline PI-103 & DMSO & $3 \mu \mathrm{M}$ & $\begin{array}{l}\text { Alexis Biochemicals, San } \\
\text { Diego, CA, USA }\end{array}$ \\
\hline SCH772984 & DMSO & $0.5-10 \mu \mathrm{M}$ & $\begin{array}{l}\text { Selleckchem, München, } \\
\text { Germany }\end{array}$ \\
\hline $\begin{array}{l}\text { Smoothened agonist } \\
\text { (SAG) }\end{array}$ & DMSO & $100-150 \mathrm{nM}$ & $\begin{array}{l}\text { Cayman chemicals, Ann } \\
\text { Arbor, MI, USA }\end{array}$ \\
\hline U0126 & DMSO & $10 \mu \mathrm{M}$ & $\begin{array}{l}\text { InvivoGen, San Diego, } \\
\text { CA, USA }\end{array}$ \\
\hline
\end{tabular}

\subsection{Plasmids}

Table 8: Plasmids and their application

\begin{tabular}{|l|l|l|}
\hline Plasmid & Application & Supplier or Reference \\
\hline pMSCVpuro & $\begin{array}{l}\text { Transduction of } \\
\text { cell lines }\end{array}$ & $\begin{array}{l}\text { CLONTECH Laboratories Inc., } \\
\text { Mountain View, CA, USA }\end{array}$ \\
\hline pMSCVpuro-HRAS ${ }^{G 12 V}$ & $\begin{array}{l}\text { Transduction of } \\
\text { cell lines }\end{array}$ & 299 \\
\hline pMSCVpuro-KRAS & $\begin{array}{l}\text { Transduction of } \\
\text { cell lines }\end{array}$ & 299 \\
\hline pMSCVpuro-NRAS & $\begin{array}{l}\text { Transduction of } \\
\text { cell lines }\end{array}$ & 299 \\
\hline$p E G F P-N 1$ & $\begin{array}{l}\text { Transfection } \\
\text { control }\end{array}$ & $\begin{array}{l}\text { CLONTECH Laboratories Inc., } \\
\text { Mountain View, CA, USA }\end{array}$ \\
\hline pGL3 9xGli-BS & Gli reporter assay & 300 \\
\hline pCR3.1 & Gli reporter assay & Invitrogen, Carlsbad, CA, USA \\
\hline$p C R 3.1-m G l i 1$ & Gli reporter assay & 301 \\
\hline$p R L-C M V$ & Gli reporter assay & $\begin{array}{l}\text { Promega GmbH, Mannheim, } \\
\text { Germany }\end{array}$ \\
\hline
\end{tabular}

\subsection{Antibodies}

The primary antibodies $(A b)$ were monoclonal $(m A b)$ or polyclonal $(p A b)$ against their target. For Western Blot analyses horseradish peroxidase (HRP) conjugated IgG (immunoglobulin G) secondary antibodies were used. Antibodies for immunohistochemically stainings were used in combination with the Dako REAL ${ }^{\mathrm{TM}}$ EnVision ${ }^{\mathrm{TM}}$ detection system (Peroxidase/DAB+, Rabbit/Mouse). 
Table 9: Primary antibodies

\begin{tabular}{|c|c|c|c|}
\hline Primary antibody & Dilution & Readout & Supplier \\
\hline $\begin{array}{l}\text { mAb mouse anti- } \alpha- \\
\text { Tubulin (Clone DM1A) }\end{array}$ & $1: 10,000$ & $\begin{array}{l}\text { WB band size: } \\
55 \mathrm{kDa}\end{array}$ & $\begin{array}{l}\text { Dianova, Hamburg, } \\
\text { Germany }\end{array}$ \\
\hline $\begin{array}{l}\text { mAb mouse anti-AKT } \\
\text { (Clone 55/PKBa/Akt) }\end{array}$ & $1: 1,000$ & $\begin{array}{l}\text { WB band size: } \\
60 \mathrm{kDa}\end{array}$ & $\begin{array}{l}\text { BD Biosciences, San } \\
\text { Jose, CA, USA }\end{array}$ \\
\hline $\begin{array}{l}\text { mAb mouse anti-Heat } \\
\text { shock cognate } 71 \mathrm{kDa} \\
\text { protein (HSC70) (B-6) }\end{array}$ & $1: 10,000$ & $\begin{array}{l}\text { WB band size: } \\
70 \mathrm{kDa}\end{array}$ & $\begin{array}{l}\text { Santa Cruz } \\
\text { Biotechnology, Santa } \\
\text { Cruz, CA, USA }\end{array}$ \\
\hline mAb mouse anti-Ki67 & $1: 50$ & $\begin{array}{l}\text { IHC: Nuclear staining } \\
\text { of dividing cells }\end{array}$ & $\begin{array}{l}\text { BD Biosciences, San } \\
\text { Jose, CA, USA }\end{array}$ \\
\hline $\begin{array}{l}\text { mAb mouse anti-pan- } \\
\text { Ras }\end{array}$ & $1: 250$ & $\begin{array}{l}\text { WB band size: } \\
21 \mathrm{kDa}\end{array}$ & $\begin{array}{l}\text { Cytoskeleton Inc, } \\
\text { Denver, CO, USA }\end{array}$ \\
\hline $\begin{array}{l}\text { mAb mouse anti-S6 } \\
\text { (54D2) }\end{array}$ & $1: 1,000$ & $\begin{array}{l}\text { WB band size: } \\
32 \mathrm{kDa}\end{array}$ & $\begin{array}{l}\text { Cell Signaling } \\
\text { Technology, Danvers, } \\
\text { MA, USA }\end{array}$ \\
\hline $\begin{array}{l}\text { mAb rabbit anti-pAKT } \\
\text { (Ser473) }(193 \mathrm{H} 12)\end{array}$ & $1: 1,000$ & $\begin{array}{l}\text { WB band size: } \\
60 \mathrm{kDa}\end{array}$ & $\begin{array}{l}\text { Cell Signaling } \\
\text { Technology, Danvers, } \\
\text { MA, USA }\end{array}$ \\
\hline pAb goat anti-GLI3 & $1: 200$ & $\begin{array}{l}\text { WB band size: } \\
190 \mathrm{kDa} \text { : full length } \\
\text { form } \\
85 \mathrm{kDa} \text { : truncated } \\
\text { repressor form }\end{array}$ & $\begin{array}{l}\text { R\&D Systems, } \\
\text { Minneapolis, MN, USA }\end{array}$ \\
\hline $\begin{array}{l}\text { pAb rabbit anti- } \\
\text { Caspase } 3\end{array}$ & $1: 1,000$ & $\begin{array}{l}\text { WB band size: } 35 \mathrm{kDa} \\
\text { Cleaved: } 19 / 17 \mathrm{kDa}\end{array}$ & $\begin{array}{l}\text { Cell Signaling } \\
\text { Technology, Danvers, } \\
\text { MA, USA }\end{array}$ \\
\hline $\begin{array}{l}\text { pAb rabbit anti-GLI1 } \\
\text { (V812) }\end{array}$ & $1: 750$ & $\begin{array}{l}\text { WB band size: } \\
160 \mathrm{kDa}\end{array}$ & $\begin{array}{l}\text { Cell Signaling } \\
\text { Technology, Danvers, } \\
\text { MA, USA }\end{array}$ \\
\hline $\begin{array}{l}\text { pAb rabbit anti-GLI2 } \\
(\text { aa46-60) }\end{array}$ & $1: 1,000$ & $\begin{array}{l}\text { WB band size: } \\
185 \mathrm{kDa}\end{array}$ & $\begin{array}{l}\text { Cell Signaling } \\
\text { Technology, Danvers, } \\
\text { MA, USA }\end{array}$ \\
\hline pAb rabbit anti-ERK & $1: 1,000$ & $\begin{array}{l}\text { WB band size: } \\
42 / 44 \mathrm{kDa}\end{array}$ & $\begin{array}{l}\text { Merck KGaA, } \\
\text { Darmstadt, Germany }\end{array}$ \\
\hline $\begin{array}{l}\text { pAb rabbit anti-pERK } \\
\text { (Thr202/Tyr204) }\end{array}$ & $1: 1,000$ & $\begin{array}{l}\text { WB band size: } \\
42 / 44 \mathrm{kDa}\end{array}$ & $\begin{array}{l}\text { Cell Signaling } \\
\text { Technology, Danvers, } \\
\text { MA, USA }\end{array}$ \\
\hline $\begin{array}{l}\text { pAB rabbit anti-Lamin } \\
\text { B1 }\end{array}$ & $1: 1,000$ & $\begin{array}{l}\text { WB band size: } 68 \mathrm{kDa} \\
\text { Cleaved: } 45 \mathrm{kDa}\end{array}$ & $\begin{array}{l}\text { Cell Signaling } \\
\text { Technology, Danvers, } \\
\text { MA USA }\end{array}$ \\
\hline $\begin{array}{l}\text { pAb rabbit anti-pS6 } \\
\text { (Ser240/244) }\end{array}$ & $1: 1,000$ & $\begin{array}{l}\text { WB band size: } \\
32 \mathrm{kDa}\end{array}$ & $\begin{array}{l}\text { Cell Signaling } \\
\text { Technology, Danvers, } \\
\text { MA, USA }\end{array}$ \\
\hline pAB rabbit anti-Ras & $1: 1,000$ & $\begin{array}{l}\text { WB band size: } \\
21 \mathrm{kDa}\end{array}$ & $\begin{array}{l}\text { Cell Signaling } \\
\text { Technology, Danvers, } \\
\text { MA, USA }\end{array}$ \\
\hline
\end{tabular}


Table 10: Secondary antibodies

\begin{tabular}{|l|l|l|l|}
\hline Secondary antibody & Conjugation & Dilution & Supplier \\
\hline $\begin{array}{l}\text { pAb donkey anti-goat } \\
\text { IgG }\end{array}$ & HRP & $1: 10,000$ & $\begin{array}{l}\text { Jackson Immuno } \\
\text { Research, } \\
\text { Cambridgeshire, UK }\end{array}$ \\
\hline $\begin{array}{l}\text { pAb goat anti-rabbit } \\
\text { IgG }\end{array}$ & HRP & $1: 10,000$ & $\begin{array}{l}\text { Dianova, Hamburg, } \\
\text { Germany }\end{array}$ \\
\hline $\begin{array}{l}\text { pAb rabbit anti-mouse } \\
\text { IgG }\end{array}$ & HRP & $1: 10,000$ & $\begin{array}{l}\text { Dianova, Hamburg, } \\
\text { Germany }\end{array}$ \\
\hline
\end{tabular}

\subsection{Synthetic Oligonucleotides}

All synthetic deoxyribonucleic acid (DNA) oligonucleotides were obtained from Eurofins Scientific SE (Luxemburg, Luxembourg). For polymerase chain reactions (PCR) and quantitative real-time PCR (qRT-PCR) a $10 \mu \mathrm{M}$ working solution of each primer was used. The appropriate dilutions and concentrations are described in sections 5.2.3 and 5.2.8.

Table 11: Oligonucleotides for PCR approaches

\begin{tabular}{|c|c|c|c|}
\hline Primer name & $\begin{array}{l}\text { Primer sequence } \\
\text { (5'-3' orientation) }\end{array}$ & $\begin{array}{l}\text { Amplicon } \\
\text { size }\end{array}$ & $\begin{array}{l}\text { Refe- } \\
\text { rence }\end{array}$ \\
\hline \multicolumn{4}{|c|}{ Primers for genotyping } \\
\hline $\begin{array}{l}\text { Exon 7-F } \\
\text { Neo-R }\end{array}$ & $\begin{array}{l}\text { AGGAAGTATATGCATTGGCAGGAG } \\
\text { GCATCAGAGCAGCCGATTGTCTG }\end{array}$ & $\begin{array}{l}950 \mathrm{bp} \\
\text { (mutated Ptch) }\end{array}$ & 302 \\
\hline $\begin{array}{l}\text { mPTCNx_f } \\
\text { mPTCwt_r.2 }\end{array}$ & $\begin{array}{l}\text { TGGTAATTCTGGGCTCCCGT } \\
\text { ACACAACAGGGTGGAGACCACT }\end{array}$ & $\begin{array}{l}445 \mathrm{bp} \\
\text { (wt Ptch) }\end{array}$ & 302 \\
\hline $\begin{array}{l}\text { eCreRasF } \\
\text { eCreRasR }\end{array}$ & $\begin{array}{l}\text { GCCATCCCTCGCGTTCCTGTAGTC } \\
\text { CCTGCCCCACCTGCCAATGAGAAG }\end{array}$ & $\begin{array}{l}622 \text { bp } \\
\text { (wt Hras) } \\
667 \text { bp } \\
\text { (mutated Hras) }\end{array}$ & 303 \\
\hline $\begin{array}{l}\text { Kras-WT-UP1 } \\
\text { Kras-URP_Lp1 } \\
\text { KrasG12Dmut_UP }\end{array}$ & $\begin{array}{l}\text { CACCAGCTTCGGCTTCCTATT } \\
\text { AGCTAATGGCTCTCAAAGGAATGTA } \\
\text { CCATGGCTTGAGTAAGTCTGC }\end{array}$ & $\begin{array}{l}270 \mathrm{bp} \\
\text { (wt Kras) } \\
170 \mathrm{bp} \\
\text { (mutated Kras) }\end{array}$ & 304 \\
\hline $\begin{array}{l}\text { mNRas-WT-For } \\
\text { mNRas-WT-Rev } \\
\text { mNRas-Mut-Rev }\end{array}$ & $\begin{array}{l}\text { AGACGCGGAGACTTGGCGAGC } \\
\text { GCTGGATCGTCAAGGCGCTTTTCC } \\
\text { AGCTAGCCACCATGGCTTGAGTAA } \\
\text { GTCTGCA }\end{array}$ & $\begin{array}{l}487 \text { bp } \\
\text { (wt Nras) } \\
345 \text { bp } \\
\text { (mutated Nras) }\end{array}$ & 220 \\
\hline $\begin{array}{l}\mathrm{cF} \\
\mathrm{cR}\end{array}$ & $\begin{array}{l}\text { GCATTTCTGGGGATTGCTTA } \\
\text { CCCGGCAAAACAGGTAGTTA }\end{array}$ & $\begin{array}{l}241 \mathrm{bp} \\
\left(\text { Myf5 } 5^{C r e E R}\right)\end{array}$ & 305 \\
\hline $\begin{array}{l}\text { CK382 } \\
\text { CK383 }\end{array}$ & $\begin{array}{l}\text { ACCCTCCAGCTCCAGACTTATC } \\
\text { CCCTGTAATGGATTCCAAGCTG }\end{array}$ & $\begin{array}{l}454 \text { bp (wt) } \\
\text { Myogenic factor } \\
5 \text { (Myf5) }\end{array}$ & 305 \\
\hline $\begin{array}{l}\text { Rosa1 } \\
\text { Rosa2 } \\
\text { Rosa3 }\end{array}$ & $\begin{array}{l}\text { AAAGTCGCTCTGAGTTGTTAT } \\
\text { GCGAAGAGTTTGTCCTCAACC } \\
\text { GGAGCGGGAGAAATGGATATG }\end{array}$ & $\begin{array}{l}500 \mathrm{bp} \text { (wt), } \\
250 \mathrm{bp} \text { (mutated) }\end{array}$ & 306 \\
\hline \multicolumn{4}{|c|}{ Primers for recombination assays } \\
\hline $\begin{array}{l}\text { mHRasG12VrelF1 } \\
\text { mHRasG12VrelR1 }\end{array}$ & $\begin{array}{l}\text { TGGGGCAGGAGCTCCTGGATT } \\
\text { GGTGTTGTTGATGGCAAATAC }\end{array}$ & $\begin{array}{l}302 \mathrm{bp} \\
\text { (Hras fragment) }\end{array}$ & 299 \\
\hline
\end{tabular}




\begin{tabular}{|l|l|l|l|}
\hline $\begin{array}{l}\text { Kras-WT_UP1 } \\
\text { Kras-URP_Lp1 }\end{array}$ & $\begin{array}{l}\text { CACCAGCTTCGGCTTCCTATT } \\
\text { AGCTAATGGCTCTCAAAGGAATGTA }\end{array}$ & $\begin{array}{l}270 \text { bp } \\
\text { (wt Kras), 304 } \\
\text { bp (recombined } \\
\text { Kras) }\end{array}$ & 304 \\
\hline $\begin{array}{l}\text { mNRas-WT-For } \\
\text { mNRas-WT-Rev }\end{array}$ & $\begin{array}{l}\text { AGACGCGGAGACTTGGCGAGC } \\
\text { GCTGGATCGTCAAGGCGCTTTTCC }\end{array}$ & $\begin{array}{l}487 \\
\text { (wt Nras), 521 } \\
\text { bp } \\
\text { (recombined } \\
\text { Nras) }\end{array}$ & 220 \\
\hline
\end{tabular}

Table 12: Oligonucleotides for qRT-PCR approaches

\begin{tabular}{|c|c|c|c|c|}
\hline $\begin{array}{l}\text { Trans- } \\
\text { cript }\end{array}$ & $\begin{array}{l}\text { Primer } \\
\text { name }\end{array}$ & $\begin{array}{l}\text { Primer sequence } \\
\text { (5'-3' orientation) }\end{array}$ & $\begin{array}{l}\text { Primer } \\
\text { location }\end{array}$ & $\begin{array}{l}\text { Ampli- } \\
\text { con size }\end{array}$ \\
\hline \multicolumn{5}{|c|}{ Primer for human and murine sequences } \\
\hline $18 S$ & $\begin{array}{l}18 S-f w d \\
18 S-r e v 2\end{array}$ & $\begin{array}{l}\text { CGCAAATTACCCACTCCCG } \\
\text { TTCCAATTACAGGGCCTCGAA }\end{array}$ & $\begin{array}{l}\text { Exon } 1 \\
\text { Exon } 1\end{array}$ & $81 \mathrm{bp}$ \\
\hline \multicolumn{5}{|c|}{ Primer for human sequences } \\
\hline HPRT & $\begin{array}{l}\text { hHPRT1_F1 } \\
\text { hHPRT1_R1 }\end{array}$ & $\begin{array}{l}\text { TGGCGTCGTGATTAGTGATG } \\
\text { CGAGCAAGACGTTCAGTCCT }\end{array}$ & $\begin{array}{l}\text { Exon } 1 / 2 \\
\text { Exon } 2 / 3\end{array}$ & $134 \mathrm{bp}$ \\
\hline GLI1 & $\begin{array}{l}\text { HsaGli1 tq F } \\
\text { HsaGli1 tq R }\end{array}$ & $\begin{array}{l}\text { AGCTACATCAACTCCGGCCA } \\
\text { GCTGCGGCGTTCAAGAGA }\end{array}$ & $\begin{array}{l}\text { Exon } 11 \\
\text { Exon } 12\end{array}$ & $116 \mathrm{bp}$ \\
\hline GLI2 & $\begin{array}{l}\text { hsGLI2F.1 } \\
\text { hsGLI2R.1 }\end{array}$ & $\begin{array}{l}\text { AAGCCCTTCAAGGCGCAGTA } \\
\text { TCGTGCTCACACACATATGGCTT }\end{array}$ & $\begin{array}{l}\text { Exon } 9 \\
\text { Exon } 10\end{array}$ & $170 \mathrm{bp}$ \\
\hline GL/3 & $\begin{array}{l}\text { hsGLI3F.1 } \\
\text { hsGLI3R.1 }\end{array}$ & $\begin{array}{l}\text { GCCAGCGCAGCCCCTAT } \\
\text { CGGCCTGGCTGACAGCCT }\end{array}$ & $\begin{array}{l}\text { Exon } 6 \\
\text { Exon } 7\end{array}$ & $128 \mathrm{bp}$ \\
\hline HHIP & $\begin{array}{l}\text { HSA_Hhip_t } \\
\text { q_FW1 } \\
\text { HSA_Hhip_t } \\
\text { q_RV1 }\end{array}$ & $\begin{array}{l}\text { ATGGTGGGTTGTGCTTTCCA } \\
\text { CAGAAGCAGTTGTGTTTGTGCT }\end{array}$ & $\begin{array}{l}\text { Exon } 3 \\
\text { Exon } 4\end{array}$ & $130 \mathrm{bp}$ \\
\hline PTCH & $\begin{array}{l}\text { hsPTC1F.2 } \\
\text { hsPTC1R.2 }\end{array}$ & $\begin{array}{l}\text { GAGGTTGGTCATGGTTACATGGA } \\
\text { TGCTGTTCTTGACTGTGCCACC }\end{array}$ & $\begin{array}{l}\text { Exon } 6 \\
\text { Exon } 7\end{array}$ & $196 \mathrm{bp}$ \\
\hline SHH & $\begin{array}{l}\text { hSHH_forw } \\
\text { hSHH_rev }\end{array}$ & $\begin{array}{l}\text { GATGACTCAGAGGTGTAAGGAC } \\
\text { CCTCGTAGTGCAGAGACTCC }\end{array}$ & $\begin{array}{l}\text { Exon } 1 / 2 \\
\text { Exon } 2 / 3\end{array}$ & $147 \mathrm{bp}$ \\
\hline \multicolumn{5}{|c|}{ Primer for murine sequences } \\
\hline Hprt & $\begin{array}{l}\text { mHPRT-FwQ } \\
\text { mHPRT-RvQ }\end{array}$ & $\begin{array}{l}\text { AGCCCCAAAATGGTTAAGGTTGC } \\
\text { TTGCAGATTCAACTTGCGCTCAT }\end{array}$ & $\begin{array}{l}\text { Exon } 6 \\
\text { Exon } 7\end{array}$ & $222 \mathrm{bp}$ \\
\hline Tbp & $\begin{array}{l}\text { mTBP-QFwd } \\
\text { mTBP-QRev }\end{array}$ & $\begin{array}{l}\text { CACCAATGACTCCTATGACCCCTA } \\
\text { CAGTTGTCCGTGGCTCTCTTATTC }\end{array}$ & $\begin{array}{l}\text { Exon } 3 \\
\text { Exon } 5\end{array}$ & $210 \mathrm{bp}$ \\
\hline Gli1 & $\begin{array}{l}\text { mGli1-tq-F } \\
\text { mGli1-tq-R }\end{array}$ & $\begin{array}{l}\text { TACATGCTGGTGGTGCACATG } \\
\text { ACCGAAGGTGCGTCTTGAGG }\end{array}$ & $\begin{array}{l}\text { Exon } 9 \\
\text { Exon } 10\end{array}$ & $115 \mathrm{bp}$ \\
\hline Gli2 & $\begin{array}{l}\text { Gli2-RT- } \\
\text { PCR-F } \\
\text { Gli2-RT- } \\
\text { PCR-R }\end{array}$ & $\begin{array}{l}\text { GGTCATCTACGAGACCAACTGC } \\
\text { GTGTCTTCAGGTTCTCCAGGC }\end{array}$ & $\begin{array}{l}\text { Exon } 8 \\
\text { Exon } 9\end{array}$ & $272 \mathrm{bp}$ \\
\hline Gli3 & $\begin{array}{l}\text { Gli3F2 } \\
\text { Gli3-sybrgree }\end{array}$ & $\begin{array}{l}\text { GAAGGAACAACCCTATCAAGGAGGA } \\
\text { CCAGCGGCACACGAACTCCTTCT }\end{array}$ & $\begin{array}{l}\text { Exon } 10 \\
\text { Exon } 11\end{array}$ & $186 \mathrm{bp}$ \\
\hline Hhip & $\begin{array}{l}\text { mHhipF.1 } \\
\text { mHhipR.2 }\end{array}$ & $\begin{array}{l}\text { GGAGCCTTACTTGGACATTCACAA } \\
\text { ACCGTTCCTGGTTGGTGGTATAA }\end{array}$ & $\begin{array}{l}\text { Exon } 4 \\
\text { Exon } 5\end{array}$ & $143 \mathrm{bp}$ \\
\hline
\end{tabular}




\begin{tabular}{|c|c|c|c|c|}
\hline Ptch & $\begin{array}{l}\text { mPtc10 } \\
\text { mPtc11R }\end{array}$ & $\begin{array}{l}\text { TACAGTCCGGGACAGCATACC } \\
\text { GTACCCATGGCCAACTTCGGCTTT }\end{array}$ & $\begin{array}{l}\text { Exon } 5 \\
\text { Exon } 6\end{array}$ & $151 \mathrm{bp}$ \\
\hline MyoD & $\begin{array}{l}\text { MyoD-ScerjF } \\
\text { MyoD-ScerjR }\end{array}$ & $\begin{array}{l}\text { CCCCGGCGGCAGAATGGCTACG } \\
\text { GGTCTGGGTTCCCTGTTCTGT }\end{array}$ & $\begin{array}{l}\text { Exon } 2 \\
\text { Exon } 3\end{array}$ & $234 \mathrm{bp}$ \\
\hline $\begin{array}{l}\text { Myo- } \\
\text { genin }\end{array}$ & $\begin{array}{l}\text { Myogenin- } \\
\text { Scerj-F } \\
\text { Myogenin- } \\
\text { Scerj-R }\end{array}$ & $\begin{array}{l}\text { GCAATGCACTGGAGTTCG } \\
\text { ACGATGGACGTAAGGGAGTG }\end{array}$ & $\begin{array}{l}\text { Exon } 2 \\
\text { Exon } 3\end{array}$ & $94 \mathrm{bp}$ \\
\hline $\begin{array}{l}\text { Myosin } \\
\text { heavy } \\
\text { chain }\end{array}$ & $\begin{array}{l}\text { MHC tq F } \\
\text { MHC tq R }\end{array}$ & $\begin{array}{l}\text { AACACGAAGCGTGTCATCCAGTA } \\
\text { GTCTCGATGTCAGCAGATGCCAG }\end{array}$ & $\begin{array}{l}\text { Exon } 7 \\
\text { Exon } 8\end{array}$ & $242 \mathrm{bp}$ \\
\hline $\begin{array}{l}\text { Tropo- } \\
\text { myosin } 3\end{array}$ & $\begin{array}{l}\text { mTropo tq F } \\
\text { mTropo tq R }\end{array}$ & $\begin{array}{l}\text { GAGGATGAACTAGCAACCATGCA } \\
\text { CCAGCTCCTCTTCAACCAGCT }\end{array}$ & $\begin{array}{l}\text { Exon } 2 \\
\text { Exon } 3\end{array}$ & $181 \mathrm{bp}$ \\
\hline p21 & $\begin{array}{l}\text { mp21 tq } F \\
\text { mp21 tq } R\end{array}$ & $\begin{array}{l}\text { CCTTGTCGCTGTCTTGCACTC } \\
\text { TCTCTTGCAGAAGACCAATCTGC }\end{array}$ & $\begin{array}{l}\text { Exon } 2 \\
\text { Exon } 3\end{array}$ & $143 \mathrm{bp}$ \\
\hline$p 27$ & $\begin{array}{l}\mathrm{mp} 27 \text { tq } \mathrm{F} \\
\mathrm{mp} 27 \text { tq } \mathrm{R}\end{array}$ & $\begin{array}{l}\text { AACTCTGAGGACCGGCATTTG } \\
\text { CGGGGAACCGTCTGAAACAT }\end{array}$ & $\begin{array}{l}\text { Exon } 1 \\
\text { Exon } 2\end{array}$ & $168 \mathrm{bp}$ \\
\hline HRas & $\begin{array}{l}\text { mHras_tqF2 } \\
\text { mHras_tqR2 }\end{array}$ & $\begin{array}{l}\text { CAGCCAAGACCCGGCAG } \\
\text { CCTGAGCCTGGTGTCAGGA }\end{array}$ & $\begin{array}{l}\text { Exon } 4 \\
\text { Exon } 5\end{array}$ & $150 \mathrm{bp}$ \\
\hline KRas & $\begin{array}{l}\text { mKras_tqF2 } \\
\text { mKras_tqR2 }\end{array}$ & $\begin{array}{l}\text { AGCGCCTTGACGATACAGC } \\
\text { TCCAAGAGACAGGTTTCTCCATC }\end{array}$ & $\begin{array}{l}\text { Exon } 2 \\
\text { Exon } 3\end{array}$ & $113 \mathrm{bp}$ \\
\hline NRas & $\begin{array}{l}\text { mNras_tqF1 } \\
\text { mNras_tqR1 }\end{array}$ & $\begin{array}{l}\text { CACAAAGCAAGCCCACGAAC } \\
\text { TCGGTACTGGCGTATCTCCC }\end{array}$ & $\begin{array}{l}\text { Exon } 4 \\
\text { Exon } 5\end{array}$ & $124 \mathrm{bp}$ \\
\hline
\end{tabular}

\subsection{Media}

\subsubsection{Media for cultivation of prokaryotic cells}

Bacterial cells were cultured in LB medium or on LB medium agar plates. To erase untransformed cells appropriate antibiotics, namely ampicillin $(100 \mu \mathrm{g} / \mathrm{ml})$ or kanamycin $(50 \mu \mathrm{g} / \mathrm{ml})$, were added to the autoclaved and cooled media. Both, media and plates, were stored at $4{ }^{\circ} \mathrm{C}$ until use.

\subsubsection{Media and reagents for cultivation of eukaryotic cells}

Eukaryotic cell lines were cultured in medium according to Tab. 13. All media and reagents were sterile or were autoclaved. All reagents were stored at $-20^{\circ} \mathrm{C}$ or $4{ }^{\circ} \mathrm{C}$ until use.

Table 13: Media and reagents

\begin{tabular}{|l|l|}
\hline Medium or reagent & Supplier \\
\hline Accutase & GE Healthcare Europe, Freiburg, Germany \\
\hline DMSO & Sigma-Aldrich Co., St. Louis, MO, USA \\
\hline $\begin{array}{l}\text { Dulbecco's Modified Eagle Medium } \\
\text { supplemented with 4.5 g/L Glucose, L- } \\
\text { Glutamine, Sodium Pyruvate (DMEM+++) }\end{array}$ & Invitrogen, Carlsbad, CA, USA \\
\hline $\begin{array}{l}\text { Dulbecco's Modified Eagle Medium } \\
\text { supplemented with 4.5 g/L Glucose, L- } \\
\text { Glutamine (DMEM++-) }\end{array}$ & Invitrogen, Carlsbad, CA, USA \\
\hline
\end{tabular}




\begin{tabular}{|c|c|}
\hline Fetal calf serum (FCS) & Invitrogen, Carlsbad, CA, USA \\
\hline G 418 disulfate salt solution $(50 \mathrm{mg} / \mathrm{ml})$ & Sigma-Aldrich Co., St. Louis, MO, USA \\
\hline 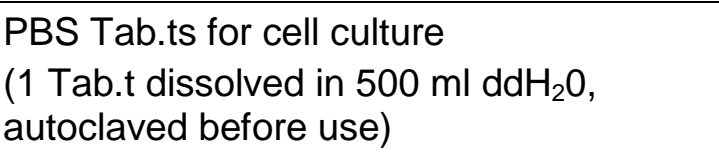 & Invitrogen, Carlsbad, CA, USA \\
\hline $\begin{array}{l}\text { Penicillin (10.000 U/ml) and Streptomycin } \\
(10 \mathrm{mg} / \mathrm{ml})(\mathrm{P} / \mathrm{S})\end{array}$ & PAN Biotech GmbH, Aidenbach, Germany \\
\hline Puromycin dihydrochloride $(10$ mg/ml) & Sigma-Aldrich Co., St. Louis, MO, USA \\
\hline RPMI 1640 (RPMI) & Invitrogen, Carlsbad, CA, USA \\
\hline TrypLE Express & Invitrogen, Carlsbad, CA, USA \\
\hline Zeocin $^{\mathrm{TM}}(100 \mathrm{mg} / \mathrm{ml})$ & $\begin{array}{l}\text { Thermo Fisher Scientific Inc., Waltham, MA, } \\
\text { USA }\end{array}$ \\
\hline
\end{tabular}

\subsection{Biological Material}

\subsubsection{Bacterial Strains}

Chemical competent Escherichia coli DH5a cells were used for transformation and amplification of plasmid DNA (pDNA). The bacteria were stored at $-80^{\circ} \mathrm{C}$ until use.

\subsubsection{Eukaryotic cell lines}

Different eukaryotic cell lines were used to perform cell culture experiments. If not indicated otherwise, the cells were obtained from the American type culture collection (ATCC). All cells were adeherent and they were cultured in appropriate cell culture media under constant conditions $\left(37^{\circ} \mathrm{C}, 5 \% \mathrm{CO}_{2}\right.$, humidified atmosphere) in a $\mathrm{CO}_{2}$-incubator.

Table 14: Eukaryotic cell lines

\begin{tabular}{|c|c|c|c|}
\hline Cell line & Specification & Culture medium & $\begin{array}{l}\text { Reference and/or } \\
\text { Supplier }\end{array}$ \\
\hline $\begin{array}{l}\text { B9 } \\
\text { also named: } \\
\text { Ptch }^{\text {flox/flox }} E R T 2^{+/-}\end{array}$ & $\begin{array}{l}\text { Adult, murine } \\
\text { fibroblast cell line } \\
\text { responsive to SHH }\end{array}$ & $\begin{array}{l}\text { DMEM +++ } \\
10 \% \text { FCS } \\
1 \% \mathrm{P} / \mathrm{S}\end{array}$ & 307 \\
\hline Daoy & $\begin{array}{l}\text { Human } \\
\text { medulloblastoma cell } \\
\text { line }\end{array}$ & $\begin{array}{l}\text { DMEM +++ } \\
10 \% \text { FCS } \\
1 \% \mathrm{P} / \mathrm{S}\end{array}$ & $\begin{array}{l}308, \\
\text { kindly provided by } \\
\text { Prof. Dr. Fritz } \\
\text { Aberger }\end{array}$ \\
\hline Daoy pMSCV & $\begin{array}{l}\text { Daoy stably } \\
\text { transduced with a } \\
\text { pMSCVpuro-control } \\
\text { vector }\end{array}$ & $\begin{array}{l}\text { DMEM +++ } \\
10 \% \text { FCS } \\
1 \% \mathrm{P} / \mathrm{S} \\
5 \mu \mathrm{g} / \mu \mathrm{l} \text { Puromycin }\end{array}$ & This work \\
\hline Daoy HRAS & $\begin{array}{l}\text { DAOY stably } \\
\text { transduced with a } \\
\text { pMSCVpuro- } \\
\text { HRAS }^{\text {G12V }} \text { vector }\end{array}$ & $\begin{array}{l}\text { DMEM +++ } \\
10 \% \text { FCS } \\
1 \% \mathrm{P} / \mathrm{S} \\
5 \mu \mathrm{g} / \mu \mathrm{l} \text { Puromycin }\end{array}$ & This work \\
\hline
\end{tabular}




\begin{tabular}{|c|c|c|c|}
\hline Daoy KRAS & $\begin{array}{l}\text { DAOY stably } \\
\text { transduced with a } \\
\text { pMSCVpuro- } \\
K R A S^{G 12 V} \text { vector }\end{array}$ & $\begin{array}{l}\text { DMEM +++ } \\
10 \% \text { FCS } \\
1 \% \text { P/S } \\
5 \mu \mathrm{g} / \mu \mathrm{l} \text { Puromycin }\end{array}$ & This work \\
\hline Daoy NRAS & $\begin{array}{l}\text { DAOY stably } \\
\text { transduced with a } \\
\text { pMSCVpuro- } \\
\text { NRAS }{ }^{G 12 V} \text { vector }\end{array}$ & $\begin{array}{l}\text { DMEM +++ } \\
10 \% \text { FCS } \\
1 \% \text { P/S } \\
5 \mu \mathrm{g} / \mu \mathrm{l} \text { Puromycin }\end{array}$ & This work \\
\hline HEK293 & $\begin{array}{l}\text { Human embryonic } \\
\text { kidney cell line }\end{array}$ & $\begin{array}{l}\text { DMEM +++ } \\
10 \% \text { FCS } \\
1 \% \mathrm{P} / \mathrm{S}\end{array}$ & $\begin{array}{l}{ }^{309}, \text { ATCC, } \\
\text { Manassas, VA, } \\
\text { USA }\end{array}$ \\
\hline HEK293 Shh-N & $\begin{array}{l}\text { Stably transduced } \\
\text { human embryonic } \\
\text { kidney cell line, } \\
\text { secreting Shh-N }\end{array}$ & $\begin{array}{l}\text { DMEM +++ } \\
10 \% \text { FCS } \\
1 \% \mathrm{P} / \mathrm{S} \\
0,4 \mu \mathrm{g} / \mathrm{ml} \mathrm{G}-418\end{array}$ & 310 \\
\hline $\mathrm{NIH} / 3 \mathrm{~T} 3$ & $\begin{array}{l}\text { Adult, murine } \\
\text { fibroblast cell line }\end{array}$ & $\begin{array}{l}\text { DMEM +++ } \\
10 \% \mathrm{FCS} \\
1 \% \mathrm{P} / \mathrm{S}\end{array}$ & $\begin{array}{l}311, \text { ATCC, } \\
\text { Manassas, VA, } \\
\text { USA }\end{array}$ \\
\hline RD & $\begin{array}{l}\text { Human ERMS cell } \\
\text { line }\end{array}$ & $\begin{array}{l}\text { DMEM +++ } \\
10 \% \text { FCS } \\
1 \% \mathrm{P} / \mathrm{S}\end{array}$ & $\begin{array}{l}312, \text { ATCC, } \\
\text { Manassas, VA, } \\
\text { USA }\end{array}$ \\
\hline RMS-13 & $\begin{array}{l}\text { Human ARMS cell } \\
\text { line }\end{array}$ & $\begin{array}{l}\text { RPMI } 1640 \\
10 \% \text { FCS } \\
1 \% \text { P/S }\end{array}$ & $\begin{array}{l}{ }^{313}, \text { ATCC, } \\
\text { Manassas, VA, } \\
\text { USA }\end{array}$ \\
\hline RMS-13 pMSCV & $\begin{array}{l}\text { RMS- } 13 \text { stably } \\
\text { transduced with a } \\
\text { pMSCVpuro-control } \\
\text { vector }\end{array}$ & $\begin{array}{l}\text { RPMI } 1640 \\
10 \% \text { FCS } \\
1 \% \mathrm{P} / \mathrm{S} \\
0.5 \mu \mathrm{g} / \mu \mathrm{l} \text { Puromycin }\end{array}$ & 299 \\
\hline RMS-13 HRAS & $\begin{array}{l}\text { RMS-13 stably } \\
\text { transduced with a } \\
\text { pMSCVpuro- } \\
H R A S^{G 12 V} \text { vector }\end{array}$ & $\begin{array}{l}\text { RPMI } 1640 \\
10 \% \text { FCS } \\
1 \% \mathrm{P} / \mathrm{S} \\
0.5 \mu \mathrm{g} / \mu \mathrm{l} \text { Puromycin }\end{array}$ & 299 \\
\hline RMS-13 KRAS & $\begin{array}{l}\text { RMS-13 stably } \\
\text { transduced with a } \\
\text { pMSCVpuro- } \\
\text { KRAS }{ }^{G 12 V} \text { vector }\end{array}$ & $\begin{array}{l}\text { RPMl } 1640 \\
10 \% \text { FCS } \\
1 \% \mathrm{P} / \mathrm{S} \\
0.5 \mu \mathrm{g} / \mu \mathrm{l} \text { Puromycin }\end{array}$ & 299 \\
\hline RMS-13 NRAS & $\begin{array}{l}\text { RMS-13 stably } \\
\text { transduced with a } \\
\text { pMSCVpuro- } \\
\text { NRAS }{ }^{G 12 V} \text { vector }\end{array}$ & $\begin{array}{l}\text { RPMl } 1640 \\
10 \% \text { FCS } \\
1 \% \mathrm{P} / \mathrm{S} \\
0.5 \mu \mathrm{g} / \mu \mathrm{l} \text { Puromycin }\end{array}$ & 299 \\
\hline $\mathrm{RUCH}-2$ & $\begin{array}{l}\text { Human ERMS cell } \\
\text { line }\end{array}$ & $\begin{array}{l}\text { DMEM +++ } \\
10 \% \text { FCS } \\
1 \% \mathrm{P} / \mathrm{S}\end{array}$ & $\begin{array}{l}{ }^{314}, \text { ATCC, } \\
\text { Manassas, VA, } \\
\text { USA }\end{array}$ \\
\hline $\mathrm{RUCH}-2$ pMSCV & $\begin{array}{l}\text { RUCH-2 stably } \\
\text { transduced with a } \\
\text { pMSCVpuro-control } \\
\text { vector }\end{array}$ & $\begin{array}{l}\text { DMEM +++ } \\
10 \% \text { FCS } \\
1 \% \text { P/S } \\
8 \mu \mathrm{g} / \mu \mathrm{l} \text { Puromycin }\end{array}$ & 299 \\
\hline
\end{tabular}




\begin{tabular}{|c|c|c|c|}
\hline RUCH-2 HRAS & $\begin{array}{l}\text { RUCH-2 stably } \\
\text { transduced with a } \\
\text { pMSCVpuro- } \\
H R A S^{G 12 V} \text { vector }\end{array}$ & $\begin{array}{l}\text { DMEM +++ } \\
10 \% \text { FCS } \\
1 \% \mathrm{P} / \mathrm{S} \\
8 \mu \mathrm{g} / \mu \mathrm{l} \text { Puromycin }\end{array}$ & 299 \\
\hline RUCH-2 KRAS & $\begin{array}{l}\text { RUCH-2 stably } \\
\text { transduced with a } \\
\text { pMSCVpuro- } \\
K R A S^{G 12 V} \text { vector }\end{array}$ & $\begin{array}{l}\text { DMEM +++ } \\
10 \% \text { FCS } \\
1 \% \mathrm{P} / \mathrm{S} \\
8 \mu \mathrm{g} / \mu \mathrm{l} \text { Puromycin }\end{array}$ & 299 \\
\hline RUCH-2 NRAS & $\begin{array}{l}\text { RUCH-2 stably } \\
\text { transduced with a } \\
\text { pMSCVpuro- } \\
N R A S^{G 12 V} \text { vector }\end{array}$ & $\begin{array}{l}\text { DMEM +++ } \\
10 \% \text { FCS } \\
1 \% \mathrm{P} / \mathrm{S} \\
8 \mu \mathrm{g} / \mu \mathrm{l} \text { Puromycin }\end{array}$ & 299 \\
\hline SHH light II & $\begin{array}{l}\mathrm{NIH} / 3 \mathrm{~T} 3 \text { stably } \\
\text { transfected with a } \\
\text { Gli-responsive } \\
\text { luciferase reporter }\end{array}$ & $\begin{array}{l}\text { DMEM +++ } \\
10 \% \text { FCS } \\
1 \% \mathrm{P} / \mathrm{S} \\
0,4 \mu \mathrm{g} / \mathrm{ml} \mathrm{G}-418 \\
0,15 \mathrm{mg} / \mathrm{ml} \text { Zeocin }\end{array}$ & 310 \\
\hline TE617.T & $\begin{array}{l}\text { Human ERMS cell } \\
\text { line }\end{array}$ & $\begin{array}{l}\text { DMEM ++- } \\
10 \% \text { FCS } \\
1 \% \text { P/S }\end{array}$ & 315 \\
\hline TE617.T pMSCV & $\begin{array}{l}\text { TE617.T stably } \\
\text { transduced with a } \\
\text { pMSCVpuro-control } \\
\text { vector }\end{array}$ & $\begin{array}{l}\text { DMEM ++- } \\
10 \% \text { FCS } \\
1 \% \mathrm{P} / \mathrm{S} \\
0.8 \mu \mathrm{g} / \mu \mathrm{l} \text { Puromycin }\end{array}$ & This work \\
\hline TE617.T H-/NRAS & $\begin{array}{l}\text { TE617.T stably } \\
\text { transduced } \\
\text { pMSCVpuro- } \\
\text { HRAS }{ }^{\text {G12V }} \text { and } \\
\text { pMSCVpuro- } \\
\text { NRAS }{ }^{\text {G12V }} \text { vectors }\end{array}$ & $\begin{array}{l}\text { DMEM ++- } \\
10 \% \text { FCS } \\
1 \% \mathrm{P} / \mathrm{S} \\
0.8 \mu \mathrm{g} / \mu \mathrm{l} \text { Puromycin }\end{array}$ & This work \\
\hline TE617.T KRAS & $\begin{array}{l}\text { TE617.T stably } \\
\text { transduced with a } \\
\text { pMSCVpuro- } \\
\text { KRAS }{ }^{\text {GI2V vector }}\end{array}$ & $\begin{array}{l}\text { DMEM ++- } \\
10 \% \text { FCS } \\
1 \% \mathrm{P} / \mathrm{S} \\
0.8 \mu \mathrm{g} / \mu \mathrm{l} \text { Puromycin }\end{array}$ & This work \\
\hline
\end{tabular}

\subsubsection{Genetically modified mouse lines}

All experiments using animals were performed in agreement with the legal and ethical requirements and have been approved by the Lower Saxony State Office for Consumer Protection and Food Safety (file numbers 33.9-42502-04-12/0805, 33.9-42502-04-17/2534, 33.9-42502-04-13/1284). All used mouse lines are listed in Tab. 15. Breeding, genotyping and experimental procedure are described in sections 5.5 and 5.2.3.1. 
Table 15: Mouse strains

\begin{tabular}{|c|c|c|c|c|}
\hline Mouse strain & $\begin{array}{l}\text { International } \\
\text { nomenclature }\end{array}$ & $\begin{array}{l}\text { Genetic } \\
\text { background }\end{array}$ & $\begin{array}{l}\text { Genetic } \\
\text { modification }\end{array}$ & $\begin{array}{l}\text { Reference } \\
\text { or Supplier }\end{array}$ \\
\hline BALB/c & BALB/c & $\mathrm{BALB} / \mathrm{c}$ & - & $\begin{array}{l}\text { The Jackson } \\
\text { Laboratory, } \\
\text { Bar Harbor, } \\
\text { ME, USA or } \\
\text { Charles } \\
\text { River } \\
\text { Laboratories, } \\
\text { Wilmington, } \\
\text { MA, USA }\end{array}$ \\
\hline C57BL/6N & C57BL/6N & C57BL/6N & - & $\begin{array}{l}\text { The Jackson } \\
\text { Laboratory, } \\
\text { Bar Harbor, } \\
\text { ME, USA or } \\
\text { Charles } \\
\text { River } \\
\text { Laboratories, } \\
\text { Wilmington, } \\
\text { MA, USA }\end{array}$ \\
\hline $\operatorname{Ptch}^{d e l /+}$ Balb & - & BALB/c & $\begin{array}{l}\text { Heterozygous } \\
\text { deletion of exon } 8 \\
\text { and } 9 \text { within the } \\
\text { Ptch gene }\end{array}$ & 316 \\
\hline HRasflox_B6 & $\operatorname{Hras}^{t m 1 J a f}$ & C57BL/6 & $\begin{array}{l}\text { Tandemly-arrayed } \\
\text { murine HRas } 1 \\
\text { genes with a wt } \\
\text { copy flanked by } \\
\text { loxP sites followed } \\
\text { by a copy } \\
\text { containing a } \\
\text { HRas }{ }^{G 12 V} \\
\text { pointmutation }\end{array}$ & $\begin{array}{l}{ }^{303} \text {, } \\
\text { kindly } \\
\text { provided by } \\
\text { Prof. Dr. } \\
\text { James A. } \\
\text { Fagin }\end{array}$ \\
\hline KRasflox_B6 & $K_{r a s}^{t m 4 T y j}$ & C57BL/6 & $\begin{array}{l}\text { A Lox-Stop-Lox } \\
\text { behind exon } 1 \text { of wt } \\
\text { KRas is followed by } \\
\text { the } K R a s^{G 12 D} \text { point } \\
\text { mutation in exon } 2\end{array}$ & $\begin{array}{l}304,317, \\
\text { kindly } \\
\text { provided by } \\
\text { Prof. Dr. } \\
\text { Dieter Saur }\end{array}$ \\
\hline NRasflox_B6 & $\operatorname{Nras}^{t m 1 T y j}$ & C57BL/6 & $\begin{array}{l}\text { A Lox-Stop-Lox } \\
\text { behind exon } 1 \text { of wt } \\
\text { NRas is followed by } \\
\text { the NRas } s^{G 12 D} \text { point } \\
\text { mutation in exon } 2\end{array}$ & 220 \\
\hline Myf5 ${ }^{\text {CreeER/+ }}$ & Myf5 $5^{t m 1\left(c r e / E s r 1^{*}\right) T r d o}$ & $\begin{array}{l}\text { Mixed: } \\
50 \% \text { BALB/c } \\
\text { and } \\
50 \%: \\
\text { C57BL/6 + } \\
129 / S v+ \\
\text { FVB/N }\end{array}$ & $\begin{array}{l}\text { Tamoxifen- } \\
\text { inducible } \\
\text { expression of the } \\
\text { cyclization } \\
\text { recombination } \\
\text { (Cre) ER } \mathrm{R}^{\mathrm{TM}} \text { fusion } \\
\text { protein from the } \\
\text { endogenous Myf5 } \\
\text { promoter/enhancer } \\
\text { elements }\end{array}$ & $\begin{array}{l}305, \\
\text { kindly } \\
\text { provided by } \\
\text { Prof. Dr. } \\
\text { Thomas A. } \\
\text { Rando }\end{array}$ \\
\hline
\end{tabular}




\begin{tabular}{|c|c|c|c|c|}
\hline Myf5 $5^{\mathrm{CreER} /+}{ }_{\text {B Balbc }}$ & $M y f 5^{t m 1\left(\left(\operatorname{cre}^{\prime} / E s 1^{*}\right) T r d o\right.}$ & $\mathrm{BALB} / \mathrm{c}$ & $\begin{array}{l}\text { Tamoxifen- } \\
\text { inducible } \\
\text { expression of the } \\
\text { CreER }{ }^{\mathrm{TM}} \text { fusion } \\
\text { protein from the } \\
\text { endogenous Myf5 } \\
\text { promoter/enhancer } \\
\text { elements }\end{array}$ & 305 \\
\hline $\mathrm{Nu} / \mathrm{Nu}$ & $\begin{array}{l}\text { Rj:NMRI- } \\
\text { Foxn1 } 1^{n u / n u}\end{array}$ & outbred & $\begin{array}{l}\text { Homozygous } \\
\text { deletion of exon } 3 \\
\text { of the Foxn } 1 \text { gene } \\
\text { (causes thymic } \\
\text { aplasia resulting in } \\
\text { a lack of T cells) }\end{array}$ & $\begin{array}{l}\text { Charles } \\
\text { River } \\
\text { Laboratories, } \\
\text { Wilmington, } \\
\text { MA, USA, } \\
318,319\end{array}$ \\
\hline$R 26 R$ & $\begin{array}{l}\text { Gt(ROSA) } \\
26 S \text { rorm1Sor }^{\text {tm1S }}\end{array}$ & C57BL/6 & $\begin{array}{l}\text { A neo cassette } \\
\text { flanked by loxP } \\
\text { sites is followed by } \\
\text { a lacZ gene and a } \\
\text { polyadenylation } \\
\text { sequence inserted } \\
\text { into the } \\
\text { endogeneous } \\
\text { Rosa26 locus }\end{array}$ & 306 \\
\hline
\end{tabular}

\subsection{Software and digital resources}

Utilized software were licensed and, if possible, used in the latest version.

Table 16: Software

\begin{tabular}{|c|c|}
\hline Software & Developer \\
\hline $4 \mathrm{D}$ & 4D Deutschland GmbH, Eching, Germany \\
\hline Adobe Photoshop CS5 & $\begin{array}{l}\text { Adobe Systems Incorporated, San Jose, } \\
\text { USA }\end{array}$ \\
\hline AlphaView Q SA 3.2.2 & Cell Bioscience, Santa Clara, CA, USA \\
\hline CellSens Dimension & Olympus Optical Co., Ltd., Tokyo, Japan \\
\hline Endnote X5 & $\begin{array}{l}\text { Thomson ISI ResearchSoft, Carlsbad, CA, } \\
\text { USA }\end{array}$ \\
\hline Fiji & 320 \\
\hline Flowing Software 2 & $\begin{array}{l}\text { Perttu Terho, Cell Imaging Core, Turku } \\
\text { Centre for Biotechnology, Finland }\end{array}$ \\
\hline FlowJo V10 & Tree Star Inc., Oregon, OR, USA \\
\hline Gen5 & $\begin{array}{l}\text { BioTek Instruments GmbH, Bad } \\
\text { Friedrichshall, Germany }\end{array}$ \\
\hline GraphPad Prism 6 & GraphPad Software, Inc., La Jolla, CA, USA \\
\hline Microsoft Office & Microsoft Co., Redmond, WA, USA \\
\hline NanoDrop 800 V2.3 & $\begin{array}{l}\text { Thermo Fisher Scientific Inc., Waltham, MA, } \\
\text { USA }\end{array}$ \\
\hline Quantum FX $\mu$ CT Software (Simple Viewer) & $\begin{array}{l}\text { PerkinElmer Health Sciences, Hopkinton, } \\
\text { MA, USA }\end{array}$ \\
\hline SDS 2.2 & Applied Biosystems, Waltham, MA, USA \\
\hline
\end{tabular}


All databases were used to get access to data and to perform further analyses.

Table 17: Databases

\begin{tabular}{|l|l|}
\hline Database & Online access \\
\hline $\begin{array}{l}\text { Basic Local Alignment Search Tool } \\
\text { (BLAST) }\end{array}$ & https://blast.ncbi.nlm.nih.gov/Blast.cgi \\
\hline $\begin{array}{l}\text { Broad-Novartis Cancer Cell Line } \\
\text { Encyclopedia }\end{array}$ & https://portals.broadinstitute.org/ccle \\
\hline $\begin{array}{l}\text { Catalogue Of Somatic Mutations In Cancer } \\
\text { (COSMIC) }\end{array}$ & https://cancer.sanger.ac.uk/cell_lines \\
\hline ClinicalTrials.gov & https://clinicaltrials.gov \\
\hline Ensembl genome browser & https://www.ensembl.org/index.html \\
\hline ExPASy Bioinformatics Resource Portal & https://www.expasy.org/ \\
\hline MGI-Mouse Genome Informatics & http://www.informatics.jax.org/ \\
\hline $\begin{array}{l}\text { National Center for Biotechnology } \\
\text { Information (NCBI) }\end{array}$ & https://www.ncbi.nlm.nih.gov/ \\
\hline $\begin{array}{l}\text { Online Mendelian Inheritance in Man } \\
\text { (OMIM) }\end{array}$ & https://www.omim.org/ \\
\hline Primer-BLAST & $\begin{array}{l}\text { https://www.ncbi.nlm.nih.gov/tools/primer- } \\
\text { blast/ }\end{array}$ \\
\hline RepeatMasker & http://www.repeatmasker.org/ \\
\hline
\end{tabular}




\section{Methods}

\subsection{Cell culture methods}

All described cell culture methods were performed under sterile conditions using appropriate laboratory equipment. Frequent microscopic examinations were performed with special attention given to morphological changes, confluence and possible contaminations of the cells.

\subsubsection{Cultivation of eukaryotic cell lines}

All used eukaryotic cell lines (see Tab. 14) were cultured in their respective media in a $\mathrm{CO}_{2^{-}}$ incubator at $37{ }^{\circ} \mathrm{C}, 5 \% \mathrm{CO}_{2}$ in a humidified atmosphere. For culture, the cells were seeded onto cell culture plates $(\varnothing 10 \mathrm{~cm}$ ). The cell culture media with respective supplements (see Tab. 14) were renewed every fourth day at the latest. The cells were passaged and split when $90 \%$ confluency was reached. For this purpose, media was removed, the cells were washed with PBS and the cell layer was covered with TrypLE Express. Cells were detached for $10-15$ min within the cell culture incubator. The detachment process was stopped by adding FCS-containing cell culture media. The cell suspensions were collected from the plates and were pelleted at $300 \times \mathrm{g}$ for $5 \mathrm{~min}$. The supernatants were aspirated and cells were resuspended in fresh cell culture medium or PBS. Afterwards the cells were counted (see section 5.1.3) or split and then seeded onto new cell culture dishes containing fresh cell culture medium.

\subsubsection{Cryoconservation of cells}

Highly confluent cells at low passage numbers were detached as described above. After pelleting, the cells were resuspended in cell culture medium containing $5 \%(\mathrm{v} / \mathrm{v})$ DMSO. The cell suspensions were aliquoted in cryo-tubes and transferred into the freezing device Mr. Frosty for a slow freezing process. The cells were gradually frozen over night at $-80^{\circ} \mathrm{C}$ and afterwards moved into a liquid nitrogen tank for long term storage.

To restore the cells, aliquots of frozen cells were quickly thawed at room temperature (RT). Thawed cells were diluted in cell culture medium and pelleted at $300 \times \mathrm{g}$ for $5 \mathrm{~min}$. The supernatants, which contained DMSO, were removed and the resulting pellets were resuspended in supplemented cell culture medium. The cells were seeded onto new cell culture plates for further usage.

\subsubsection{Counting of cells}

Cell numbers of replicates were defined to ensure comparability of the respective experiments. The seeding densities were adjusted to the different experimental setups (Tab. 18). 
The cells were detached and diluted in medium or PBS as described in section 5.1.1. Appropriate dilutions of cell suspensions containing trypan blue $(0.004 \%)$, that stains dead cells, were used for counting. Then, $10 \mu \mathrm{l}$ of every dilution was pipetted onto a hemocytometer $\left(0.100 \mathrm{~mm}\right.$ depth, $\left.0.0025 \mathrm{~mm}^{2}\right)$ and the cell numbers in all 4 big quadrants were counted manually. Dead/blue cells were not counted. The number of living cells was calculated using the following formula:

$$
\frac{\text { Cells }}{\mathrm{ml}}=\frac{\text { number of cells } \times 10^{4}}{\text { number of counted big squares }} \times \text { dilution factor }
$$

Afterwards, dilutions with desired cell amounts were prepared and the cells were seeded for experiments as described in Tab. 18.

Table 18: Conditions for in vitro assays

\begin{tabular}{|c|c|c|c|c|}
\hline Experimental setup & $\begin{array}{l}\text { Plate } \\
\text { format }\end{array}$ & $\begin{array}{l}\text { Technical } \\
\text { replicates }\end{array}$ & $\begin{array}{l}\text { Seeding } \\
\text { density }\end{array}$ & $\begin{array}{l}\text { Total volume } \\
\text { of medium }\end{array}$ \\
\hline Cell cycle analyses & $\begin{array}{l}\varnothing 10 \mathrm{~cm} \text { cell } \\
\text { culture dish }\end{array}$ & Duplicates & $1 \times 10^{6}$ cells $/$ plate & $8 \mathrm{ml} /$ plate \\
\hline $\begin{array}{l}\text { Cell viability assay } \\
\text { (WST- } 1 \text { assay) }\end{array}$ & 96 well plate & $\begin{array}{l}\text { Triplicates - } \\
\text { Sextuplicates }\end{array}$ & $5 \times 10^{3}$ cells $/$ well & $100 \mu \mathrm{l} /$ well \\
\hline $\begin{array}{l}\text { Co-culture } \\
\text { experiments }\end{array}$ & $\begin{array}{l}96 \text { well plate } \\
\text { black }\end{array}$ & Triplicates & $\begin{array}{l}5 \times 10^{3} \mathrm{SHH} \text { light } \\
\text { II cells }+7.5 \times \\
10^{3} \text { cells } / \text { well }\end{array}$ & $100 \mu \mathrm{l} /$ well \\
\hline Electroporation & 6 well plate & Duplicates & $5 \times 10^{5}$ cells $/$ well & $2 \mathrm{ml} /$ well \\
\hline Gene expression & 6 well plate & Triplicates & $2 \times 10^{5}$ cells $/$ well & $1 \mathrm{ml} / \mathrm{well}$ \\
\hline GLI reporter assay & $\begin{array}{l}96 \text { well plate } \\
\text { black }\end{array}$ & Triplicates & $5 \times 10^{3}$ cells $/$ well & $100 \mu \mathrm{l} /$ well \\
\hline $\begin{array}{l}\text { Proliferation assay } \\
\text { (BrdU assay) }\end{array}$ & $\begin{array}{l}96 \text { well plate } \\
\text { black }\end{array}$ & $\begin{array}{l}\text { Triplicates - } \\
\text { Sextuplicates }\end{array}$ & $5 \times 10^{3}$ cells $/$ well & $100 \mu \mathrm{l} /$ well \\
\hline Protein expression & $\begin{array}{l}ø 10 \mathrm{~cm} \text { cell } \\
\text { culture dish }\end{array}$ & - & $\begin{array}{l}1 \times 10^{6}-1.5 \times \\
10^{6} \text { cells/plate }\end{array}$ & $8 \mathrm{ml} /$ plate \\
\hline
\end{tabular}

\subsubsection{Stable transduction of cell lines}

Stable transduction of RMS cell lines was part of a former doctoral thesis ${ }^{299}$. Briefly, virus particles with the expression plasmids pMSCVpuro, pMSCVpuro-HRAS ${ }^{G 12 V}$, pMSCVpuro$K R A S^{G 12 V}$, pMSCVpuro-NRAS $S^{G 12 V}$ were generated in collaboration with the Institute of Cellular and Molecular Immunology, University Medical Center Göttingen (RMS cell lines) or in collaboration with the Department of Biosciences, Paris-Lodron University of Salzburg (Daoy cell line). For this purpose, retroviral packaging cells were transfected with $3 \mu \mathrm{g}$ of the plasmids. Cells were allowed to grow in fresh culture medium for $48 \mathrm{~h}$. Afterwards, the virus particle containing supernatant was sterile filtered. For stable transduction 2 batches of each cell line were incubated with this supernatant. The virus containing media were refreshed daily. The cells with integrated viral genomes were selected by puromycin addition to the 
media 3 days after transduction. Different amounts of puromycin were applied to determine adequate concentrations for efficient selection.

\subsubsection{Plasmid identity verification}

The identities of the transduced plasmids were analyzed using a complementary DNA (cDNA) based PCR approach [95 ${ }^{\circ} \mathrm{C}(4 \mathrm{~min}), 35$ cycles of: $95^{\circ} \mathrm{C}(30 \mathrm{sec})+55^{\circ} \mathrm{C}(1 \mathrm{~min})+$ $72{ }^{\circ} \mathrm{C}(1 \mathrm{~min})$ and $72{ }^{\circ} \mathrm{C}$ for $5 \mathrm{~min}$ ]. For this purpose, a forward primer located within the extended packaging sequence of the pMSCVpuro fragment and a mixture of 3 reverse primers located within the $H R A S^{G 12 V}, K R A S^{G 12 V}$ or $N R A S^{G 12 V}$ fragments were employed, which should result in plasmid specific amplificates (HRAS: 453 bp; KRAS: 596 bp; NRAS: 319 bp).

\subsubsection{Proliferation assay}

The cellular proliferation was measured using an ELISA-Kit according to the manufacturer's instructions. The assay itself is based on DNA incorporation of the thymidine analog 5-bromo-2'-deoxyuridine (BrdU) in DNA of proliferating cells and its detection via a chemiluminescent reaction. Briefly, $5 \times 10^{3}$ cells were seeded in black 96 well cell culture plates with clear bottom and were allowed to attach for $24 \mathrm{~h}$. Afterwards the media were replaced by incubation medium for $24 \mathrm{~h}-72 \mathrm{~h}$. Simultaneously, the cells were labeled by addition of $10 \mu \mathrm{M}$ BrdU to the respective incubation medium. Cells without BrdU labelling served as negative control. After the incubation, the cells were fixed and DNA was denatured by adding FixDenat solution for $30 \mathrm{~min}$ at RT. Fixed cells were incubated with a peroxidase conjugated anti-BrdU antibody (1:100) for $1 \mathrm{~h}$ at RT. The antibody solution was aspirated and wells were washed 3 times with the provided washing buffer. After removing the washing buffer, a peroxidase substrate solution was added sequentially by injectors of the SynergyMx microplate reader to all wells of the plate and luminescence was measured in the microplate reader with Gen5 software. Data were analyzed using Microsoft Excel and GraphPad Prism 6 software.

\subsubsection{Cell viability assay}

The sable tetrazolium salt WST-1 is cleaved into a soluble formazan by metabolically intact cells and was used to assess cell viability. The cells were seeded in a clear 96 well cell culture plate and were allowed to adhere for $24 \mathrm{~h}$. Afterwards the media were replaced by medium containing respective drugs or reagents for $24 \mathrm{~h}-72 \mathrm{~h}$. At the end of treatment the incubation media were removed to prevent interactions between drugs and the tetrazolium salt. Then, the cells were incubated for $4 \mathrm{~h}$ at $37^{\circ} \mathrm{C}$ with WST-1 reagent, which was diluted 1:25 in fresh cell culture medium. Empty wells served as negative control. Afterwards, absorbance was measured at $450 \mathrm{~nm}$ and $655 \mathrm{~nm}$ in the microplate reader with Gen5 software. The cell viability was calculated after subtraction of the reference wavelength 
$(655 \mathrm{~nm})$ from the wavelength used for quantification of WST-1 cleavage (450 nm) using Microsoft Excel.

\subsubsection{Cell cycle analyses}

Cell cycle distribution was investigated by PI staining and subsequent fluorescence-activated cell scanning (FACS). The cells were seeded and allowed to grow for $48 \mathrm{~h}$ before harvest. Accutase was used to detach cells for $5 \mathrm{~min}$ at $37^{\circ} \mathrm{C}$. Then, cell culture medium was added to stop the reaction. The cell suspensions were pelleted at $300 \times \mathrm{g}$ for $5 \mathrm{~min}$ and the supernatants were discarded. The pellets were resuspended in $1 \mathrm{ml}$ of ice-cold PBS. The cells suspensions were transferred into pre-cooled $\left(-80^{\circ} \mathrm{C}\right)$ pure $\mathrm{EtOH}$ while shaking and then placed on dry ice. Afterwards, the cells were fixed in EtOH at $-20^{\circ} \mathrm{C}$ for at least $3 \mathrm{~h}$. Fixed cells were pelleted at $600 \times \mathrm{g}$ and $4^{\circ} \mathrm{C}$ for $5 \mathrm{~min}$. The cells were washed with ice-cold PBS and centrifuged again at $600 \times \mathrm{g}$ and $4{ }^{\circ} \mathrm{C}$ for $5 \mathrm{~min}$. The supernatants were discarded and the pellets were resuspended in $450 \mu \mathrm{PI}$-staining solution $(10 \mu \mathrm{g} / \mathrm{mL} \mathrm{PI}$ and $100 \mu \mathrm{g} / \mathrm{mL}$ RNase $A$ in PBS) and incubated for $30 \mathrm{~min}$ at $37^{\circ} \mathrm{C}$. Staining intensities were measured by flow cytometry (FACS Calibur) on the FL-3 channel. A minimum of $5 \times 10^{5}$ cells/sample were counted and data analysis was performed with Flowing Software 2.

\subsubsection{Transfection}

Cells were transfected with pDNA by electroporation using the Neon Transfection system according to the manufacturer's instructions. A few days ahead of electroporation, the cells were cultured until $70 \%$ - $90 \%$ confluency in culture medium without antibiotics. The cells were detached as described in section 5.1 and the cell pellets were resuspended and washed with PBS. Cell counting was performed as described in section 5.1.3. The cell suspensions containing the desired cell number $\left(0.5 \times 10^{6}\right.$ cells/electroporation) were transferred into new reaction tubes and pelleted again at $300 \times \mathrm{g}$ for $5 \mathrm{~min}$. The supernatants were removed and cells were resuspended in resuspension buffer $\mathrm{R}$ at a final density of $4.5 \times 10^{6} \mathrm{cells} / \mathrm{ml}$. For transfection itself, $0.5 \times 10^{6}$ cells were mixed with $4.5 \mu \mathrm{g}$ pDNA in a final volume of $110 \mu \mathrm{l}$. Electroporation was performed under conditions shown in Tab. 19.

Table 19: Electroporation conditions for ERMS cell lines

\begin{tabular}{ll} 
RD cells & \\
\hline Pulse voltage $(\mathrm{V})$ & 1.000 \\
Pulse width $(\mathrm{ms})$ & 30 \\
Pulse number & 2
\end{tabular}

\begin{tabular}{ll} 
RUCH-2 cell lines & \\
\hline Pulse voltage $(\mathrm{V})$ & 1.200 \\
Pulse width $(\mathrm{ms})$ & 40 \\
Pulse number & 1
\end{tabular}

After electroporation, cells were seeded in 6 well plates with pre-warmed cell culture medium without antibiotics. Transfection with an enhanced green fluorescent protein (EGFP) expression plasmid served as transfection control. Cells treated with an electric field pulse only served as additional control. All cells were allowed to attach for at least $18 \mathrm{~h}$ and were checked for viability and EGFP expression before performing further experiments. The 
mentioned transfection conditions for each cell line had been established with different amounts of the the pEGFP-N1 plasmid using different electroporation conditions and cell amounts. They yielded over $70 \%$ transfection efficiency as measured by flow cytometric analysis (BD LSR II flow cytometer and data evaluation by FlowJo).

\subsubsection{GLI reporter assay}

A luciferase-based GLI reporter system was used to measure transcriptional activity of GLI proteins. ERMS cell lines were transfected with a firefly luciferase reporter plasmid containing 9x GLI protein binding sites ( $p G L-9 x G l i B S$ ) and a vector expressing constitutively active renilla ( $p R L-C M V)$ which served as an internal control. A plasmid overexpressing murine Gli1 served as positive control, whereas its pCR3.1 backbone was used in the negative control. Additionally, $p E G F P-N 1$ transfected cells were included as transfection control. The transfections themselves were done by electroporation (see section 5.1.8). For transfection of cells that were grown ahead to $>75 \%$ confluency, the plasmid concentrations in Tab. 20 were used.

Table 20: Plasmid composition for GLI reporter assay in ERMS cell lines

\begin{tabular}{ll}
\hline \multicolumn{2}{c}{ Positive control } \\
\hline Plasmid & amount \\
\hline$p G L-9 x G l i B S$ & $3.5 \mu \mathrm{g}$ \\
$p R L-C M V$ & $0.5 \mu \mathrm{g}$ \\
$p C R 3.1 \mathrm{mGli1}$ & $0.5 \mu \mathrm{g}$ \\
$p C R 3.1$ & -
\end{tabular}

\begin{tabular}{ll}
\hline \multicolumn{2}{c}{$\begin{array}{c}\text { Treatment } \\
\text { or treatment control }\end{array}$} \\
\hline Plasmid & amount \\
\hline$p G L-9 x G l i B S$ & $3.5 \mu \mathrm{g}$ \\
pRL-CMV & $0.5 \mu \mathrm{g}$ \\
pCR3.1 mGli1 & - \\
pCR3.1 & $0.5 \mu \mathrm{g}$
\end{tabular}

\begin{tabular}{ll}
\hline \multicolumn{2}{c}{ Negative control } \\
\hline Plasmid & amount \\
\hline$p G L-9 x G l i B S$ & - \\
$p R L-C M V$ & $0.5 \mu \mathrm{g}$ \\
$p C R 3.1$ mGli1 & - \\
$p C R 3.1$ & $4 \mu \mathrm{g}$
\end{tabular}

The transfected cells were detached after $24 \mathrm{~h}$ and seeded again in a black 96 well plate with clear bottom at a density of $5 \times 10^{3}$ cells/well (see section 5.1 for procedure). The cells were allowed to attach for at least $18 \mathrm{~h}$ before incubation with reagents/inhibitors for $24 \mathrm{~h}$. Cells were checked for viability and EGFP expression microscopically before analyzing luciferase activity (see section 5.1.10).

\subsubsection{Dual luciferase reporter assay}

The dual luciferase reporter assay was performed according to the manufacturer's instructions. Briefly, the transfected cells were washed and lysed with $21 \mu \mathrm{l}$ of passive lysis buffer per well of a 96 well plate. The lyses were performed at RT for 15 min on a shaker (250 rounds per minute (rpm)). Afterwards culture plates containing the lysates were frozen at $-80^{\circ} \mathrm{C}$ for a minimum of $15 \mathrm{~min}$, thawed at RT and shaken at $250 \mathrm{rpm}$ for $1 \mathrm{~min}$. LARII and Stop'n'Glo reagents were prepared freshly for each measurement. Firefly and renilla activities were measured after serial injection of the 2 substrates and subsequent luminescence measurement of each well using the SynergyMx microplate reader and the Gen5 software. For determination of the relative luciferase activity, the readouts from firefly luciferase activity were normalized to renilla luciferase activity. 


\subsubsection{Generation of conditioned medium (CM)}

Stably transfected HEK293 Shh-N cells and untransfected HEK293 cells were used to prepare Shh-CM and control-CM ${ }^{310}$. For this purpose, the cells were cultured to a confluency of about $70 \%$. Then, the media were aspirated, cells were washed with PBS and cell culture media were replaced by low serum cell culture medium containing $2 \%$ FCS instead of $10 \%$ FCS. After $24 \mathrm{~h}$ to $48 \mathrm{~h}$ the CM was removed from the cell layer and sterile filtered through a $0.2 \mu \mathrm{m}$ pore filter. The CMs were selead with parafilm and stored at $4{ }^{\circ} \mathrm{C}$ for up to one month. Supernatants of ERMS cell lines were also used to generate CM under the same conditions.

\subsubsection{Analyses of $\mathrm{HH}$ ligand secretion and responsiveness}

In order to analyze whether cells were able to secrete $\mathrm{HH}$ ligands and thus to stimulate the $\mathrm{HH}$ pathway in surrounding cells, different cell culture approaches were applied.

\subsubsection{Incubation of cells with CM}

The Shh responsive B9 cells were seeded at a density of $2 \times 10^{5}$ cells in wells of a 6 well plate and allowed to attach for $24 \mathrm{~h}$. Then, the culture media were replaced by CM derived from control and ERMS cell lines (see section 5.1.11) for $48 \mathrm{~h}$. Afterwards RNA was isolated, reverse transcribed and analyzed for the expression of 18S, Hprt and Gli1 (see section 5.2.8). An increase in Gli1 expression was indicative for secretion of $\mathrm{HH}$ ligands into the cell culture medium. The results from Shh-CM treatment served as positive control.

When responsiveness of ERMS cell lines to $\mathrm{SHH}$ was analyzed, the ERMS cells were seeded with a density of $2 \times 10^{5}$ cells/well in a 6 well plate and allowed to adhere for $24 \mathrm{~h}$. Then the culture media were replaced by either Shh-CM or control-CM (see section 5.1.11) for $48 \mathrm{~h}$. Afterwards RNA was isolated, reverse transcribed and the expression of 18S, Hprt and Gli1 was analyzed (see section 5.2.8). B9 cells were included in the experiments as a positive control.

\subsubsection{Co-culture experiments with the SHH light II reporter cell line}

Furthermore, the cells potentially secreting $\mathrm{SHH}$ were co-cultured with $\mathrm{SHH}$ light II cells, that harbor a Gli responsive luciferase reporter. For this purpose, $\mathrm{SHH}$ light II cells were seeded in a black 96 well plate with clear bottom at a density of $5 \times 10^{3}$ cells/well (see section 5.1.1 for procedure) together with $7.5 \times 10^{3}$ cells of either HEK293 cells, HEK293 Shh-N cells or ERMS cells. After $24 \mathrm{~h}$ the media were replaced by starvation medium containing $0.5 \%$ FCS for further $24 \mathrm{~h}$ to enhance responsiveness of $\mathrm{SHH}$ light II cells to a potential $\mathrm{HH}$ stimulus. Afterwards the dual luciferase reporter assay was performed as described in section 5.1.10 to analyze $\mathrm{HH}$ signaling activity in the SHH light II cells. SHH light II cells stimulated with Smoothened agonist (SAG) and SHH light II cells co-cultured with HEK293 Shh-N cells served as positive controls, whereas co-culture of $\mathrm{SHH}$ light II cells with HEK293 cells served 
as negative control. The culture of cells without a Gli responsive luciferase reporter was used as a further negative control.

\subsection{Molecular biology}

\subsubsection{Plasmid cloning}

All required equipment for bacterial transformation and plasmid amplification were sterilized by an autoclave or a gas flame.

\subsubsection{Transformation of bacteria}

For cloning applications the Escherichia coli strain DH5a was used. Aliquots of $50 \mu \mathrm{l}$ of competent bacteria were thawed on ice and mixed with $1 \mu \mathrm{l}$ of pDNA. After 20 min of incubation a $30 \mathrm{sec}$ heat shock was performed at $42{ }^{\circ} \mathrm{C}$. Samples were cooled down on ice for approximately $1 \mathrm{~min}$ before adding $450 \mu \mathrm{l}$ S.O.C. medium. The suspensions were shaken at $400 \mathrm{rpm}$ and $37^{\circ} \mathrm{C}$ for $50 \mathrm{~min}$. Afterwards $150 \mu \mathrm{l}$ were plated on LB agar plates containing adequate antibiotics for selection $(100 \mu \mathrm{g} / \mathrm{ml}$ ampicillin or $50 \mu \mathrm{g} / \mathrm{ml}$ kanamycin). After a short drying period the plates were incubated upside down at $37^{\circ} \mathrm{C}$ overnight.

\subsubsection{Plasmid amplification, isolation and purification}

Single colonies of transformed $\mathrm{DH} 5 \alpha$ were picked the day after transformation (see section 5.2.1.1) and inoculated into $100 \mathrm{ml}$ LB medium containing the adequate selection antibiotic $(100 \mu \mathrm{g} / \mathrm{ml}$ ampicillin or $50 \mu \mathrm{g} / \mathrm{ml}$ kanamycin). For plasmid amplification bacteria were grown overnight on a shaker at $155 \mathrm{rpm}$ and $37^{\circ} \mathrm{C}$.

The PureLink HiPure Plasmid DNA Purification Kit was used for isolation and purification of pDNA according to the manufacturer's instruction. For this purpose, the bacterial suspensions were distributed into $50 \mathrm{ml}$ reaction tubes and centrifuged at $10,000 \times \mathrm{g}$ for $10 \mathrm{~min}$ at $4{ }^{\circ} \mathrm{C}$. The supernatants were discarded and all pellets were resuspended in $4 \mathrm{ml}$ of resuspension buffer $(\mathrm{R} 3)$. Then, $4 \mathrm{ml}$ of lysis buffer $(\mathrm{L} 7)$ were added to each tube and the tubes were inverted once to mix the suspension. Lyses were performed for 5 min at RT and afterwards $4 \mathrm{ml}$ precipitation buffer (N3) were added to the lysates. The suspensions were again mixed by inverting the tube. Then the tubes were centrifuged at $10,000 \times \mathrm{g}$ for $10 \mathrm{~min}$ at $4{ }^{\circ} \mathrm{C}$. Meanwhile the DNA extraction columns were equilibrated with $10 \mathrm{ml}$ equilibration buffer (EQ1). The supernatants from the centrifuged suspensions were then loaded onto the columns and were allowed to drain by gravity flow. Afterwards the columns were washed twice with $10 \mathrm{ml}$ of washing buffer (W8). The bound pDNA was eluted by adding $5 \mathrm{ml}$ of elution buffer (E4). The eluates were collected in falcon tubes and aliquoted in $1 \mathrm{ml}$ aliquots. To each reaction tube $1 \mathrm{ml}$ of pure isopropanol was added to precipitate the pDNA. The precipitation was performed at $-20^{\circ} \mathrm{C}$ overnight or at $-80^{\circ} \mathrm{C}$ for $30 \mathrm{~min}$. The reaction tubes were centrifuged for $30 \mathrm{~min}$ at $13,000 \mathrm{rpm}$ and $4{ }^{\circ} \mathrm{C}$. Supernatants were discarded and the pellets were dried at $55^{\circ} \mathrm{C}$ for $5 \mathrm{~min}$. The isolated pDNAs were dissolved in $20 \mu \mathrm{l}$ of ultrapure 
$\mathrm{H}_{2} \mathrm{O}$ each by shaking at $42^{\circ} \mathrm{C}$ with $1400 \mathrm{rpm}$ for $10 \mathrm{~min}$. pDNA concentration was quantified using the Nanodrop system (see section 5.2.6).

\subsubsection{Restriction enzyme hydrolysis}

The plasmid identity was analyzed by test-restriction hydrolysis. Based on the plasmid sequence, 2 adequate restriction endonucleases were chosen for hydrolysis. The digestions were performed using $500 \mathrm{ng}$ of purified pDNA mixed with 3 units of the respective enzymes and hydrolysis buffer in a total volume of $10 \mu \mathrm{l}$. The incubation temperatures and times were chosen according to the manufacturer's recommendations. The reactions were stopped by a heat shock at $70^{\circ} \mathrm{C}$ for 10 min followed by incubation on ice. The products were analyzed after addition of $6 \times$ loading dye solution by separation on an agarose gel (see section 5.2.4).

\subsubsection{Isolation of genomic DNA (gDNA)}

\subsubsection{Biopsies}

Biopsies from mouse tail tip, ear or tissue were used to isolate gDNA and to perform PCRbased genotyping of animals. The biopsies were digested in $500 \mu \mathrm{l}$ of STE buffer with $0.25 \mathrm{mg}$ proteinase $\mathrm{K}$ per sample at $55^{\circ} \mathrm{C}$ overnight. The next day the samples were shaken thoroughly and afterwards they were centrifuged at 13,000 rpm at RT for $10 \mathrm{~min}$. Then, $300 \mu \mathrm{l}$ of the supernatant were transferred into $1 \mathrm{ml}$ of pure denatured $\mathrm{EtOH}$ to precipitate the gDNA. The samples were centrifuged for $30 \mathrm{~min}$ at $13,000 \mathrm{rpm}$ and $4{ }^{\circ} \mathrm{C}$. The supernatants were discarded and the pellets were washed with $200 \mu \mathrm{l}$ of $70 \% \mathrm{EtOH}$ and centrifuged again at $13,000 \mathrm{rpm}$ and $4{ }^{\circ} \mathrm{C}$ for $10 \mathrm{~min}$. The supernatants were discarded again and the pellets were dried upside down at $55^{\circ} \mathrm{C}$ for approximately $10 \mathrm{~min}$. The isolated gDNA was dissolved in $125 \mu \mathrm{l}$ ultrapure $\mathrm{H}_{2} \mathrm{O}$ and shaken at $1400 \mathrm{rpm} 10 \mathrm{~min}$ at $42{ }^{\circ} \mathrm{C}$.

\subsubsection{Paraffin-embedded tissue}

The isolation of gDNA from embedded tissue was performed using the QIAamp DNA FFPE Tissue kit according to the manufacturer's instructions. Briefly, 8 freshly cut sections with a maximal thickness of $10 \mu \mathrm{m}$ of formalin-fixed and paraffin-embedded tissue were prepared. Excess paraffin was removed from the sections using a scalpel. The sections were transferred into a reaction tube and $1 \mathrm{ml}$ of xylene was added. After vigorous mixing the samples were centrifuged at 13,000 rpm and RT for 2 min. The supernatants were discarded and the pellets were resuspended in $1 \mathrm{ml}$ of $96 \%$ pure EtOH. After a further mixing step samples were centrifuged again at $13,000 \mathrm{rpm}$ and RT for $2 \mathrm{~min}$. The supernatants were discarded and the remaining $\mathrm{EtOH}$ was allowed to evaporate at $37^{\circ} \mathrm{C}$. The completely dried pellets were resuspended in $180 \mu \mathrm{l}$ of ATL buffer. After adding $20 \mu \mathrm{l}$ of proteinase $\mathrm{K}$ and mixing, the samples were incubated at $56^{\circ} \mathrm{C}$ until they were completely lysed. Subsequently, the formaldehyde modifications were reversed by incubating the samples in ATL buffer at $90{ }^{\circ} \mathrm{C}$ for $1 \mathrm{~h}$. Afterwards, $200 \mu \mathrm{l}$ of AL buffer were added to the samples. After a thorough 
mixing step, $200 \mu \mathrm{l}$ of $96 \%$ pure $\mathrm{EtOH}$ were added and samples were mixed again and spun down. Then the lysates were transferred to elution columns (located in $2 \mathrm{ml}$ collection tubes) and centrifuged at $8000 \mathrm{rpm}$ for $1 \mathrm{~min}$. The elution columns with bound gDNA were transferred into new $2 \mathrm{ml}$ collection tube. After 2 washing steps with $500 \mu \mathrm{l}$ of AW1 and $500 \mu \mathrm{l}$ of AW2 buffer by centrifugation at $8000 \mathrm{rpm}$ for $1 \mathrm{~min}$, the elution columns were dried by centrifugation at $13,000 \mathrm{rpm}$ and RT for $3 \mathrm{~min}$. For elution of the bound gDNA the columns were transferred into new $1.5 \mathrm{ml}$ reaction tubes and incubated with $50 \mu \mathrm{l}$ of ATE buffer for $5 \mathrm{~min}$ at RT. Afterwards the columns were centrifuged at $13,000 \mathrm{rpm}$ and RT for $1 \mathrm{~min}$. The isolated gDNA was either used directly or stored at $-20^{\circ} \mathrm{C}$.

\subsubsection{Polymerase chain reaction}

\subsubsection{PCR-based genotyping analyses}

Genotyping of mice was performed by different PCR approaches within a total volume of $10 \mu \mathrm{l}$. Each reaction contained $10-100 \mathrm{ng}$ of gDNA template $(0.75 \mu \mathrm{l}-1.25 \mu \mathrm{l}), 0.5 \mu \mathrm{M}$ forward primer (in $0.5 \mu \mathrm{l} \mathrm{H}_{2} \mathrm{O}$ ), $0.5 \mu \mathrm{M}$ reverse primer (in $0.5 \mu \mathrm{l} \mathrm{H}_{2} \mathrm{O}$ ), $0.2 \mu \mathrm{M}$ dNTPs (in $0.2 \mu \mathrm{l}$ $\mathrm{H}_{2} \mathrm{O}$ ), $0.3 \mathrm{mM} \mathrm{MgCl}_{2}$ (in $0.6 \mu \mathrm{H}_{2} \mathrm{O}$ ), $10 \%(\mathrm{v} / \mathrm{v})$ Cresol $(1 \mu \mathrm{l})$, polymerase buffer (in $1 \mu \mathrm{l}$ ), $0.1 \mathrm{U}$ MolTaq polymerase (in $0.1 \mu \mathrm{l}$ buffer) and was filled with ultrapure $\mathrm{H}_{2} \mathrm{O}$ to $10 \mu \mathrm{l}$. In case 2 reverse primers were needed the concentration of the forward primer was doubled $(1 \mu \mathrm{M})$ and the amount of added $\mathrm{H}_{2} \mathrm{O}$ was reduced. The cycling conditions used for genotyping are listed in Tab. 21. All used Primers and size of PCR products are described in Tab. 11.

Table 21: PCR approaches for genotyping

\begin{tabular}{|c|c|c|c|c|c|c|c|c|c|c|c|c|}
\hline \multirow[b]{2}{*}{ Step } & \multicolumn{3}{|c|}{ Mutant Ptch } & \multicolumn{3}{|c|}{ Wildtype Ptch } & \multicolumn{3}{|c|}{ Wildtype Myf5 } & \multicolumn{3}{|c|}{ Mutant Myf5 } \\
\hline & Temp. & Time & Cycles & Temp. & Time & Cycles & Temp. & Time & Cycles & Temp. & Time & Cycles \\
\hline First & $94^{\circ} \mathrm{C}$ & $5 \min$ & & $95^{\circ} \mathrm{C}$ & $5 \mathrm{~min}$ & & $95^{\circ} \mathrm{C}$ & $5 \min$ & & $95^{\circ} \mathrm{C}$ & $5 \mathrm{~min}$ & \\
\hline Amplification & $\begin{array}{l}94{ }^{\circ} \mathrm{C} \\
62{ }^{\circ} \mathrm{C} \\
72{ }^{\circ} \mathrm{C}\end{array}$ & $\begin{array}{l}1 \mathrm{~min} \\
1 \mathrm{~min} \\
3 \mathrm{~min}\end{array}$ & $35 x$ & $\begin{array}{l}95^{\circ} \mathrm{C} \\
60^{\circ} \mathrm{C} \\
72^{\circ} \mathrm{C}\end{array}$ & $\begin{array}{l}20 \mathrm{sec} \\
20 \mathrm{sec} \\
45 \mathrm{sec}\end{array}$ & $35 x$ & $\begin{array}{l}95^{\circ} \mathrm{C} \\
59^{\circ} \mathrm{C} \\
72^{\circ} \mathrm{C}\end{array}$ & $\begin{array}{l}30 \mathrm{sec} \\
30 \mathrm{sec} \\
90 \mathrm{sec}\end{array}$ & $35 x$ & $\begin{array}{l}95^{\circ} \mathrm{C} \\
58^{\circ} \mathrm{C} \\
72^{\circ} \mathrm{C}\end{array}$ & $\begin{array}{l}30 \mathrm{sec} \\
40 \mathrm{sec} \\
40 \mathrm{sec}\end{array}$ & $35 x$ \\
\hline $\begin{array}{l}\text { Final } \\
\text { Extension }\end{array}$ & $72^{\circ} \mathrm{C}$ & $5 \mathrm{~min}$ & & $72{ }^{\circ} \mathrm{C}$ & $5 \mathrm{~min}$ & & $72{ }^{\circ} \mathrm{C}$ & $5 \mathrm{~min}$ & & $72^{\circ} \mathrm{C}$ & $5 \mathrm{~min}$ & \\
\hline & Wildty & $\begin{array}{l}\text { e and } n \\
\text { HRas }\end{array}$ & mutant & Wildty & $\begin{array}{l}\text { e and } \mathrm{m} \\
\text { KRas }\end{array}$ & nutant & Wildty & $\begin{array}{l}\text { e and } \mathrm{n} \\
\text { NRas }\end{array}$ & nutant & Wildty & $\begin{array}{l}\text { e and } n \\
\text { Bosa26 }\end{array}$ & nutant \\
\hline & Temp. & Time & Cycles & Temp. & Time & Cycles & Temp. & Time & Cycles & Temp. & Time & Cycles \\
\hline $\begin{array}{l}\text { First } \\
\text { Denaturation }\end{array}$ & $95^{\circ} \mathrm{C}$ & $5 \min$ & & $95^{\circ} \mathrm{C}$ & $5 \mathrm{~min}$ & & $94^{\circ} \mathrm{C}$ & $5 \mathrm{~min}$ & & $95^{\circ} \mathrm{C}$ & $5 \mathrm{~min}$ & \\
\hline Amplification & $\begin{array}{l}95^{\circ} \mathrm{C} \\
64^{\circ} \mathrm{C} \\
72^{\circ} \mathrm{C}\end{array}$ & $\begin{array}{c}30 \mathrm{sec} \\
30 \mathrm{sec} \\
1 \mathrm{~min}\end{array}$ & $30 x$ & $\begin{array}{l}95^{\circ} \mathrm{C} \\
55^{\circ} \mathrm{C} \\
72^{\circ} \mathrm{C}\end{array}$ & $\begin{array}{c}30 \mathrm{sec} \\
30 \mathrm{sec} \\
1 \mathrm{~min}\end{array}$ & $30 x$ & $\begin{array}{l}94^{\circ} \mathrm{C} \\
68^{\circ} \mathrm{C} \\
72^{\circ} \mathrm{C}\end{array}$ & $\begin{array}{c}30 \mathrm{sec} \\
1 \mathrm{~min} \\
1 \mathrm{~min}\end{array}$ & $25 x$ & $\begin{array}{l}95^{\circ} \mathrm{C} \\
60^{\circ} \mathrm{C} \\
72^{\circ} \mathrm{C}\end{array}$ & $\begin{array}{l}20 \mathrm{sec} \\
20 \mathrm{sec} \\
45 \mathrm{sec}\end{array}$ & $30 x$ \\
\hline $\begin{array}{l}\text { Final } \\
\text { Extension }\end{array}$ & $72^{\circ} \mathrm{C}$ & $5 \mathrm{~min}$ & & $72^{\circ} \mathrm{C}$ & $5 \mathrm{~min}$ & & $72^{\circ} \mathrm{C}$ & $5 \min$ & & $72^{\circ} \mathrm{C}$ & $5 \mathrm{~min}$ & \\
\hline
\end{tabular}

\subsubsection{PCR-based recombination assays}

Recombination assays were performed to prove efficient recombination the floxed Ras loci in tissue of genetically modified mice. For this purpose $1 \mu \mathrm{l}$ of a gDNA (KRas and NRas) or 
cDNA-template (HRas) was mixed with $0.5 \mu \mathrm{M}$ forward primer (in $1 \mu \mathrm{l} \mathrm{H}_{2} \mathrm{O}$ ), $0.5 \mu \mathrm{M}$ reverse primer (in $1 \mu \mathrm{l} \mathrm{H}_{2} \mathrm{O}$ ), $0.2 \mu \mathrm{M}$ dNTPs (in $0.4 \mu \mathrm{H}_{2} \mathrm{O}$ ), $0.2 \mathrm{mM} \mathrm{MgCl}_{2}$ (in $0.8 \mu \mathrm{H}_{2} \mathrm{O}$ ), $10 \%$ (v/v) Cresol $(2 \mu \mathrm{l})$, polymerase buffer $(2 \mu \mathrm{l}), 0.1 \mathrm{U}$ MolTaq polymerase (in $0.2 \mu \mathrm{l}$ buffer). The reaction was filled with ultrapure $\mathrm{H}_{2} \mathrm{O}$ to $20 \mu \mathrm{l}$. The used primers for the different recombination assays and their sequences are listed in Tab. 11. The utilized PCR programs are listed in Tab. 22.

Table 22: PCR approaches for recombination assays

\begin{tabular}{|c|c|c|c|c|c|c|c|c|c|}
\hline \multirow[b]{2}{*}{ Step } & \multicolumn{3}{|c|}{ HRas } & \multicolumn{3}{|c|}{ KRas } & \multicolumn{3}{|c|}{ NRas } \\
\hline & Temp. & Time & Cycles & Temp. & Time & Cycles & Temp. & Time & Cycles \\
\hline \multirow{2}{*}{$\begin{array}{l}\overline{\text { First }} \\
\text { Denaturation }\end{array}$} & $95^{\circ} \mathrm{C}$ & $1 \mathrm{~min}$ & & $95^{\circ} \mathrm{C}$ & $5 \min$ & & $94^{\circ} \mathrm{C}$ & $5 \min$ & \\
\hline & $95^{\circ} \mathrm{C}$ & $30 \mathrm{sec}$ & & $95^{\circ} \mathrm{C}$ & $30 \mathrm{sec}$ & & $94^{\circ} \mathrm{C}$ & $30 \mathrm{sec}$ & $35 x$ \\
\hline \multirow[t]{2}{*}{ Amplification } & $65^{\circ} \mathrm{C}$ & $30 \mathrm{sec}$ & $45 x$ & $55^{\circ} \mathrm{C}$ & $30 \mathrm{sec}$ & $40 x$ & $68^{\circ} \mathrm{C}$ & $1 \mathrm{~min}$ & \\
\hline & $72^{\circ} \mathrm{C}$ & $45 \mathrm{sec}$ & & $72{ }^{\circ} \mathrm{C}$ & $1 \mathrm{~min}$ & & $72^{\circ} \mathrm{C}$ & $1 \mathrm{~min}$ & \\
\hline $\begin{array}{l}\text { Final } \\
\text { Extension }\end{array}$ & $72{ }^{\circ} \mathrm{C}$ & $5 \min$ & & $72{ }^{\circ} \mathrm{C}$ & $5 \mathrm{~min}$ & & $72^{\circ} \mathrm{C}$ & $5 \mathrm{~min}$ & \\
\hline
\end{tabular}

\subsection{KRas and NRas recombination assays}

The PCR products from KRas and NRas recombination assays were analyzed directly by agarose gel electrophoresis (see section 5.2.4). For both assays a double band (Kras: 270 bp for wt and 304 bp for recombined KRas; NRas: 487 bp for wt and 521 bp for recombined NRas) indicated efficient recombination whereas a single band (KRas: 270 bp for wt KRas; NRas: 487 bp for wt NRas) indicated no recombination.

\subsection{HRas recombination assays}

The recombination assay for HRas comprised an enzymatic digestion of PCR-amplified HRas fragments with Bpml. The enzyme recognizes the wt sequence, whereas the mutant HRas sequence is not recognized by the enzyme due to the HRas ${ }^{G 12 V}$ mutation ${ }^{303}$.

For the recombination assay $12.5 \mu \mathrm{l}$ of PCR-amplified HRas cDNA were mixed with $0.5 \mathrm{U}$ Bpml (in $0.25 \mu \mathrm{l}$ buffer) and 3.1 NEBuffer $^{\mathrm{TM}}(2 \mu \mathrm{l}$ ), and the reactions were filled up with ultrapure $\mathrm{H}_{2} \mathrm{O}$ to $20 \mu \mathrm{l}$. The enzyme hydrolyses were performed at $37{ }^{\circ} \mathrm{C}$ for $30 \mathrm{~min}$ and reactions were stopped by a heat shock at $65^{\circ} \mathrm{C}$ for $2 \mathrm{~min}$. The products were analyzed by agarose gel electrophoresis (see section 5.2.4). Not digested samples, lacking the restriction enzyme, were used as negative control. Potential results from the recombination assay are shown and explained in Fig. 5. 

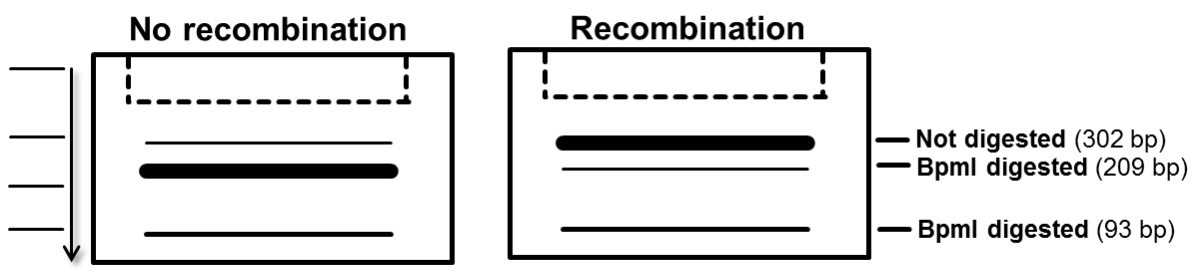

Figure 5: Potential readouts from HRas recombination assays

Heterozygous mice without recombination will show 2 strong digestion fragments (209 bp and 93 bp) and a weak undigested fragment (302 bp) (left cartoon). Heterozygous mice with successful recombination will show weak digestion bands (209 bp and $93 \mathrm{bp}$ ) and a strong undigested fragment (302 bp) (right cartoon). Since complete digestion was not feasible in this experimental setting an undigested fragment (302 bp) was always expected.

\subsubsection{Agarose gel electrophoresis}

DNA fragments were separated by agarose gel electrophoresis. Depending on the expected product sizes $1 \%$ to $3 \%(\mathrm{w} / \mathrm{v})$ agarose gels were prepared in TBE buffer. The solutions were boiled for $3 \mathrm{~min}$ in a microwave oven at $1000 \mathrm{~W}$ to dissolve the agarose powder. The liquid gel was cooled down and a few droplets of ethidium bromide $(0.07 \%)$ were added. The agarose was poured into trays and combs were placed. After solidification, the combs were removed and the gels were covered with TBE buffer in an electrophoresis chamber. The samples were loaded and an electric field was applied (80-120 V, $500 \mathrm{~mA}$, separation: $30 \mathrm{~min}-2.5 \mathrm{~h}$ ). Appropriate markers were used to indicate the DNA size. Fragments were visualized in an UV transilluminator and documented using the INTAS GDS 3.39 software.

\subsubsection{Ribonucleic acid (RNA) isolation}

To protect RNA from degradation, the isolation was performed on ice if not indicated otherwise. Filter tips and equipment was RNAse-free. For isolation, the Trizol reagent was used according to the manufacturer's recommendations.

\subsubsection{Isolation of total RNA from eukaryotic cell lines}

The cultured cells were washed twice with ice-cold PBS and $1 \mathrm{ml}$ of cold Trizol was added to one well of a 6 well plate. The suspensions were transferred into $2 \mathrm{ml}$ tubes and were mixed thoroughly for 2 min on a shaker. After a 5 min incubation step at RT $200 \mu$ chloroform were added to each sample. Again, the samples were mixed thoroughly for $20 \mathrm{sec}$ on a shaker and incubated for $3 \mathrm{~min}$ at RT. A centrifugation step at $12,000 \mathrm{rpm}$ and $4{ }^{\circ} \mathrm{C}$ for $10 \mathrm{~min}$ resulted in a phase separation. Approximately $600 \mu \mathrm{l} / \mathrm{sample}$ of the clear upper and aqueous phase were transferred into a tube with $700 \mu \mathrm{l}$ of pre-cooled isopropanol. After precipitating overnight at $-20^{\circ} \mathrm{C}$, the samples were centrifuged at $12,000 \mathrm{rpm}$ and $4{ }^{\circ} \mathrm{C}$ for $30 \mathrm{~min}$. The supernatants were discarded and the pellets were washed with $700 \mu \mathrm{l}$ of pre-cooled $70 \%$ pure $\mathrm{EtOH}$. After 2 further washing steps (consisting of a centrifugation at 12,000 rpm and $4{ }^{\circ} \mathrm{C}$ for $15 \mathrm{~min}$, the removal of the supernatants and the addition of $700 \mu$ l of pre-cooled $70 \%$ pure $\mathrm{EtOH}$ ) the RNA pellet was air-dried for about $1 \mathrm{~h}$ and solubilized in $15 \mu \mathrm{l}-45 \mu \mathrm{l}$ ultrapure $\mathrm{H}_{2} \mathrm{O}$ while shaking at $900 \mathrm{rpm}$ and $56^{\circ} \mathrm{C}$ for $10 \mathrm{~min}$. The RNA concentrations were quantified (see section 5.2.6) and samples were stored at $-80^{\circ} \mathrm{C}$. 


\subsubsection{Isolation of total RNA from tissue samples}

Approximately $20 \mathrm{mg}$ of frozen tissue sample were chopped in a petri dish on dry-ice using a scalpel blade. The chopped tissue was transferred into a $2 \mathrm{ml}$ tube and covered with $1 \mathrm{ml}$ of cold Trizol. Then the tissue samples were homogenized on ice using a disperser tool until a homogenous solution was achieved. The tool itself was cleaned after each sample. Further lyses were performed by incubation of the homogenates in Trizol for $5 \mathrm{~min}$. The following steps were performed as described in section 5.2.5.1.

\subsubsection{Photometric quantification of nucleic acids}

The NanoDrop 8000 spectrophotometer was used to photometrically determine DNA and RNA concentrations. Optical densities (OD) of each sample were measured at $230 \mathrm{~nm}$, $260 \mathrm{~nm}, 280 \mathrm{~nm}$ and $340 \mathrm{~nm} . \mathrm{OD}_{260}$ provides the concentration of nucleic acids, whereby an $\mathrm{OD}_{260}$ of 1.0 reflects $50 \mu \mathrm{g} / \mathrm{ml}$ pure dsDNA or $40 \mu \mathrm{g} / \mathrm{ml}$ pure RNA. Thus, DNA or RNA concentrations were calculated by multiplying the measured $O D_{260}$ values with 50 or with 40 , respectively. $\mathrm{OD}_{230}$ of the sample provides a measurement of the concentration of sugars, salts and phenols, $O D_{280}$ of the sample provides the concentration of proteins and $O_{340}$ measures turbidity and background signals. DNA and RNA samples with an $\mathrm{OD}_{260} / \mathrm{OD}_{280}$ ratio between 1.8 and 2 and an $O D_{260} / O D_{230}$ ratio $\geq 2$, respectively, were considered as pure nucleic acids. $\mathrm{OD}_{340}$ values were optimally close to zero.

\subsubsection{Reverse transcription}

For cDNA synthesis, the SuperScript II Reverse Transcriptase kit was used based on the manufacturer's recommendations. In detail, $2 \mu \mathrm{g}$ of total RNA (for isolation see section 5.2.5) were diluted in $7 \mu \mathrm{l}$ of ultrapure $\mathrm{H}_{2} \mathrm{O}$ and mixed with $250 \mathrm{ng}$ of random hexamer oligonucleotides (in $5 \mu \mathrm{l} \mathrm{H}_{2} \mathrm{O}$ ) and incubated for $10 \mathrm{~min}$ at $70{ }^{\circ} \mathrm{C}$. A mixture of $0.5 \mathrm{mM} \mathrm{dNTPs}$ (in $1 \mu \mathrm{l} \mathrm{H}_{2} \mathrm{O}$ ), $10 \mathrm{mM}$ DTT (in $2 \mu \mathrm{H}_{2} \mathrm{O}$ ) and first strand buffer $(4 \mu \mathrm{l}$ ) were added to the samples and the mixtures were incubated for $10 \mathrm{~min}$ at RT. After pre-warming at $42{ }^{\circ} \mathrm{C}$ for $2 \mathrm{~min}, 100 \mathrm{U}$ (in $1 \mu \mathrm{l}$ ) of reverse transcriptase were added (final volume of $20 \mu \mathrm{l}$ ). The enzyme-driven cDNA synthesis was performed at $42{ }^{\circ} \mathrm{C}$ for $1 \mathrm{~h}$. A heat inactivation step at $70{ }^{\circ} \mathrm{C}$ for 10 min stopped the synthesis. Assuming a reaction efficiency of $50 \%$ the final cDNA concentration theoretically was $50 \mathrm{ng} / \mu \mathrm{l}$. The samples were stored at $-20^{\circ} \mathrm{C}$.

\subsubsection{Quantitative real time PCR}

Gene expression analyses were performed by SYBR-green based quantitative real time PCR (qRT-PCR). Dependent on the gene of interest (GOI) either the Platinum SYBR Green qPCR Super Mix (Invitrogen) or QuantiTect SYBR Green PCR (Qiagen) were applied using different qRT-PCR programs (see Tab. 23). For qRT-PCR reactions, $2 \mu$ of diluted cDNA (see Tab. 24) were added to $8 \mu \mathrm{l}$ of a prepared mastermix (see Tab. 23) resulting in a total reaction volume of $10 \mu \mathrm{l}$. Details of the used primer pairs are listed in Tab. 12. All 
measurements were performed in triplicates in a sealed black 384 well plate on an ABI Prism $7900 \mathrm{HT}$ device using the SDS software.

The gene expression values were calculated using the standard curve method. To generate the standard curve a sample with high and constant expression of the GOI was chosen. Of this sample $20 \mathrm{ng} / 2 \mu \mathrm{l}$ cDNA or $250 \mathrm{pg} / 2 \mu \mathrm{l}$ cDNA were subjected to a 5 -fold serial dilution row and amplified with primers specific for the GOI or $18 S$ ribosomal RNA (rRNA), respectively. Logarithmic values of the calculated CDNA concentration from the dilution series were plotted against the corresponding measured cycle threshold (CT) from the same sample. A trend line was plotted and its formula was used to calculate the amount of GOI cDNA in the target samples. The resulting transcript levels of the GOI were normalized to those of $18 S$ rRNA of the same sample. Furthermore, the GOI transcript levels were also normalized to the reference genes HPRT/Hprt or TBP/Tbp. The standard curves for these genes were generated by 5 -fold serial dilutions starting with $20 \mathrm{ng} / 2 \mu \mathrm{l}$ cDNA. Further analyses were done using the SDS 2.2, Microsoft Excel and GraphPad Prism 6 software. Additionally, the results were relativized to experimental control samples, such as solvent controls.

Table 23: Mastermix and conditions for qRT-PCR

\begin{tabular}{l|l}
\hline \multicolumn{2}{c}{ Mastermix } \\
\hline \multicolumn{1}{c}{ Component } & \multicolumn{1}{c}{ Volume } \\
\hline SYBR Green & $5 \mu \mathrm{l}$ \\
Forward primer & $0.4 \mu \mathrm{l}(0.4 \mu \mathrm{M})$ \\
Reverse primer & $0.4 \mu \mathrm{l}(0.4 \mu \mathrm{M})$ \\
$\mathrm{H}_{2} \mathrm{O}$ & $2.2 \mu \mathrm{l}$ \\
& \\
\hline cDNA template & $2 \mu \mathrm{l}$
\end{tabular}

\begin{tabular}{c|c|c}
\hline \multicolumn{3}{c}{ Qiagen } \\
\hline Temp. & Time & Cycles \\
\hline $50^{\circ} \mathrm{C}$ & $2 \mathrm{~min}$ & \\
$95^{\circ} \mathrm{C}$ & $15 \mathrm{~min}$ & \\
\hline $95^{\circ} \mathrm{C}$ & $15 \mathrm{sec}$ & \\
$60^{\circ} \mathrm{C}$ & $30 \mathrm{sec}$ & $40 \mathrm{x}$ \\
$72^{\circ} \mathrm{C}$ & $30 \mathrm{sec}$ & \\
\hline \multicolumn{3}{c}{ Dissociation stage } \\
$\left(95^{\circ} \mathrm{C}: 15 \mathrm{sec}, 60^{\circ} \mathrm{C:} 15 \mathrm{sec}\right.$, \\
\multicolumn{3}{c}{$\left.95^{\circ} \mathrm{C}: 15 \mathrm{sec}\right)$}
\end{tabular}
$95^{\circ} \mathrm{C}: 15 \mathrm{sec}$ )

\begin{tabular}{c|c|c}
\hline \multicolumn{3}{c}{ Invitrogen } \\
\hline Temp. & Time & Cycles \\
\hline $50^{\circ} \mathrm{C}$ & 2 min & \\
$95^{\circ} \mathrm{C}$ & $2 \mathrm{~min}$ & \\
\hline $95^{\circ} \mathrm{C}$ & $30 \mathrm{sec}$ & \\
$60^{\circ} \mathrm{C}$ & $1 \mathrm{~min}$ & $40 \mathrm{x}$ \\
& & \\
\hline \multicolumn{3}{l}{ Dissociation stage }
\end{tabular}
$\left(95^{\circ} \mathrm{C}\right.$ : $15 \mathrm{sec}, 60^{\circ} \mathrm{C}: 15 \mathrm{sec}$, $95^{\circ} \mathrm{C}: 15 \mathrm{sec}$ )

Table 24: Assay informations for qRT-PCR

\begin{tabular}{l|l|l|l}
\hline \multicolumn{4}{|c}{ Human genes } \\
\hline GOI & Standard & $\begin{array}{l}\text { Sample } \\
\text { dilution }\end{array}$ & $\begin{array}{l}\text { SYBR } \\
\text { Green }\end{array}$ \\
\hline 18S rRNA & E12.5 & $1: 13,500$ & $\begin{array}{l}\text { Qiagen, } \\
\text { Invitrogen } \\
\text { Invitrogen }\end{array}$ \\
HPRT & RMS-13 & $1: 10$ & Invitrogen \\
& RMS-13 & $1: 10$ & Qiagen \\
GLI1 & RMS-13 & $1: 10$ & Qiagen \\
GLI2 & RUCH-2 & $1: 10$ & Invitrogen \\
GLI3 & RMS-13 & $1: 10$ & Qiagen \\
HHIP & RMS-13 & $1: 10$ & Qiagen \\
PTCH & MET-4 & undiluted & SHH
\end{tabular}

\begin{tabular}{|c|c|c|c|}
\hline \multicolumn{4}{|c|}{ Murine genes } \\
\hline GOI & Standard & $\begin{array}{l}\text { Sample } \\
\text { dilution }\end{array}$ & $\begin{array}{l}\text { SYBR } \\
\text { Green }\end{array}$ \\
\hline $18 S$ rRNA & E12.5 & $1: 13,500$ & $\begin{array}{l}\text { Qiagen, } \\
\text { Invitrogen }\end{array}$ \\
\hline Hprt & E12.5 & $1: 20$ & $\begin{array}{l}\text { Qiagen, } \\
\text { Invitrogen }\end{array}$ \\
\hline Tbp & E12.5 & $1: 20$ & Invitrogen \\
\hline Gli1 & E12.5 & $1: 20$ & Invitrogen \\
\hline Gli2 & E12.5 & $1: 20$ & Qiagen \\
\hline Gli3 & RMS & $1: 20$ & Invitrogen \\
\hline Hhip & E12.5 & $1: 20$ & Qiagen \\
\hline Ptch & E12.5 & $1: 20$ & Qiagen \\
\hline MyoD & RMS & $1: 20$ & Qiagen \\
\hline Myogenin & RMS & $1: 20$ & Invitrogen \\
\hline $\begin{array}{l}\text { Myosin heavy } \\
\text { chain (MyHC) }\end{array}$ & RMS & $1: 20$ & Qiagen \\
\hline Tropomyosin 3 & RMS & $1: 20$ & Qiagen \\
\hline p21 & RMS & $1: 20$ & Qiagen \\
\hline p27 & RMS & $1: 20$ & Qiagen \\
\hline
\end{tabular}




\subsection{Protein biochemistry}

The protein isolations were performed on ice if not indicated otherwise. Protein samples were stored at $-80^{\circ} \mathrm{C}$.

\subsubsection{Protein isolation from cell culture}

Subconfluent cells grown on a $10 \mathrm{~cm}$ culture plate were used to detect the proteins pERK/ERK, pAKT/AKT, pS6/S6, pan-RAS, Caspase 3 and HSC70. For examination of nuclear and cytoplasmic GLI proteins 5 cell culture plates were pooled (see section 5.3.2).

The cell layers were washed twice with ice-cold PBS. Afterwards $500 \mu \mathrm{l}$ of ice-cold PBS were added and the cells were scraped off the plate. The cell suspensions were transferred into cooled $2 \mathrm{ml}$ tubes. The samples were centrifuged at 2,000 rpm and $4{ }^{\circ} \mathrm{C}$ for $5 \mathrm{~min}$, afterwards the supernatants were discarded. The cell pellets were snap frozen in liquid nitrogen and thawed on ice. The pellets were resuspended in $50 \mu \mathrm{l}-100 \mu \mathrm{l}$ of lysis buffer (depending on the pellet size) and passed several times through a $30 \mathrm{G}$ needle using a $1 \mathrm{ml}$ syringe. Lysis was performed $45 \mathrm{~min}$ on ice and samples were gently mixed every $15 \mathrm{~min}$. Then the lysates were centrifuged at $13,000 \mathrm{rpm}$ and $4{ }^{\circ} \mathrm{C}$ for $30 \mathrm{~min}$. The supernatants containing the cellular proteins were transferred into new tubes.

\subsubsection{Subcellular fractionation of cellular lysates}

The protocol for subcellular fractionation is based on other protocols described in the literature ${ }^{321,322}$. The cells were scraped off and washed as described in section 5.3.1. The pellets were resuspended in $500 \mu \mathrm{l}$ PBS and the cell suspensions were split into 2 tubes to isolate cytosolic/nuclear proteins or the total protein fraction. Both tubes were centrifuged at 2,000 rpm and $4{ }^{\circ} \mathrm{C}$ for $5 \mathrm{~min}$ and the supernatants were discarded. Isolation of the total fraction was performed as described above (see section 5.3.1). The samples for isolation of the cytosolic and nuclear proteins were thoroughly resuspended in $250 \mu \mathrm{l}$ of subcellular fractionation (SF) buffer and passed several times through a $30 \mathrm{G}$ needle using a $1 \mathrm{ml}$ syringe. Lysis was performed $45 \mathrm{~min}$ on ice and the samples were gently mixed every $15 \mathrm{~min}$. Afterwards the samples were centrifuged at $3,000 \mathrm{rpm}$ and $4{ }^{\circ} \mathrm{C}$ for $15 \mathrm{~min}$. The supernatants from this step were used to isolate cytosolic proteins, whereas the pellet was used to isolate nuclear proteins.

For isolation of cytosolic proteins, the supernatants were transferred into a new $1.5 \mathrm{ml}$ tube and centrifuged at $8,000 \mathrm{rpm}$ and $4^{\circ} \mathrm{C}$ for $12 \mathrm{~min}$. The resulting supernatant contained the cytosolic and membrane fractions.

To isolate nuclear proteins, the pellets were resuspended in $500 \mu \mathrm{l}$ of SF buffer and washed by centrifugation at $3000 \mathrm{rpm}$ and $4{ }^{\circ} \mathrm{C}$ for $10 \mathrm{~min}$. The supernatants were discarded and the pellets were snap frozen in liquid nitrogen and thawed on ice. After thawing the pellets were resuspended in $50 \mu \mathrm{l}$ of nuclear lysis buffer (NL buffer) and incubated for $45 \mathrm{~min}$ on ice and 
gently mixed every $15 \mathrm{~min}$. After lysis, the samples were centrifuged at $3000 \mathrm{rpm}$ and $4{ }^{\circ} \mathrm{C}$ for $30 \mathrm{~min}$ and the supernatants containing the nuclear proteins were collected.

\subsubsection{Protein isolation from murine tissue samples}

Approximately $30 \mathrm{mg}$ of a frozen tissue sample was chopped in a petri dish on dry ice using a scalpel blade. The chopped tissue was transferred into a $2 \mathrm{ml}$ tube and covered with $200 \mu \mathrm{l}$ of cold modified RIPA buffer. Tissue samples were homogenized on ice using a homogenizer. The homogenates were snap frozen in liquid nitrogen and thawed on ice. Afterwards the lysates were clarified by centrifugation at $10,000 \mathrm{rpm}$ and $4{ }^{\circ} \mathrm{C}$ for $20 \mathrm{~min}$. The supernatants, which contained cellular proteins, were collected and transferred into new tubes. The homogenizer was thoroughly cleaned before homogenizing another sample.

\subsubsection{Quantification of isolated protein samples}

The protein concentration was measured using the Pierce BCA (bicinchoninic acid) protein assay kit according to the manufacturer's recommendations. Briefly, the proteins were quantified in technical triplicates by adding $1 \mu$ protein lysate to a well of a clear 96 well plate. Then, $200 \mu \mathrm{l}$ of freshly prepared substrate solution was added to each well and the plate was incubated at $37^{\circ} \mathrm{C}$ for $30 \mathrm{~min}$ to allow for the colorimetric reaction. A BSA dilution series in the respective lysis buffer was used to generate a standard curve. Absorbance was measured at $540 \mathrm{~nm}$ in a SynergyMx microplate photometer. The total protein concentration was calculated using the standard curve values.

\subsubsection{Western Blot}

For Western Blot analyses $20-45 \mu \mathrm{g}$ of protein lysate were dissolved in $20 \mu \mathrm{l}$ of ultrapure $\mathrm{H}_{2} \mathrm{O}$. SDS loading buffer was added and thereby diluted to a one fold concentration. The samples were denatured by boiling for $5 \mathrm{~min}$ at $96{ }^{\circ} \mathrm{C}$ and $500 \mathrm{rpm}$. After cooling on ice the samples were loaded onto appropriate SDS gels. The SDS gel electrophoresis was performed on ice.

\subsubsection{Semi-dry blotting}

Semi-dry blotting was used to detect smaller proteins with a maximal size of $100 \mathrm{kDa}$. For this purpose, proteins were separated on 4-12\% Bis-Tris gels using the MES SDS running buffer. The denaturated protein samples and an appropriate protein marker were loaded onto the gels and separated at $110-160 \mathrm{~V}$ and $160 \mathrm{~mA}$ for approximately $1.5 \mathrm{~h}$. The separated proteins were blotted onto a nitrocellulose (NC) membrane with $0.2 \mu \mathrm{m}$ pore size using semidry blotting buffer. The blotting itself was performed in a Trans-Blot® SD Semi-Dry Transfer Cell at $120 \mathrm{~mA}$ and $20 \mathrm{~V}$ for $1 \mathrm{~h} 25 \mathrm{~min}$. 


\subsubsection{Tank blotting}

The tank blotting was used to detect larger proteins. For this purpose, denaturated samples were loaded onto 3-8\% Tris-acetate gels. A high range protein marker was loaded to determine protein size. Separation by SDS gel electrophoresis was performed in Tris-acetate SDS running buffer at $100-110 \mathrm{~V}$ and $100 \mathrm{~mA}$ for approximately $2.5 \mathrm{~h}$. The separated proteins were blotted onto a NC membrane with $0.45 \mu \mathrm{m}$ pore size at $55 \mathrm{~V}$ and $300 \mathrm{~mA}$ for $2 \mathrm{~h} 35 \mathrm{~min}$ at $4{ }^{\circ} \mathrm{C}$ in a tank containing constantly stirred tank blotting buffer.

\subsubsection{Antigen detection and visualization}

After blotting, the membranes were blocked with $5 \%(\mathrm{w} / \mathrm{v})$ milk powder dissolved in TBST for $1 \mathrm{~h}$ at RT on a shaker. Afterwards the membranes were washed $3 \times 10 \mathrm{~min}$ with TBST. The blocked membranes were incubated with primary antibodies dissolved in BSA-azide (for dilutions compare Tab. 9) at $4^{\circ} \mathrm{C}$ on a roller overnight. The membranes were washed again $3 \times 10$ min with TBST. Then HRP-conjugated secondary antibodies were added in $5 \%(w / v)$ milk in TBST for $1 \mathrm{~h}$ at RT (see Tab. 10). After 3 washing steps with TBST, signals were detected using an enhanced chemiluminiescence reagent (ECL) in combination with the FluorChem $Q$ system. For this purpose, luminol and peroxidase substrate were mixed 1:1 directly before use. The membranes were covered with the solution and after a short incubation time excess ECL was removed. Picture acquisition and processing was done with AlphaView Q SA and Adobe Photoshop CS5 softwares.

\subsubsection{Stripping of membranes}

For detection of multiple proteins of a similar size on the same membrane, the antibodies were stripped off. For this purpose, the membranes were washed with TBST for $2 \times 10 \mathrm{~min}$ to remove the ECL reagent. The bound antibodies were stripped off by incubation of the membrane with stripping buffer at $55^{\circ} \mathrm{C}$ for 30 min under constant rotation. Afterwards the membranes were washed thoroughly at least 4 times for $10 \mathrm{~min}$ in TBST. Then the membranes were blocked again and incubated with new primary antibodies solutions (section 5.3.5.3).

\subsubsection{Ras pull-down activation assay}

The Ras activation assay was strictly performed according to the manufacturer's instructions.

\subsubsection{Cell culture samples}

Subconfluent cells grown on a $10 \mathrm{~cm}$ cell culture plate were washed twice with ice-cold PBS and scraped off the plate using $500 \mu \mathrm{l}$ of ice-cold PBS. The suspensions of 4 plates were pooled and centrifuged at 2,000 rpm and $4^{\circ} \mathrm{C}$ for $5 \mathrm{~min}$. The supernatants were discarded and cells were resuspended in $500 \mu \mathrm{l}$ of the provided ice-cold lysis buffer. The lyses were performed for $10 \mathrm{~min}$ on ice and samples were centrifuged at $10,000 \mathrm{rpm}$ and $4^{\circ} \mathrm{C}$ for $2 \mathrm{~min}$. 
For protein quantification and detection of total Ras protein $60 \mu$ of lysates were separated. The remaining cell lysates were immediately snap frozen in liquid nitrogen. Afterwards the protein concentrations were determined utilizing the BCA assay (see section 5.3.4).

As control, one sample was either loaded with GTPYS or GDP. For this purpose, $200 \mu \mathrm{g}$ of protein were mixed with one-tenth volume of loading buffer. Immediately one-hundredth volume of supplied GTPyS or GDP was added. The samples were incubated at $37^{\circ} \mathrm{C}$ for $30 \mathrm{~min}$ at $300 \mathrm{rpm}$ on a shaker. Afterwards, the samples were mixed with one-tenth volume of stop buffer and stored on ice until the pulldown assay was performed. These GTPYS- or GDP-loaded samples were used to prove an efficient pulldown of active Ras protein. Furthermore, the kit supplied a pure His-Ras control protein, which was diluted in $2 \times$ Laemmli buffer and water before use. This protein served as a size marker. Moreover, $30 \mu \mathrm{g}$ of total lysate of each analyzed sample was used to detect total Ras protein on a separate gel. These lysates were diluted in $20 \mu \mathrm{l}$ of ultrapure $\mathrm{H}_{2} \mathrm{O}$ and SDS loading buffer and seubjected to Western Blot analyses.

For the pulldown assay, $200 \mu \mathrm{g}$ of protein were loaded onto $100 \mu \mathrm{g}(30 \mu \mathrm{l})$ of Raf-RBD beads on platform shaker at $4{ }^{\circ} \mathrm{C}$ for $1 \mathrm{~h}$. Afterwards, the beads were pelleted by centrifugation at $10,000 \mathrm{rpm}$ at $4{ }^{\circ} \mathrm{C}$ for $2 \mathrm{~min}$. The supernatant was carefully discarded and the beads were washed with $500 \mu \mathrm{l}$ of supplied washing buffer and centrifuged again at $10,000 \mathrm{rpm}$ and $4{ }^{\circ} \mathrm{C}$ for $3 \mathrm{~min}$. The supernatant was discarded and the bead pellet was resuspended in $15 \mu \mathrm{l}$ of $2 \times$ Laemmli buffer. All prepared samples were boiled at $96^{\circ} \mathrm{C}$ and $400 \mathrm{rpm}$ for $3 \mathrm{~min}$ and then rapidly cooled down on ice. Afterwards, samples were loaded onto 4-12 \% Bis-Tris gels and semi-dry blotting was performed as described in section 5.3.5.1.

\subsubsection{Tissue samples}

Approximately $30 \mathrm{mg}$ of a frozen tissue sample was chopped in a petri dish on dry ice using a scalpel blade. The chopped tissue was transferred into a $2 \mathrm{ml}$ tube containing $200 \mu \mathrm{l}$ of cold lysis buffer. Tissue samples were homogenized on ice. The homogenates were clarified by centrifugation at $10,000 \mathrm{rpm}$ and $4{ }^{\circ} \mathrm{C}$ for $2 \mathrm{~min}$. The supernatants containing the protein lysates were transferred into new tubes and immediately snap frozen. The following steps were identical to the procedure described above (see section 5.3.6.1) with the exception that $600 \mu \mathrm{g}$ of protein were loaded onto $100 \mu \mathrm{g}(30 \mu \mathrm{l})$ of Raf-RBD beads.

\subsection{Immunohistochemical stainings}

Tissue samples were fixed in $4 \%$ (w/v) PFA in PBS for $24 \mathrm{~h}-48 \mathrm{~h}$ at RT and then transferred into cold PBS and stored at $4{ }^{\circ} \mathrm{C}$ until embedding. The paraffin embedding was performed by Anke Frommhold and in cooperation with the Institute of Neuropathology, University Medical Center Göttingen. 
The paraffin-embedded tissues were cut into 4-5 $\mu \mathrm{m}$ sections on a microtome. The sections were mounted onto microscope glass slides or superfrost glass slides and dried at $37^{\circ} \mathrm{C}$ overnight prior immunohistochemical stainings.

\subsubsection{Haematoxylin and eosin staining}

For haematoxylin and eosin (HE) staining, sections were deparaffinized 2 times in xylene for 10 min and then rehydrated by a descending ethanol series $(2 \times 99 \%, 96 \%, 80 \%$ and $70 \%$ ). After a thorough washing step under running $\mathrm{ddH}_{2} \mathrm{O}$, the slides were stained in hematoxylin solution for $20 \mathrm{~min}$. Afterwards, the slides were washed under running warm tap water until hematoxylin was completely washed out from the cuvette. Then the slides were incubated with $1 \%$ eosin solution for a maximum of $20 \mathrm{sec}$ and shortly washed under running $\mathrm{ddH}_{2} \mathrm{O}$. Immediately after washing, the sections were dehydrated using ascending ethanol solutions (70\%, $80 \%, 96 \%, 99 \%)$ and placed in fresh xylene twice in succession. Finally, the sections were mounted with Pertex and dried at least for $20 \mathrm{~min}$ at $55^{\circ} \mathrm{C}$.

\subsubsection{Ki67 staining}

For Ki67 staining the sections were deparaffinized 2 times in xylene for 10 min and were rehydrated by a descending ethanol series (2x $99 \%, 96 \%, 80 \%$ and $70 \%)$. After washing under running $d \mathrm{dH}_{2} \mathrm{O}$, antigen-retrieval was performed by cooking the slides in citric acid buffer ( $\mathrm{pH} 6$ ) once for $4 \mathrm{~min}$ and 3 times for $3 \mathrm{~min}$ at $600 \mathrm{~W}$ in a microwave oven. Afterwards, the slides were cooled down to RT while shaking. Then the slides were washed 2 times in TBS buffer. Blocking of endogenous peroxidase activity was performed for 20 min on a shaker by incubating the sections in $3 \% \mathrm{H}_{2} \mathrm{O}_{2}$ in TBS buffer. The slides were washed for 5 min with $\mathrm{ddH}_{2} \mathrm{O}$ and then placed in a moist chamber. A blocking against unspecific antibody binding was performed by adding $0.2 \%$ casein in TBS buffer onto the slides. The primary antibody against Ki67 was diluted 1:50 in TBS and $50 \mu$ of this solution were applied to each tissue section and incubated overnight at $4{ }^{\circ} \mathrm{C}$. Then the slides were washed 3 times with TBST and afterwards they were incubated with the HRP-conjugated secondary antibody from the Dako EnVision kit for 30 min within a moist chamber at RT. After washing with TBST the staining was visualized by incubation with AEC staining solution. Haematoxylin was used for counter staining. Then, the slides were mounted with glycergel.

The results were evaluated by counting the number of $\mathrm{Ki} 67^{+}$nuclei compared to the total number of nuclei. For this purpose, the staining was documented by 6 or 10 consecutive pictures of randomly chosen areas within the tumor tissue. The pictures were taken at $200 \times$ magnification with the CellSens Dimension software and total number of nuclei, as well as Ki $67^{+}$nuclei were counted manually using AlphaView Q SA software. 


\subsubsection{X-Gal staining}

For X-Gal staining, the tissue samples were embedded in cryoblock media. For this purpose, freshly isolated tissue was fixed in $4 \%$ PFA on ice for $2 \mathrm{~h}$. Afterwards the tissue samples were washed 3 times with PBS for 20 min while shaking. The fixed tissues were equilibrated overnight in $25 \%(\mathrm{w} / \mathrm{v})$ sucrose in PBS at $4{ }^{\circ} \mathrm{C}$. The next day, the tissue samples were embedded in cryoblock media on dry ice and cut into thin sections at $-20^{\circ} \mathrm{C}$ to $-22^{\circ} \mathrm{C}$ using a cryotome. The sections were mounted onto superfrost glass slides and were dried at RT for at least $2 \mathrm{~h}$. The dried sections were incubated for $10 \mathrm{~min}$ with $0.2 \%(\mathrm{v} / \mathrm{v})$ glutaraldehyd in PBS on ice. Afterwards, the sections were washed 3 times with LacZ buffer (see Tab. 4) for 5 min on a shaker. Subsequently the sections were incubated with LacZ staining solution (see Tab. 4) at $30^{\circ} \mathrm{C}$ overnight. If necessary, the staining solution was renewed after $24 \mathrm{~h}$ to enhance the signal intensity. The reactions were stopped by washing with PBS. Finally, the sections were mounted with mounting medium containing DAPI. Then pictures were taken at 600 x magnification using a Color View camera operated by CellSens software.

\subsection{Animal experiments}

All animal experiments were performed after approval of the Lower Saxony State Office for Consumer Protection and Food Safety and in accordance with all relevant ethical and legal requirements. Housing and breeding of animals was performed within the animal facility at the Institute of Human Genetics, University Medical Center Göttingen. In general, mice were housed at a $12 \mathrm{~h}$ light-dark cycle at $20 \pm 2{ }^{\circ} \mathrm{C}$ and a relative humidity of $55 \pm 10 \%$ in individually ventilated Makrolon type 2 cages located in air-flow racks. Health checks were performed daily by animal caretakers. Mice received tap water and food pellets ad libitum. All used mouse lines are listed in Tab. 15.

\subsubsection{Tumor xenografts}

Immunodeficient $\mathrm{Nu} / \mathrm{Nu}$ mice were used for transplantation studies and were purchased from Charles River Laboratories (Wilmington, USA). These mice were housed in autoclaved and individually ventilated type 2 cages and received sterilized food pellets as well as autoclaved water ad libitum. Genotypes of $\mathrm{Nu} / \mathrm{Nu}$ mice were determined by the presence $(\mathrm{Nu} /+)$ or absence $(\mathrm{Nu} / \mathrm{Nu})$ of hairs.

For analyses of the in vivo growth behavior of oncRAS-expressing ERMS cell lines, cells harboring the control vector or cells expressing oncRAS were transplanted subcutaneously into the left and right flank of one $\mathrm{Nu} / \mathrm{Nu}$ mouse, respectively. For the transplantation experiments animals of both genders at an age between 8 and 11 weeks were used.

Ahead of transplantation ERMS cell lines were grown in cell culture to $90 \%$ confluence. One day before transplantation the cells were split 1:3 to ensure exponential growth. On the day of transplantation cells were collected and counted (compare sections 5.1.1 and 5.1.3). 
Then, $2 \times 10^{6}$ TE617.T cells in PBS or $9 \times 10^{6} \mathrm{RUCH}-2$ cells in 1:1 Matrigel:PBS in a total volume of $200 \mu \mathrm{l}$ were transferred into pre-cooled Sub-Q syringes and kept on ice. Mice were anesthetized with 1-3\% isoflurane in a 1:1 air/oxygen mix. Then the cells were injected subcutaneously. After transplantation mice were carefully monitored and tumor size was measured every second or every day by a caliper. The tumor volume was calculated by assuming an ellipsoid shape using de formula:

$$
\text { Tumor volume }=\frac{\text { tumor width } \mathrm{x} \text { height } \mathrm{x} \text { length }}{2}
$$

Mice were sacrificed when a tumor reached a diameter of $1.5 \mathrm{~cm}$ or latest 55 days after transplantation. The tumors were isolated, their exact size and weight was documented and then they were fixed in $4 \%$ PFA in PBS. If possible, parts of the tumor tissue were frozen on dry ice and stored at $-80^{\circ} \mathrm{C}$ for further experiments.

Transplantation and tumor monitoring of TE617.T KRAS xenografts was part of the doctoral thesis of $\mathrm{N}$. Cuvelier ${ }^{299}$.

\subsubsection{Breeding of mice}

For ERMS monitoring studies Ptch ${ }^{\text {del/ }}$ Balb mice were used. These mice harbor a heterozygous deletion of exon 8 and 9 within the Ptch gene and spontaneously develop RMS, which resembles human ERMS ${ }^{137,143}$. These mice were bred to conditional HRasflox_B6 ${ }^{303}$, KRasflox_B6 ${ }^{317}$ or NRasflox_B6 ${ }^{220}$ mice. The latter mice are heterozygous for a floxed oncogenic Ras allele that is expressed upon Cre-mediated recombination. The resulting Ptch ${ }^{\text {del/+ }}$ oncRas ${ }^{f /+}$ offspring were crossed to Myf5 $5^{\mathrm{CreER} /+}$ mice ${ }^{305}$. Since, as in humans, RMS of Ptch ${ }^{\text {del/ }}$ Balb mice express high levels of Myf5 ${ }^{143,323}$, activation of the Cre recombinase in this model should result in expression of oncogenic Ras isoforms in the tumors. An overview of the breeding is displayed below (Fig. 6).

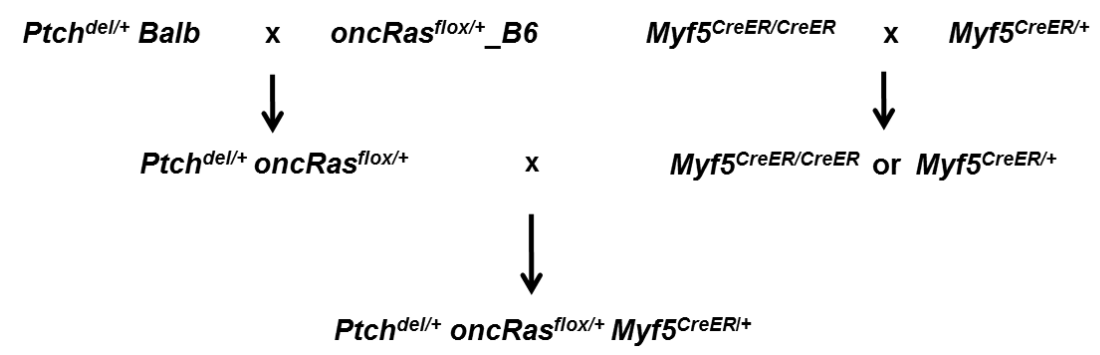

Figure 6: Breeding scheme for tumor monitoring studies

Overview of breeding strategies for generating and maintaining colonies of Ptch ${ }^{\mathrm{del} /+}$ oncRas ${ }^{\mathrm{fl} /+} \mathrm{Myf5} \mathrm{CreER}^{\mathrm{mice}}$. For details, see text.

When analyzing potential oncRas-dependent effects on ERMS precursor lesions the parental $M y f 5^{\mathrm{CreER} /+}$ mice were on a mixed C57BL/6 $\times$ BALB/c background, whereas those used for the analyses of oncRas-dependent effects in established ERMS were incipient-congenic and had been backcrossed 8 generations to BALB/c. Backcrossing had been done because the BALB/c background confers high susceptibility to ERMS ${ }^{324,325}$. 


\subsubsection{Identification of mice}

Mice were weaned at the age of 3 weeks and were numbered by ear clipping. Younger mice, which still were not weaned, were labeled by a tattoo code on their paws. At the same time tail tip biopsies were taken and were used for genotyping of the respective mice (see section 5.2.3.1).

\subsubsection{Tamoxifen application}

To induce recombination of the floxed Ras loci in Ptch $^{\text {del/+}}$ oncRas ${ }^{f /+} M y f 5^{C r e E R /+}$ mice $1 \mathrm{mg}$ of tamoxifen in $100 \mu \mathrm{l}$ solvent was injected intraperitoneally (i.p.) for 5 consecutive days resulting in a total dose of $5 \mathrm{mg}$ tamoxifen per mouse. Tamoxifen was prepared by mixing $200 \mathrm{mg}$ tamoxifen with $20 \mathrm{ml}$ Sunflower seed oil and $800 \mu \mathrm{l}$ pure $\mathrm{EtOH}$. The solution without tamoxifen served as solvent control. The solutions were aliquoted into syringes and frozen at $-20^{\circ} \mathrm{C}$ until use.

\subsubsection{Tissue isolation}

Mice were euthanized by $\mathrm{CO}_{2}$ or isoflurane narcosis and subsequent cervical dislocation. All tumors, skeletal muscles from the leg and back, cysts or suspicious tissues were taken and washed with PBS. If possible, tumors were weighed and measured using a caliper. Tumor tissue, cysts and suspicious tissues were fixed in $4 \%$ PFA in PBS and were embedded in paraffin for immunohistochemical stainings (see section 5.4). The skeletal muscles and parts of the tumor samples were frozen on dry ice or snap frozen in liquid nitrogen and stored at $-80{ }^{\circ} \mathrm{C}$ for protein and gene expression analyses.

\subsubsection{Testing of the Myf5 ${ }^{\mathrm{CreER} /+}$ deleter}

To check the activity of the Myf5 ${ }^{\mathrm{CreER} /+}$ deleter in ERMS, Ptch ${ }^{\mathrm{del} /+} M y f 5^{\mathrm{CreER} /+} R 26 \mathrm{R}^{+/-}$reporter mice were generated ${ }^{299}$. Tumor bearing mice were injected with $1 \mathrm{mg}$ tamoxifen on 5 consecutive days and sacrificed 1 or 5 weeks thereafter. X-Gal stainings were performed on frozen sections of brain, heart, intestine, skeletal muscle and ERMS as described in section 2.4.3.

\subsubsection{Tumor monitoring: induction of oncRas in ERMS precursor lesions}

At the age of 4 weeks mice were injected with $1 \mathrm{mg}$. of tamoxifen i.p for 5 consecutive days to induce cre-mediated recombination at the respective Ras loci. Mice were monitored once a week for palpable tumors and were visually controlled for other abnormalities until the age of 200 days. The appearance of palpable tumors was recorded. Animals with poor general condition or those carrying tumors exceeding a size of $1.5 \mathrm{~cm}$ were sacrificed. Tissue was isolated as described in section 5.5.5. An overview of the study design is shown in Fig. 7. 
Tamoxifen

application

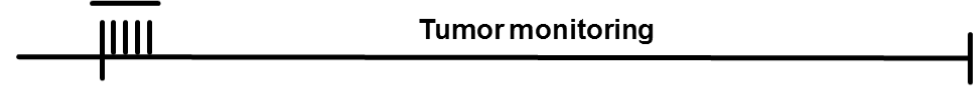

Age of 4 weeks

Age of 200 days

Figure 7: Study design focusing on induction of Ras mutations in ERMS precursor lesions

Ptch $^{\text {del/t+ }}$ or Ptch ${ }^{\text {del/t }}$ oncRas ${ }^{\text {tl/t }}$ Myf5 $^{\text {CreER/t }}$ mice at the age of 4 weeks were injected with tamoxifen for 5 consecutive days or left untreated. Afterwards mice were monitored weekly until the age of 200 days. For details, see text.

The studies were performed using tamoxifen-treated $\operatorname{Ptch}^{\text {del/+}} H_{R a s} f / /+M y f 5^{C r e E R /+}$,

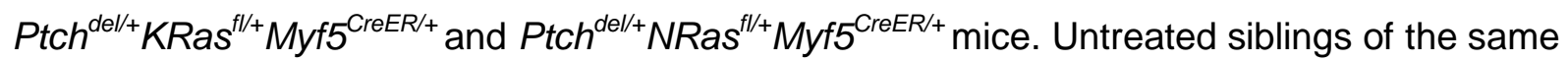
genotype served as control. In order to analyze the effect of tamoxifen itself on tumor growth, ERMS-growth of tamoxifen- and untreated $\mathrm{Ptch}^{\text {del/+ }}$ mice from the same breeding were used. Part of these experiments have been done by N. Cuvelier and are described in her doctoral thesis ${ }^{299}$. Here, the already generated data were re-analyzed and the collected material was used for further analyses. Thus, the genotypes of each mouse were verified by a second round of genotyping PCR (see section 5.2.3.1). For this purpose, frozen and embedded tissue samples were used. In addition, recombination assays were performed using frozen or embedded samples from skeletal muscle and ERMS (see section 5.2.2). Finally, the study using $\mathrm{PtCh}^{\mathrm{del} /+} \mathrm{NRas}{ }^{\mathrm{fl} /+} \mathrm{Myf5} 5^{\mathrm{CreER} /+}$ mice was completely repeated.

\subsubsection{Tumor monitoring: induction of oncRas in already established ERMS}

After weaning, mice were monitored once a week for palpable ERMS and were visually controlled for other abnormalities. Tumors occurred mainly at the extremities and the lower back and were observed until they reached a diameter of approximately $0.5 \mathrm{~cm}$. Then the mice were subjected to micro computed tomography $(\mu \mathrm{CT})$ measurement to determine the exact tumor volume (see section 5.5.9). Afterwards the mice were injected with $1 \mathrm{mg}$ of tamoxifen for 5 consecutive days to induce the cre-mediated recombination at the Ras loci. After tamoxifen induction the mice were further monitored for changes in ERMS growth and general health conditions. Seven weeks after onset of the tamoxifen treatment, the mice underwent a second $\mu \mathrm{CT}$ measurement, which was defined as the end point of the study. Animals were euthanized, and tissue samples were taken as described in section 5.5.5. An overview of the study design is shown in Fig. 8.

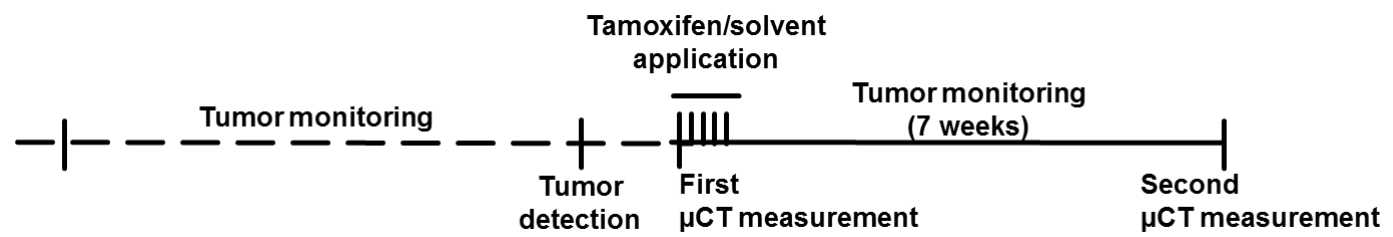

Figure 8: Study design focusing on induction of Ras mutations in established ERMS

After weaning, Ptch ${ }^{\text {del/+ }}$ or Ptch ${ }^{\text {del/+ }}$ oncRas ${ }^{f / /} \mathrm{Myf5}^{\mathrm{CreER/+}}$ mice were monitored for palpable tumors. After tumor detection, mice were subjected to micro computed tomography $(\mu \mathrm{CT})$ measurement and were injected with tamoxifen or solvent for 5 consecutive days. The mice were monitored for further 7 weeks and then subjected to a second $\mu \mathrm{CT}$ measurement. For more details, see text. 
The study was performed with $\mathrm{Ptch}^{\mathrm{del/}+} \mathrm{HRas}^{\mathrm{fl/}+} \mathrm{Myf5}^{\mathrm{CreER} /+}, \mathrm{Ptch}^{\mathrm{del/}+} \mathrm{KRas}^{\mathrm{fl/}+} \mathrm{Myf5} 5^{\mathrm{CreER} /+}$ and Ptch $^{\text {del/ }}$ NRas ${ }^{f / /} M y f 5^{C r e E R /+}$ mice. Mice were injected with $1 \mathrm{mg}$ of tamoxifen i.p. for 5 consecutive days to induce cre-mediated recombination or with solvent as a control. In addition, tamoxifen-treated or solvent-treated $\mathrm{Ptch}^{\text {del/ }}$ siblings from each breeding cohort served as controls.

\subsubsection{Tumor volume measurement by $\mu \mathrm{CT}$}

A low dose in vivo $\mu \mathrm{CT}$ (QuantumFX) was used to measure the tumor volume in living animals. The data acquisition was performed at $90 \mathrm{kVp}$ tube voltage, $200 \mu \mathrm{A}$ tube current and with 2 min total acquisition time. Mice were anesthetized with 1-3\% isoflurane in a 1:1 air/oxygen mix. Then the contrast agent Imeron $300(5 \mathrm{ml} / \mathrm{kg})$ was injected intravenously (i.v.) into the tail vain or into the retro-bulbar venous plexus. Approximately $30 \mathrm{sec}$ later, the imaging was performed. Data sets were reconstructed with a voxel size of $80 \mu \mathrm{m}$ and analyzed. Size of each tumor (precisely tumor width, height and length) at onset and end of the study was determined using simple viewer software.

The tumor volume was calculated by assuming an ellipsoid shape using the formula:

$$
\text { Tumor volume }=\frac{\text { tumor width } \mathrm{x} \text { height } \mathrm{x} \text { length }}{2}
$$

For data evaluation logarithmic values of the calculated tumor volume were plotted.

\subsection{Statistical analyses}

Statistical analyses were performed with MS Office Excel or GraphPad Prism 6 software. Data were considered significant when probability values ( $p$-values) were $<0.05$. Comparison of 2 samples or 2 groups was done by unpaired, non-parametric t-test (Mann Whitney) or Student's t-test. In order to compare more than 2 groups a one-way analysis of variance (ANOVA) and Dunn's multiple comparisons test were performed. Differences in ERMS-free survival were tested by Log-rank (Mantel-Cox) test and tumor latency time was tested by Gehan-Breslow-Wilcoxon test. Differences in tumor incidence and multiplicity were tested by Chi-square test. If not indicated otherwise graphs represent mean + standard error of the mean (SEM) values. Statistical significant results were visualized in graphs by * or $\$$ ( $p$-values $<0.05) ;{ }^{* *}$ or $\$ \$$ (p-values $\left.<0.01\right){ }^{* * *}$ or $\$ \$(p$-values $<0.001)$ and ${ }^{* * * *}$ or $\$ \$ \$ \$$ (p-values $<0.0001)$. 


\section{Results}

\subsection{Effects of oncogenic RAS mutations on human ERMS cell lines}

Previous studies indicated a crosstalk of RAS and $\mathrm{HH}$ signaling in human RMS cell lines, whereby the interaction of the signaling pathways seemed to be differently regulated in cell lines of the embryonal and alveolar subtype. The studies showed that oncRAS isoforms can suppress the expression of the main $\mathrm{HH}$ target GLI1 in a MEK-dependent manner at least in the ERMS cell line RUCH-2 ${ }^{299}$.

In this work some of the already performed experiments were repeated and the role of oncRAS isoforms in regulation of $\mathrm{HH}$ targets and associated cellular responses of ERMS cells were analyzed in more depth. For this purpose, ERMS cell lines, originally wt for RAS, were stably transduced with different plasmids expressing oncogenic HRAS, KRAS or NRAS (collectively named oncRAS) isoforms (see section 5.1.4). Stably transduced cell lines with the empty plasmid (pMSCV) served as controls. In addition, experiments were performed with the human ERMS cell line RD, which harbors a NRAS ${ }^{\text {661H }}$ mutation ${ }^{312,326}$.

All described experiments within section 6.1 were also performed with untransduced (wt) cells. These experiments served as control for potential vector-dependent effects. Since no significant differences between wt cells and cells transduced with pMSCV were detected, the respective data were not included into the graphs of this thesis.

\subsubsection{Characterization of stably transduced RMS cell lines with oncRAS isoforms}

Ahead of all experiments, the stably transduced TE617.T, RUCH-2 and RMS-13 cell lines were analyzed to confirm successful transduction. In order to further characterize the cell lines, the impact of oncRAS isoforms on phosphorylation of downstream kinases, relative RAS activity and cell cycle distribution were analyzed.

\subsubsection{Successful transduction of human RMS cell lines}

The successful transduction of human RMS cell lines with the plasmids pMSCVpuro (pMSCV), pMSCVpuro-HRAS ${ }^{G 12 V}$ (oncHRAS), pMSCVpuro-KRAS G12V (oncKRAS) or pMSCVpuro-NRAS ${ }^{G 12 V}$ (oncNRAS) was examined by PCR (see section 5.1.4.1). For this purpose, cDNAs from the stably transduced cell lines were analyzed with a common forward primer within the pMSCVpuro sequence and with 3 reverse primers specific for the transcribed oncRAS isoform (Fig. 9). All cell lines were screened using all primers to rule out potential contamination.

Successful transduction with vectors for pMSCV, oncHRAS, oncKRAS or oncNRAS was confirmed for the RMS-13 and RUCH-2 cell lines (Fig. 9B and Fig. 9C). The TE617.T cell line 
(Fig. 9A) had been successfully transduced with oncKRAS. Unfortunately, oncHRAS and oncNRAS were expressed in one and the same TE617.T line probably due to a mix-up of the plasmids or a cross contamination of the cells during production. The PCR was also done on the pure single plasmids or on a mixture of all plasmids, which served as positive control (Fig. 9D).

A

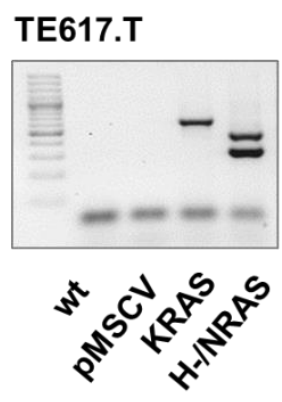

B RUCH-2

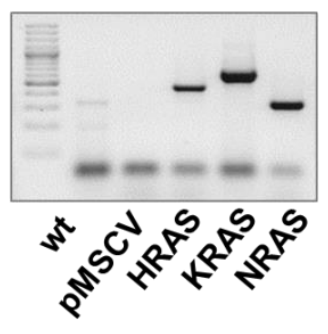

C

RMS-13

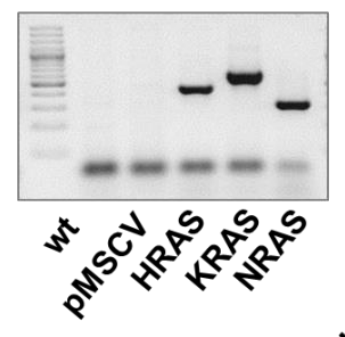

D

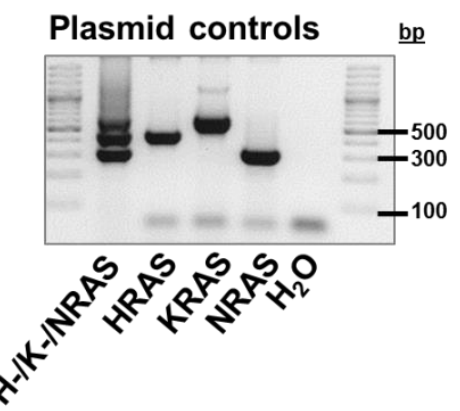

Figure 9: Successful transduction of RMS cell lines

RNA was isolated from TE617.T (A), RUCH-2 (B) and RMS-13 (C) cell lines, that have been stably transduced with the empty plasmid (pMSCV) or plasmids expressing oncHRAS (HRAS), oncKRAS (KRAS), oncNRAS (NRAS), or remained untransduced (wt). RNA were subjected to CDNA synthesis and analyzed by PCR with a common forward primer and isoform-specific reverse primers. Amplificates were separated by agarose gel electrophoreses and analyzed. Single plasmids or a mixture of the plasmids (100 ng/reaction) served as positive control (D). H-/NRAS indicate expression of oncHRAS and oncNRAS in one and the same cell line.

\subsubsection{Transduction of RMS cell lines with oncRAS isoforms results in elevated protein level of RAS and pERK}

Next, the stably transduced cell lines were analyzed by Western Blot for the general expression level of RAS proteins (pan-RAS), for the expression and activation of downstream kinases of RAS, which are pERK/ERK, pAKT/AKT, pS6/S6, and for caspase 3 cleavage to investigate apoptosis induction. Representative results for TE617.T cells (Fig. 10A), RUCH-2 cells (Fig. 10B) and RMS-13 cells (Fig. 10C) are shown.

In general, the level of RAS proteins were higher in all cell lines after transduction with any oncRAS isoform. Transduction with oncKRAS resulted in a protein double band, because $K R A S^{G 12 V}$ expressed by the pMSCVpuro-KRAS ${ }^{G 12 V}$ plasmid contains a Hemagglutinin (HA)tag sequence ${ }^{299}$. The transduction with oncRAS isoforms did not influence the protein level of pAKT/AKT and pS6/S6. It also did not influence caspase 3 cleavage, which was investigated as a readout for apoptosis. In contrast, pERK protein level were elevated in oncRAS-expressing RUCH-2 and RMS-13 cell lines. The exceptions were the oncRAStransduced TE617.T cell lines and RUCH-2 KRAS cells, which did not show elevated level of ERK phosphorylation in comparison to pMSCV control cells. 
A

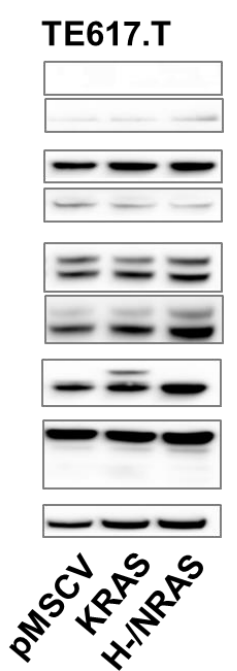

B

$$
\text { RUCH-2 }
$$

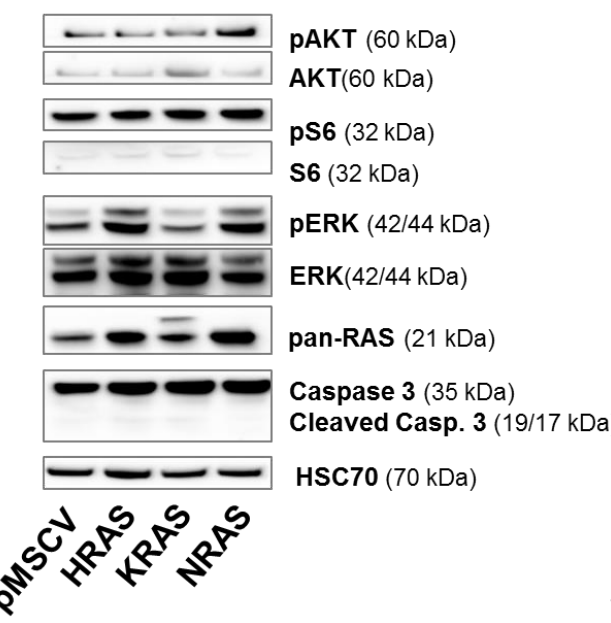

C

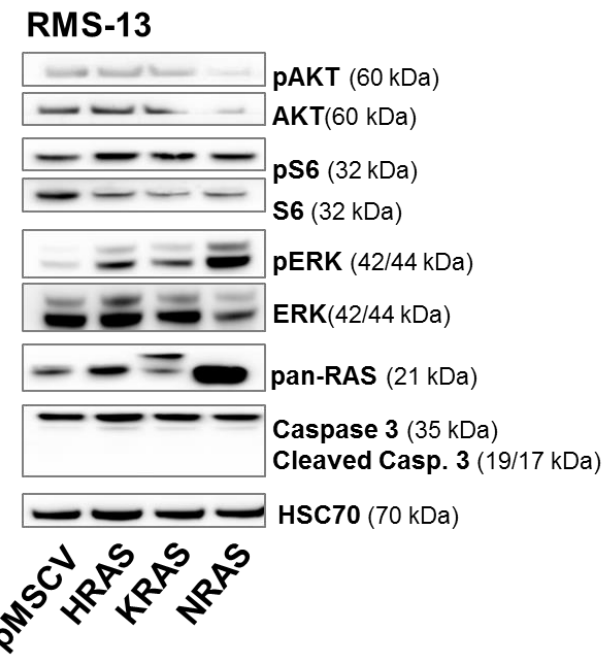

Figure 10: Characterization of protein expression of transduced RMS cell lines

Protein was isolated from TE617.T (A), RUCH-2 (B) and RMS-13 (C) cell lines, that have been stably transduced with the empty plasmid (pMSCV) or plasmids expressing oncHRAS (HRAS), oncKRAS (KRAS), oncNRAS (NRAS) or a mixture of oncHRas and oncNRAS (H-/NRAS). Western Blot analyses were done to detect the protein level of pAKT/AKT, pS6/S6, pERK/ERK, pan-RAS and caspase 3 cleavage (Caspase 3 and cleaved Casp. 3) with specific antibodies. HSC70 served as loading control. Protein names and sizes in $\mathrm{kDa}$ are displayed on the right side of the blots. The blots are representative for 2 independent experiments.

\subsubsection{OncRAS isoforms are active in transduced RMS cell lines}

Since not all cell lines showed phosphorylation of the RAS-downstream target ERK (see above), RAS activity in the cells was also investigated in an RAS activity assay (for experimental procedure compare section 5.3.6).

The analysis revealed that RAS activity was higher in all oncRAS-transduced cell lines in comparison to cell lines that have been transduced with the control vector. A densitometrical quantification (histograms in Fig. 11) indicated a 16-fold or 12-fold upregulation of RAS activity in TE617.T cells expressing oncKRAS or oncH-/NRAS, respectively, in comparison to cells harboring the pMSCV vector (Fig. 11A). For RUCH-2 cells a 2.5-fold (oncHRAS), 2.3fold (oncKRAS) or 1.8-fold (oncNRAS) increase of RAS activity was measured after stable transduction with oncRAS isoforms (Fig. 11B). In the ARMS cell line RMS-13, stable transduction with oncRAS isoforms increased RAS activity approximately 4.7-fold (oncHRAS) 8.8-fold (oncKRAS) or 8.4-fold (oncNRAS) in comparison to RMS-13 pMSCV cells (Fig. 11C). 
A

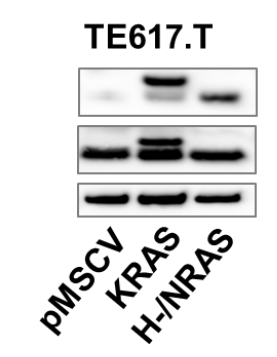

TE617.T

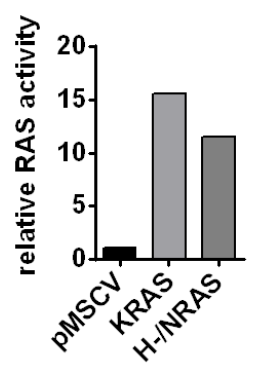

B

RUCH-2

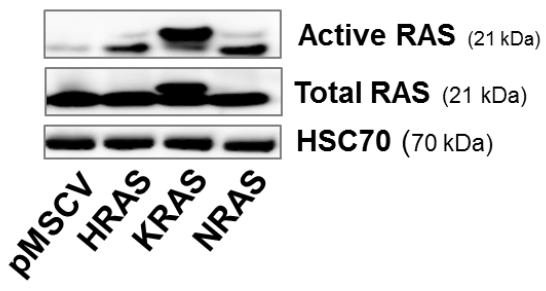

C

RMS-13

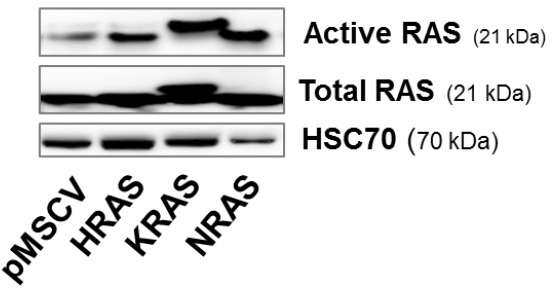

RMS-13

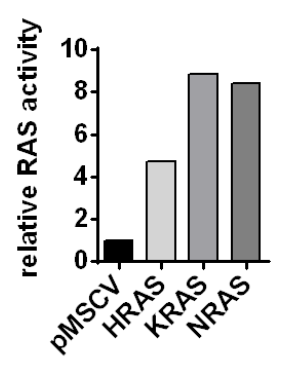

Figure 11: RAS activity assay of transduced RMS cell lines

Protein was isolated from TE617.T (A), RUCH-2 (B) and RMS-13 (C) cell lines, that have been stably transduced with the empty plasmid (pMSCV) or plasmids expressing oncHRAS (HRAS), oncKRAS (KRAS), oncNRAS (NRAS) or a mixture of oncHRas and oncNRAS (H-/NRAS). Afterwards cell lysates were subjected to a beadbased pull-down assay to precipitate active RAS. Whole lysates of the same cells were used to detect total RAS. Afterwards precipitated and not-precipitated lysates were analyzed by Western Blot to detect the protein level of active RAS and total RAS with specific antibodies. HSC70 served as loading control for total RAS. Protein names and sizes in $\mathrm{kDa}$ are displayed on the right side of the blots. The relative RAS activity was calculated by normalization of active RAS to total RAS/HSC70 and is displayed in histograms below the representative Western Blots. The results are representative for 1 or 2 independent experiments.

\subsubsection{OncRAS isoforms do not influence cell cycle distributions of RMS cell lines}

OncRAS isoforms are well-established modulators of cell cycle progression ${ }^{183}$. In order to investigate whether oncRAS modulate the cell cycle distribution of the stably transduced RMS cell lines, the cells were stained with PI and analyzed by flow cytometry $48 \mathrm{~h}$ after seeding (see section 5.1.7). An analysis of stably transduced RUCH-2 cell lines was not performed, because it was not possible to detach these cells with accutase.

OncRAS isoforms did not change cell cycle distribution in TE617.T cells (Fig. 12A). Thus, approximately $28.3 \%$ (pMSCV), $25.3 \%$ (oncKRAS) or $33.9 \%$ (oncH-/NRAS) of TE617.T cells were in G1/G0 phase, whereas $4.8 \%$ (pMSCV), $6.5 \%$ (oncKRAS) or $4.0 \%$ (oncH/NRAS) were in S phase and $17.6 \%$ (pMSCV), $17.9 \%$ (oncKRAS) or $22.4 \%$ (oncH-/NRAS) were in G2/M phase. In the same experimental setup oncRAS isoforms did not change the cell cycle distribution of RMS-13 cells (Fig. 12B). Thus, approximately $37.9 \%$ (pMSCV), $33.9 \%$ (oncHRAS), $34 \%$ (oncKRAS) or $35.8 \%$ (oncNRAS) of RMS-13 cells were in G1/G0 phase, whereas $6.9 \%$ (pMSCV), $7.8 \%$ (oncHRAS), $7.8 \%$ (oncKRAS) or $5.5 \%$ (oncNRAS) were in S phase and $27.9 \%$ (pMSCV), $32.1 \%$ (oncHRAS), $35.2 \%$ (oncKRAS) or $24.5 \%$ (oncNRAS) were in G2/M phase.

Taken together, there might be a difference in cell cycle distribution between TE617.T and RMS-13 cell lines. However, oncRAS isoforms do not influence cell cycle progression. 
A

TE617.T

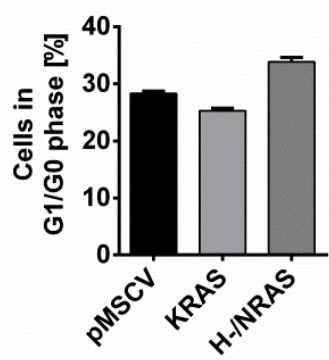

TE617.T

TE617.T

B
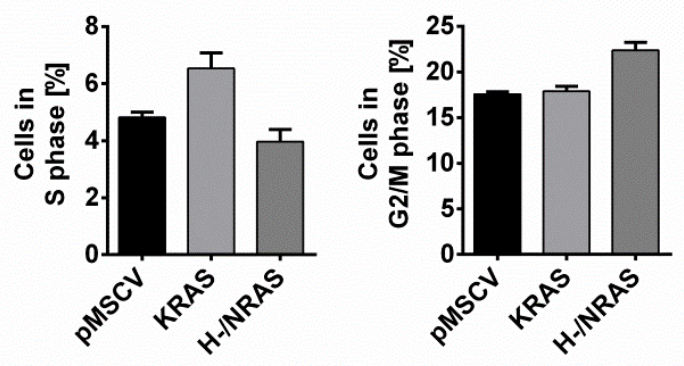

RMS-13

RMS-13
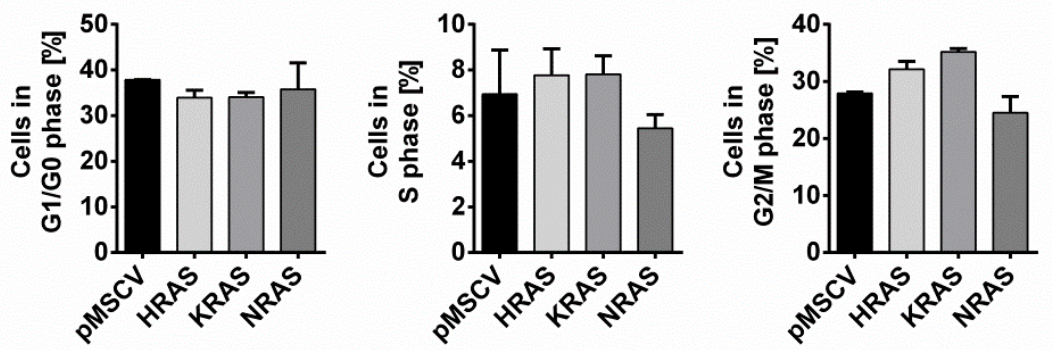

Figure 12: OncRAS isoforms do not influence cell cycle distribution of TE617.T and RMS-13 cells

TE617.T (A) and RMS-13 (B) cell lines that have been stably transduced with the empty plasmid (pMSCV) or plasmids expressing oncHRAS (HRAS), oncKRAS (KRAS), oncNRAS (NRAS) or a mixture of oncHRas and oncNRAS (H-/NRAS) were subjected to cell cycle analyses $48 \mathrm{~h}$ after seeding. Cells were detached, fixed and stained with PI. Cell cycle distribution was analyzed by flow cytometry and the relative amounts of cells resident in G1/G0 phase, S phase and G2/M phase were calculated. Bars represent the mean + SEM of 3 independent experiments performed in technical duplicates. For statistical analyses non-parametric t-tests (Mann Whitney) were performed.

In summary, the data presented in chapter 6.1 demonstrate that the human ERMS cell lines TE617.T and RUCH-2 and the human ARMS cell line RMS-13 express oncRAS isoforms after transduction with respective constructs. The activity of oncRAS isoforms in the cells was demonstrated by phosphorylation of the RAS-downstream kinase ERK and/or by a RAS activity assay. However, oncRAS isoforms apparently do not induce apoptosis as measured by caspase 3 cleavage in Western Blots. They also do not alter the cell cycle distribution of the cells. Moreover, no obvious morphological changes of the cells were detected microscopically (data not shown).

\subsubsection{OncRAS isoforms modulate mRNA expression of HH signaling pathway members}

\subsubsection{OncRAS isoforms downregulate GLI1 expression in RMS cell lines}

Previous studies revealed an oncRAS-dependent downregulation of GLI1 transcription in RUCH-2 and RMS-13 cell lines ${ }^{299}$. Here, the expression of the $\mathrm{HH}$ target GLI1 was measured in stably transduced TE617.T. The measurement was also repeated in RUCH-2 and RMS-13 cell lines. Additionally, the HH-responsive medulloblastoma cell line Daoy ${ }^{327}$, stably transduced with oncRAS-expressing plasmids, was analyzed for GL/1 expression. GLI1 was chosen as readout, because it is considered to be the most reliable marker for $\mathrm{HH}$ signaling activity ${ }^{69}$. For qRT-PCR analyses, $18 S$ rRNA and HPRT were chosen as suitable 
reference genes ${ }^{328}$. The data confirmed that oncRAS decrease GLI1 mRNA expression irrespective of the RMS subtype and the RAS isoform (see Fig. 13A for ERMS and Fig. 13B for ARMS cell lines) ${ }^{299}$. In contrast, oncRAS had no significant effect on GL/1 mRNA level in Daoy cells (Fig. 13C). This indicates that oncRAS-mediated GLI1 downregulation may be specific for RMS cell lines.

A

TE617.T

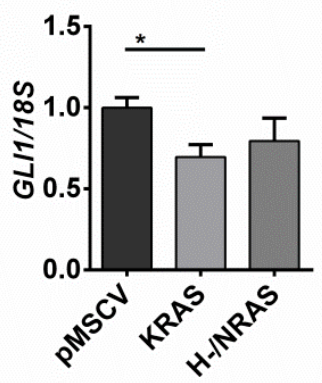

TE617.T

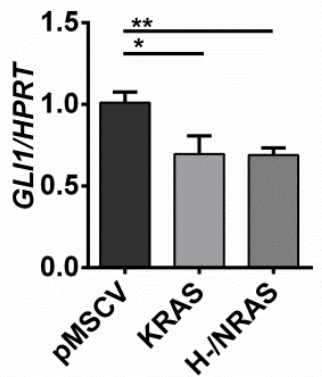

ERMS cell lines

RUCH-2

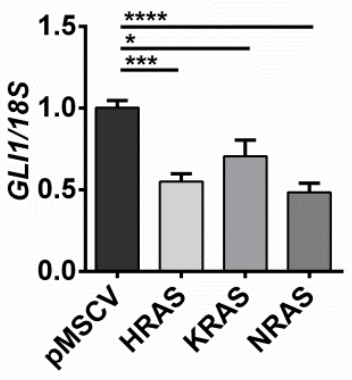

RUCH-2

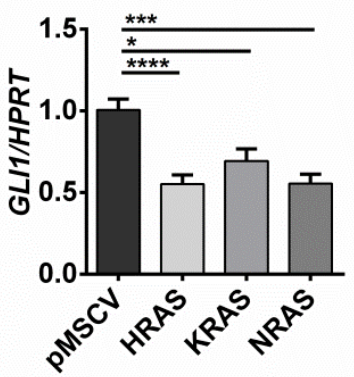

B ARMS cell line

RMS-13

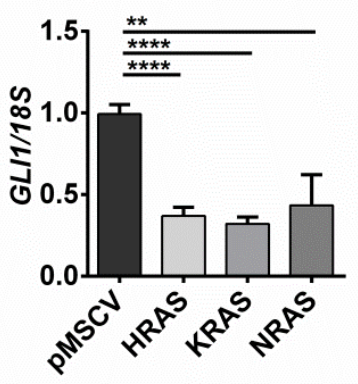

RMS-13

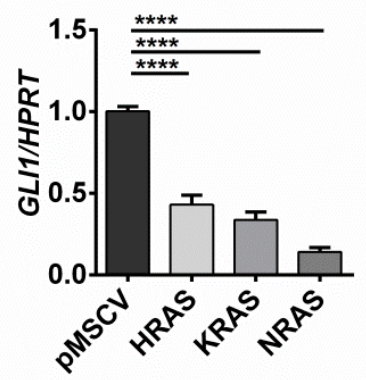

C MB cell line

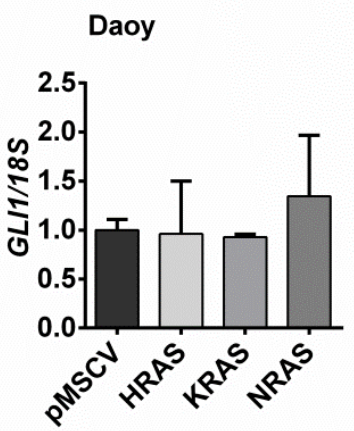

Daoy

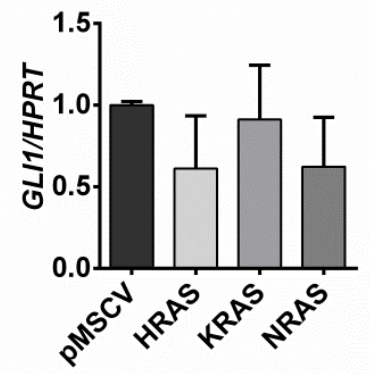

Figure 13: OncRAS isoforms downregulate relative GLI1 expression in RMS cell lines

The ERMS cell lines TE617.T and RUCH-2 (A), the ARMS cell line RMS-13 (B) and the Medulloblastoma (MB) cell line Daoy (C) stably transduced with the pMSCV control vector or oncRAS isoforms (HRAS, KRAS, NRAS, H/NRAS) were subjected to RNA isolation, CDNA synthesis and subsequent qRT-PCR analyses of the HH target gene GLI1. The expression data were normalized to 18S rRNA (18S, upper row) and HPRT (lower row) and are shown as fold expression to respective pMSCV control cells that were set to 1. Bars represent the mean + SEM of 1 (Daoy), 3 (RUCH-2) or 4 (TE617.T, RMS-13) independent experiments performed in technical triplicates. For statistical analyses a non-parametric t-test (Mann Whitney) was performed. ${ }^{*} p<0.05,{ }^{* *} p<0.01,{ }^{* * *} p<0.001$, ${ }^{* * *} p<0.0001$ compared to expression level of pMSCV control cells.

\subsubsection{Different oncRAS isoforms modify gene expression of GLI3 and SHH in ERMS cells}

In the following the focus is on the ERMS cell lines TE617.T and RUCH-2 stably transduced with oncRAS isoforms. After oncRAS-dependent downregulation of GL/1 has been confirmed in these cell lines (see Fig. 13), the expression of other genes of the $\mathrm{HH}$ signaling pathway, namely GLI2, GLI3, PTCH1 (in the following named PTCH), HHIP and SHH, was analyzed.

TE617.T cells expressing oncKRAS showed a moderate downregulation of the $\mathrm{HH}$ signaling activator GLI2 and the $\mathrm{HH}$ ligand SHH in comparison to pMSCV control cells. In contrast, oncNRAS downregulated the $\mathrm{HH}$ signaling inhibitor GL/3 and the $\mathrm{HH}$ ligand receptor $P T C H$ 
in comparison to pMSCV cells. The effects on GLI2 and PTCH level were dependent on the reference gene used and were consequently considered as a trend in regulation. Relative gene expression of the $\mathrm{HH}$ signaling inhibitor protein HHIP was not significantly (n.s.) influenced by the oncRAS mutations (Fig. 14).

\section{TE617.T cell lines}

GLI2
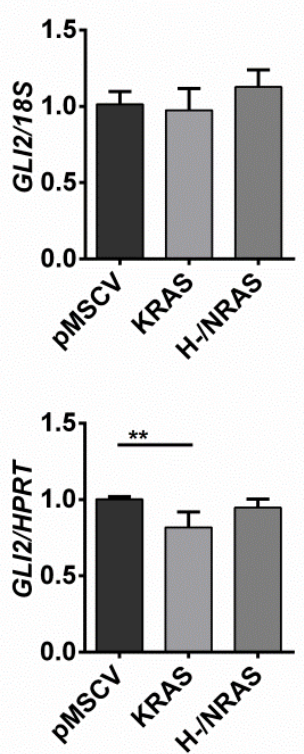

GLI3
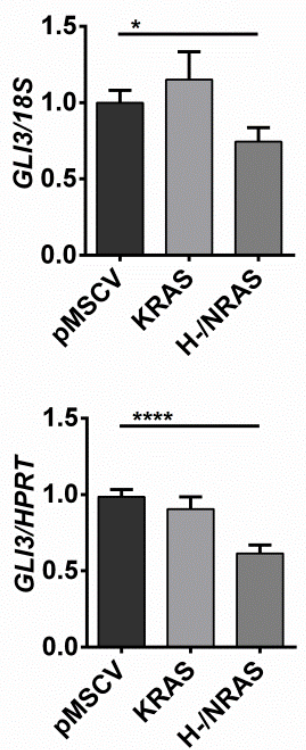

PTCH
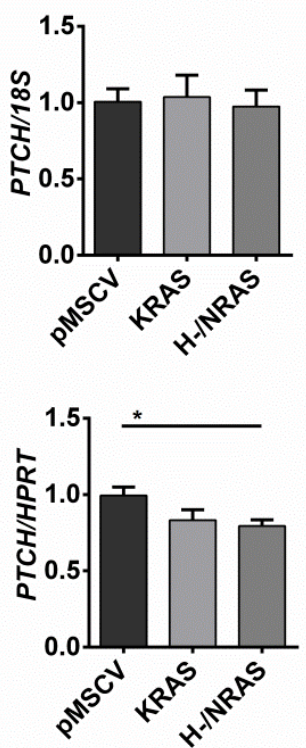

HHIP
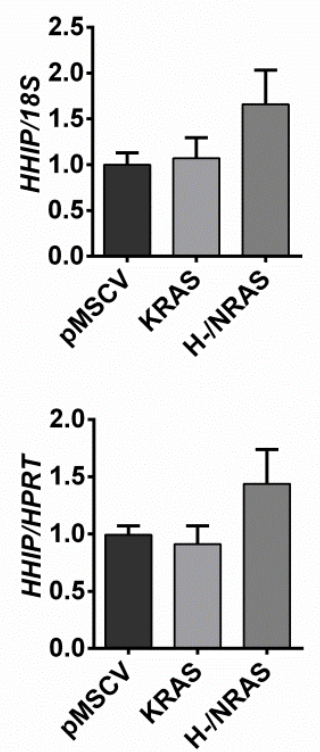

SHH
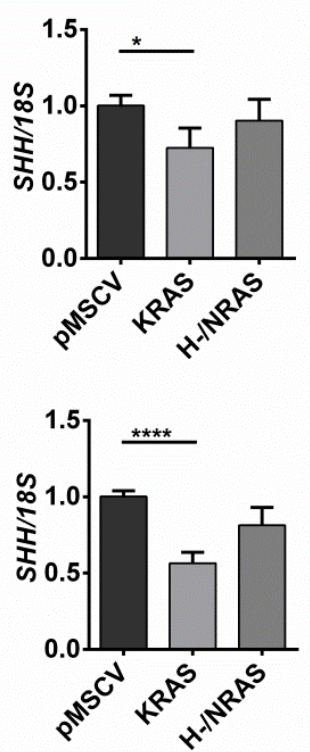

Figure 14: OncKRAS decreases SHH, whereas oncH-/NRAS decrease GLI3 in TE617.T cells

TE617.T cells stably transduced with the pMSCV control vector or oncRAS isoforms (KRAS, H-/NRAS) were subjected to RNA isolation, CDNA synthesis and subsequent qRT-PCR analyses of the HH signaling pathway genes GLI2, GLI3, PTCH, HHIP and SHH. The expression data were normalized to 18S rRNA (18S, upper row) and HPRT (lower row) and are shown as fold expression to TE617.T pMSCV control cells that were set to 1. Bars represent the mean + SEM of 4 independent experiments performed in technical triplicates. For statistical analyses a non-parametric t-test (Mann Whitney) was performed. ${ }^{*} p<0.05,{ }^{* *} p<0.01,{ }^{* * *} p<0.0001$ compared to expression level of pMSCV control cells.

In RUCH-2 cells all oncRAS isoforms significantly downregulated GL/2 expression in comparison to pMSCV control cells (Fig. 15). Interestingly, and in contrast to TE617.T cells, all oncRAS isoforms increased the expression of the $\mathrm{HH}$ ligand $\mathrm{SHH}$. Furthermore, GLI3 expression was decreased by oncNRAS. The oncogenic isoforms of HRAS and KRAS increased the expression of $P T C H$, while the expression of HHIP was not affected in any of the settings (Fig. 15). 
GLI2
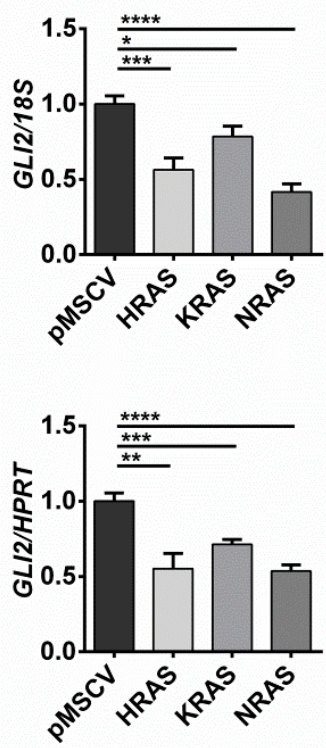

GLI3
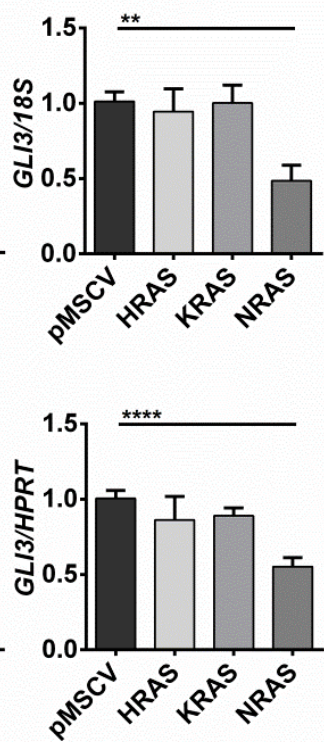

PTCH
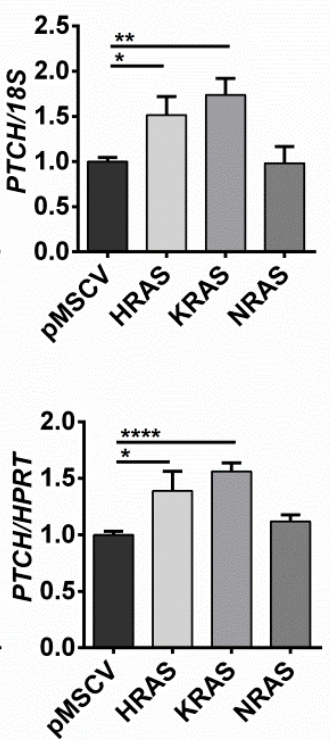

HHIP

SHH
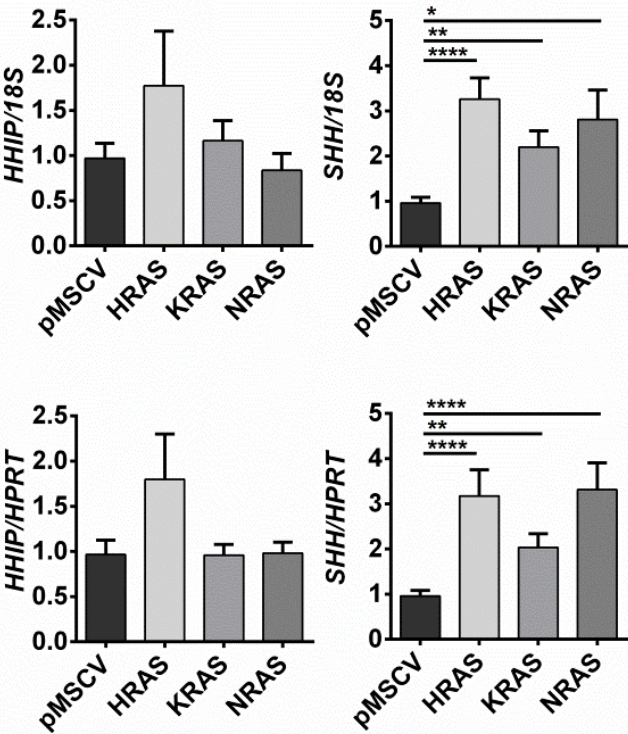

Figure 15: OncRAS isoforms modify GLI2 and SHH expression in RUCH-2 cells

RUCH-2 cells stably transduced with the pMSCV control vector or oncRAS isoforms (HRAS, KRAS, NRAS) were subjected to RNA isolation, CDNA synthesis and subsequent qRT-PCR analyses of the HH signaling pathway genes GLI2, GLI3, PTCH, HHIP and SHH. The expression data were normalized to 18S rRNA (18S, upper row) and HPRT (lower row) and are shown as fold expression to RUCH-2 pMSCV control cells that were set to 1. Bars represent the mean + SEM of 3 independent experiments performed in technical triplicates. For statistical analyses a non-parametric t-test (Mann Whitney) was performed. ${ }^{*} p<0.05,{ }^{* *} p<0.01,{ }^{* \star *} p<0.001,{ }^{* \star * *} p<0.0001$ compared to expression level of pMSCV control cells.

Taken together, the results from chapter 6.1.2 highlight that oncRAS isoforms apparently inhibit $\mathrm{HH}$ signaling in RMS cell lines, because the expression of the main $\mathrm{HH}$ target gene GL/1 decreases. This phenomenon is apparently specific for RMS cell lines, because it was not observed in medulloblastoma cells. Furthermore, oncRAS isoforms also modify the gene expression level of other central players of the $\mathrm{HH}$ signaling pathway such as GLI2 (RUCH-2 cells only), GL/3, PTCH (RUCH-2 cells only) and SHH. However, the modulation is different between the ERMS cell lines TE617.T and RUCH-2.

\subsubsection{Canonical HH signaling plays a subordinate role in ERMS cell lines}

In oncRAS-transduced RUCH-2 and TE617.T cell lines the expression of SHH was up- or downregulated, respectively (see section 6.1.2.2). This suggested that oncRAS isoforms may affect canonical $\mathrm{HH}$ signaling in ERMS due to secretion of $\mathrm{SHH}$. In order to test this hypothesis, the ability of the cells to secrete $\mathrm{HH}$ ligands was analyzed. In addition, it was analyzed whether the cells itself respond to the $\mathrm{HH}$ stimulus.

\subsubsection{ERMS cell lines do not secrete HH ligands}

In order to investigate whether ERMS cell lines are able to secrete $\mathrm{HH}$ ligands, $\mathrm{CM}$ of the transduced cell lines was prepared as described in section 5.1.11. Then, the murine $\mathrm{HH}$ responsive cell line B9 was incubated for $48 \mathrm{~h}$ with the $\mathrm{CM}$ and expression of Gli1 was measured by qRT-PCR. The supernatants from HEK293 or HEK293-Shh cells were used as 
controls. Preliminary results already showed that oncRAS-transduced RUCH-2 cells are not able to secrete $\mathrm{HH}$ ligands ${ }^{299}$. As indicated here (Fig. 16), this was similar for oncRAStransduced TE617.T cells. Thus, whereas HEK293-Shh CM strongly increased Gli1 expression in B9 cells, incubation with CM from TE617.T pMSCV, TE617.T KRAS or TE617.T H-/NRAS cells did not influence the Gli1 level of B9.

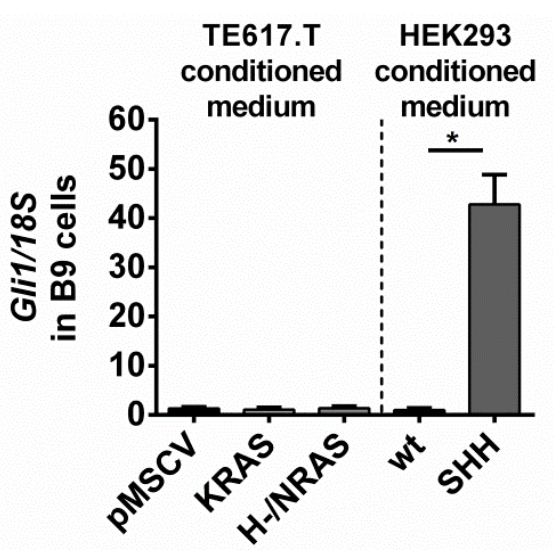

Figure 16: OncRAS-transduced TE617.T cells are not able to secrete $\mathrm{HH}$ ligands

B9 cells were incubated with conditioned media from TE617.T cells stably transduced with the pMSCV control vector or oncRAS isoforms (KRAS, H-/NRAS), or with media of HEK293 (wt) or HEK293-Shh $(\mathrm{SHH})$ cells for $48 \mathrm{~h}$. Afterwards $\mathrm{B} 9$ cells were subjected to RNA isolation, cDNA synthesis and subsequent qRT-PCR analyses of the $\mathrm{HH}$ target gene Gli1. The data were normalized to $18 \mathrm{~S}$ rRNA (18S) and are shown as fold expression in comparison to B9 cells incubated with TE617.T pMSCV (pMSCV) conditioned medium which was set to 1. Bars represent the mean + SEM of 3 independent experiments performed in technical triplicates. For statistical analyses a nonparametric t-test (Mann Whitney) was performed. ${ }^{*} \mathrm{p}<0.05,{ }^{* *} \mathrm{p}<0.01$, ${ }^{* * *} p<0.001,{ }^{* * *} p<0.0001$ compared to expression level of B9 cells were incubated with conditioned media from HEK293 cells.

The ability of stably transduced $\mathrm{RUCH}-2$ cells or RD cells to secrete $\mathrm{HH}$ ligands was also tested by co-culture with the $\mathrm{HH}$-responsive $\mathrm{SHH}$ light II reporter cell line. The activity of the $\mathrm{HH}$ signaling cascade in $\mathrm{SHH}$ light II reporter cells can be measured by a dual luciferase reporter assay, because these cells harbor a Gli responsive luciferase reporter system ${ }^{310}$ (compare section 5.1.12.2).
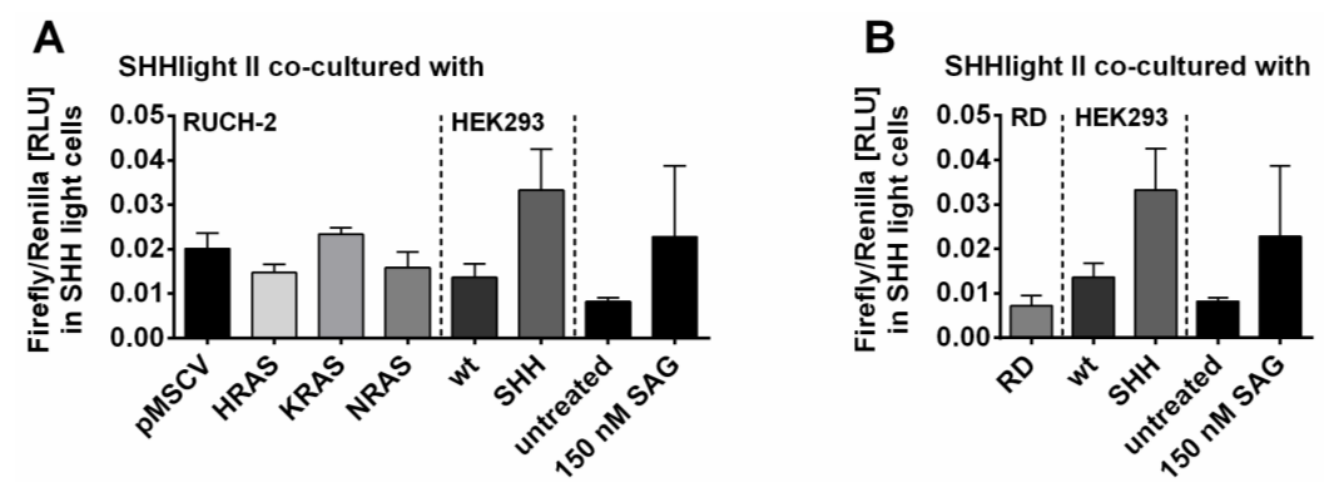

Figure 17: OncRAS-transduced RUCH-2 cells and RD cells do not stimulate Gli reporter activity in cocultured SHH light II cells

SHH light II cells were either co-cultured with RUCH-2 cells (A) stably transduced with the pMSCV control vector or oncRAS isoforms (HRAS, KRAS, NRAS) or RD cells (B) for $24 \mathrm{~h}$. SHH light Il cells co-cultured with HEK293 Shh cells $(\mathrm{SHH})$ or treated with $150 \mathrm{nM}$ SAG served as positive controls, whereas SHH light II cells alone (untreated) or co-cultured with HEK293 cells (wt) served as negative controls. Afterwards the relative activity of the $\mathrm{HH}$ signaling cascade in $\mathrm{SHH}$ light II cells was determined by a dual luciferase assay. The luminescence readout from firefly luciferase activity was normalized to that of renilla luciferase activity and is displayed in relative light units $(R L U)$. Bars represent the mean + SEM of 3 independent experiments performed in technical triplicates. For statistical analyses a non-parametric t-test (Mann Whitney) was performed.

Neither RUCH-2 cells with or without oncRAS (Fig. 17A) nor RD cells (Fig. 17B) were able to stimulate $\mathrm{HH}$ signaling in co-cultured SHH light II cells. Positive controls, i.e. stimulation with SAG or co-culturing with HEK293-Shh cells, increased the Gli reporter activity in SHH light II cells in comparison to the negative controls, which were untreated $\mathrm{SHH}$ light II cells or $\mathrm{SHH}$ light II cells co-cultured with HEK293 cells. However, the stimulation was not significant (Fig. 17A and Fig. 17B). 
Taken together, the results demonstrate that the ERMS cell lines TE617.T, RUCH-2 and RD are in all likelihood not able to secrete $\mathrm{HH}$ ligands, regardless if they harbor a oncRAS mutation or not.

\subsubsection{Moderate activation of $\mathrm{HH}$ signaling in ERMS cells by SHH-CM}

Next, it was tested whether the $\mathrm{HH}$ signaling pathway could be activated in ERMS cells. For this purpose, stably transduced RUCH-2 cells were incubated for $48 \mathrm{~h}$ with CM from HEK293 or HEK293-Shh cells. Additionally, B9 cells were incubated with the same media and served as controls. Then the expression of GL/1/Gli1 was measured. The results were dependent on the reference gene used for normalization (compare Fig. 18A and Fig. 18B). When the data were normalized to $18 S$ rRNA the results obtained from 3 independent experiments showed that the CM from HEK293-Shh cells moderately regulated the expression of GLI1 in RUCH-2 HRAS and RUCH-2 KRAS cells, whereas it did not affect GLI1 expression in RUCH-2 pMSCV and RUCH-2 NRAS cells. The functionality of Shh containing medium was proven by a strong Gli1 induction in B9 cells.
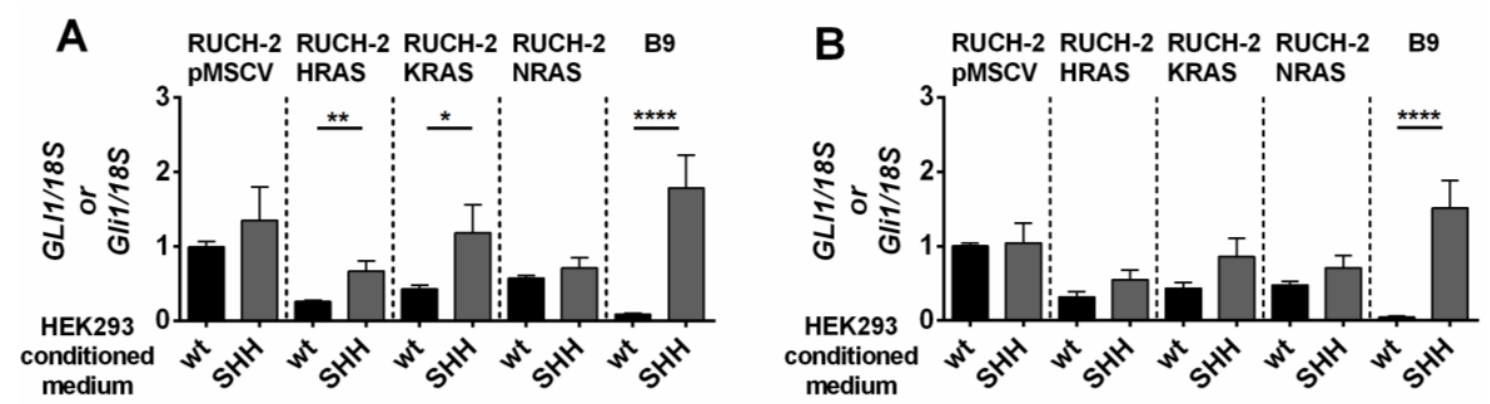

Figure 18: SHH moderately induces GLI1 transcription in oncRAS-expressing RUCH-2 cells

$\mathrm{RUCH}-2$ cells stably transduced with the pMSCV control vector or oncRAS isoforms (HRAS, KRAS, NRAS) were incubated with conditioned media from HEK293 (wt) or HEK293-Shh (SHH) cells for $48 \mathrm{~h}$. B9 cells incubated with conditioned media from HEK293 or HEK293-Shh were used as negative and positive controls, respectively. Afterwards cells were subjected to RNA isolation, cDNA synthesis and subsequent qRT-PCR analyses of the HH target gene GL/1/Gli1. The data were normalized to $18 \mathrm{~S}$ rRNA (18S, A) or HPRT (B) and are shown as fold expression in comparison to RUCH-2 pMSCV cells incubated with HEK293 conditioned medium, which was set to 1. Bars represent the mean + SEM of 3 independent experiments performed in technical triplicates. For statistical analyses a non-parametric t-test (Mann Whitney) was performed. ${ }^{*} \mathrm{p}<0.05,{ }^{* *} \mathrm{p}<0.01,{ }^{* \star * *} \mathrm{p}<0.0001$ compared to expression level of control medium treated cell lines.

To sum up, the data from section 6.1.3 indicate that the ERMS cell lines TE617.T and RUCH-2 stably transduced with the pMSCV control vector or oncRAS isoforms, and RD cells probably are not able to secrete $\mathrm{HH}$ ligands. Additionally, stimulation with $\mathrm{SHH}$ may marginally regulate $\mathrm{HH}$ signaling activity, as measured by GLI1 expression in RUCH-2 cell lines that express oncHRAS and oncKRAS isoforms.

\subsubsection{OncRAS isoforms regulate GLI1 expression in ERMS cells via the MEK/ERK axis}

Next, it was investigated whether oncRAS isoforms regulate GL/1 expression in a noncanonical manner via the PI3K/AKT/mTOR or the MEK/ERK axes. In order to inhibit $\mathrm{PI} 3 \mathrm{~K} / \mathrm{AKT} / \mathrm{mTOR}$ signaling the dual PI3K/mTOR inhibitor $\mathrm{PI}-103^{329}$ was used, whereas the 
RAF/MEK/ERK axis was targeted with the specific MEK inhibitor U0126 ${ }^{330}$ or the specific ERK1/2 inhibitor SCH772984 ${ }^{331}$. Additionally, the SMO inhibitor HhAntag (HhA) ${ }^{332}$ was employed. The experiments were performed in accordance with previous work, which indicated an oncRAS-dependent regulation of the $\mathrm{HH}$ signaling pathway via the MEK axis in RUCH-2 cells ${ }^{299}$.

The inhibitors HhA $(30 \mu \mathrm{M})$, PI-103 $(3 \mu \mathrm{M})$ and U0126 $(10 \mu \mathrm{M})$ were applied in concentrations as described ${ }^{299}$. The concentration of the ERK inhibitor $\mathrm{SCH} 772984$ was first assessed in RUCH-2 cells in a range between $0.1 \mu \mathrm{M}$ to $10 \mu \mathrm{M}$ applied for $24 \mathrm{~h}$. A Western Blot of RUCH-2 HRAS cells shows that all applied concentrations of SCH772984 inhibited phosphorylation of ERK protein level in comparison to solvent (DMSO) treated cells without showing an apoptotic effect (Fig. 19). The exception was $1 \mu \mathrm{M} \mathrm{SCH772984,} \mathrm{which} \mathrm{only}$ moderately inhibited ERK phosphorylation. This result was not only seen in RUCH-2 HRAS cells but also in other stably transduced $\mathrm{RUCH}-2$ cell lines and in the MET-1 cell line, which is also used in our group. This effect is hard to explain. However, it is possible that specific concentrations of $\mathrm{SCH} 772984$ influence other signaling molecules that in turn phosphorylate ERK. Indeed, a similar scenario has been described for other small molecules such as the SMO Agonist SAG. Thus, SAG usually activates GLI1 expression, but inhibits GLI1 when used at concentration above $1 \mu \mathrm{M}^{310}$.

Based on these results and observations, a concentration of $0.5 \mu \mathrm{M}$ SCH772984 was employed in subsequent experiments.

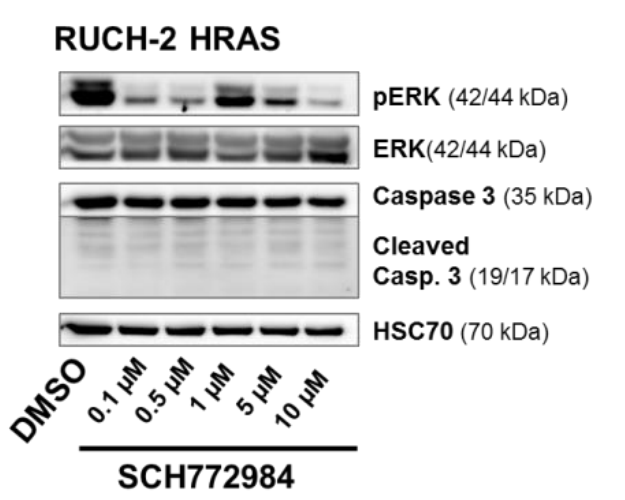

Figure 19: SCH772984 inhibits phosphorylation of ERK in different concentrations

Protein was isolated from RUCH-2 cells stably transduced with oncHRAS (RUCH-2 HRAS) after incubation with $0.1 \mu \mathrm{M}$ to $10 \mu \mathrm{M}$ $\mathrm{SCH} 772984$ for $24 \mathrm{~h}$. The total cell lysates were analyzed by Western Blot for protein expression of pERK/ERK and caspase 3 cleavage (Caspase 3 and cleaved casp. 3) with specific antibodies. HSC70 served as loading control. Protein names and sizes in $\mathrm{kDa}$ are displayed on the right side of the blot. The depicted results were also obtained in experiments with $\mathrm{RUCH}-2$ pMSCV and RUCH-2 KRAS and NRAS cells (data not shown).

The functionality of HhA, PI103, UO126 and SCH772984 was tested by analyses of protein level of pAKT/AKT, pS6/S6, pERK/ERK after treatment of the cells for $24 \mathrm{~h}$ (Fig. 20). Additionally, caspase 3 cleavage was analyzed. Representative Western Blots of TE617.T cells (Fig. 20A), RUCH-2 cells (Fig. 20B) and RD cells (Fig. 20C) show that in general $\mathrm{SCH} 772984$ effectively downregulated the pERK level in all cell lines. SCH772984 also slightly downregulated AKT level in TE617.T pMSCV cells, whereas it strongly reduced it in $\mathrm{RUCH}-2$ cells stably transduced with oncRAS isoforms (Fig. 20B). However, this result is based on 1 biological replicate and needs further validation. Nevertheless, a downregulation of AKT protein level after SCH772984 treatment was also described for BxPC-3 and HPAC cells in the literature ${ }^{333}$. 
A

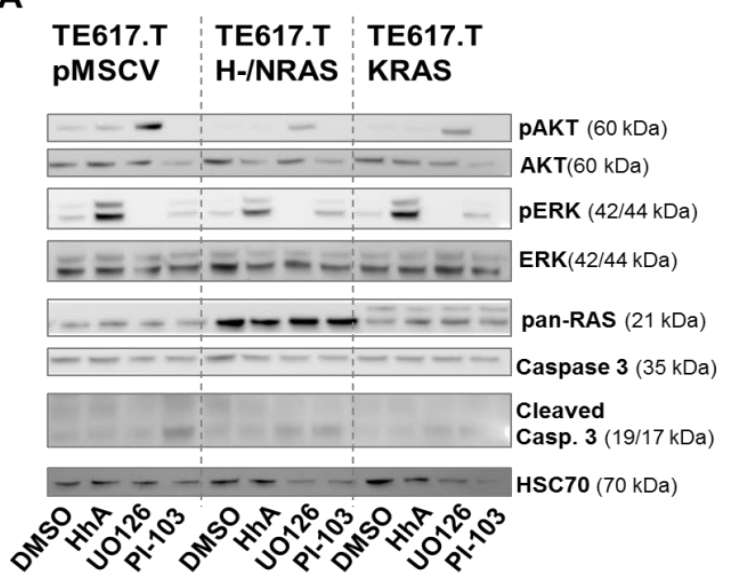

TE617.T

pMSCV

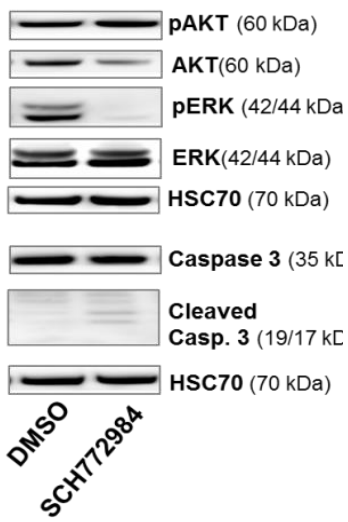

C

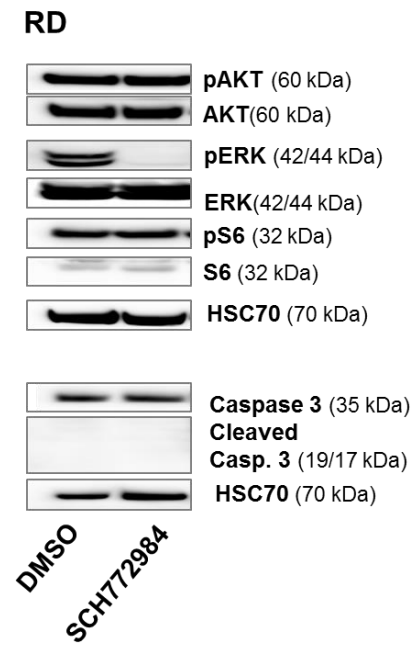

B

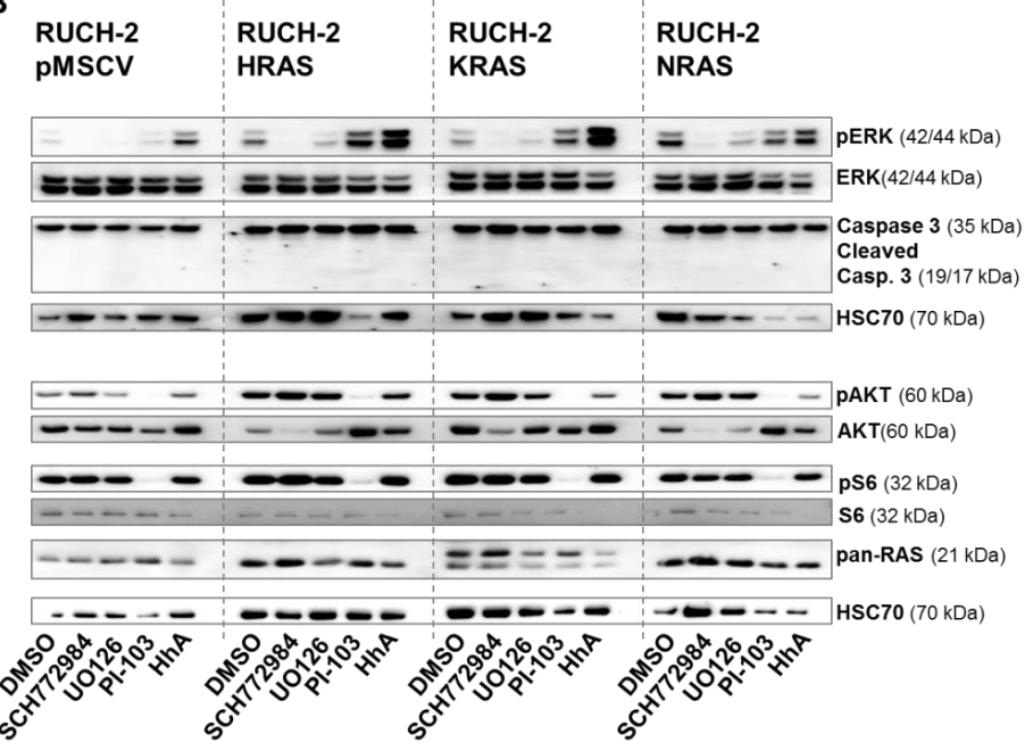

Figure 20: PI-103, U0126 and SCH772984 inhibit phosphorylation of their downstream kinases in TE617.T, RUCH-2 and RD cells

Protein was isolated from TE617.T (A) and RUCH-2 (B) cells stably transduced with the pMSCV control vector or oncRAS isoforms (HRAS, KRAS, NRAS, H-/NRAS) and RD cells (C) that have been incubated with $\mathrm{HhA}(30 \mu \mathrm{M})$, PI-103 $(3 \mu \mathrm{M})$, UO126 $(10 \mu \mathrm{M})$ or SCH772984 $(0.5 \mu \mathrm{M})$ for $24 \mathrm{~h}$. The total cell lysates were used for Western Blot analyses to detect the protein level of pAKT/AKT, pS6/S6, pERK/ERK, pan-RAS and caspase 3 cleavage (Caspase 3 and cleaved casp. 3) with specific antibodies. HSC70 served as loading control. Protein names and sizes in $\mathrm{kDa}$ are displayed on the right side of the blots. The results are representative for 1 (TE617.T + $\mathrm{SCH772984,} \mathrm{RUCH-2),} 3$ (TE617.T + HhA, PI-103 or UO126) or 4 (RD) independent experiments.

As expected, the MEK inhibitor U0126 decreased phosphorylation of ERK in all used cell lines and additionally increased phosphorylation of AKT in all TE617.T cell lines. This increase has already been described for other RMS cell lines ${ }^{271}$. These observations are already described in the literature, e.g. in breast cancer and RMS cells ${ }^{271,333,334}$. It has been suggested that the MEK inhibitor-induced activation of PI3K/AKT results from an inhibitory phosphorylation in conserved domains of the EGFR, which leads to hyperactivation of ErbB2 Receptor Tyrosine Kinase 3 (ERBB3) that in turn upregulates the PI3K/AKT signaling pathway ${ }^{335}$. In $\mathrm{RUCH}-2$ and TE617.T cells the dual PI3K/mTOR inhibitor PI-103 downregulated phosphorylation of AKT and S6 (Fig. 20A, Fig. 20B). Unfortunately, 
phosphorylation of S6 was not measured in TE617.T cells. Additionally, PI-103 slightly induced phosphorylation of ERK and modified basal level of AKT in oncRAS-expressing RUCH-2 cells (Fig. 20B). Increased pERK level upon inhibition of mTOR has been described by others ${ }^{336}$. The SMO inhibitor HhA increased phosphorylation of ERK in all RUCH-2 and TE617.T cell lines (Fig. 20A, Fig. 20B). Furthermore, it decreased pAKT in all RUCH-2 cell lines (Fig. 20B). This phenomenon has already been described by our group ${ }^{299,337}$. These secondary actions of $\mathrm{HhA}$ were considered as an additional hint for an interaction of $\mathrm{HH}$ and RAS signaling, either via the PI3K/AKT/mTOR axis, or via the RAF/MEK/ERK pathway.

\subsubsection{ERK inhibits GLI1 expression in TE617.T cells, in oncRAS-expressing RUCH-2 cells and in RD cells}

The above-mentioned inhibitors were then used to investigate if oncRAS-mediated downregulation of GL/1 expression is regulated via the PI3K/AKT/mTOR axis or via the RAF/MEK/ERK pathway.

\subsection{GLI1 expression in TE617.T is inhibited by ERK without general involvement of oncRAS isoforms}

The stably transduced TE617.T cells were treated for $24 \mathrm{~h}$ with $\mathrm{HhA}(30 \mu \mathrm{M}), \mathrm{PI}-103(3 \mu \mathrm{M})$, U0126 $(10 \mu \mathrm{M})$ or SCH772984 $(0.5 \mu \mathrm{M})$ and GLI1 expression was analyzed via qRT-PCR. The inhibition of SMO did not influence GLI1 expression in any of the TE617.T cell lines (Fig. 21).
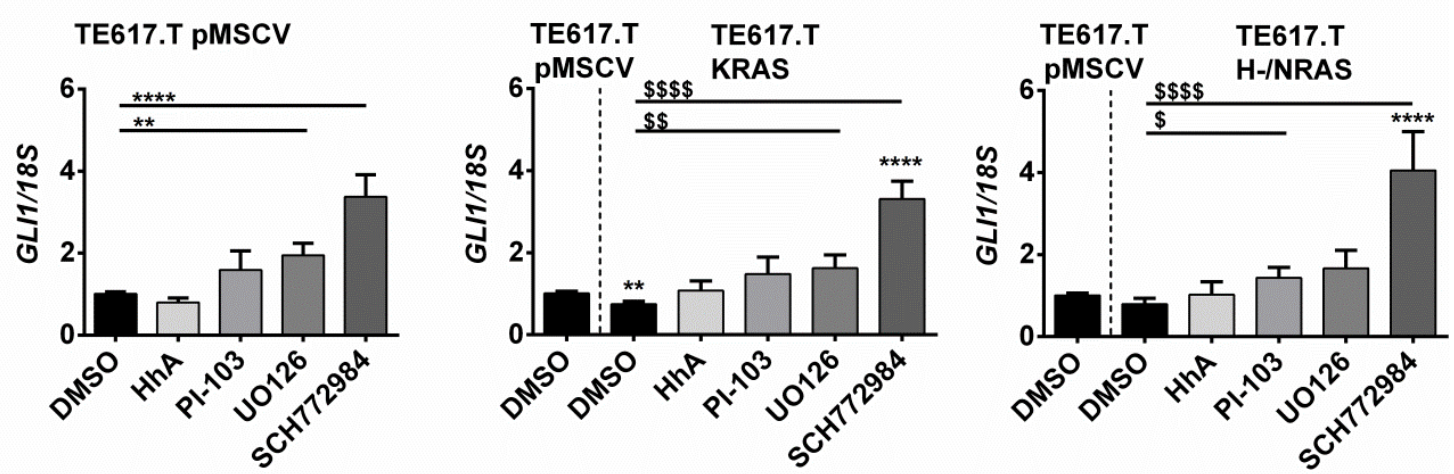

Figure 21: MEK and ERK suppress GLI1 in TE617.T irrespective of oncRAS mutations

TE617.T stably transduced with the pMSCV control vector or oncRAS isoforms (KRAS, H-/NRAS) were incubated with DMSO, HhA $(30 \mu \mathrm{M})$, PI-103 $(3 \mu \mathrm{M})$ and UO126 $(10 \mu \mathrm{M})$ or SCH772984 $(0.5 \mu \mathrm{M})$ for $24 \mathrm{~h}$. Afterwards cells were subjected to RNA isolation, CDNA synthesis and subsequent GRT-PCR analyses of the HH target gene GLI1. The data were normalized to 18S rRNA (18S) and are shown as fold expression in comparison to TE617.T pMSCV cells incubated with DMSO, which was set to 1 . The respective bar is shown in each histogram as a reference. Bars represent the mean + SEM of 4 independent experiments performed in technical triplicates. For statistical analyses a non-parametric t-test (Mann Whitney) was performed. * indicate significance compared to DMSO treated TE617.T pMSCV cells, whereas $\$$ indicate significance compared to solvent control of the respective cell line. $\$ p<0.05,{ }^{* *} / \$ p<0.01,{ }^{* \star * *} / \$ \$ \$ p<0.0001$

This indicates again that it is not possible to modulate $\mathrm{HH}$ signaling via the canonical axis in these cells. PI-103 increased GLI1 expression in oncH-/NRAS-expressing TE617.T cells, however not in oncKRAS-expressing or TE617.T control cells. The treatment with the MEK inhibitor U0126 increased GLI1 level in oncKRAS-expressing and control cells, whereas inhibition of ERK increased GLI1 in all TE617.T cell lines. Taken together, these data 
indicate that inhibition of ERK (and also of MEK) results in a significant increase of GL/1 expression in all TE617.T cells investigated. In fact, the observed effect was independent of oncRAS mutations, since it was also observed in control cells.

\subsection{ERK mediates oncRAS-induced downregulation of GL/1 expression in RUCH-2 cells}

In RUCH-2 pMSCV control cells inhibition of PI3K/mTOR significantly decreased GL/1 expression, whereas treatment with the other inhibitors had no significant effect (Fig. 22A).

A RUCH-2 pMSCV
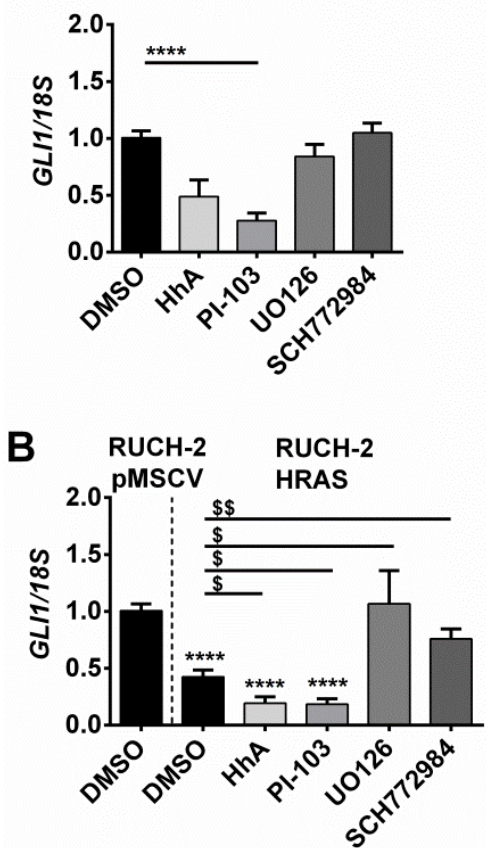
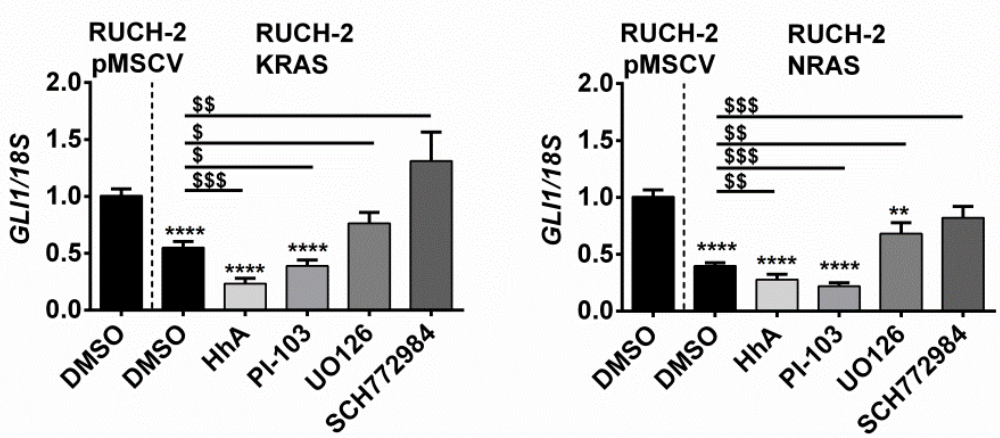

Figure 22: ERK mediates oncRAS-induced downregulation of GLI1 in RUCH-2 cells

RUCH-2 cells stably transduced with the pMSCV control vector (A) or oncRAS isoforms (HRAS, KRAS, NRAS) (B) were incubated with DMSO, HhA $(30 \mu \mathrm{M})$, PI-103 $(3 \mu \mathrm{M})$, UO126 $(10 \mu \mathrm{M})$ or SCH772984 $(0.5 \mu \mathrm{M})$ for $24 \mathrm{~h}$. Afterwards cells were subjected to RNA isolation, cDNA synthesis and subsequent qRT-PCR analyses of the HH target gene GLI1. The data were normalized to 18S rRNA (18S) and are shown as fold expression in comparison to RUCH-2 pMSCV cells incubated with DMSO, which was set to 1 . The respective bar is shown in each histogram as a reference. Bars represent the mean + SEM of 3 independent experiments performed in technical triplicates. For statistical analyses a non-parametric t-test (Mann Whitney) was performed. * indicate significance compared to DMSO treated RUCH-2 pMSCV cells, whereas \$ indicate significance compared to solvent control of the respective cell line. $\$ p<0.05,{ }^{* *} / \$ p<0.01, \$ \$ \$ p<0.001,{ }^{* * * *} p<0.0001$

In contrast, in RUCH-2 cells stably transduced with oncRAS isoforms the incubation with HhA or PI-103 decreased the relative GLI1 expression in comparison to solvent-treated cells, whereas treatment with UO126 or SCH772984 significantly increased GLI1 in comparison to DMSO treated RUCH-2 oncRAS cell lines. Moreover, inhibition of MEK in RUCH-2 HRAS and RUCH-2 KRAS cells or inhibition of ERK in all oncRAS-expressing cells restored GLI1 expression back to the basal level of control RUCH-2 pMSCV cells (Fig. 22B). These results show that oncRAS-dependent downregulation of $G L / 1$ in RUCH-2 cells is mediated by ERK. 


\subsection{ERK inhibits GLI1 expression in RD cells}

In addition to ERMS cell lines stably transduced with oncRAS isoforms, RD cells harboring an endogenous oncNRAS mutation were incubated with $0.5 \mu \mathrm{M} \mathrm{SCH} 772984$ for $24 \mathrm{~h}$. In this cell line and as already demonstrated by our group, $\mathrm{Pl}-103$ treatment results in a decrease of GLI1 expression whereas U0126 treatment increases GLI1 ${ }^{160}$. Here, the ERK inhibitor SCH772984 increased the GLI1 level (Fig. 23). This result indicates that the oncRAS mutation in RD cells might suppress GL/1 expression via the ERK axis, which is similar to RUCH-2 cells (compare section 6.1.4.1.2).

\section{RD cells}
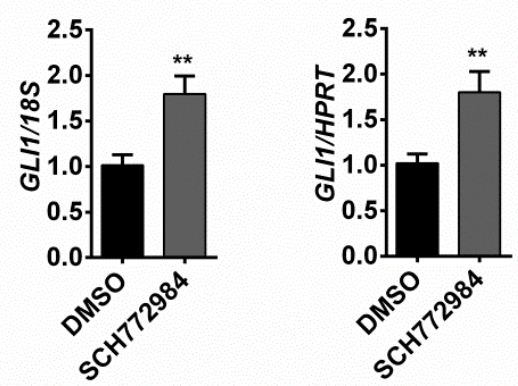

Figure 23: ERK inhibition increases GLI1 expression in RD cells

$\mathrm{RD}$ cells were incubated with DMSO or SCH772984 $(0.5 \mu \mathrm{M})$ for $24 \mathrm{~h}$. Afterwards cells were subjected to RNA isolation, cDNA synthesis and subsequent qRT-PCR analyses of the HH target gene GLI1. The data were normalized to $18 S$ rRNA (18S, left) or HPRT (right) and are shown as fold expression in comparison to RD cells incubated with DMSO, which was set to 1. Bars represent the mean + SEM of 3 independent experiments performed in technical triplicates. For statistical analyses a non-parametric t-test (Mann Whitney) was performed. ${ }^{* *} p<0.01$ compared to expression level of DMSO treated RD cells

\subsubsection{ERK regulates $P T C H$ and $S H H$ expression in TE617.T cells, $S H H$ expression in oncRAS-expressing RUCH-2 cells and GLI3 in RD cells}

Next it was analyzed whether the ERK inhibitor SCH772984 also influences the gene expression level of GLI2, GLI3, PTCH, HHIP and SHH in stably transduced TE617.T and $\mathrm{RUCH}-2$ cells and in RD cells.

\subsection{PTCH and SHH expression in TE617.T cells is inhibited by ERK without general involvement of oncRAS}

In TE617.T pMSCV control cells, ERK inhibition did not influence the expression of GLI2 or GLI3, but generally increased transcription of $P T C H, H H I P$ and $S H H$ (Fig. 24). 


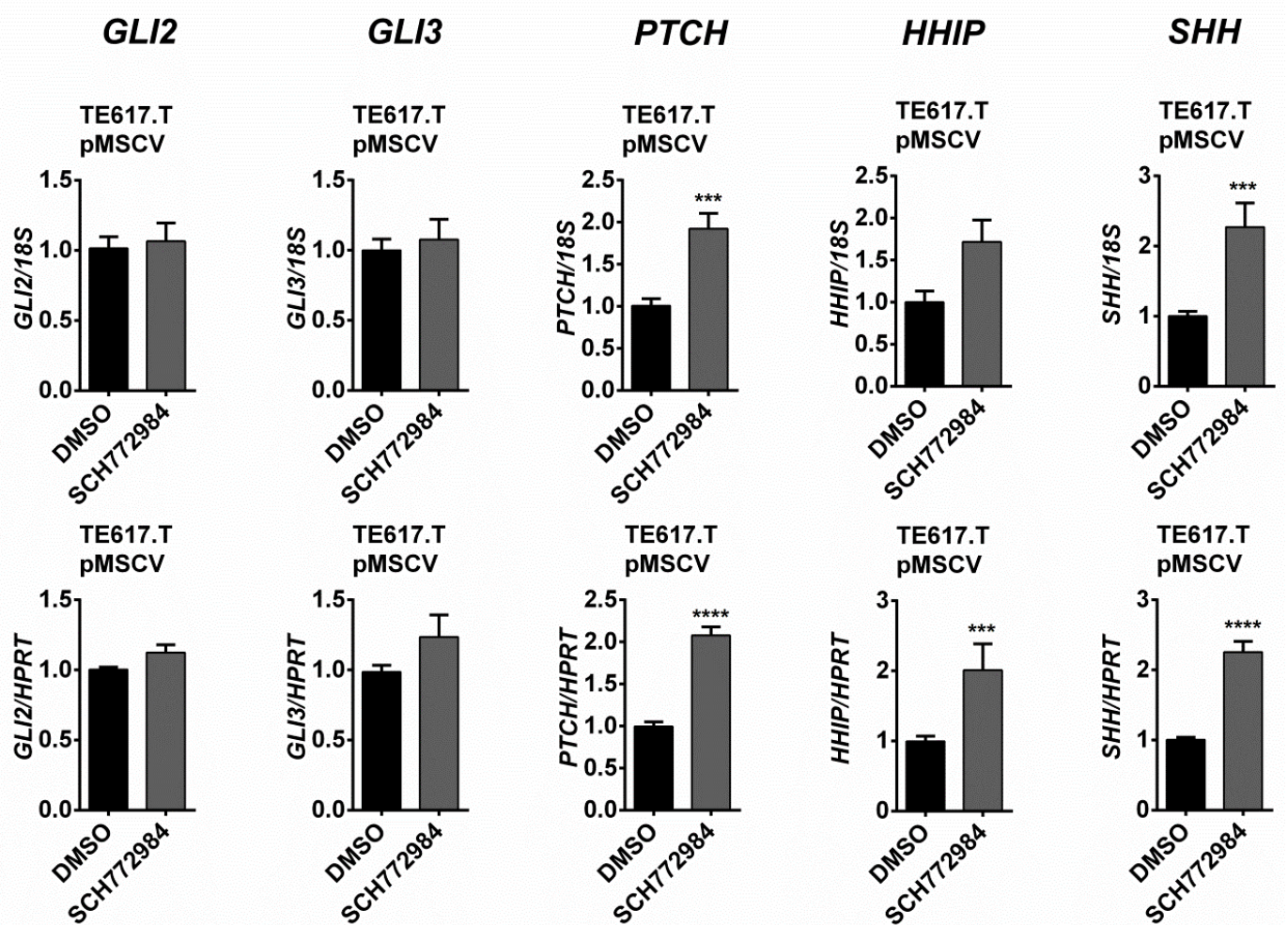

Figure 24: ERK inhibits PTCH and SHH expression in TE617.T pMSCV cells

TE617.T cells stably transduced with the pMSCV control vector were incubated with DMSO or SCH772984 $(0.5 \mu \mathrm{M})$ for $24 \mathrm{~h}$. Afterwards cells were subjected to RNA isolation, cDNA synthesis and subsequent qRT-PCR analyses of the $\mathrm{HH}$ signaling pathway genes GLI2, GLI3, PTCH, HHIP and SHH. The data were normalized to $18 S$ rRNA (18S, upper row) or HPRT (lower row) and are shown as fold expression in comparison to cells incubated with DMSO, which was set to 1. Bars represent the mean + SEM of 4 independent experiments performed in technical triplicates. For statistical analyses a non-parametric t-test (Mann Whitney) was performed. ${ }^{* * *} p<0.001,{ }^{* * * *} p<0.0001$ compared to expression level of DMSO treated cells

In TE617.T KRAS cells, which showed an oncKRAS-dependent downregulation of SHH, application of SCH772984 restored SHH back to basal level of pMSCV control cells. Furthermore, SCH772984 downregulated GLI2 and upregulated PTCH transcription, whereas gene expression of GLI3 and HHIP were not affected (Fig. 25). 
GLI2

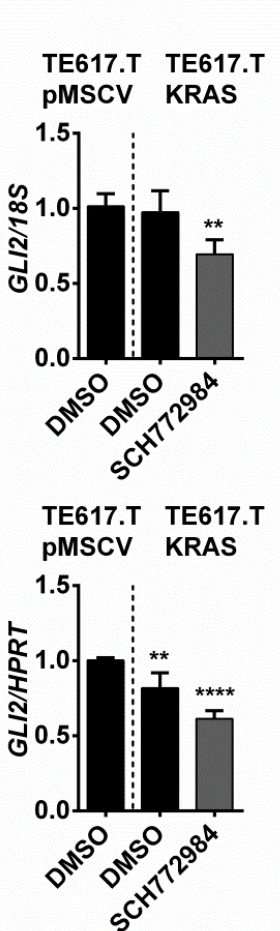

GL/3
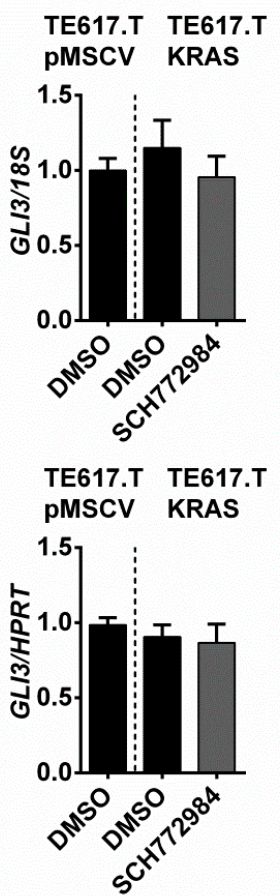

PTCH
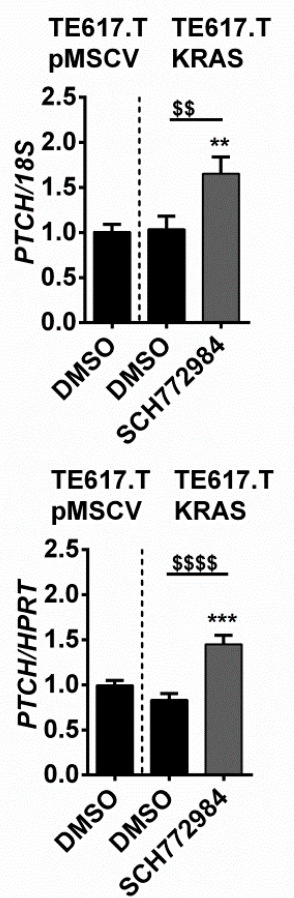

HHIP

SHH
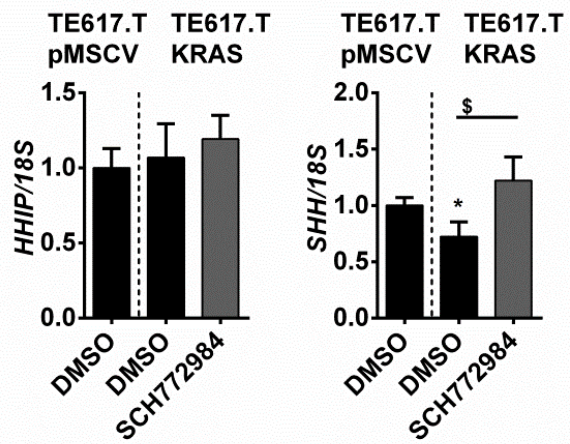

TE617.T TE617.T PMSCV KRAS
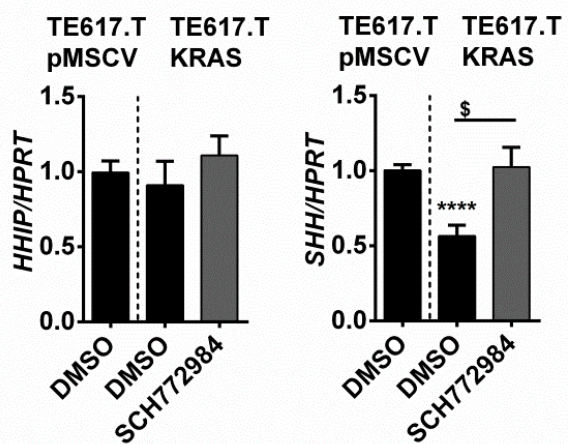

Figure 25: ERK activates GLI2 and inhibits PTCH expression in TE617.T KRAS cells and restores oncKRAS-dependent decrease of SHH back to basal level

TE617.T cells stably transduced with the pMSCV control vector or oncKRAS (KRAS) were incubated with DMSO or SCH772984 $(0.5 \mu \mathrm{M})$ for $24 \mathrm{~h}$. Afterwards cells were subjected to RNA isolation, cDNA synthesis and subsequent qRT-PCR analyses of the HH signaling pathway genes GLI2, GLI3, PTCH, HHIP and SHH. The data were normalized to $18 S$ rRNA (18S, upper row) or HPRT (lower row) and are shown as fold expression in comparison to DMSO treated TE617.T pMSCV cells, which was set to 1. The respective bar is shown in each histogram as a reference. Bars represent the mean + SEM of 4 independent experiments performed in technical triplicates. For statistical analyses a non-parametric t-test (Mann Whitney) was performed. * indicate significance compared to DMSO treated TE617.T pMSCV cells, whereas \$ indicate significance compared to TE617.T KRAS cells treated with DMSO. ${ }^{\star} / \$ p<0.05,{ }^{* *} / \$ \$ p<0.01,{ }^{* * *} p<0.001,{ }^{* * \star *} / \$ \$ \$ \$ p<0.0001$

In TE617.T H-/NRAS cells SCH772984 had no obvious impact on GLI2 or HHIP level. It also had no clear-cut effect on GL/3, which is downregulated in these cells by oncH-/NRAS compared to the pMSCV control cells. Like in TE617.T pMSCV cells, SCH772984 increased the relative mRNA level of SHH. However, SCH772984 increased the expression of PTCH. The latter result was considered as a tendency, since the result was only significant upon normalization to HPRT but not to $18 S$ rRNA (Fig. 26).

Taken together, SCH772984 generally increases PTCH and SHH in TE617.T cells irrespective of an oncRAS mutation. 
GL/2

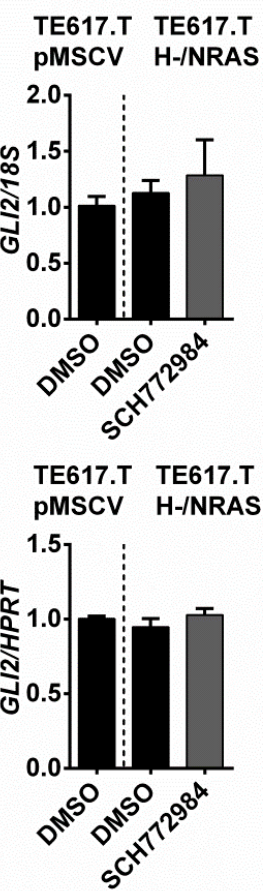

GL/3
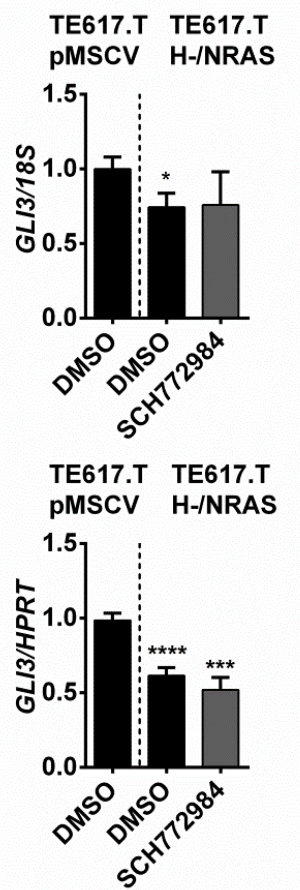

PTCH
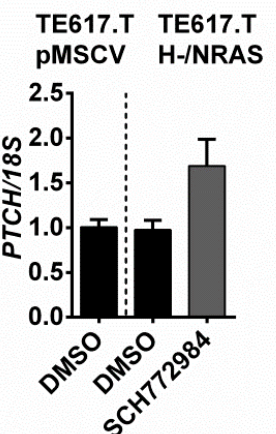

TE617.T TE617.T

pMSCV H-/NRAS

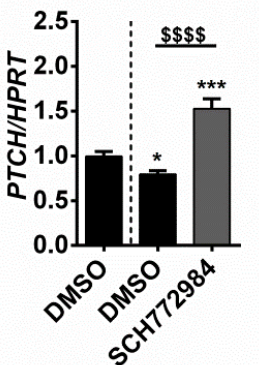

HHIP

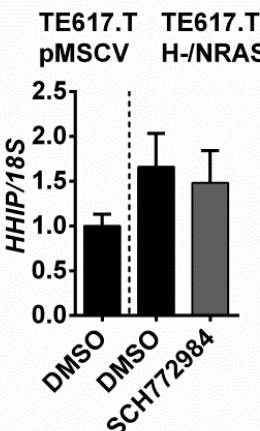

TE617.T TE617.T PMSCV H-INRAS

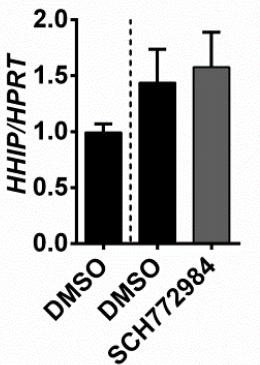

SHH
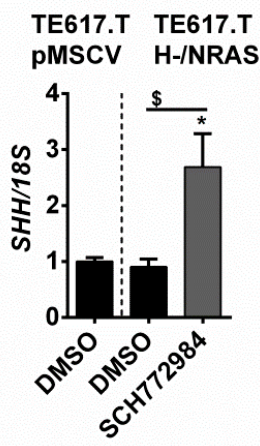

TE617.T TE617.T pMSCV H-INRAS

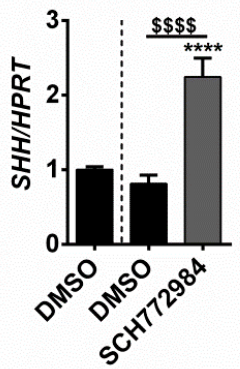

Figure 26: ERK inhibits PTCH and SHH expression in TE617.T H-/NRAS cells

TE617.T cells stably transduced with the pMSCV control vector or oncH-/NRAS (H-/NRAS) were incubated with DMSO or SCH772984 $(0.5 \mu \mathrm{M})$ for $24 \mathrm{~h}$. Afterwards cells were subjected to RNA isolation, cDNA synthesis and subsequent qRT-PCR analyses of the HH signaling pathway genes GLI2, GLI3, PTCH, HHIP and SHH. The data were normalized to $18 S$ rRNA (18S, upper row) or HPRT (lower row) and are shown as fold expression in comparison to DMSO treated TE617.T pMSCV cells, which was set to 1. The respective bar is shown in each histogram as a reference. Bars represent the mean + SEM of 4 independent experiments performed in technical triplicates. For statistical analyses a non-parametric t-test (Mann Whitney) was performed. * indicate significance compared to DMSO treated TE617.T pMSCV cells, whereas \$ indicate significance compared to TE617.T H/NRAS cells treated with DMSO.* $/ \$ p<0.05,{ }^{* * *} p<0.001,{ }^{* * * *} / \$ \$ \$ p<0.0001$

\subsection{OncRAS-mediated upregulation of SHH expression in RUCH-2 cells depends on ERK}

The expression of the $\mathrm{HH}$ signaling pathway genes GLI2, GLI3, PTCH, HHIP and SHH were also measured in $\mathrm{RUCH}-2$ cell lines, which were treated with $0.5 \mu \mathrm{M}$ of the ERK inhibitor $\mathrm{SCH} 772984$ for $24 \mathrm{~h}$ and $48 \mathrm{~h}$. Since the results after $24 \mathrm{~h}$ and $48 \mathrm{~h}$ were identical, only the $24 \mathrm{~h}$ values are shown.

In RUCH-2 pMSCV control cells SCH772984 did not significantly influence expression of any of the analyzed genes (Fig. 27). 
GLI2

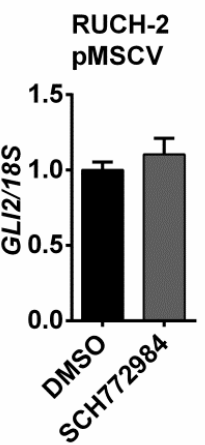

RUCH-2

pMSCV

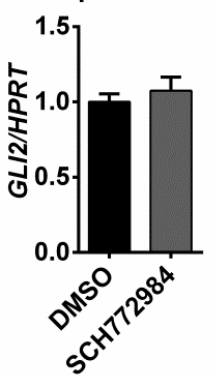

GLI3

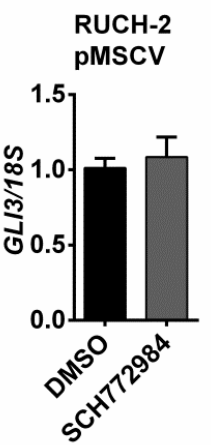

RUCH-2

pMSCV

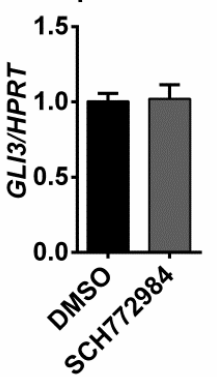

PTCH

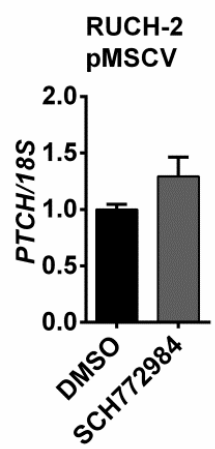

RUCH-2

pMSCV

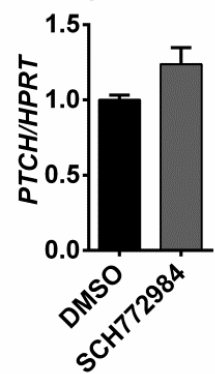

HHIP

SHH
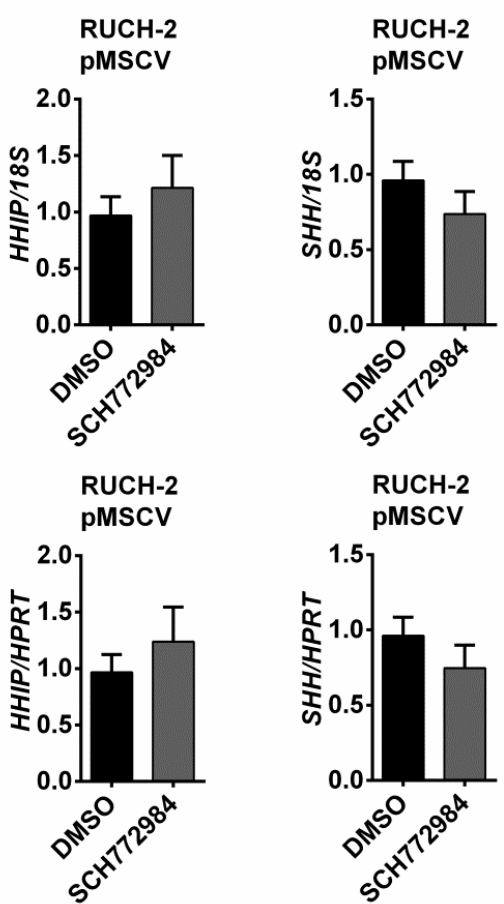

Figure 27: ERK inhibition does not influence expression of $\mathrm{HH}$ signaling genes in RUCH-2 pMSCV cells RUCH-2 cells stably transduced with the pMSCV control vector were incubated with DMSO or SCH772984 $(0.5 \mu \mathrm{M})$ for $24 \mathrm{~h}$. Afterwards cells were subjected to RNA isolation, cDNA synthesis and subsequent qRT-PCR analyses of the $\mathrm{HH}$ signaling pathway genes GLI2, GLI3, PTCH, HHIP and SHH. The data were normalized to $18 S$ rRNA (18S, upper row) or HPRT (lower row) and are shown as fold expression in comparison to cells incubated with DMSO, which was set to 1. Bars represent the mean + SEM of 3 independent experiments performed in technical triplicates. For statistical analyses a non-parametric t-test (Mann Whitney) was performed.

GLI2

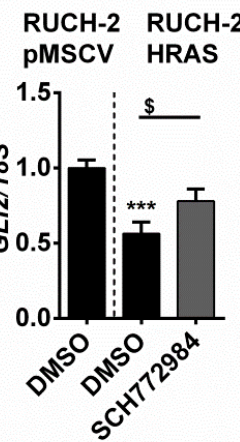

RUCH-2 RUCH-2 PMSCV HRAS

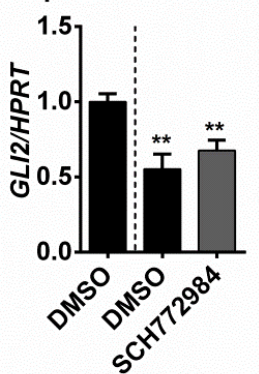

GLI3
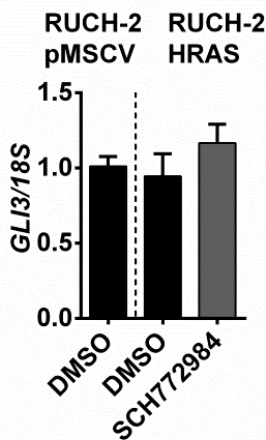

RUCH-2 RUCH-2 PMSCV HRAS

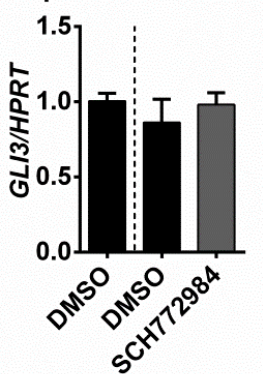

PTCH

$\begin{array}{ll}\text { RUCH-2 } & \text { RUCH-2 } \\ \text { pMSCV } & \text { HRAS }\end{array}$

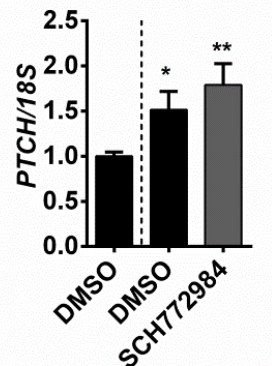

RUCH-2 RUCH-2 PMSCV HRAS

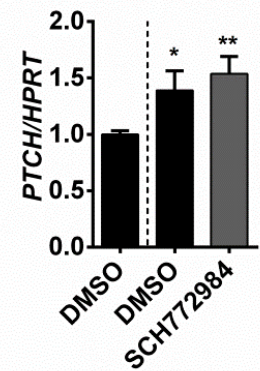

HHIP

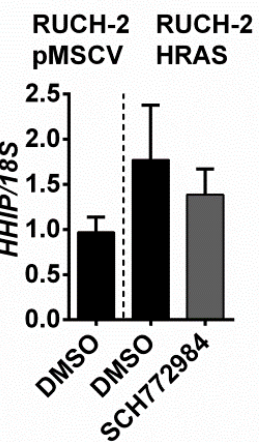

RUCH-2 RUCH-2 PMSCV HRAS

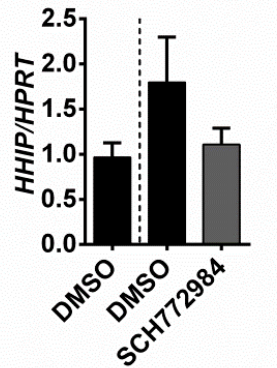

SHH

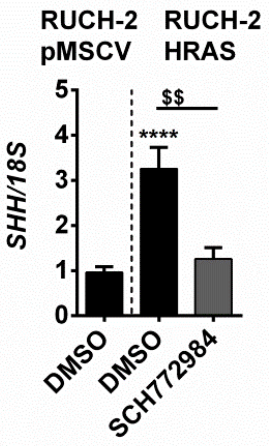

RUCH-2 RUCH-2 pMSCV HRAS

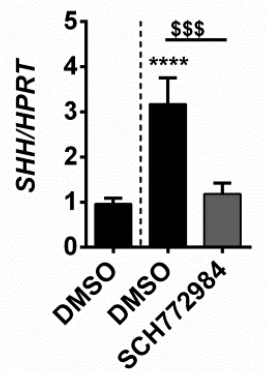

Figure 28: ERK mediates oncHRAS-dependent increase of SHH in RUCH-2 cells RUCH-2 cells stably transduced with the pMSCV control vector or oncHRAS (HRAS) were incubated with DMSO or $\mathrm{SCH} 772984(0.5 \mu \mathrm{M})$ for $24 \mathrm{~h}$. Afterwards cells were subjected to RNA isolation, cDNA synthesis and 
subsequent qRT-PCR analyses of the HH signaling pathway genes GLI2, GLI3, PTCH, HHIP and SHH. The data were normalized to $18 S$ rRNA (18S, upper row) or HPRT (lower row) and are shown as fold expression in comparison to DMSO treated RUCH-2 pMSCV cells, which was set to 1 . The respective bar is shown in each histogram as a reference. Bars represent the mean + SEM of 3 independent experiments performed in technical triplicates. For statistical analyses a non-parametric t-test (Mann Whitney) was performed. * indicate significance compared to DMSO treated RUCH-2 pMSCV cells, whereas \$ indicate significance compared to RUCH-2 HRAS cells treated with DMSO. ${ }^{*} \$ p<0.05,{ }^{* *} / \$ \$ p<0.01, \$ \$ \$ p<0.001,{ }^{* \star * *} p<0.0001$

Treatment of oncHRAS-expressing RUCH-2 cells, with SCH772984 restored oncRASmediated downregulation of GLI2 back to the basal expression level of the control RUCH-2 pMSCV cells. However, this was only seen after normalization to $18 S$ rRNA, but not upon normalization to HPRT. In contrast, the oncHRAS-dependent increase in SHH transcription was significantly downregulated and did not differ from the expression level of the control $\mathrm{RUCH}-2$ pMSCV cells. Finally, the oncHRAS-mediated upregulation of $\mathrm{PTCH}$ was not affected by application of SCH772984 (Fig. 28).

GLI2

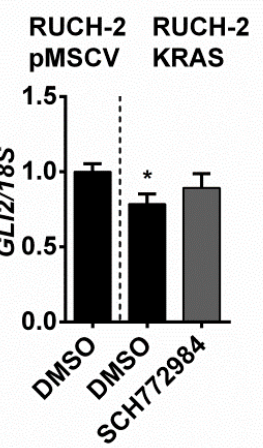

RUCH-2 RUCH-2 PMSCV KRAS

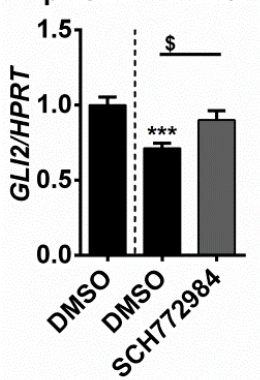

GLI3

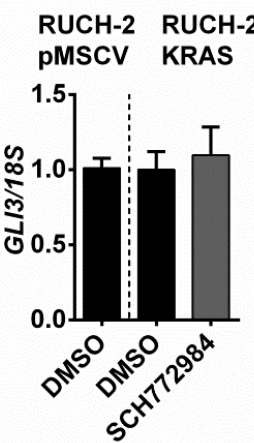

RUCH-2 RUCH-2 PMSCV KRAS

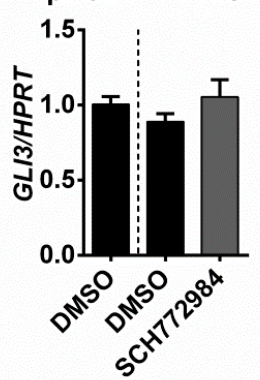

PTCH

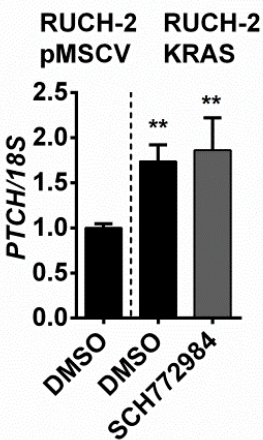

RUCH-2 RUCH-2 PMSCV KRAS

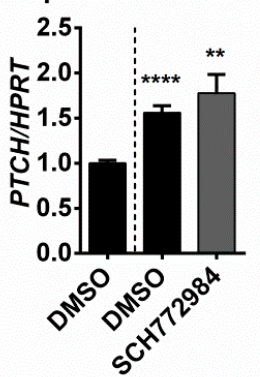

HHIP

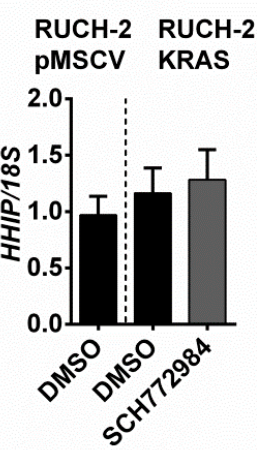

RUCH-2 RUCH-2 PMSCV KRAS

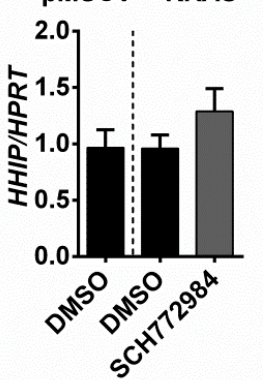

\section{SHH}

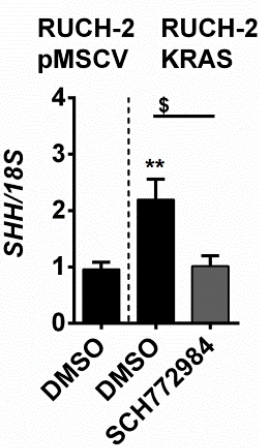

RUCH-2 RUCH-2 PMSCV KRAS

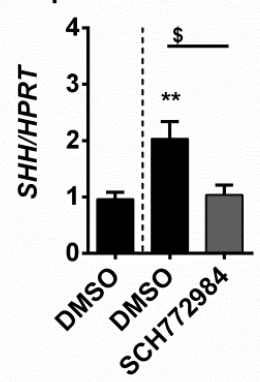

Figure 29: ERK mediates oncKRAS-dependent increase of $\mathrm{SHH}$ in RUCH-2 cells $\mathrm{RUCH}-2$ cells stably transduced with the pMSCV control vector or oncKRAS (KRAS) were incubated with DMSO or SCH772984 $(0.5 \mu \mathrm{M})$ for $24 \mathrm{~h}$. Afterwards cells were subjected to RNA isolation, cDNA synthesis and subsequent qRT-PCR analyses of the HH signaling pathway genes GLI2, GLI3, PTCH, HHIP and SHH. The data were normalized to $18 S$ rRNA (18S, upper row) or HPRT (lower row) and are shown as fold expression in comparison to DMSO treated RUCH-2 pMSCV cells, which was set to 1. The respective bar is shown in each histogram as a reference. Bars represent the mean + SEM of 3 independent experiments performed in technical triplicates. For statistical analyses a non-parametric t-test (Mann Whitney) was performed. * indicate significance compared to DMSO treated RUCH-2 pMSCV cells, whereas \$ indicate significance compared to RUCH-2 KRAS cells treated with DMSO. ${ }^{\star} / \$ p<0.05,{ }^{* *} p<0.01,{ }^{* \star *} p<0.001,{ }^{* \star \star *} p<0.0001$ 
vector harboring cells. The treatment with SCH772984 did not alter HHIP level. It however restored GLI2 and SHH level back to basal expression of the control RUCH-2 pMSCV cells, whereas PTCH expression was not affected by ERK inhibition (Fig. 29).

OncNRAS-expressing RUCH-2 cells showed a downregulation of GLI2 and an upregulation of SHH and PTCH, whereas HHIP was not affected. Treatment with SCH772984 increased the GLI2 expression level, however without reaching the basal expression level of control RUCH-2 pMSCV cells. The oncNRAS-mediated decrease in GL/3 expression was not affected, whereas the oncNRAS-dependent upregulation of $S H H$ was restored to basal level of the control. Additionally, $\mathrm{SCH} 772984$ increased the expression of $\mathrm{PTCH}$, at least after normalization to HPRT. The relative expression of HHIP was not affected (Fig. 30).
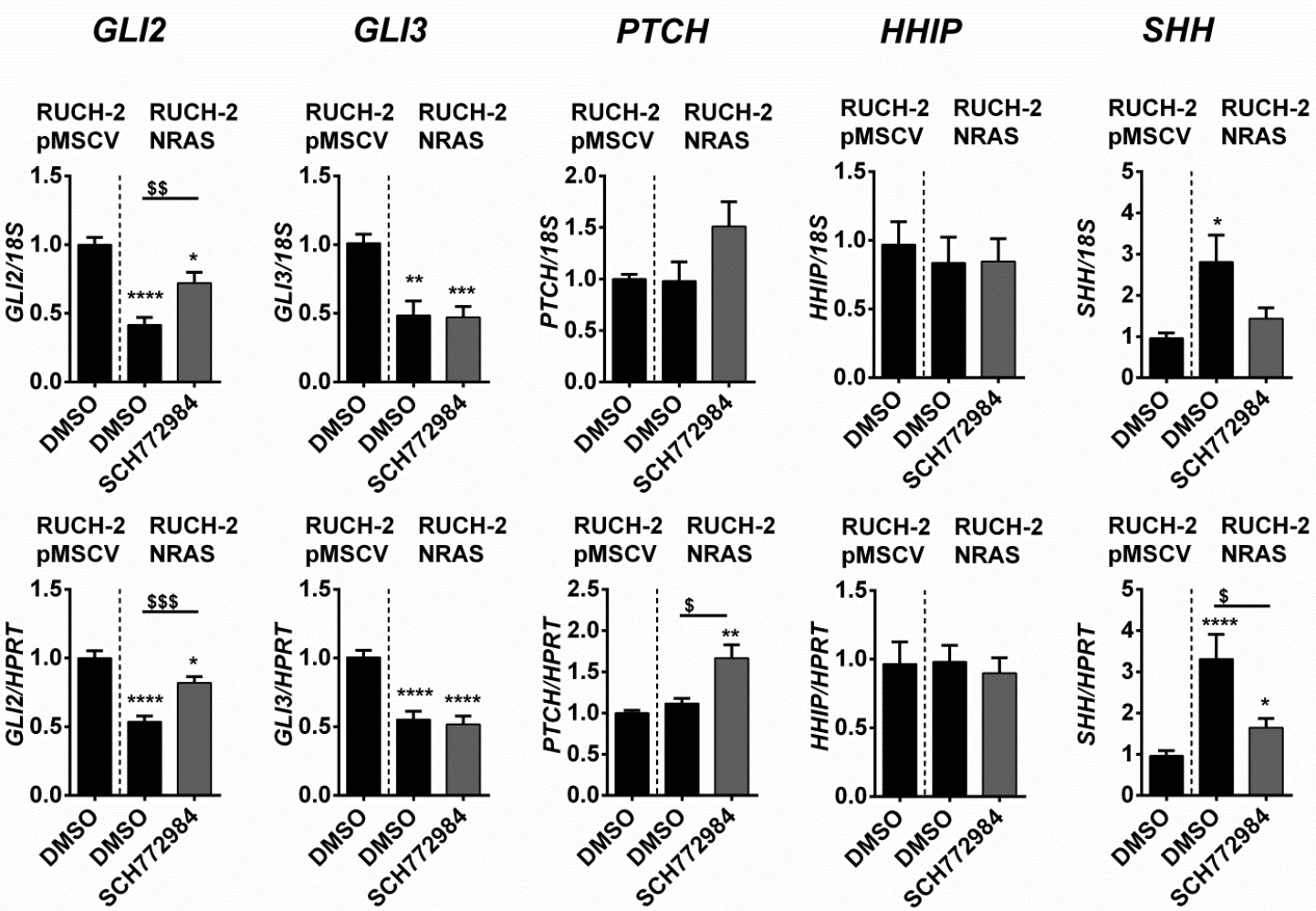

Figure 30: ERK mediates oncNRAS-dependent decrease in GLI2 and increase in SHH in RUCH-2 cells $\mathrm{RUCH}-2$ cells stably transduced with the pMSCV control vector or oncNRAS (NRAS) were incubated with DMSO or SCH772984 $(0.5 \mu \mathrm{M})$ for $24 \mathrm{~h}$. Afterwards cells were subjected to RNA isolation, cDNA synthesis and subsequent qRT-PCR analyses of the HH signaling pathway genes GLI2, GLI3, PTCH, HHIP and SHH. The data were normalized to $18 S$ rRNA (18S, upper row) or HPRT (lower row) and are shown as fold expression in comparison to DMSO treated RUCH-2 pMSCV cells, which was set to 1 . The respective bar is shown in each histogram as a reference. Bars represent the mean + SEM of 3 independent experiments performed in technical triplicates. For statistical analyses a non-parametric t-test (Mann Whitney) was performed. * indicate significance compared to DMSO treated RUCH-2 pMSCV cells, whereas \$ indicate significance compared to RUCH-2 NRAS cells treated with DMSO. $* \$ p<0.05,{ }^{\star *} / \$ \$ p<0.01, \$ \$ \$ p<0.001,{ }^{* \star * \star} p<0.0001$

Taken together, ERK is responsible for the oncRAS-mediated upregulation of $S H H$ in RUCH2 cells, whereas (in contrast to GLI1) it's involvement in oncRAS-mediated downregulation of GLI2 is not unambiguously clear. Furthermore, ERK is generally not involved in oncHRAS and oncKRAS-mediated induction of $\mathrm{PTCH}$ expression or in oncNRAS-dependent downregulation of $G L / 3$. 


\subsection{ERK inhibits GL/3 expression in RD cells}

The data from section 6.1.4 show that ERK upregulates GL/1 mRNA expression in RD cells. When analyzing the expression level of GLI2, GLI3, PTCH, HHIP and SHH after SCH772984 treatment, GLI2 and SHH expression slightly increased, whereas the GLI3 mRNA level was significantly upregulated. PTCH and HHIP expression level were not affected (Fig. 31).

RD cells
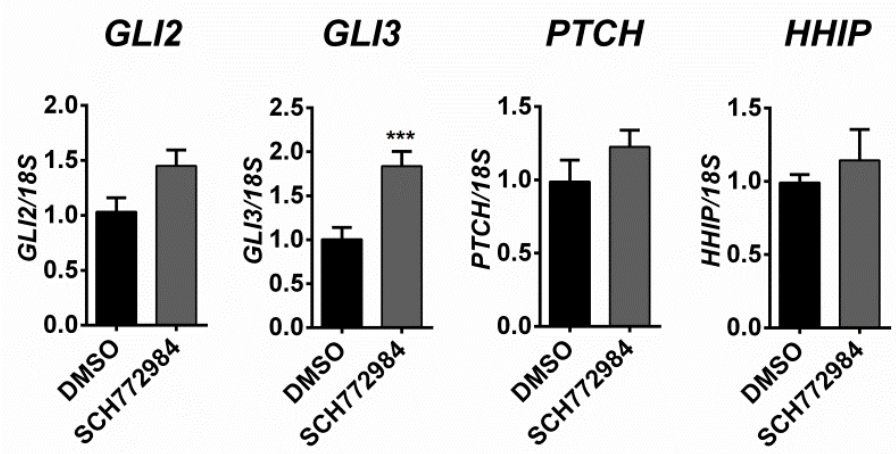

\section{SHH}
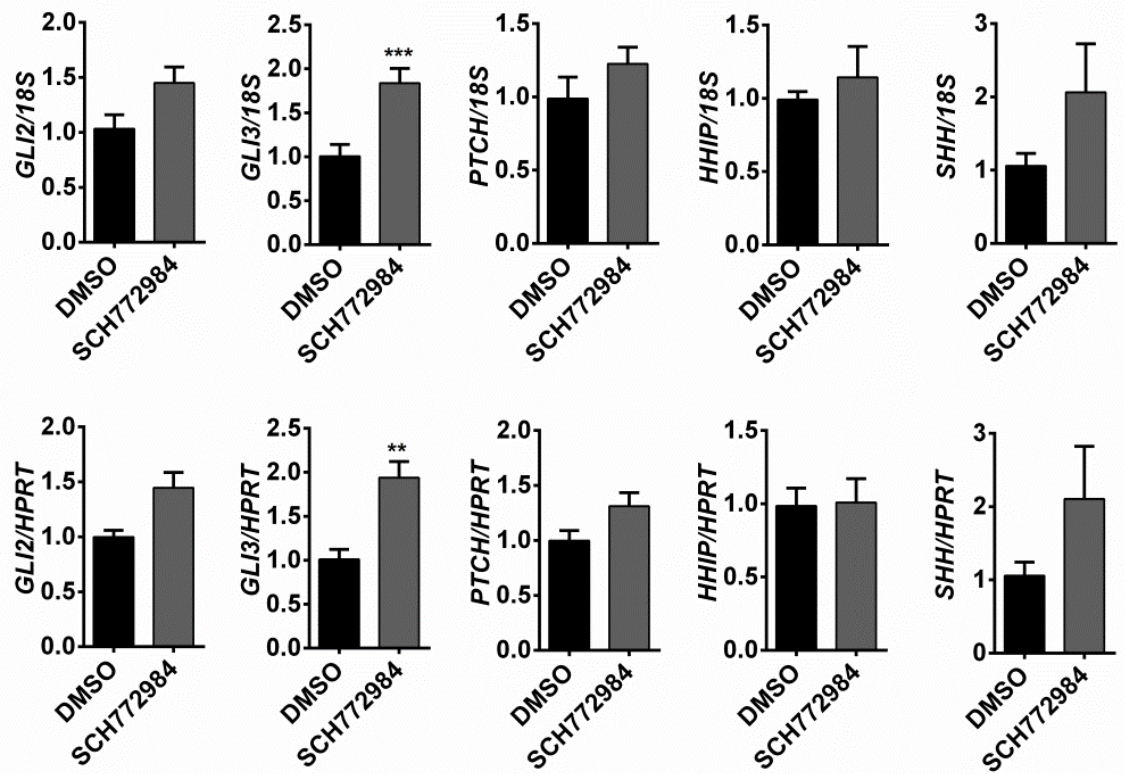

Figure 31: ERK inhibits GL/3 expression in RD cells

$\mathrm{RD}$ cells were incubated with DMSO or SCH772984 $(0.5 \mu \mathrm{M})$ for $24 \mathrm{~h}$. Afterwards cells were subjected to RNA isolation, cDNA synthesis and subsequent qRT-PCR analyses of the HH signaling pathway genes GLI2, GLI3, PTCH1, HHIP and SHH. The data were normalized to $18 S$ rRNA (18S, upper row) or HPRT (lower row) and are shown as fold expression in comparison to cells incubated with DMSO, which was set to 1. Bars represent the mean + SEM of 3 independent experiments performed in technical triplicates. For statistical analyses a nonparametric t-test (Mann Whitney) was performed. ${ }^{* *} p<0.01,{ }^{* * *} \mathrm{p}<0.001$ compared to expression level of DMSO treated RD cells.

To sum up, the results from sections 6.1.4.1 show that ERK (and MEK) inhibit GL/1 in TE617.T cells and in RUCH-2 cells with oncRAS isoforms. Additionally, ERK inhibits GLI1 in RD cells, harboring an oncNRAS mutation. In TE617.T cells ERK inhibits PTCH and SHH irrespective of an oncRAS mutation. Furthermore, the oncRAS-mediated upregulation of $S H H$ in RUCH-2 cells is dependent on ERK. In RD cells, ERK inhibits GL/3. The implication of ERK in regulation of GLI2 in these ERMS cell lines is not clear since statistical significance is not given in all cases. In contrast, ERK is not involved in oncHRAS and oncKRASmediated induction of $P T C H$ expression in RUCH-2 cells. It is also not involved in oncNRASand oncH-/NRAS-dependent downregulation of GLI3 in RUCH-2 and TE617.T cells, respectively.

\subsubsection{ERK inhibits GLI transcriptional activity in RD cells}

To investigate whether oncRAS itself or the inhibition of ERK indeed modifies the activation status of GLI transcription factors and thus of the $\mathrm{HH}$ signaling cascade, a GLI reporter assay 
was performed as described in section 5.1.9. The cells were transfected with a firefly luciferase reporter plasmid and a constitutively active renilla expression plasmid. The transfected cells were incubated for $24 \mathrm{~h}$ with DMSO or SCH772984 and measurement of GLI reporter activity was performed.

ERK inhibition did not influence activity of the GLI reporter neither in wt RAS nor in RUCH-2 cells expressing oncRAS (Fig. 32A). This is in contrast to GLI1 mRNA level that was suppressed by oncRAS in an ERK-dependent manner (compare section 6.1.4.1). On the one hand that may indicate that the suppression of GL/1 level apparently is regulated independently of GLI transcription factors. On the other hand, and more likely, the assay did simply not work in this very cell line, because the luciferase activity in the positive control was also not significantly elevated over the negative control. However, electroporation with the pEGFP-N1 control plasmid yielded over $70 \%$ transfection efficiency in RUCH-2 cell lines (data not shown). This is sufficient and consequently other parameters of the assay need to be optimized.

A
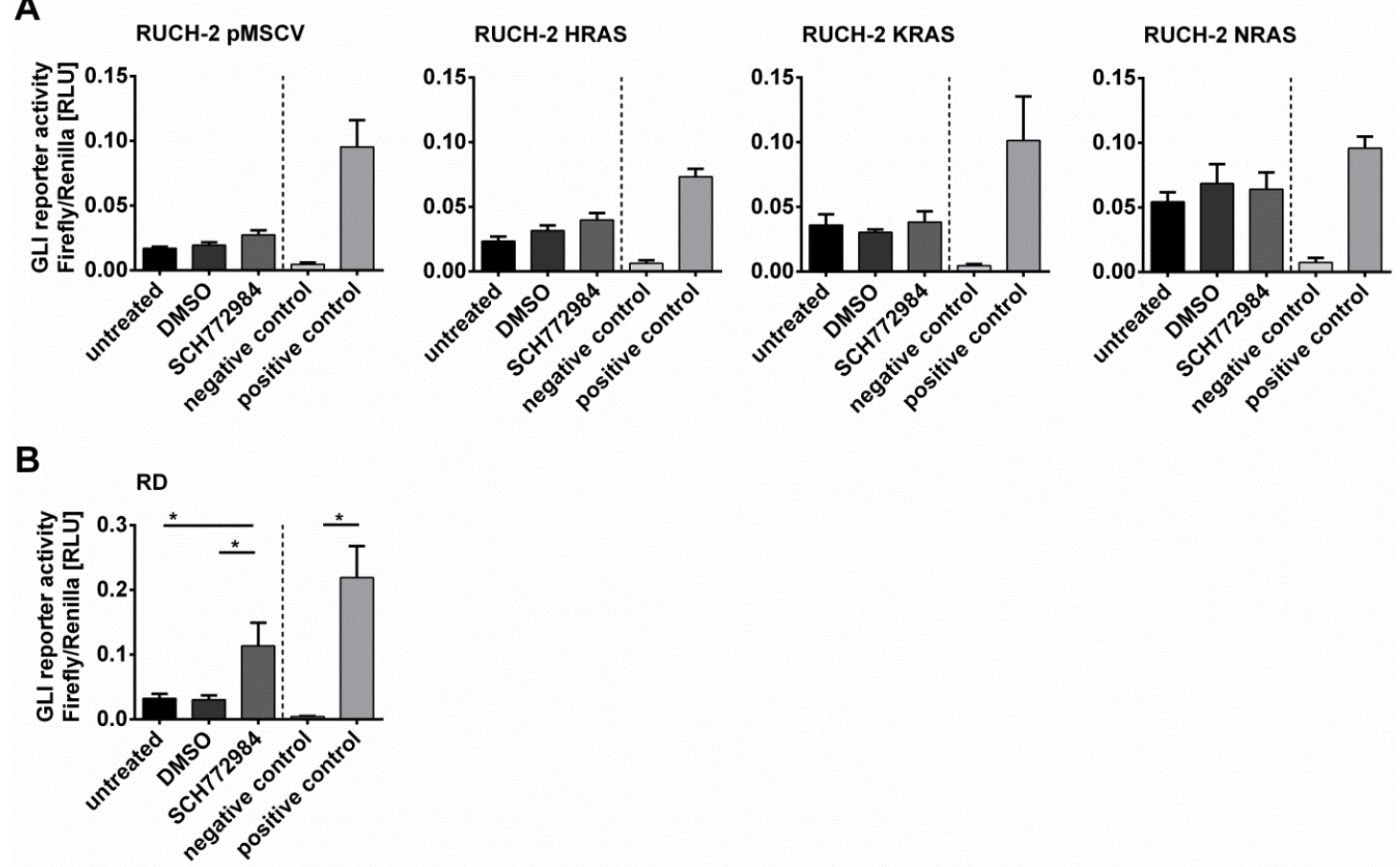

Figure 32: ERK suppresses GLI activity in RD cells but not in stably transduced RUCH-2 cell lines

$\mathrm{RUCH}-2$ cells stably transduced with the pMSCV control vector or oncRAS isoforms (HRAS, KRAS, NRAS) (A) and RD cells $(B)$ were transfected with plasmids for a GLI reporter assay. The cells were incubated with DMSO or $0.5 \mu \mathrm{M}$ SCH772984 for $24 \mathrm{~h}$. Afterwards, the relative GLI reporter activity was determined by a dual luciferase assay. The luminescence readout from firefly luciferase activity was normalized to renilla luciferase activity. The transfection with an mGli1 overexpressing plasmid (positive control), its pCR3.1 backbone (negative control) or untreated RMS cell lines transfected with the firefly luciferase reporter plasmid and the renilla vector served as controls. Bars represent the mean + SEM of $3(\mathrm{RUCH}-2)$ or $4(\mathrm{RD})$ independent experiments performed in technical sextuplicates or triplicates. For statistical analyses a non-parametric t-test (Mann Whitney) was performed. ${ }^{*} \mathrm{p}<0.05$

This was different in RD cells. In these cells SCH772984 significantly increased GLI reporter activity in comparison to DMSO treated or untreated cells. In addition, also the positive control revealed significant different results (Fig. 32B). In conclusion, ERK inhibits GLI 
activity and thus $\mathrm{HH}$ signaling activity in RD cells. This is in line with gene expression analyses, which showed that ERK inhibits the transcription of GL/1 and GL/3 (compare section 6.1.4.1.3 and section 6.1.4.2.3).

\subsubsection{OncRAS decrease GLI1 protein level in RUCH-2 cells}

Since oncRAS isoforms decreased GLI1 mRNA expression in all ERMS cell lines, further experiments focused on examination of GLI protein level and on the translocation of GLI repressor and activator forms into the nucleus. For this purpose, protein lysates were fractionated into total, cytosolic and nuclear fractions and a Western Blot for GLI proteins was established and performed (see section 5.3.2 and 5.3.5.2).

\section{RUCH-2}

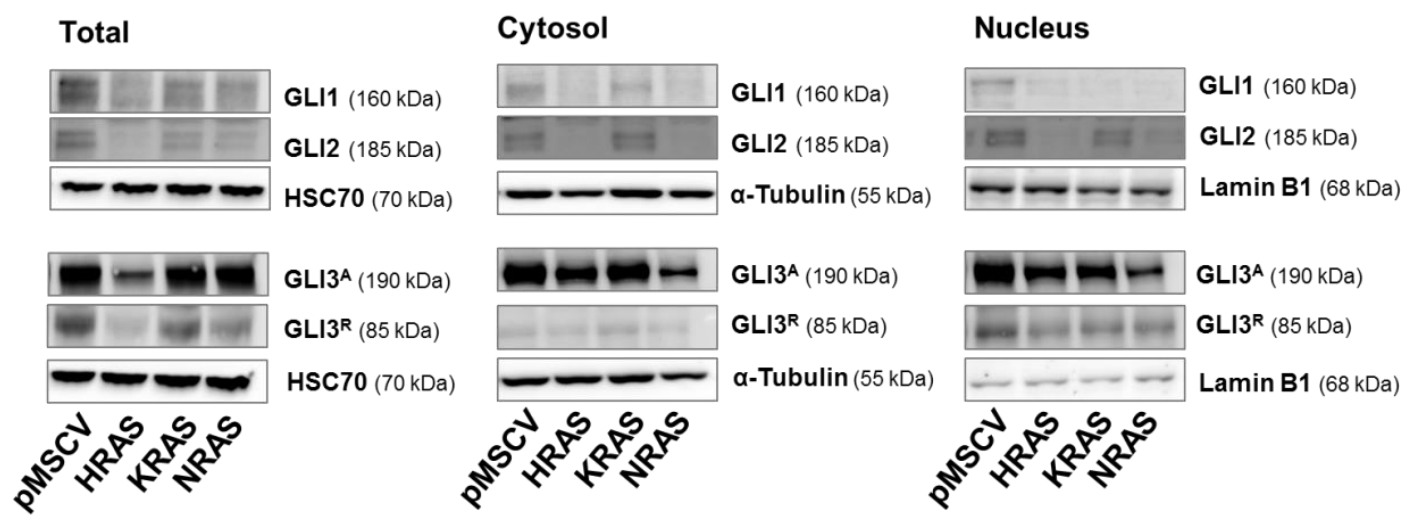

Figure 33: OncRAS isoforms modulate GLI protein expression in different cellular compartments in RUCH-2 cells

Protein was isolated from RUCH-2 cells stably transduced with the pMSCV control vector or oncRAS isoforms (HRAS, KRAS, NRAS). Afterwards the lysates were fractionated into total, cytosolic and nuclear lysates and subjected to Western Blot analyses. Protein level of GLI1, GLI2 and GLI3 activator (GLI3 ${ }^{A}$ ) and repressor forms $\left(G L I 3^{R}\right)$ were detected using specific primary antibodies. HSC70 served as reference protein for total fraction, $\alpha$ Tubulin as reference for cytosolic fraction and LaminB1 as reference for nuclear fraction. Protein names and sizes in $\mathrm{kDa}$ are displayed on the right side of the blots. The results are representative for 3 independent experiments.

As seen in RUCH-2 cells, oncRAS isoforms downregulated GLI1 regardless of the cellular compartment (Fig. 33). This result was consistent in 3 independent experiments. Furthermore, a downregulation of the full length GLI2 activator form and probably also the GLI3 full length activator and truncated repressor proteins were detected regardless of the cellular compartment. However, these results were uniformly seen only in 2 out of 3 experiments and thus need to be considered with care.

\subsubsection{OncRAS-dependent decrease of GLI1 is mediated by ERK in RUCH-2 cells}

Next it was investigated whether ERK inhibition in RUCH-2 oncRAS cells restores GLI1 protein level and also that of GLI2, GLI3 ${ }^{A}$ and $\mathrm{GLI} 3^{\mathrm{R}}$ back to basal level of RUCH-2 pMSCV control cells. For this purpose, the cells were incubated with $\mathrm{SCH} 772984$ for $24 \mathrm{~h}$. The protein lysates of cytosolic and nuclear fraction were used for a Western Blot analyses. As controls, lysates from HH-responsive Daoy cells treated with DMSO or SAG, or lysates from RMS-13 cells, which show GLI1 amplification ${ }^{326}$, were used. In most Western Blots the 
efficient fractionation in the cytosolic and nuclear fraction was revealed by level of the reference proteins $\alpha$-Tubulin and Lamin B1, respectively (Fig. 34). Unfortunately, the GLI2 and GLI3 data were not evaluable due to highly variable results between the 5 experiments. However, the experiments unambiguously showed that SCH772984 elevated GLI1 protein level in all oncRAS expressing cell lines (Fig. 34A: RUCH-2 HRAS, Fig. 34B: RUCH-2 KRAS, Fig. 34C: RUCH-2 NRAS) in both the cytosolic and nuclear fraction up to basal level detected in the control. This again confirms that oncRAS-mediated decrease of GLI1 is regulated by ERK.

RD cells were also treated with SCH772984 (data not shown). In this cell line ERK inhibition by $\mathrm{SCH} 772984$ did not change the protein level of any of the analyzed GLI proteins. However, similar to RUCH-2 cells the results were ambiguous and varied between the experiments and thus were not reliable.

\section{A RUCH-2}

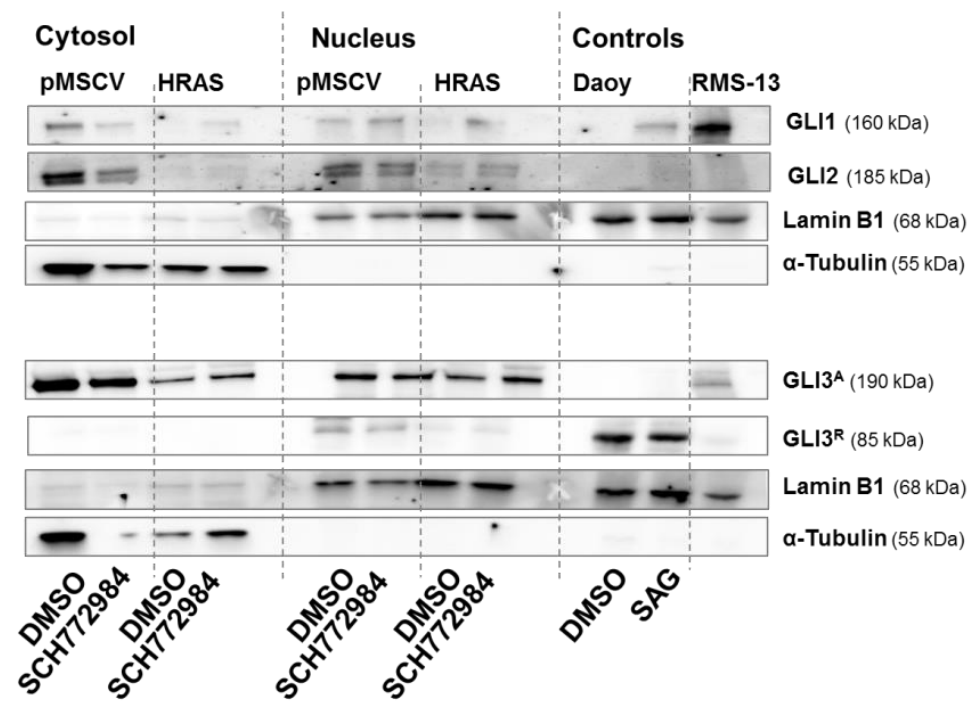

B RUCH-2

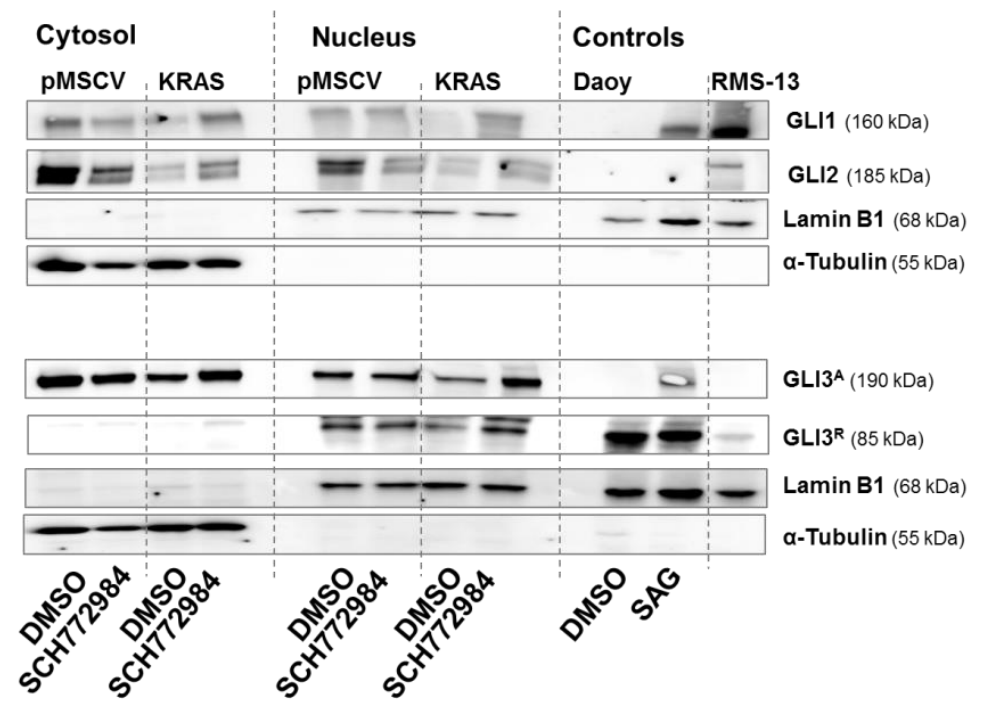


C RUCH-2

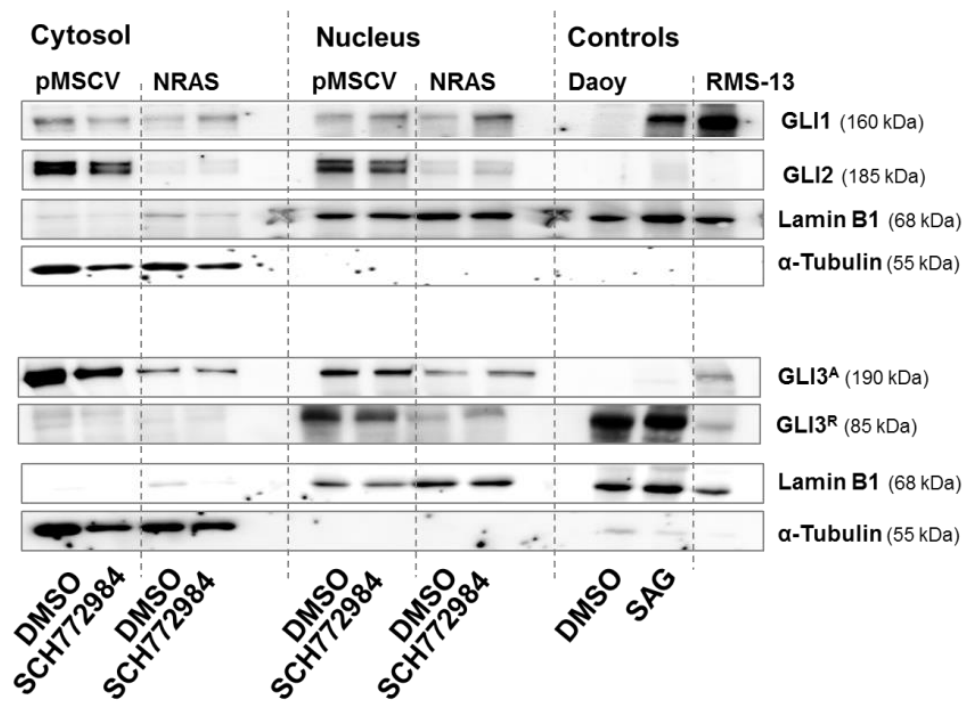

Figure 34: ERK inhibition reverses oncRAS-dependent decrease of GLI1 protein in RUCH-2 cells

RUCH-2 cells stably transduced with the pMSCV control vector or oncRAS isoforms (HRAS, KRAS, NRAS) were treated for $24 \mathrm{~h}$ with $0.5 \mu \mathrm{M} \mathrm{SCH772984}$. Afterwards protein was isolated from RUCH-2 pMSCV, RUCH-2 HRAS (A), RUCH-2 KRAS (B) and RUCH-2 NRAS (C) and the lysates were fractionated into cytosolic and nuclear lysates and subjected to Western Blot analyses. Protein level of GLI1, GLI2 and GLI3 activator (GLI3 ${ }^{A}$ ) and repressor forms $\left(G L I 3^{R}\right)$ were detected using specific primary antibodies. Protein lysates from starved Daoy cells treated with DMSO served as size control for GLI3 ${ }^{\mathrm{R}}$, whereas lysates from starved Daoy cells treated with $150 \mathrm{nM}$ SAG and lysates of RMS-13 cells served as control for GLI1, GLI2 and GLI3 ${ }^{A}$. $\alpha$-Tubulin served as reference for cytosolic fraction and LaminB1 as reference for nuclear fraction. Protein names and sizes in $\mathrm{kDa}$ are displayed on the right side of the blot. The results are representative for 5 independent experiments.

\subsubsection{OncRAS isoforms induce proliferation of TE617.T and RUCH-2 cells}

Next, the impact of oncRAS on the proliferative and metabolic activity of ERMS cell lines was investigated. For this purpose, BrdU incorporation assays and WST-1 based colorimetric assays (see section 5.1.5 and 5.1.6) were performed on TE617.T and RUCH-2 cells with and without oncRAS mutations. The assays were conducted $24 \mathrm{~h}$ after seeding for TE617.T cell lines. Analyses for $\mathrm{RUCH}-2$ cell lines were performed in a serial experiment from $24 \mathrm{~h}$ to $72 \mathrm{~h}$, because $\mathrm{RUCH}-2$ cells are slow-growing.

The results show that oncRAS strongly induced proliferation (Fig. 35A) and increased metabolic activity (Fig. 35B) in TE617.T cells. In RUCH-2 cells expressing oncHRAS a significant increase in proliferation was detected $72 \mathrm{~h}$ after seeding, whereas proliferation of $\mathrm{RUCH}-2$ cells expressing oncKRAS increased $48 \mathrm{~h}$ and $72 \mathrm{~h}$ after seeding in comparison to pMSCV control cells. The oncNRAS mutation apparently had no impact on proliferation within this time frame (Fig. 35C). Furthermore, none of the oncRAS mutations altered metabolic activity of RUCH-2 cells (Fig. 35D). 
A

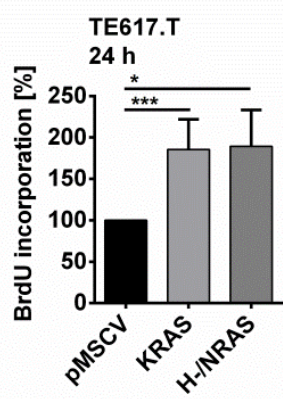

B

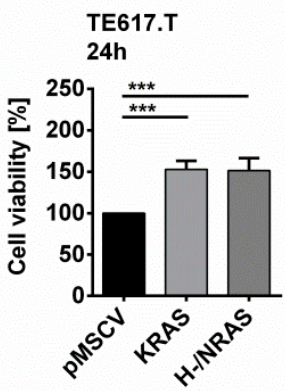

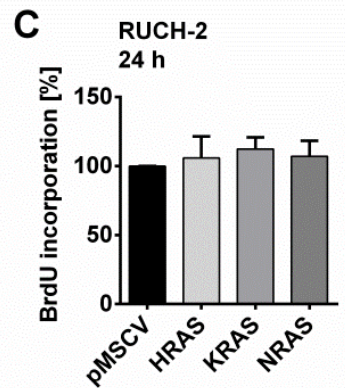

D RUCH-2

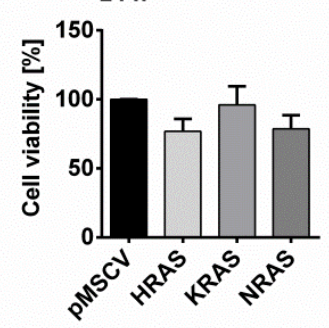

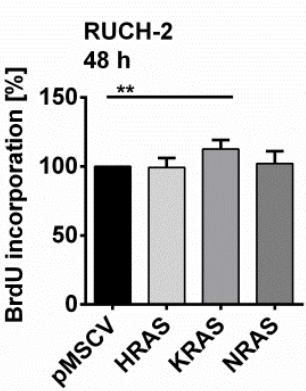
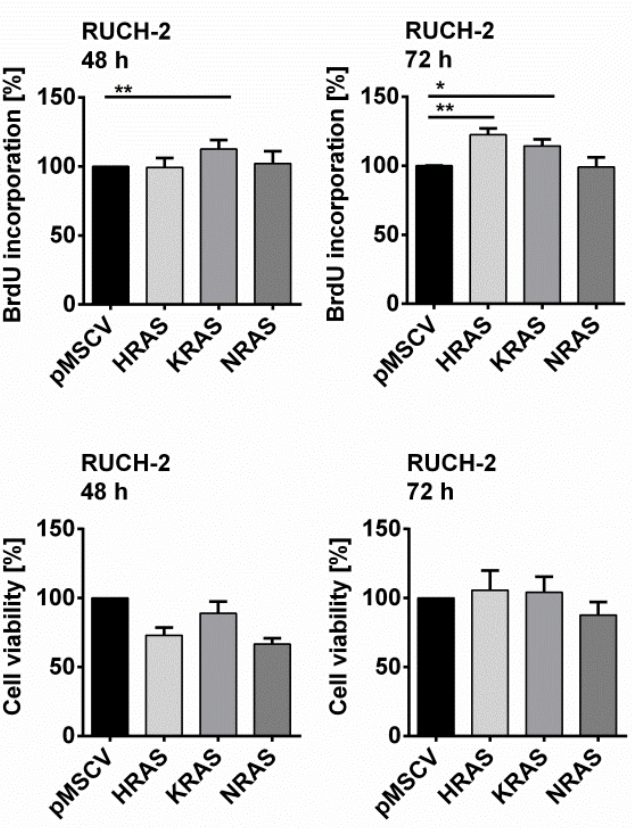

Figure 35: Impact of oncRAS on proliferation and metabolic activity of ERMS cell lines In TE617.T stably transduced with the pMSCV control vector or oncRAS isoforms (KRAS, H-/NRAS) (A, B) and RUCH-2 cells stably transduced with the pMSCV control vector or oncRAS isoforms (HRAS, KRAS, NRAS) (C, D) the proliferative (A, C) and metabolic activity (B, D) were measured $24 \mathrm{~h}$ (TE617.T, RUCH-2), or $48 \mathrm{~h}$ and $72 \mathrm{~h}$ (RUCH-2) after seeding. BrdU incorporation and cell viability of pMSCV control cells were set to $100 \%$. Bars represent the mean + SEM of $3(\mathrm{RUCH}-2)$ or 7 (TE617.T) independent experiments performed in technical sextuplicates or triplicates, respectively. For statistical analyses a non-parametric t-test (Mann Whitney) was performed. ${ }^{\star} p<0.05,{ }^{* \star} p<0.01,{ }^{* * *} p<0.001,{ }^{* * \star} p<0.0001$ compared to level of respective pMSCV control cells.

\subsubsection{Chapter summary}

In summary, the results of chapter 6.1 show that RMS cell lines, which are wt for RAS, have been successfully transduced with oncH-, oncK- or oncNRAS isoforms. A PCR using vector specific primers confirms successful transduction of all cell lines. Western Blot analyses confirm an increase in pERK and pan-RAS protein expression level. Additionally RAS activity is increased in these cell lines. Further analyses reveal that oncRAS mutations decrease GLI1 mRNA expression irrespective of the RMS subtype and the RAS isoform. Additionally, oncRAS does not only influences GL/1 expression, which is the major readout for $\mathrm{HH}$ signaling activity, but also the expression of other central stakeholders of the signaling pathway like GLI2, PTCH and SHH.

Since oncRAS isoforms increase or decrease $S H H$ expression in RUCH-2 oncRAS or TE617.T oncKRAS cells, respectively, it was also investigated whether the cells secrete $\mathrm{SHH}$ or not. Medium transfer experiments demonstrate that none of the investigated ERMS cell line was able to secrete $\mathrm{HH}$ ligands, regardless of the oncRAS mutation status. In addition, the data show that it is not possible to significantly activate $\mathrm{HH}$ signaling at least in RUCH-2 cells. Together these data suggest a non-canonical regulation of $\mathrm{HH}$ signaling or at least of GLI1 expression in ERMS by oncRAS.

Subsequent application of several kinase inhibitors shows that the oncRAS-mediated downregulation of GLI1 in RD and RUCH-2 cell lines is ERK-dependent. In TE617.T cells, 
GLI1 expression is inhibited already intrinsically by ERK and can be strengthened by oncRAS. A subsequent GLI reporter assay shows that ERK indeed regulates GLI activity in $\mathrm{RD}$ cells. However, this is not seen in $\mathrm{RUCH}-2$ cells, in which the assay probably does not work efficiently.

Furthermore, Western Blot analyses reveal that oncRAS mutations indeed downregulate the protein level of GLI1 both in the cellular and nuclear compartment of RUCH-2 cells and that ERK inhibition restores the protein expression back to basal level. Unfortunately, the data for GLI2, GLI3 ${ }^{A}$ and $\mathrm{GLI}^{\mathrm{R}}$ are too heterogeneous to make a final statement.

Finally, oncRAS induces proliferation of TE617.T and RUCH-2 cell lines despite downregulation of GL/1/GLI1. This indicates that the level of $\mathrm{HH}$ signaling, or at least of GL/1/GLI1, is not associated with the proliferative capacity of ERMS cells.

\subsection{Effects of oncRAS isoforms on xenografts derived from ERMS cell lines}

In vitro results described in section 6.1.5 and section 6.1.2.1 showed that oncRAS induces proliferation of ERMS cell lines despite GLI1 downregulation. In order to see, if the tumor cells behave similarly in the in vivo situation, all stably transduced ERMS cell lines were transplanted subcutaneously into flanks of 8-10 weeks old $\mathrm{Nu} / \mathrm{Nu}$ mice. In this experimental setting, pMSCV control cells were implanted into the left flank and oncRAS-expressing cells into the right flank of one and the same animal. The cohorts consisted of 8-12 animals. The approximate tumor volume was measured every or every second day with a caliper. When a tumor reached a diameter of $1.5 \mathrm{~cm}$ the mice were sacrificed. The exact tumor volume and the tumor weight were assessed after isolation. In order to see whether the tumor cells influence expression of $\mathrm{HH}$ target genes in the tumor microenvironment, species specific primers were used in qRT-PCR analyses of tumor samples.

\subsubsection{OncRAS increase tumorigenicity of TE617.T cells}

For the generation of tumors $2 \times 10^{6}$ TE617.T pMSCV, TE617.T KRAS or TE617.T H-/NRAS cells were injected into the animals. As already mentioned, all mice were sacrificed when a tumor reached a diameter of $1.5 \mathrm{~cm}$ or latest after 55 days. The transplantation studies were performed with either 8 (TE617.T pMSCV and TE617.T KRAS) or 12 (TE617.T pMSCV and TE617.T H-/NRAS) Nu/Nu mice.

\subsubsection{OncRAS enhance tumor growth and weight of TE617.T xenografts}

Transplanted TE617.T KRAS and TE617.T H-/NRAS cells resulted in a more aggressive tumor growth in comparison to simultaneously transplanted TE617.T pMSCV cells. Thus, the approximate tumor volume in living mice (measured by caliper), tumor weight and exact tumor volume after tumor isolation were significantly increased in comparison to the control (see Fig. 36A for TE617.T KRAS and Fig. 36B for TE617.T H-/NRAS). 
These results are in line with cell culture experiments, which showed an increased proliferation rate of TE617.T cells with an oncRAS mutation in comparison to control cells (section 6.1.5).

A

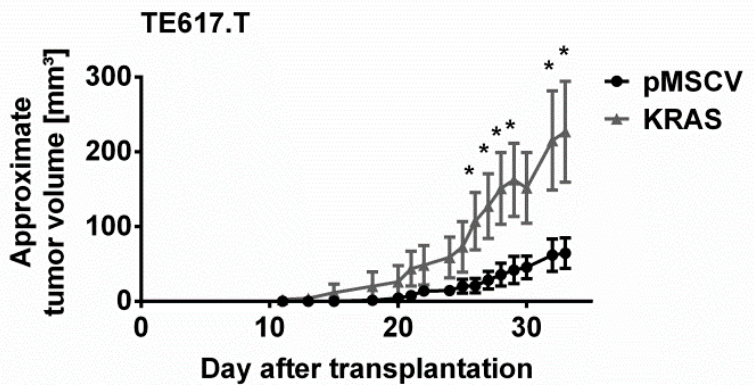

B

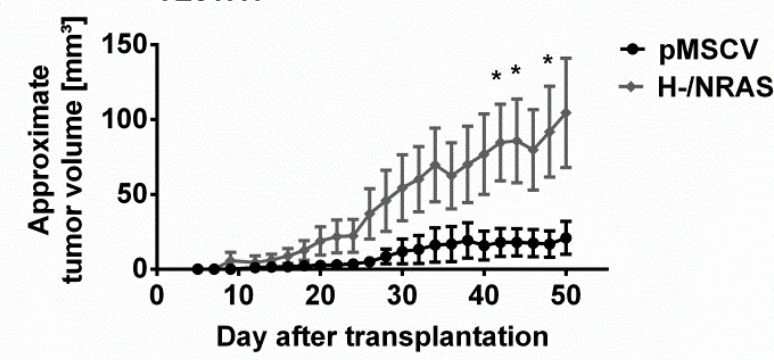

TE617.T

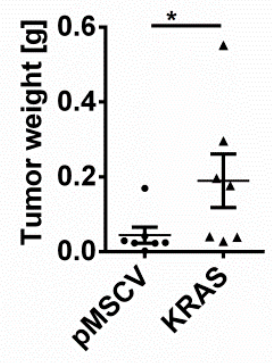

TE617.T

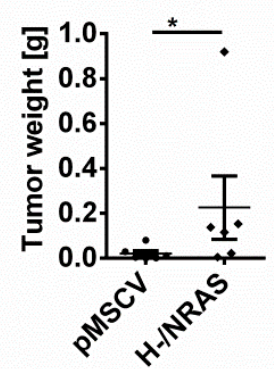

TE617.T

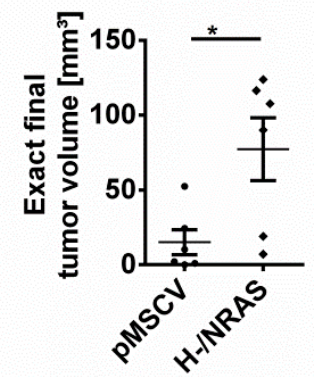

Figure 36: OncRAS isoforms increase tumor growth and weight of TE617.T xenografts

$2 \times 10^{6}$ TE617.T pMSCV and $2 \times 10^{6}$ TE617.T KRAS (A) or $2 \times 10^{6}$ TE617.T H-/NRAS (B) cells in $200 \mu$ PBS were transplanted into the left or right flanks, respectively, of $\mathrm{Nu} / \mathrm{Nu}$ mice ( $\mathrm{n}=8$ for TE617.T pMSCV and TE617.T KRAS, $n=12$ for TE617.T pMSCV and TE617.T H-/NRAS). Tumor size was measured with a caliper every or every second day after transplantation and the approximate tumor volume was calculated. The results are shown in the tumor growth curves in the left panels. At the end of the study tumors were isolated, weighed and measured to determine exact tumor volume. The results are shown in the respective middle and right panels. For statistical analyses multiple t-tests (growth curve) and non-parametric t-tests (Mann Whitney; for tumor weight and exact tumor volume) were performed. * indicate significance compared to characteristics of TE617.T pMSCV xenografts. ${ }^{*} p<0.05$

\subsubsection{OncH-/NRAS may influence tumorintrinsic SHH expression in TE617.T xenografts}

In cultured TE617.T cells the oncRAS mutations resulted in a slight decrease in GLI1 and SHH mRNA level (compare section 6.1.2). In order to analyze, whether this is still true for transplanted cells, the expression of these genes was also measured in the xenografts using primers specific for the human transcripts (Fig. 37A). Although the cultured cells apparently did not secrete $S H H$ (compare section 6.1.3.1), the potential effects of Hh signaling was also analyzed, i.e. on expression of murine mGli1, mGli2 in the surrounding murine stroma cells using primers specific for murine transcripts (Fig. 37B).

The RNA was isolated from all available frozen tumor samples of TE617.T pMSCV $(n=7)$, TE617.T KRAS $(n=5)$ and TE617.T H/NRAS $(n=6)$. Data were normalized to gene expression of TE617.T pMSCV tumors that have been transplanted simultaneously in the same animal. The results indicate that tumor-intrinsic $h G L / 1$ expression was slightly, but not significantly, decreased in tumors of oncKRAS and oncH/NRAS-expressing TE617.T cells in comparison to pMSCV control tumors. Additionally, a significant decrease of $h S H H$ was 
detected in oncH/NRAS tumors, whereas no influence on hGLI2 was measured (Fig. 37A). Analyses of mGli1 and mGli2 expression in the tumor microenvironment indicated no significant changes induced by oncRAS-expressing tumors (Fig. 37B). These results partly reflect the situation in cell culture (at least for $S H H$; compare section 6.1.2.2). They also suggest that oncRAS-expressing TE617.T xenografts do not influence Hh signaling in the tumor microenvironment.
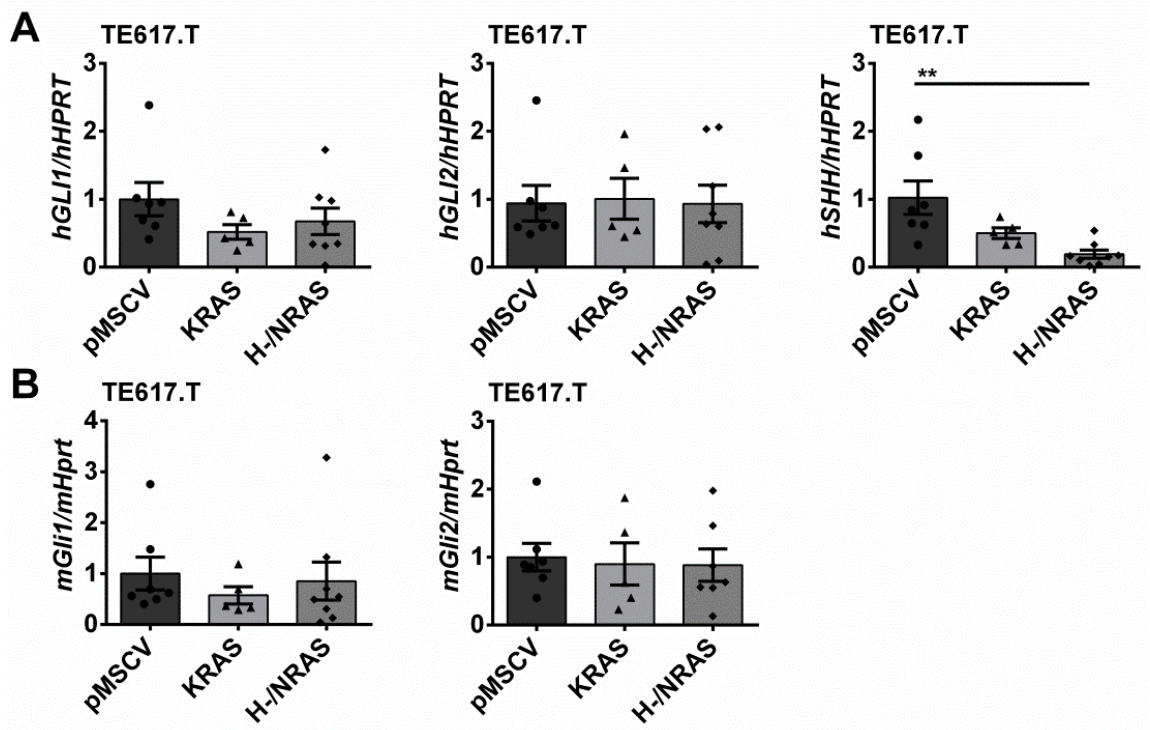

Figure 37: OncRAS do not significantly change the expression of $h G L / 1 / m G l i 1, h G L / 2 / m G l i 2$ in TE617.T xenografts

Xenograft tumors were subjected to RNA isolation, cDNA synthesis and subsequent qRT-PCR analyses of the $\mathrm{HH}$ signaling pathway genes $h$ GLI1/mGli1, hGLI2/mGli2, $h S H H$ using species specific primers for human (A) and murine genes (B). The data were normalized to $h H P R T$ for human gene expression (A) and to $m H p r t$ for murine gene expression (B) and are shown as fold expression to TE617.T pMSCV xenografts that were set to 1. Bars represent the mean \pm SEM of 7 (pMSCV), 5 (KRAS) or 6 (H/NRAS) isolated tumors. For statistical analyses nonparametric t-tests (Mann Whitney) were performed. ${ }^{* *} \mathrm{p}<0.01$ compared to expression level of TE617.T pMSCV xenografts.

\subsubsection{OncKRAS and oncNRAS increase tumorigenicity of RUCH-2 cells}

The transplantation of RUCH-2 cell lines were performed with $8 \mathrm{Nu} / \mathrm{Nu}$ mice for each cohort. In contrast to TE617.T cells, $9 \times 10^{6} \mathrm{RUCH}-2$ cells in matrigel were implanted. All mice were sacrificed when a tumor reached a diameter of $1.5 \mathrm{~cm}$ or latest after 21 days.

\subsubsection{OncKRAS and oncNRAS increase tumor growth and weight of RUCH-2 xenografts}

The transplantation of RUCH-2 KRAS (Fig. 38B) and RUCH-2 NRAS (Fig. 38C) cells resulted in a strongly enhanced tumor growth in comparison to simultaneously transplanted $\mathrm{RUCH}-2$ pMSCV cells. In contrast, RUCH-2 HRAS cells did not grow and the tumor volume started to regress early after transplantation (Fig. 38A). However, since BrdU incorporation in cultured RUCH-2 HRAS cells was significant (see section 6.1.5) and since RUCH-2 KRAS and RUCH-2 NRAS xenotransplants grew very fast, it is likely that the RUCH-2 HRAS cells have died prior or during the transplantation procedure. Nevertheless, this study should be repeated to see whether this assumption is true or not. 
A
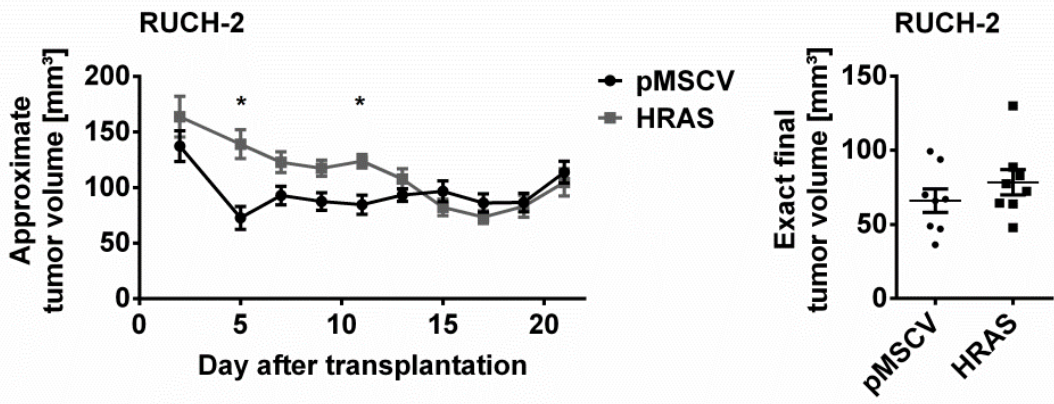

RUCH-2

B

RUCH-2

RUCH-2
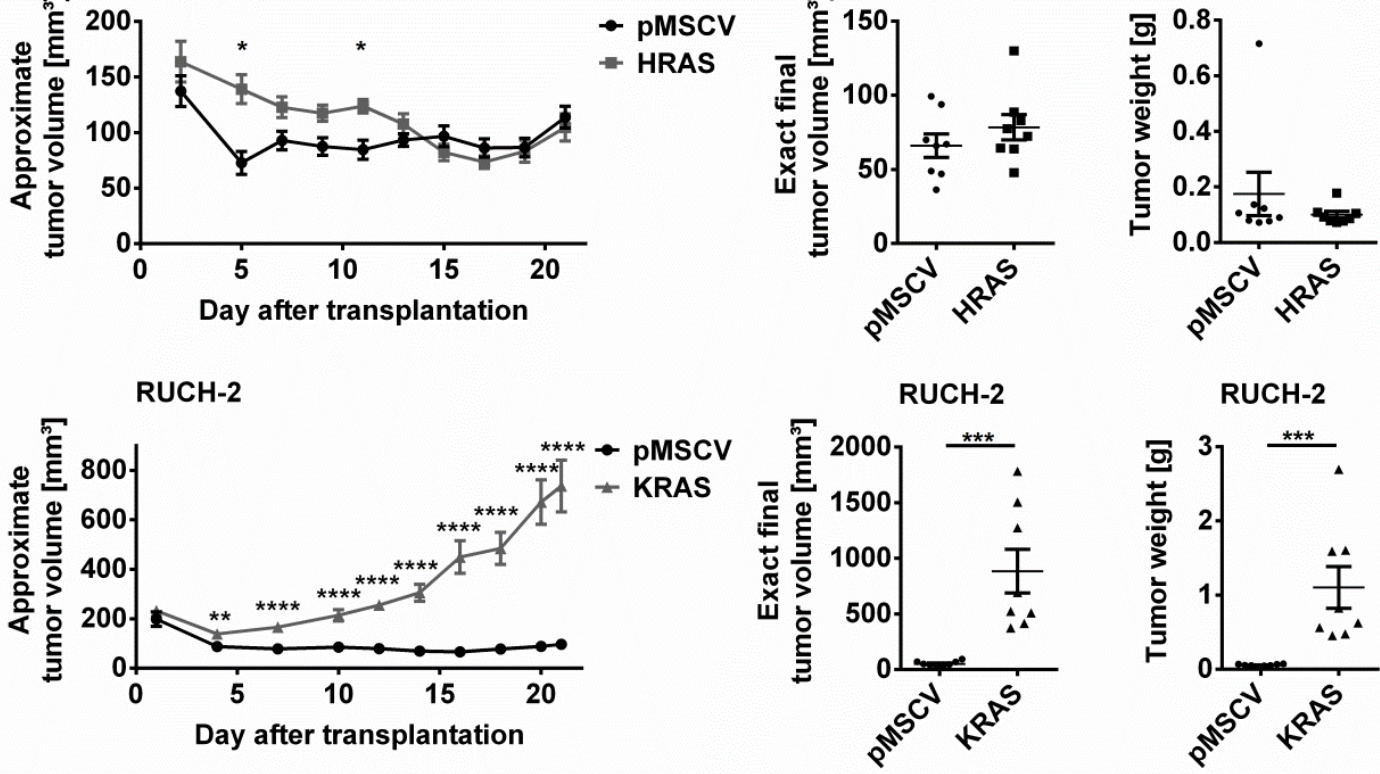

RUCH-2

C

RUCH-2

RUCH-2
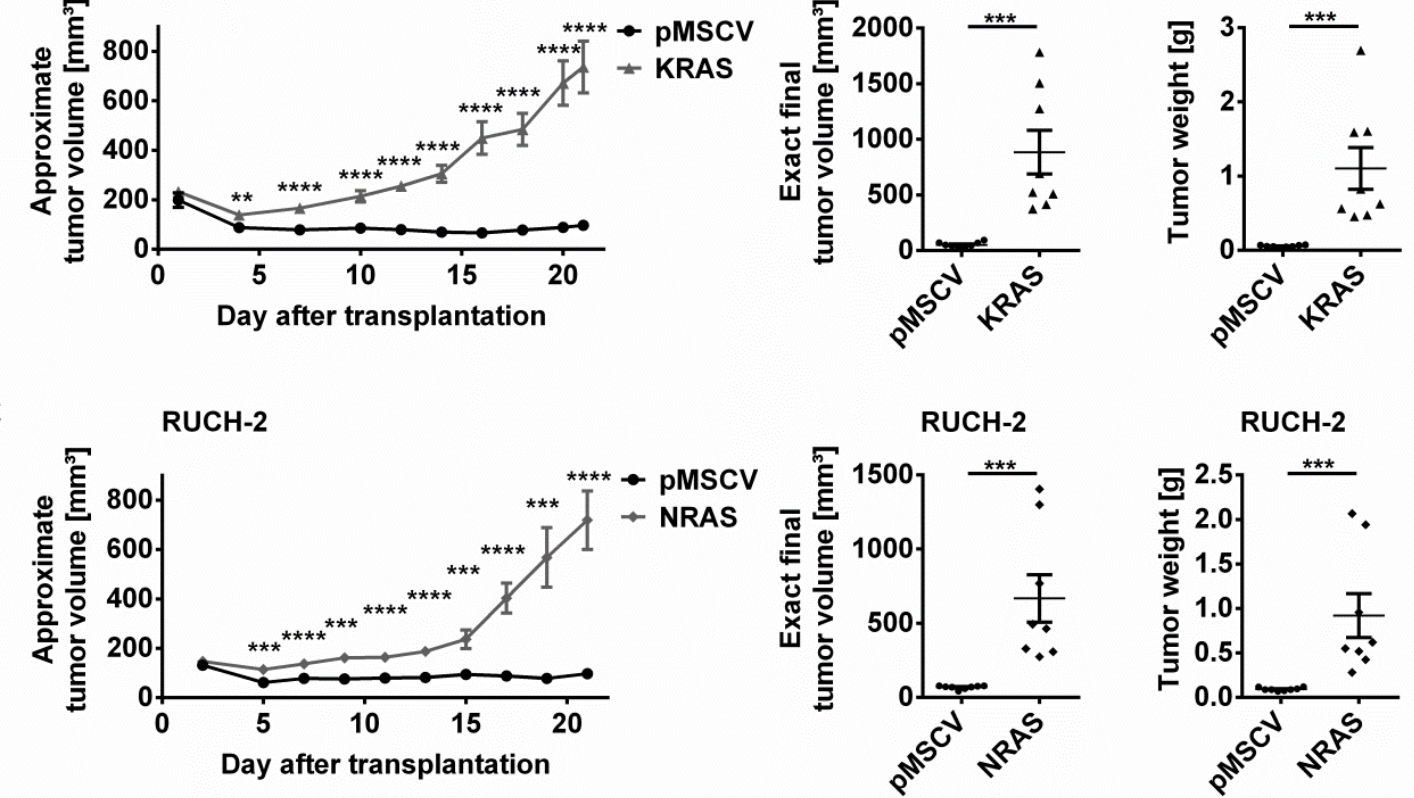

RUCH-2

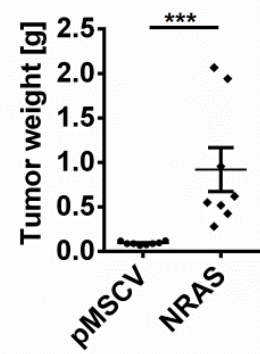

Figure 38: OncKRAS and oncNRAS increase tumor growth and weight of RUCH-2 xenografts

$9 \times 10^{6} \mathrm{RUCH}-2$ pMSCV, RUCH-2 HRAS (A), RUCH-2 KRAS (B) or RUCH-2 NRAS (C) cells in $200 \mu$ l PBS were transplanted into the left or right flanks, respectively, of $\mathrm{Nu} / \mathrm{Nu}$ mice $(\mathrm{n}=8$ for each cohort). Tumor size was measured with a caliper every or every second day after transplantation and the approximate tumor volume was calculated. The results are shown in the tumor growth curves in the left panels. At the end of the study tumors were isolated, weighed and measured to determine the exact tumor volume. The results are shown in the respective middle and right panels. For statistical analyses multiple t-tests (growth curve) and non-parametric ttests (Mann Whitney; for tumor weight and exact tumor volume) were performed. * indicate significance compared to characteristics of RUCH-2 pMSCV xenografts. ${ }^{*} p<0.05,{ }^{* *} p<0.01,{ }^{* * *} p<0.001,{ }^{* * * *} p<0.0001$

The approximate tumor volume of RUCH-2 xenografts with oncKRAS or oncNRAS mutations in living mice, and their weight and exact tumor volume after tumor isolation were significantly increased, when compared to RUCH-2 pMSCV xenografts (Fig. 38). For oncKRAS this result fits to cell culture experiments, in which oncKRAS also increased the proliferation rate. However, the in vivo results for the oncNRAS-expressing RUCH-2 cell line are different from the in vitro situation, in which oncNRAS did not increase the proliferation rate, even not after $72 \mathrm{~h}$ of incubation with BrdU (compare section 6.1.5).

\subsubsection{OncRAS may downregulate GLI1 expression in tumor cells and upregulate} Gli2 expression in stromal cells of RUCH-2 xenografts

In vitro experiments using oncRAS-expressing RUCH-2 cell lines showed a decrease in GLI1 and GLI2 mRNA level and a simultaneous increase in SHH mRNA level in comparison to the control (compare section 6.1.2). The expression of these genes was also analyzed in the 
xenografts. In addition and in order to see, whether RUCH-2 cell with oncRAS secrete SHH in vivo, the expression of Gli1 and Gli2 was measured in the tumor stroma.

In xenografts derived from oncKRAS-expressing $\mathrm{RUCH}-2$ cells the expression of $h G L / 1$ and $h S H H$ was somewhat lower in comparison to RUCH-2 pMSCV xenografts. However, these results were not significant. In addition, the level of $h G L I 2$ remained unchanged (Fig. 39A). When the expression level of $m$ Gli1 and $m$ Gli2 were measured, an increase in xenografts derived from oncKRAS-expressing RUCH-2 was detected, which was not significant for Gli1 but significant for Gli2. This indicates a potential impact of oncKRAS-expressing tumor cells on $\mathrm{HH}$ signaling in surrounding stromal cells (Fig. 39B). However, since $\mathrm{SHH}$ was rather downregulated in these xenografts, the increase in mGli1 or mGli2 is rather not mediated by secretion of the SHH ligand by tumor cells.

A

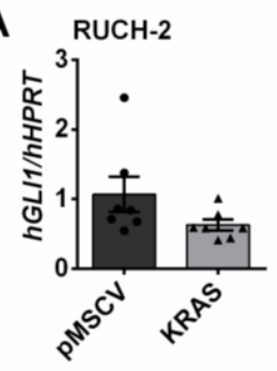

B

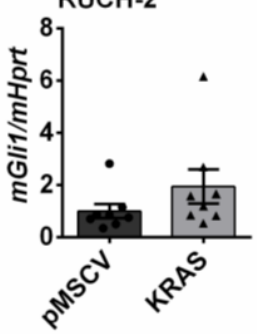

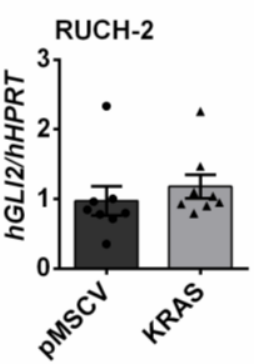

RUCH-2

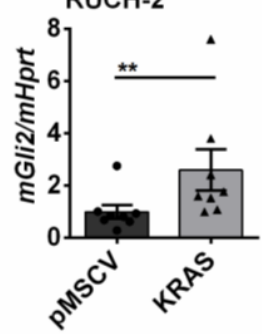

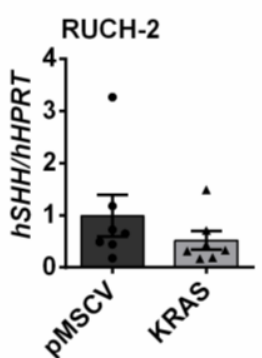

Figure 39: OncKRAS significantly induces $m$ Gli2 expression in the stroma of RUCH-2 xenografts

Xenograft tumors were subjected to RNA isolation, cDNA synthesis and subsequent qRT-PCR analyses of the $\mathrm{HH}$ signaling pathway genes $h$ GLI1/mGli1, hGLI2/mGli2, $h S H H$ using species specific primers for human (A) and murine genes (B). The data were normalized to $h H P R T$ for human gene expression (A) and to $m H$ prt for murine gene expression (B) and are shown as fold expression to RUCH-2 pMSCV xenografts that were set to 1. Bars represent the mean \pm SEM of 8 isolated tumors of each cohort. For statistical analyses non-parametric $t$-tests (Mann Whitney) were performed. ${ }^{* *} \mathrm{p}<0.01$ compared to expression level of RUCH-2 pMSCV xenografts.

Gene expression analyses of xenografts derived from oncNRAS-expressing RUCH-2 cells revealed that, as seen in cell culture, oncNRAS decreased hGLI1 and $h G L I 2$ in the tumor cells. Whereas the decrease in GL/1 was significant, the decrease in hGL/2 was not. In contrast to cell culture, oncNRAS also decreased $h S H H$ in comparison to RUCH-2 pMSCV xenografts (Fig. 40A). In the murine stroma, no significant changes in mRNA level of mGli1 and $m$ Gli2 were measured (Fig. 40B). 
A
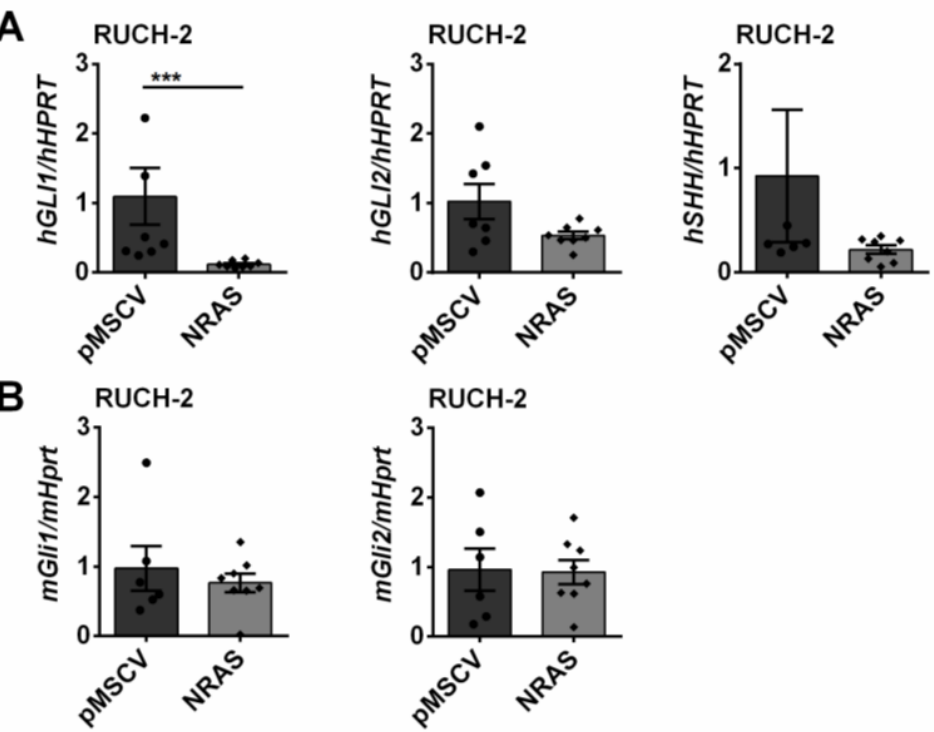

Figure 40: OncNRAS significantly decreases $h$ GLI1 expression in tumor cells of RUCH-2 xenografts

Xenograft tumors were subjected to RNA isolation, cDNA synthesis and subsequent qRT-PCR analyses of the $\mathrm{HH}$ signaling pathway genes $h \mathrm{GL} / 1 / \mathrm{mGli1}, h \mathrm{GL} / 2 / \mathrm{mGli2}$, $h S H H$ using species specific primers for human (A) and murine genes (B). The data were normalized to $h H P R T$ for human gene expression $(A)$ and to mHprt for murine gene expression (B) and are shown as fold expression to RUCH-2 pMSCV xenografts that were set to 1. Bars represent the mean \pm SEM of 8 isolated tumors of each cohort. For statistical analyses non-parametric t-tests (Mann Whitney) were performed. ${ }^{* * *} p<0.001$ compared to expression level of RUCH-2 pMSCV xenografts.

Taken together, the results show that transplanted RUCH-2 cells with oncKRAS or oncNRAS behave somewhat different when compared to cell culture (compare section 6.1.2). Thus, $h G L I 1$ is only moderately decreased in RUCH-2 oncKRAS xenografts (it however is significantly decreased in RUCH-2 oncNRAS xenografts) and an upregulation of $h S H H$ is observed in none of the analyzed xenografts. Nevertheless, the expression of mGli2 in the tumor stroma is significantly increased, at least in oncKRAS xenografts.

\subsubsection{Chapter summary}

In chapter 6.2, the impact of oncRAS on growth and $\mathrm{HH}$ signaling activity in ERMS xenotransplants is described. As in cell culture, the tumor growth is significantly stimulated by oncRAS mutations in ERMS cell lines. In addition, oncRAS tend to decrease tumorintrinsic GLI1 expression, although the respective results are only significant for oncNRASexpressing $\mathrm{RUCH}-2$ xenografts. In contrast, the transplantation of oncRAS cells rather results in a decrease in $\mathrm{SHH}$ expression (which was significant for oncH-/NRAS expressing TE617.T cells), whereas SHH expression of cultured oncRAS RUCH-2 or oncRAS TE617.T cells is elevated or decreased, respectively. Finally, tumor-extrinsic Gli2 expression in oncKRAS-expressing RUCH-2 xenografts is increased, which may indicate that the transplanted tumor cells indeed secrete $\mathrm{HH}$ ligands and thus may affect $\mathrm{HH}$ signaling activity in the tumor microenvironment. 


\subsection{Effects of oncRas mutations on ERMS of Ptch $^{\text {del/+ }}$ mice}

In addition, a genetic approach was pursued to study possible interactions of $\mathrm{Hh}$ and Ras signaling in ERMS. For this purpose the Ptch ${ }^{\text {del/t }}$ mouse model was used. These mice spontaneously develop RMS, which resemble ERMS in humans and show active Hh signaling ${ }^{137,143,323,324}$. Ptch ${ }^{\text {del/+ }}$ mice were crossed to mice which conditionally express one of the oncRas genes. In order to activate the expression of oncRas, the Myf5 $5^{\mathrm{CreER}}$ deleter ${ }^{305}$ mouse was used.

\subsubsection{Pilot testing and validation of the utilized mouse models}

\subsubsection{Testing the activity of the $M y f 5^{C r e E R}$ driver in ERMS using the $R 26 R^{+/}$reporter strain}

In a pilot test, the activity of the $M y f 5^{\text {CreER }}$ driver was analyzed in ERMS of $\mathrm{Ptch}^{\mathrm{del} /+}$ mutant mice. This Cre driver was chosen, because human and murine ERMS from Ptch mutant mice highly express $M y f 5^{323}$. In order to ensure that the oncRas mutations indeed will be induced in ERMS of Ptch ${ }^{\text {del/+ }}$ mice, Ptch ${ }^{\text {del/ }} M y f 5^{C r e E R}$ mice were bred to the cre-reporter strain R26R. When the mice developed a palpable tumor, they were injected i.p. with tamoxifen or solvent for 5 consecutive days and were sacrificed 1 or 5 weeks thereafter. ERMS and skeletal muscle (SM) as well as brain, heart (negative controls, not shown) and intestine (positive control due to endogenous $\beta$-galactosidase activity, not shown) were isolated and subjected to X-Gal stainings (see section 5.4.3). Another positive control was SM from Rosa26-lacZ mice. These mice express lac $Z$ and thus show high $\beta$-galactosidase activity in every organ of the body ${ }^{306}$.

Tissue sections of SM and ERMS from solvent-treated $P t c h^{\text {del/ }} M y f 5^{\mathrm{CreER}} R 26 R^{+/}$mice showed no X-Gal staining, whereas ERMS from tamoxifen-treated $P t c h{ }^{\text {del/ }} M y f 5^{\mathrm{CreER}} R 26 R^{+/}$mice stained positive (Fig. 41). The galactosidase activity visualized by $X$-Gal staining was detected in ERMS 1 or 5 weeks after treatment. Since no staining was detected in SM, it was concluded that the $M y f 5^{\mathrm{CreER}}$ driver is primarily active in ERMS and also does not show any leakiness i.e. it is not active without tamoxifen. Nevertheless, the staining itself was not as strong as expected from literature ${ }^{305}$. 


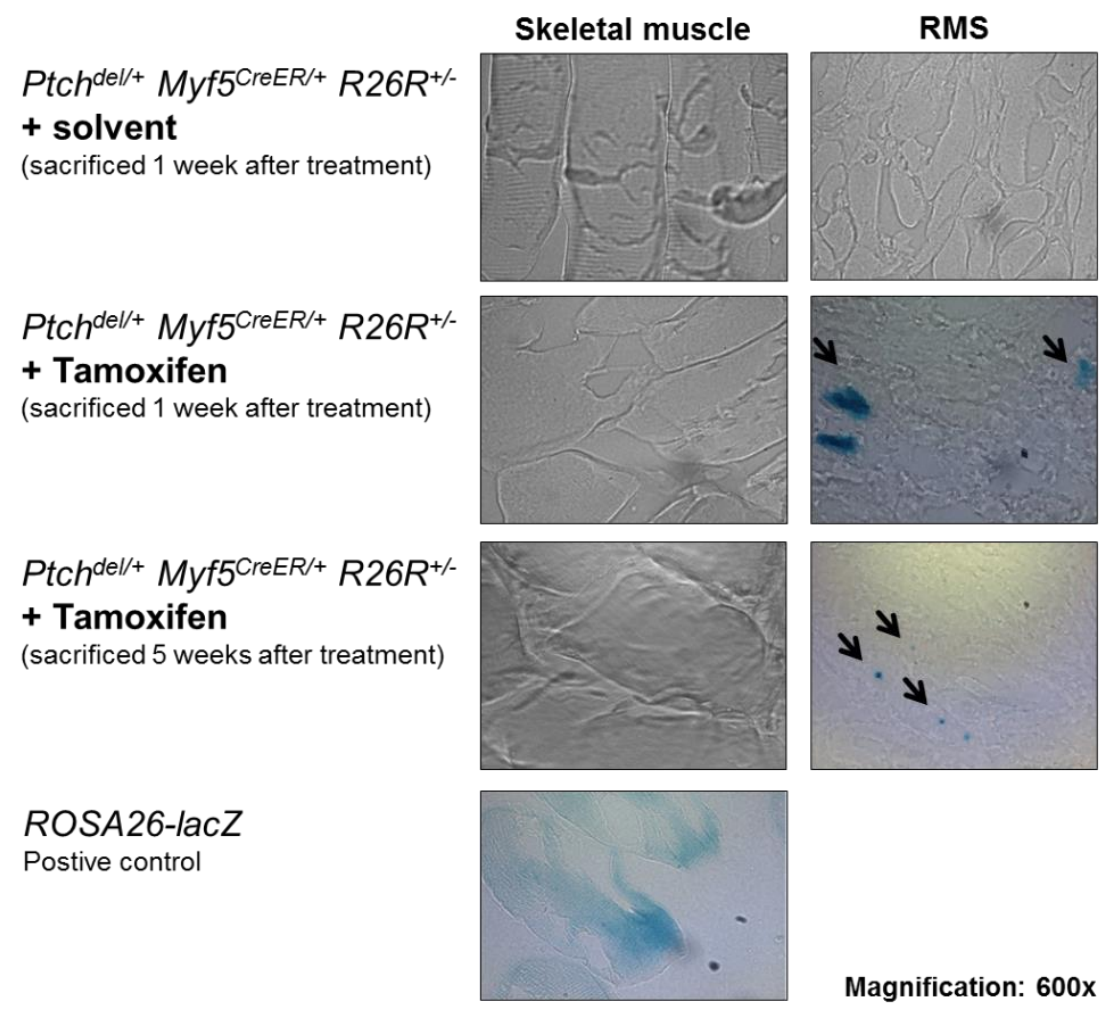

Figure 41: X-Gal staining of skeletal muscle and ERMS isolated from solvent- or tamoxifen-treated Ptch $^{\text {del/+}}$ Myf5 $^{\mathrm{CreER} /+} \mathrm{R}^{26 R^{+/ /}}$mice

Cryo-embedded sections of skeletal muscle (SM) and ERMS (RMS) from solvent- or tamoxifen-treated Ptch $^{\text {del/ }+} \mathrm{Myf5}^{\mathrm{CreER/+}}{ }^{\mathrm{R}} 26 R^{+-}$mice were subjected to X-Gal staining. Cryo-embedded sections of SM from ROSA26lacZ mice served as positive control. The arrows point to areas of staining. Pictures were taken at $600 x$ fold magnification.

\subsubsection{HRas, KRas and NRas are expressed in SM and ERMS of Ptch ${ }^{d e l /+}$ mice}

Next, the expression of HRas, KRas and NRas were analyzed by PCR and qRT-PCR in SM and ERMS from Ptch ${ }^{\text {del/+ }}$ mice. These analyses were done to confirm that the Ras isoforms are expressed mainly in ERMS: if Ras should not be expressed in ERMS from Ptch ${ }^{\mathrm{del} /+}$ mice, an activation of oncRas from the endogenous Ras locus is not possible. As shown in Fig. 42, HRas, KRas and NRas are expressed in SM and ERMS tissue, respectively (Fig. 42A, Fig. 42C and Fig. 42E, respectively). Moreover, qRT-PCR data showed that the level of HRas expression is equal in SM and ERMS, whereas KRas and NRas level are higher in ERMS compared to SM (Fig. 42B, Fig. 42D and Fig. 42F, respectively).

In addition, the Ras loci were sequenced to rule out endogenous mutations in the 3 genes. However, all 3 Ras loci were wt in more than 5 analyzed RMS from Ptch $^{\text {del/ }}$ mice (data not shown). 


\section{A HRas}

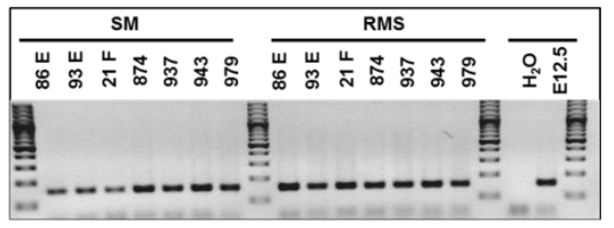

C KRas

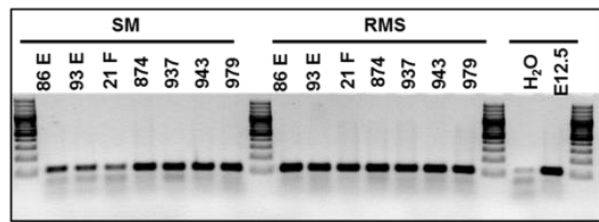

E NRas

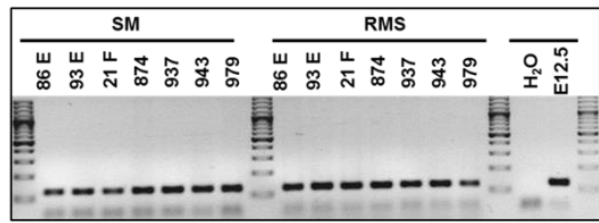

B
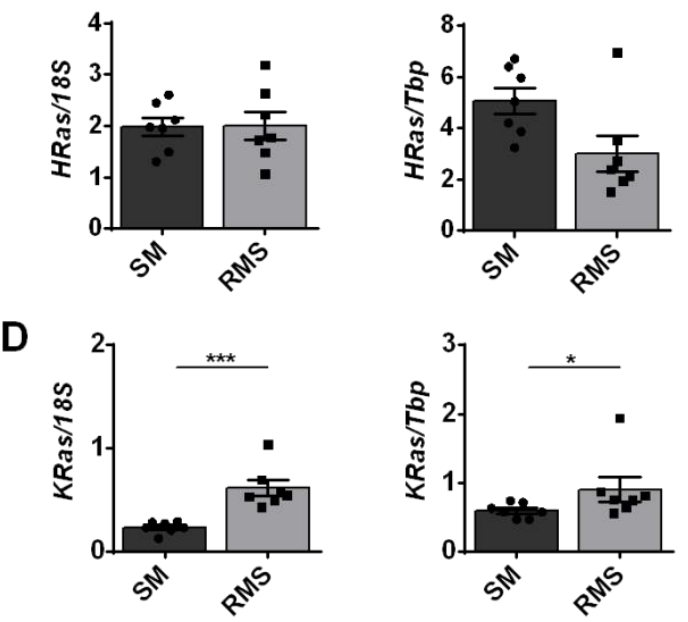

$\mathbf{F}$

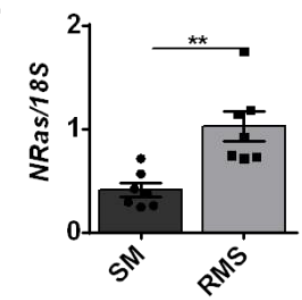

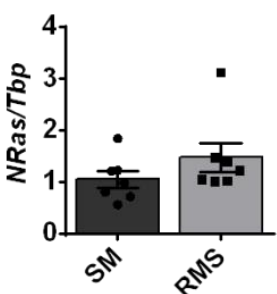

Figure 42: Ras isoforms are expressed in SM and ERMS tissue samples of $\mathrm{Ptch}^{\mathrm{del/}+}$ mice

The basal expression of HRas (A, B), KRas (C, D) and NRas (E, F) were analyzed in skeletal muscle (SM) and ERMS (RMS) tissue samples of Ptch ${ }^{d e l /}$ mice by PCR (A, C, E) and quantified by qRT-PCR (B, D, E). The numbers in $A, C$ and $E$ indicate the mouse identification number. The expression in embryos at E12.5 served as positive control. The histograms shown in B, D and F represent qRT-PCR analyses and show the mean gene expression \pm SEM of 7 tissue samples for SM and ERMS. Data were normalized to $18 \mathrm{~S} r R N A$ (18S, left) or Tbp (right). For statistical analyses non-parametric t-tests (Mann Whitney) were performed. ${ }^{*} \mathrm{p}<0.05,{ }^{* *} \mathrm{p}<0.01$, ${ }^{* * *} p<0.001$ compared to expression level within SM.

\subsubsection{Testing Myf5 ${ }^{\text {CreER }}$ activity at the Ras loci in ERMS of Ptch $^{\text {del/+}}$ oncRas ${ }^{f /+}$ Myf5 $^{\mathrm{CreER} /+}$ mice}

After having checked the activity of the Myf5 ${ }^{\mathrm{CreER}}$ driver in ERMS (see section 6.3.1.1), it was tested whether this Cre driver also efficiently targets the 3 oncogenic Ras loci. This was done because it is well known that the recombination efficiency of one and the same Cre driver can vary at different loci ${ }^{338-340}$. The recombination assays were performed on frozen or paraffin-embedded tissue samples from SM and ERMS of $\mathrm{Ptch}^{\mathrm{del} /+} \mathrm{HRas}^{\mathrm{fl}+} \mathrm{Myf5}^{\mathrm{CreER} /+}$, $\mathrm{Ptch}^{\mathrm{del} /+} \mathrm{KRas}^{\mathrm{fl} /+} \mathrm{Myf5}^{\mathrm{CreER} /+}$ and $\mathrm{Ptch}^{\text {del/+}} \mathrm{NRas}^{\mathrm{fl} /+} \mathrm{Myf5}^{\mathrm{CreRE} /+}$ mice (compare section 5.2.3.2). Additionally, frozen tissue samples from these mice were used for a second round of genotyping to confirm the genetic setting (compare section 5.2.3.1).

The recombination assay for HRas was done on PCR-amplified cDNA by enzymatic digestion with Bpml. The enzyme recognizes the wt sequence (derived from the wt and the floxed locus), whereas the mutant HRas exon is not recognized due to the HRas ${ }^{G 12 V}$ mutation ${ }^{303}$ (compare section 5.2.3.2.2). As already described, successful recombination was indicated by weak $209 \mathrm{bp}$ and 93 bp digestion bands and a strong undigested fragment of $302 \mathrm{bp}$. 
SM tissue samples from untreated, solvent-treated (not shown) and tamoxifen-treated $\mathrm{Ptch}^{\text {del/+}} \mathrm{HRas}^{\mathrm{fl/}+} \mathrm{Myf5}^{\mathrm{CreER} /+}$ mice showed a weak band for undigested transcript and a strong band for the digested, wt transcripts. The same bands were also observed in ERMS samples from untreated and solvent-treated (not shown) $\mathrm{Ptch}^{\mathrm{del/}+\mathrm{HRas}}{ }^{\mathrm{fl}+} \mathrm{Myf5} 5^{\mathrm{CreER} /+}$ mice (Fig. 43). This might indicate that the $M y f 5^{\mathrm{CreER}}$ driver is leaky at the HRas loci. However, it could also mean that the Bpml-mediated digestion of the cDNA was incomplete. Nevertheless, the recombination efficiency at the HRas locus increased in ERMS samples of tamoxifen-treated mice (Fig. 43). Thus, a strong band for the undigested, recombined transcript and a weak band for the digested, wt transcripts were observed, which indicated efficient recombination at the HRas locus in ERMS.

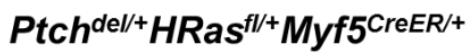

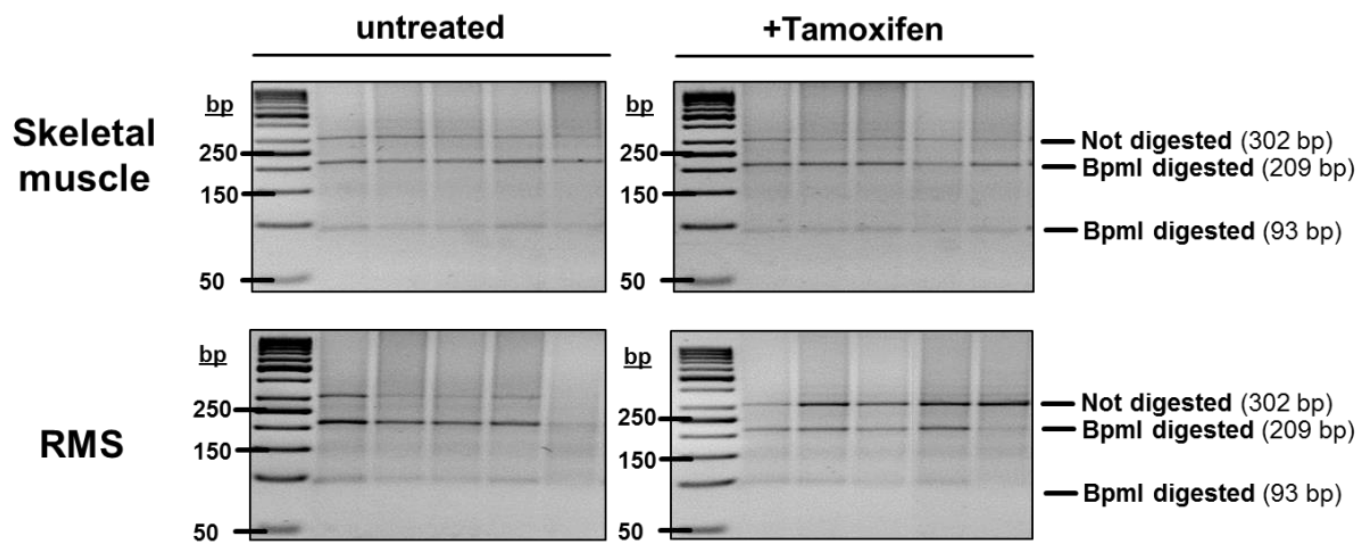

Figure 43: Recombination assays for the floxed HRas loci

Skeletal muscle (SM) and ERMS (RMS) tissue samples were subjected to RNA isolation and subsequent cDNA synthesis. Fragments of the HRas gene were PCR-amplified and then digested using Bpml. Products were separated by agarose gel electrophoresis. A successful recombination is indicated by weak digestion bands (209 bp and $93 \mathrm{bp}$ ) and a strong band for the undigested fragment (302 bp). No recombination should be indicated by strong digestion bands (209 bp and $93 \mathrm{bp}$ ) and lack of the undigested band (302 bp). However, due to either incomplete digestion or leakiness of the Cre driver at the floxed HRas locus the undigested band was always present. For more details, see text.

The recombination assay for KRas was done on PCR-amplified gDNA samples. A band of 304 bp represents the recombined KRas allele, whereas a band of 270 bp represents the wt KRas allele. Due to the fact that all mice were heterozygous for the floxed Ras alleles, efficient recombination at the KRas locus was demonstrated by the occurrence of the $304 \mathrm{bp}$ fragment in addition to the 270 bp band. A double band was clearly observed in ERMS samples from tamoxifen-treated mice, whereas it was only detected in very rare cases of untreated or solvent-treated (data not shown) mice (Fig. 44). This suggests that the Myf5 ${ }^{\text {CreER }}$ driver might be leaky at the floxed KRas locus in very few cases. Due to these data the ERMS incidence of tamoxifen- and untreated $\mathrm{Ptch}^{\mathrm{del/+}} K \mathrm{Ras}^{\mathrm{fl/}+} \mathrm{Myf5} 5^{\mathrm{CreER} /+}$ mice were compared, whereas all untreated $P t c h^{\text {del/+}} K_{R a s^{f /+} M y f 5^{C r e E R /+}}$ mice showing spontaneous recombination have been excluded from analyses (see section 6.3.2.3). 


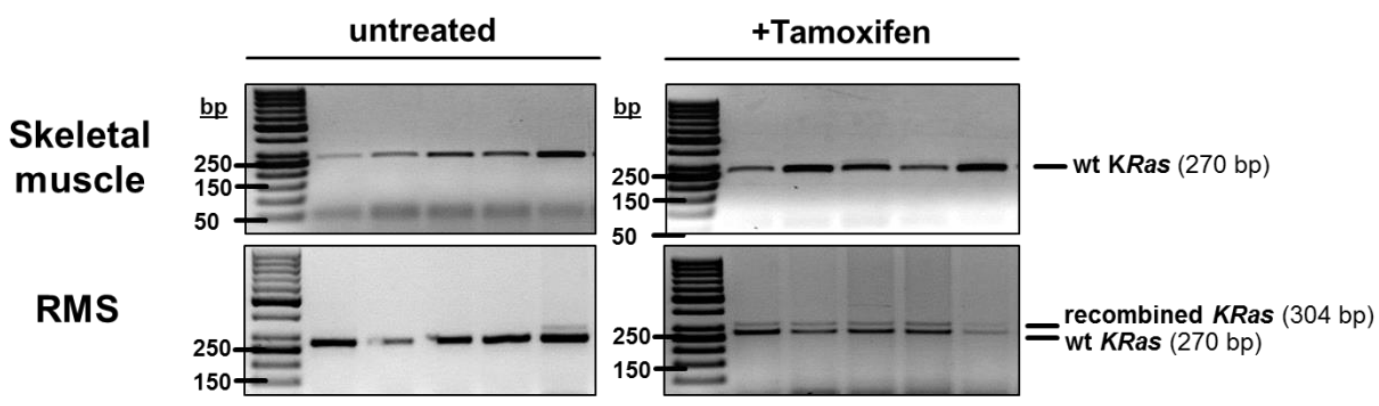

Figure 44: Recombination assays for the floxed KRas loci

Skeletal muscle (SM) and ERMS (RMS) tissue samples were subjected to gDNA isolation and subsequent PCR which was used to prove efficient recombination at the floxed KRas locus. Amplificates were separated by agarose gel electrophoresis and analyzed afterwards. A double band (270 bp for wt and $304 \mathrm{bp}$ for the floxed KRas locus after recombination) indicated efficient recombination, whereas a single band (270 bp for wt KRas) indicated no recombination.

The recombination assay for NRas was also done with PCR-amplified gDNA samples. As already stated above, all mice were heterozygous for the floxed Ras alleles. Therefore, efficient recombination at the floxed NRas locus was demonstrated by the occurrence of the $521 \mathrm{bp}$ fragment in addition to the $487 \mathrm{bp}$ band that represents the wt NRas allele. The analysis revealed that the double band only occurred in ERMS samples isolated from tamoxifen-treated mice, whereas it was never seen in ERMS from untreated Ptch $^{\text {del/+}} N \operatorname{Ras}^{f l /+} M y f 5^{C r e E R /+}$ mice (Fig. 45). However, in rare cases recombination also occurred in SM of tamoxifen-treated $\mathrm{Ptch}^{\text {del/+}} \mathrm{NRas}^{\mathrm{fl}+} \mathrm{Myf5}^{\mathrm{CreER} /+}$ mice (data not shown). Since the latter fact probably is of no importance for ERMS growth, all tamoxifen-treated $\mathrm{Ptch}^{\mathrm{del} /+} \mathrm{NRas}{ }^{\mathrm{fl}+} \mathrm{Myf5}{ }^{\mathrm{CreER} /+}$ mice (and all untreated mice) with the correct genotype were included in the analysis described in section 6.3.2.4.

Ptch $^{\text {del/+}}$ RRas $^{f /+}$ Myf5 $^{\mathrm{CreER} /+}$

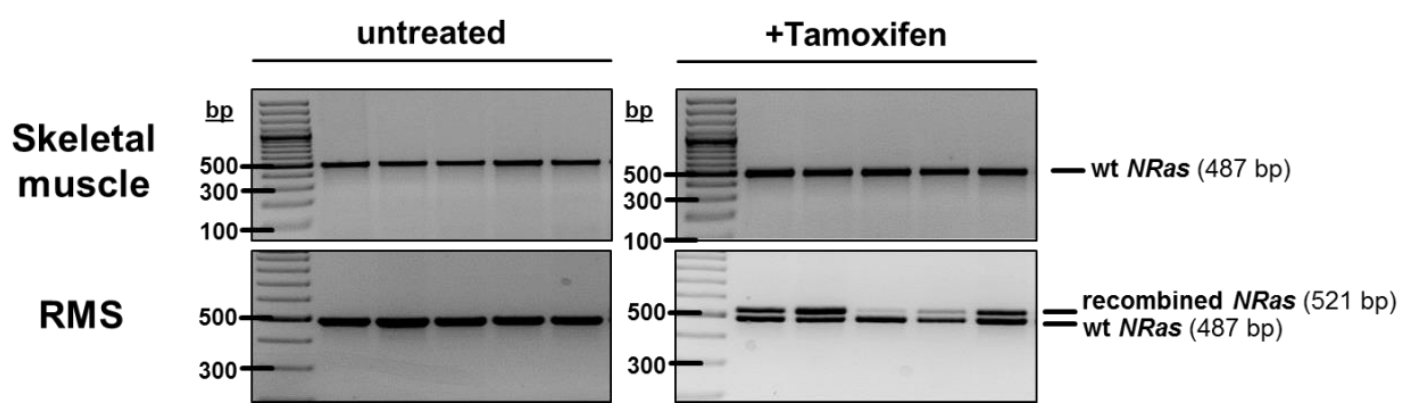

Figure 45: Recombination assays for the floxed NRas loci

Skeletal muscle (SM) and ERMS (RMS) tissue samples were subjected to gDNA isolation and subsequent PCR, which was used to prove efficient recombination at the floxed NRas locus. Amplificates were separated by agarose gel electrophoresis and analyzed afterwards. A double band (487 bp for wt and 521 bp for the recombined floxed NRas alleles) indicated efficient recombination, whereas a single band (487 bp for the wt NRas allele) indicated no recombination. 


\subsubsection{Testing Ras activity in ERMS of tamoxifen-treated Ptch $^{\text {del/+}}$ oncRas ${ }^{f l /+} M_{y f 5} 5^{C r e E R /+}$ mice}

Next, the functionality of the expressed oncRas alleles was investigated. For this purpose, ERMS samples from tamoxifen-treated $\mathrm{Ptch}^{\text {del/+}}$ oncRas $^{\mathrm{fl}+} \mathrm{Myf5}^{\mathrm{CreER} /+}$ mice were analyzed in a Ras activity assay (experimental details are explained in section 5.3.6). The densitometrical analysis (Fig. 46A) of two independent experiments and a representative Western Blot (Fig. 46B) highlight an approximate twofold increase in Ras activity in tumor tissue of tamoxifen-treated Ptch ${ }^{\text {del/ }}$ mice with oncRas mutation.

A

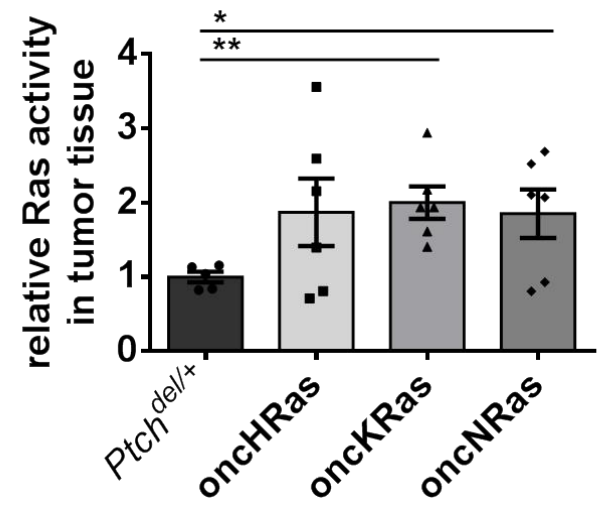

B Mouse \#

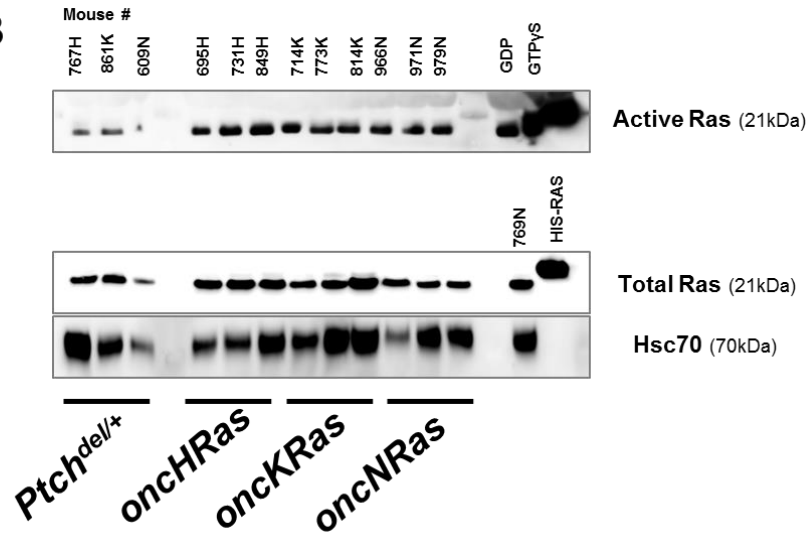

Figure 46: Ras is active in ERMS tissue samples of tamoxifen-treated $\mathrm{Ptch}^{\mathrm{del/}+}$ oncRas ${ }^{\mathrm{fl}+\mathrm{Myf5}}{ }^{\mathrm{CreER} /+}$ mice Protein was isolated from tumor samples of tamoxifen-treated Ptch ${ }^{\text {del/t }}$ and Ptch ${ }^{\text {del/t }}$ OncRas $^{\text {fl/t+}} \mathrm{Myf5}^{\mathrm{CreER} /+}$ (oncHRas, oncKRas, oncNRas) mice. Afterwards cell lysates were subjected to a bead-based pull-down assay to precipitate active Ras. Whole lysates of the same samples were used to detect total Ras. Afterwards, precipitated and whole lysates were analyzed by Western Blot to detect the protein level of active Ras and total Ras with specific antibodies. Hsc70 served as loading control for total Ras. The relative Ras activity was calculated by normalization of active Ras to total Ras/Hsc70 and is displayed in histograms showing the mean Ras activity of 6 tumors each cohort \pm SEM. Ras activity in ERMS from Ptch ${ }^{\text {del/ }}$ mice served as control and was set to 1 (A). A representative Western Blot is shown in (B). Protein names and sizes in $\mathrm{kDa}$ are displayed on the right side of the blot. The depicted results are representative for 6 tumors of each cohort analyzed in two independent experiments. For statistical analyses unpaired non-parametric t-tests (Mann Whitney) were performed. ${ }^{\star} \mathrm{p}<0.05$, ${ }^{* *} \mathrm{p}<0.01$ compared to relative Ras activity within tumor tissue from $\mathrm{Ptch}^{\mathrm{del} /+}$ mice.

Taken together, the results described in section 6.3.1 show that ERMS of $\mathrm{Ptch}^{\text {del/+ }}$ mice express wt HRas, KRas and NRas. In order to activate oncRas expression in $\mathrm{Ptch}^{\text {del/+ }}$ oncRas ${ }^{\mathrm{fl} / \mathrm{+}}$ mice the Myf5 ${ }^{\mathrm{CreER}}$ driver was used. Indeed, tamoxifen-mediated activation of this driver induces recombination of the conditional floxed oncRas alleles primarily in the tumor tissue. Moreover, Ras activity assays verify the successful Ras activation in ERMS of tamoxifen-treated Ptch ${ }^{\text {del/+ }}$ oncRas ${ }^{f / /+} \mathrm{Myf5}^{\mathrm{CreER} /+}$ mice.

\subsubsection{Activation of oncRas in ERMS precursor lesions}

ERMS in Ptch $^{\text {del/+ }}$ mice are initiated before birth and become conspicuous and palpable earliest at the age of approximately 7 weeks ${ }^{323}$. In order to analyze the impact of oncRas on ERMS precursor lesions, the expression of oncRas in $\mathrm{Ptch}^{\mathrm{del} /+} H \mathrm{Ras}^{\mathrm{fl} /+} \mathrm{Myf5} 5^{\mathrm{CreER} /+}$,

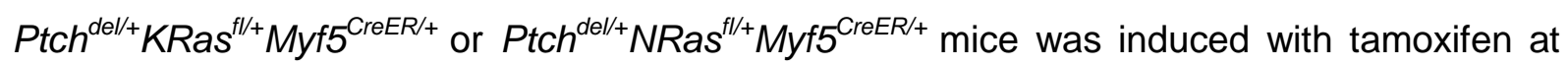
the age of 4 weeks. Untreated siblings of the same genotype or untreated or tamoxifentreated $P_{t c h}{ }^{d e l / t}$ mice served as controls. 
Breeding and tumor monitoring of the mice was part of another doctoral thesis ${ }^{299}$. Here, the data were evaluated again and the monitoring study of $\mathrm{PtCh}^{\mathrm{del/}+\mathrm{NRas}}{ }^{\mathrm{fl}+} \mathrm{Myf5}{ }^{\mathrm{CreER} /+}$ mice was repeated entirely. Overall survival was defined as the percentage of mice, which remained alive within the time frame of monitoring. RMS-free survival indicated the time point of first detection of a palpable ERMS of a mouse. On this basis the mean ERMS-free survival and the median latency time until tumor detection of the cohort was calculated. The tumor incidence specifies the percentage of mice with a detected ERMS in the complete cohort. The tumor multiplicity was calculated as proportion of mice with 1 or more ERMS compared to all ERMS-bearing mice.

\subsubsection{Tamoxifen does not influence growth or incidence of ERMS of Ptch $^{\text {del/+ }}$ mice}

First, it was tested whether tamoxifen itself modulates ERMS in Ptch ${ }^{d e l++}$ mice. For this purpose, $\mathrm{Ptch}^{\mathrm{del} /+}$ mice were treated with tamoxifen at an age of 4 weeks and monitored for ERMS development. All Ptch ${ }^{\text {del/+ }}$ mice were the siblings of all $\mathrm{Ptch}^{\text {del/+}}$ oncRas ${ }^{f /+}$ Myf5 $5^{\mathrm{CreER} /+}$ mice. The time point of first tumor detection was recorded for approximately 200 days. The details and characteristics of all animals are listed in Tab. 25. The respective Kaplan-Meier curves for overall survival and ERMS-free survival and graphs for tumor incidence and multiplicity are shown in Fig. 47A, Fig. 47B, Fig. 47C and Fig. 47D, respectively. The analyses did not reveal any significant differences between untreated and tamoxifen-treated Ptch $^{\text {del/t+ }}$ mice.

Table 25: Influence of tamoxifen treatment on ERMS development of 4 week old Ptch $^{\text {del/ }}$ mice Absolute numbers, median survival, premature death, ERMS incidence, latency time and further observed abnormalities of Ptch ${ }^{\text {del/ }+}$ mice with and without tamoxifen injection. The respective Kaplan-Meier curves and graphs are shown in Fig. 47.

\begin{tabular}{|l|l|l|l|l|l|l|l|}
\hline Treatment & $\begin{array}{l}\text { Number } \\
\text { of mice }\end{array}$ & $\begin{array}{l}\text { Median } \\
\text { overall } \\
\text { survival } \\
\text { (range) }\end{array}$ & $\begin{array}{l}\text { Healthy // } \\
\text { premature } \\
\text { death }\end{array}$ & $\begin{array}{l}\text { Mice with } \\
\text { ERMS } \\
\text { (incidence) }\end{array}$ & $\begin{array}{l}\text { Mice with } \\
\geq 2 \text { ERMS } \\
\text { (incidence) }\end{array}$ & $\begin{array}{l}\text { Median } \\
\text { latency } \\
\text { time }\end{array}$ & $\begin{array}{l}\text { Further } \\
\text { observations }\end{array}$ \\
\hline Untreated & 27 & $\begin{array}{l}200 \text { days } \\
(60-206)\end{array}$ & $23 / / 4$ & $\begin{array}{l}12 \\
(44 \%)\end{array}$ & $\begin{array}{l}3 \\
(11 \%)\end{array}$ & 73 days & $\begin{array}{l}\text { Cysts/ Cavernous } \\
\text { angioma: } 6 \\
\text { Medulloblastoma: } 1\end{array}$ \\
\hline Tamoxifen & 27 & $\begin{array}{l}200 \text { days } \\
(90-209)\end{array}$ & $21 / / 6$ & $\begin{array}{l}13 \\
(48 \%)\end{array}$ & $\begin{array}{l}4 \\
(15 \%)\end{array}$ & 105 days & $\begin{array}{l}\text { Cysts/ Cavernous } \\
\text { angioma: } 4 \\
\text { Medulloblastoma: } 1\end{array}$ \\
\hline
\end{tabular}



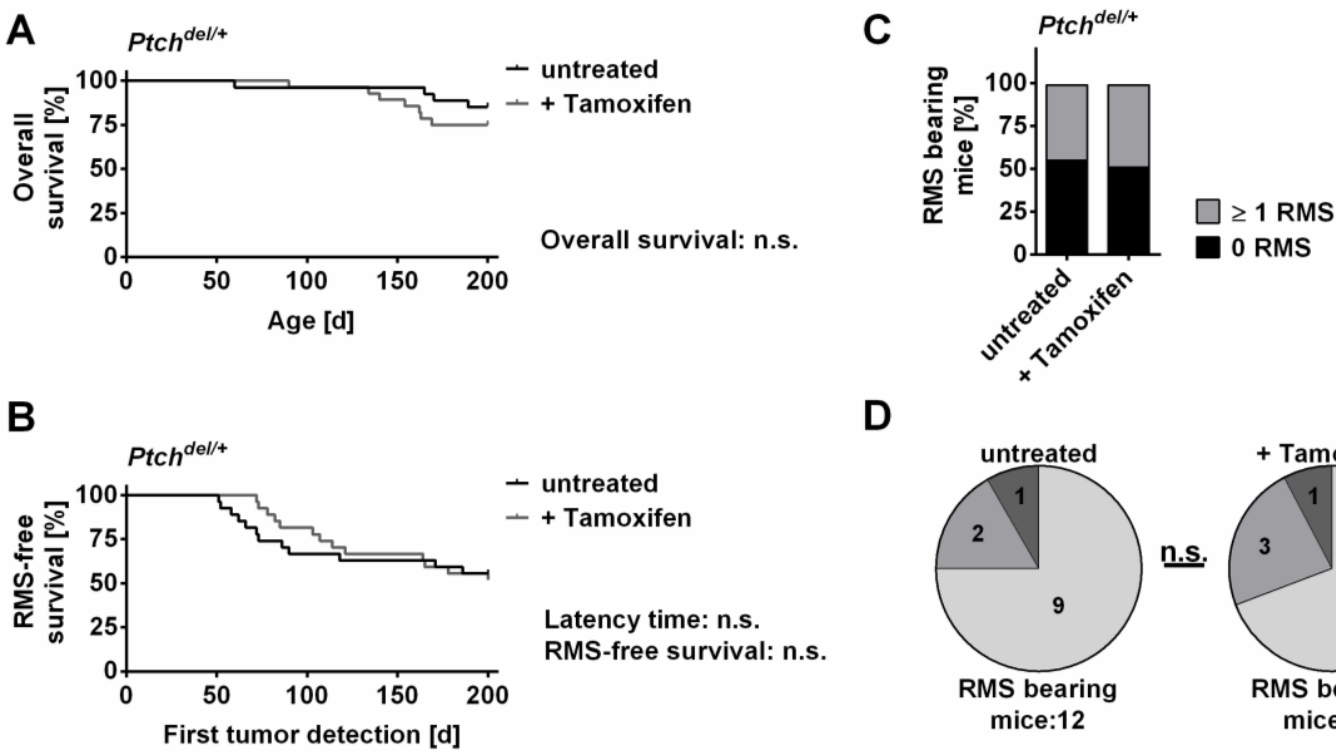

D

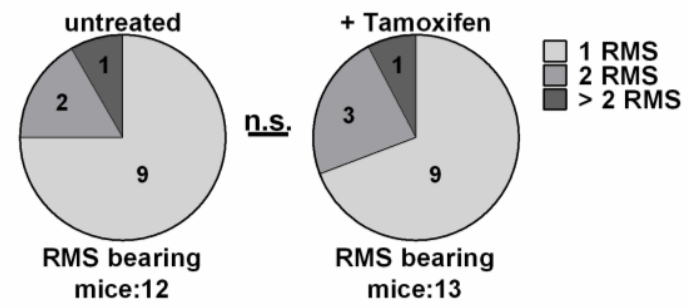

Figure 47: Tamoxifen treatment does not influence ERMS development in Ptch $^{\text {del/ }}{ }_{\text {mice }}$

$\mathrm{Ptch}^{\mathrm{del} / \mathrm{+}}$ mice were injected with tamoxifen at the age of 4 weeks or remained untreated. Mice were monitored until the age of approximately 200 days and the time point of first tumor detection and death were recorded. Kaplan-Meier curves of overall (A) and ERMS-free (B) survival of untreated (black) and tamoxifen-treated (grey) $\mathrm{Ptch}^{\text {del/ }+}$ mice are shown. The data were analyzed by Gehan-Breslow-Wilcoxon test for statistical differences in overall and ERMS-free survival. Differences in latency time were analyzed by Log-rank (Mantel-Cox) test. Differences in total number of animals with ERMS (C) and in tumor multiplicity (D) were analyzed by Chi square tests. For more details see Tab. 25.

\subsubsection{OncHRas increases the ERMS incidence in Ptch ${ }^{\text {del/+ }}$ mice}

$\mathrm{Ptch}^{\mathrm{del/} H} \mathrm{HRas}^{\mathrm{fl/}} \mathrm{Myf5}^{\mathrm{CreER} /+}$ mice were treated with tamoxifen at an age of 4 weeks. Untreated animals served as controls. The details and characteristics of all animals of this cohort are listed in Tab. 26. The respective Kaplan-Meier curves for overall and ERMS-free survival are shown in Fig. 48A and Fig. 48B, respectively. The results show that the ERMS incidence was significantly higher in tamoxifen-treated $\mathrm{Ptch}^{\text {del/+}} \mathrm{HRas}^{\mathrm{fl} /+} \mathrm{Myf5} 5^{\mathrm{CreER} /+}$ mice compared to untreated mice (Fig. 48C). In addition, the time until detection of palpable ERMS was shorter and just missed significance (Fig. 48B). However, no significant differences in the median overall survival, tumor multiplicity (Fig. 48D) or other abnormalities were observed (Tab. 26).

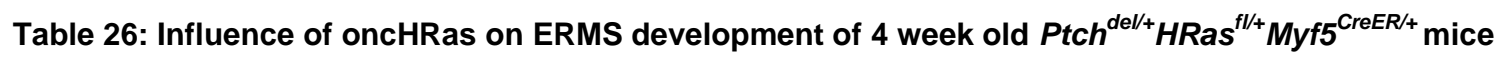
Absolute numbers, median survival, premature death, ERMS incidence, latency time and further observed abnormalities of Ptch $^{\text {del/t}} H R a s^{f /+} M y f 55^{C r e E R /+}$ mice with and without tamoxifen injection. The respective KaplanMeier curves and graphs are shown in Fig. 48.

\begin{tabular}{|l|l|l|l|l|l|l|l|}
\hline Treatment & $\begin{array}{l}\text { Number } \\
\text { of mice }\end{array}$ & $\begin{array}{l}\text { Median } \\
\text { overall } \\
\text { survival } \\
\text { (range) }\end{array}$ & $\begin{array}{l}\text { Healthy // } \\
\text { premature } \\
\text { death }\end{array}$ & $\begin{array}{l}\text { Mice with } \\
\text { ERMS } \\
\text { (incidence) }\end{array}$ & $\begin{array}{l}\text { Mice with } \\
\geq 2 \text { ERMS } \\
\text { (incidence) }\end{array}$ & $\begin{array}{l}\text { Median } \\
\text { latency } \\
\text { time }\end{array}$ & $\begin{array}{l}\text { Further } \\
\text { observations }\end{array}$ \\
\hline Untreated & 32 & $\begin{array}{l}200 \text { days } \\
(65-211)\end{array}$ & $20 / / 12$ & $\begin{array}{l}18 \\
(56 \%)\end{array}$ & $\begin{array}{l}6 \\
(19 \%)\end{array}$ & 96 days & $\begin{array}{l}\text { Cysts/ Cavernous } \\
\text { angioma: } 4 \\
\text { Medulloblastoma: } 3 \\
\text { Papilloma: } 1\end{array}$ \\
\hline Tamoxifen & 32 & $\begin{array}{l}200 \text { days } \\
(76-204)\end{array}$ & $22 / / 10$ & $\begin{array}{l}24 \\
(74 \%)\end{array}$ & $\begin{array}{l}7 \\
(22 \%)\end{array}$ & 83 days & $\begin{array}{l}\text { Cysts/ Cavernous } \\
\text { angioma: } 4 \\
\text { Medulloblastoma: } 1 \\
\text { Papilloma: } 1\end{array}$ \\
\hline
\end{tabular}



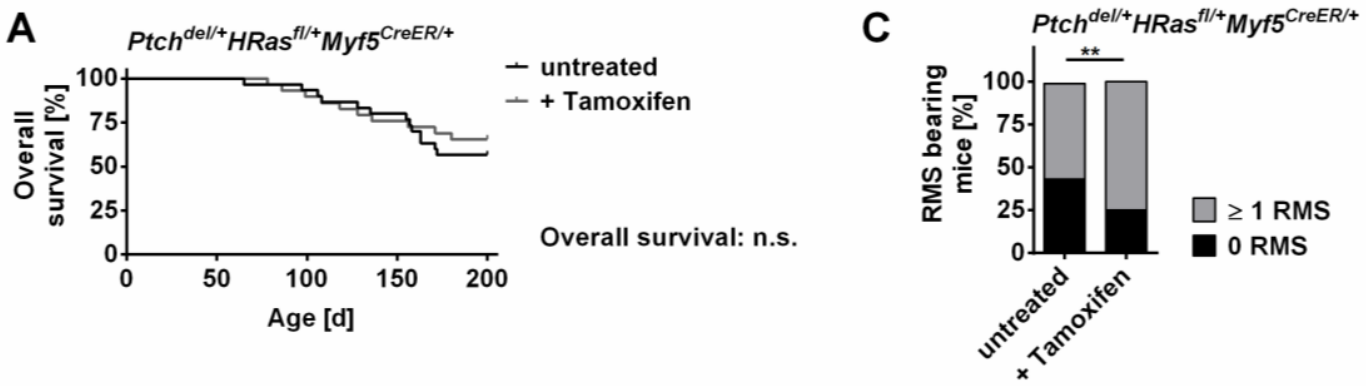

B

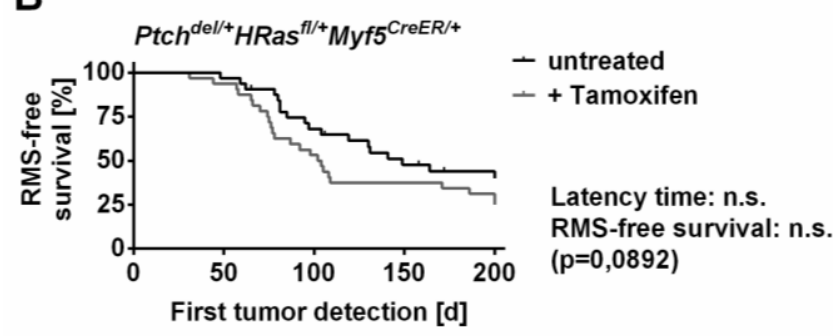

D

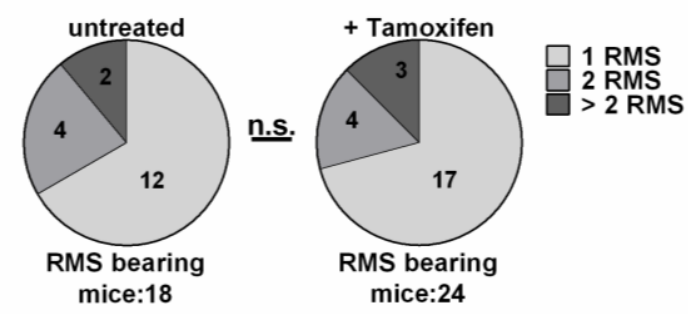

Figure 48: OncHRas increases tumor incidence and slightly reduces ERMS-free survival in $\mathrm{Ptch}^{\text {del/+ }}$ mice

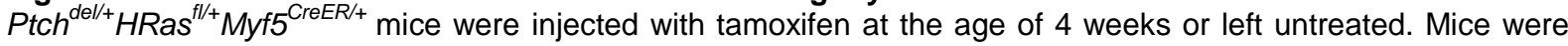
monitored until the age of approximately 200 days and the time point of first tumor detection and death were recorded. Respective Kaplan-Meier curves for overall (A) and ERMS-free (B) survival of untreated (black) and tamoxifen-treated (grey) Ptch ${ }^{\text {del/+}} H$ Ras $^{f /+}$ Myf5 ${ }^{\text {CreER/+ }}$ mice are shown. The data were analyzed by Gehan-BreslowWilcoxon test for statistical differences in overall and ERMS-free survival. Differences in latency time were analyzed by Log-rank (Mantel-Cox) test. Differences in total number of animals with ERMS (C) and in tumor multiplicity (D) were analyzed by Chi square tests. ${ }^{* *} \mathrm{p}<0.01$ compared untreated $P t c h^{\text {del/+}} H$ Ras $^{f / /+} M y f 5^{\mathrm{CreER} /+}$ mice. For more details see Tab. 26.

\subsubsection{OncKRas increases tumor incidence and reduces ERMS-free survival in Ptch $^{\text {del/+ }}$ mice}

The $\mathrm{Ptch}^{\mathrm{del/+}}$ KRas ${ }^{\mathrm{fl} /+} \mathrm{Myf5} 5^{\mathrm{CreER} /+}$ cohorts were treated as described above. Untreated mice served as controls. The details and characteristics of the animals are listed in Tab. 27 and are shown in Fig. 49. The data reveal that oncKRas significantly decreased the overall survival and ERMS-free survival (Tab. 27 and Fig. 49A, Fig. 49B). It also significantly increased the tumor incidence (Fig. 49C). On the other hand, oncKRas did not influence the occurrence of other abnormalities or tumor multiplicity (Tab. 27 and Fig. 49D).

Table 27: Influence of oncKRas on ERMS development of 4 week old Ptch $^{\text {del/+ }}$ KRas $^{f l /+}$ Myf5 $^{\mathrm{CreER} /+}$ mice Absolute numbers, median survival, premature death, ERMS incidence, latency time and further observed abnormalities of $\mathrm{Ptch}^{\mathrm{del/}+} K \mathrm{Ras}^{f /+} \mathrm{Myf5}{ }^{\mathrm{CreER/+}}$ mice with and without tamoxifen injection. The respective KaplanMeier curves and graphs are shown in Fig. 49.

\begin{tabular}{|l|l|l|l|l|l|l|l|}
\hline Treatment & $\begin{array}{l}\text { Number } \\
\text { of mice }\end{array}$ & $\begin{array}{l}\text { Median } \\
\text { overall } \\
\text { survival } \\
\text { (range) }\end{array}$ & $\begin{array}{l}\text { Healthy // } \\
\text { premature } \\
\text { death }\end{array}$ & $\begin{array}{l}\text { Mice with } \\
\text { ERMS } \\
\text { (incidence) }\end{array}$ & $\begin{array}{l}\text { Mice with } \\
\geq 2 \text { ERMS } \\
\text { (incidence) }\end{array}$ & $\begin{array}{l}\text { Median } \\
\text { latency } \\
\text { time }\end{array}$ & $\begin{array}{l}\text { Further } \\
\text { observations }\end{array}$ \\
\hline Untreated & 24 & $\begin{array}{l}200 \text { days } \\
(83-209)\end{array}$ & $17 / / 7$ & $\begin{array}{l}10 \\
(41 \%)\end{array}$ & $\begin{array}{l}4 \\
(17 \%)\end{array}$ & 109 days & $\begin{array}{l}\text { Cysts/ Cavernous } \\
\text { angioma: } 3 \\
\text { Medulloblastoma: } 3\end{array}$ \\
\hline Tamoxifen & 29 & $\begin{array}{l}122 \text { days } \\
(69-201)\end{array}$ & $12 / / 17$ & $\begin{array}{l}22 \\
(76 \%)\end{array}$ & $\begin{array}{l}13 \\
(45 \%)\end{array}$ & 78 days & $\begin{array}{l}\text { Cysts/ Cavernous } \\
\text { angioma: } 4 \\
\text { Medulloblastoma: } 0\end{array}$ \\
\hline
\end{tabular}



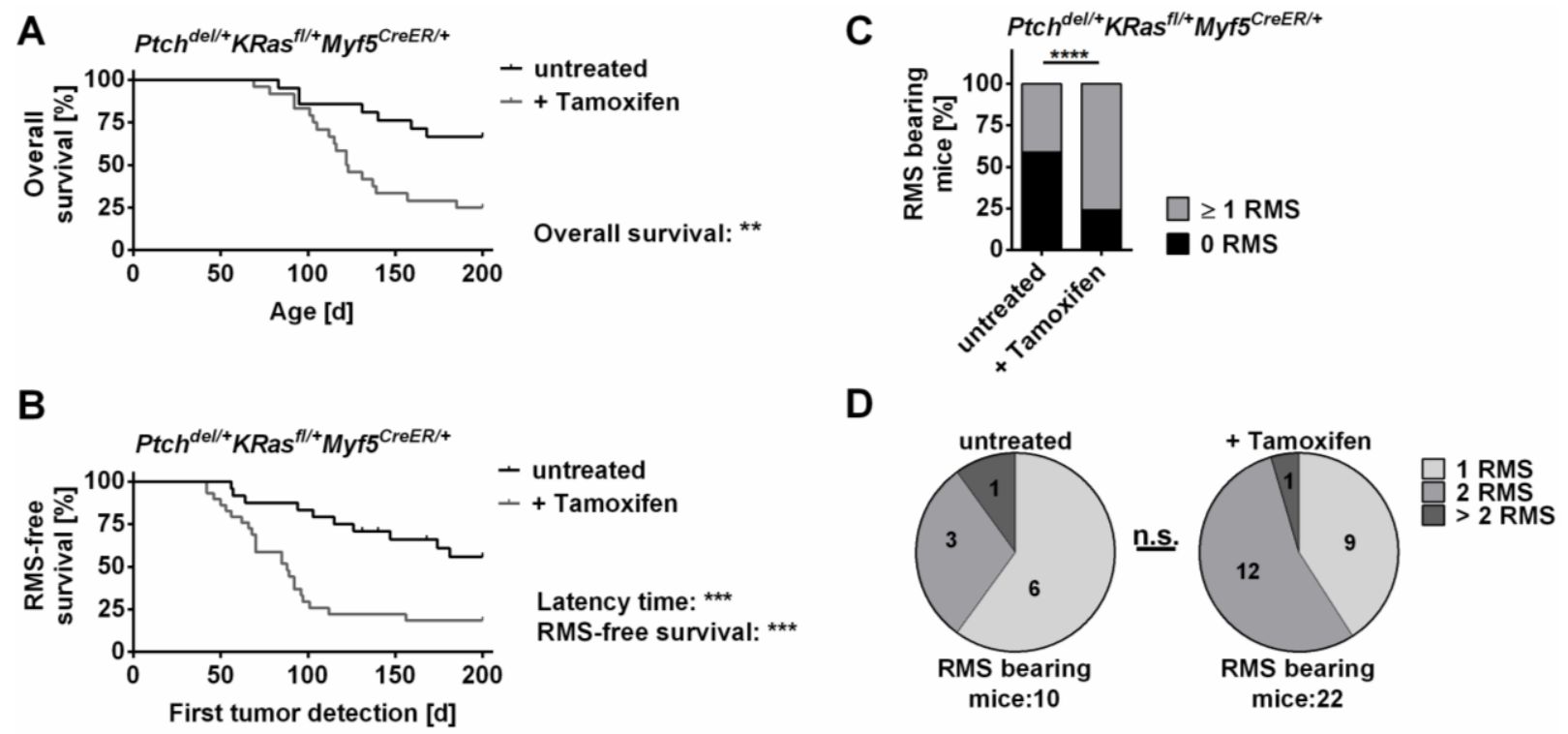

Figure 49: OncKRas increases tumor incidence and decreases ERMS-free survival in Ptch ${ }^{\text {del/+ }}$ mice $^{\text {ice }}$ $\mathrm{Ptch}^{\mathrm{del/}+} \mathrm{KRas}^{\mathrm{fl/}+} \mathrm{Myf5} 5^{\mathrm{CreER} /+}$ mice were injected with tamoxifen at the age of 4 weeks or left untreated. Mice were monitored until the age of approximately 200 days and the time point of first tumor detection and death were recorded. Respective Kaplan-Meier curves for overall (A) and ERMS-free (B) survival of untreated (black) and tamoxifen-treated (grey) Ptch ${ }^{\text {del/+}} K \operatorname{Ras}^{f / /} \mathrm{Myf5}{ }^{\mathrm{CreER} /+}$ mice are shown. The data were analyzed by Gehan-BreslowWilcoxon test for statistical differences in overall and ERMS-free survival. The data were analyzed for differences in latency time using the Log-rank (Mantel-Cox) test. Differences in total tumor incidence (C) or tumor multiplicity (D) were analyzed with Chi square tests. ${ }^{* *} p<0.01,{ }^{* *} p<0.001,{ }^{* * * *} p<0.0001$ compared to untreated Ptch $^{\text {del/t+}}$ KRas Rl/t+Mf5 $^{\text {CreER/+ }}$ mice. For more details see Tab. 27.

\subsubsection{OncNRas does not influence ERMS growth of $\mathrm{Ptch}^{\mathrm{del} /+}$ mice}

Mice from the $\mathrm{Ptch}^{\text {del/+}} \mathrm{NRas}{ }^{\mathrm{fl} /+} \mathrm{Myf5} 5^{\mathrm{CreER} /+}$ cohorts were treated as described above. Untreated mice served as controls. The details and characteristics of the animals are shown below (Tab. 28 and Fig. 50A, Fig. 50B, Fig. 50C and Fig. 50D). The data show that oncNRas does neither significantly influence overall survival, ERMS free survival, ERMS latency time, tumor incidence nor multiplicity (Fig. 50A, Fig. 50B, Fig. 50C and Fig. 50D). It also does not influence the occurrence of other abnormalities (Tab. 28).

Table 28: Influence of oncNRas on ERMS development of 4 week old Ptch $^{\text {del/+ }} \mathrm{NRas}^{\mathrm{fl} /+} \mathrm{Myf5}^{\mathrm{CreER} / \mathrm{+}}$ mice Absolute numbers, median survival, premature death, ERMS incidence, latency time and further observed abnormalities of Ptch $^{\text {del/+}} \mathrm{NRas}^{\mathrm{fl} / \mathrm{Myf5}} \mathrm{CreER/+}^{\mathrm{C}}$ mice with and without tamoxifen injection. The respective KaplanMeier curves and graphs are shown in Fig. 50.

\begin{tabular}{|l|l|l|l|l|l|l|l|}
\hline Treatment & $\begin{array}{l}\text { Number } \\
\text { of mice }\end{array}$ & $\begin{array}{l}\text { Median } \\
\text { overall } \\
\text { survival } \\
\text { (range) }\end{array}$ & $\begin{array}{l}\text { Healthy // } \\
\text { premature } \\
\text { death }\end{array}$ & $\begin{array}{l}\text { Mice with } \\
\text { ERMS } \\
\text { (incidence) }\end{array}$ & $\begin{array}{l}\text { Mice with } \\
\geq 2 \text { ERMS } \\
\text { (incidence) }\end{array}$ & $\begin{array}{l}\text { Median } \\
\text { latency } \\
\text { time }\end{array}$ & $\begin{array}{l}\text { Further } \\
\text { observations }\end{array}$ \\
\hline Untreated & 26 & $\begin{array}{l}200 \text { days } \\
(131- \\
212)\end{array}$ & $19 / / 7$ & $\begin{array}{l}17 \\
(65 \%)\end{array}$ & $\begin{array}{l}10 \\
(38 \%)\end{array}$ & 63 days & $\begin{array}{l}\text { Cysts/ Cavernous } \\
\text { angioma: } 4 \\
\text { Medulloblastoma: } 1\end{array}$ \\
\hline Tamoxifen & 28 & $\begin{array}{l}200 \text { days } \\
(76-206)\end{array}$ & $22 / / 6$ & $\begin{array}{l}20 \\
(71 \%)\end{array}$ & $\begin{array}{l}8 \\
(29 \%)\end{array}$ & 94 days & $\begin{array}{l}\text { Cysts/ Cavernous } \\
\text { angioma: } 6 \\
\text { Medulloblastoma: } 1\end{array}$ \\
\hline
\end{tabular}



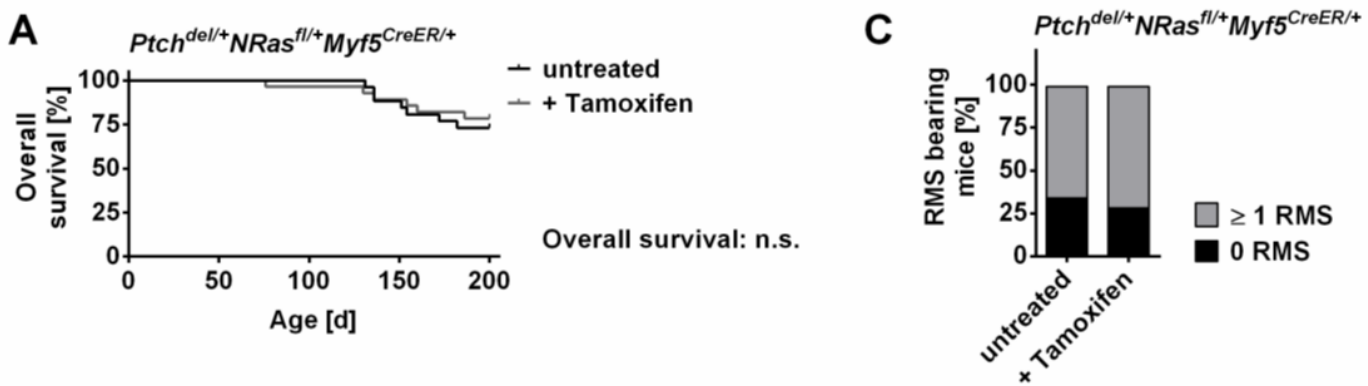

B

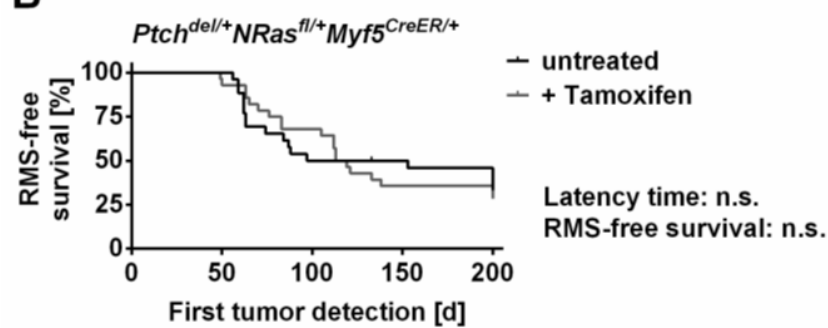

D

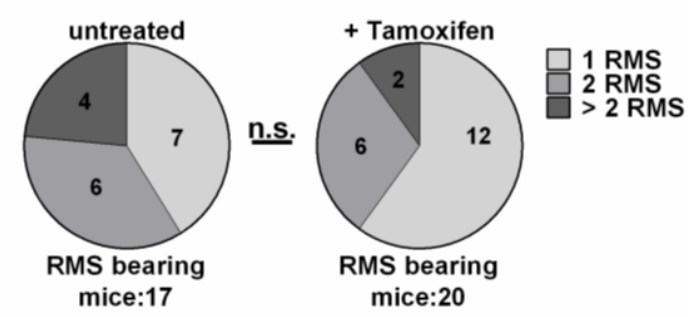

Figure 50: OncNRas does not influence ERMS-free survival, tumor incidence or multiplicity in Ptch ${ }^{\text {ael/+ }}$ mice

Ptch $^{\text {del/+}}{ }^{2} \operatorname{Ras}^{f / /+} \mathrm{Myf5}^{\mathrm{CreER} /+}$ mice were injected with tamoxifen at the age of 4 weeks or left untreated. Mice were monitored until the age of approximately 200 days and the time point of first tumor detection and death were recorded. Respective Kaplan-Meier curves for overall (A) and ERMS-free (B) survival of untreated (black) and tamoxifen-treated (grey) Ptch ${ }^{\mathrm{del} /+} \mathrm{NRas} \mathrm{s}^{\mathrm{fl}+} \mathrm{Myf5} \mathrm{CreER/+}^{\mathrm{mice}}$ are shown. The data were analyzed by Gehan-BreslowWilcoxon test for statistical differences in overall and tumor free survival. The data were analyzed for differences in latency time using the Log-rank (Mantel-Cox) test. Differences in total tumor incidence (C) or tumor multiplicity

(D) were analyzed with Chi square tests. For more details see Tab. 28.

\subsubsection{OncHRas and oncKRas increase proliferation rate of ERMS in $\mathrm{Ptch}^{d e l /+}$ mice, whereas oncNRas does not}

Next, the impact of oncRas isoforms on proliferation of ERMS was analyzed by staining of paraffin sections for $\mathrm{Ki} 7^{+}$nuclei (compare section 5.4.2).

Tamoxifen treatment did not influence proliferation of ERMS in Ptch $^{\text {del/t }}$ mice (Fig. 51A). In contrast, an increase in $\mathrm{Ki} 67^{+}$nuclei in ERMS of tamoxifen-treated $\mathrm{Ptch}^{\mathrm{del} /+} H \mathrm{Ras}^{\mathrm{fl} /+} \mathrm{Myf5} 5^{\mathrm{CreER} /+}$ (Fig. 51B) and Ptch ${ }^{\text {del/+}}$ KRas ${ }^{f / /} M y f 5^{C r e E R /+}$ (Fig. 51C) mice was observed in comparison to untreated mice of the same cohort. OncNRas induction did not influence proliferation of ERMS in Ptch ${ }^{d e l /+}$ mice (Fig. 51D). Thus, the mean of Ki67 ${ }^{+}$nuclei in tumors of untreated mice from all cohorts ranged between $5.5 \%$ and $6.5 \%$ regardless of the genotype and did not differ significantly between the analyzed groups. In tumors of tamoxifen-treated mice the mean of $\mathrm{Ki}^{+} 7^{+}$nuclei ranged between $6.0 \%$ and $13 \%$. In contrast, tumors with onchRas or oncKRas mutations showed a significantly higher proliferation rate than ERMS from tamoxifen-treated $\mathrm{Ptch}^{\text {del/+ }}$ mice and tumors with oncNRas mutations.

Additionally, the tumor weight and volume were assessed for ERMS from untreated and tamoxifen-treated $\mathrm{Ptch}^{\mathrm{del/}+} \mathrm{NRas}^{\mathrm{fl}+} \mathrm{Myf5}^{\mathrm{CreER} /+}$ mice. However, oncNRas did not influence the respective parameters (data not shown). 
A

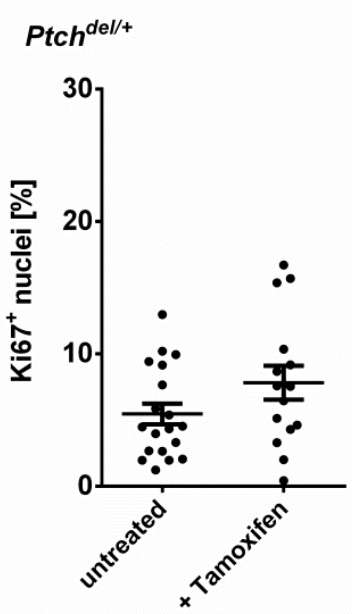

B

Ptch $^{\text {del/+ }}$ RRas $^{f l /+}$ Myf5 $5^{\text {CreER/+ }}$

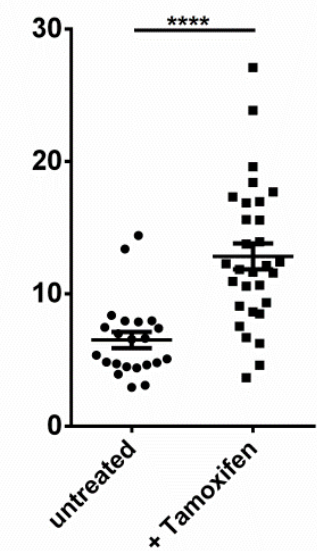

C

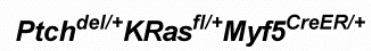

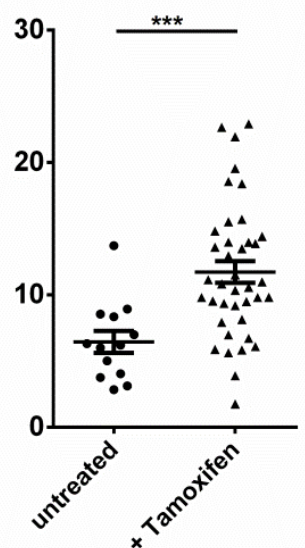

D

Ptch $^{\text {del/++}}$ RRas $^{f l /+}$ Myf5 $^{\mathrm{CreER} /+}$

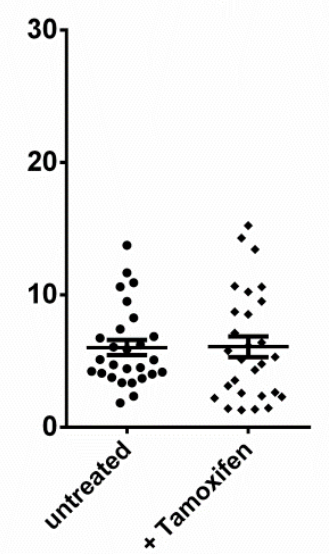

Figure 51: OncHRas and oncKRas increase the percentage of $\mathrm{Ki}^{+} 7^{+}$nuclei in ERMS from $\mathrm{Ptch}^{\text {del/t+}}$ mice $^{\text {ince }}$ ERMS tissue sections from untreated $(n=19$ ERMS from 10 mice) and tamoxifen-treated $(n=15$ ERMS from 12 mice) Ptch ${ }^{\text {del/ }}$ mice $(A)$, untreated ( $n=22$ ERMS from 13 mice) and tamoxifen-treated $(n=30$ ERMS from 22 mice) Ptch $^{\text {del/t+}}$ HRas $^{\mathrm{fl} /+} \mathrm{Myf5}^{\mathrm{CreER} /+}$ mice $(\mathrm{B})$, untreated $(\mathrm{n}=14$ ERMS from 10 mice) and tamoxifen-treated $(\mathrm{n}=39 \mathrm{ERMS}$ from 21 mice) Ptch $^{\text {del/+ }}$ KRas $^{f / /+} \mathrm{MyfS}^{\mathrm{CreER/+}}$ mice $(\mathrm{C})$ and untreated ( $\mathrm{n}=27$ ERMS from 14 mice) and tamoxifentreated ( $n=28$ ERMS from 19 mice) Ptch ${ }^{\text {del/ }}$ NRas $^{t / /+} \mathrm{Myf5}^{\mathrm{CreER} /+}$ mice (D) were stained with a specific antibody against the proliferation marker Ki67. Number of all nuclei and $\mathrm{Ki} 67^{+}$nuclei were counted manually in 10 pictures of each tumor and percentage of $\mathrm{Ki}^{+} 7^{+}$nuclei was calculated. For statistical analyses non-parametric t-tests (Mann Whitney) were performed. ${ }^{* * *} p<0.001,{ }^{* * * *} p<0.0001$ compared to untreated Ptch ${ }^{\text {del/t+}}$ oncRas ${ }^{f /+}$ Myf5 $^{\text {CreER/+ }}$ mice from the respective cohort.

\subsubsection{OncRas isoforms do not change expression of Hh target genes in ERMS of Ptch $^{\text {del/t }}$ mice}

Next, SM and ERMS tissue samples were analyzed for the expression level of the major $\mathrm{Hh}$ target Gli1 and of other downstream targets, namely Gli2, Gli3, Ptch and Hhip (Fig. 52). The expression of $18 S$ rRNA or Tbp was used for normalization. Furthermore, the expression of the respective gene is shown as fold induction over the expression level in SM of the same animal, which was set to 1 . Unfortunately, only 2 freshly frozen tumor samples of untreated

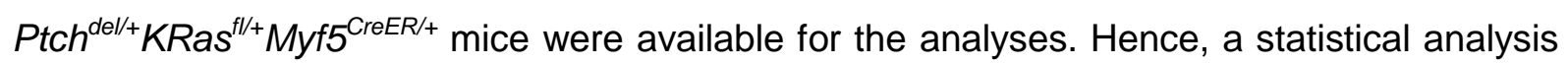
was not possible for this cohort.

None of the comparisons showed significant differences (Fig. 52). Thus, tamoxifen itself did not have significant effects on $\mathrm{Hh}$ target gene expression in tumors of $\mathrm{Ptch}^{\mathrm{del} / \mathrm{t}}$ mice (Fig. 52A) and no significant differences between mRNA expression of tumors with and without oncRas were detected (Fig. 52B, Fig. 52C, Fig. 52D). Nevertheless, a tendency for downregulation of Gli1 in oncRas-expressing tumors was observed. This is notable because a similar, but significant downregulation of GL/1 was revealed in human ERMS cell lines (see section 6.1.2.1). 


\section{A $P t c h^{\text {del/+ }}$}
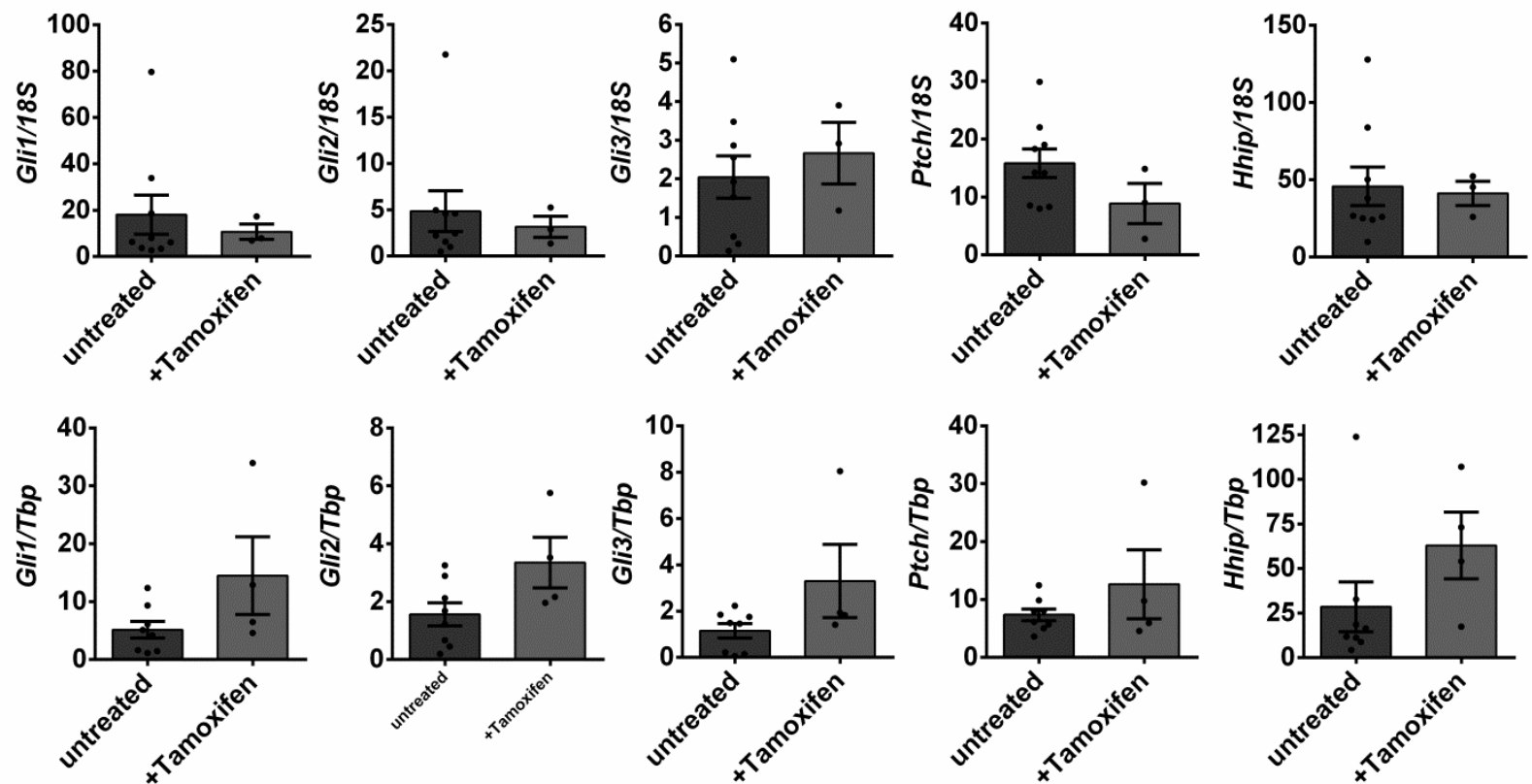

B Ptch $^{\text {del/+}}$ HRas $^{f l /+}$ Myf5 ${ }^{\text {CreER/+ }}$
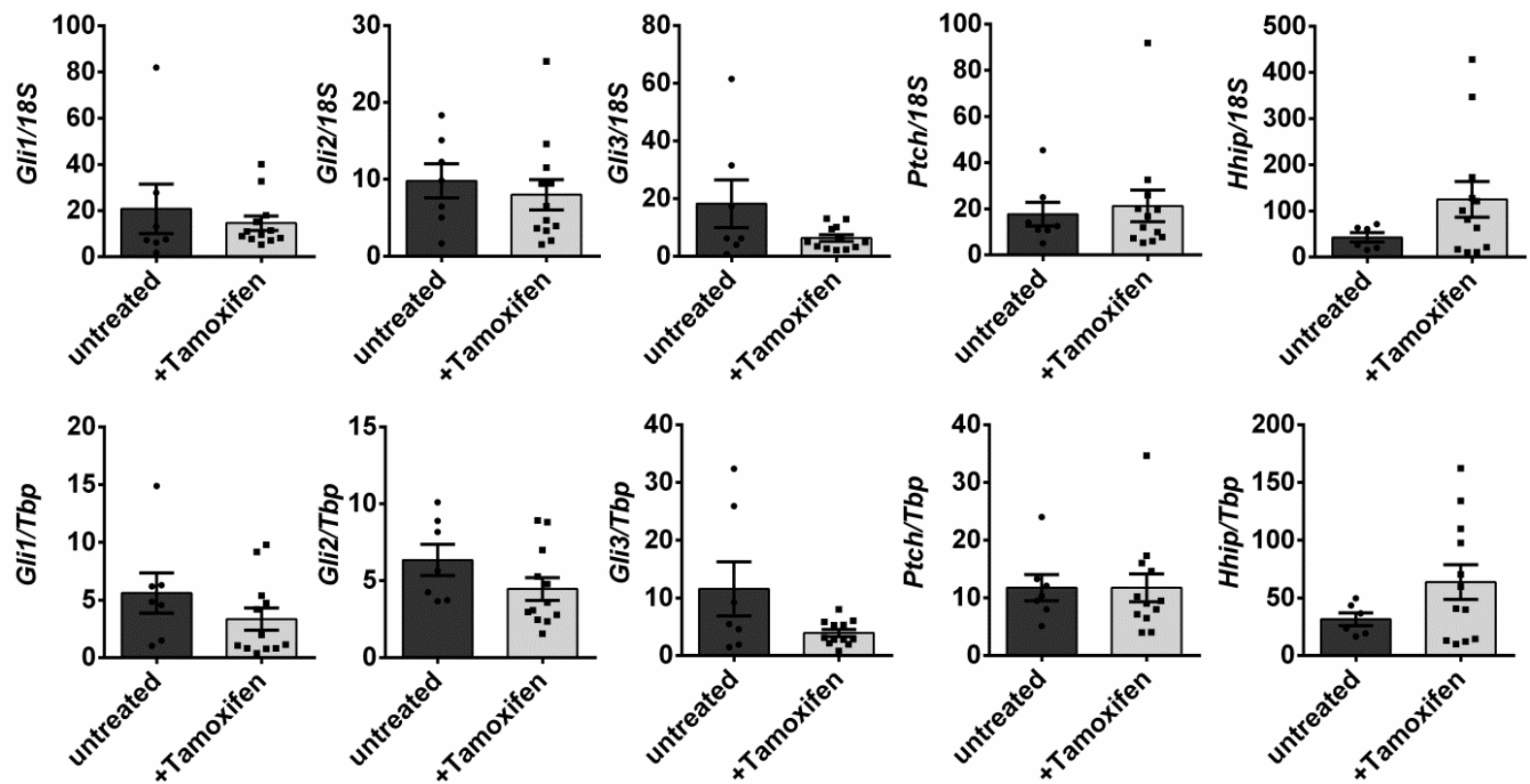
C

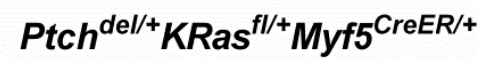
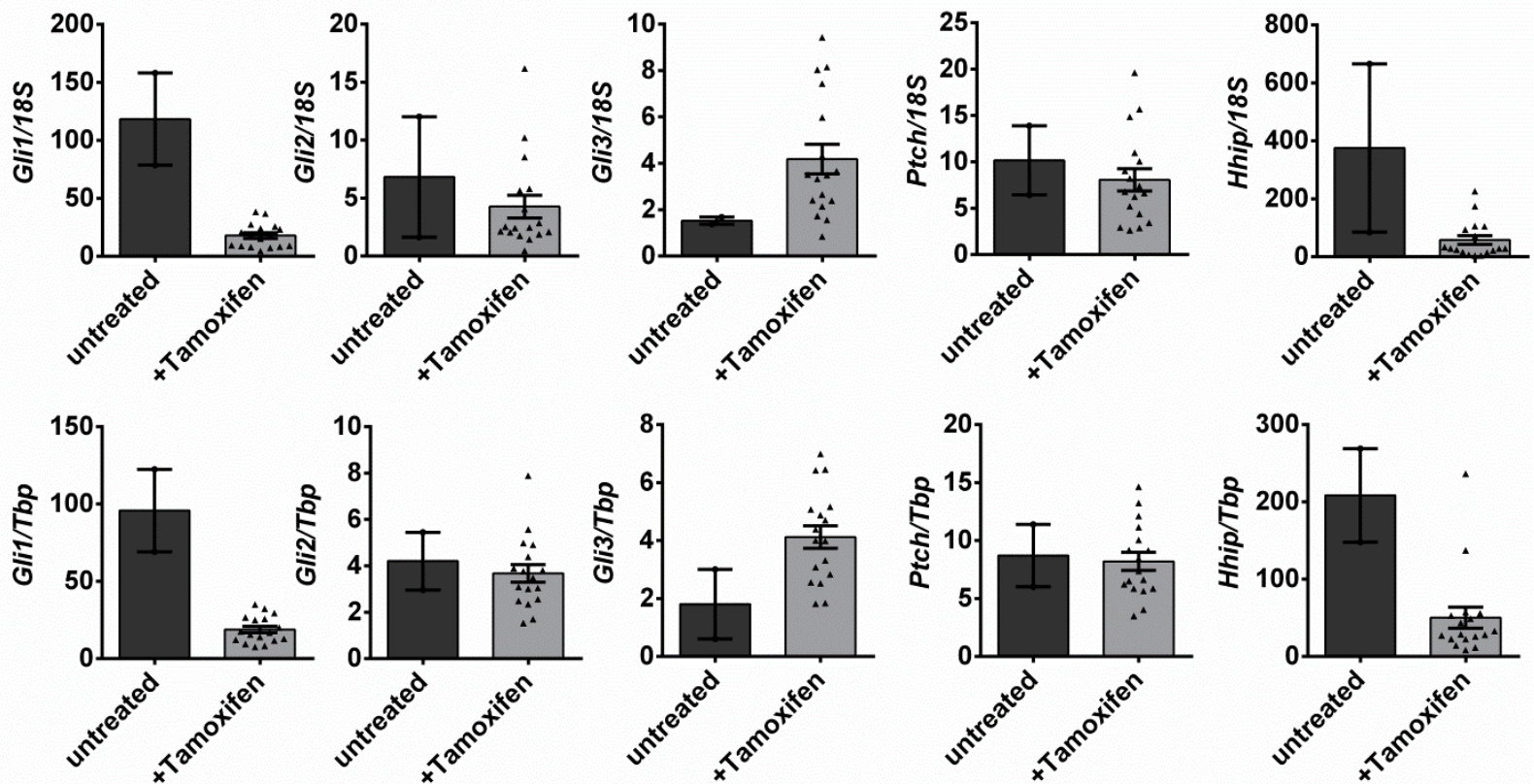

D Ptch $^{\text {del/+ }}$ Ras $^{f l /+}$ Myf5 $^{\mathrm{CreER/+}}$
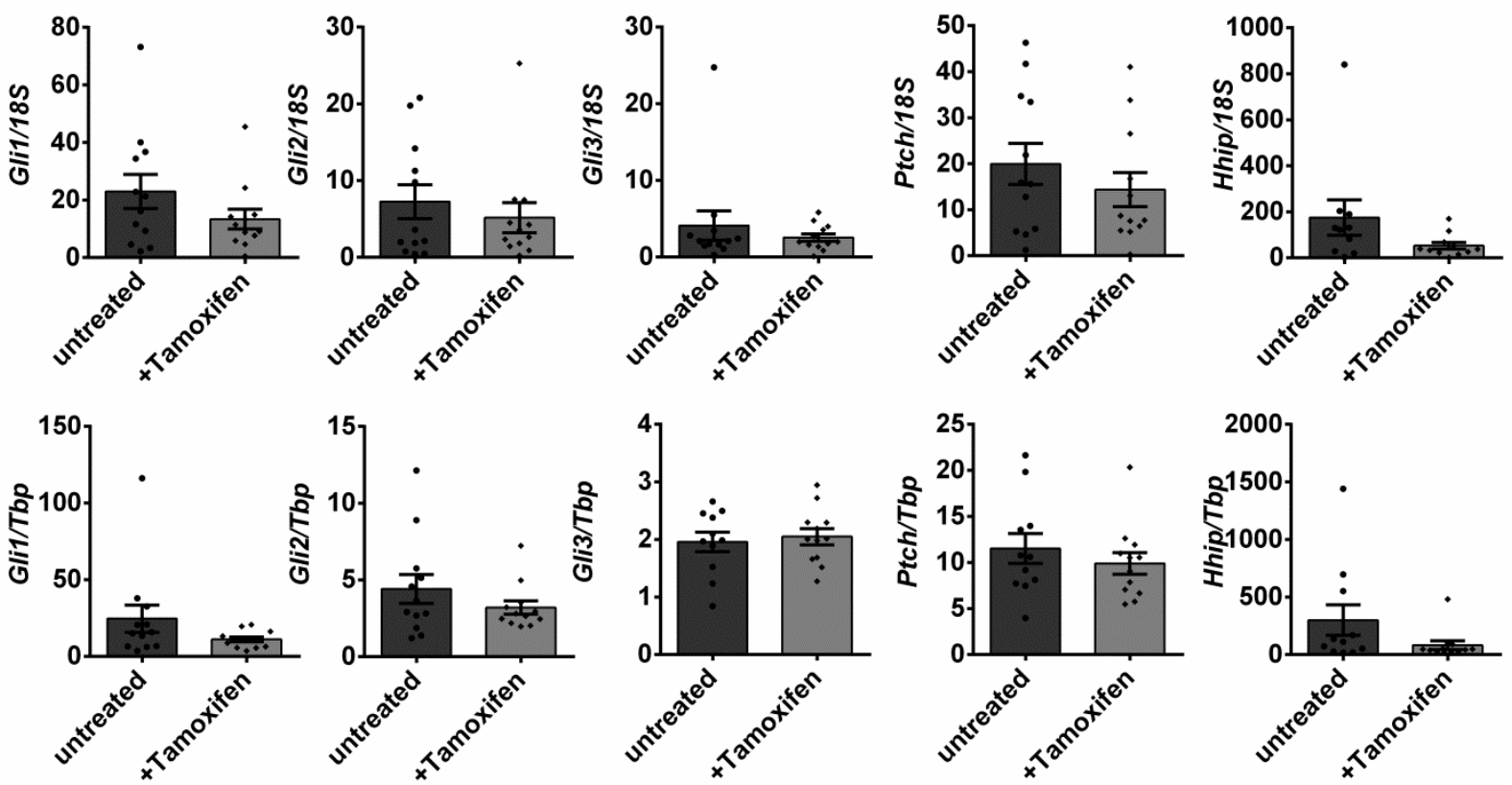

Figure 52: OncRas does not influence the expression of Hh signaling genes in ERMS

ERMS and skeletal muscle (SM) tissue samples were isolated from untreated $(n=9)$ and tamoxifen-treated $(n=4)$ Ptch $^{\text {del/ }+}$ mice $(A)$, untreated $(n=7)$ and tamoxifen-treated $(n=12)$ Ptch $^{\text {del/+}}$ HRas $^{f / /}$ Myf5 $5^{\mathrm{CreER/+}}$ mice $(\mathrm{B})$, untreated $(\mathrm{n}=2)$ and tamoxifen-treated $(\mathrm{n}=17) \mathrm{Ptch}^{\text {del/+}} K \operatorname{Ras}^{\mathrm{fl}+}{ }^{+} M y f 5^{\mathrm{CreER} /+}$ mice $(\mathrm{C})$ and untreated $(\mathrm{n}=12)$ and tamoxifentreated $(n=12)$ Ptch $^{\text {del/+ } N R a s}{ }^{f l+} M y f 5^{C r e E R /+}$ mice (D). Afterwards tissue samples were subjected to RNA isolation, cDNA synthesis and subsequent qRT-PCR analyses of the Hh signaling pathway genes Gli1, Gli2, Gli3, Ptch1 and Hhip. The data were normalized to $18 S$ rRNA (18S, upper row) or Tbp (lower row) and are shown as fold expression to the expression of the same gene within SM of the respective mouse, which was set to 1. Bars show the mean \pm SEM of one cohort and represent measurements in technical triplicates. For statistical analyses nonparametric t-tests (Mann Whitney) were performed in comparison to ERMS from untreated mice of the same cohort. 


\subsubsection{OncNRas, but not oncHRas or oncKRas, increases the expression of muscle differentiation markers in ERMS of Ptch $^{\text {del/+ }}$ mice}

Next, the expression of the muscle differentiation marker MyoD, Myogenin, Tropomyosin 3 and Myosin Heavy Chain (MyHC) was analyzed in SM and ERMS samples by qRT-PCR. The expression of $18 \mathrm{~S}$ rRNA or Tbp was used for normalization. Again the data are shown in relation to the expression of the respective gene in SM tissue of the same animal that was set to 1. Data are shown for tamoxifen-treated Ptch ${ }^{\text {del } /+}$ mice (Fig. 53A),

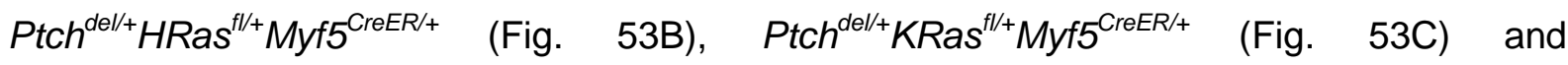
Ptch $^{\text {del/+}} \mathrm{NRas}^{\mathrm{fl}+} \mathrm{Myf5}^{\mathrm{CreER} /+}$ (Fig. 53D) mice in comparison to the untreated controls.

The expression level of $M y o D$ and Myogenin are reflective for proliferation and differentiation of muscle precursors during myogenesis and are considered to be early differentiation markers. The expression level of Tropomyosin 3 and $\mathrm{MyHC}$ indicate differentiation of already established muscle cells and are considered to be late differentiation markers ${ }^{341}$. As demonstrated in Fig. 53A no significant differences in the expression of MyoD, Myogenin, Tropomyosin 3 and MyHC mRNA level were detected in RMS from Ptch $^{\text {del/+ }}$ mice after tamoxifen treatment (Fig. 53A) or upon expression of oncHRas or oncKRas (Fig. 53B, Fig. 53C). In contrast, oncNRas significantly increased mRNA expression of Myogenin (at least when the data was normalized to $18 S$ rRNA) and Tropomyosin 3 (Fig. 53D). This implicates that oncNRas induces a higher differentiation status of ERMS and thus potentially a less aggressive phenotype.

\section{A Ptch $^{\text {del/+ }}$}
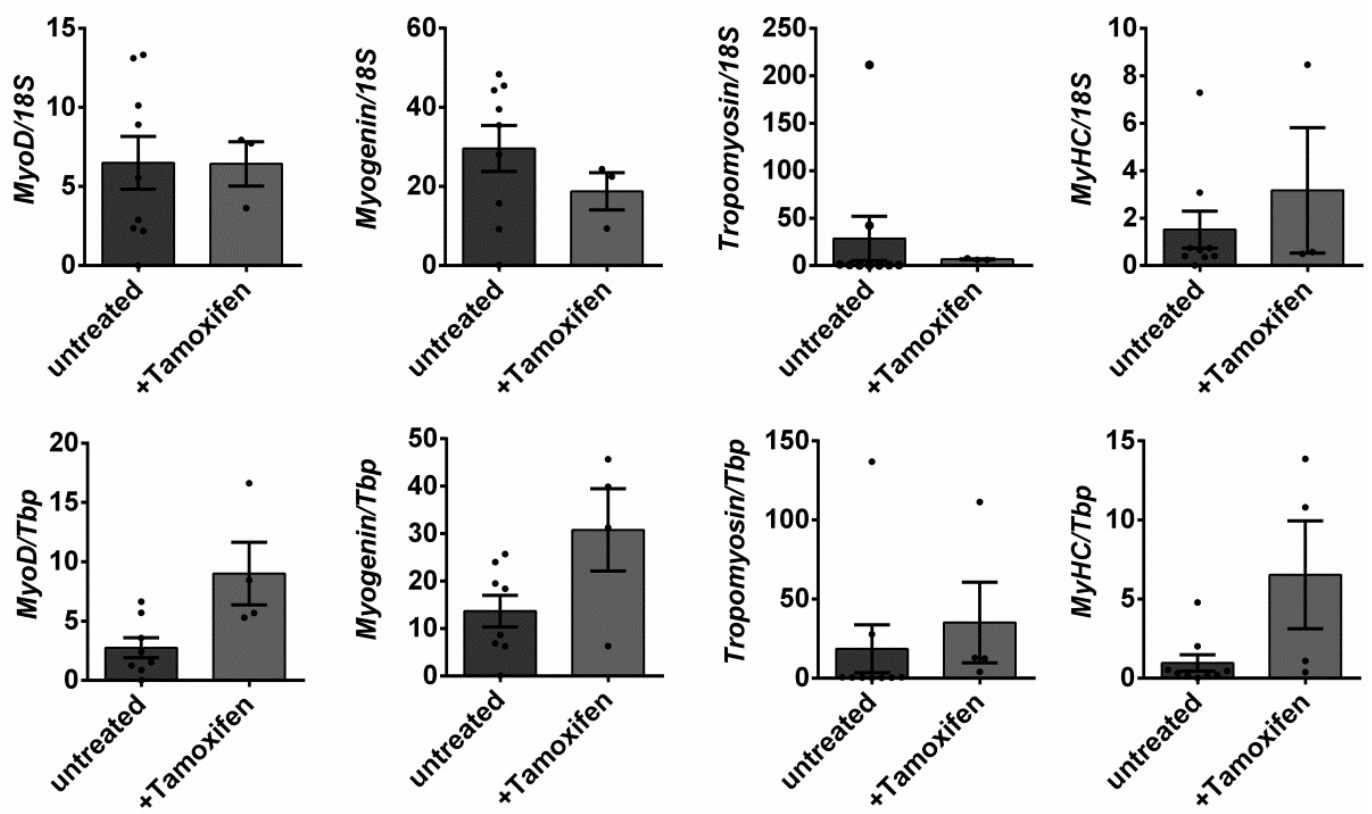
B Ptch $^{\text {del/+}} H_{\text {Ras }}{ }^{f / /+} M y f 5^{C r e E R /+}$
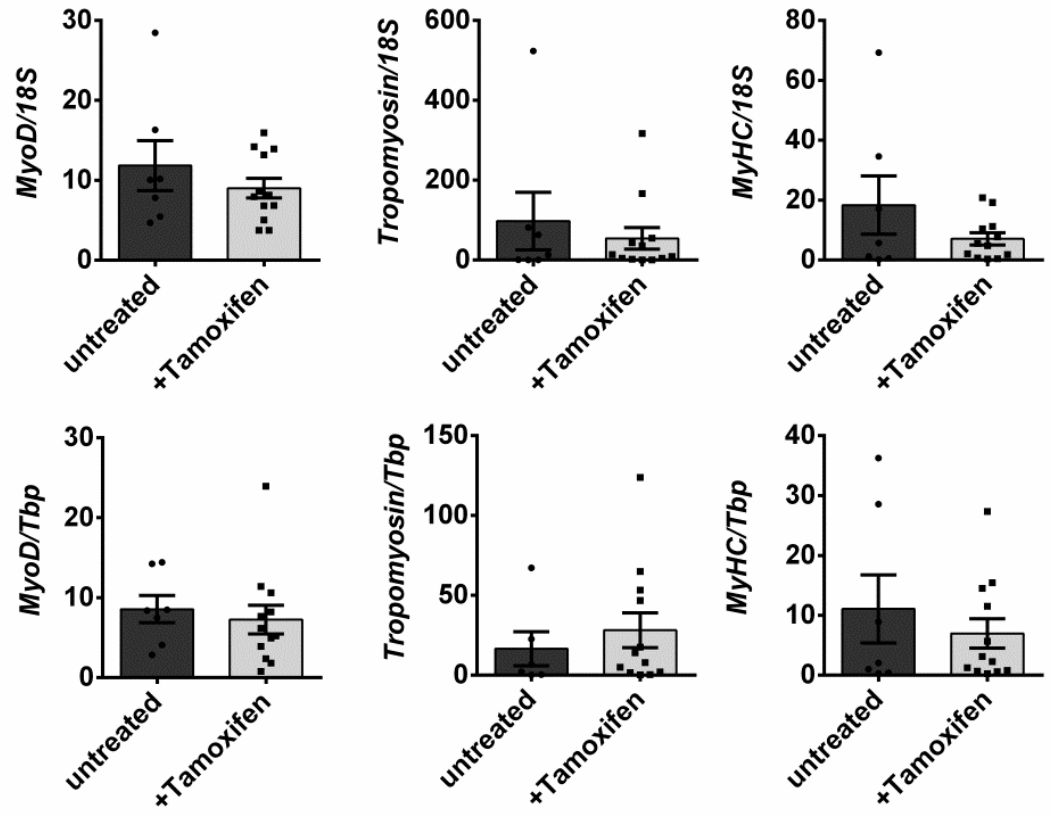

C Ptch $^{\text {del/+ }}$ KRas $^{f /+}$ Myf5 ${ }^{C r e E R /+}$
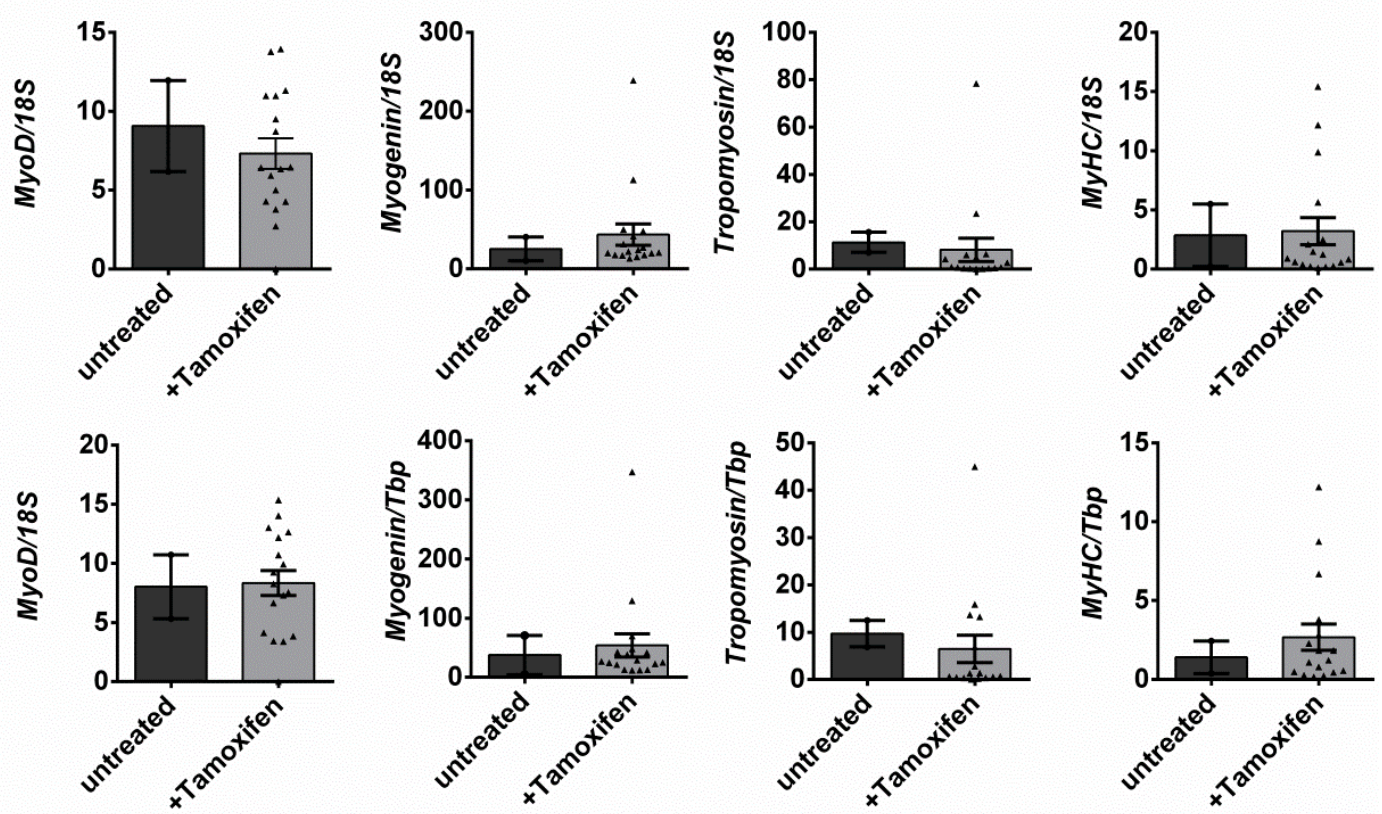
D $\operatorname{Ptch}^{\mathrm{del} /+} \mathrm{NRas}{ }^{\mathrm{fl} /+} \mathrm{Myf5} \mathrm{CreER/+}^{\mathrm{s}}$
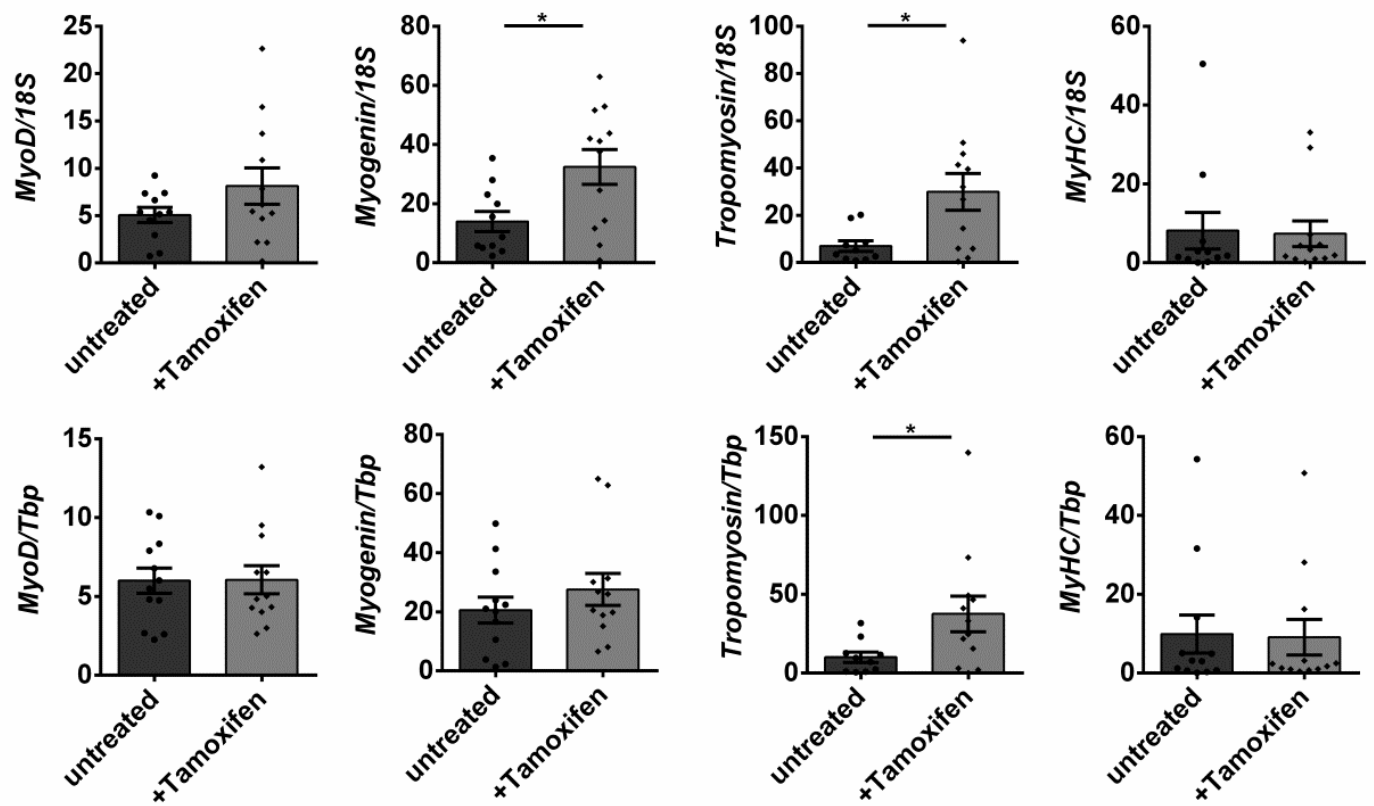

Figure 53: OncNRas induces expression of myogenic differentiation markers in ERMS, whereas oncHRas and oncKRas do not

ERMS and skeletal muscle (SM) tissue samples were isolated from untreated $(n=9)$ and tamoxifen-treated $(n=4)$ Ptch $^{\text {del/ } /+}$ mice $(A)$, untreated $(n=7)$ and tamoxifen-treated $(n=12)$ Ptch $^{\text {del/ }}$ HRas ${ }^{f / /}$ Myf5 $5^{C r e E R /+}$ mice $(B)$, untreated $(\mathrm{n}=2)$ and tamoxifen-treated $(\mathrm{n}=17) \mathrm{Ptch}^{\text {del/+}} \mathrm{KRas}^{\mathrm{fl}+} \mathrm{Myf5} \mathrm{CreER/+}^{\mathrm{mice}}(\mathrm{C})$ and untreated $(\mathrm{n}=12)$ and tamoxifentreated $(\mathrm{n}=12) \mathrm{Ptch}^{\mathrm{del/+}} \mathrm{NRas}{ }^{\mathrm{fl} /+} \mathrm{Myf5}^{\mathrm{CreER/+}}$ mice (D). Afterwards tissue samples were subjected to RNA isolation, cDNA synthesis and subsequent qRT-PCR analyses of the myogenic differentiation markers MyoD, Myogenin, Tropomyosin 3 and Myosin Heavy Chain (MyHC). The data were normalized to $18 S$ rRNA (18S, upper row) or $\mathrm{Tbp}$ (lower row) and are shown as fold expression to the expression of the same gene within SM of the respective mouse, which was set to 1 . Bars show the mean \pm SEM of one cohort and represent measurements in technical triplicates. For statistical analyses non-parametric t-tests (Mann Whitney) were performed in comparison to ERMS from untreated mice of the same cohort. ${ }^{*} p<0.05$ compared to untreated mice from the respective cohort

When the tumors were reviewed histologically by the pathologist Prof. Dr. med. Hans-Ulrich Schildhaus, no general differences between untreated and tamoxifen-treated tumors were detected. However, single tumor samples expressing oncRas were less differentiated than control tumors. In addition, single ERMS expressing oncKRas showed a more pleomorphic phenotype and more signs of necrosis in comparison to ERMS with oncHRas or oncNRas.

Due to these data, we also examined the expression of the cell cycle marker p21 that influences apoptosis, proliferation and cell cycle arrest ${ }^{342}$. However, no differences between the tumor samples were observed (data not shown).

\subsubsection{No obvious changes in pAKT, pERK, pS6 or caspase 3 cleavage in oncRas- expressing ERMS of Ptch $^{\text {del/+ }}$ mice}

Finally, the protein expression level of phosphorylated Erk, Akt and S6 and cleavage of caspase 3 in SM and ERMS of untreated and tamoxifen-treated Ptch ${ }^{\mathrm{del} /+} H \mathrm{Ras}^{\mathrm{fl} /+} \mathrm{Myf5} 5^{\mathrm{CreER} /+}$ and $\mathrm{Ptch}^{\mathrm{del} /+}$ KRas ${ }^{f /+} \mathrm{Myf5} 5^{\mathrm{CreER} /+}$ mice was compared. In general, the results were very heterogeneous and no common differences between control ERMS and oncRas-expressing ERMS were detected (Fig. 54A and Fig. 54B). 
A Ptch $^{\text {del/+} H R a s^{f l /+} M y f 5^{C r e E R /+}}$
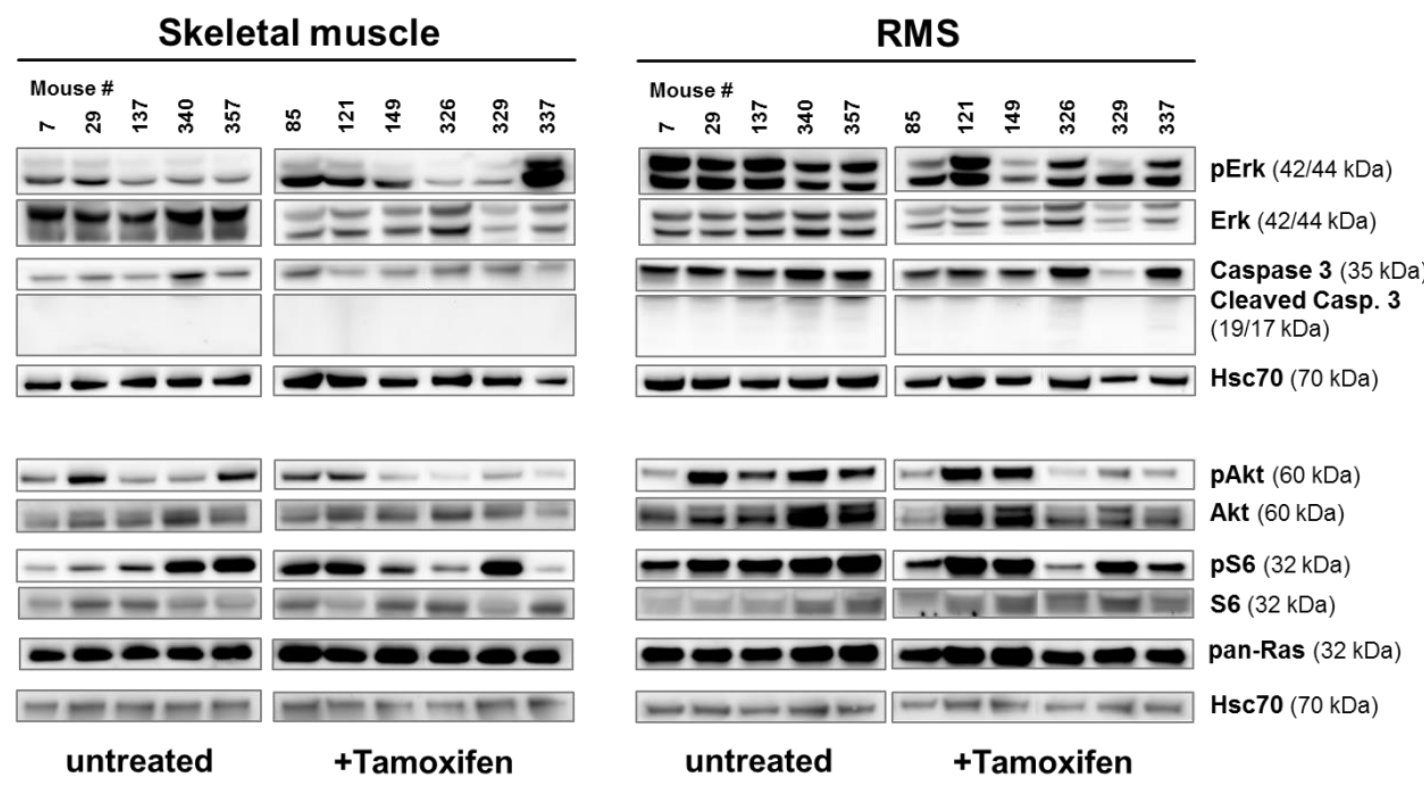

B

$\operatorname{Ptch}^{\mathrm{del} /+} \mathrm{KRas}^{\mathrm{fl} /+} \mathrm{Myf5} \mathrm{CreER/+}^{\mathrm{C}}$
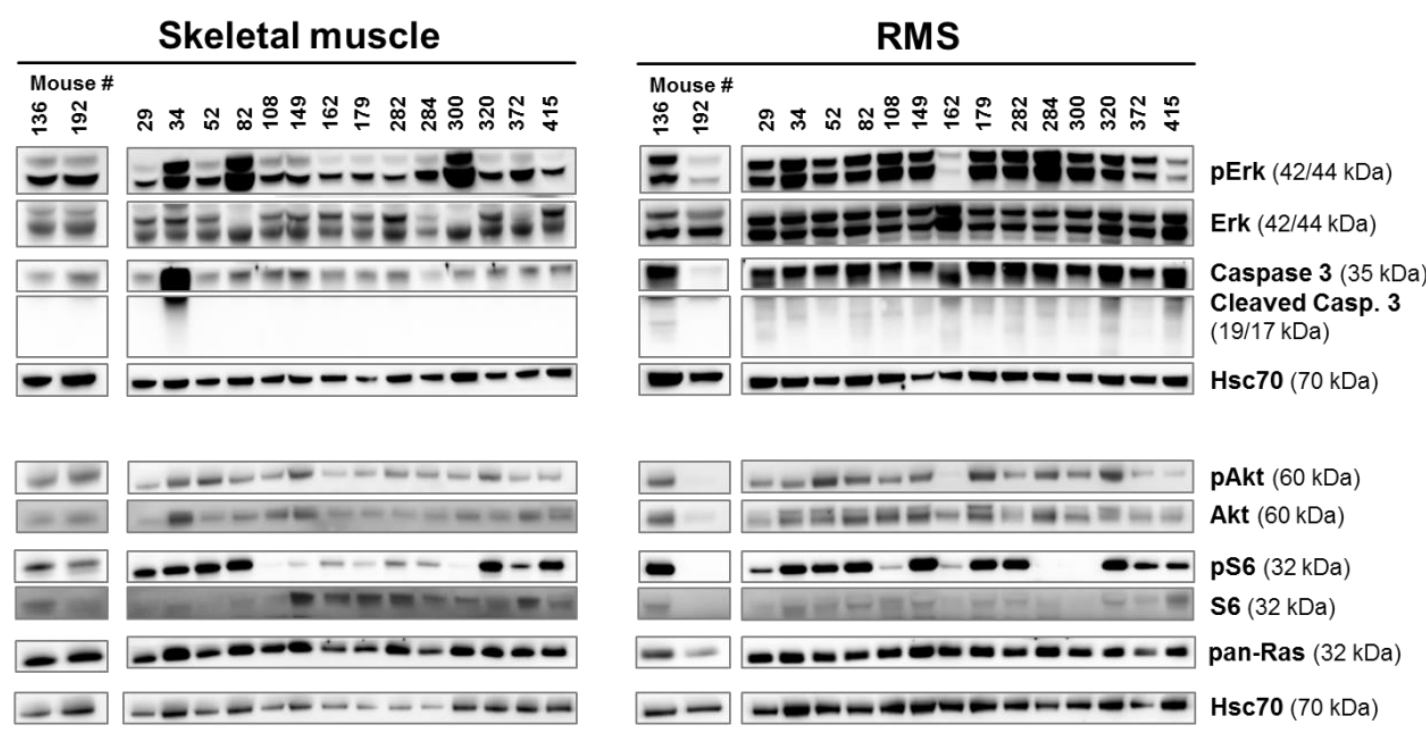

un-

+Tamoxifen

treated

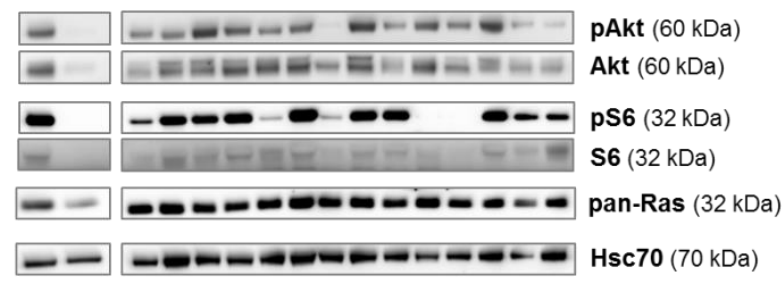

un-

+Tamoxifen

Figure 54: Impact of oncHRas and oncKRas on phosphorylation of Erk, Akt and S6 and caspase cleavage in ERMS of Ptch $^{\text {del/t+ }}$ mice

Protein was isolated from Skeletal muscle (SM) and ERMS (RMS) of untreated ( $n=5)$ and tamoxifen-treated

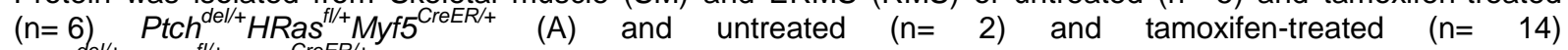
Ptch $^{\text {del/ }}$ KRas $^{\text {tl/ }}$ Myf5 $^{\text {CreER/+ }}$ (B) mice. Afterwards cell lysates were subjected to Western Blot analyses. Phosphorylation of Erk, Akt and S6 and cleavage of caspase 3 were detected using specific primary antibodies. Hsc70 served as reference protein and loading control. The Western Blots are representative for at least two independent technical replicates. Protein names and sizes in $\mathrm{kDa}$ are displayed on the right side of the Blots.

Unfortunately, only 2 control ERMS samples from untreated $\mathrm{Ptch}^{\mathrm{del} /+} \mathrm{KRas}^{\mathrm{fl}+} \mathrm{Myf5} 5^{\mathrm{CreER} /+}$ mice were available for the analyses (Fig. 54B). Therefore, it is not possible to judge whether there are real differences between control ERMS and oncKRas-expressing ERMS in this cohort. Nevertheless, the results show that phosphorylation either of Erk, Akt or S6 as well as caspase 3 cleavage is generally higher in tumors compared to normal skeletal muscle. 
These results are similar to those shown by our group in $2004{ }^{138}$. However, due to these heterogeneous results and the time-consuming procedure the analysis of tissue samples from $\mathrm{Ptch}^{\mathrm{del/+}}$ or $\mathrm{Ptch}^{\mathrm{del/+}} \mathrm{NRas^{f//+ }} \mathrm{Myf5}^{\mathrm{CreER} /+}$ mice was set aside.

To sum up, the data within section 6.3.2 highlight that the expression of oncKRas and oncHRas accelerate Hh-associated ERMS formation, whereas oncNRas does not. This was measured by overall and ERMS-free survival, tumor incidence and the proliferation status of the tumors. Interestingly, oncNRas elevated the expression of specific muscle differentiation markers in ERMS, which thus correlates with the lack of increased aggressiveness of the tumors. In addition, oncRas seem to generally decrease the expression of Gli1 in the tumors. Although the decrease was not significant, these results are similar to human ERMS cell lines.

\subsubsection{Activation of oncRas in established ERMS}

In a next study, oncRas mutations were induced in already established ERMS of Ptch ${ }^{\text {del/+ }}$ mice. For this purpose, mice with palpable tumors (diameter of approximately $0.5 \mathrm{~cm}$ ) were subjected to $\mu \mathrm{CT}$ measurement to document the exact tumor size. Then the Ptch $^{\text {del/t }}$ oncRas ${ }^{f l /+} \mathrm{Myf5}^{\mathrm{CreER} /+}$ mice were injected i.p. 5 times with tamoxifen to induce Cremediated recombination and thereby oncRas expression in the tumor. Solvent-treated ERMS-bearing Ptch ${ }^{d e l /+}$ oncRas ${ }^{f / /+} M y f 5^{C r e E R /+}$ siblings served as controls. In addition, the ERMS growth of solvent or tamoxifen-treated $\mathrm{Ptch}^{\text {del/+ }}$ mice was analyzed. Seven weeks after tamoxifen injection the tumor volume was again analyzed by $\mu \mathrm{CT}$.

\subsubsection{OncRas isoforms do not influence growth of established ERMS of Ptch ${ }^{\text {del/+ }}$ mice}

As stated above, the tumor volume of $\mathrm{Ptch}^{\mathrm{del} /+} \mathrm{oncRas}^{\mathrm{fl}+} \mathrm{Myf5}^{\mathrm{CreER} /+}$ mice were analyzed by $\mu \mathrm{CT}$ before and 7 weeks after induction of oncRas expression. The relative tumor volumes at the first and last $\mu \mathrm{CT}$ measurement are shown in Fig. 55A. The data were plotted on a logarithmic scale with linear trend lines for assumed tumor growth curves. The relative tumor growth, calculated as percentage increase of the tumor volume when comparing the absolute tumor volume at the first and last $\mu \mathrm{CT}$ measurement, is displayed on logarithmic scale as well (Fig. 55B). Solvent-treated mice served as controls. 
A

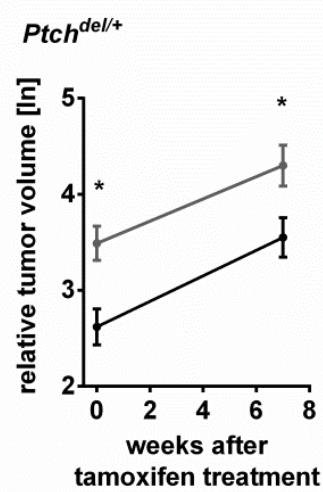

Ptch $^{\text {del/++} H R a s^{f l /+} M y f 5^{C r e E R /+}}$

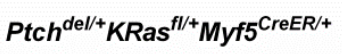

Ptch $^{\text {del/+ }}$ NRas ${ }^{f /+}$ Myf5 $5^{\text {CreER/+ }}$

tamoxifen treatment
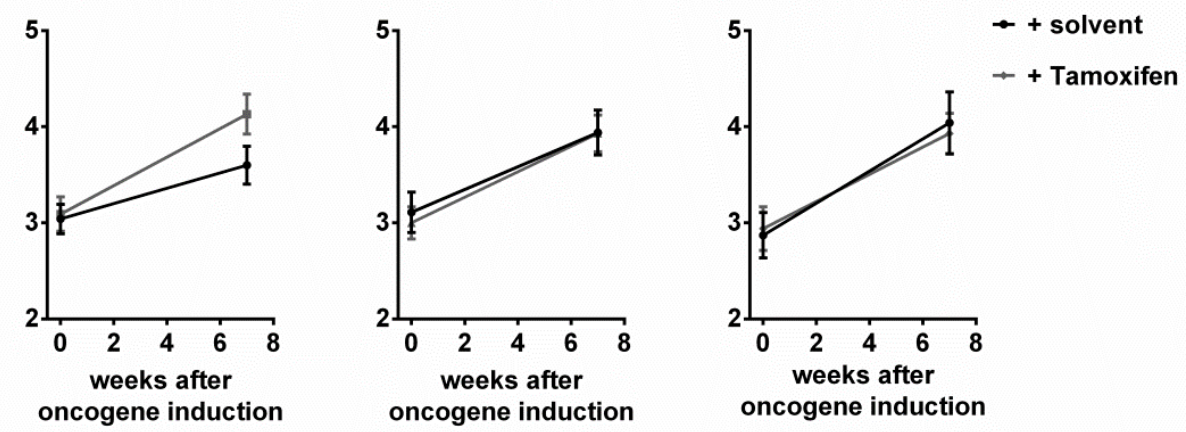

B
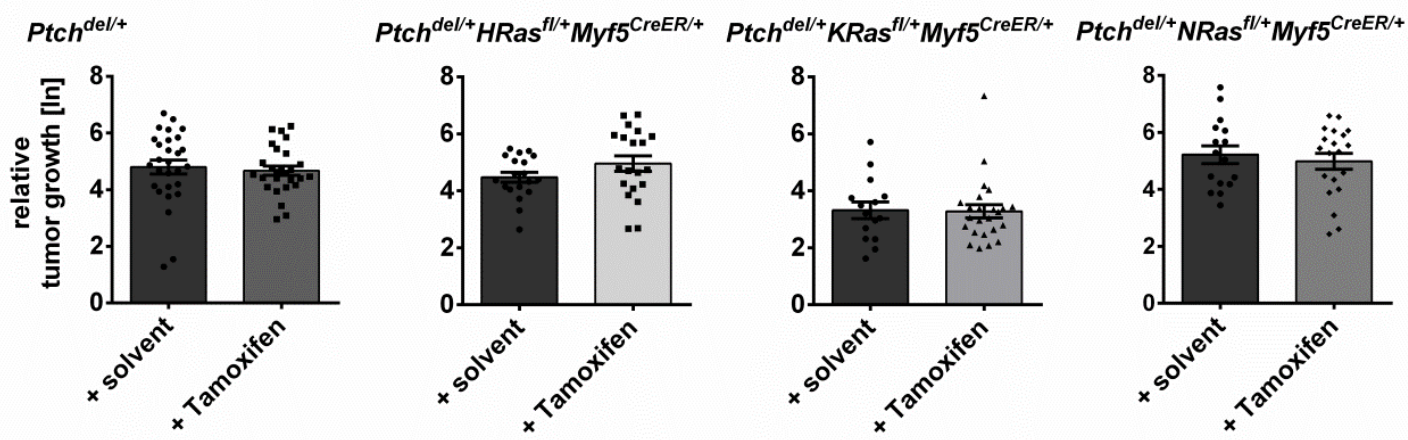

Figure 55: Tamoxifen treatment and oncRAS mutations do not influence growth of established ERMS of Ptch $^{\text {del/t }}$ mice

Mice with palpable tumors were subjected to $\mu \mathrm{CT}$ measurements before and 7 weeks after solvent or tamoxifen treatment and tumor volume was calculated (A). The relative percentage of increase was additionally calculated for each tumor (B). Solvent or tamoxifen treatment is represented by black or grey graphs, respectively. Multiple ERMS within the same mouse were analyzed as individual tumors. Data analyses was performed for solventtreated ( $n=29$ ERMS from 17 mice) or tamoxifen-treated ( $n=27$ ERMS from 18 mice) Ptch $h^{\text {del/ }+}$ mice, solventtreated ( $n=19$ ERMS from 12 mice) or tamoxifen-treated ( $n=20$ ERMS from 11 mice) Ptch ${ }^{\text {del/t+}} \mathrm{HRas}^{\mathrm{tl/}+} \mathrm{Myf5}^{\mathrm{CreER} /+}$ mice, solvent-treated $(n=15$ ERMS from 12 mice) or tamoxifen-treated ( $n=24$ ERMS from 15 mice)

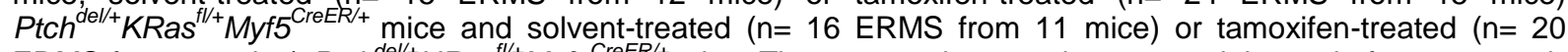

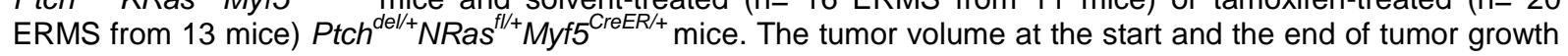
measurement and percental increase of each tumor are displayed on a logarithmic scale. For statistical analyses Student's t-tests were performed in comparison to tumor volume from solvent-treated mice of the same cohort.

At the onset of the study the sizes of all RMS of the Ptch ${ }^{\text {del/t }}$ oncRas ${ }^{f / /}$ Myf5 $5^{\mathrm{CreER} /+}$ cohorts were almost identical. This was different in $\mathrm{Ptch}^{\text {del/t }}$ control mice, in which the mean tumor volume of mice that underwent tamoxifen-injection was accidentally larger. Seven weeks after solvent or tamoxifen treatment, all tumors had grown. However, neither tamoxifen nor oncRas had significantly influenced ERMS growth (Fig. 55A). This is also demonstrated in Fig. 55B, which represents the relative tumor growth of individual tumors. Finally, a comparison between tumors expressing different oncRas isoforms also revealed no significant differences (data not shown). 


\subsubsection{OncRas isoforms do not influence proliferation of established ERMS of $\mathrm{Ptch}^{\text {del/+ }}$ mice}

Next, all available tumor samples were analyzed for the expression of the proliferation marker Ki67. In all analyzed tumors the mean amount of $\mathrm{Ki} 67^{+}$nuclei ranged between $2.5 \%$ and $4.0 \%$ and did not differ significantly between the cohorts (Fig. 56). Together with the data shown in section 6.3.2.1, the results demonstrate that oncRas isoforms have no impact on proliferation of established ERMS of $\mathrm{Ptch}^{\text {del/+ }}$ mice.
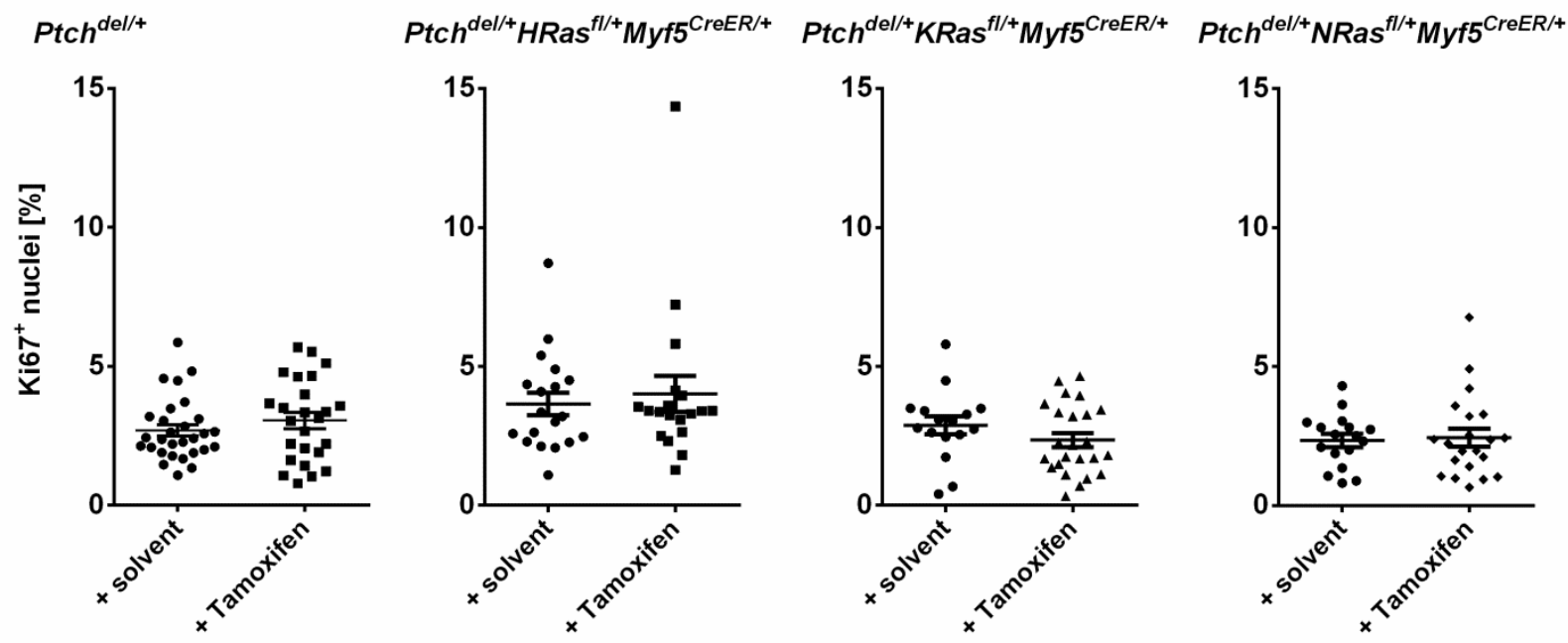

Figure 56: Percentage of $\mathrm{Ki}^{+} 7^{+}$nuclei in established ERMS from Ptch ${ }^{\text {del/+ }}$ mice with and without oncRas ERMS tissue sections from solvent-treated $(n=29$ ERMS from 17 mice) and tamoxifen-treated $(n=27$ ERMS from 18 mice) $P_{t c h}{ }^{d e l /+}$ mice, solvent-treated ( $n=29$ ERMS from 12 mice) and tamoxifen-treated $(n=20$ ERMS from 11 mice) Ptch ${ }^{\text {del/+}}$ HRas $^{f /+}$ Myf5 $^{\mathrm{CreER/+}}$ mice, solvent-treated ( $\mathrm{n}=15$ ERMS from 12 mice) and tamoxifen-treated $(\mathrm{n}=24$ ERMS from 15 mice) $\mathrm{Ptch}^{\mathrm{del/}+} \mathrm{KRas}^{\mathrm{fl} /+} \mathrm{Myf5}^{\mathrm{CreER} /+}$ mice and solvent-treated ( $\mathrm{n}=16$ ERMS from 11 mice) and tamoxifen-treated $\left(n=20\right.$ ERMS from 13 mice) $\mathrm{Ptch}^{\mathrm{del/+}} \mathrm{NRas} \mathrm{s}^{\mathrm{fl}+} \mathrm{Myf5} \mathrm{CreER/+}^{\mathrm{C}}$ mice were stained with a specific antibody against the proliferation marker Ki67. Number of all nuclei and Ki67 $7^{+}$nuclei were counted manually in 6 pictures of each tumor and the percentage of $\mathrm{Ki}^{+} 7^{+}$nuclei was calculated. For statistical analyses non-parametric t-tests (Mann Whitney) were performed.

\subsubsection{OncRas does not change expression of Hh target genes in established ERMS}

Afterwards, the expression level of the Hh genes Gli1 and Gli2 were analyzed in the SM and ERMS tissue samples (Fig. 57). The expression of $18 S$ rRNA or Tbp was used for normalization.

Again and as already mentioned, the expression of the respective gene in ERMS is shown relative to the expression in SM of the same animal and the expression level of the gene in SM was set to 1. However, the analyses revealed no significant differences in Gli1 and Gli2 mRNA expression between ERMS of solvent- or tamoxifen-treated Ptch $^{\text {del/+}}$ oncRas ${ }^{f /+} M y f 5^{C r e E R /+}$ mice. This was true for Ptch $^{\text {del/+}} \mathrm{HRas}^{\mathrm{fl} /+} \mathrm{Myf5} 5^{\mathrm{CreER} /+}$ (Fig. 57B),

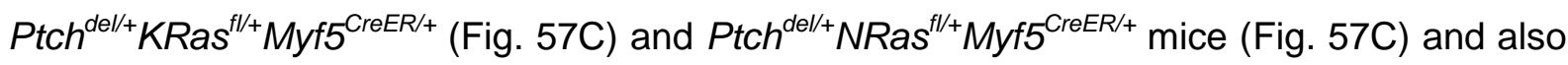
for Ptch ${ }^{\text {del/+ }}$ mice (Fig. 57A). 


\section{A $\quad$ Ptch $^{\text {del/++}}$}
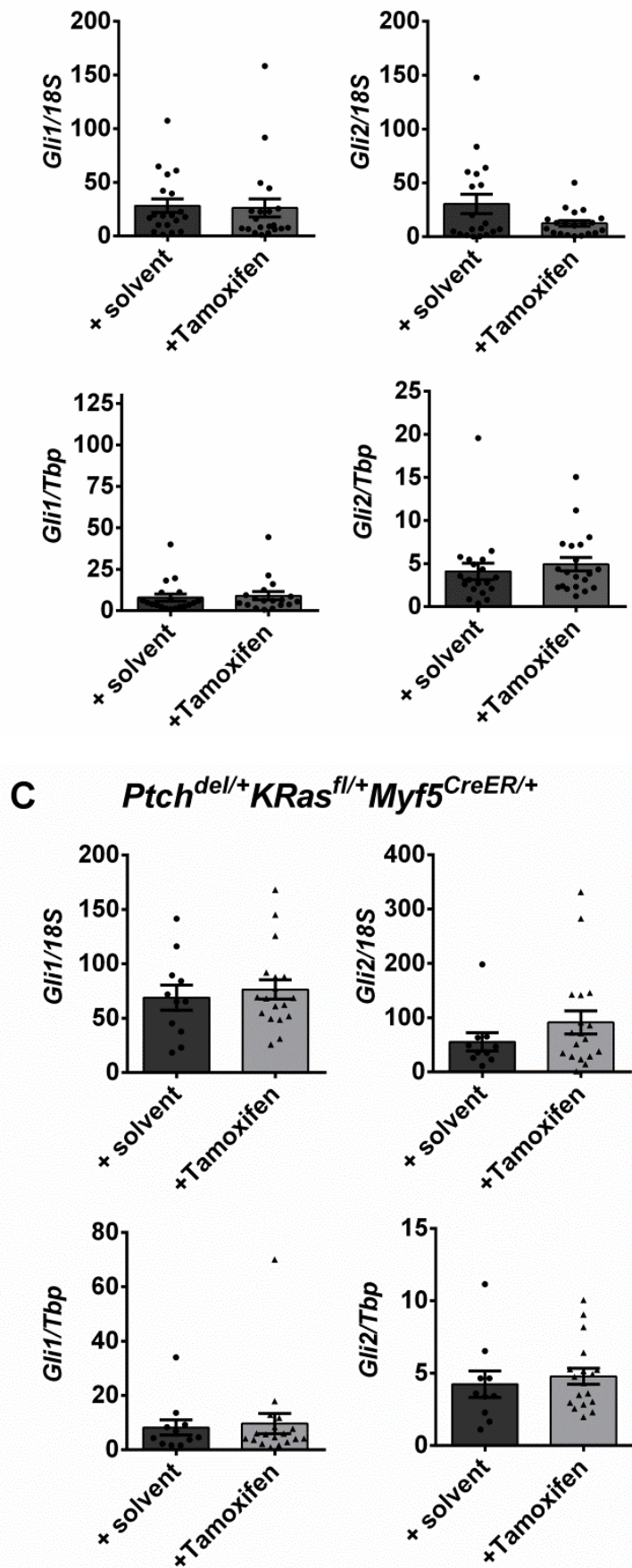

\section{B Ptch $^{\text {del/++}{ }^{H R a s}}{ }^{\mathrm{fl} /+} \mathrm{Myf5}^{\mathrm{CreER} /+}$}
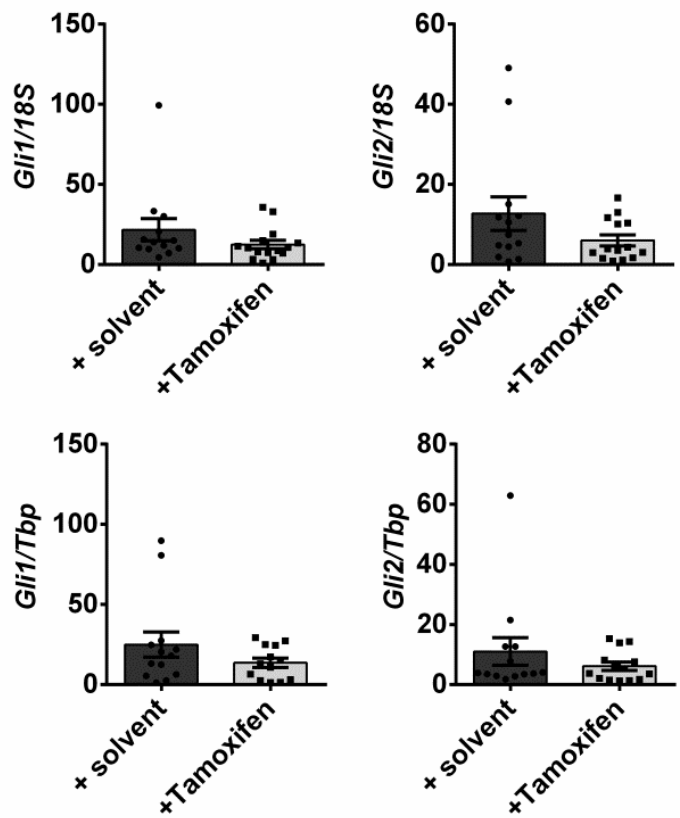

D $\quad$ Ptch $^{\text {del/+ }}$ Ras $^{f l /+} M_{y f 5}{ }^{\mathrm{CreER} /+}$
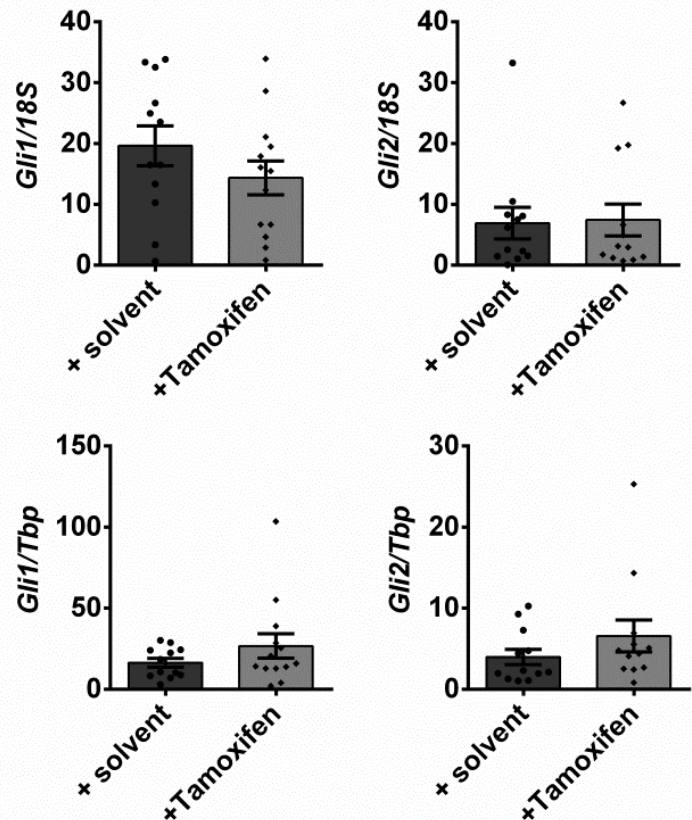

Figure 57: Tamoxifen treatment and oncRas mutations do not influence expression of Gli1 and Gli2 in established ERMS in $\mathrm{Ptch}^{\text {del/+ }}$ mice

ERMS and skeletal muscle (SM) tissue samples were isolated from solvent-treated $(n=19)$ and tamoxifen-treated $(n=20)$ Ptch $^{\text {del/t+}}$ mice $(A)$, solvent-treated $(n=13)$ and tamoxifen-treated $(n=15)$ Ptch $^{\text {del/ }}$ HRas ${ }^{\mathrm{fl} /+}$ Myf5 $5^{\mathrm{CreER} /+}$ mice (B), solvent-treated $(n=11)$ and tamoxifen-treated $(n=18)$ Ptch $^{d e l /+} K R^{t / l+} M y f 5^{C r e E R / t}$ mice $(C)$ and solvent-treated $(n=12)$ and tamoxifen-treated $(n=13)$ Ptch $^{\text {del/ }}$ NRas ${ }^{t / /}$ Myf5 $5^{\text {CreER } /+}$ mice (D). Afterwards tissue samples were subjected to RNA isolation, CDNA synthesis and subsequent qRT-PCR analyses of the Hh signaling genes Gli1 and Gli2. The data were normalized to $18 \mathrm{~S}$ rRNA (18S, left) or Tbp (right) and are shown as fold expression to expression of the same gene within SM of the respective mouse, which was set to 1. Bars show the mean \pm SEM of one cohort and represent measurements in technical triplicates. For statistical analyses non-parametric t-tests (Mann Whitney) were performed in comparison to RMS from untreated mice of the same cohort. 


\subsubsection{OncRas do not influence expression of muscle differentiation markers in established ERMS}

Subsequently, the expression of the muscle differentiation markers MyoD, Myogenin, Tropomyosin 3 and $M y H C$ were analyzed in SM and ERMS. The analyses were done as described in the previous chapters.

The results show that there was no significant difference between mRNA expression of muscle differentiation markers in established tumors with and without tamoxifen treatment or with and without oncRas expression (Fig. 58A-Fig. 58D).

\section{A $P t c h^{\text {del/+ }}$}
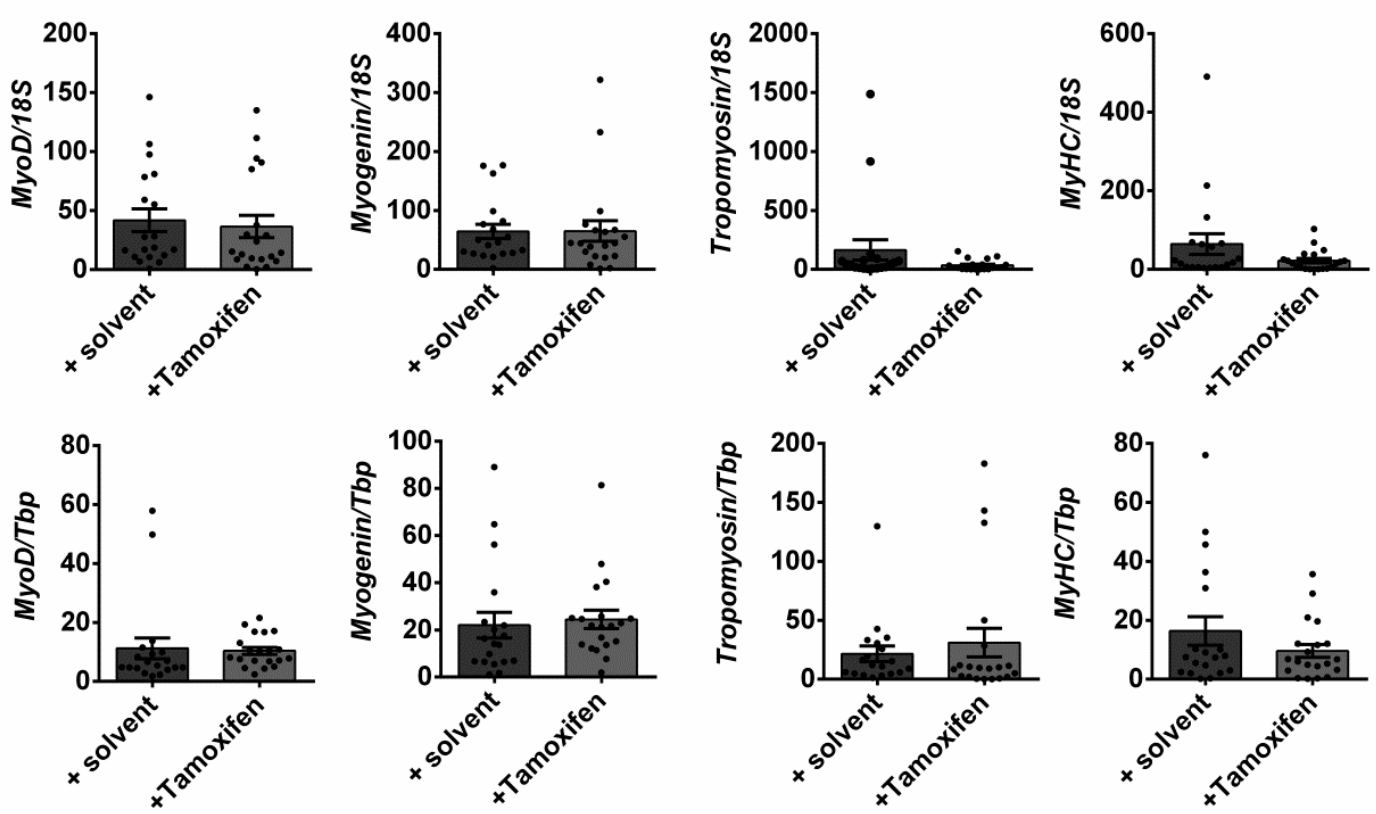

B Ptch ${ }^{\text {del/+ }}$ RRas $^{f / /+}{ }^{\text {Myf5 }}{ }^{\text {CreER/+ }}$
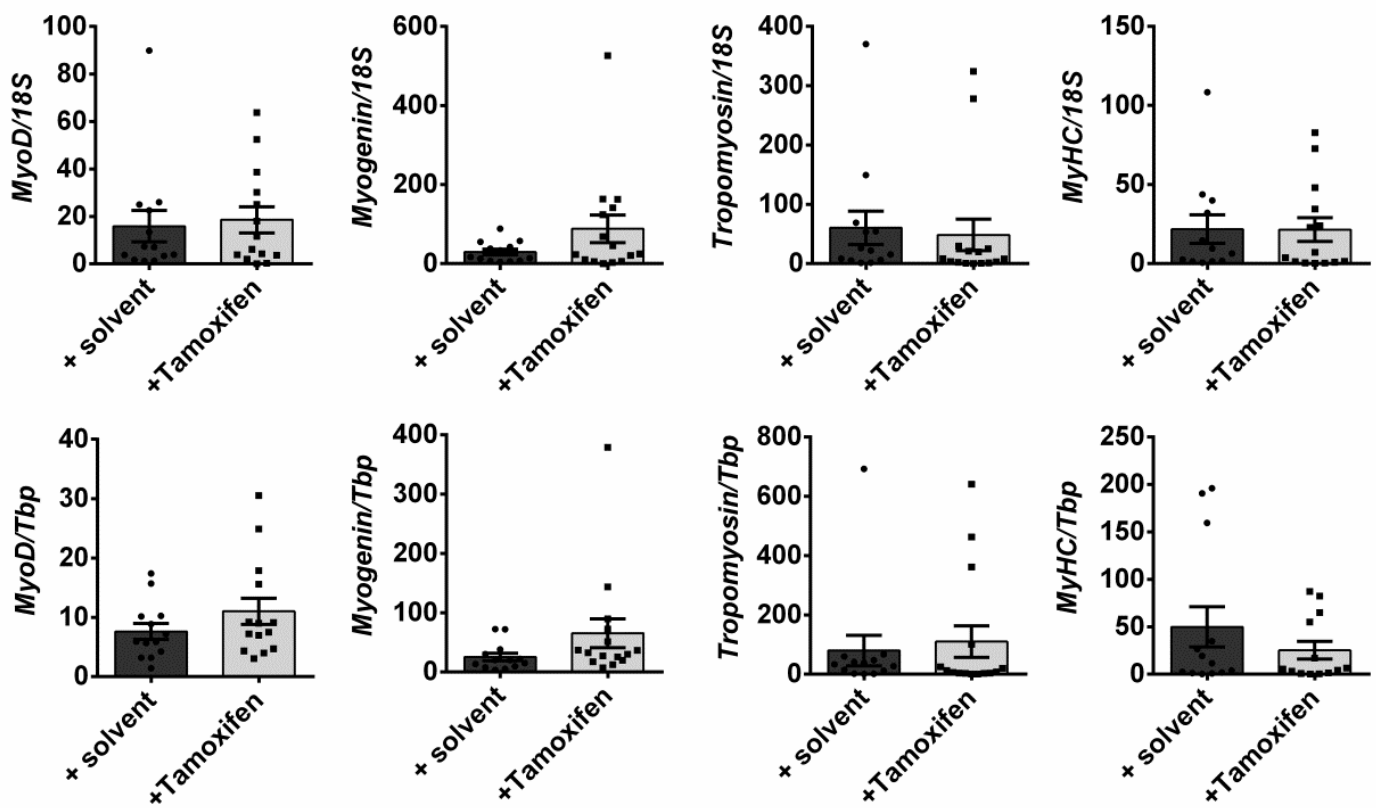


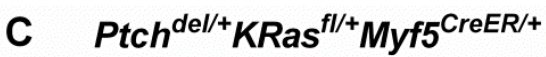
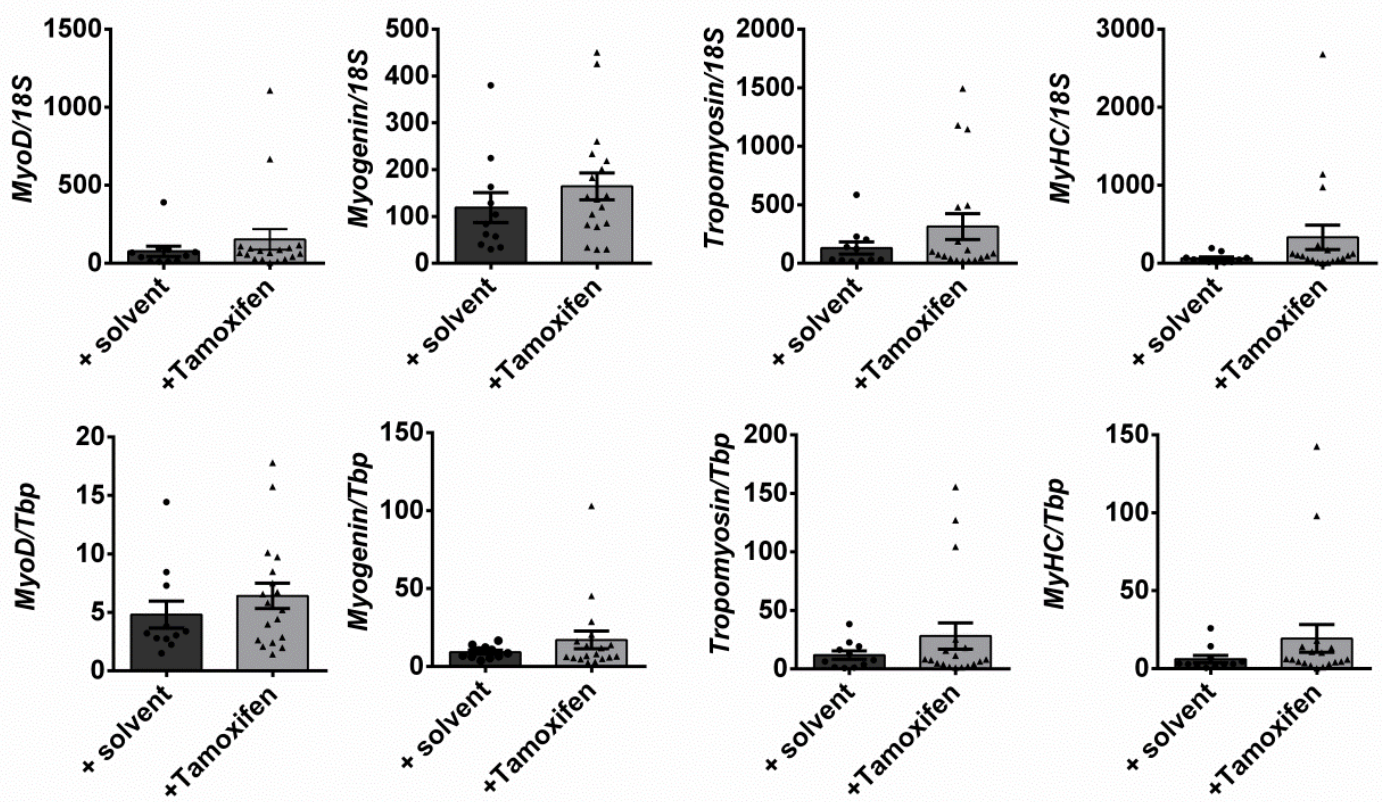

\section{Ptch $^{\mathrm{del} / /+} \mathrm{NRas}^{\mathrm{fl} / \mathrm{M}} \mathrm{Myf5} 5^{\mathrm{CreER} /+}$}
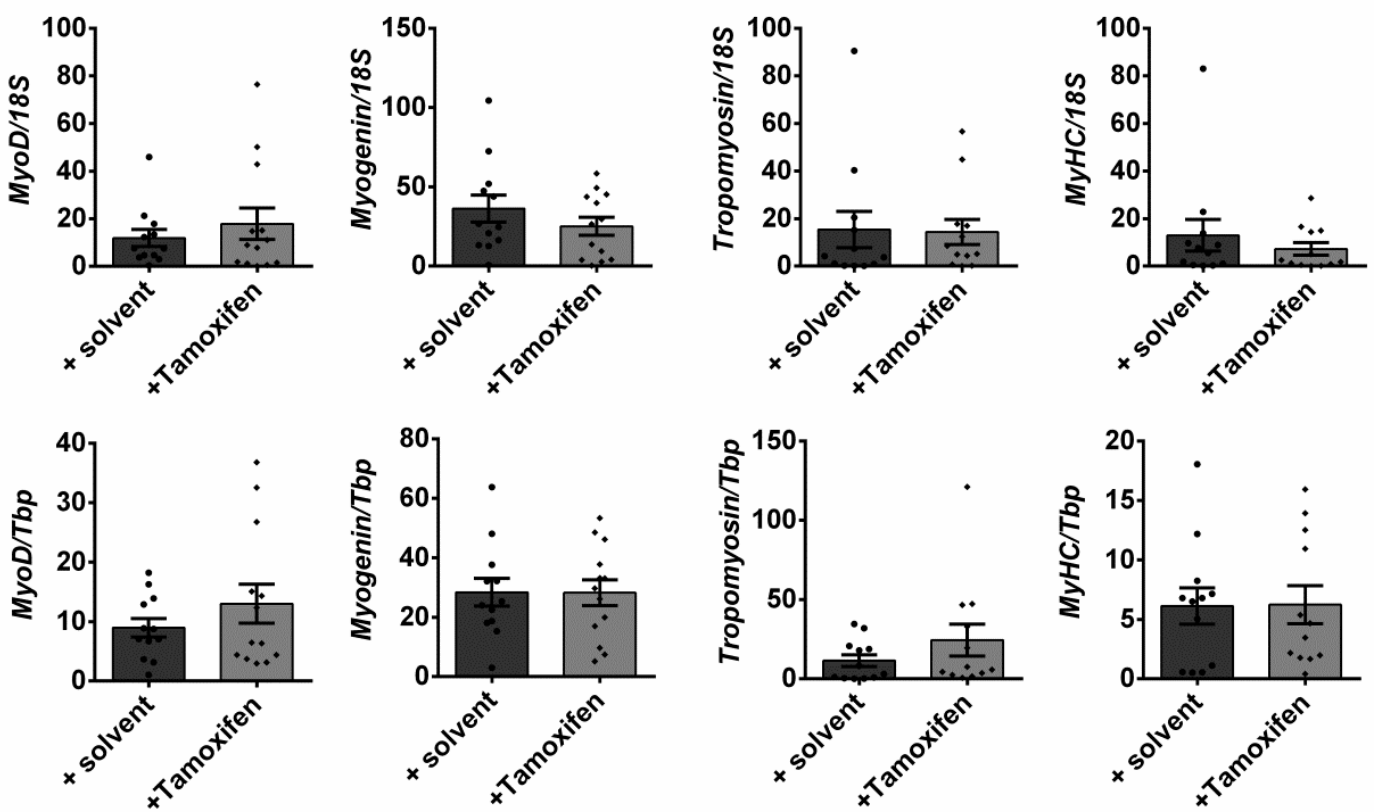

Figure 58: Tamoxifen treatment and oncRas mutations do not influence myogenic differentiation in established ERMS in $\mathrm{Ptch}^{\text {del/t+ }}$ mice

ERMS and skeletal muscle (SM) tissue samples were isolated from solvent-treated $(n=19)$ and tamoxifen-treated $(n=20)$ Ptch $^{\text {del/t+}}$ mice $(A)$, solvent-treated $(n=13)$ and tamoxifen-treated $(n=15)$ Ptch $^{\text {del/+ }}$ HRas ${ }^{\mathrm{fl} /+}$ Myf5 $5^{\mathrm{CreER} /+}$ mice (B), solvent-treated $(n=11)$ and tamoxifen-treated $(n=18)$ Ptch $^{\text {del/t+}} K R a s^{f / t} M y f 5^{\mathrm{CreER} /+}$ mice $(C)$ and solvent-treated $(n=12)$ and tamoxifen-treated $(n=13)$ Ptch $^{\mathrm{del} /+}$ NRas $^{\mathrm{H} / /+} M y f^{5} 5^{\mathrm{CreER} /+}$ mice (D). Afterwards tissue samples were subjected to RNA isolation, CDNA synthesis and subsequent qRT-PCR analyses of the myogenic differentiation markers MyoD, Myogenin, Tropomyosin 3 and Myosin Heavy Chain $(M y H C)$. The data were normalized to $18 S$ rRNA (18S, upper row) or Tbp (lower row) and are shown as fold expression to the expression of the same gene within SM of the respective mouse which was set to 1 . Bars show the mean \pm SEM of one cohort and represent measurements in technical triplicates. For statistical analyses non-parametric t-tests (Mann Whitney) were performed.

To sum up, the results from chapter 6.3.3 indicate that oncRas do not influence growth, proliferation and thus aggressiveness of established ERMS. Furthermore, oncRas isoforms do not influence the expression of different muscle differentiation markers. Moreover, oncRas isoforms do not downregulate targets of Hh signaling such as Gli1 and Gli2. 


\subsubsection{Chapter summary}

Within chapter 6.3 the effect of oncRas on Hh/Ptch-driven ERMS in Ptch ${ }^{\text {del/t }}$ mice is described. The data show that all 3 Ras isoforms are expressed in SM and ERMS of Ptch ${ }^{\text {del/+ }}$ mice and are not mutated. In addition, activity of the Myf5 $5^{\mathrm{CreER}}$ driver, which was used to conditionally activate oncRas isoforms, is indeed mainly active in ERMS. This is not only revealed by using $\mathrm{Ptch}^{\text {del/+}} \mathrm{Myf5}{ }^{\mathrm{CreER/+}} R 26 R^{+/}$mice, but also by recombination assays using normal SM and ERMS tissue samples and Ras activity assays using ERMS tissue samples from tamoxifen-treated Ptch ${ }^{\text {del/+ }}$ and $\mathrm{Ptch}^{\mathrm{del/}+}$ oncRas ${ }^{\mathrm{fl}+} \mathrm{Myf5}^{\mathrm{CreER} /+}$ mice.

The results reporting induction of oncRas in ERMS precursor lesions also show that oncKRas and most likely also oncHRas accelerate Hh-associated ERMS formation, whereas

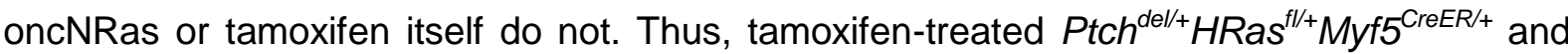
Ptch $^{\text {del/+}}$ KRas ${ }^{f /+} M y f 5^{C r e E R /+}$ mice show an increased ERMS incidence in comparison to untreated mice and oncKRas mutations even decrease overall survival of $\mathrm{Ptch}^{\mathrm{del/}+}$ mice. OncKRas and oncHRas also increase proliferation of tumor cells, whereas oncNRas does not. However, oncHRas, oncNRas, and most likely also oncKRas (please note that there were only 2 control samples available for analysis), do not significantly influence $\mathrm{Hh}$ signaling, although a tendency of downregulation of Gli1 was detected. OncHRas and oncKRas also do not influence myogenic differentiation of ERMS, whereas oncNRas induces the expression of late myogenic differentiation markers in ERMS. Finally, the analyses of the phosphorylation status of Erk, Akt and S6 in SM and ERMS show very heterogeneous results and no unambiguous influence of the oncRas mutations. However, as already shown by our group before, the phosphorylation of the mentioned proteins was in generally higher in ERMS as in SM (please note that tamoxifen treatment itself did not modulate any of the mentioned parameters).

When expression of oncRas isoforms is induced in established ERMS, the relative tumor volume, relative tumor growth and proliferation of ERMS do not change. On molecular level, oncRas also do not modulate gene expression of Gli1, Gli2, MyoD, Myogenin, Tropomyosin 3 and $M y H C$. Together, these results show that oncRas isoforms do not influence any of the analyzed parameters in established ERMS.

In summary, the results highlight that oncHRas and oncKRas mutations affect Hh-associated ERMS precursor lesions but not full-blown ERMS. This was most obvious when analyzing the aggressiveness of the tumors by proliferation, tumor incidence and ERMS-free survival. In contrast, oncNRas never influences these parameters but apparently induces a more differentiated ERMS phenotype. Finally, it has to be mentioned that the results differ from that of cultured ERMS cell lines, in which all oncRAS mutations induces a more aggressive tumor phenotype. 


\section{Discussion}

RMS, the most common malignant soft tissue sarcoma in children, is currently treated with multimodal therapies. However, the efficiency is limited ${ }^{3,4,13,23,25}$. This indicates a need for a deeper understanding of the tumor's pathology to design improved therapies for the patients. Interestingly, human RMS, especially ERMS, frequently show an activation of the $\mathrm{HH}$ signaling cascade and mutations within the RAS signaling pathway ${ }^{6,14,15,141-143}$. Furthermore, interactions between these signaling pathways have been discovered ${ }^{284,343}$. In dependency of the cellular context and the experimental setting oncRas signaling can either activate or suppress Hh signaling activity ${ }^{75,84,295,296,298}$ (for more details, see section 2.4). This shows a cooperation of both pathways in tumor development, maintenance or progression and led to the conclusion that the RAS and/or the $\mathrm{HH}$ signaling pathways could also be interesting therapeutic targets in RMS.

Indeed, recently our group has discovered a crosstalk between both pathways in RMS ${ }^{299}$. As already stated above, ERMS, but not ARMS, strongly express $\mathrm{HH}$ target genes and show oncRAS mutations. Therefore, the focus of this thesis was on unravelling the role of oncRAS mutations in regulation of genes implicated in the $\mathrm{HH}$ signaling pathway and associated cellular responses of ERMS. Moreover, the impact of a crosstalk between both pathways in ERMS pathogenesis, growth and aggressiveness was analyzed. For this purpose, oncRAS/oncRas signaling was activated in human cell lines derived from sporadic ERMS and in precursor lesions and full-blown ERMS of Ptch $^{\text {del/+ }}$ oncRas ${ }^{f /+} M y f 5^{C r e E R /+}$ mice, which is a $\mathrm{Hh} /$ Ptch-driven ERMS mouse model. Finally, some of the already performed experiments of our group were validated.

\subsection{OncRAS mutations stimulate growth of cell lines derived from sporadic ERMS despite inhibition of the major HH target GLI1}

\subsubsection{Differences and limitations of the utilized RMS cell lines}

To unravel interactions between $\mathrm{HH}$ and RAS signaling, the human ERMS cell lines TE617.T and $\mathrm{RUCH}-2$ and the human ARMS cell line RMS-13, all wt for RAS, were stably transduced with different oncRAS ${ }^{\mathrm{G} 12 \mathrm{~V}}$ isoforms ${ }^{299}$. In addition to experiments with stably transduced cell lines, experiments were performed with the ERMS cell line RD that harbors an endogenous NRAS ${ }^{\mathrm{Q} 61 \mathrm{H}}$ mutation ${ }^{312,326}$.

After generation of RMS cell lines that stably express oncRAS isoforms, a PCR-based assay detected that a TE617.T clone has been generated, which expresses both oncHRAS and oncNRAS (Fig. 9). This was probably due to a mistake during production. Nevertheless, these cells were analyzed in the same manner as the other cell clones. The analyses 
showed that oncRAS-expressing TE617.T cells have an increased RAS activity (Fig. 11), measured by a pulldown assay with beads that are coated with the RBD of RAF-1 kinase that specifically binds to active RAS ${ }^{344}$. However, the cells do not show a strong activation of the MEK/ERK or the PI3K/AKT/mTOR axes (Fig. 10). Whether other RAS target pathways or molecules, such as JNK, p38 and ERK5, are activated by RAS/RAF is currently unknown. In contrast to TE617.T cells, oncRAS-transduced RUCH-2 and RMS-13 cell lines showed elevated levels of pERK (Fig. 10). Since RAS activity in these cells was high, whereas no changes in pAKT or pS6 levels were detected, the MEK/ERK axis must be the main, or at least one of the main active downstream effector of oncRAS in these cell lines.

As described in the results sections, culture experiments showed that the RMS cell lines also respond differently to e.g. ERK inhibition. To a certain extent, these findings can be explained by the origin of these cells and by their specific genetic make-up.

Thus, the TE617.T cell line was originally isolated from the connective tissue of a 1.7-yearold girl with ERMS ${ }^{315,326}$. Although this cell line is wt for RAS, it shows protein-changing mutations in MAP3K14 (different splice variant) and MAP3K1 (threonine deletion at position 949) ${ }^{345}$. The MAP3K14 gene encodes for the Nuclear factor "kappa-light-chainenhancer" of activated B-cells (NFKB)-inducing kinase (NIK) and is involved in the alternative NFKB induction through tumor necrosis factor (TNF), CD95 and interleukin (IL)-1 $24{ }^{346}$. $M A P 3 K 1$ encodes for the Mitogen-activated protein kinase kinase kinase 1 (MEKK1) and can activate the ERK and JNK kinase pathways by phosphorylation of MAPK8, MAP2K1 and MAP2K4 ${ }^{347,348}$. The indicated protein changes are not located within structural motifs, like the catalytic domain. Nevertheless, an effect on protein functionality and on the functionality function of the MAPK pathways cannot be excluded. Consequently, these mutations could be responsible for the effects discussed in sections 7.1.2 and 7.1.3.

The $\mathrm{RUCH}-2$ cell line, which is also wt for RAS, was established from a primary ERMS of the botryoid type detected in the vagina of a 1.3-year-old girl and shows multiple chromosomal rearrangements ${ }^{314,315,326,349}$. Until now not many characteristics have been described for this cell line ${ }^{326,349}$. However, it is known that $\mathrm{RUCH}-2$ cells originally expressed MYF3 and MYF5 but lost the expression of these markers during cell culture ${ }^{314}$. MYF5, together with MYOD and the calcineurin pathway, is known to activate the transcription of different $\mathrm{MyHC}$ genes 350 . This could explain why RUCH-2 cells do not express further myogenic markers, like MyHC1 and myogenic regulatory factor (MRF). In addition, RUCH-2 cells show increased invasiveness at higher passages ${ }^{314}$.

$\mathrm{RD}$ is the most commonly used RMS cell line and was isolated from an recurrent pelvic ERMS of a 7-year-old girl ${ }^{312}$. Besides a heterozygous NRAS ${ }^{\mathrm{Q} 1 \mathrm{H}}$ mutation, the cells have an amplification of the MYC oncogene and a homozygous mutation of TP53 ${ }^{16,275,312,326,351}$. Thus, 
this cell line is a valid model system for ERMS since these characteristic mutations are also observed in human ERMS 14,15,141,231,232,267. Nevertheless, due to the endogenous NRAS mutation, a comparison to "baseline" expression without oncRAS mutation of e.g. GL/1 was not possible.

The RMS-13 cell line was isolated from a bone marrow metastasis of a 17-year-old boy and shows alveolar histology. The cell line is PAX3:FOXO1a fusion-positive, shows a TP53 mutation and amplifications of CDK4 and GL/1 ${ }^{313,352,353}$. A limitation of the RMS-13 cell line is the fact that until now RAS mutations have not been described in fusion-positive ARMS 14,15,141. Consequently, experiments with the fusion-positive ARMS cell line RMS-13 do not necessarily represent the biology of human ARMS. However, the focus of this thesis was on ERMS and only few experiments were done with this cell line.

Finally, cultured cells poorly mimic the conditions of primary tumors ${ }^{354}$. Hence, all cell culture experiments are limited to the specific characteristics of the utilized cell lines and do not necessarily reflect the situation in vivo.

\subsubsection{Influence of oncRAS mutations on expression of GLI1 and the related mechanisms}

The data show that oncRAS mutations in general decrease the mRNA expression of the major $\mathrm{HH}$ target GLI1 (Fig. 13). This effect was not only detected in cell culture, but also in vivo in transplanted oncRAS-expressing cells (Fig. 37, Fig. 39, Fig. 40). In cultured TE617.T cells the oncH-/NRAS-induced decrease of GLI1 is dependent on the reference gene. The discrepancy in statistical significance is due to a higher SEM in gene expression of oncH/NRAS-expressing TE617.T cells after normalization to $18 S$ rRNA (Fig. 13). Furthermore, an oncRAS-dependent decrease of GLI1 was observed in RUCH-2 and RMS-13 cells and thereby confirmed previous results ${ }^{299}$ (Fig. 13). In xenotransplants, an oncRAS-mediated downregulation of GL/1 was also observed, which however was very weak and not significant. This effect can be explained by the tumor microenvironment, which is missing in cell culture.

Similar to RMS cell lines, a suppressive effect of oncKRAS on GL/1 expression has been described for pancreatic cancer cells ${ }^{84}$. However, these findings are in contrast to other studies, which show that oncNRAS or oncHRAS can stimulate expression of GL/1. This has been shown in melanoma cells ${ }^{75}$. Additionally, oncHRAS and oncKRAS increase GL/1 in thyroid cancer cells ${ }^{298}$. This shows that oncRAS-mediated modulation of GLI1 can have oppositional effects in different tumor entities. Indeed, this is also suggested by the current experiments that show that oncRAS downregulate GLI1 in RMS cell lines, but not in the MB cell line Daoy. 


\subsubsection{ERMS cell lines do not secrete HH ligands and are not HH-responsive}

The ERMS cell lines TE617.T, RUCH-2 and RD generally express SHH but were not able to secrete this ligand, regardless if they harbor an oncRAS mutation or not (Fig. 16, Fig. 17 and ${ }^{299}$ ). In contrast, data published for pancreatic cancer cell lines suggest that onKRAS induces $\mathrm{SHH}$ expression and secretion, which results in activation of $\mathrm{HH}$ signaling activity in neighboring cells ${ }^{84}$. However, this was not the case in ERMS cell lines. One possible explanation is that cholesterol-dependent binding of SHH to DISP or an autocatalytic cleavage of the $\mathrm{HH}$ ligand (that is required for ligand secretion ${ }^{355}$ ), do not occur in ERMS cell lines. To test this hypothesis, a Western Blot to detect cleaved and precursor $\mathrm{HH}$ ligands could be performed with lysates from cells cultured in cholesterol-lacking or cholesterolsupplemented media. An additional explanation could be the lack of extracellular Scube proteins in the used ERMS cell lines. This group of proteins enhances the solubility of the cholesterol-modified $\mathrm{HH}$ ligands and is necessary for $\mathrm{HH}$ ligand secretion ${ }^{355}$. Western Blot analyses for Scube proteins could shed light on this question. Moreover, it is possible that the SHH protein is degraded in ERMS cell lines and therefore is not secreted. This could be tested in experiments with proteasome inhibitors, e.g. Bortezomib, which then should increase the intracellular level of $\mathrm{SHH}$ and could allow for $\mathrm{SHH}$ secretion as well.

Vice versa, stimulation with $\mathrm{SHH}$ did not significantly activate $\mathrm{HH}$ signaling in $\mathrm{RUCH}-2$ cells with and without oncRAS mutation (Fig. 18). This was also seen in RD cells, which neither react to stimulation with SHH-CM nor to the SMO agonist SAG at the level of GLI1, HHIP or $P T C H^{159}$. However, it has been reported that in RD cells, depletion of $I H H$ or $D H H$ results in a decrease of GLI1, whereas $\mathrm{SHH}$ downregulation does not affect GL/1 expression ${ }^{150}$. Therefore, it is possible that $\mathrm{IHH}$ and $\mathrm{DHH}$ are more important in $\mathrm{RMS}$ than $\mathrm{SHH}$. Nevertheless, the current data and data from our group using SMO inhibitors indicate that canonical $\mathrm{HH}$ signaling only plays a subordinate role in ERMS cell lines ${ }^{159,337}$, regardless if they harbor an oncRAS mutation or not. This is partially conflicting with the expression of $\mathrm{IHH}$ and $\mathrm{DHH}$ in ERMS ${ }^{150}$ (see above) and with other reports, showing that especially ERMS display elevated expression level of GLI1, GLI2, GLI3 and PTCH, which actually is indicative for an active canonical $\mathrm{HH}$ signaling cascade ${ }^{141,142}$. However, $\mathrm{HH}$ target gene expression not always stands for an active $\mathrm{HH}$ signaling cascade, because the respective genes can also be regulated non-canonically (compare section 2.2.2). Indeed and as recently described by our group, a non-canonical regulation of the $\mathrm{HH}$ signaling pathway is supported by the fact that $\mathrm{RUCH}-2$ and RD cells rarely develop cilia ${ }^{159}$. Cilia play a central role in canonical $\mathrm{HH}$ signal transduction ${ }^{356}$. Consequently, canonical $\mathrm{HH}$ signaling cannot be properly activated in $\mathrm{RD}$ and RUCH-2 cells. 


\subsubsection{OncRAS mutations decrease GLI1/GLI1 expression via the MEK/ERK axis in ERMS cells}

The fact that it is not possible to stimulate or inhibit canonical $\mathrm{HH}$ signaling via the $\mathrm{PTCH} / \mathrm{SMO}$ axis led to the hypothesis that oncRAS isoforms decrease the expression of GLI1 in a non-canonical i.e. HH/PTCH/SMO-independent manner. Consequently, the expression of GLI1 was measured in TE617.T and RUCH-2 cell lines with and without oncRAS after application of PI-103, UO126 or SCH772984 (Fig. 21, Fig. 22). Additionally, SCH772984 was applied to RD cells (Fig. 23). Finally, the expression of GL/1 was measured after incubation of the cells with HhA. Ahead of the experiments, the inhibitor functionality was validated, and results are described and explained in section 6.1.4.

Treatment with HhA failed to decrease GLI1 in any of the TE617.T cell lines. Similar results have been obtainend in other RMS cell lines ${ }^{337}$, including $\mathrm{RUCH}-2$ control cells. Since HhA is a SMO inhibitor, these observations underline the hypothesis, that canonical $\mathrm{HH}$ signaling plays only a minor role in ERMS cell lines (see section 7.1.2.1). Likewise, the application of PI-103 did not influence GLI1 in any of the TE617.T cells. In contrast, treatment with UO126 or SCH772984 resulted in a significant increase of GL/1 expression in all TE617.T cells. However, this is independent of oncRAS mutations, since the effect was also observed in control TE617.T cells. This might depend on the MAP3K1 mutation in these cells. Assuming that this mutation is an activating one, this would result in an increased basal activation of ERK and consequently in an ERK-dependent suppression of GLI1 in TE617.T control cells. The stable transduction with oncRAS isoforms could additionally increase ERK activity and thus strengthen the decrease of GL/1. Consequently, the application of SCH772984 would result in an increase of GLI1 in all TE617.T cells. If this hypothesis is true, it would support the assumption that oncRAS isoforms downregulate GLI1 expression and thus the $\mathrm{HH}$ signaling pathway through activation of the ERK axis.

Indeed, in RUCH-2 cells, in which HhA activates ERK, GLI1 expression was downregulated. This effect was significant for oncRAS-expressing cells, but was also seen as a trend in wt cells. Nevertheless, downregulation of GLI1 can also depend on SMO inhibition. Finally, it also can be explained by toxic effects of the drug because the used concentration of $10 \mu \mathrm{M}$ decreases cell viability (measured by WST-1 assay) of oncRAS-expressing RUCH-2 ${ }^{299,337}$. In contrast, application of HhA to TE617.T cells did not influence cell viability (data not shown). A treatment with PI-103 decreased GLI1 mRNA expression in RUCH-2 cell lines with and without oncRAS. This indicates that $\mathrm{PI} 3 \mathrm{~K} / \mathrm{mTOR}$ signaling in general activates the expression of GLI1 in RUCH-2 cells and is not involved in oncRAS-mediated downregulation of GLI1. It is possible that $\mathrm{PI}-103$ decreases GLI1 via AKT or S6, which are downstream of the inhibited kinases PI3K and mTOR. Thus, AKT can inactivate GSK3 and PKA and thereby decrease the inhibitory effects of these kinases on GLI1/2 activity ${ }^{54,79,357}$. In addition, S6 
triggers S6K1-dependent phosphorylation of GLI1 and induced the release of GLI1 from SUFU ${ }^{79}$. On the other hand, downregulation of GL/1 by PI-103 could be a toxic effect, because the same concentration of $\mathrm{PI}-103$ decreased cell viability (measured by WST-1 assay) in oncRAS-expressing RUCH-2 cells ${ }^{299}$. However, because PI-103 also decreases cell viability of TE617.T cells (data not shown), but not the expression of GLI1 (see above) the latter explanation this is rather unlikely. Finally, inhibition of ERK restored oncRASinduced downregulation of GLI1 back to basal level of RUCH-2 control cells. Similar results were obtained on protein level. Thus, oncRAS decreased the GLI1 protein level, which was reversed by ERK inhibition irrespective of the cellular compartment (Fig. 33). This confirms that oncRAS-mediated decrease of GLI1/GLI1 can be regulated by ERK in ERMS, which thus is different from pancreatitic ductal epithel cells, in which oncRAS (or at least oncKRAS) stabilizes GLI1 protein ${ }^{297}$.

Like in oncRAS-expressing RUCH-2 cells, ERK also inhibited GL/1 expression in RD cells (Fig. 23). This was supported by the fact that the transcriptional activity of a GLI reporter significantly increased after incubation with SCH772984 (Fig. 32).

Together, these data indicate an ERK-dependent regulation of GL/1 in RUCH-2 and RD cells. Indeed and as already mentioned, non-canonical interactions between the $\mathrm{HH}$ and RAS signaling pathways via the MEK/ERK pathway have been described ${ }^{71,284,343}$. Thus, Gli1 was identified as a potential substrate of Erk and supposedly can be phosphorylated by this kinase in a Mek-dependent manner ${ }^{286-288}$. Therefore it was first hypothesized that ERK regulates GLI1 through phosphorylation in ERMS and thereby prevents the translocation of the GLI transcrition factors into the nucleus. However, no differences between the GLI level in cytosol and nucleus were observed, at least not in RUCH-2 cells (Fig. 33, Fig. 34). Consequently, the oncRAS-dependent downregulation of GLI1 is most likely not due to the translocation of $\mathrm{GLI}^{\mathrm{A}}$ and $\mathrm{GLI}^{\mathrm{R}}$ forms into the nucleus. This result is in contrast to findings from melanoma model systems where oncNRAS or oncHRAS stimulate nuclear localization of GLI1 ${ }^{75}$. However, and as already described in the results section, GLI2 and GLI3 protein level were highly variable between biological replicates and were probably not regulated by the oncRAS/ERK axis. Thus, it is possible that GLI1 is selectively degradated by the proteasom in an ERK-dependent manner. This is supported by the finding that the MEK/ERK pathway can lead to selective protein degradation in other cellular settings ${ }^{187}$. To test this hypothesis, expression of GLI proteins in ERMS cell lines should be measured within time row experiments after application of a proteasome inhibitor. Another explanation for the decrease of GLI1/GLI1 in oncRAS-expressing RUCH-2 is an ERK-dependent regulation of GLI1 transcription. This is even more likely than a proteasome-dependent regulation of GLI1, because GLI2 and GLI3 are in most likeliness not regulated by ERK. ERK itself, or its downstream targets ETS-like gene tyrosine kinase 1 (Elk1), c-Fos and c-Jun, that activate 
the AP1 transcription factor ${ }^{358}$, can regulate transcriptional activity of ERK target genes. However, it remains to be elucidated if the GLI1 promotor is a direct target of ERK signaling. To confirm this hypothesis, the GLI1 promotor sequence should be screened for ERKspecific (or Elk1-, c-Fos- C-Jun or AP1-specific) binding sites. Additionally, respective chromatin immunoprecipitation (ChIP) assays can be performed.

\subsubsection{Influence of oncRAS mutations on expression of other genes implicated in the $\mathrm{HH}$ signaling cascade}

In TE617.T cells, there is an insignificant trend for an oncKRAS- or oncH-/NRAS-dependent decrease of GLI2 or PTCH, respectively, without affecting HHIP expression level (Fig. 14). ERK inhibits PTCH in TE617.T cells irrespective of an oncRAS mutation, whereas its impact in regulation of GLI2 is not clear-cut (Fig. 24, Fig. 25, Fig. 26). In xenografts derived from TE617.T cells that express oncKRAS or oncH-/NRAS isoforms, the tumorintrinsic expression of $h$ GLI2 is not affected (Fig. 37). However, this differences might be explained by the presence of tumorextrinsic effects in xenografts through the tumor's micorenvironment.

In $\mathrm{RUCH}-2$ cells, oncRAS isoforms reduce GLI2 expression without affecting HHIP expression level (Fig. 15). Additionally, oncHRAS and oncKRAS increase PTCH expression in cultured RUCH-2 cells (Fig. 15) and ERK is not involved in the regulation of PTCH expression in this very cell line (Fig. 28, Fig. 29, Fig. 30). However and in contrast to cell cell culture experiments, oncKRAS or oncNRAS did not significantly decrease hGLI2 in xenografts (Fig. 39, Fig. 40), which might be an effect of the xenograft microenvironment.

GLI1, PTCH and HHIP are considered to be mammalian HH target genes and GLI2 is a positive regulator of $\mathrm{HH}$ signaling ${ }^{31,69}$. In a canonical regulation of $G L / 1$ through $\mathrm{HH}$ signaling, an oncRAS-dependent decrease of GLI1 would be probably accompanied by a downregulation of PTCH, HHIP and also of GLI2. However, this was not the case, neither in cell culture nor in xenotransplants derived neither from TE617.T nor in RUCH-2 cells. These observations together with the fact that it is rather impossible to stimulate or to inhibit canonical $\mathrm{HH}$ signaling via the $\mathrm{PTCH} / \mathrm{SMO}$ axis (see also chapter 7.1.2.1) strengthens the hypothesis, that oncRAS isoforms decrease the expression of GLI1/GLI1 in a non-canonical i.e. $\mathrm{HH} / \mathrm{PTCH} / \mathrm{SMO}$-independent manner.

Moreover, the expression of GL/3 was decreased in an oncNRAS-dependent manner in TE617.T and RUCH-2 cells (Fig. 14, Fig. 15). However and in contrast to GLI1, GLI3 is not a $\mathrm{HH}$ target gene. In TE617.T and RUCH-2 cells, the oncNRAS-dependent downregulation of GLI3 is independent of ERK (Fig. 26, Fig. 30). This is in contrast to RD cells, where ERK inhibits GLI3 (Fig. 31). The differences between the cell lines might rely on cell line specific mutations (see section 7.1). 
Despite a lack of $\mathrm{HH}$ ligand secretion, all ERMS cell lines show basal mRNA expression of $\mathrm{SHH}$. In oncRAS-transduced TE617.T cell lines the expression of SHH was decreased in comparison to control cells (Fig. 14). Additionally, xenografts derived from TE617.T cells with oncKRAS or oncH-/NRAS also showed decreased tumorintrinsic expression of $h S H H$, which was however only significant for oncH-/NRAS tumors (Fig. 37). In general, transcriptional regulation of $\mathrm{SHH}$ is mechanistically not fully understood. However, it can be mediated via NFKB, which normally induces SHH expression ${ }^{359-362}$. Additionally, it is known that oncRAS isoforms can induce the activation of NFKB through the NIK(MAP3K14)/IKK-pathway ${ }^{363,364 .}$ In addition, NIK also can influence phosphorylation and thus activity of ERK ${ }^{365}$. The regulation becomes even more complicated because ERK can activate NFKB by IKK ${ }^{366,367}$ or inhibit NFKB-driven transcription, which is dependent on the cellular context ${ }^{368}$. Thus, it is possible that the MAP3K14 (NIK) mutation in TE617.T impairs the activity of both NFKB and ERK, which could also affect SHH expression in a specific, but so far unknown mechanism.

In contrast, RUCH-2 cells show an oncRAS-dependent increase of $\mathrm{SHH}$ in cell culture (Fig. 15). This similar to pancreatic cancer cells, in which oncKRAS also upregulates the expression of $S H H^{84,295}$. Additionally, the data from this work show that this increase is ERKdependent (Fig. 28, Fig. 29, Fig. 30). This is in line with findings from the literature, in which an enhanced $S H H$ expression correlates with the oncRAS mutational status ${ }^{84,369}$. In contrast to the observation in cell culture, xenografts derived from RUCH-2 cells with oncKRAS or oncNRAS show a slightly decreased tumorintrinsic $\mathrm{SHH}$ expression (Fig. 39, Fig. 40). The discrepancy between $\mathrm{SHH}$ expression in cell culture experiments and xenografts can also be explained by microenvironmental effects that occur only in the in vivo setting. However, it is also possible that this relies on a difference in transcriptional regulation of the SHH promotor, which could be different between cultured and transplanted cells.

Despite the tumorintrinsic decrease of $S H H$, tumorextrinsic mGli2 expression is increased in oncKRAS-expressing RUCH-2 xenografts. This indicates that the transplanted tumor cells may indeed secrete SHH (despite being downregulated). Nevertheless, this is against the finding, that mGli1 is not upregulated in the tumor stroma and that $\mathrm{RUCH}-2$ cells in general do not secrete $\mathrm{SHH}$. However, and as already mentioned in section 7.1.2.1, it is still possible that $\mathrm{RUCH}-2$ secrete $\mathrm{IHH}$ or $\mathrm{DHH}$.

Besides the impact on $\mathrm{HH}$ signaling genes, these experiments show that different RAS proteins can have non-redundant (oncNRAS decreases GLI3 expression in TE617.T and $\mathrm{RUCH}-2$ cells, whereas oncH/-KRAS do not) or partially overlapping functions (both oncHRAS and oncKRAS increase the expression of PTCH in RUCH-2 cells) in ERMS cell lines. Isoform-specific functions of RAS proteins have also been described in other tumor entities. It is hypothesized that this is due to the different intracellular distribution of RAS 
isoforms or to the induction of different biological responses through diverse downstream effectors ${ }^{174,208,211-215}$ (compare also section 2.3.1).

Taken together, these results show that an ERK-dependent downregulation of GLI1 is a common feature in ERMS cell lines with oncRAS mutation (compare section 7.1.2), whereas the expression of other $\mathrm{HH}$ target genes such as $P T C H, G L I 2$ or HHIP are either inhibited, activated or not affected by ERK. This depends on the used cell line and on the respective oncRAS isoform. Furthermore, these results are in support of a RAS/ERK-dependent regulation of GLI1 expression on transcriptional level, which is independent of the SHH/PTCH/SMO/GLI2-3 axis (Fig. 59). One possibility to verify that the oncRAS-dependent regulation of GLI1 is indeed non-canonical, the experiments could be repeated after inhibition of SUFU, a negative regulator of canonical $\mathrm{HH}$ signaling ${ }^{59}$.

Finally, the differences between TE617.T, RUCH-2 and RD cell lines are hard to explain. Most likely they depend on the different activation status of the MAPK signaling pathway within the cells. As already mentioned, RD cells and oncRAS-expressing RUCH-2 cells show hyperactive MEK/ERK signaling, whereas oncRAS does not affect phosphorylation of ERK in TE617.T cells. However, TE617.T cells harbor protein-changing mutations in MAP3K14 and MAP3K1 ${ }^{345,349}$. These mutations might alter activation of ERK and of JNK, as well as of NFKB. Consequently, it is possible that the effects of oncRAS mutations or of MEK/ERKinhibition are masked in this very cell line. This also would fit to the observation that oncRAS/MEK/ERK-associated downregulation of GLI1 in TE617.T is weaker than in the other cell lines (Fig. 13). It is possible that elevated level of pERK were not detected in the TE617.T cell line due to a lack of sensitivity of the Western Blot. Immunoprecipitation of active ERK and in vitro kinase activity assays could help to prove this assumption.

The differences between RUCH-2 and RD cell lines in oncRAS-mediated regulation of other $\mathrm{HH}$ targets than GL/1 can also be explained by the mutational status of the cell lines. For example, RD cells harbor a TP53 mutation ${ }^{16,275,312,326,351}$. In melanoma, p53 can suppress GLI1 activity and GLI1 expression ${ }^{72}$ and a mutation in p53 would consequently increase GLI1 transcription. On the other hand, MEK and ERK can transcriptionally activate $p 53^{370,371}$, which thus may contribute to suppression of GLI1 transcription. However, the a final statement about the precise role of the p53 tumor suppressor in combination with oncRAS mutations in ERMS cell lines needs further investigations. Nevertheless, mutations such as TP53 are likely to influence cellular signaling networks and thus may influence the effect of oncRAS mutations in ERMS. 


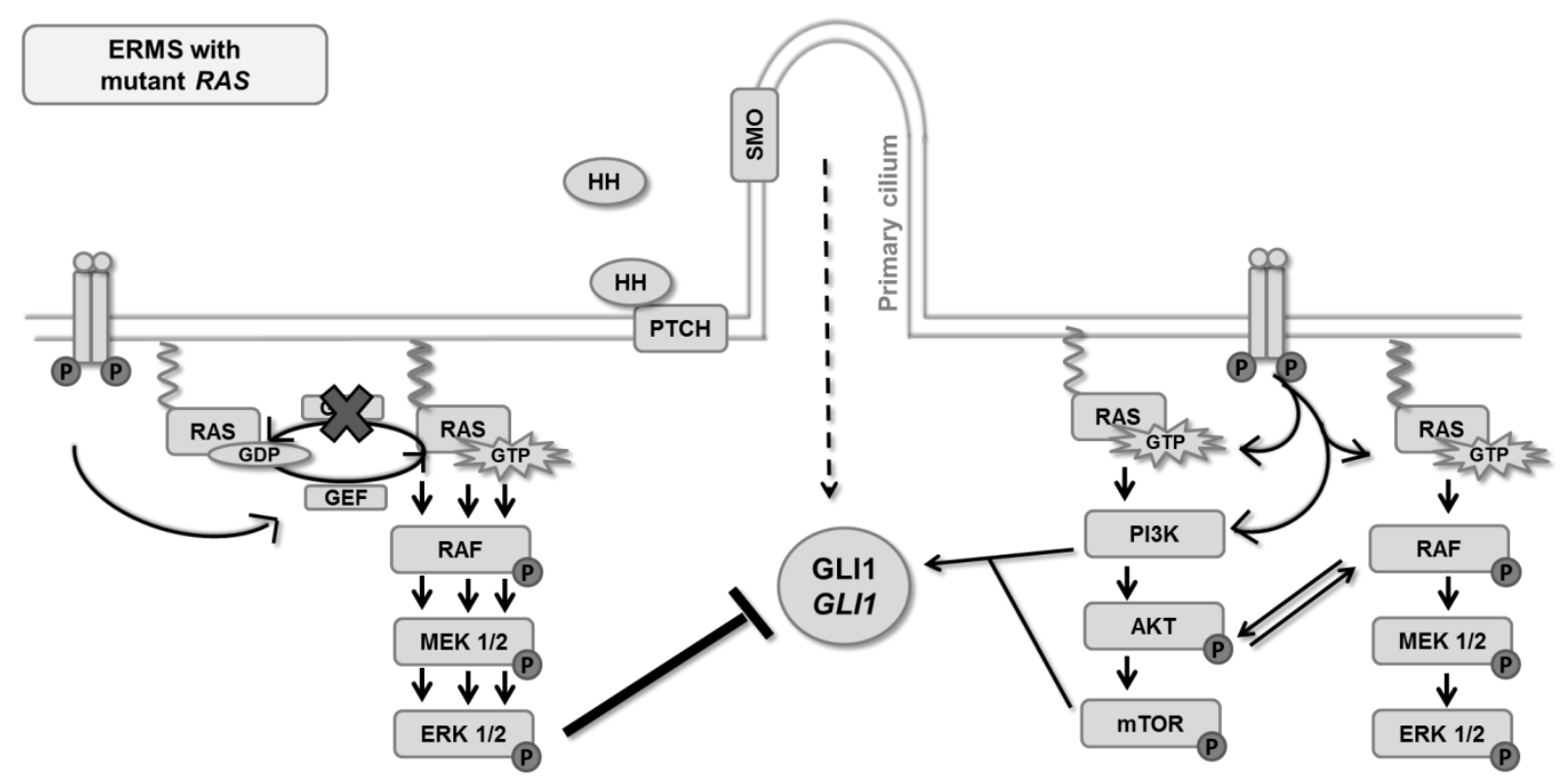

Figure 59: Model system for HH/RAS interactions in ERMS with oncRAS mutations

In ERMS with activating RAS mutations, the MEK/ERK axis is hyperactivated and GL/1/GLI1 is suppressed. Thereby the MEK/ERK axis negatively regulates GLI1 transcription and GLI1 protein expression, whereas the $\mathrm{PI} 3 \mathrm{~K} / \mathrm{AKT} / \mathrm{mTOR}$ axis may positively regulate GLI1 transcription (at least in RD and RUCH-2 cells). Canonical $\mathrm{HH}$ signaling seems to play a subordinate role in regulation of GL/1/GLI1 (dashed arrow). For more details, see text.

\subsubsection{Influence of oncRAS mutations on proliferation}

OncRas isoforms can promote deregulation of cell cycle progression and can have positive or negative effects on the regulation of apoptosis, depending on the cell type and other cellular factors ${ }^{184,372}$. Additionally, oncRas can promote malignant transformation, characterized by increased proliferation and desensitization to apoptosis ${ }^{167}$. However, oncRAS isoforms do not induce apoptosis and do not alter the cell cycle distribution in RMS cell lines (Fig. 10, Fig. 12). Nevertheless, the cells show a more aggressive phenotype as measured by proliferative capacity in cell culture (Fig. 35 and ${ }^{299}$ ) and tumorigenicity in xenografts (Fig. 36, Fig. 38 and ${ }^{299}$ ).

In TE617.T cells oncRAS isoforms strongly induce proliferation (Fig. 35) and additionally increase growth and weight of xenografts (Fig. 36). However, oncRAS do not change the cell cycle distribution in this cell line (Fig. 12). Experiments with RMS-13 cells showed similar results (Fig. 12 and ${ }^{299}$ ). These inconsistent results (i.e. strongly induced proliferation and tumorigenicity, but lack of increased cell numbers in S phase) can be explained by the fact that the cells were not synchronized ahead of the cell cycle analyses. During synchronization (e.g. by serum starvation or a double thymidine block ${ }^{373}$ ) distinct subpopulations of cells are in the same stages of the cell cycle, which makes shifts in cell cycle distribution more evident. Additionally, the protocol for cell cycle analyses should be optimized e.g. by inclusion of BrdU labeling of proliferating cells. This would make the analyses more precise because both, cell cycle distribution and the percentage of proliferating cells would be investigated ${ }^{374}$. 
RUCH-2 cells grow slowly in comparison to other RMS cell lines. OncHRAS or oncKRAS increased proliferation of cultured RUCH-2 cells, whereas oncNRAS had no impact on proliferation (Fig. 35). These findings are in contrast to previous observations from our group, in which oncRAS decreased proliferation $24 \mathrm{~h}$ after seeding ${ }^{299}$. However and as shown here, at least $48-72$ hours are needed to detect an oncRAS-dependent increase of proliferation in this very cell line. For oncNRAS transduced cells an even a longer period might be necessary. Indeed, RUCH-2 xenografts that express oncKRAS or oncNRAS show a strongly increased growth and weight of the tumors (Fig. 38). Additionally, RUCH-2 xenotransplants with and without oncRAS mutations grow very efficiently when injected within a matrigel matrix but do marginally grow when injected in PBS (data not shown). This shows that microenvironmental effects might improve attachment and growth of RUCH-2 cells more efficiently than regular cell culture medium. Besides, these experiments verify the finding that oncRAS isoforms can increase proliferation of $\mathrm{RUCH}-2$ cell lines.

It has to be mentioned that oncHRAS-expressing RUCH-2 cells did not grow in vivo (Fig. 38). In most likelyhood this observation is due to an experimental failure. However, it could also rely on oncHRAS-induced senescence, which has been described for the HRAS ${ }^{G 12 V}$ mutation ${ }^{174}$. The induction of senescence occurs downstream of RAS, most likely via the p53/p19 ARF and/or p16 ${ }^{\text {INK4A }}$ pathways and requires a high cell density ${ }^{185}$. Indeed, the cell density of oncHRAS-expressing cells is strongly elevated within tumor xenografts in comparison to cell culture experiments. This might explain why the cells grew normal in cell culture but failed to establish tumors in Nu/Nu mice. To test if oncHRAS-induced senescence indeed hampered tumor growth of RUCH-2 cells, tumor sections should be examined for senescence-associated $\beta$-galactosidase activity with $X$-Gal staining. Nevertheless, the transplantation experiment using oncHRAS-transduced $\mathrm{RUCH}-2$ cells needs to be repeated.

The fact that all oncRAS mutations (with the exception of transplanted RUCH-2 oncHRAS cells; see above) strongly induce proliferation despite downregulation of GLI1/GLI1 indicate that the $\mathrm{HH}$ signaling pathway is not the main driver of growth and aggressiveness of cell lines derived from sporadic ERMS, like the TE617.T and RUCH-2 cells. However, aberrant activation of the $\mathrm{HH}$ pathway can drive the initiation of RMS, since heterozygous loss of PTCH/Ptch in humans and mice is associated with ERMS development ${ }^{21,99,100,108,324,325,375}$. On the other hand, PTCH mutations are a very rare event in human ERMS (compare section 2.2.4). Nevertheless, also established ERMS show high level of GLI1 and PTCH, which is indicative for an active $\mathrm{HH}$ signaling cascade ${ }^{141,142}$. However, ERMS are insensitive to SMO-inhibition, at least if they do not harbor a mutation in $P T C H^{158,159}$. Interestingly, they are sensitive to the specific GLI1/2 inhibitor GANT61, which reduces growth of ERMS cells in vitro and in vivo ${ }^{155}$. This indicates that GLI transcription factors indeed drive proliferative processes of ERMS, which are most likely independent of canonical $\mathrm{HH}$ signaling. 
In this context and at the first glance, the results showing that oncRAS-mediated downregulation of GL/1/GLI1 is associated with a more aggressive ERMS growth, seems to be paradox. However, it is possible that oncRAS is such a potent proliferative stimulus that permits simultaneous downregulation of other proliferative stimuli such as GL/1/GLI1. Of whether a complete GLI1 knockdown would still allow for oncRAS-driven ERMS proliferation is unclear. This question could be answered by transfection of oncRAS-expressing ERMS cell lines with e.g. GLI1 specific siRNA or by incubation of the cells with GANT61. In addition, it also would be interesting to see if the proliferative capacity of ERMS cell lines is dependent on the MEK/ERK axis. This could be done by inhibition of either MEK or ERK. To exclude that other signaling pathways are involved in cellular proliferation, GLI and MEK/ERK should be blocked simultaneously. If the cells indeed will stop to proliferate upon this co-treatment, this combinatory treatment should be tested as a therapeutic approach in e.g. ERMS xenografts.

Taken together, oncRAS isoforms increase proliferation despite a decrease of GLI1 expression in human RMS cell lines. In the ERMS cell lines RUCH-2 and RD the downregulation of GLI1 is ERK-dependent. Hence, it would be highly valuable to analyze, if the occurrence of high RAS signaling with concurrent low $\mathrm{HH}$ signaling is a general feature in human ERMS. This could be done by analysis of public available RMS microarray datasets, like ${ }^{275}$. If these data are consistent with the findings from cell culture, ERK should be considered as a target in future therapies in ERMS.

\subsection{Specific oncRas mutations can increase $\mathrm{Hh} / \mathrm{Ptch}$-driven ERMS incidence and growth when expressed at an early tumor stage}

To investigate the role of Ras signaling in $\mathrm{Hh} /$ Ptch-driven ERMS in an immunocompetent in vivo setting, a genetic approach was pursued. For this purpose, Ptch ${ }^{d e l /+}$ mice, which spontaneously develop ERMS-like tumors with active Hh signaling ${ }^{137,143,323,324}$, were bred to mice, which conditionally express one of the oncRas genes ${ }^{220,303,304}$ and to Myf5 ${ }^{\mathrm{CreER}}$ deleter mice ${ }^{305}$. The resulting $\mathrm{Ptch}^{\mathrm{del/}+} \mathrm{OncRas}^{\mathrm{fl} /+} \mathrm{Myf5}^{\mathrm{CreER} /+}$ mice were used to study the effect of oncRAS mutations in ERMS precursor lesions and full-blown ERMS.

Ptch $^{\text {del/+}}$ oncRas ${ }^{f /+} \mathrm{Myf5}^{\mathrm{CreER} /+}$ mice are a suitable model to analyze Ras signaling in $\mathrm{Hh} / \mathrm{Ptch}-$ driven ERMS because their tumors express wtHRas, wtKRas and wtNRas and because the $M y f 5^{\text {CreER }}$ driver induces tamoxifen-mediated recombination primarily in tumor tissue (Fig. 41, Fig. 42). This was crucial because the expression of Myf5 is detected in different muscle populations but is also found in non-muscle tissues, such as preadipocytes and neurons ${ }^{376-}$ ${ }^{378}$. Indeed, an experiment utilizing $R 26 R$ reporter mice, which conditionally can express lacZ and basically can show high $\beta$-galactosidase activity in every organ of the body ${ }^{306}$, indicated that the tamoxifen-inducible $M y f 5^{\mathrm{CreER}}$ driver is primarily active in tumor tissue without 
leakiness. However, the galactosidase activity visualized by X-Gal staining was not as strong as expected from literature ${ }^{305}$. This is most likely due to technical issues, such as an incorrect $\mathrm{pH}$ or temperature of the staining solutions or too much contact to light (X-gal is light sensitive). In addition to its ERMS-specificity, the Myf5 ${ }^{\mathrm{CreER}}$ driver also efficiently mediated recombination at the different Ras loci (Fig. 43, Fig. 44, Fig. 45). This was important, because differently floxed loci have different sensitivities to cre-mediated recombination ${ }^{339,379}$. Additionally, increased Ras activity was verified in ERMS of tamoxifentreated Ptch $^{\text {del/+ }}$ oncRas ${ }^{f /+} M y f 5^{\mathrm{CreER} /+}$ mice (Fig. 46). Finally, the results revealed that tamoxifen itself (which is necessary to activate the CreER) has no impact on median overall survival, median tumor latency time, mean ERMS-free survival, tumor incidence or tumor multiplicity (Fig. 47, Tab. 25). Together, these experiments indicate that $\mathrm{Ptch}^{\text {del/+}}$ oncRas ${ }^{\mathrm{fl}+} \mathrm{Myf5}^{\mathrm{CreER/+}}$ mice are a suitable model to study the role of Ras signaling in Hh/Ptch-driven ERMS.

\subsubsection{Influence of oncRas mutations on Hh/Ptch-associated ERMS precursor lesions}

The 3 different oncRas mutations were induced in ERMS precursor lesions of $\mathrm{Ptch}^{\text {del/+ }}$ oncRas $^{\mathrm{fl} /+} \mathrm{Myf5}^{\mathrm{CreER} /+}$ mice. Interestingly, oncHRas and oncKRas mutations influence the tumor growth, whereas oncNRas does not (Fig. 48, Fig. 49, Fig. 50). Thus, activation of oncHRas in ERMS precursor lesions significantly increased the tumor incidence and resulted in a trend to decrease mean ERMS-free survival. It however did not influence median overall survival, median tumor latency time or tumor multiplicity (Fig. 48, Tab. 26). In contrast, activation of oncKRas significantly decreased median overall survival, median tumor latency time, mean ERMS-free survival and significantly increases tumor incidence without affecting tumor multiplicity (Fig. 49, Tab. 27). These data indicate that both oncKRas and oncHRas increase the susceptibility to $\mathrm{HH}$-associated ERMS formation. OncKRas also accelerates ERMS formation and thus decreases the ERMS-free survival and latency time until tumor detection. In addition, it significantly decreased the life span of the mice. At the first glance, these differences point out diverse roles or functions of the HRas and KRas oncogenes in ERMS pathogenesis. One explanation is the different expression levels of the Ras genes in SM and ERMS. Thus, the level of HRas expression are similar in SM and RMS, whereas KRas level are higher in RMS compared to SM (Fig. 42). A higher level of KRas most likely also results in a higher level of oncKRas, which may explain the faster tumor growth and thus the reduction of the latency time when the mutation was set in ERMS precursors. However, it is also possible that the tumor detection in the HRas cohort by manual palpation was not as efficient as in the KRas cohort, because several experimenters were involved in the tumor monitoring of the HRas cohort. Indeed, like ERMS with oncKRas, paraffin sections of ERMS with oncHRas show a significantly higher amount of $\mathrm{Ki} 67^{+}$nuclei than the respective controls, suggesting a faster tumor growth of the tumors with oncHRas. Unfortunately, the final tumor 
size and tumor weight were not recorded, for neither the HRas nor the KRas cohorts. Consequently, it is very hard to judge if an oncKRas mutation indeed induces an ERMS growth behavior that is different from that of an oncHRas mutation. Nevertheless, oncKRas mutations in ERMS precursor lesions decreased the median overall survival, which was not observed in mice with oncHRas mutations. Since other tumors than ERMS occurred at similar numbers in both cohorts and since all mice were sacrificed when the tumors reached a size of $1.5 \mathrm{~cm}$, the data indeed favor the idea that oncKRas induces a more aggressive ERMS growth compared to oncHRas.

In contrast, oncNRas mutations neither influenced median overall survival, median tumor latency time, mean ERMS-free survival, tumor incidence, tumor multiplicity nor proliferation of ERMS in Ptch ${ }^{\text {del/t+}}$ mice (Fig. 50, Tab. 28, Fig. 51). These results highlight that oncNRas mutations, which are set at a very early ERMS stages do not alter the aggressiveness of the tumors. This is similar to a mouse model for colon cancers, where oncKRas stimulates hyperproliferation in the colonic epithelium, whereas oncNRas does not alter the growth properties of the tissue ${ }^{220}$. Similar differences between Ras isoforms have been described for endodermal progenitor cells. OncKRas promotes proliferation and maintains stem cell characteristics and oncHRas promotes differentiation and growth arrest. In contrast, oncNRas has no impact on any of these parameters ${ }^{221}$. These findings underline that different oncRas isoforms can lead to different cellular fates. This can be due to collaborative effects between oncRas and different wtRas proteins, which contribute for the cancer phenotype 236,238,239. For example, wtKRas and wtNRas promote oncHRas-dependent papilloma development ${ }^{239}$. However, in other settings, wtRas can act as a tumor suppressor in oncRas-expressing cancers ${ }^{239-241}$. An additional explanation for this non-redundant functions is the different cellular compartmentalization of Ras isoforms, which can influence the ability of Ras proteins to activate their downstream effectors ${ }^{206}$. However, whether one of these mechanisms is also involved in ERMS precursor lesions is not clear so far.

The observation that oncNRas mutations do not influence the growth of ERMS precursor lesions of $P_{t c h} h^{d e /+}$ mice is suprising, because in human RMS, oncNRAS mutations are the most frequent RAS mutations ${ }^{14,15,141}$. However, it is possible that this modification is due to species-specific differences in tumor pathobiology. This has already been described for several other knockout mouse models ${ }^{380}$. For example, loss of the $R B$ gene is associated with the development of retinoblastomas and osteosarcomas in humans, whereas mice that have a $R b$ deletion fail to develop these tumor types ${ }^{381}$. Similar, NF2 mutations in humans lead to schwannomas, whereas conventional $\mathrm{Nf2}$ knockout mice develop osteosarcomas ${ }^{382}$.

It has to be noted that tamoxifen-treated $\mathrm{Ptch}^{\mathrm{del/+}}$ oncRas ${ }^{f / /} \mathrm{Myf5} 5^{\mathrm{CreER} /+}$ mice show similar tumor incidences (oncHRas: $74 \%$, oncKRas: $76 \%$, oncNRas: $71 \%$ ). However, whereas the tumor incidence of the oncHRas and oncKRas cohorts differed from the respective control 
cohorts, that of the oncNRas cohort did not. This finding indicates that untreated Ptch $^{\text {del/+} N R a s}{ }^{f /+} \mathrm{Myf5}^{\mathrm{CreER} /+}$ mice develop more tumors than other untreated $\mathrm{Ptch}^{\text {del/+}}$ oncRas ${ }^{\mathrm{fl}+} \mathrm{Myf5}^{\mathrm{CreER/+}}$ mice. The underlying reason in most likelihood is the genetic background of the NRas cohort, since leakiness of the $M y f 5^{C r e E R}$ deleter and spontaneous recombination at the floxed NRas locus were precluded. In addition, all mice with suspect genotypes or recombination patterns (regardless of which cohort) were excluded from the analyses. The finding that ERMS from tamoxifen-treated $\mathrm{Ptch}^{\mathrm{del/}+} \mathrm{NRas} \mathrm{s}^{\mathrm{fl}+} \mathrm{Myf5} 5^{\mathrm{CreER} /+}$ mice did not show a higher proliferation rate than ERMS from untreated mice together with the fact

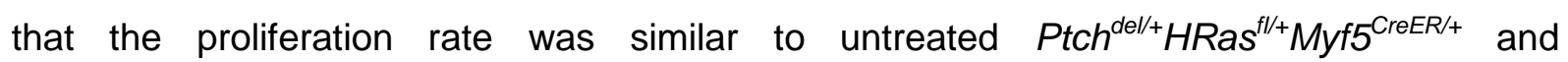
$\mathrm{Ptch}^{\mathrm{del/}+} \mathrm{KRas}^{\mathrm{fl} /+} \mathrm{Myf5}^{\mathrm{CreER} /+}$ mice (Fig. 51) supports the conclusion that oncNRas mutations do not accelerate formation of (Ptch/Hh-associated) ERMS. Hence, the presence of an oncNRas mutation in ERMS does not necessarily reflect the individual tumor's aggressiveness, which could also be true for human tumors. Nevertheless, when considering the high prevalence of NRAS mutations in human ERMS, it is also possible that the $N \operatorname{Ras}^{G 12 D}$ mutation in the mouse model is simply not functional. However, the fact that tumors, in which the oncNRas mutation was induced with tamoxifen, showed a higher Ras activity than the controls, strongly argues against this assumption (Fig. 46). Furthermore, it is also possible that the expression of the $\mathrm{NRas}^{\mathrm{Q61H}}$ mutation, which is frequently seen in human ERMS ${ }^{267}$, will be a more potent oncogene than the NRas ${ }^{\mathrm{G} 12 \mathrm{D}}$ mutation. However, the fact that the expression level of the muscle differentiation markers Myogenin and Tropomyosin 3 were significantly higher in tamoxifen-treated $\mathrm{Ptch}^{\mathrm{del/}+} \mathrm{NRas}^{\mathrm{fl/}+} \mathrm{Myf5} 5^{\mathrm{CreER} /+}$ mice compared to the other cohorts (Fig. 53), strongly argues for the conclusion that oncNRas mutations indeed do not accelerate formation of (Ptch/Hh-associated) ERMS, at least in mice. It however induces myogenic differentiation, because myogenin is a reliable and specific marker for rhabdomyoblastic differentiation ${ }^{383}$ and Tropomyosin 3 encodes for a sarcomeric protein implicated in in skeletal muscle cell differentiation ${ }^{384}$. This is not the case for ERMS expressing oncHRas or oncKRas mutations (Fig. 53). Hence, oncNRas mutations may have a different role than oncHRas and oncKRas in ERMS. This would be similar to colonic tumors, in which oncKRas and oncNRas have differential effects on proliferation, differentiation and tumor progression. Thus, expression of oncKRas ${ }^{\mathrm{G} 12 \mathrm{D}}$ in the colonic epithelium stimulates hyperproliferation, whereas oncNRas ${ }^{\mathrm{G} 2 \mathrm{D}}$ does not alter the growth properties of the epithelium, but is able to confer resistance to apoptosis ${ }^{220}$. If oncNRas indeed has a different function than the other oncRas isoforms in Ptch/Hh-associated ERMS, this would be different from fusion-negative RMS cell lines, in which all oncRAS isoforms inhibit myogenic differentiation through an ERK-dependent inhibition of the myogenic transcription factor $M Y O G^{385}$. 


\subsubsection{OncRas mutations do not influence the expression of Hh signaling genes or the phosphorylation status of Erk, Akt and S6 in ERMS}

All oncRas-expressing ERMS show a moderate downregulation of Gli1 when compared to the control. This is similar to cell culture and xenotransplantation experiments discussed in section 7.1.2. However, these results did not reach significance in murine ERMS. Thus, it is rather unlikely that oncRas mutations altered the Hh signaling pathway in the mouse, especially because the expression of Gli2, Gli3, Ptch and Hhip was also not modified in SM and RMS tissue samples (Fig. 52). Additionally, the phosphorylation status of Erk, Akt and S6 was very heterogeneous in in ERMS from mice with and without oncRas mutation (Fig. 54). The final statemant from Western Blot analyses, that phosphorylation of these proteins is generally higher in tumors compared to normal skeletal muscle, is similar to findings from the literature ${ }^{138}$.

The result that oncRas isoforms rather do not influence $\mathrm{Hh}$ signaling or the mRNA expression of Hh signaling members in murine ERMS is in contrast to findings from cultured human ERMS cells. It is possible that this relies on the mutational status of the systems or on the tumor microenvironment. However, it is also possible that oncRas mutations simply do not play a role in regulation of $\mathrm{Hh}$ signaling genes in $\mathrm{Hh} / \mathrm{Ptch}$-associated ERMS. This suggests that the oncRAS-mediated changes of the tumor phenotype must be driven by other molecular mechanisms, which could be analyzed by RNA sequencing (RNAseq) of tumor samples from tamoxifen-treated, solvent-treated and untreated Ptch $^{\text {del/+ }}$ oncRas ${ }^{f / /}$ Myf5 $^{\text {CreER/+ }}$ mice.

\subsubsection{Influence of oncRas mutations on $\mathrm{Hh} / \mathrm{Ptch}$-associated full-blown ERMS}

The impact of oncRas mutations was also analyzed in full-blown ERMS. For this purpose the expression of oncRas was induced in palpable tumors of $\mathrm{Ptch}^{\mathrm{del} /+} \mathrm{HRas}^{\mathrm{fl} /+} \mathrm{Myf5}^{\mathrm{CreER} /+}$,

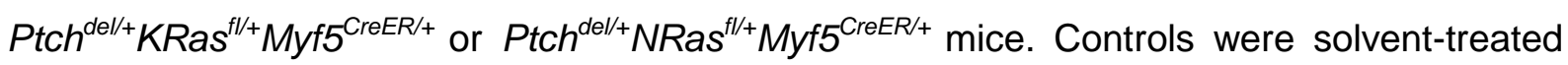
siblings of the same genotype, solvent-treated or tamoxifen-treated Ptch ${ }^{\text {del/+ }}$ mice, which all had palpable ERMS of approximately the same size. In this setting, none of the oncRas mutations did influence tumor growth (Fig. 55). OncRas mutations also did not alter proliferation of the tumors (Fig. 56). They also did not modulate the expression of the $\mathrm{Hh}$ target genes Gli1 and Gli2 (Fig. 57) or of muscle differentiation markers (Fig. 58).

\subsubsection{Comparison of the role of oncRAS in Hh/Ptch-associated ERMS precursor lesions and full-blown ERMS}

Together, the data from Ptch $^{\text {del/+}}$ oncRas ${ }^{f / /} M y f 5^{C r e E R /+}$ mice indicate that oncRAS mutations influence growth of $\mathrm{Hh}$ /Ptch-associated ERMS precursor lesion but not of full blown ERMS. This favors the hypothesis that oncRas are early events in ERMS development and that they might be a driver mutation in ERMS. However, oncRAS germline mutations do not predispose mice to the development of ERMS ${ }^{277}$. This strongly argues against the "ERMS- 
driver" hypothesis (for further discussion see also section 7.3). In contrast, Hh/Ptchassociated ERMS of mice are initiated before birth ${ }^{386}$, showing that Ptch mutations can be "ERMS-drivers". Nevertheless, in general oncRas mutations also seem to be early events in different other tumor entities. For example, HRAS mutations are early events during development and progression of bladder cancer ${ }^{387}$. Additionally, KRAS mutations occur in early stages during colorectal carcinoma progression ${ }^{388}$. Likewise, NRAS mutations are early events during melanoma development ${ }^{389}$.

In contrast to Hh/Ptch-driven ERMS precursor lesions, full-blown ERMS do not care about the expression of oncRAS mutations. This indicates that ERMS cells at later stages of tumor progression are insensitive to oncRAS mutations because of their specific genetic make-up. However, it is also possible that this insensitivity is a matter of the used animal model or of e.g. the tumor stem cell population (for further discussion see section 7.3). Finally, it has to mentioned that oncHRas and oncKRas increase ERMS formation from $\mathrm{Hh} / \mathrm{Ptch}$-associated precursor lesions and increase the proliferative capacity of the tumors, without notably affecting the $\mathrm{Hh}$ signaling pathway. This again indicate that $\mathrm{HH} / \mathrm{Hh}$ signaling is extremely important for growth of $\mathrm{Hh} /$ Ptch-mutant ERMS.

\subsection{Potential roles of active Ras or Hh signaling in ERMS initiation and progression}

As stated above, oncRas mutations differently affect aggressiveness of ERMS of Ptch del/+ mice, cell culture experiments and xenografts. All oncRAS isoforms increase proliferation and tumorigenicity of cultured cells derived from sporadic ERMS (Fig. 35, Fig. 36, Fig. 38), whereas oncKRas and oncHRas accelerate growth of $\mathrm{Hh}$ /Ptch-driven ERMS precursor lesions (Fig. 48, Fig. 49) but not of full-blown ERMS (Fig. 55). This indicates that oncRas mutations differently effect diverse developmental stages of ERMS as discussed above.

Similarly, oncRAS mutations inhibit GLI1 expression in a non-canonical manner in cell lines derived from sporadic ERMS, whereas this is rather not seen in $\mathrm{Hh} / \mathrm{Ptch}$-associated ERMS of $P t c h^{d e l /+}$ mice. These findings are summarized in Tab. 29. 
Table 29: Overview of oncRas-dependent effects in cell lines derived from sporadic ERMS, Hh/Ptch-driven ERMS precursor lesions and full-blown ERMS

This table summarizes the discussed effects of different oncRas isoforms in ERMS. For more details, see sections 7.1 (ERMS cell lines), 7.2.1 (ERMS precursor lesions) and 7.2.2 (full-blown ERMS).

$\uparrow:$ increase; $\downarrow$ : decrease; $\leftrightarrow$ : no effect

\begin{tabular}{|c|c|c|c|c|c|c|c|c|}
\hline & \multicolumn{2}{|c|}{$\begin{array}{l}\text { ERMS cell lines } \\
\text { derived from full- } \\
\text { blown sporadic } \\
\text { tumors }\end{array}$} & \multicolumn{3}{|c|}{$\begin{array}{c}\text { ERMS precursor of } \\
\text { Ptch }{ }^{d e l /+} \text { mice }\end{array}$} & \multicolumn{3}{|c|}{$\begin{array}{c}\text { Full-blown ERMS of } \\
\text { Ptch }{ }^{d e l /+} \text { mice }\end{array}$} \\
\hline $\begin{array}{l}\text { Canonical HH } \\
\text { signaling }\end{array}$ & \multicolumn{2}{|c|}{$\begin{array}{l}\text { Sporadic, Ptch wt ERMS } \\
\text { which do not secrete HH } \\
\text { ligands,are not } \\
\text { HH-responsive and do } \\
\text { not respond to SMO } \\
\text { inhibition }\end{array}$} & \multicolumn{3}{|c|}{$\begin{array}{l}\text { Hh/Ptch-driven ERMS } \\
\text { due to a heterozygous } \\
\text { Ptch mutation }\end{array}$} & \multicolumn{3}{|c|}{$\begin{array}{l}\text { Hh/Ptch-driven ERMS } \\
\text { due to a heterozygous } \\
\text { Ptch mutation; respond to } \\
\text { SMO inhibitors }\end{array}$} \\
\hline $\begin{array}{l}\text { RAS/Ras } \\
\text { mutation }\end{array}$ & $\begin{array}{l}\text { Onc } \\
\text { HRAS }\end{array}$ & $\begin{array}{l}\text { Onc } \\
\text { NRAS }\end{array}$ & $\begin{array}{l}\text { Onc } \\
\text { HRas }\end{array}$ & $\begin{array}{l}\text { Onc } \\
\text { KRas }\end{array}$ & $\begin{array}{l}\text { Onc } \\
\text { NRas }\end{array}$ & $\begin{array}{l}\text { Onc } \\
\text { HRas }\end{array}$ & $\begin{array}{l}\text { Onc } \\
\text { KRas }\end{array}$ & $\begin{array}{l}\text { Onc } \\
\text { NRas }\end{array}$ \\
\hline \multirow{2}{*}{$\begin{array}{l}\text { Non-canonical HH } \\
\text { signaling }\end{array}$} & \multicolumn{2}{|c|}{$\begin{array}{c}\text { GLI1/GLI1 } \downarrow \\
\text { (ERK-dependent in } \\
\text { RUCH-2 and RD) }\end{array}$} & \multirow{2}{*}{\multicolumn{3}{|c|}{$\begin{array}{c}\text { insignificant oncRas- } \\
\text { dependent reduction of } \\
\text { GLI1 }\end{array}$}} & \multirow{2}{*}{\multicolumn{3}{|c|}{$\leftrightarrow$}} \\
\hline & $\begin{array}{c}P T C H \uparrow \\
(\mathrm{RUCH}-2)\end{array}$ & $\begin{array}{l}\text { GLI3 } \downarrow \\
\text { (RUCH-2, } \\
\text { TE617.T) }\end{array}$ & & & & & & \\
\hline $\begin{array}{l}\text { Myogenic } \\
\text { differentiation } \\
\text { markers }\end{array}$ & \multicolumn{2}{|c|}{ not applicable } & \multicolumn{2}{|c|}{$\leftrightarrow$} & $\uparrow$ & \multicolumn{3}{|c|}{$\leftrightarrow$} \\
\hline Proliferation & \multicolumn{2}{|c|}{$\begin{array}{c}\uparrow \\
\text { (cell culture, xenografts) }\end{array}$} & \multicolumn{2}{|c|}{$\uparrow$} & $\leftrightarrow$ & \multicolumn{3}{|c|}{$\leftrightarrow$} \\
\hline Overall survival & \multicolumn{2}{|c|}{ not applicable } & $\leftrightarrow$ & $\downarrow$ & $\leftrightarrow$ & \multicolumn{3}{|c|}{ not applicable } \\
\hline $\begin{array}{l}\text { ERMS-free } \\
\text { survival }\end{array}$ & \multicolumn{2}{|c|}{ not applicable } & $\stackrel{\leftrightarrow}{(\downarrow)}$ & $\downarrow$ & $\leftrightarrow$ & \multicolumn{3}{|c|}{ not applicable } \\
\hline Tumor incidence & \multicolumn{2}{|c|}{ not applicable } & $\uparrow$ & $\uparrow$ & $\leftrightarrow$ & \multicolumn{3}{|c|}{ not applicable } \\
\hline
\end{tabular}

One hypothesis for the discrepancy of the role of oncRAS between sporadic and Hh/Ptchdriven tumors may be the mode of tumor formation. Whereas $\mathrm{Ptch}^{\mathrm{del} /+}$ mice develop ERMS due to a heterozygous Ptch mutation ${ }^{21}$, activating mutations in $\mathrm{PTCH}$ or other genes of the $\mathrm{HH}$ pathway are very rare in sporadic ERMS. PTCH mutations have been excluded in RD cells and probably also do not occur in TE617.T and RUCH-2 cells 15,142,144,145,147,155. Therefore, it is possible that the growth of already established HH/PTCH (Hh/Ptch)associated tumors solely depend on active canonical $\mathrm{HH} / \mathrm{Hh}$ signaling, whereas this pathway rather plays a subsidiary role in ERMS without $P T C H / P t c h$ mutations. Indeed, recent work from our lab shows that full-blown Hh/Ptch-associated ERMS cells react to SMO inhibitors, whereas those without $P T C H$ mutations do not ${ }^{159}$. Vice versa, it is possible that RAS mutations elicit different cellular responses in ERMS cells with and without PTCH mutation. However, this is pure speculation and should be verified by e.g. a PTCH knock-down in TE617.T and RUCH-2 cells with and without oncRAS mutations or in the RD cell line. However and as already mentioned above, it is likely that canonical $\mathrm{HH}$ signaling plays a 
subordinate role in ERMS cell lines, which are wt for PTCH. Indeed, oncRAS decrease the expression of the main HH target GLI1/GLI1 in a non-canonical manner via ERK, whereas cell proliferation is strongly enhanced. This shows that the HH pathway or at least GLI1 is not the main driver of ERMS that are wt for $\mathrm{PTCH}$.

The data from the genetic experiments are highly interesting. The findings indicate that oncHRas and oncKRas mutations increase the aggressiveness of Hh-associated ERMS precursor lesions but do not affect proliferation of full-blown ERMS. In contrast, oncNRas does not influence proliferation and aggressiveness of ERMS in any of these settings, while inducing a more differentiated ERMS phenotype when activated in precursor lesion. Together, these findings indicate that oncRAS mutations in different isoforms affect diverse developmental stages of ERMS in a different manner. In the case of the oncNRas mutation it must be noticed that ERMS in the Ptch ${ }^{\text {del/+ }}$ model are derived from Delta1-positive, Myf5negative, Myogenin-negative and Pax3-negative mesodermal progenitors that can undergo myogenic differentiation but lack stable lineage commitment ${ }^{386}$. Therefore it is possible that oncNRas pushes the cells into myogenic differentiation, whereas oncHRas and oncKRas rather keep the cells in a more undifferentiated stages and push proliferation of the ERMS precursors. The underlying molecular mechanisms must be specific for very early ERMS, because they do not operate at an advanced tumor stage.

In addition, and since RAS mutations usually occur at a very early stage during tumor development (see above) it is tempting to speculate that oncRas mutations are driver mutations. Indeed, this also has been suggested for ERMS. For example, oncRas mutations were proposed to be necessary to convert normal primary human skeletal muscle myoblasts into tumorigenic cells mimicking ERMS ${ }^{278}$ (compare section 2.3.4). This is in line with genetic syndromes e.g. Costello and Noonan syndrome, in which RAS germline mutations can confer susceptibility to ERMS development ${ }^{242,243}$. However, this is apparently different in the mouse, in which Ras germline mutations do not result in ERMS ${ }^{277}$. It is also different from several reports, indicating that RAS mutations are rather modifiers in ERMS. Thus microarray-based data of human RMS samples show that an oncRAS signature only occurs in combination with other pathway signatures ${ }^{275}$. Nevertheless, the increased ERMS susceptibility in patients with e.g. Noonan syndrome strongly favors the "driver" hypothesis. However, the Noonan syndrome can be caused by KRAS ${ }^{\mathrm{P} 34 \mathrm{R}}$, KRAS ${ }^{\mathrm{D} 153 \mathrm{~V}}$ and KRAS $\mathrm{K}^{\mathrm{F} 156 \mathrm{~L}}$ mutations in the KRAS protein ${ }^{256}$ or by NRAS ${ }^{\mathrm{G} 60 \mathrm{E}}$, NRAS ${ }^{\text {T71A }}$, NRAS ${ }^{\mathrm{C} 101 \mathrm{~T}}$, NRAS ${ }^{\mathrm{C} 149 \mathrm{~T}}$ or NRAS $^{\mathrm{G} 179 \mathrm{~A}}$ mutations in the NRAS protein ${ }^{257,390}$. These mutations are different from the oncRAS $^{\mathrm{G} 12}$, oncRAS ${ }^{\mathrm{G} 13}$ and oncRAS ${ }^{\mathrm{Q61}}$ mutations, which commonly occur in cancer ${ }^{231,233}$. This observation together with the fact, that mice with oncRas mutations alone do not develop ERMS ${ }^{277}$, opens the intriguing possibility that the oncRAS mutations found in human sporadic ERMS are not ERMS driver mutations, but rather passenger mutations that, 
dependent on the tumor stage or the affected cell subpopulation, can either accelerate or decelerate tumor progression. Indeed, whereas Xia et al. ${ }^{20}$ and Chen et al. ${ }^{15}$ reported a worse prognosis in ERMS patients with RAS mutations, another study shows the opposite. Martinelli et al. showed that gain-of-function mutations within the RAS genes occur more frequently in ERMS patients with a better outcome ${ }^{267}$. Similar findings were described for NRAS mutations in melanoma patients ${ }^{391}$.

Hh/Ptch-associated ERMS of mice are initiated before birth. Thus, deletion of a single copy of the Ptch allele at E9.5 results in a tumor incidence of $88 \%$ but reaches only $44 \%$ and $12 \%$ when the Ptch allele is inactivated at E11.5 and E13.5, respectively ${ }^{323}$. Similarly, induction of the Ptch mutation at E9.5 also significantly shortens ERMS-free survival and results in an increased tumor multiplicity ${ }^{323}$. This shows that Ptch mutations are real ERMS-driver mutations, at least in the mouse. In contrast, oncRas mutations rather act as some kind of "passenger" mutations in ERMS. Thus, as already stated several times, they by themselves do not initiate ERMS at least not in the mouse. However, they can accelerate tumor growth or modify tumor differentiation of already initiated ERMS precursor lesions (oncHRas and oncKRas or oncNRas, respectively). They also can accelerate growth of cultured cells or xenotransplants derived from sporadic ERMS. This may indicate that oncRas mutations only affect already initiated ERMS precursor cells and/or cancer stem cells (CSCs) within the heterogeneous tumor mass, whereas they do not affect the total cancer cell population. This would be in line with oncRas being not an ERMS-predisposing mutation, but rather an advantageous mutation for ERMS. As suggested by Kuhner and colleagues, a mutation which is advantageous but not predisposing, is a mutation that occurs in a specific somatic cell and confers growth or survival advantage on this very cell lineage, but otherwise does not contribute to tissue invasion or metastasis ${ }^{392}$. These cells then might be selectively favored early during tumor development. If this hypothesis is true for ERMS, it could explain the high number of tumors showing RAS mutations (12\% ${ }^{16}, 22 \%{ }^{266}, 35 \%{ }^{267}$ or even $46 \%{ }^{141}$ of RMS, depending on the analyzed tumor subset). Intriguingly, one study shows that all ERMS (or fusion-negative RMS) with RAS mutations show LOH of $11 \mathrm{p} 15.5^{393}$. $\mathrm{LOH}$ results from uniparental disomy or trisomy, which is usually associated with loss of maternal genetic information and duplication of the paternal one ${ }^{394} .11 \mathrm{p} 15.5$ is the location of the IGF2 gene, which is normally imprinted and is exclusively expressed from the paternal allele. Almost all RMS overexpress IGF2 ${ }^{395,396}$, which is due either to loss of imprinting with reexpression of IGF2 from the normally silent maternal allele or results from $\mathrm{LOH}$ with paternal disomy or trisomy ${ }^{4}$. Although both, $\mathrm{LOH}$ of $11 \mathrm{p} 15.5$ and RAS mutations, apparently are very early events in the evolutionary history of fusion-negative RMS ${ }^{393}$, it is possible that $\mathrm{LOH}$ with overexpression of IGF2 is the ERMS initiating event, whereas the RAS mutations are advantageous for ERMS growth. This could also be true for recurrent gains of chromosome 8 that are also described for all ERMS with RAS mutations ${ }^{14}$. 
It is also possible that RAS mutations only are advantageous when they occur in CSCs. CSCs are tumor cells that show self-renewal, clonal tumor initiation and clonal long-term repopulation potential ${ }^{397}$. In this context, it is interesting to know that $\mathrm{Hh}$ and Egfr signaling synergistically contribute to oncogenic transformation of keratinocytes via the Raf/Mek/Erk axis ${ }^{289-291}$. Thereby the pathways synergistically regulate the expression of the stem cell markers Sox2, Sox9 and Cxcr4, which are also required for growth of BCC cells ${ }^{292}$. The total number of CSCs is variable depending on the cell line and tissue ${ }^{397,398}$. We assume that human ERMS cell lines derived from sporadic tumors carry a relatively high number of CSCs. Indeed, preliminary data of our lab using the putative CSCs marker in sarcoma cells CD133 ${ }^{399,400}$ suggest the presence of a subpopulation with stem cell characteristics. Thus, transduction of ERMS cell lines with oncRAS might have targeted many CSCs, which could be selectively favored during tumor development. This can explain the increased proliferative capacity of oncRAS cells both in vitro and in vivo settings. However, if this is true, one would expect that targeting oncRas mutations to full-blown ERMS of $\mathrm{Ptch}^{\mathrm{del/}+} \mathrm{oncRas}^{\mathrm{fl}+\mathrm{Myf5}} \mathrm{CreER/+}^{\mathrm{s}}$ mice would similarly enhance ERMS growth. However, this was not the case (see section 7.2.2.1). There are several explanations for this circumstance. One the one hand, it is possible that only few CSCs exist in Hh/Ptch-driven full-blown ERMS (whereas many of them exist in precursor lesions). On the other hand, it is possible that CSCs do not express Myf5. This would prevent the induction of oncRAS in these cells. Indeed, CSCs usually show a different gene expression pattern than the bulk tumor mass ${ }^{401-403}$. Finally, it is possible that CSCs in $\mathrm{Hh} /$ Ptch-driven ERMS are solely dependent on $\mathrm{Hh}$ signaling (the role of $\mathrm{Hh}$ signaling in CSCs is described in detail in ${ }^{404-406}$ ). To verify the existence of CSCs in fullblown ERMS of Ptch ${ }^{\text {del/ }+}$ mice the tumors should be screened for CD133, aldehyde dehydrogenase 1 (Aldh1) or Sox2 expression, which are all established CSCs marker for ERMS ${ }^{400,407-409}$. In addition and to verify the hypothesis that oncRAS/oncRas mutations selectively favor ERMS growth from CSCs, but not from the bulk tumor mass, one should test the proliferative capacity of CSCs and the bulk cells from ERMS cell lines with and without oncRas mutation. This can be done by FACS sorting of living cells and by subsequent BrdU proliferation assays and transplantation studies of the sorted cells. 


\section{Summary and Conclusion}

This work aimed for a deeper unterstandig of the role of RAS signaling in $\mathrm{HH} / \mathrm{PTCH}$ associated ERMS and to study potential interactions between both pathways. Sporadic ERMS usually show high expression of $\mathrm{HH}$ target genes despite lacking mutations in members of the $\mathrm{HH}$ pathway. However, subsets of ERMS are $\mathrm{HH}$-driven by e.g. inactivating PTCH mutations, which is mimicked in mice that are heterozygous for Ptch. The data from this work show that oncRAS mutations decrease the expression of the major $\mathrm{HH}$ target GL/1 in cell lines that are derived from 3 sporadic ERMS and 1 sporadic ARMS. Furthermore, oncRAS can also regulate the expression of $P T C H, G L I 2, G L / 3$ and $S H H$, which depends on the oncRAS isoform and the individual cell line, e.g. all oncRAS isoforms increase or decrease GLI2 and $S H H$, respectively, in the ERMS cell line RUCH-2. Although oncRAS mutations can modify the expression of SHH, ERMS cell lines (TE617.T, RUCH-2 and RD) are in all likelihood not able to secret $\mathrm{HH}$ ligands. They are also not responsive to a $\mathrm{HH}$ stimulus. Together with results from other lab members, these data suggest a subordinate role of canonical $\mathrm{HH} / \mathrm{PTCH} / \mathrm{SMO}$ signaling in sporadic ERMS. They also suggest an oncRAS-dependent, non-canonical regulation of GLI1 expression in ERMS. Indeed, experiments utilizing several kinase inhibitors show that the oncRAS-mediated downregulation of GLI1 in RD and RUCH-2 cell lines is ERK-dependent. Similarly, oncRASmediated downregulation of GLI1 in TE617.T also depends on ERK. However, this cell line already shows an intrinsic block of GLI1 expression. Subsequent experiments revealed that the oncRAS/ERK-mediated downregulation of GLI1 is also seen on protein level and occurs in the cytoplasm and in the nucleus of $\mathrm{RUCH}-2$ cells. This indicates that oncRAS/ERK regulate GLI1/GLI1 levels probably on transcriptional level. ERK is also involved in regulation of other $\mathrm{HH}$ pathway members (GLI2, GLI3, PTCH and SHH), which however is cell linespecific and probably depends on the individual genetic make-up of the individual cell line. Further experiments are needed to prove the latter findings and to complete the knowledge about the role of oncRAS isoforms in regulation of $\mathrm{HH}$ targets in sporadic ERMS.

Interestingly, oncRAS mutations induce proliferation of TE617.T and RUCH-2 cell lines despite downregulation of GL/1/GLI1 in cell culture. Increased proliferation is also seen in the respective xenografts. This indicates that GLI1/GLI1, and thereby $\mathrm{HH}$ signaling activity, is not associated with the proliferative capacity of ERMS cells. In addition, in xenotransplants, oncRAS isoforms tend to decrease tumorintrinsic GLI1 and SHH expression, whereas tumorextrinsic expression of Gli2 is increased in oncKRAS-expressing RUCH-2 xenografts. This indicates that specific oncRAS mutations might affect $\mathrm{HH}$ signaling activity in the tumor microenvironment. Further experiments are needed to verify this assumption. 
In Hh/Ptch-driven ERMS of Ptch ${ }^{d e l /+}$ mice, oncKRas and oncHRas accelerate Hh-associated ERMS formation as measured by tumor incidence, ERMS-free survival and the proliferation marker Ki67, whereas oncNRas does not. However, oncNRas induces myogenic differentiation. This indicates that oncRas isoform have divergent tumorigenic functions. Interestingly, and in contrast to ERMS precursor lesions, oncRas mutations do not influence growth and proliferation of full-blown tumors in $\mathrm{Ptch}^{\text {del/t+}}$ mice. This underlines that oncRas mutations have a different impact on different developmental stages of ERMS. However, irrespective of the tumor developmental stage, oncRas do not significantly modulate $\mathrm{Hh}$ signaling in murine ERMS, suggesting that the growth of the tumors depend on the latter pathway.

Since oncRas mutation themselves do not drive ERMS formation but can enhance tumor progression of ERMS precursor lesions, it is possible that oncRAS mutations act as a "passenger" mutations in ERMS, which modulate the tumor's aggressiveness at early stages of tumor development. This is different from Ptch mutations that drive ERMS formation. In already established ERMS, Ras mutations have no or only a minor impact on tumor aggressiveness. However, this has to be verified e.g. by treatment of ERMS-bearing mice with RAS inhibitors.

Finally, the difference of the oncRAS-mediated impact on growth of ERMS cell lines derived from sporadic full-blown ERMS and on full-blown Hh/Ptch-driven ERMS must be noted. At the first glance, it is tempting to speculate that this discrepancy is caused by the Ptch/PTCH mutation status of the tumors. However, the differences might also dependent on the impact of oncRAS/oncRas mutation on CSC subpopulations within ERMS cell lines and murine ERMS, which again fosters the "passenger" hypothesis. However, this must be elucidated in further experiment. 


\section{Bibliography}

1 Ferrari, A. et al. The challenge of the management of adolescents and young adults with soft tissue sarcomas. Pediatric blood \& cancer 65, e27013, doi:10.1002/pbc.27013 (2018).

2 Ferrari, A. et al. Soft tissue sarcoma across the age spectrum: a population-based study from the Surveillance Epidemiology and End Results database. Pediatric blood \& cancer 57, 943-949, doi:10.1002/pbc.23252 (2011).

3 Miller, K. D. et al. Cancer treatment and survivorship statistics, 2016. CA: a cancer journal for clinicians 66, 271-289, doi:10.3322/caac.21349 (2016).

4 Dagher, R. \& Helman, L. Rhabdomyosarcoma: an overview. The oncologist 4, 34-44 (1999).

5 El Demellawy, D., McGowan-Jordan, J., de Nanassy, J., Chernetsova, E. \& Nasr, A. Update on molecular findings in rhabdomyosarcoma. Pathology 49, 238-246, doi:10.1016/j.pathol.2016.12.345 (2017).

6 Parham, D. M. \& Barr, F. G. Classification of rhabdomyosarcoma and its molecular basis. Advances in anatomic pathology 20, 387-397, doi:10.1097/PAP.0b013e3182a92d0d (2013).

7 Parham, D. M. \& Ellison, D. A. Rhabdomyosarcomas in adults and children: an update. Arch Pathol Lab Med 130, 1454-1465, doi:10.1043/15432165(2006)130[1454:RIAACA]2.0.CO;2 (2006).

8 Egas-Bejar, D. \& Huh, W. W. Rhabdomyosarcoma in adolescent and young adult patients: current perspectives. Adolescent health, medicine and therapeutics 5, 115125, doi:10.2147/AHMT.S44582 (2014).

9 Jo, V. Y. \& Fletcher, C. D. WHO classification of soft tissue tumours: an update based on the 2013 (4th) edition. Pathology 46, 95-104, doi:10.1097/PAT.0000000000000050 (2014).

10 Fletcher, C. D. M., Bridge, J.A., Hogendoorn, P., Mertens F. WHO Classification of Tumours of Soft Tissue and Bone - 4th Edition. (IARC Press, 2013).

11 Dodd, L. G., Bui, M. M. in Soft tissue and bone pathology (New York : Demos Medical, United States, 2015).

12 Galili, N. et al. Fusion of a fork head domain gene to PAX3 in the solid tumour alveolar rhabdomyosarcoma. Nature genetics 5, 230-235, doi:10.1038/ng1193-230 (1993).

13 Williamson, D. et al. Fusion gene-negative alveolar rhabdomyosarcoma is clinically and molecularly indistinguishable from embryonal rhabdomyosarcoma. J Clin Oncol 28, 2151-2158 (2010).

14 Shern, J. F. et al. Comprehensive genomic analysis of rhabdomyosarcoma reveals a landscape of alterations affecting a common genetic axis in fusion-positive and fusion-negative tumors. Cancer discovery 4, 216-231, doi:10.1158/2159-8290.CD-130639 (2014).

15 Chen, $X$. et al. Targeting oxidative stress in embryonal rhabdomyosarcoma. Cancer cell 24, 710-724, doi:10.1016/j.ccr.2013.11.002 (2013).

16 Shukla, N. et al. Oncogene mutation profiling of pediatric solid tumors reveals significant subsets of embryonal rhabdomyosarcoma and neuroblastoma with mutated genes in growth signaling pathways. Clinical cancer research : an official journal of the American Association for Cancer Research 18, 748-757, doi:10.1158/1078-0432.CCR-11-2056 (2012).

17 Hennekam, R. C. Costello syndrome: an overview. American journal of medical genetics. Part C, Seminars in medical genetics 117C, 42-48, doi:10.1002/ajmg.c.10019 (2003).

18 Miller, R. W. \& Rubinstein, J. H. Tumors in Rubinstein-Taybi syndrome. Am J Med Genet 56, 112-115, doi:10.1002/ajmg.1320560125 (1995).

19 Ferrari, A. et al. Soft-tissue sarcomas in children and adolescents with neurofibromatosis type 1. Cancer 109, 1406-1412, doi:10.1002/cncr.22533 (2007). 
Xia, S. J., Pressey, J. G. \& Barr, F. G. Molecular pathogenesis of rhabdomyosarcoma. Cancer biology \& therapy 1, 97-104 (2002).

21 Hahn, H. et al. Rhabdomyosarcomas and radiation hypersensitivity in a mouse model of Gorlin syndrome. Nat Med 4, 619-622 (1998).

Gorlin, R. J. \& Peterson, W. C., Jr. Oral disease in man and animals based on analysis of 1,135 cases in a variety of species. Arch Dermatol 96, 390-403 (1967).

Yang, L., Takimoto, T. \& Fujimoto, J. Prognostic model for predicting overall survival in children and adolescents with rhabdomyosarcoma. BMC Cancer 14, 654, doi:10.1186/1471-2407-14-654 (2014).

24 Hawkins, D. S., Gupta, A. A. \& Rudzinski, E. R. What is new in the biology and treatment of pediatric rhabdomyosarcoma? Curr Opin Pediatr 26, 50-56, doi:10.1097/MOP.0000000000000041 (2014).

25 Hettmer, S. et al. Rhabdomyosarcoma: current challenges and their implications for developing therapies. Cold Spring Harbor perspectives in medicine 4, a025650, doi:10.1101/cshperspect.a025650 (2014).

26 Nusslein-Volhard, C. \& Wieschaus, E. Mutations affecting segment number and polarity in Drosophila. Nature 287, 795-801 (1980).

27 Lee, J. J., von Kessler, D. P., Parks, S. \& Beachy, P. A. Secretion and localized transcription suggest a role in positional signaling for products of the segmentation gene hedgehog. Cell 71, 33-50 (1992).

Mohler, J. \& Vani, K. Molecular organization and embryonic expression of the hedgehog gene involved in cell-cell communication in segmental patterning of Drosophila. Development 115, 957-971 (1992).

29 Tabata, T., Eaton, S. \& Kornberg, T. B. The Drosophila hedgehog gene is expressed specifically in posterior compartment cells and is a target of engrailed regulation. Genes \& development 6, 2635-2645 (1992).

30 Teperino, R., Aberger, F., Esterbauer, H., Riobo, N. \& Pospisilik, J. A. Canonical and non-canonical Hedgehog signalling and the control of metabolism. Seminars in cell \& developmental biology 33, 81-92, doi:10.1016/j.semcdb.2014.05.007 (2014).

Ingham, P. W. \& McMahon, A. P. Hedgehog signaling in animal development: paradigms and principles. Genes \& development 15, 3059-3087, doi:10.1101/gad.938601 (2001).

Briscoe, J. \& Therond, P. P. The mechanisms of Hedgehog signalling and its roles in development and disease. Nature reviews. Molecular cell biology 14, 416-429, doi:10.1038/nrm3598 (2013).

33 Hammerschmidt, M., Brook, A. \& McMahon, A. P. The world according to hedgehog. Trends Genet 13, 14-21 (1997).

34 Heussler, H. S. \& Suri, M. Sonic hedgehog. Mol Pathol 56, 129-131 (2003).

35 Vortkamp, A. et al. Regulation of rate of cartilage differentiation by Indian hedgehog and PTH-related protein. Science 273, 613-622 (1996).

36 Bitgood, M. J. \& McMahon, A. P. Hedgehog and Bmp genes are coexpressed at many diverse sites of cell- cell interaction in the mouse embryo. Developmental biology 172, 126-138 (1995).

37 Pathi, S. et al. Comparative biological responses to human Sonic, Indian, and Desert hedgehog. Mechanisms of development 106, 107-117 (2001).

38 Porter, J. A. et al. Hedgehog patterning activity: role of a lipophilic modification mediated by the carboxy-terminal autoprocessing domain. Cell 86, 21-34 (1996).

39 Burke, R. et al. Dispatched, a novel sterol-sensing domain protein dedicated to the release of cholesterol-modified hedgehog from signaling cells. Cell 99, 803-815 (1999).

40 Porter, J. A. et al. The product of hedgehog autoproteolytic cleavage active in local and long-range signalling. Nature 374, 363-366 (1995).

41 Goodrich, L. V., Johnson, R. L., Milenkovic, L., McMahon, J. A. \& Scott, M. P. Conservation of the hedgehog/patched signaling pathway from flies to mice: induction of a mouse patched gene by Hedgehog. Genes \& development 10, 301-312 (1996). Cohen, M. M., Jr. Hedgehog signaling update. American journal of medical genetics. Part A 152A, 1875-1914, doi:10.1002/ajmg.a.32909 (2010). 
43 Cohen, M. M., Jr. The hedgehog signaling network. American journal of medical genetics. Part A 123, 5-28 (2003).

44 Allen, B. L. et al. Overlapping Roles and Collective Requirement for the Coreceptors GAS1, CDO, and BOC in SHH Pathway Function. Dev Cell 20, 775-787 (2011).

45 Rohatgi, R., Milenkovic, L. \& Scott, M. P. Patched1 regulates hedgehog signaling at the primary cilium. Science 317, 372-376, doi:10.1126/science.1139740 (2007).

46 Hooper, J. E. \& Scott, M. P. Communicating with Hedgehogs. Nature reviews. Molecular cell biology 6, 306-317, doi:10.1038/nrm1622 (2005).

47 Alcedo, J., Ayzenzon, M., Von Ohlen, T., Noll, M. \& Hooper, J. E. The Drosophila smoothened gene encodes a seven-pass membrane protein, a putative receptor for the hedgehog signal. Cell 86, 221-232 (1996).

48 Ruiz i Altaba, A., Mas, C. \& Stecca, B. The Gli code: an information nexus regulating cell fate, stemness and cancer. Trends in cell biology 17, 438-447, doi:10.1016/j.tcb.2007.06.007 (2007).

49 Aberger, F. \& Ruiz, I. A. A. Context-dependent signal integration by the GLI code: the oncogenic load, pathways, modifiers and implications for cancer therapy. Seminars in cell \& developmental biology 33, 93-104, doi:10.1016/j.semcdb.2014.05.003 (2014).

50 Lee, R. T., Zhao, Z. \& Ingham, P. W. Hedgehog signalling. Development 143, 367372, doi:10.1242/dev.120154 (2016).

51 Pasca di Magliano, M. \& Hebrok, M. Hedgehog signalling in cancer formation and maintenance. Nat Rev Cancer 3, 903-911 (2003).

52 Rubin, L. L. \& de Sauvage, F. J. Targeting the Hedgehog pathway in cancer. Nature reviews. Drug discovery 5, 1026-1033, doi:10.1038/nrd2086 (2006).

53 Hui, C. C. \& Angers, S. Gli proteins in development and disease. Annual review of cell and developmental biology 27, 513-537, doi:10.1146/annurev-cellbio-092910154048 (2011).

54 Niewiadomski, P. et al. Gli protein activity is controlled by multisite phosphorylation in vertebrate Hedgehog signaling. Cell reports 6, 168-181, doi:10.1016/j.celrep.2013.12.003 (2014).

$55 \mathrm{Jia}$, J. Phosphorylation regulation of Hedgehog signaling. Vitamins and hormones 88, 253-272, doi:10.1016/B978-0-12-394622-5.00011-0 (2012).

56 Pan, Y., Bai, C. B., Joyner, A. L. \& Wang, B. Sonic hedgehog signaling regulates Gli2 transcriptional activity by suppressing its processing and degradation. Molecular and cellular biology 26, 3365-3377, doi:10.1128/MCB.26.9.3365-3377.2006 (2006).

57 Buttitta, L., Mo, R., Hui, C. C. \& Fan, C. M. Interplays of Gli2 and Gli3 and their requirement in mediating Shh-dependent sclerotome induction. Development 130, 6233-6243, doi:10.1242/dev.00851 (2003).

58 Bai, C. B., Stephen, D. \& Joyner, A. L. All mouse ventral spinal cord patterning by hedgehog is Gli dependent and involves an activator function of Gli3. Dev Cell 6, 103115 (2004).

59 Cheng, S. Y. \& Yue, S. Role and regulation of human tumor suppressor SUFU in Hedgehog signaling. Adv Cancer Res 101, 29-43, doi:10.1016/S0065230X(08)00402-8 (2008).

60 Ingham, P. W. Hedgehog signaling. Cold Spring Harbor perspectives in biology 4, doi:10.1101/cshperspect.a011221 (2012).

61 Wang, B., Fallon, J. F. \& Beachy, P. A. Hedgehog-regulated processing of Gli3 produces an anterior/posterior repressor gradient in the developing vertebrate limb. Cell 100, 423-434 (2000).

62 Goetz, S. C., Ocbina, P. J. \& Anderson, K. V. The primary cilium as a Hedgehog signal transduction machine. Methods Cell Biol 94, 199-222, doi:10.1016/S0091679X(08)94010-3 (2009).

63 Tukachinsky, H., Lopez, L. V. \& Salic, A. A mechanism for vertebrate Hedgehog signaling: recruitment to cilia and dissociation of SuFu-Gli protein complexes. J Cell Biol 191, 415-428, doi:10.1083/jcb.201004108 (2010).

64 Ruiz i Altaba, A. Hedgehog signaling and the Gli code in stem cells, cancer, and metastases. Science signaling 4, pt9, doi:10.1126/scisignal.2002540 (2011). 
65 Scales, S. J. \& de Sauvage, F. J. Mechanisms of Hedgehog pathway activation in cancer and implications for therapy. Trends Pharmacol Sci (2009).

66 Hahn, $\mathrm{H}$. et al. Patched target Igf2 is indispensable for the formation of medulloblastoma and rhabdomyosarcoma. The Journal of biological chemistry 275, 28341-28344, doi:10.1074/jbc.C000352200 (2000).

67 Pandolfi, S. \& Stecca, B. Cooperative integration between HEDGEHOG-GLI signalling and other oncogenic pathways: implications for cancer therapy. Expert reviews in molecular medicine 17, e5, doi:10.1017/erm.2015.3 (2015).

68 Lee, J., Platt, K. A., Censullo, P. \& Ruiz i Altaba, A. Gli1 is a target of Sonic hedgehog that induces ventral neural tube development. Development 124, 2537-2552 (1997).

69 Stecca, B. \& Ruiz, I. A. A. Context-dependent regulation of the GLI code in cancer by HEDGEHOG and non-HEDGEHOG signals. J Mol Cell Biol 2, 84-95 (2010).

70 Robbins, D. J., Fei, D. L. \& Riobo, N. A. The Hedgehog signal transduction network. Science signaling 5, re6, doi:10.1126/scisignal.2002906 (2012).

71 Aberger, F., Kern, D., Greil, R. \& Hartmann, T. N. Canonical and noncanonical Hedgehog/GLI signaling in hematological malignancies. Vitamins and hormones $\mathbf{8 8}$, 25-54, doi:10.1016/B978-0-12-394622-5.00002-X (2012).

72 Stecca, B. \& Ruiz i Altaba, A. A GLI1-p53 inhibitory loop controls neural stem cell and tumour cell numbers. Embo J 28, 663-676 (2009).

73 Abe, Y. et al. Hedgehog signaling overrides p53-mediated tumor suppression by activating Mdm2. Proc Natl Acad Sci $U S A$ 105, 4838-4843, doi:10.1073/pnas.0712216105 (2008).

74 Dennler, S. et al. Induction of sonic hedgehog mediators by transforming growth factor-beta: Smad3-dependent activation of Gli2 and Gli1 expression in vitro and in vivo. Cancer research 67, 6981-6986, doi:10.1158/0008-5472.CAN-07-0491 (2007).

75 Stecca, B. et al. Melanomas require HEDGEHOG-GLI signaling regulated by interactions between GLI1 and the RAS-MEK/AKT pathways. Proc Natl Acad Sci U S A 104, 5895-5900 (2007).

76 Riobo, N. A., Lu, K., Ai, X., Haines, G. M. \& Emerson, C. P., Jr. Phosphoinositide 3kinase and Akt are essential for Sonic Hedgehog signaling. Proc Natl Acad Sci U S A 103, 4505-4510 (2006).

77 Katoh, Y. \& Katoh, M. Integrative genomic analyses on GLI1: positive regulation of GLI1 by Hedgehog-GLI, TGFbeta-Smads, and RTK-PI3K-AKT signals, and negative regulation of GLI1 by Notch-CSL-HES/HEY, and GPCR-Gs-PKA signals. International journal of oncology 35, 187-192 (2009).

78 Zhou, J. et al. Non-canonical GLI1/2 activation by PI3K/AKT signaling in renal cell carcinoma: A novel potential therapeutic target. Cancer letters 370, 313-323, doi:10.1016/j.canlet.2015.11.006 (2016).

79 Wang, Y. et al. The crosstalk of mTOR/S6K1 and Hedgehog pathways. Cancer cell 21, 374-387, doi:10.1016/j.ccr.2011.12.028 (2012).

80 Agarwal, N. K., Qu, C., Kunkalla, K., Liu, Y. \& Vega, F. Transcriptional regulation of serine/threonine protein kinase (AKT) genes by glioma-associated oncogene homolog 1. The Journal of biological chemistry 288, 15390-15401, doi:10.1074/jbc.M112.425249 (2013).

81 Ehe, B. K. et al. Identification of a DYRK1A-mediated phosphorylation site within the nuclear localization sequence of the hedgehog transcription factor GLI1. Biochemical and biophysical research communications 491, 767-772, doi:10.1016/j.bbrc.2017.07.107 (2017).

82 Mao, J. et al. Regulation of Gli1 transcriptional activity in the nucleus by Dyrk1. The Journal of biological chemistry 277, 35156-35161, doi:10.1074/jbc.M206743200 (2002).

83 Varjosalo, M. et al. Application of active and kinase-deficient kinome collection for identification of kinases regulating hedgehog signaling. Cell 133, 537-548, doi:10.1016/j.cell.2008.02.047 (2008).

84 Lauth, M. et al. DYRK1B-dependent autocrine-to-paracrine shift of Hedgehog signaling by mutant RAS. Nat Struct Mol Biol 17, 718-725, doi:10.1038/nsmb.1833 (2010). 
85 Gruber, W. et al. DYRK1B as therapeutic target in Hedgehog/GLI-dependent cancer cells with Smoothened inhibitor resistance. Oncotarget, doi:10.18632/oncotarget.6910 (2016).

86 Keramati, A. R. et al. A form of the metabolic syndrome associated with mutations in DYRK1B. N Engl J Med 370, 1909-1919, doi:10.1056/NEJMoa1301824 (2014).

87 Singh, R., Dhanyamraju, P. K. \& Lauth, M. DYRK1B blocks canonical and promotes non-canonical Hedgehog signaling through activation of the mTOR/AKT pathway. Oncotarget 8, 833-845, doi:10.18632/oncotarget.13662 (2017).

88 Thibert, C. et al. Inhibition of neuroepithelial patched-induced apoptosis by sonic hedgehog. Science 301, 843-846 (2003).

89 Chinchilla, P., Xiao, L., Kazanietz, M. G. \& Riobo, N. A. Hedgehog proteins activate pro-angiogenic responses in endothelial cells through non-canonical signaling pathways. Cell Cycle 9, 570-579, doi:10.4161/cc.9.3.10591 (2010).

90 Barnes, E. A., Kong, M., Ollendorff, V. \& Donoghue, D. J. Patched1 interacts with cyclin B1 to regulate cell cycle progression. Embo J 20, 2214-2223 (2001).

91 Takizawa, C. G. \& Morgan, D. O. Control of mitosis by changes in the subcellular location of cyclin-B1-Cdk1 and Cdc25C. Curr Opin Cell Biol 12, 658-665 (2000).

92 Polizio, A. H. et al. Heterotrimeric Gi proteins link Hedgehog signaling to activation of Rho small GTPases to promote fibroblast migration. The Journal of biological chemistry 286, 19589-19596, doi:10.1074/jbc.M110.197111 (2011).

93 Bijlsma, M. F., Borensztajn, K. S., Roelink, H., Peppelenbosch, M. P. \& Spek, C. A. Sonic hedgehog induces transcription-independent cytoskeletal rearrangement and migration regulated by arachidonate metabolites. Cellular signalling 19, 2596-2604, doi:10.1016/j.cellsig.2007.08.011 (2007).

94 Yam, P. T., Langlois, S. D., Morin, S. \& Charron, F. Sonic hedgehog guides axons through a noncanonical, Src-family-kinase-dependent signaling pathway. Neuron 62, 349-362, doi:10.1016/j.neuron.2009.03.022 (2009).

95 Belgacem, Y. H. \& Borodinsky, L. N. Sonic hedgehog signaling is decoded by calcium spike activity in the developing spinal cord. Proc Natl Acad Sci U S A 108, $4482-$ 4487, doi:10.1073/pnas.1018217108 (2011).

96 Brennan, D., Chen, X., Cheng, L., Mahoney, M. \& Riobo, N. A. Noncanonical Hedgehog signaling. Vitamins and hormones 88, 55-72, doi:10.1016/B978-0-12394622-5.00003-1 (2012).

97 Ayers, K. L. \& Therond, P. P. Evaluating Smoothened as a G-protein-coupled receptor for Hedgehog signalling. Trends in cell biology 20, 287-298, doi:10.1016/j.tcb.2010.02.002 (2010).

98 Teperino, R. et al. Hedgehog partial agonism drives Warburg-like metabolism in muscle and brown fat. Cell 151, 414-426, doi:10.1016/j.cell.2012.09.021 (2012).

99 Hahn, H. et al. Mutations of the human homolog of Drosophila patched in the nevoid basal cell carcinoma syndrome. Cell 85, 841-851 (1996).

100 Johnson, R. L. et al. Human homolog of patched, a candidate gene for the basal cell nevus syndrome. Science 272, 1668-1671 (1996).

101 Gorlin, R. J. \& Goltz, R. W. Multiple nevoid basal-cell epithelioma, jaw cysts and bifid rib. A syndrome. New Eng J Med 262, 908-912 (1960).

102 Gorlin, R. J. Nevoid basal cell carcinoma (Gorlin) syndrome: unanswered issues. J Lab Clin Med 134, 551-552 (1999).

103 Xie, J., Bartels, C. M., Barton, S. W. \& Gu, D. Targeting hedgehog signaling in cancer: research and clinical developments. OncoTargets and therapy 6, 1425-1435, doi:10.2147/OTT.S34678 (2013).

104 Beddis, I. R., Mott, M. G. \& Bullimore, J. Case report: nasopharyngeal rhabdomyosarcoma and Gorlin's naevoid basal cell carcinoma syndrome. Med Pediatr Oncol 11, 178-179 (1983).

105 Cajaiba, M. M., Bale, A. E., Alvarez-Franco, M., McNamara, J. \& Reyes-Mugica, M. Rhabdomyosarcoma, Wilms tumor, and deletion of the patched gene in Gorlin syndrome. Nature clinical practice. Oncology 3, 575-580, doi:10.1038/ncponc0608 (2006). 
106 Herzberger, J. J. \& Wiskemann, A. Die fünfte Phakomatose. Basalzellnävus mit familiärer Belastung und Medulloblastom. Dermatologica 126, 106-123 (1963).

107 Lo Muzio, L. Nevoid basal cell carcinoma syndrome (Gorlin syndrome). Orphanet journal of rare diseases 3, 32, doi:10.1186/1750-1172-3-32 (2008).

108 Unden, A. B. et al. Mutations in the human homologue of Drosophila patched (PTCH) in basal cell carcinomas and the Gorlin syndrome: different in vivo mechanisms of PTCH inactivation. Cancer research 56, 4562-4565 (1996).

109 Unden, A. B., Zaphiropoulos, P. G., Bruce, K., Toftg ard, R. \& St ahle-Backdahl, M. Human patched (PTCH) mRNA is overexpressed consistently in tumor cells of both familial and sporadic basal cell carcinoma. Cancer research 57, 2336-2340 (1997).

110 Wolter, M., Reifenberger, J., Sommer, C., Ruzicka, T. \& Reifenberger, G. Mutations in the human homologue of the Drosophila segment polarity gene patched (PTCH) in sporadic basal cell carcinomas of the skin and primitive neuroectodermal tumors of the central nervous system. Cancer research 57, 2581-2585 (1997).

111 Gailani, M. R. et al. The role of the human homologue of Drosophila patched in sporadic basal cell carcinomas [see comments]. Nature genetics 14, 78-81 (1996).

112 Pietsch, T. et al. Medulloblastomas of the desmoplastic variant carry mutations of the human homologue of Drosophila patched. Cancer research 57, 2085-2088 (1997).

113 Yang, L., Xie, G., Fan, Q. \& Xie, J. Activation of the hedgehog-signaling pathway in human cancer and the clinical implications. Oncogene 29, 469-481, doi:10.1038/onc.2009.392 (2010).

114 Xie, J. et al. Activating Smoothened mutations in sporadic basal-cell carcinoma. Nature 391, 90-92 (1998).

115 Lam, C. W. et al. A frequent activated smoothened mutation in sporadic basal cell carcinomas. Oncogene 18, 833-836 (1999).

116 Reifenberger, J. et al. Somatic mutations in the PTCH, SMOH, SUFUH and TP53 genes in sporadic basal cell carcinomas. Br J Dermatol 152, 43-51 (2005).

117 Reifenberger, J. et al. Missense mutations in $\mathrm{SMOH}$ in sporadic basal cell carcinomas of the skin and primitive neuroectodermal tumors of the central nervous system. Cancer research 58, 1798-1803 (1998).

118 Shou, Y. et al. A five-gene hedgehog signature developed as a patient preselection tool for hedgehog inhibitor therapy in medulloblastoma. Clinical cancer research : an official journal of the American Association for Cancer Research 21, 585-593, doi:10.1158/1078-0432.CCR-13-1711 (2015).

119 Kijima, C., Miyashita, T., Suzuki, M., Oka, H. \& Fujii, K. Two cases of nevoid basal cell carcinoma syndrome associated with meningioma caused by a PTCH1 or SUFU germline mutation. Familial cancer 11, 565-570, doi:10.1007/s10689-012-9548-0 (2012).

120 Brastianos, P. K. et al. Genomic sequencing of meningiomas identifies oncogenic SMO and AKT1 mutations. Nature genetics 45, 285-289, doi:10.1038/ng.2526 (2013).

121 Singh, R. R. et al. Sonic hedgehog signaling pathway is activated in ALK-positive anaplastic large cell lymphoma. Cancer research 69, 2550-2558, doi:10.1158/00085472.CAN-08-1808 (2009).

122 Watkins, D. N. et al. Hedgehog signalling within airway epithelial progenitors and in small-cell lung cancer. Nature 422, 313-317 (2003).

123 Collins, V. P. Gene amplification in human gliomas. Glia 15, 289-296, doi:10.1002/glia.440150309 (1995).

124 Kinzler, K. W. et al. Identification of an amplified, highly expressed gene in a human glioma. Science 236, 70-73 (1987).

125 Kar, S. et al. Intricacies of hedgehog signaling pathways: a perspective in tumorigenesis. Experimental cell research 318, 1959-1972, doi:10.1016/j.yexcr.2012.05.015 (2012).

126 Berman, D. M. et al. Widespread requirement for Hedgehog ligand stimulation in growth of digestive tract tumours. Nature 425, 846-851 (2003).

127 Watkins, D. N. \& Peacock, C. D. Hedgehog signalling in foregut malignancy. Biochemical pharmacology 68, 1055-1060 (2004). 
128 Thayer, S. P. et al. Hedgehog is an early and late mediator of pancreatic cancer tumorigenesis. Nature 425, 851-856, doi:10.1038/nature02009 (2003).

129 Fei, D. L. et al. Hedgehog signaling regulates bladder cancer growth and tumorigenicity. Cancer research 72, 4449-4458, doi:10.1158/0008-5472.CAN-114123 (2012).

130 Shin, K. et al. Hedgehog signaling restrains bladder cancer progression by eliciting stromal production of urothelial differentiation factors. Cancer cell 26, 521-533, doi:10.1016/j.ccell.2014.09.001 (2014).

131 Geng, L. et al. Hedgehog signaling in the murine melanoma microenvironment. Angiogenesis 10, 259-267 (2007).

132 Das, S. et al. The hedgehog pathway transcription factor GLI1 promotes malignant behavior of cancer cells by up-regulating osteopontin. The Journal of biological chemistry 284, 22888-22897, doi:10.1074/jbc.M109.021949 (2009).

133 Alexaki, V. I. et al. GLI2-mediated melanoma invasion and metastasis. Journal of the National Cancer Institute 102, 1148-1159, doi:10.1093/jnci/djq257 (2010).

134 Sheng, T. et al. Activation of the hedgehog pathway in advanced prostate cancer. Molecular cancer 3, 29, doi:10.1186/1476-4598-3-29 (2004).

135 Kasper, M., Jaks, V., Fiaschi, M. \& Toftgard, R. Hedgehog signalling in breast cancer. Carcinogenesis 30, 903-911, doi:10.1093/carcin/bgp048 (2009).

136 Zhao, H. et al. The Hedgehog signaling pathway is associated with poor prognosis in breast cancer patients with the CD44+/CD24 phenotype. Molecular medicine reports 14, 5261-5270, doi:10.3892/mmr.2016.5856 (2016).

137 Kappler, R. et al. Molecular characterization of Patched-associated rhabdomyosarcoma. The Journal of pathology 200, 348-356, doi:10.1002/path.1361 (2003).

138 Kappler, R. et al. Profiling the molecular difference between Patched- and p53dependent rhabdomyosarcoma. Oncogene 23, 8785-8795, doi:10.1038/sj.onc.1208133 (2004).

139 Lee, Y. et al. Loss of suppressor-of-fused function promotes tumorigenesis. Oncogene 26, 6442-6447, doi:10.1038/sj.onc.1210467 (2007).

140 Mao, J. et al. A novel somatic mouse model to survey tumorigenic potential applied to the Hedgehog pathway. Cancer research 66, 10171-10178 (2006).

141 Paulson, V. et al. High-resolution array CGH identifies common mechanisms that drive embryonal rhabdomyosarcoma pathogenesis. Genes, chromosomes \& cancer 50, 397-408, doi:10.1002/gcc.20864 (2011).

142 Tostar, U. et al. Deregulation of the hedgehog signalling pathway: a possible role for the PTCH and SUFU genes in human rhabdomyoma and rhabdomyosarcoma development. The Journal of pathology 208, 17-25, doi:10.1002/path.1882 (2006).

143 Zibat, A. et al. Activation of the hedgehog pathway confers a poor prognosis in embryonal and fusion gene-negative alveolar rhabdomyosarcoma. Oncogene 29, 6323-6330, doi:10.1038/onc.2010.368 (2010).

144 Pressey, J. G., Anderson, J. R., Crossman, D. K., Lynch, J. C. \& Barr, F. G. Hedgehog pathway activity in pediatric embryonal rhabdomyosarcoma and undifferentiated sarcoma: A report from the Children's Oncology Group. Pediatric blood \& cancer (2011).

145 Teot, L. A. et al. Clinical and mutational spectrum of highly differentiated, paired box 3:forkhead box protein o1 fusion-negative rhabdomyosarcoma: A report from the Children's Oncology Group. Cancer 124, 1973-1981, doi:10.1002/cncr.31286 (2018).

146 Bridge, J. A. et al. Genomic gains and losses are similar in genetic and histologic subsets of rhabdomyosarcoma, whereas amplification predominates in embryonal with anaplasia and alveolar subtypes. Genes, chromosomes \& cancer 33, 310-321 (2002).

147 Bridge, J. A. et al. Novel genomic imbalances in embryonal rhabdomyosarcoma revealed by comparative genomic hybridization and fluorescence in situ hybridization: an intergroup rhabdomyosarcoma study. Genes, chromosomes \& cancer 27, 337-344 (2000). 
148 Calzada-Wack, J. et al. Analysis of the PTCH coding region in human rhabdomyosarcoma. Human mutation 20, 233-234, doi:10.1002/humu.9056 (2002).

149 Ragazzini, P. et al. Amplification of CDK4, MDM2, SAS and GLI genes in leiomyosarcoma, alveolar and embryonal rhabdomyosarcoma. Histol Histopathol 19, 401-411 (2004).

150 Almazan-Moga, A. et al. Ligand-dependent Hedgehog pathway activation in Rhabdomyosarcoma: the oncogenic role of the ligands. Br J Cancer 117, 1314-1325, doi:10.1038/bjc.2017.305 (2017).

151 Satheesha, S. et al. Targeting hedgehog signaling reduces self-renewal in embryonal rhabdomyosarcoma. Oncogene, doi:10.1038/onc.2015.267 (2015).

152 Oue, T., Uehara, S., Yamanaka, H., Nomura, M. \& Usui, N. Hedgehog signal inhibitors suppress the invasion of human rhabdomyosarcoma cells. Pediatric surgery international 29, 1153-1158, doi:10.1007/s00383-013-3369-6 (2013).

153 Lauth, M., Bergstrom, A., Shimokawa, T. \& Toftgard, R. Inhibition of GLI-mediated transcription and tumor cell growth by small-molecule antagonists. Proc Natl Acad Sci U S A 104, 8455-8460, doi:10.1073/pnas.0609699104 (2007).

154 Srivastava, R. K. et al. GLI inhibitor GANT-61 diminishes embryonal and alveolar rhabdomyosarcoma growth by inhibiting Shh/AKT-mTOR axis. Oncotarget 5, 1215112165 (2014).

155 Tostar, U., Toftgard, R., Zaphiropoulos, P. G. \& Shimokawa, T. Reduction of human embryonal rhabdomyosarcoma tumor growth by inhibition of the hedgehog signaling pathway. Genes \& cancer 1, 941-951, doi:10.1177/1947601910385449 (2010).

156 Lauth, M. et al. Antipsychotic drugs regulate hedgehog signaling by modulation of 7dehydrocholesterol reductase levels. Molecular pharmacology 78, 486-496, doi:10.1124/mol.110.066431 (2010).

157 Kawabata, N. et al. Pharmacological inhibition of the Hedgehog pathway prevents human rhabdomyosarcoma cell growth. International journal of oncology 39, 899-906, doi:10.3892/ijo.2011.1076 (2011).

158 Ecke, I. et al. Cyclopamine treatment of full-blown Hh/Ptch-associated RMS partially inhibits Hh/Ptch signaling, but not tumor growth. Molecular carcinogenesis 47, 361372, doi:10.1002/mc.20394 (2008).

159 Geyer, N. et al. Different Response of Ptch Mutant and Ptch Wildtype Rhabdomyosarcoma Toward SMO and PI3K Inhibitors. Frontiers in oncology 8, doi:10.3389/fonc.2018.00396 (2018).

160 Geyer, N. Targeting the Hedgehog and PI3K/AKT/mTOR signaling pathways in rhabdomyosarcoma, Georg-August-University Goettingen (2018).

161 Malumbres, M. \& Barbacid, M. RAS oncogenes: the first 30 years. Nature reviews. Cancer 3, 459-465, doi:10.1038/nrc1097 (2003).

162 Barbacid, M. ras genes. Annual review of biochemistry 56, 779-827, doi:10.1146/annurev.bi.56.070187.004023 (1987).

163 Schafer, W. R. et al. Genetic and pharmacological suppression of oncogenic mutations in ras genes of yeast and humans. Science 245, 379-385 (1989).

164 Schafer, W. R. et al. Enzymatic coupling of cholesterol intermediates to a mating pheromone precursor and to the ras protein. Science 249, 1133-1139 (1990).

165 Hancock, J. F., Magee, A. I., Childs, J. E. \& Marshall, C. J. All ras proteins are polyisoprenylated but only some are palmitoylated. Cell 57, 1167-1177 (1989).

166 Hancock, J. F., Cadwallader, K., Paterson, H. \& Marshall, C. J. A CAAX or a CAAL motif and a second signal are sufficient for plasma membrane targeting of ras proteins. Embo J 10, 4033-4039 (1991).

167 Downward, J. Targeting RAS signalling pathways in cancer therapy. Nature reviews. Cancer 3, 11-22, doi:10.1038/nrc969 (2003).

168 Gideon, P. et al. Mutational and kinetic analyses of the GTPase-activating protein (GAP)-p21 interaction: the C-terminal domain of GAP is not sufficient for full activity. Molecular and cellular biology 12, 2050-2056 (1992).

169 Wolfman, A. \& Macara, I. G. A cytosolic protein catalyzes the release of GDP from p21ras. Science 248, 67-69 (1990). 
170 Downward, J., Riehl, R., Wu, L. \& Weinberg, R. A. Identification of a nucleotide exchange-promoting activity for p21ras. Proc Natl Acad Sci U S A 87, 5998-6002 (1990).

171 Bos, J. L., Rehmann, H. \& Wittinghofer, A. GEFs and GAPs: critical elements in the control of small G proteins. Cell 129, 865-877, doi:10.1016/j.cell.2007.05.018 (2007).

172 Daub, H., Weiss, F. U., Wallasch, C. \& Ullrich, A. Role of transactivation of the EGF receptor in signalling by G-protein-coupled receptors. Nature 379, 557-560, doi:10.1038/379557a0 (1996).

173 Bos, J. L. ras oncogenes in human cancer: a review. Cancer research 49, 4682-4689 (1989).

174 Hobbs, G. A., Der, C. J. \& Rossman, K. L. RAS isoforms and mutations in cancer at a glance. Journal of cell science 129, 1287-1292, doi:10.1242/jcs.182873 (2016).

175 Ponting, C. P. \& Benjamin, D. R. A novel family of Ras-binding domains. Trends Biochem Sci 21, 422-425 (1996).

176 Chang, L. \& Karin, M. Mammalian MAP kinase signalling cascades. Nature 410, 3740. (2001).

177 Marais, R., Light, Y., Paterson, H. F., Mason, C. S. \& Marshall, C. J. Differential regulation of Raf-1, A-Raf, and B-Raf by oncogenic ras and tyrosine kinases. The Journal of biological chemistry 272, 4378-4383 (1997).

178 Kolch, W. Meaningful relationships: the regulation of the Ras/Raf/MEK/ERK pathway by protein interactions. The Biochemical journal 351 Pt 2, 289-305 (2000).

179 Yan, M. \& Templeton, D. J. Identification of 2 serine residues of MEK-1 that are differentially phosphorylated during activation by raf and MEK kinase. The Journal of biological chemistry 269, 19067-19073 (1994).

180 Kyriakis, J. M. et al. Raf-1 activates MAP kinase-kinase. Nature 358, 417-421, doi:10.1038/358417a0 (1992).

181 Zheng, C. F., Ohmichi, M., Saltiel, A. R. \& Guan, K. L. Growth factor induced MEK activation is primarily mediated by an activator different from c-raf. Biochemistry 33, 5595-5599 (1994).

182 Zhang, W. \& Liu, H. T. MAPK signal pathways in the regulation of cell proliferation in mammalian cells. Cell research 12, 9-18, doi:10.1038/sj.cr.7290105 (2002).

183 Chang, F. et al. Regulation of cell cycle progression and apoptosis by the Ras/Raf/MEK/ERK pathway (Review). International journal of oncology 22, 469-480 (2003).

184 Downward, J. Ras signalling and apoptosis. Current opinion in genetics \& development 8, 49-54 (1998).

185 Dimauro, T. \& David, G. Ras-induced senescence and its physiological relevance in cancer. Current cancer drug targets 10, 869-876 (2010).

186 Sears, R., Leone, G., DeGregori, J. \& Nevins, J. R. Ras enhances Myc protein stability. Molecular cell 3, 169-179 (1999).

187 Deschenes-Simard, X. et al. Tumor suppressor activity of the ERK/MAPK pathway by promoting selective protein degradation. Genes \& development 27, 900-915, doi:10.1101/gad.203984.112 (2013).

188 Courtois-Cox, S., Jones, S. L. \& Cichowski, K. Many roads lead to oncogene-induced senescence. Oncogene 27, 2801-2809 (2008).

189 Castellano, E. \& Downward, J. RAS Interaction with PI3K: More Than Just Another Effector Pathway. Genes \& cancer 2, 261-274, doi:10.1177/1947601911408079 (2011).

190 Manning, B. D. \& Toker, A. AKT/PKB Signaling: Navigating the Network. Cell 169, 381-405, doi:10.1016/j.cell.2017.04.001 (2017).

191 Dibble, C. C. \& Cantley, L. C. Regulation of mTORC1 by PI3K signaling. Trends in cell biology 25, 545-555, doi:10.1016/j.tcb.2015.06.002 (2015).

192 Engelman, J. A. Targeting PI3K signalling in cancer: opportunities, challenges and limitations. Nature reviews. Cancer 9, 550-562, doi:10.1038/nrc2664 (2009).

193 Hemmings, B. A. \& Restuccia, D. F. PI3K-PKB/Akt pathway. Cold Spring Harbor perspectives in biology 4, a011189, doi:10.1101/cshperspect.a011189 (2012). 
194 Aksamitiene, E., Kiyatkin, A. \& Kholodenko, B. N. Cross-talk between mitogenic Ras/MAPK and survival PI3K/Akt pathways: a fine balance. Biochem Soc Trans 40, 139-146, doi:10.1042/BST20110609 (2012).

195 Kelley, G. G., Reks, S. E., Ondrako, J. M. \& Smrcka, A. V. Phospholipase C(epsilon): a novel Ras effector. Embo J 20, 743-754, doi:10.1093/emboj/20.4.743 (2001).

196 Aspenstrom, P. Integration of signalling pathways regulated by small GTPases and calcium. Biochimica et biophysica acta 1742, 51-58, doi:10.1016/j.bbamcr.2004.09.029 (2004).

197 Matsui, M. S., Chew, S. L. \& DeLeo, V. A. Protein kinase C in normal human epidermal keratinocytes during proliferation and calcium-induced differentiation. The Journal of investigative dermatology 99, 565-571 (1992).

198 Porat-Shliom, N., Kloog, Y. \& Donaldson, J. G. A unique platform for H-Ras signaling involving clathrin-independent endocytosis. Mol Biol Cell 19, 765-775, doi:10.1091/mbc.e07-08-0841 (2008).

199 Tall, G. G., Barbieri, M. A., Stahl, P. D. \& Horazdovsky, B. F. Ras-activated endocytosis is mediated by the Rab5 guanine nucleotide exchange activity of RIN1. Dev Cell 1, 73-82 (2001).

200 Leblanc, V., Tocque, B. \& Delumeau, I. Ras-GAP controls Rho-mediated cytoskeletal reorganization through its SH3 domain. Molecular and cellular biology 18, 5567-5578 (1998).

201 Hall, A. Ras-related GTPases and the cytoskeleton. Mol Biol Cell 3, 475-479, doi:10.1091/mbc.3.5.475 (1992).

202 Leon, J., Guerrero, I. \& Pellicer, A. Differential expression of the ras gene family in mice. Molecular and cellular biology 7, 1535-1540 (1987).

203 Muller, R. et al. Transcription of c-onc genes c-rasKi and c-fms during mouse development. Molecular and cellular biology 3, 1062-1069 (1983).

204 Lampson, B. L. et al. Rare codons regulate KRas oncogenesis. Current biology : CB 23, 70-75, doi:10.1016/j.cub.2012.11.031 (2013).

205 Pershing, N. L. et al. Rare codons capacitate Kras-driven de novo tumorigenesis. J Clin Invest 125, 222-233, doi:10.1172/JCI77627 (2015).

206 Jura, N., Scotto-Lavino, E., Sobczyk, A. \& Bar-Sagi, D. Differential modification of Ras proteins by ubiquitination. Molecular cell 21, 679-687, doi:10.1016/j.molcel.2006.02.011 (2006).

207 Lau, K. S. \& Haigis, K. M. Non-redundancy within the RAS oncogene family: insights into mutational disparities in cancer. Molecules and cells 28, 315-320, doi:10.1007/s10059-009-0143-7 (2009).

208 Castellano, E. \& Santos, E. Functional specificity of ras isoforms: so similar but so different. Genes \& cancer 2, 216-231, doi:10.1177/1947601911408081 (2011).

209 Buhrman, G. et al. Analysis of binding site hot spots on the surface of Ras GTPase. Journal of molecular biology 413, 773-789, doi:10.1016/j.jmb.2011.09.011 (2011).

210 Hancock, J. F. Ras proteins: different signals from different locations. Nature reviews. Molecular cell biology 4, 373-384, doi:10.1038/nrm1105 (2003).

211 Walsh, A. B. \& Bar-Sagi, D. Differential activation of the Rac pathway by Ha-Ras and K-Ras. The Journal of biological chemistry 276, 15609-15615, doi:10.1074/jbc.M010573200 (2001).

212 Yan, J., Roy, S., Apolloni, A., Lane, A. \& Hancock, J. F. Ras isoforms vary in their ability to activate Raf-1 and phosphoinositide 3-kinase. The Journal of biological chemistry 273, 24052-24056 (1998).

213 Voice, J. K., Klemke, R. L., Le, A. \& Jackson, J. H. Four human ras homologs differ in their abilities to activate Raf-1, induce transformation, and stimulate cell motility. The Journal of biological chemistry 274, 17164-17170 (1999).

214 Hamilton, M. \& Wolfman, A. Ha-ras and N-ras regulate MAPK activity by distinct mechanisms in vivo. Oncogene 16, 1417-1428, doi:10.1038/sj.onc.1201653 (1998).

215 Omerovic, J., Hammond, D. E., Clague, M. J. \& Prior, I. A. Ras isoform abundance and signalling in human cancer cell lines. Oncogene 27, 2754-2762, doi:10.1038/sj.onc.1210925 (2008). 
216 Keller, J. W. et al. Oncogenic K-RAS subverts the antiapoptotic role of N-RAS and alters modulation of the N-RAS:gelsolin complex. Oncogene 26, 3051-3059, doi:10.1038/sj.onc.1210103 (2007).

217 Khokhlatchev, A. et al. Identification of a novel Ras-regulated proapoptotic pathway. Current biology : CB 12, 253-265 (2002).

218 Maher, J., Baker, D. A., Manning, M., Dibb, N. J. \& Roberts, I. A. Evidence for cellspecific differences in transformation by N-, H- and K-ras. Oncogene 11, 1639-1647 (1995).

219 Whitwam, T. et al. Differential oncogenic potential of activated RAS isoforms in melanocytes. Oncogene 26, 4563-4570, doi:10.1038/sj.onc.1210239 (2007).

220 Haigis, K. M. et al. Differential effects of oncogenic K-Ras and N-Ras on proliferation, differentiation and tumor progression in the colon. Nature genetics 40, 600-608, doi:10.1038/ng.115 (2008).

221 Quinlan, M. P., Quatela, S. E., Philips, M. R. \& Settleman, J. Activated Kras, but not Hras or Nras, may initiate tumors of endodermal origin via stem cell expansion. Molecular and cellular biology 28, 2659-2674, doi:10.1128/MCB.01661-07 (2008).

222 Johnson, L. et al. K-ras is an essential gene in the mouse with partial functional overlap with N-ras. Genes \& development 11, 2468-2481 (1997).

223 Koera, K. et al. K-ras is essential for the development of the mouse embryo. Oncogene 15, 1151-1159, doi:10.1038/sj.onc.1201284 (1997).

224 Esteban, L. M. et al. Targeted genomic disruption of $\mathrm{H}$-ras and $\mathrm{N}$-ras, individually or in combination, reveals the dispensability of both loci for mouse growth and development. Molecular and cellular biology 21, 1444-1452, doi:10.1128/MCB.21.5.1444-1452.2001 (2001).

225 Khalaf, W. F. et al. K-Ras is essential for normal fetal liver erythropoiesis. Blood 105, 3538-3541, doi:10.1182/blood-2004-05-2021 (2005).

226 Potenza, N. et al. Replacement of K-Ras with H-Ras supports normal embryonic development despite inducing cardiovascular pathology in adult mice. EMBO Rep 6, 432-437, doi:10.1038/sj.embor.7400397 (2005).

227 Nakamura, K. et al. Partial functional overlap of the three ras genes in mouse embryonic development. Oncogene 27, 2961-2968, doi:10.1038/sj.onc.1210956 (2008).

228 Ise, $\mathrm{K}$. et al. Targeted deletion of the $\mathrm{H}$-ras gene decreases tumor formation in mouse skin carcinogenesis. Oncogene 19, 2951-2956, doi:10.1038/sj.onc.1203600 (2000).

229 Umanoff, H., Edelmann, W., Pellicer, A. \& Kucherlapati, R. The murine N-ras gene is not essential for growth and development. Proc Natl Acad Sci U S A 92, 1709-1713 (1995).

230 Perez de Castro, I. et al. Mice deficient for N-ras: impaired antiviral immune response and T-cell function. Cancer research 63, 1615-1622 (2003).

231 Bamford, S. et al. The COSMIC (Catalogue of Somatic Mutations in Cancer) database and website. Br J Cancer 91, 355-358, doi:10.1038/sj.bjc.6601894 (2004).

232 Forbes, S. A. et al. COSMIC: exploring the world's knowledge of somatic mutations in human cancer. Nucleic acids research 43, D805-811, doi:10.1093/nar/gku1075 (2015).

233 Cox, A. D., Fesik, S. W., Kimmelman, A. C., Luo, J. \& Der, C. J. Drugging the undruggable RAS: Mission possible? Nature reviews. Drug discovery 13, 828-851, doi:10.1038/nrd4389 (2014).

234 Prior, I. A., Lewis, P. D. \& Mattos, C. A comprehensive survey of Ras mutations in cancer. Cancer research 72, 2457-2467, doi:10.1158/0008-5472.CAN-11-2612 (2012).

235 Fotiadou, P. P., Takahashi, C., Rajabi, H. N. \& Ewen, M. E. Wild-type NRas and KRas perform distinct functions during transformation. Molecular and cellular biology 27, 6742-6755, doi:10.1128/MCB.00234-07 (2007).

236 Jeng, H. H., Taylor, L. J. \& Bar-Sagi, D. Sos-mediated cross-activation of wild-type Ras by oncogenic Ras is essential for tumorigenesis. Nature communications $\mathbf{3}$, 1168, doi:10.1038/ncomms2173 (2012). 
237 Grabocka, E. et al. Wild-type $\mathrm{H}$ - and N-Ras promote mutant K-Ras-driven tumorigenesis by modulating the DNA damage response. Cancer cell 25, 243-256, doi:10.1016/j.ccr.2014.01.005 (2014).

238 Young, A., Lou, D. \& McCormick, F. Oncogenic and wild-type Ras play divergent roles in the regulation of mitogen-activated protein kinase signaling. Cancer discovery 3, 112-123, doi:10.1158/2159-8290.CD-12-0231 (2013).

239 To, M. D., Rosario, R. D., Westcott, P. M., Banta, K. L. \& Balmain, A. Interactions between wild-type and mutant Ras genes in lung and skin carcinogenesis. Oncogene 32, 4028-4033, doi:10.1038/onc.2012.404 (2013).

240 Bremner, R. \& Balmain, A. Genetic changes in skin tumor progression: correlation between presence of a mutant ras gene and loss of heterozygosity on mouse chromosome 7. Cell 61, 407-417 (1990).

241 Weyandt, J. D. et al. Wild-Type Hras Suppresses the Earliest Stages of Tumorigenesis in a Genetically Engineered Mouse Model of Pancreatic Cancer. PloS one 10, e0140253, doi:10.1371/journal.pone.0140253 (2015).

242 Rauen, K. A. The RASopathies. Annual review of genomics and human genetics 14, 355-369, doi:10.1146/annurev-genom-091212-153523 (2013).

243 Fernandez-Medarde, A. \& Santos, E. Ras in cancer and developmental diseases. Genes \& cancer 2, 344-358, doi:10.1177/1947601911411084 (2011).

244 Wallace, M. R. et al. Type 1 neurofibromatosis gene: identification of a large transcript disrupted in three NF1 patients. Science 249, 181-186 (1990).

245 Viskochil, D. et al. Deletions and a translocation interrupt a cloned gene at the neurofibromatosis type 1 locus. Cell 62, 187-192 (1990).

246 Eerola, I. et al. Capillary malformation-arteriovenous malformation, a new clinical and genetic disorder caused by RASA1 mutations. American journal of human genetics 73, 1240-1249, doi:10.1086/379793 (2003).

247 Niihori, T. et al. Germline KRAS and BRAF mutations in cardio-facio-cutaneous syndrome. Nature genetics 38, 294-296, doi:10.1038/ng1749 (2006).

248 Rodriguez-Viciana, P. et al. Germline mutations in genes within the MAPK pathway cause cardio-facio-cutaneous syndrome. Science 311, 1287-1290, doi:10.1126/science.1124642 (2006).

249 Brems, H. et al. Germline loss-of-function mutations in SPRED1 cause a neurofibromatosis 1-like phenotype. Nature genetics 39, 1120-1126, doi:10.1038/ng2113 (2007).

250 Aoki, Y. et al. Germline mutations in HRAS proto-oncogene cause Costello syndrome. Nature genetics 37, 1038-1040, doi:10.1038/ng1641 (2005).

251 Cordeddu, V. et al. Mutation of SHOC2 promotes aberrant protein N-myristoylation and causes Noonan-like syndrome with loose anagen hair. Nature genetics 41, $1022-$ 1026, doi:10.1038/ng.425 (2009).

252 Martinelli, S. et al. Heterozygous germline mutations in the CBL tumor-suppressor gene cause a Noonan syndrome-like phenotype. American journal of human genetics 87, 250-257, doi:10.1016/j.ajhg.2010.06.015 (2010).

253 Tartaglia, M. et al. Mutations in PTPN11, encoding the protein tyrosine phosphatase SHP-2, cause Noonan syndrome. Nature genetics 29, 465-468, doi:10.1038/ng772 (2001).

254 Tartaglia, M. et al. Gain-of-function SOS1 mutations cause a distinctive form of Noonan syndrome. Nature genetics 39, 75-79, doi:10.1038/ng1939 (2007).

255 Razzaque, M. A. et al. Germline gain-of-function mutations in RAF1 cause Noonan syndrome. Nature genetics 39, 1013-1017, doi:10.1038/ng2078 (2007).

256 Schubbert, S. et al. Biochemical and functional characterization of germ line KRAS mutations. Molecular and cellular biology 27, 7765-7770, doi:10.1128/MCB.00965-07 (2007).

257 Cirstea, I. C. et al. A restricted spectrum of NRAS mutations causes Noonan syndrome. Nature genetics 42, 27-29, doi:10.1038/ng.497 (2010).

258 Pandit, B. et al. Gain-of-function RAF1 mutations cause Noonan and LEOPARD syndromes with hypertrophic cardiomyopathy. Nature genetics 39, 1007-1012, doi:10.1038/ng2073 (2007). 
259 Kratz, C. P., Rapisuwon, S., Reed, H., Hasle, H. \& Rosenberg, P. S. Cancer in Noonan, Costello, cardiofaciocutaneous and LEOPARD syndromes. American journal of medical genetics. Part C, Seminars in medical genetics 157C, 83-89, doi:10.1002/ajmg.c.30300 (2011).

260 Salem, B., Hofherr, S., Turner, J., Doros, L. \& Smpokou, P. Childhood Rhabdomyosarcoma in Association With a RASopathy Clinical Phenotype and Mosaic Germline SOS1 Duplication. Journal of pediatric hematology/oncology 38, e278-e282, doi:10.1097/MPH.0000000000000566 (2016).

261 Sanchez-Montenegro, C. et al. Costello Syndrome and Umbilical Ligament Rhabdomyosarcoma in Two Pediatric Patients: Case Reports and Review of the Literature. Case reports in genetics 2017, 1587610, doi:10.1155/2017/1587610 (2017).

262 Chen, Y. et al. Mutations of the PTPN11 and RAS genes in rhabdomyosarcoma and pediatric hematological malignancies. Genes, chromosomes \& cancer 45, 583-591, doi:10.1002/gcc.20322 (2006).

263 Bisogno, G., Murgia, A., Mammi, I., Strafella, M. S. \& Carli, M. Rhabdomyosarcoma in a patient with cardio-facio-cutaneous syndrome. Journal of pediatric hematology/oncology 21, 424-427 (1999).

264 Innes, A. M. \& Chudley, A. E. Rhabdomyosarcoma in a patient with Cardio-FacioCutaneous syndrome. Journal of pediatric hematology/oncology 22, 546-547 (2000).

265 Heney, D., Lockwood, L., Allibone, E. B. \& Bailey, C. C. Nasopharyngeal rhabdomyosarcoma and multiple lentigines syndrome: a case report. Med Pediatr Oncol 20, 227-228 (1992).

266 Stratton, M. R., Fisher, C., Gusterson, B. A. \& Cooper, C. S. Detection of point mutations in N-ras and K-ras genes of human embryonal rhabdomyosarcomas using oligonucleotide probes and the polymerase chain reaction. Cancer research 49, 6324-6327 (1989).

267 Martinelli, S. et al. RAS signaling dysregulation in human embryonal Rhabdomyosarcoma. Genes, chromosomes \& cancer 48, 975-982, doi:10.1002/gcc.20702 (2009).

268 Seki, M. et al. Integrated genetic and epigenetic analysis defines novel molecular subgroups in rhabdomyosarcoma. Nature communications 6, 7557, doi:10.1038/ncomms8557 (2015).

269 Dolgikh, N., Hugle, M., Vogler, M. \& Fulda, S. NRAS-Mutated Rhabdomyosarcoma Cells Are Vulnerable to Mitochondrial Apoptosis Induced by Coinhibition of MEK and PI3Kalpha. Cancer research, doi:10.1158/0008-5472.CAN-17-1737 (2018).

270 Graab, U., Hahn, H. \& Fulda, S. Identification of a novel synthetic lethality of combined inhibition of hedgehog and PI3K signaling in rhabdomyosarcoma. Oncotarget 6, 8722-8735 (2015).

271 Guenther, M. K., Graab, U. \& Fulda, S. Synthetic lethal interaction between PI3K/Akt/mTOR and Ras/MEK/ERK pathway inhibition in rhabdomyosarcoma. Cancer letters 337, 200-209, doi:10.1016/j.canlet.2013.05.010 (2013).

272 Renshaw, J. et al. Dual blockade of the PI3K/AKT/mTOR (AZD8055) and RAS/MEK/ERK (AZD6244) pathways synergistically inhibits rhabdomyosarcoma cell growth in vitro and in vivo. Clinical cancer research : an official journal of the American Association for Cancer Research 19, 5940-5951, doi:10.1158/10780432.CCR-13-0850 (2013).

273 Hettmer, S. et al. Sarcomas induced in discrete subsets of prospectively isolated skeletal muscle cells. Proc Natl Acad Sci U S A 108, 20002-20007, doi:10.1073/pnas.1111733108 (2011).

274 Langenau, D. M. et al. Effects of RAS on the genesis of embryonal rhabdomyosarcoma. Genes \& development 21, 1382-1395, doi:10.1101/gad.1545007 (2007).

275 Rubin, B. P. et al. Evidence for an Unanticipated Relationship between Undifferentiated Pleomorphic Sarcoma and Embryonal Rhabdomyosarcoma. Cancer Cell 19, 177-191 (2011). 
276 Zhu, B. \& Davie, J. K. New insights into signalling-pathway alterations in rhabdomyosarcoma. Br J Cancer 112, 227-231, doi:10.1038/bjc.2014.471 (2015).

277 Kashi, V. P., Hatley, M. E. \& Galindo, R. L. Probing for a deeper understanding of rhabdomyosarcoma: insights from complementary model systems. Nature reviews. Cancer 15, 426-439, doi:10.1038/nrc3961 (2015).

278 Linardic, C. M. \& Counter, C. M. Genetic modeling of Ras-induced human rhabdomyosarcoma. Methods Enzymol 438, 419-427, doi:10.1016/S00766879(07)38028-2 (2008).

279 Jacks, T. et al. Tumor spectrum analysis in p53-mutant mice. Current biology : CB 4, 1-7. (1994).

280 Harvey, M. et al. Spontaneous and carcinogen-induced tumorigenesis in p53deficient mice. Nature genetics 5, 225-229, doi:10.1038/ng1193-225 (1993).

281 Doyle, B. et al. p53 mutation and loss have different effects on tumourigenesis in a novel mouse model of pleomorphic rhabdomyosarcoma. The Journal of pathology 222, 129-137, doi:10.1002/path.2748 (2010).

282 Tsumura, H., Yoshida, T., Saito, H., Imanaka-Yoshida, K. \& Suzuki, N. Cooperation of oncogenic K-ras and p53 deficiency in pleomorphic rhabdomyosarcoma development in adult mice. Oncogene 25, 7673-7679, doi:10.1038/sj.onc.1209749 (2006).

283 Blum, J. M. et al. Distinct and overlapping sarcoma subtypes initiated from muscle stem and progenitor cells. Cell reports 5, 933-940, doi:10.1016/j.celrep.2013.10.020 (2013).

284 Brechbiel, J., Miller-Moslin, K. \& Adjei, A. A. Crosstalk between hedgehog and other signaling pathways as a basis for combination therapies in cancer. Cancer treatment reviews 40, 750-759, doi:10.1016/j.ctrv.2014.02.003 (2014).

285 Chang, H., Li, Q., Moraes, R. C., Lewis, M. T. \& Hamel, P. A. Activation of Erk by sonic hedgehog independent of canonical hedgehog signalling. Int $J$ Biochem Cell Biol 42, 1462-1471, doi:10.1016/j.biocel.2010.04.016 (2010).

286 Riobo, N. A., Haines, G. M. \& Emerson, C. P., Jr. Protein kinase C-delta and mitogenactivated protein/extracellular signal-regulated kinase-1 control GLI activation in hedgehog signaling. Cancer research 66, 839-845, doi:10.1158/0008-5472.CAN-052539 (2006).

287 Whisenant, T. C. et al. Computational prediction and experimental verification of new MAP kinase docking sites and substrates including Gli transcription factors. PLoS computational biology 6, doi:10.1371/journal.pcbi.1000908 (2010).

288 Bardwell, L., Bardwell, J.A., Wu, B., Waterman, M. in Experimental Biology Abstracts 2016 Vol. 30 (The FASEB Journal, 2016).

289 Kasper, M. et al. Selective modulation of Hedgehog/GLI target gene expression by epidermal growth factor signaling in human keratinocytes. Molecular and cellular biology 26, 6283-6298, doi:10.1128/MCB.02317-05 (2006).

290 Schnidar, H. et al. Epidermal growth factor receptor signaling synergizes with Hedgehog/GLI in oncogenic transformation via activation of the MEK/ERK/JUN pathway. Cancer research 69, 1284-1292, doi:10.1158/0008-5472.CAN-08-2331 (2009).

291 Mangelberger, D., Kern, D., Loipetzberger, A., Eberl, M. \& Aberger, F. Cooperative Hedgehog-EGFR signaling. Front Biosci (Landmark Ed) 17, 90-99 (2012).

292 Eberl, M. et al. Hedgehog-EGFR cooperation response genes determine the oncogenic phenotype of basal cell carcinoma and tumour-initiating pancreatic cancer cells. EMBO molecular medicine 4, 218-233, doi:10.1002/emmm.201100201 (2012).

293 Chabu, C., Li, D. M. \& Xu, T. EGFR/ARF6 regulation of Hh signalling stimulates oncogenic Ras tumour overgrowth. Nature communications 8, 14688, doi:10.1038/ncomms14688 (2017).

294 Seto, M. et al. Regulation of the hedgehog signaling by the mitogen-activated protein kinase cascade in gastric cancer. Molecular carcinogenesis 48, 703-712, doi:10.1002/mc.20516 (2009). 
295 Mills, L. D. et al. Loss of the transcription factor GLI1 identifies a signaling network in the tumor microenvironment mediating KRAS oncogene-induced transformation. The Journal of biological chemistry 288, 11786-11794, doi:10.1074/jbc.M112.438846 (2013).

296 Rajurkar, M. et al. The activity of Gli transcription factors is essential for Kras-induced pancreatic tumorigenesis. Proc Natl Acad Sci U S A 109, E1038-1047, doi:10.1073/pnas.1114168109 (2012).

297 Ji, Z., Mei, F. C., Xie, J. \& Cheng, X. Oncogenic KRAS activates hedgehog signaling pathway in pancreatic cancer cells. The Journal of biological chemistry 282, 1404814055, doi:10.1074/jbc.M611089200 (2007).

298 Parascandolo, A. et al. A dual mechanism of activation of the Sonic Hedgehog pathway in anaplastic thyroid cancer: crosstalk with RAS-BRAF-MEK pathway and ligand secretion by tumor stroma. Oncotarget 9, 4496-4510, doi:10.18632/oncotarget.23388 (2018).

299 Cuvelier, N. The interaction between Hedgehog/Patched and Ras signaling in Rhabdomyosarcoma Georg-August University Goettingen (2016).

300 Beer, C., Buhr, P., Hahn, H., Laubner, D. \& Wirth, M. Gene expression analysis of murine cells producing amphotropic mouse leukaemia virus at a cultivation temperature of 32 and 37 degrees C. The Journal of general virology 84, 1677-1686, doi:10.1099/vir.0.18871-0 (2003).

301 Fritsch, A. Analysen zu Interaktionen zwischen dem Vitamin-D-Rezeptor Signalweg und der Hedgehog Signalkaskade, Georg-August-Universität, (2014).

302 Uhmann, A. et al. The Hedgehog receptor Patched controls lymphoid lineage commitment. Blood 110, 1814-1823, doi:10.1182/blood-2007-02-075648 (2007).

303 Chen, X. et al. Endogenous expression of Hras(G12V) induces developmental defects and neoplasms with copy number imbalances of the oncogene. Proc Natl Acad Sci U S A 106, 7979-7984, doi:10.1073/pnas.0900343106 (2009).

304 Tuveson, D. A. et al. Endogenous oncogenic K-ras(G12D) stimulates proliferation and widespread neoplastic and developmental defects. Cancer cell 5, 375-387 (2004).

305 Biressi, S. et al. Myf5 expression during fetal myogenesis defines the developmental progenitors of adult satellite cells. Developmental biology 379, 195-207, doi:10.1016/j.ydbio.2013.04.021 (2013).

306 Soriano, P. Generalized lacZ expression with the ROSA26 Cre reporter strain. Nature genetics 21, 70-71, doi:10.1038/5007 (1999).

307 Uhmann, A. et al. Antitumoral effects of calcitriol in basal cell carcinomas involve inhibition of hedgehog signaling and induction of vitamin $D$ receptor signaling and differentiation. Molecular cancer therapeutics 10, 2179-2188, doi:10.1158/15357163.MCT-11-0422 (2011).

308 Jacobsen, P. F., Jenkyn, D. J. \& Papadimitriou, J. M. Establishment of a human medulloblastoma cell line and its heterotransplantation into nude mice. Journal of neuropathology and experimental neurology 44, 472-485 (1985).

309 Graham, F. L., Smiley, J., Russell, W. C. \& Nairn, R. Characteristics of a human cell line transformed by DNA from human adenovirus type 5 . The Journal of general virology 36, 59-74, doi:10.1099/0022-1317-36-1-59 (1977).

310 Chen, J. K., Taipale, J., Young, K. E., Maiti, T. \& Beachy, P. A. Small molecule modulation of Smoothened activity. Proc Natl Acad Sci U S A 99, 14071-14076, doi:10.1073/pnas.182542899 (2002).

311 Jainchill, J. L., Aaronson, S. A. \& Todaro, G. J. Murine sarcoma and leukemia viruses: assay using clonal lines of contact-inhibited mouse cells. Journal of virology 4, 549-553 (1969).

312 McAllister, R. M., Melnyk, J., Finkelstein, J. Z., Adams, E. C., Jr. \& Gardner, M. B. Cultivation in vitro of cells derived from a human rhabdomyosarcoma. Cancer 24, 520-526 (1969).

313 Roberts, W. M., Douglass, E. C., Peiper, S. C., Houghton, P. J. \& Look, A. T. Amplification of the gli gene in childhood sarcomas. Cancer Res 49, 5407-5413 (1989). 
314 Scholl, F. A., Betts, D. R., Niggli, F. K. \& Schafer, B. W. Molecular features of a human rhabdomyosarcoma cell line with spontaneous metastatic progression. $\mathrm{Br} J$ Cancer 82, 1239-1245, doi:10.1054/bjoc.1999.1069 (2000).

315 Missiaglia, E. et al. Genomic imbalances in rhabdomyosarcoma cell lines affect expression of genes frequently altered in primary tumors: an approach to identify candidate genes involved in tumor development. Genes, chromosomes \& cancer 48 , 455-467, doi:10.1002/gcc.20655 (2009).

316 Zibat, A. et al. Time-point and dosage of gene inactivation determine the tumor spectrum in conditional Ptch knockouts. Carcinogenesis 30, 918-926, doi:10.1093/carcin/bgp068 (2009).

317 Jackson, E. L. et al. Analysis of lung tumor initiation and progression using conditional expression of oncogenic K-ras. Genes \& development 15, 3243-3248, doi:10.1101/gad.943001 (2001).

318 Cordier, A. C. \& Haumont, S. M. Development of thymus, parathyroids, and ultimobranchial bodies in NMRI and nude mice. The American journal of anatomy 157, 227263, doi:10.1002/aja.1001570303 (1980).

319 Pelleitier, M. \& Montplaisir, S. The nude mouse: a model of deficient T-cell function. Methods and achievements in experimental pathology 7, 149-166 (1975).

320 Schindelin, J. et al. Fiji: an open-source platform for biological-image analysis. Nature methods 9, 676-682, doi:10.1038/nmeth.2019 (2012).

Abcam. Subcellular fractionation https://www.abcam.com/protocols/subcellular-fractionation-protocol

322 Yu, Z., Huang, Z. and Lung, M. L. Subcellular Fractionation of Cultured Human Cell Lines. Bio-protocol 3, e754 (2013).

323 Nitzki, F. et al. Uncommitted precursor cells might contribute to increased incidence of embryonal rhabdomyosarcoma in heterozygous Patched1-mutant mice. Oncogene 30, 4428-4436, doi:10.1038/onc.2011.157 (2011).

324 Hahn, H. et al. Genetic mapping of a Ptch1-associated rhabdomyosarcoma susceptibility locus on mouse chromosome 2. Genomics 84, 853-858, doi:10.1016/j.ygeno.2004.07.002 (2004).

325 Nitzki, F., Kruger, A., Reifenberg, K., Wojnowski, L. \& Hahn, H. Identification of a genetic contamination in a commercial mouse strain using two panels of polymorphic markers. Laboratory animals 41, 218-228, doi:10.1258/002367707780378104 (2007).

326 Sokolowski, E., Turina, C. B., Kikuchi, K., Langenau, D. M. \& Keller, C. Proof-ofconcept rare cancers in drug development: the case for rhabdomyosarcoma. Oncogene 33, 1877-1889, doi:10.1038/onc.2013.129 (2014).

327 Gotschel, F. et al. Synergism between Hedgehog-GLI and EGFR signaling in Hedgehog-responsive human medulloblastoma cells induces downregulation of canonical Hedgehog-target genes and stabilized expression of GLI1. PloS one 8, e65403, doi:10.1371/journal.pone.0065403 (2013).

328 Lemma, S., Avnet, S., Salerno, M., Chano, T. \& Baldini, N. Identification and Validation of Housekeeping Genes for Gene Expression Analysis of Cancer Stem Cells. PloS one 11, e0149481, doi:10.1371/journal.pone.0149481 (2016).

329 Park, S. et al. PI-103, a dual inhibitor of Class IA phosphatidylinositide 3-kinase and mTOR, has antileukemic activity in AML. Leukemia 22, 1698-1706, doi:10.1038/leu.2008.144 (2008).

330 Favata, M. F. et al. Identification of a novel inhibitor of mitogen-activated protein kinase. The Journal of biological chemistry 273, 18623-18632 (1998).

331 Morris, E. J. et al. Discovery of a novel ERK inhibitor with activity in models of acquired resistance to BRAF and MEK inhibitors. Cancer discovery 3, 742-750, doi:10.1158/2159-8290.CD-13-0070 (2013).

332 Williams, J. A. et al. Identification of a small molecule inhibitor of the hedgehog signaling pathway: Effects on basal cell carcinoma-like lesions. Proc Natl Acad Sci U $S A$ (2003).

333 Zhou, J. et al. Cucurbitacin B and SCH772984 exhibit synergistic anti-pancreatic cancer activities by suppressing EGFR, PI3K/Akt/mTOR, STAT3 and ERK signaling. Oncotarget 8, 103167-103181, doi:10.18632/oncotarget.21704 (2017). 
334 Normanno, N. et al. The MEK/MAPK pathway is involved in the resistance of breast cancer cells to the EGFR tyrosine kinase inhibitor gefitinib. Journal of cellular physiology 207, 420-427, doi:10.1002/jcp.20588 (2006).

335 Turke, A. B. et al. MEK inhibition leads to PI3K/AKT activation by relieving a negative feedback on ERBB receptors. Cancer research 72, 3228-3237, doi:10.1158/00085472.CAN-11-3747 (2012).

336 Carracedo, A. et al. Inhibition of mTORC1 leads to MAPK pathway activation through a PI3K-dependent feedback loop in human cancer. J Clin Invest 118, 3065-3074, doi:10.1172/JCl34739 (2008).

337 Ridzewski, R. et al. Hedgehog Inhibitors in Rhabdomyosarcoma: A Comparison of Four Compounds and Responsiveness of Four Cell Lines. Frontiers in oncology 5, 130, doi:10.3389/fonc.2015.00130 (2015).

338 Feil, S., Valtcheva, N. \& Feil, R. Inducible Cre mice. Methods Mol Biol 530, 343-363, doi:10.1007/978-1-59745-471-1_18 (2009).

339 Hayashi, S. \& McMahon, A. $\bar{P}$. Efficient recombination in diverse tissues by a tamoxifen-inducible form of Cre: a tool for temporally regulated gene activation/inactivation in the mouse. Developmental biology 244, 305-318, doi:10.1006/dbio.2002.0597 (2002).

340 Vooijs, M., Jonkers, J. \& Berns, A. A highly efficient ligand-regulated Cre recombinase mouse line shows that LoxP recombination is position dependent. EMBO Rep 2, 292-297, doi:10.1093/embo-reports/kve064 (2001).

341 Chal, J. \& Pourquie, O. Making muscle: skeletal myogenesis in vivo and in vitro. Development 144, 2104-2122, doi:10.1242/dev.151035 (2017).

342 Gartel, A. L. \& Tyner, A. L. The role of the cyclin-dependent kinase inhibitor p21 in apoptosis. Molecular cancer therapeutics 1, 639-649 (2002).

343 Lauth, M. RAS and Hedgehog--partners in crime. Front Biosci (Landmark Ed) 16, 2259-2270 (2011).

344 Cytoskeleton. Ras Pull-down Activation Assay Biochem Kit (bead pull-down format), https://www.cytoskeleton.com/bk008

345 Barretina, J. et al. The Cancer Cell Line Encyclopedia enables predictive modelling of anticancer drug sensitivity. Nature 483, 603-607, doi:10.1038/nature11003 (2012).

346 Malinin, N. L., Boldin, M. P., Kovalenko, A. V. \& Wallach, D. MAP3K-related kinase involved in NF-kappaB induction by TNF, CD95 and IL-1. Nature 385, 540-544, doi:10.1038/385540a0 (1997).

347 Xia, Y., Wu, Z., Su, B., Murray, B. \& Karin, M. JNKK1 organizes a MAP kinase module through specific and sequential interactions with upstream and downstream components mediated by its amino-terminal extension. Genes \& development 12, 3369-3381 (1998).

348 Ye, B., Yu, W. P., Thomas, G. M. \& Huganir, R. L. GRASP-1 is a neuronal scaffold protein for the JNK signaling pathway. FEBS letters 581, 4403-4410, doi:10.1016/j.febslet.2007.08.008 (2007).

349 Hinson, A. R. et al. Human rhabdomyosarcoma cell lines for rhabdomyosarcoma research: utility and pitfalls. Frontiers in oncology 3, 183, doi:10.3389/fonc.2013.00183 (2013).

350 Beylkin, D. H., Allen, D. L. \& Leinwand, L. A. MyoD, Myf5, and the calcineurin pathway activate the developmental myosin heavy chain genes. Developmental biology 294, 541-553, doi:10.1016/j.ydbio.2006.02.049 (2006).

351 Kouraklis, G., Triche, T. J., Wesley, R. \& Tsokos, M. Myc oncogene expression and nude mouse tumorigenicity and metastasis formation are higher in alveolar than embryonal rhabdomyosarcoma cell lines. Pediatric research 45, 552-558, doi:10.1203/00006450-199904010-00015 (1999).

352 Khan, J. et al. Gene expression profiling of alveolar rhabdomyosarcoma with cDNA microarrays. Cancer Res 58, 5009-5013. (1998).

353 Chen, Y. et al. Mutation and expression analyses of the MET and CDKN2A genes in rhabdomyosarcoma with emphasis on MET overexpression. Genes, chromosomes \& cancer 46, 348-358, doi:10.1002/gcc.20416 (2007). 
354 Lopes-Ramos, C. M. et al. Regulatory network changes between cell lines and their tissues of origin. BMC genomics 18, 723, doi:10.1186/s12864-017-4111-x (2017).

355 Tukachinsky, H., Kuzmickas, R. P., Jao, C. Y., Liu, J. \& Salic, A. Dispatched and scube mediate the efficient secretion of the cholesterol-modified hedgehog ligand. Cell reports 2, 308-320, doi:10.1016/j.celrep.2012.07.010 (2012).

356 Wheway, G., Nazlamova, L. \& Hancock, J. T. Signaling through the Primary Cilium. Frontiers in cell and developmental biology 6, 8, doi:10.3389/fcell.2018.00008 (2018).

357 Fang, X. et al. Phosphorylation and inactivation of glycogen synthase kinase 3 by protein kinase A. Proc Natl Acad Sci $U S S A$ 97, 11960-11965, doi:10.1073/pnas.220413597 (2000).

358 Yordy, J. S. \& Muise-Helmericks, R. C. Signal transduction and the Ets family of transcription factors. Oncogene 19, 6503-6513, doi:10.1038/sj.onc.1204036 (2000).

359 Nakashima, $\mathrm{H}$. et al. Nuclear factor-kappaB contributes to hedgehog signaling pathway activation through sonic hedgehog induction in pancreatic cancer. Cancer research 66, 7041-7049, doi:10.1158/0008-5472.CAN-05-4588 (2006).

360 Gu, D., Schlotman, K. E. \& Xie, J. Deciphering the role of hedgehog signaling in pancreatic cancer. Journal of biomedical research 30, 353-360, doi:10.7555/JBR.30.20150107 (2016).

361 ten Haaf, $\mathrm{A}$. et al. Paradox of sonic hedgehog (SHH) transcriptional regulation: Alternative transcription initiation overrides the effect of downstream promoter DNA methylation. Epigenetics : official journal of the DNA Methylation Society 6, 465-477 (2011).

362 Cui, W. et al. Expression and regulation mechanisms of Sonic Hedgehog in breast cancer. Cancer science 101, 927-933, doi:10.1111/j.1349-7006.2010.01495.x (2010).

363 Kim, B. Y., Gaynor, R. B., Song, K., Dritschilo, A. \& Jung, M. Constitutive activation of NF-kappaB in Ki-ras-transformed prostate epithelial cells. Oncogene 21, 4490-4497, doi:10.1038/sj.onc.1205547 (2002).

364 Mayo, M. W., Norris, J. L. \& Baldwin, A. S. Ras regulation of NF-kappa B and apoptosis. Methods Enzymol 333, 73-87 (2001).

365 Dhawan, P. \& Richmond, A. A novel NF-kappa B-inducing kinase-MAPK signaling pathway up-regulates NF-kappa B activity in melanoma cells. The Journal of biological chemistry 277, 7920-7928, doi:10.1074/jbc.M112210200 (2002).

366 Nakano, H. et al. Differential regulation of IkappaB kinase alpha and beta by two upstream kinases, NF-kappaB-inducing kinase and mitogen-activated protein kinase/ERK kinase kinase-1. Proc Natl Acad Sci U S A 95, 3537-3542 (1998).

367 Zhao, Q. \& Lee, F. S. Mitogen-activated protein kinase/ERK kinase kinases 2 and 3 activate nuclear factor-kappaB through IkappaB kinase-alpha and IkappaB kinasebeta. The Journal of biological chemistry 274, 8355-8358 (1999).

368 Carter, A. B. \& Hunninghake, G. W. A constitutive active MEK --> ERK pathway negatively regulates NF-kappa B-dependent gene expression by modulating TATAbinding protein phosphorylation. The Journal of biological chemistry 275, 2785827864, doi:10.1074/jbc.M003599200 (2000).

369 Yauch, R. L. et al. A paracrine requirement for hedgehog signalling in cancer. Nature (2008).

370 Persons, D. L., Yazlovitskaya, E. M. \& Pelling, J. C. Effect of extracellular signalregulated kinase on p53 accumulation in response to cisplatin. The Journal of biological chemistry 275, 35778-35785, doi:10.1074/jbc.M004267200 (2000).

371 Fung, M. K. et al. Role of MEK/ERK pathway in the MAD2-mediated cisplatin sensitivity in testicular germ cell tumour cells. $\mathrm{Br} J$ Cancer 95, 475-484, doi:10.1038/sj.bjc.6603284 (2006).

372 Cox, A. D. \& Der, C. J. The dark side of Ras: regulation of apoptosis. Oncogene 22, 8999-9006, doi:10.1038/sj.onc.1207111 (2003).

373 Banfalvi, G. Overview of cell synchronization. Methods Mol Biol 761, 1-23, doi:10.1007/978-1-61779-182-6_1 (2011).

374 Cecchini, M. J., Amiri, M. \& Dick, F. A. Analysis of cell cycle position in mammalian cells. Journal of visualized experiments : JoVE, doi:10.3791/3491 (2012). 
375 Hasenpusch-Theil, K. et al. Gorlin syndrome: identification of 4 novel germ-line mutations of the human patched (PTCH) gene. Human mutation 11, 480 (1998).

376 Francetic, T. \& Li, Q. Skeletal myogenesis and Myf5 activation. Transcription 2, 109114, doi:10.4161/trns.2.3.15829 (2011).

377 Ott, M. O., Bober, E., Lyons, G., Arnold, H. \& Buckingham, M. Early expression of the myogenic regulatory gene, myf-5, in precursor cells of skeletal muscle in the mouse embryo. Development 111, 1097-1107 (1991).

378 Summerbell, D. et al. The expression of Myf5 in the developing mouse embryo is controlled by discrete and dispersed enhancers specific for particular populations of skeletal muscle precursors. Development 127, 3745-3757 (2000).

379 Liu, J. et al. Non-parallel recombination limits Cre-LoxP-based reporters as precise indicators of conditional genetic manipulation. Genesis 51, 436-442, doi:10.1002/dvg.22384 (2013).

380 Rangarajan, A. \& Weinberg, R. A. Comparative biology of mouse versus human cells: modelling human cancer in mice. Nature Reviews Cancer 3, 952, doi:10.1038/nrc1235 (2003).

381 Robanus-Maandag, E. et al. p107 is a suppressor of retinoblastoma development in pRb-deficient mice. Genes \& development 12, 1599-1609 (1998).

382 Giovannini, M. et al. Conditional biallelic Nf2 mutation in the mouse promotes manifestations of human neurofibromatosis type 2. Genes \& development 14, 16171630 (2000).

383 Kumar, S., Perlman, E., Harris, C. A., Raffeld, M. \& Tsokos, M. Myogenin is a specific marker for rhabdomyosarcoma: an immunohistochemical study in paraffin-embedded tissues. Mod Pathol 13, 988-993 (2000).

384 Muthuchamy, M., Pajak, L., Howles, P., Doetschman, T. \& Wieczorek, D. F. Developmental analysis of tropomyosin gene expression in embryonic stem cells and mouse embryos. Molecular and cellular biology 13, 3311-3323 (1993).

385 Yohe, M. E. et al. MEK inhibition induces MYOG and remodels super-enhancers in RAS-driven rhabdomyosarcoma. Science translational medicine 10, doi:10.1126/scitransImed.aan4470 (2018).

386 Nitzki, F. et al. Hedgehog/Patched-associated rhabdomyosarcoma formation from delta1-expressing mesodermal cells. Oncogene, doi:10.1038/onc.2015.346 (2015).

387 Castillo-Martin, M., Domingo-Domenech, J., Karni-Schmidt, O., Matos, T. \& CordonCardo, C. Molecular pathways of urothelial development and bladder tumorigenesis. Urologic oncology 28, 401-408, doi:10.1016/j.urolonc.2009.04.019 (2010).

388 Nash, G. M. et al. KRAS mutation and microsatellite instability: two genetic markers of early tumor development that influence the prognosis of colorectal cancer. Annals of surgical oncology 17, 416-424, doi:10.1245/s10434-009-0713-0 (2010).

389 Omholt, K. et al. Screening of $\mathrm{N}$-ras codon 61 mutations in paired primary and metastatic cutaneous melanomas: mutations occur early and persist throughout tumor progression. Clinical cancer research : an official journal of the American Association for Cancer Research 8, 3468-3474 (2002).

390 Denayer, E. et al. NRAS Mutations in Noonan Syndrome. Molecular syndromology 3 , 34-38, doi:10.1159/000338467 (2012).

391 Ugurel, S. et al. B-RAF and N-RAS mutations are preserved during short time in vitro propagation and differentially impact prognosis. PloS one 2, e236-e236, doi:10.1371/journal.pone.0000236 (2007).

392 Kuhner, M. K., Kostadinov, R. \& Reid, B. J. Limitations of the Driver/Passenger Model in Cancer Prevention. Cancer prevention research (Philadelphia, Pa.) 9, 335-338, doi:10.1158/1940-6207.capr-15-0343 (2016).

393 Chen, L. et al. Clonality and evolutionary history of rhabdomyosarcoma. PLoS genetics 11, e1005075, doi:10.1371/journal.pgen.1005075 (2015).

394 Makishima, H. \& Maciejewski, J. P. Pathogenesis and consequences of uniparental disomy in cancer. Clinical cancer research : an official journal of the American Association for Cancer Research 17, 3913-3923, doi:10.1158/1078-0432.ccr-10-2900 (2011). 
395 Krskova, L. et al. Rhabdomyosarcoma: molecular analysis of Igf2, MyoD1 and Myogenin expression. Neoplasma 58, 415-423 (2011).

396 Makawita, S. et al. Expression of insulin-like growth factor pathway proteins in rhabdomyosarcoma: IGF-2 expression is associated with translocation-negative tumors. Pediatric and developmental pathology : the official journal of the Society for Pediatric Pathology and the Paediatric Pathology Society 12, 127-135 (2009).

397 Plaks, V., Kong, N. \& Werb, Z. The cancer stem cell niche: how essential is the niche in regulating stemness of tumor cells? Cell stem cell 16, 225-238, doi:10.1016/j.stem.2015.02.015 (2015).

398 Kondo, T. Stem cell-like cancer cells in cancer cell lines. Cancer biomarkers : section A of Disease markers 3, 245-250 (2007).

399 Veselska, R., Skoda, J. \& Neradil, J. Detection of Cancer Stem Cell Markers in Sarcomas. Klinicka onkologie Journal 25, 2s16-12s20 (2012).

400 Dela Cruz, F. S. Cancer stem cells in pediatric sarcomas. Frontiers in oncology 3, 168, doi:10.3389/fonc.2013.00168 (2013).

401 Rich, J. N. Cancer stem cells: understanding tumor hierarchy and heterogeneity. Medicine 95, S2-S7, doi:10.1097/md.0000000000004764 (2016).

402 Baccelli, I. \& Trumpp, A. The evolving concept of cancer and metastasis stem cells. The Journal of cell biology 198, 281-293, doi:10.1083/jcb.201202014 (2012).

403 Kreso, A. \& Dick, John E. Evolution of the Cancer Stem Cell Model. Cell stem cell 14, 275-291, doi: 10.1016/j.stem.2014.02.006 (2014).

404 Merchant, A. A. \& Matsui, W. Targeting Hedgehog--a cancer stem cell pathway. Clinical cancer research : an official journal of the American Association for Cancer Research 16, 3130-3140, doi:10.1158/1078-0432.ccr-09-2846 (2010).

405 Cochrane, C. R., Szczepny, A., Watkins, D. N. \& Cain, J. E. Hedgehog Signaling in the Maintenance of Cancer Stem Cells. Cancers 7, 1554-1585, doi:10.3390/cancers7030851 (2015).

406 Takebe, N. et al. Targeting Notch, Hedgehog, and Wnt pathways in cancer stem cells: clinical update. Nature Reviews Clinical Oncology 12, 445, doi:10.1038/nrclinonc.2015.61 (2015).

407 Pressey, J. G. et al. CD133 marks a myogenically primitive subpopulation in rhabdomyosarcoma cell lines that are relatively chemoresistant but sensitive to mutant HSV. Pediatric blood \& cancer 60, 45-52, doi:10.1002/pbc.24117 (2013).

408 Walter, D. et al. CD133 positive embryonal rhabdomyosarcoma stem-like cell population is enriched in rhabdospheres. PloS one 6, e19506, doi:10.1371/journal.pone.0019506 (2011).

409 Nakahata, K. et al. Aldehyde Dehydrogenase 1 (ALDH1) Is a Potential Marker for Cancer Stem Cells in Embryonal Rhabdomyosarcoma. PloS one 10, e0125454, doi:10.1371/journal.pone.0125454 (2015). 


\section{Acknowledgements}

It has been a long way to finish this thesis and it would not have been possible without the continuous support of all the people, which have been involved during this process.

First, I would like to express my deep gratitude to Prof. Dr. Heidi Hahn, my research supervisor, for her patient guidance, useful critiques and encouragement throughout this work. Thank you for your support, continuous mentoring, constructive discussions and proofreading of this work. Especially I would like to thank you for the confidence you have placed in me and for giving me the opportunity to work on exciting research projects.

In addition, I would like to express my great appreciation to Prof. Dr. Matthias Dobbelstein and Prof. Dr. Dieter Kube for their valuable and constructive suggestions during our thesis committee meetings. Thank you for your advice and ideas.

My grateful thanks go to Dr. Christian Dullin for his help with the $\mu \mathrm{CT}$ measurements. Additionally, I would like to thank Dr. Verena Reupke, Christina Malowsky, Sarah Garbode and Jonas Albers for enabling me to perform all the $\mu \mathrm{CT}$ measurements on time. Thanks for your competent work and the pleasant atmosphere during several measurements. In addition, my sincere thanks go to Prof. Dr. Hans-Ulrich Schildhaus for reviewing and evaluating numerous histological slides. Thank you for your interpretation and helpful explanations. Special thanks go to Dr. Kai Dittmann, who supported me with acquisition and interpretation of flow cytometry data. Thank you for your help and the nice atmosphere. Furthermore, I would like to thank Dr. Albert Rosenberger for statistical advice.

My special thanks are extended to Prof. Dr. Fritz Aberger, Dominik Elmer and Christina Sternberg. Thank you for the initial Western Blot analyses of my samples, the helpful assistance in the establishment of the GLI Western Blots, the stable transduction of Daoys and the opportunity to visit Salzburg and learn your method at first hand. In addition, I would like to acknowledge Prof. Dr. James A. Fagin for providing the Hras ${ }^{\text {tm } 1 \text { Jaf }}$ mice and thereby supporting this work. Furthermore, I would like to thank Prof. Dr. Thomas A. Rando, who kindly provided the Myf5 $5^{t m 1\left(\left(c r e / E s r 1^{*}\right) T r d o\right.}$ mice. Many thanks go to Prof. Dr. Dieter Saur for generously providing $\operatorname{Kras}^{\text {tm } 4 T y j}$ mice to our lab.

Many people accompanied me on my way to complete this study and I am very grateful to all members of the department. Sincere thanks go to all present and former members of our working group for creating an atmosphere I enjoyed to work in. In particular, I would like to thank PD. Dr. Anja Uhmann for having a sympathetic ear for all the questions and problems that accompany a PhD. Thank you for inspiring discussions on scientific and non-scientific issues, technical advice and helpful suggestions, sharing your knowledge and experiences and always being supportive and reliable. Without our small coffee breaks, this PhD would 


\section{ii | ACKNOWLEDGEMENTS}

not have been the same. Moreover, I especially would like to thank Dr. Natalie Geyer and Dominik Botermann for the time we spent together at the $\mu \mathrm{CT}$ and on the way to the clinics and back. I additionally wish to acknowledge all the further support provided by Dominik Botermann. Thank you for being a great laboratory partner and taking care of my mice when I was not around. Moreover, I thank Dr. Nicole Cuvelier for the guidance at the beginning of my project. My grateful thanks go to our technicians for their help and technical support in everyday lab work. Especially, I would like to thank Anke Frommhold for taking the time to prepare tissue sections, her assistance with stainings and the immense support in the collection of my Ki67 data. Similar, my gratitude goes to Ina Heß for her support in second genotyping. Many thanks also go to all the other past and present lab members: Dr. Benedikt Linder, Dr. Marco Becker, Dr. Rosalie Ridzewski, Dr. Julia Dräger, Dr. Joanna Pyczek and Nadine Brandes. I am grateful for being part of such a wonderful working group. Thank you so much for all the support in the regular duties and responsibilities of the lab work, the various scientific and non-scientific discussions, a lot of fun and laughter in long hours of experiments, helpful encouragement in hard moments and sometimes being more than just colleagues. Thanks to the animal caretakers, especially Lea Piontek, Shari Bötticher and Susann Peter, who always had an eye on all the mice and thereby supported this work. Additionally, I would like to thank some of the "short-term" members of our working group. Thanks to Wiebke Maurer and Maria Kuzyakova for the nice time, we shared in the lab. Thanks to Simran, Soraia and Lukas for showing me what it means to be a supervisor.

Most importantly, I wish to thank my family for their endless support and encouragement throughout my studies and this thesis. Without you this would not have been possible and I am very grateful that you have faith in everything I do. Loving thanks go to my parents, Silvia and Karl-Heinz, for the countless ways in which, throughout my life, they have supported me. Thank you Nils, for providing the soundtrack to the good and bad days, for distraction from problems and the daily routine and being the best brother one could imagine. Additionally, many thanks go to my friends, who were always there for me and excused so many unplanned delays.

Finally, I gratefully thank my husband and best friend Sven. I thank you from the bottom of my heart for your patience, for celebrating each small progress, for cheering me up in critical phases, for your calming influence and for being around whenever I needed you. Your love was the greatest support throughout this thesis. Thank you! 